\title{
The effectiveness of risk assessments in informing decision makers
}

\author{
By \\ Christopher Peace
}

\begin{abstract}
A thesis
submitted to Victoria University of Wellington

in fulfilment of the requirements for the degree of

Doctor of Philosophy

in Management
\end{abstract}

Victoria University of Wellington

2019 



\section{Abstract}

Purpose: This research examined the effectiveness of risk assessments in an organisational setting and found that risk assessors may not effectively assess risks and so may not provide the best available information or effective advice to decision makers. However, guidance on the conduct of risk assessments is scattered across many organisational, economic and technological domains with little consistency in definitions and processes, perhaps contributing to ineffective risk assessments. This is an area of academic and practical relevance that can be investigated rigorously and has the potential to improve decision making.

Design/methodology: The main research question was:

$R Q$. Can a generic goal tree, populated with critical success factors and necessary conditions derived from the literature and case studies, be developed that would help decision makers and risk assessors to evaluate the effectiveness of risk assessments before they are used to aid a decision?

The research described here used a pragmatist approach to managerial practice and associated practitioner problems related to (1) how effectively risk assessments informed decision makers before decisions were made; (2) how formal risk assessments were carried out; and (3) how risk assessments might be improved. Following a comprehensive literature review, an online survey was used to determine what methods are employed currently, while case studies investigated the conduct of risk assessments in context. The literature review indicated that risk has many connotations and diverse definitions and conceptualisations, leading to the conclusion that a given risk assessment should state the definition of risk used. The ISO31000 definitions of risk ("effect of uncertainty on objectives") and risk assessments were found to be most useful for this research. The online survey of risk and safety practitioners found little use of structured techniques or consideration of human factors, a finding also reflected in the case studies.

Potential critical success factors and necessary conditions for an effective risk assessment were identified from the literature review and linked using the Theory of Constraints logic processes to form a tentative goal tree (GT) including the entities and relationships underpinning effective risk assessment. This also provided a means of structuring and reporting the online survey data, and critiquing a pilot study and five further case studies, and selected professional practice developments.

The case studies explored in detail how risk assessments were carried out in support of a management decision. Each case was investigated using document and literature reviews, and structured, one-on-one interviews, including review of the tentative GT by interviewees. 
Qualitative data from the case studies was analysed using NVivo and quantitative data from the online survey was analysed using SPSS.

Findings: This research demonstrated the ontological and epistemological basis of the GT, justifying it as effective research tool and enquiry system and the goal tree diagram as an effective problem representation system. Together, the goal tree process and diagram provide guidance to practice, and in this research, act as a qualitative tool for predicting the effectiveness of risk assessments.

Research limitations: This work was limited to an online survey, a pilot study and five case studies to explore risk assessments in an organisational setting. However, the findings corroborate anecdotal evidence that risk assessments are not effective, and the need for mechanisms for improvement.

Practical implications: This research has identified a need for training in risk assessments in New Zealand. Mechanisms for improving risk assessments are identified, with one (a 'risk canvas') being developed for and tested during a series of training workshops and found to improve performance and confidence (but not consistency or reproducibility of risk assessment results). Other proposed mechanisms include use of the McKinsey 7-S model in gap analysis; open access research evidence; and further development of the goal tree.

Originality: The research used a single goal tree and magnitudinal ratings of necessary conditions to judge the effectiveness of risk assessments in five organisations. The risk canvas to aid basic risk assessments was shown to provide improved risk assessment process. 


\section{Acknowledgements}

Many people - supervisors, family and friends - have given me direct and indirect support in the conduct of this research.

My wife, Ruth Brassington, supported me during the research process and my search for plain English - and gave editorial advice. Thank you.

Professor Victoria Mabin introduced me to the goal tree and the Theory of Constraints. Both have enriched my research and professional practice. Thank you for your considerable comments and encouragement, even when you had other, major commitments.

Thanks to Professor Carolyn Cordery who quietly criticised my work and helped straighten out some of my thinking.

To the research participants who shared their knowledge and helped me see bigger pictures - thank you.

The Victoria Business School PhD suite opened part way through my research and provided a great place to think and write, and many people in Student Learning, the Library and Faculty of Graduate Research helped in many ways.

My thanks to Roger Estall who, over many years, has given me insights in the field of risk management, especially some of the implications of the definition of risk. Thanks also to Russell Bell, Grant Purdy and other past and present members of the joint standards committees, OB007and QR005, with whom I have had so many enriching debates. 


\section{Table of contents}

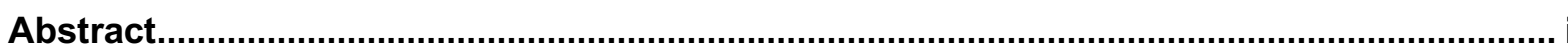

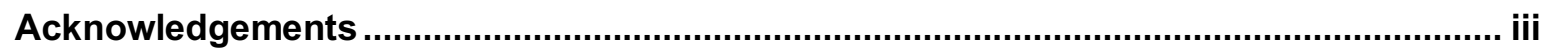

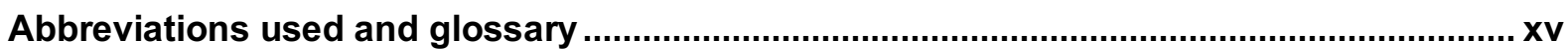

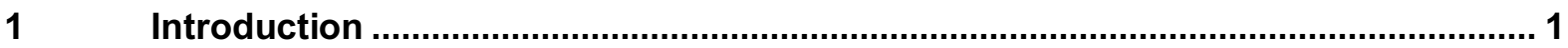

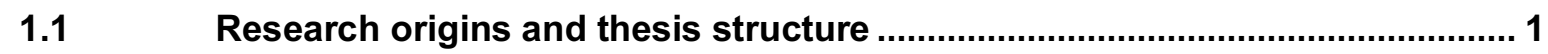

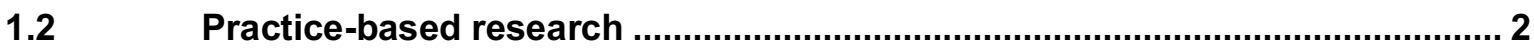

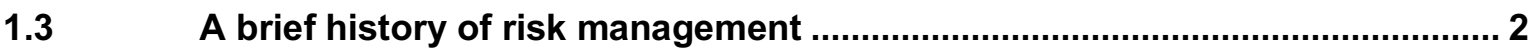

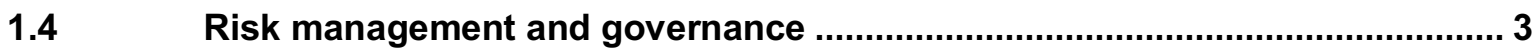

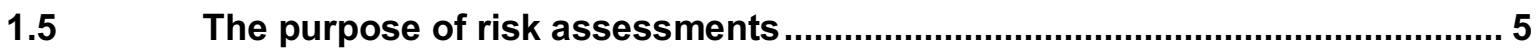

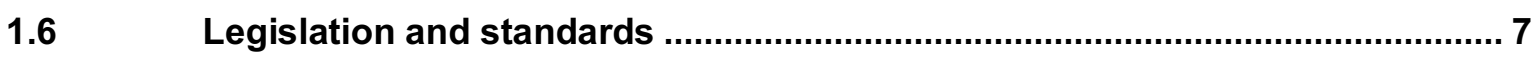

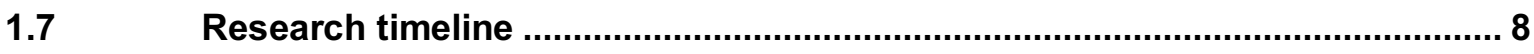

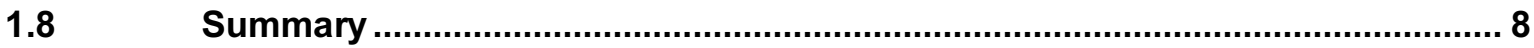

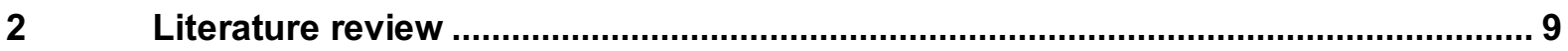

2.1 Definitions of risk: in search of a Goldilocks definition ................................. 9

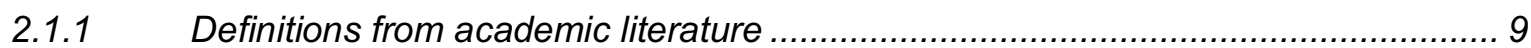

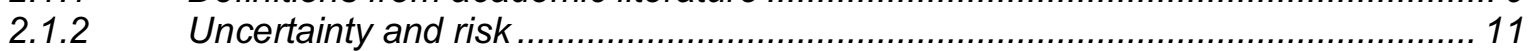

2.1.3 Definitions from legislation, standards and guidance documents ........................ 13

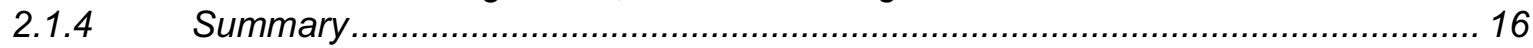

2.2 Risk assessors and sophistication of risk assessments .............................16

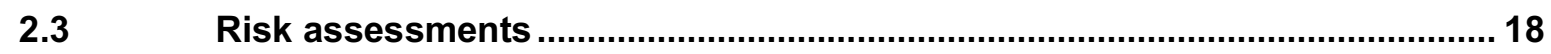

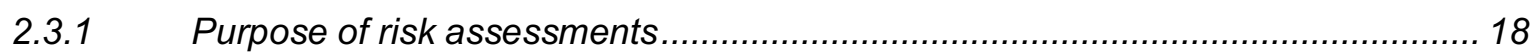

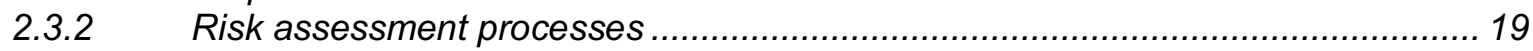

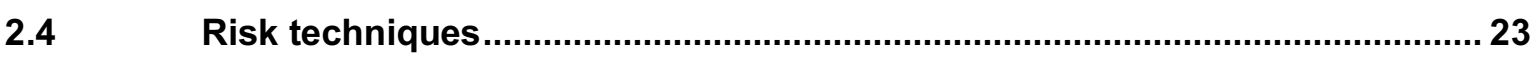

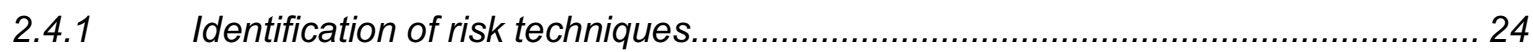

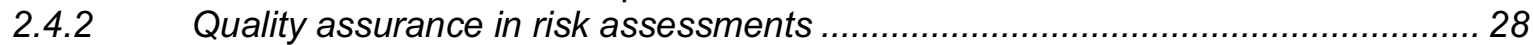

2.4.3 Risk techniques identification key and maturity modelling .................................... 28

$2.5 \quad$ Critical success factors for risk assessments ............................................. 31

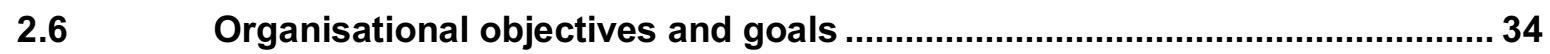

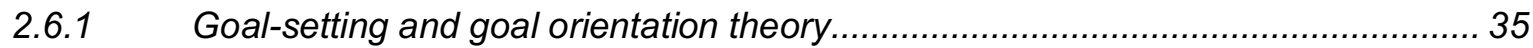

2.6.2 Origins and philosophical foundations of the goal tree (GT) .............................. 36

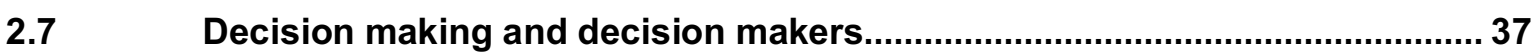

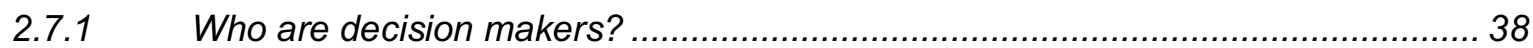

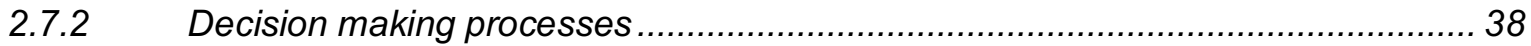

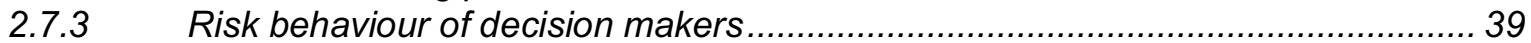

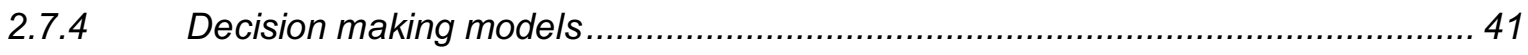




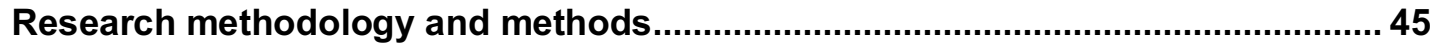

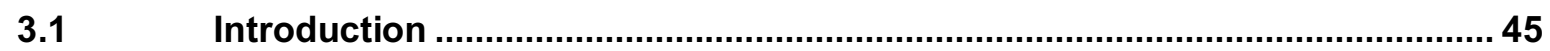

3.1.1 Ontology, epistemology and Pragmatism ............................................................. 45

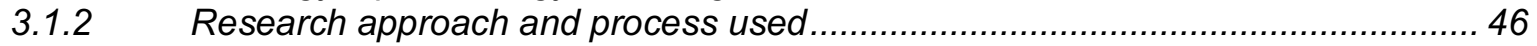

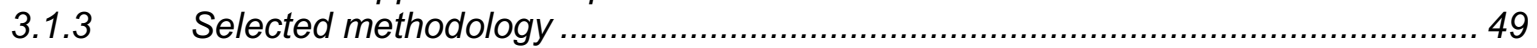

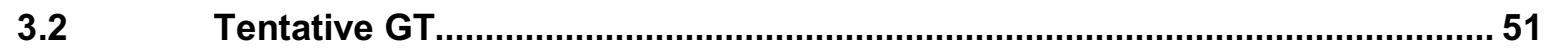

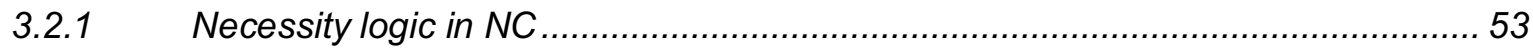

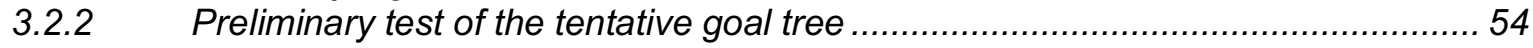

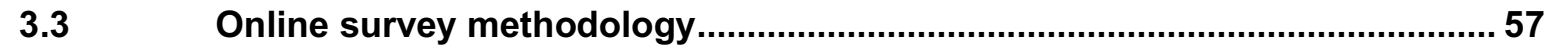

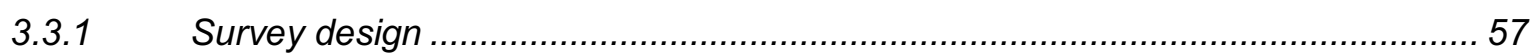

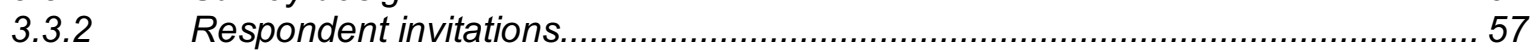

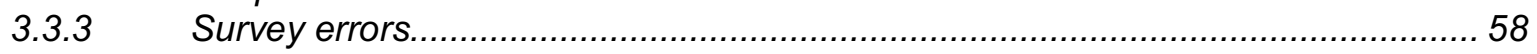

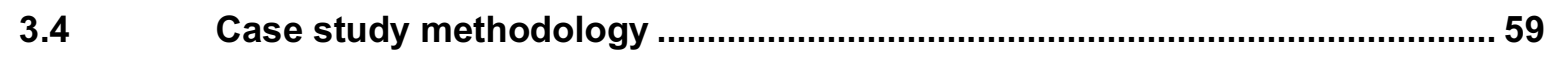

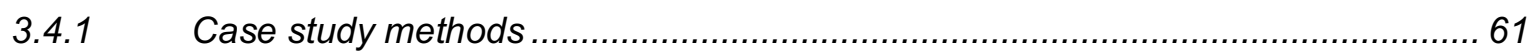

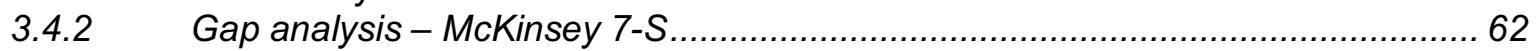

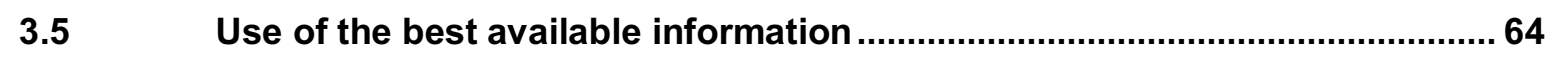

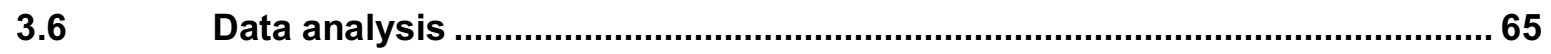

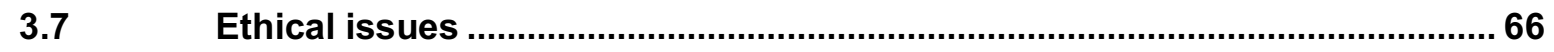

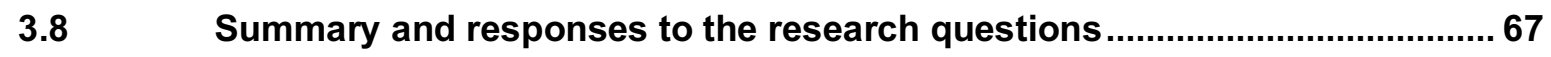

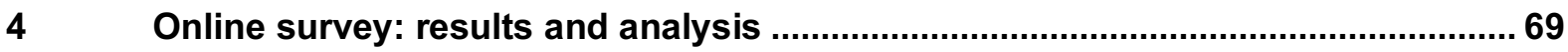

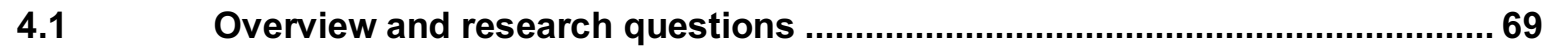

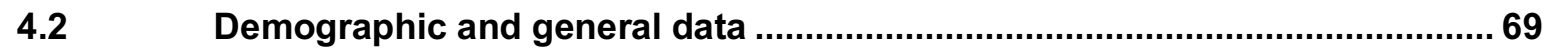

4.3 Reporting using the tentative goal tree CSF and NC ....................................70

4.3.1 Literature or document review fairly sets out data (NC 01) .................................. 70

4.3.2 Terms of reference for risk assessment are clear (NC 02) ................................. 71

4.3.3 Relevant qualifications and experience stated or available (NC 03)...................... 72

4.3.4 Impartiality in terms of funding and mandate (NC 04) ........................................ 76

4.3.5 Stakeholders and risk assessors have a shared understanding of risk (NC 05) ... 76

4.3.6 Appropriate engagement with stakeholders (NC 06) ........................................ 76

4.3.7 Competent or impartial risk assessor or team leader (NC 07) ............................ 80

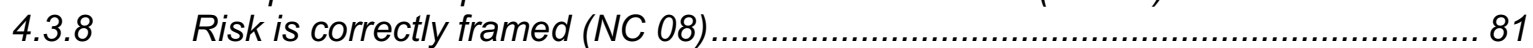

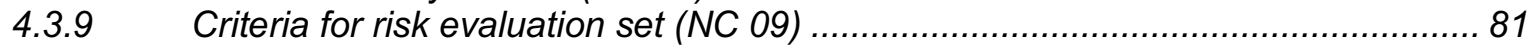

4.3.10 Appropriate language, graphics and layout (NC 10) .................................... 83

4.3.11 Systematic hazard or risk identification (NC 11) ........................................... 84

4.3.12 Appropriate risk analysis techniques have been used (NC 12)........................... 86

4.3.13 Appropriate risk evaluation techniques have been used (NC 13) .................... 90

4.3.14 Risk assessment appropriately communicated to decision makers (CSF 01) ... 91

4.3.15 All relevant factors including controversies and uncertainty have been fully and

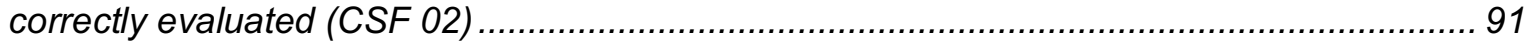

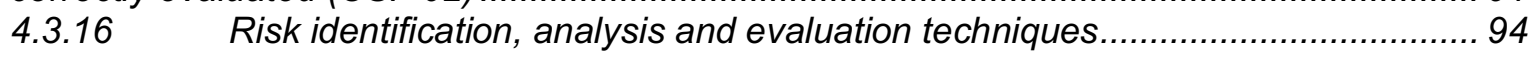

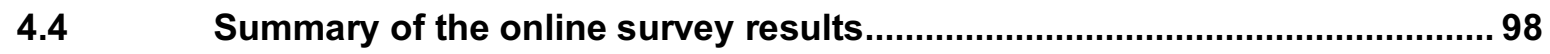

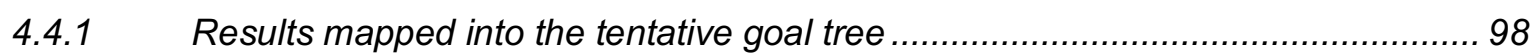

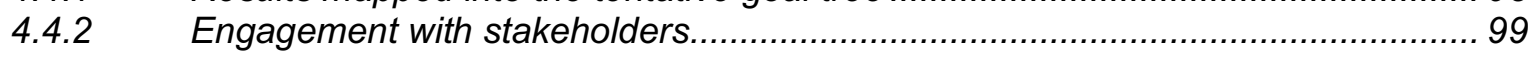

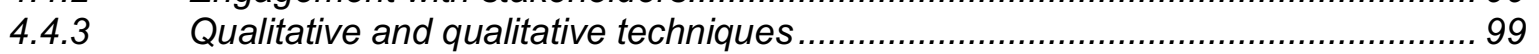




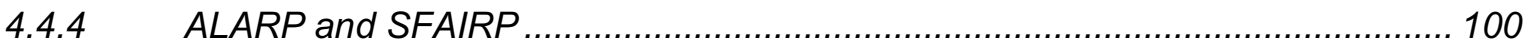

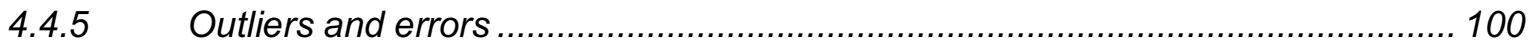

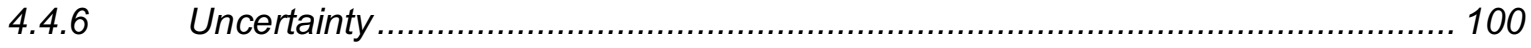

4.4.7 Conclusions from the online survey and research questions........................... 101

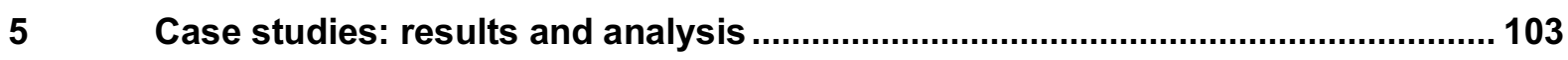

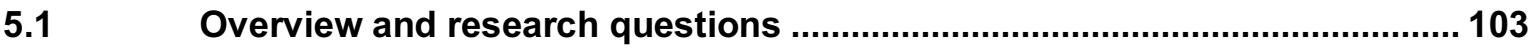

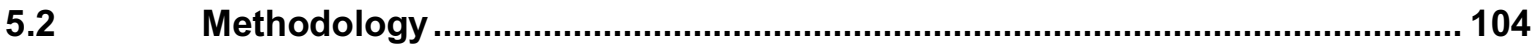

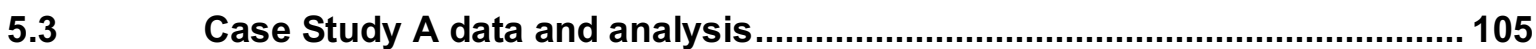

5.3.1 Business environment of the decision ............................................................... 105

5.3.2 Case study documents and interviewees ........................................................ 106

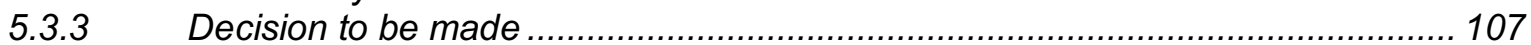

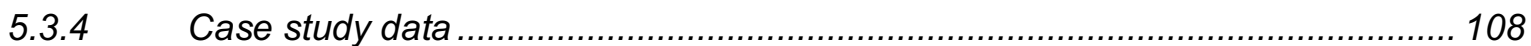

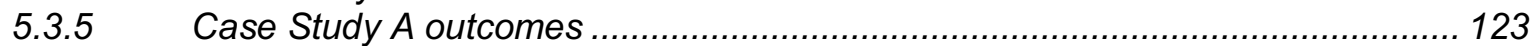

5.3.6 Summary of Case Study A risk assessment and outcomes .............................. 129

5.3.7 Evaluation of Case Study A risk assessment using the goal tree........................ 129

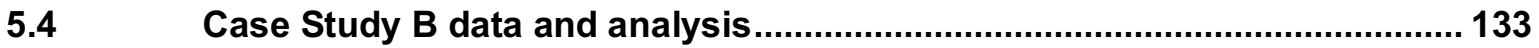

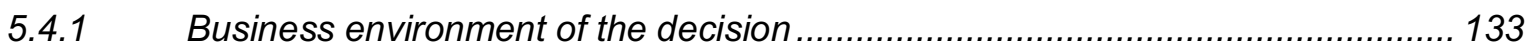

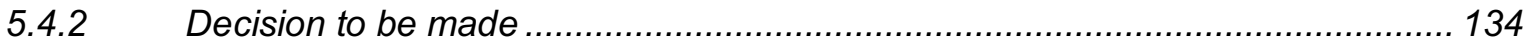

5.4.3 Case study documents and interviewees....................................................... 134

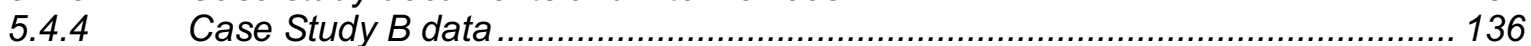

5.4.5 Summary of Case Study B outcomes and gap analysis .................................. 154

5.4.6 Evaluation of Case Study B risk assessment using the goal tree ....................... 158

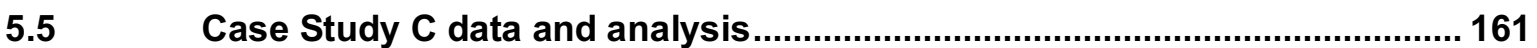

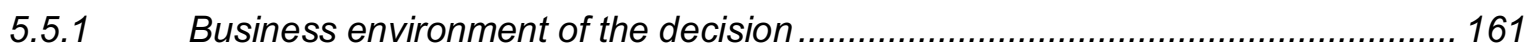

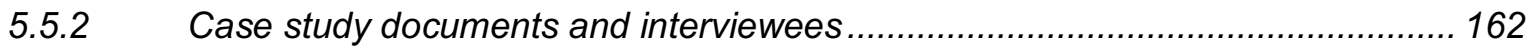

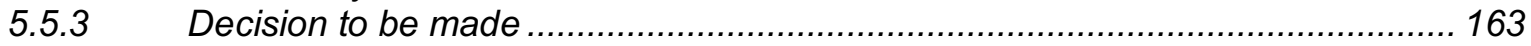

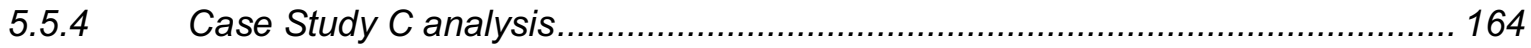

5.5.5 Summary of the risk assessment and outcomes........................................... 173

5.5.6 Evaluation of Case Study C risk assessment using the goal tree........................ 176

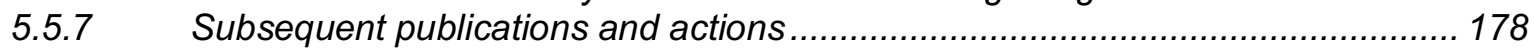

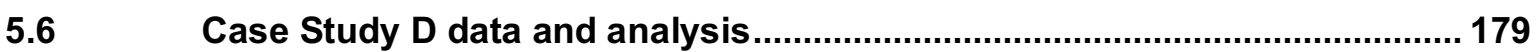

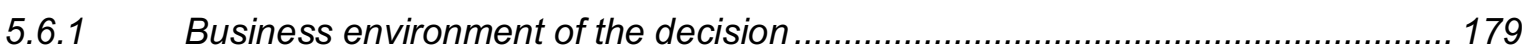

5.6.2 Case Study Documents and interviewees....................................................... 180

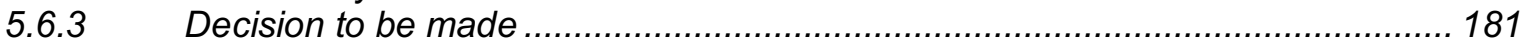

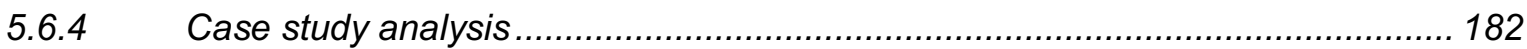

5.6.5 Summary of the risk assessment and outcomes................................................. 189

5.6.6 Evaluation of Case Study D risk assessment using the goal tree........................... 191

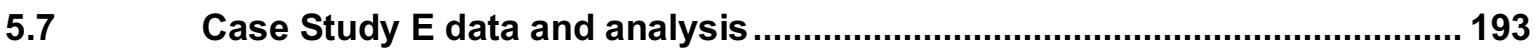

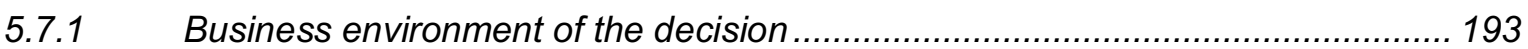

5.7.2 Case study documents and interviewees ...................................................... 193

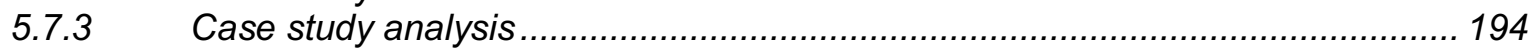

5.7.4 Summary of the risk assessment and outcomes........................................... 198

5.7.5 Evaluation of Case Study E risk assessment using the goal tree ....................... 198

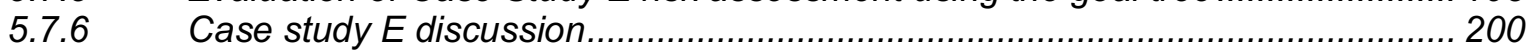




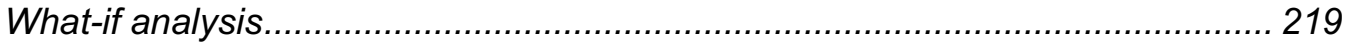

The risk canvas: evolution and testing

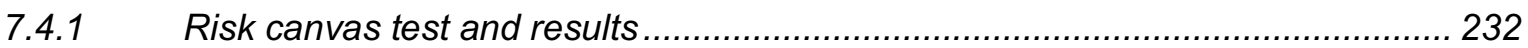

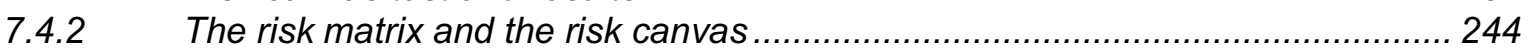

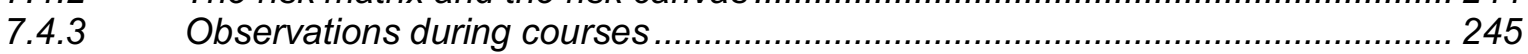

7.4.4 Suggested changes to the risk canvas............................................................. 245

7.4.5 Risk canvas and the Shoreham Airshow risk assessment................................ 246

7.4.6 Reliability when using the risk canvas......................................................... 246

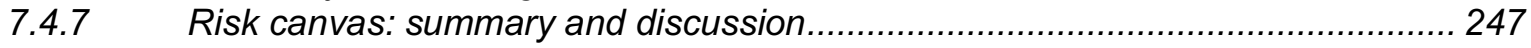

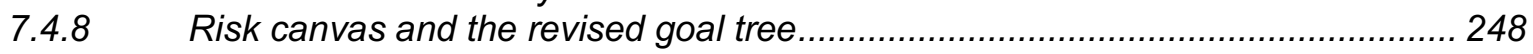




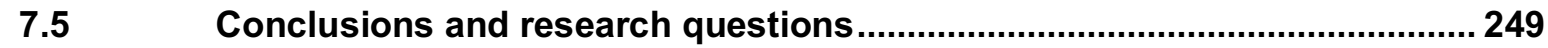

8 Discussion 251

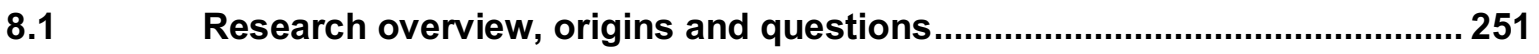

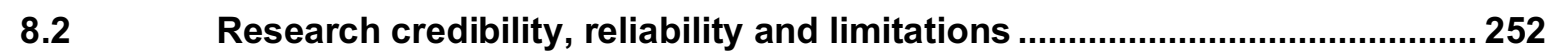

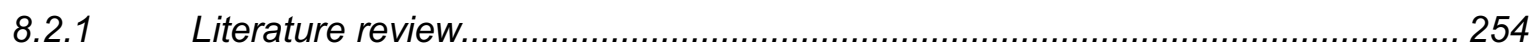

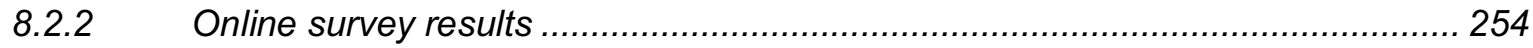

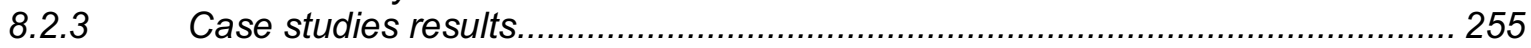

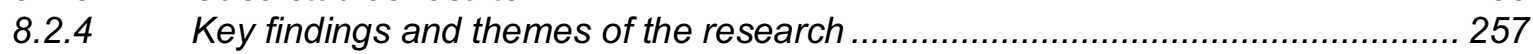

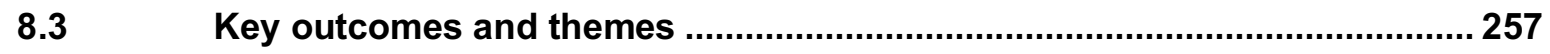

8.3.1 The goal tree: philosophy and applicability as a research and practical tool....... 257

8.3.2 Risk canvas as a pragmatic training tool ........................................................ 262

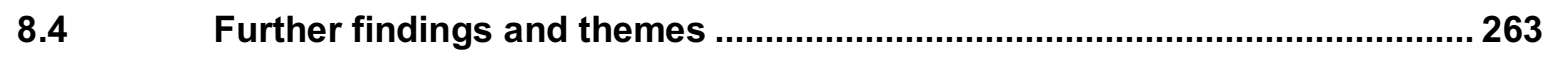

8.4.1 Risk definitions in risk assessments ......................................................... 263

8.4.2 Professional judgement as a pervasive problem............................................. 264

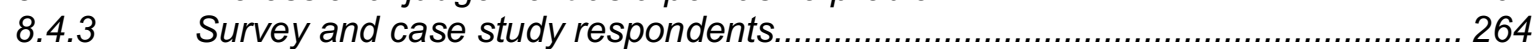

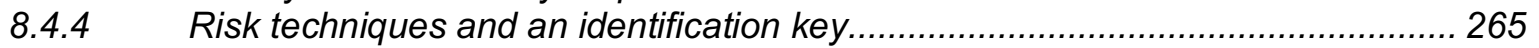

8.4.5 Use of McKinsey 7-S as a gap analysis technique ........................................ 265

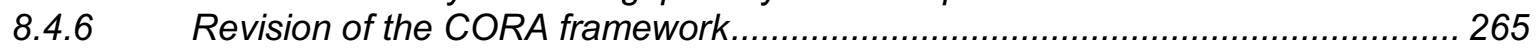

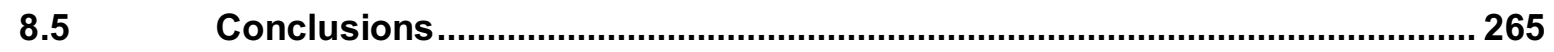

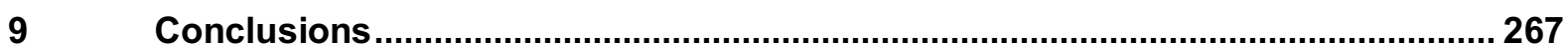

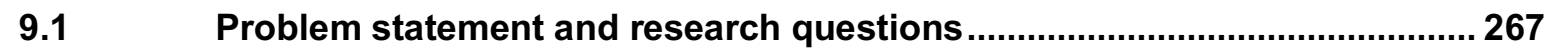

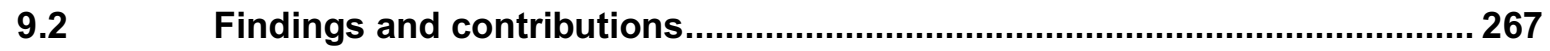

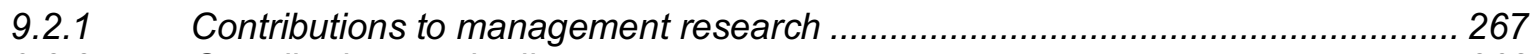

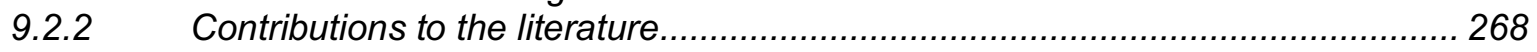

9.2.3 Contributions to the practice of risk assessment............................................ 271

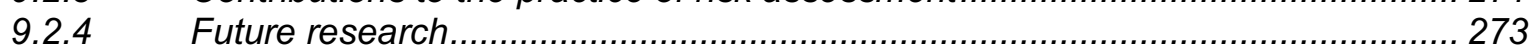

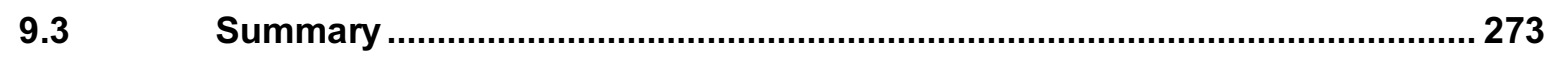

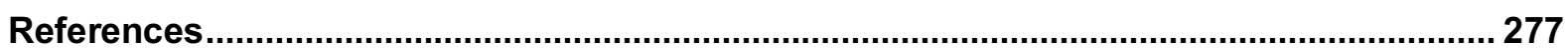

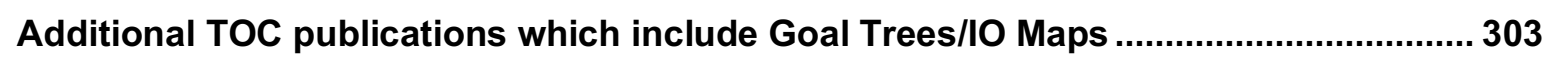

Additional conference papers on TOC which include Goal Trees/IO Maps.................... 303

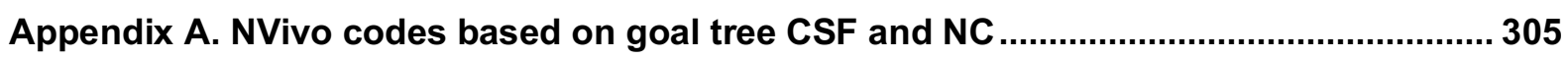

Appendix B. Human Ethics Committee Approvals ............................................................ 311

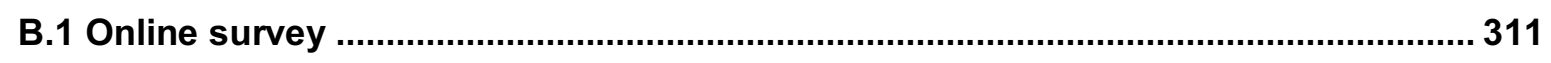

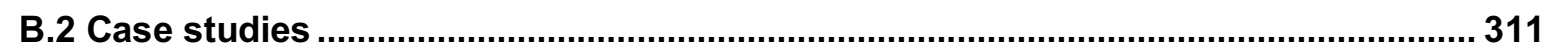

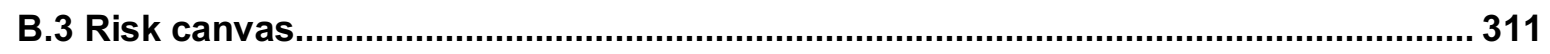

\section{Short literature searches within case studies}

Box 1. Literature relevant for Case Study A: OHS management...................................... 109

Box 2. Literature relevant for Case Study B: Earthquake-related risk ..............................137

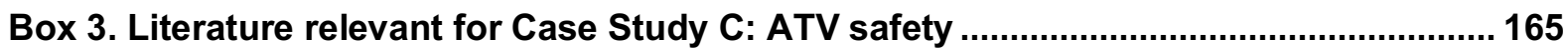

Box 4. Literature relevant for Case Study D: OHS in mushroom growing .......................... 183 


\section{Table of Tables}

Table 1. Evidence for the benefits of effective risk management by sector or activity ......... 4

Table 2. Effectiveness of risk assessments for informing decision makers .........................5

Table 3. Summary of definitions of risk from standards, codes and guidance.................... 15

Table 4. Comparison of common risk management processes.......................................... 22

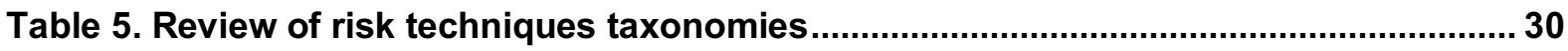

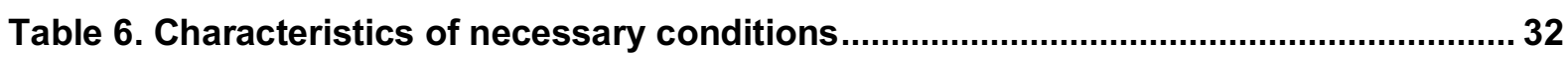

Table 7. Summary of research on two decision making processes ................................... 38

Table 8. Comparison of some decision making and risk management stages .................... 42

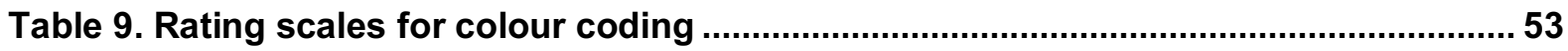

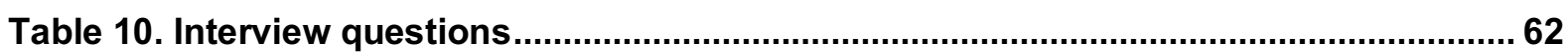

Table 11. Nature of decision and whether supported by a risk assessment .......................70

Table 12. Risk techniques used in establishing the context ............................................. 71

Table 13. Cross tabulation of highest qualification and time in current role.........................72

Table 14. Cross tabulation of jobs and highest qualifications ........................................... 73

Table 15. Cross tabulation of jobs and time in current role............................................. 74

Table 16. Level of qualifications of respondents by country of respondent ....................... 75

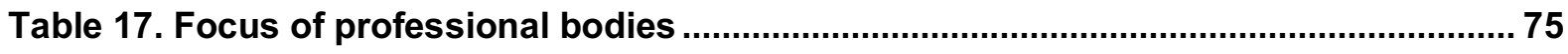

Table 18. Whether stakeholders were consulted in the risk assessment ............................77

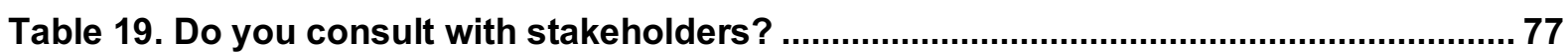

Table 20. Risk techniques used to identify stakeholders in a risk assessment................... 78

Table 21. Techniques used to decide how to consult or communicate ............................... 79

Table 22. Whether risk assessors communicate or consult in each sector .........................80

Table 23. Whether the risk assessment included discussion of the context ...................... 81

Table 24. Whether the risk assessment used predefined risk criteria or risk appetite ....... 82

Table 25. Risk management documents most frequently referred to by respondents ....... 84

Table 26. Risk techniques used in risk identification...................................................... 85

Table 27. Risk techniques used in qualitative risk analysis ........................................... 86

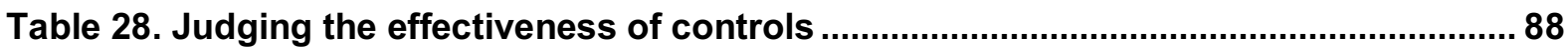

Table 29. Risk techniques used in quantitative risk analysis................................................ 89

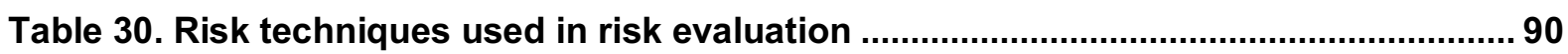

Table 31. Whether uncertainty was discussed in relation to the decision........................... 92

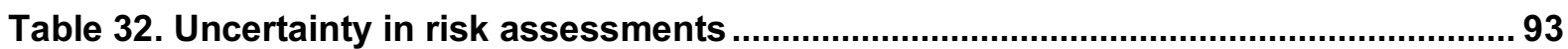

Table 33. Whether the risk assessment used named techniques or methods ..................... 94

Table 34. Summary of reported usage of risk techniques ............................................... 96

Table 35. Summary of case studies characteristics ......................................................... 103 


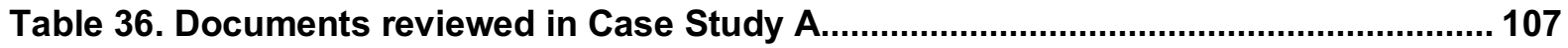

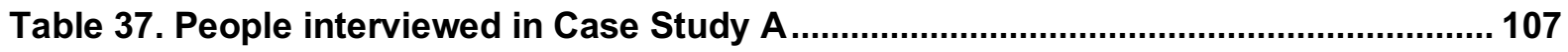

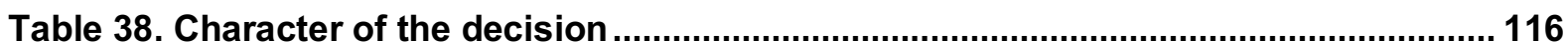

Table 39. Documents reviewed in Case Study B......................................................... 134

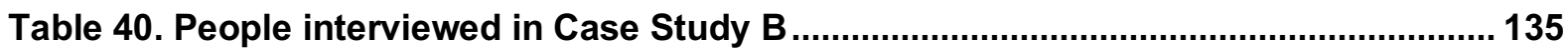

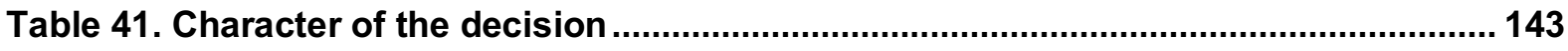

Table 42. Casualties due to building contents in a Wellington earthquake........................146

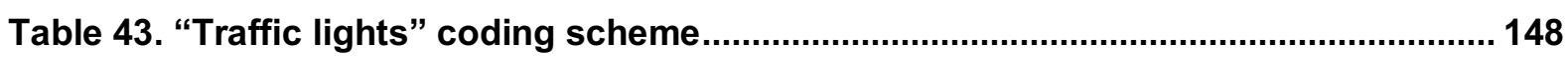

Table 44. Case Study B scaled major events ................................................................... 149

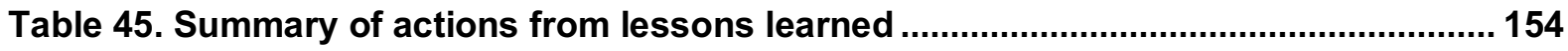

Table 46. Damage in one high-rise building in the 2013 and 2016 earthquakes ............... 158

Table 47. Documents reviewed in Case Study C.......................................................... 162

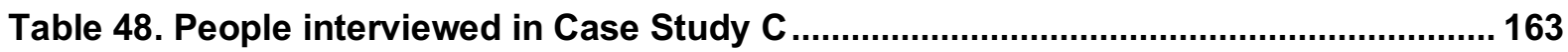

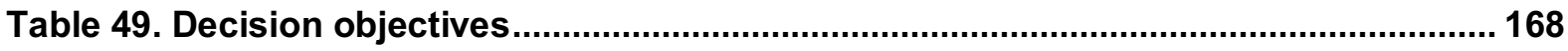

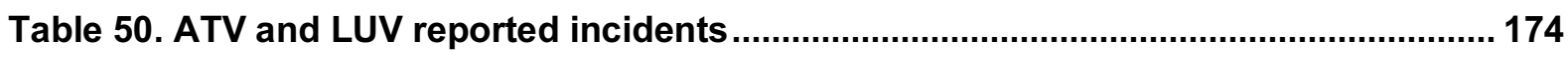

Table 51. Documents reviewed in Case Study D......................................................... 180

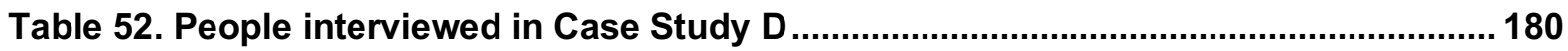

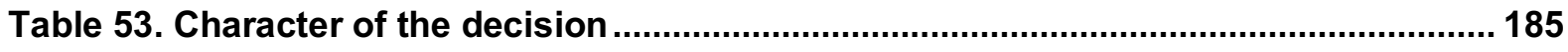

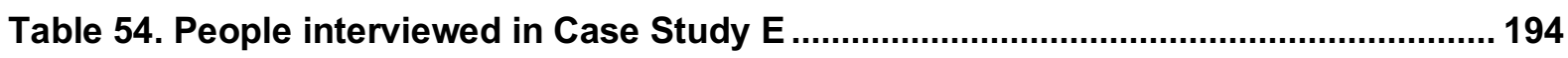

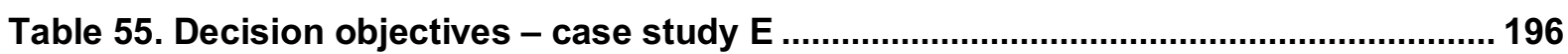

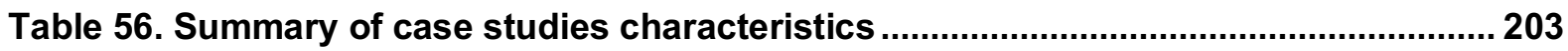

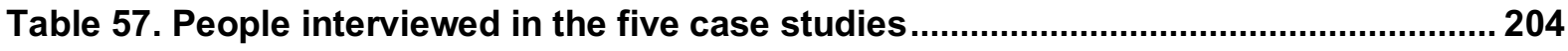

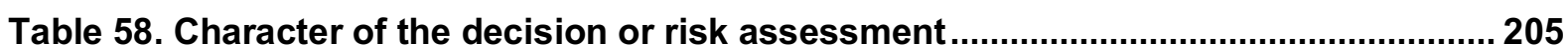

Table 59. Summary of the effectiveness of each goal tree ............................................... 208

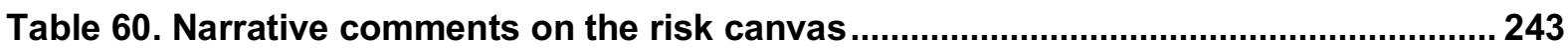

Table 61. Philosophical assumptions underlying the TOC goal tree ................................ 259

Table 62. Mapping the philosophical foundations of the goal tree .................................... 259

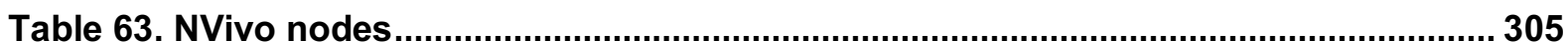




\section{Table of Figures}

Figure 1. Known/unknowns matrix 11

Figure 2. A taxonomy of some sources of epistemic uncertainty in risk assessments 12

Figure 3. Risk assessment sophistication. 17

Figure 4. Risk techniques in the risk management process................................................. 26

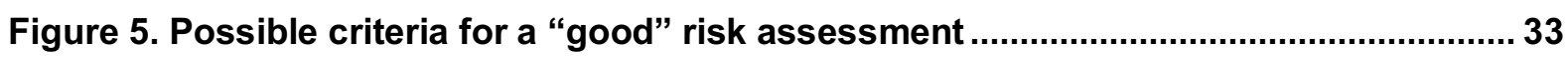

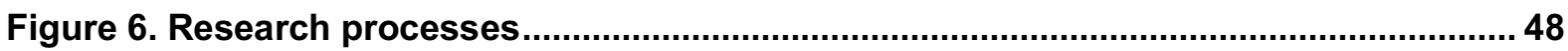

Figure 7. Summary of planned mixed methods methodology .........................................50

Figure 8. Process for constructing a goal tree ................................................................ 51

Figure 9. Tentative goal tree for effective risk assessments ...........................................52

Figure 10. The goal tree and the risk assessment from the Shoreham air show crash ...... 55

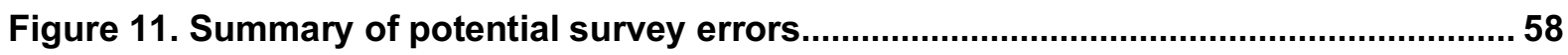

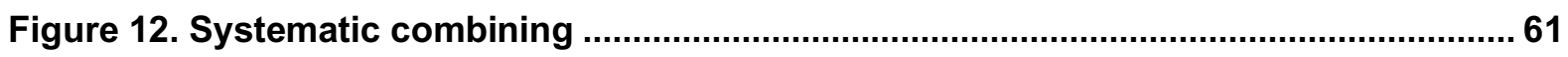

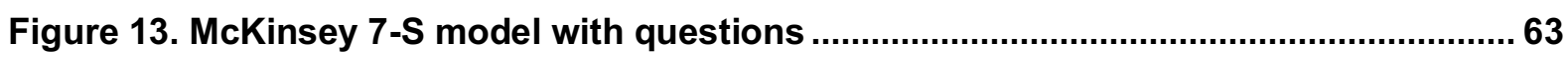

Figure 14. Cross tabulation of highest qualification and time in current role ......................72

Figure 15. Comparison between jobs and highest qualifications .......................................... 73

Figure 16. Comparison between jobs and time in current role .......................................... 74

Figure 17. Percentages of decision types that used predefined risk criteria ....................... 82

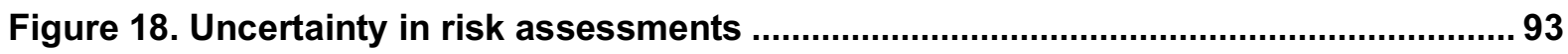

Figure 19. Reported use of a technique cross-tabulated against decision nature ..............94

Figure 20. Most frequently selected risk assessment techniques........................................ 95

Figure 21. Online survey results mapped into the goal tree............................................. 98

Figure 22. Timeline of the Case Study A decision, risk assessment and documents....... 106

Figure 23. Feedback flows in the risk assessment ........................................................ 112

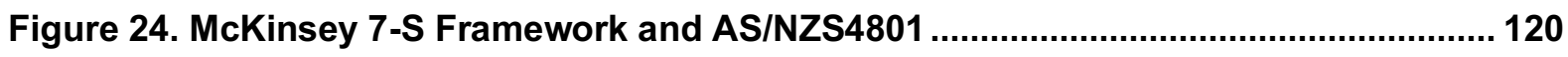

Figure 25. Case Study A qualitative influence diagram ................................................... 124

Figure 26. Effectiveness of the risk assessment compared with outcomes ......................129

Figure 27. The goal tree and the risk assessment in Case Study $A$.................................... 130

Figure 28. Timeline of the Case Study B decision, risk assessment and documents....... 133

Figure 29. Feedback and engagement in the risk assessment ....................................... 142

Figure 30. Simple bowtie analysis for loss of use of a building due to an earthquake ..... 147

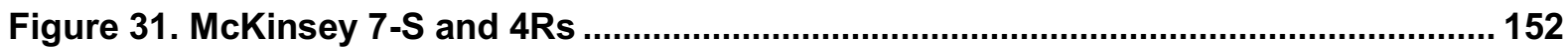

Figure 32. Case Study B qualitative influence diagram .................................................... 156

Figure 33. Effectiveness of a risk assessment compared with outcomes.......................... 157

Figure 34. The goal tree and the risk assessment in Case Study B ................................... 159

Figure 35. Timeline of the Case Study $\mathrm{C}$ decision, risk assessment and documents....... 161

Figure 36. Human and performance-shaping factors ....................................................... 170

Figure 37. ATV and LUV reported incidents .............................................................. 174 
Figure 38. Case Study C qualitative influence diagram 175

Figure 39. Effectiveness of the risk assessment compared with outcomes ...................... 176

Figure 40. The goal tree and the risk assessment in Case Study C .................................. 177

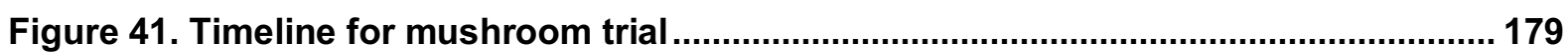

Figure 42 Cultivation cycle for common mushroom ..................................................... 181

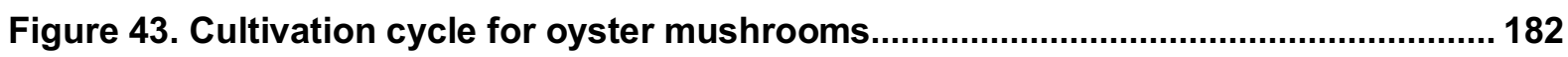

Figure 44. Case Study D qualitative influence diagram ................................................. 190

Figure 45. Effectiveness of a risk assessment compared with outcomes ......................... 190

Figure 46. The goal tree and the risk assessment in Case Study D .................................. 191

Figure 47. Timeline of the Case Study E decision ........................................................ 193

Figure 48. Effectiveness of a risk assessment compared with outcomes ......................... 198

Figure 49. The goal tree and the risk assessment in Case Study E.................................. 199

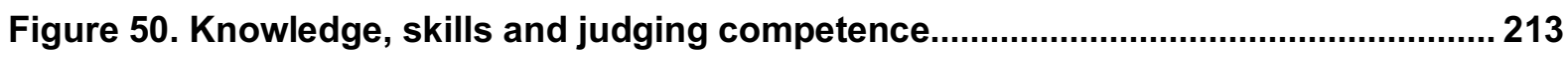

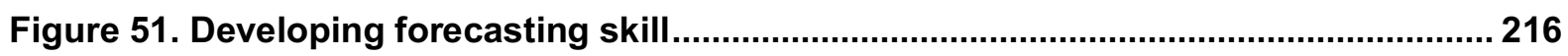

Figure 52. Revised goal tree for an effective risk assessment........................................ 222

Figure 53. Risk management research, teaching, practice and policy in New Zealand .... 225

Figure 54. Three-point format for questions about probabilities ..................................... 228

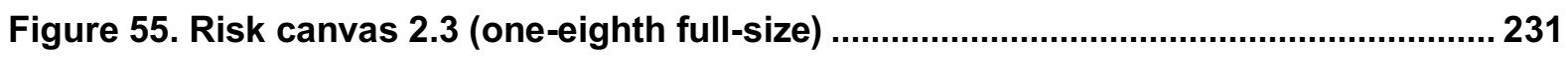

Figure 56. Extract from the risk canvas - document review ......................................... 232

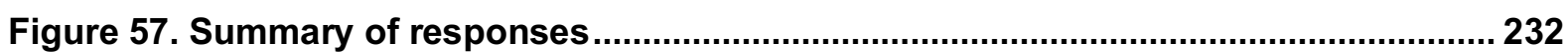

Figure 58. Extract from risk canvas - engagement …...................................................... 233

Figure 59. Summary of responses to space for the engagement plan............................... 233

Figure 60. Extract from the risk canvas - PESTLE analysis............................................. 234

Figure 61. Summary of responses to space to record a PESTLE analysis........................ 234

Figure 62. Extract from the risk canvas - SWOT analysis ............................................ 235

Figure 63. Summary of responses to space to record a SWOT analysis........................... 235

Figure 64. Extract from the risk canvas - objectives .................................................... 236

Figure 65. Summary of responses to space to record objectives .................................... 236

Figure 66. Summary of responses to space to record key $5 \mathrm{~W} 1 \mathrm{H}$ results ........................... 237

Figure 67. Part of the causal effects (left) side of a bowtie................................................. 238

Figure 68. Part of the consequences (right) side of a bowtie .......................................... 238

Figure 69. Responses to provision of a grid for the bowtie analysis ................................ 239

Figure 70. Responses to guidance on the probability of risk consequences ....................240

Figure 71. Extract from the risk canvas - controls characteristics .................................... 241

Figure 72. Extract from the risk canvas - controls effectiveness.................................... 241

Figure 73. Responses to guidance on control characteristics......................................... 241

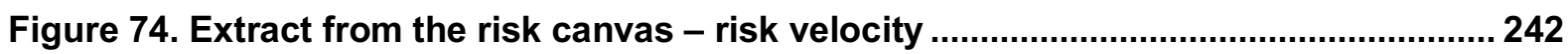

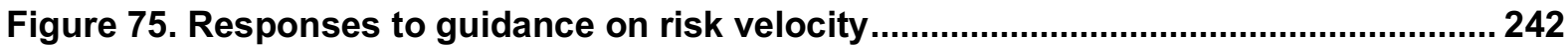


Figure 76. Summary of overall response to the risk canvas ............................................ 243

Figure 77. Changes in perception of the level of risk due to bowtie analysis ....................244

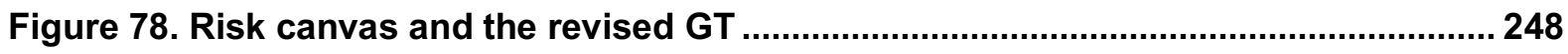

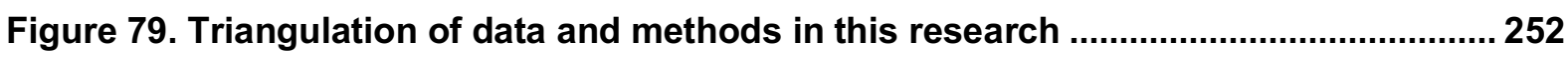

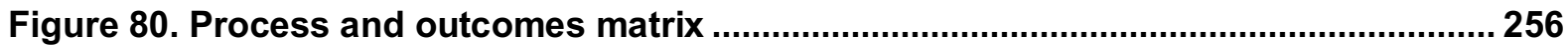

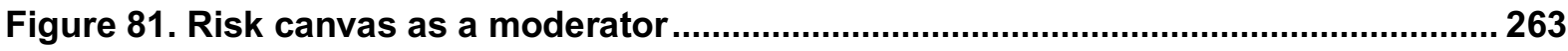




\section{Abbreviations used and glossary}

ACC

ATV

BAI

CORA

COSO

CSF

FAO

GT

HACCP

HAZOP

HSE

HSWA

$\mathrm{ICl}$

IEC

IPPC

IRGC

ISO

LCE

LUV

MED

NC

NVivo

OHS

PMBoK

SPSS

SRA

TOC

WHO

WOAH

WOE

WSMP

WYSIATI

MMR
Accident Compensation Corporation

All-terrain vehicle (also known as a quad bike)

Best available information

Credibility of risk assessment

Committee of Sponsoring Organizations of the Treadway Commission

Critical success factor

Food and Agriculture Organization

Goal tree

Hazard analysis and critical control points

Hazard and operability study

Health and Safety Executive, UK regulatory agency for industrial and major risks Health and Safety at Work Act

Imperial Chemical Industries, a UK chemicals company 1926-2008

International Electrotechnical Commission

International Plant Protection Convention

International Risk Governance Council

International Standards Organization

Loss of control event

Light utility vehicle

Ministry for Economic Development

Necessary condition

Qualitative research software

Occupational health and safety

Project Management Book of Knowledge

Statistical package for social sciences

Society for Risk Analysis

Theory of Constraints

World Health Organization

World Organization for Animal Health

Weight of evidence

Workplace safety management practices, an insurance-based rewards scheme What you see is all there is

Mixed methods research 


\section{Introduction}

\subsection{Research origins and thesis structure}

This research is derived from 40 years' experience carrying out and reviewing reports describing risk assessment failures and led to the following research problem:

Risk assessments often fail to inform decision makers effectively about uncertainty in the form of causes of possible events, the consequences that might follow, the effectiveness of existing controls and the options for treating risk.

To help respond to this problem, this chapter introduces the topics of risk, risk management and risk assessment, briefly tracing their history and showing their importance and value for corporate governance.

Chapter 2, the literature review, examines the definitions of risk before briefly considering risk assessors and risk assessments, including risk techniques, and then examining critical success factors for risk assessments. Of key importance is the selected definition of risk as the "effect of uncertainty on objectives", leading to an exploration of organisational goals and objectives and uncertainty about their achievement before setting out the research question and two sub-questions in section 2.9.

Chapter 3 describes the mixed methods research methodology used, including development of a goal tree (section 3.2) and ethical issues.

Chapter 4 describes the data gathered in the online survey and analysis of that data before concluding with a summary of the results, so partially responding to research sub-question 1. Chapter 5 describes five case studies, data gathered and analysis of that data using the goal tree before concluding with a high-level summary of the results and further responding to research sub-question 1.

Chapter 6 analyses in more depth the data from both the online survey and case studies, discussing and comparing the results and further responding to research sub-question 1.

Chapter 7 then responds to research sub-question 2 by describing mechanisms that might facilitate or improve risk assessments, including a revised goal tree and the 'risk canvas' (section 7.4).

Chapter 8 draws together and discusses the preceding chapters, showing how the goal tree facilitated this research, and how risk assessments might be improved. 
Chapter 9 draws conclusions from the research overall, showing how the research question and sub-questions were answered, summarises the contributions from this research and outlines areas for further research.

\subsection{Practice-based research}

Toffel (2016, p. 1495) posed three questions about such practice-based research. "Is the research problem novel to academics? Is the research question relevant to practice? Can the research question be answered rigorously?". Wein (2009) raised four similar questions: Is the problem very important? Has the problem been sufficiently addressed in the academic literature? Has the problem been sufficiently addressed by policy makers? Would the problem be sufficiently challenging to work on?

Reviewing these questions shows the problem investigated here is not novel to researchers working in the area of occupational health and safety-related risk assessments (Gadd, Keeley, \& Balmforth, 2003) or the credibility of science-based risk assessments (Wiedemann et al, 2013). It is, however, highly relevant to practice in New Zealand where occupational health and safety (OHS) has a poor record (Driscoll et al, 2004), risk assessments do fail to inform decision makers (sometimes with catastrophic consequences (Macfie, 2013)), and manufacturing management is less than optimal (Green et al, 2010). This may be due to the pressure on academics and practitioners to deliver, resulting in a failure to attain the profile of explorer, integrator, practitioner and teacher (Smallman, 2006, p. 773). This problem of sub-optimal risk assessments does not seem to have been sufficiently addressed by New Zealand academics and needs to be investigated rigorously yet pragmatically.

Within organisational research the structure and conduct of risk assessments should be well established (Weick, 2016) yet there remain substantial differences between research and practice, between different schools of risk assessment practice, and between time and country. This leaves scope for pragmatic research such as this current work to challenge and extend earlier research (Davis, 2015).

\subsection{A brief history of risk management}

In a prior review of the history of risk management, Kloman (2010, p. 491) argued that evolution favoured those members of the human species able to manage the uncertainties of food, warmth and shelter, leaving them with sufficient time for forward planning that further favoured those able to take advantage of opportunities presented in their environments. Development of human societies enabled record-keeping beyond the lifetimes of individuals and an increasing ability to try to forecast the future (Bernstein, 1996). In Europe, the Middle Ages brought the concept of free will and, over the subsequent millennium, steady growth of risk-related concepts: fatalism, for example, seemed to have been replaced with an ability to 
forecast some aspects of the future. However, the industrial revolution brought increasing complexity and uncertainty, sometimes marked by major disasters, perhaps due to a lack of effective risk assessments.

The $20^{\text {th }}$ century saw a growing awareness of risk concepts, terms and definitions. A disconnect between academic research and professional practice led to conflicting and diverse definitions of risk, risk management and related terms (Rockett, 1999) and the development of risk management processes and frameworks. Some are generic, while others are topic- or sector-specific. Those relating to professional practice were characterised by Bowden \& Green (2010, p. 107) as the "enactment of the role of a professional group in serving or contributing to society".

A range of guidance documents, including management system standards published by the International Standards Organization (ISO), arose following stakeholder dissatisfaction with decision making and management of risks by organisations (Heras-Saizarbitoria \& Boiral, 2013). However, some of those standards have sometimes resulted in controversy (Leitch, 2010), with little agreement about the meanings of "risk" and "risk management" or the value of commonly used techniques (Leitch et al, 2016).

\subsection{Risk management and governance}

The term "risk governance" emerged in the mid-1990s as a descriptor for how risks are governed outside the corporate setting through horizontal and vertical networks (Boholm, Corvellec, \& Karlsson, 2012). Such networks include a wide range of actors, compliance obligations and societal pressures that influence how risk information is used and risk decisions made (Renn, 2008a) by organisations.

Decision making under risk is often undertaken pragmatically by managers with biased experiences (perhaps with multiple and inconsistent goals) who are working on uncertain, illstructured problems with many potential outcomes, using incomplete information and ambiguous feedback, while distracted by the need to attain some performance target (Farjoun, Ansell, \& Boin, 2015; March \& Shapira, 1987). The consequences of such decisions may lie at some time in the future when other factors that were not, or could not be, anticipated affect the outcomes. Such decoupling may complicate rational action in the present, while enabling attachment of blame or failure to assign credit at some future point. In such situations, demonstrating a good process (supported by relevant techniques, imagination and learning from previous events) may be important for avoidance of severe criticism or for allocation of appropriate credit. 


\section{Some effects of risk management}

As summarised in Table 1 effective risk management has been shown to have positive financial and other effects on organisational performance, while ineffective risk management may have negative effects.

Table 1. Evidence for the benefits of effective risk management by sector or activity

\begin{tabular}{|c|c|}
\hline Sector or activity & Research findings \\
\hline $\begin{array}{l}\text { Corporate } \\
\text { governance and } \\
\text { share market } \\
\text { performance }\end{array}$ & $\begin{array}{l}\text { Australian research investigated companies that had adopted the Australian Securities Exchange (ASX) Corporate } \\
\text { Governance Council's Principles of Good Corporate Governance and Best Practice Recommendations (ASX } \\
\text { Corporate Governance Principles). The companies with greatest compliance with the Principles were found to } \\
\text { outperform less compliant companies in shareholder performance, operating performance and one-year sales growth } \\
\text { (Brown \& Gørgens, 2009) }\end{array}$ \\
\hline $\begin{array}{l}\text { Environmental } \\
\text { events }\end{array}$ & $\begin{array}{l}\text { Environmental incidents have an effect on firm value in Europe but less so in the USA with European companies } \\
\text { taking more voluntary action to avoid such events (Lundgren \& Olsson, 2010) }\end{array}$ \\
\hline Firm value & $\begin{array}{l}\text { Using the recent Standard \& Poors risk management rating, there was evidence of a positive relationship between } \\
\text { increasing levels of risk management capability and firm value (McShane, Nair, \& Rustambekov, 2011) }\end{array}$ \\
\hline $\begin{array}{l}\text { Intangibles: trust } \\
\text { in organisations }\end{array}$ & $\begin{array}{l}\text { Trust is hard to create and maintain and easy to destroy. While trust is intangible its loss can lead to financial damage } \\
\text { or to the value of "goodwill" (Kramer, 1999; Schnietz \& Epstein, 2005) }\end{array}$ \\
\hline $\begin{array}{l}\text { Occupational } \\
\text { health and safety } \\
\text { (OHS) \& financial }\end{array}$ & $\begin{array}{l}\text { Collective action in the process industry helps reduce the destruction of financial and non-financial value if a major } \\
\text { event causes significant loss of life (Brown et al, 2015) }\end{array}$ \\
\hline $\begin{array}{l}\text { OHS in } \\
\text { construction }\end{array}$ & $\begin{array}{l}\text { In the UK the Construction (Design and Management) Regulations (CONDAM) have driven professionalisation of } \\
\text { some parts of the construction industry and led to designers becoming involved earlier in projects than was previously } \\
\text { the case (Bennett \& Gilbertson, 2006) }\end{array}$ \\
\hline $\begin{array}{l}\text { OHS in } \\
\text { construction }\end{array}$ & $\begin{array}{l}\text { "Human characteristics like respect, trust, clarity, pre-emption, challenge, consistency, collaboration, motivation, } \\
\text { empowerment, communication, openness, fairness and assurance" were key to the positive outcomes for the London } \\
\text { Olympic Park. Many of the research findings offer benefits across a wide range of construction projects and for } \\
\text { different companies in the construction supply chain (Bolt et al, 2012; Cheyne et al, 2012) }\end{array}$ \\
\hline OHS in general & $\begin{array}{l}\text { Safety management has a positive influence on safety performance, competitiveness performance, and economic- } \\
\text { financial performance and provides evidence of the compatibility between worker protection and corporate } \\
\text { competitiveness (Fernández-Muñiz, Montes-Peón, \& Vázquez-Ordás, 2009) }\end{array}$ \\
\hline OHS in general & $\begin{array}{l}\text { There is increasing evidence that a healthy and safe working environment can increase productivity and, in turn, } \\
\text { business profits. Certain necessary ingredients are required including effective engagement of employees by } \\
\text { management (Finneran et al, 2012) }\end{array}$ \\
\hline OHS in general & $\begin{array}{l}\text { There is some evidence for a link between occupational health and safety, business performance and productivity in } \\
\text { New Zealand but the data appears to be skewed towards larger firms (Lamm, Massey, \& Perry, 2007) }\end{array}$ \\
\hline OHS in general & $\begin{array}{l}\text { A desktop audit of management of safety-related risks by the } 150 \text { largest companies listed on the Australian stock } \\
\text { exchange found a positive link between corporate safety management and share price (Larsson, Mather, \& Dell, 2007) }\end{array}$ \\
\hline $\begin{array}{l}\text { Price/earnings } \\
\text { ratio }\end{array}$ & $\begin{array}{l}\text { Effective management of physical or insurable risks was found to reduce the frequency of losses and so improve the } \\
\text { price/earnings ratio. The study found that companies with strong management of physical risks (caused by, for } \\
\text { example, fire, flood or earthquake) on average had earnings that fluctuated by } 17.9 \% \text { whereas companies with weak } \\
\text { physical risk management practices, on average, had earnings that fluctuated by } 31.4 \% \text {. "The stronger the physical } \\
\text { risk management practices, the lower the earnings volatility; the weaker the physical risk management practices, the } \\
\text { higher the earnings volatility" (Pretty, 2011) }\end{array}$ \\
\hline Share price & $\begin{array}{l}\text { A positive effect on share price was found in companies forming captive insurers (although other research has found } \\
\text { no benefits or even dis-benefits) (Cross, Davidson, \& Thornton, 1986) }\end{array}$ \\
\hline Share price & $\begin{array}{l}\text { Research on some insurers in the United States found a gain of about } 17 \% \text { of stock value for those companies that } \\
\text { used enterprise risk management (Hoyt, Moore, \& Liebenberg, 2008) }\end{array}$ \\
\hline Share price & $\begin{array}{l}\text { A reputation for social responsibility can protect companies from a fall in share prices after a crisis (Knight \& Pretty, } \\
\text { 2002) }\end{array}$ \\
\hline $\begin{array}{l}\text { Supply chain } \\
\text { disruption }\end{array}$ & $\begin{array}{l}\text { On average, supply chain disruption led to a } 10 \% \text { reduction in share price. Later research found the reduction could be } \\
\text { as high as } 40 \% \text { (Hendricks \& Singhal, } 2003,2005 \text { ) }\end{array}$ \\
\hline
\end{tabular}


Applied research by Ernst \& Young (2012) also found that companies with the highest levels of risk management maturity had, on average, double the annual growth rates of less mature competitors, suggesting that risk management acts to reduce uncertainty and facilitates achievement of objectives. Since the 1990s, such effects and those in Table 1 have led to incorporation of requirements for risk assessments as part of risk management in guidance on effective corporate governance (Financial Markets Authority, 2018; Hampel, 1998; New Zealand Stock Exchange, 2017; OECD, 2004).

Research into decision making over a 30-year period (Flyvbjerg, Bruzelius, \& Rothengatter, 2003; King \& Crewe, 2013; Lovallo \& Sibony, 2010; Nutt, 2002) showed that more than half of all decisions failed, with even some successful outcomes having unintended short-, medium-, or long-term negative effects on organisational and societal objectives, suggesting decision makers may not be well informed about risks in or to the decision to be made.

Decisions can be judged retrospectively as successful or unsuccessful but this may be unacceptable if the outcomes are adverse (Falconer, 2002), including whether they used a good or poor process and took account of the best available information. Falconer's two approaches have been combined in Table 2 to provide a judgement gradient from 1 (gaining rewards) to 4 (incurring severe criticism).

Table 2. Effectiveness of risk assessments for informing decision makers

\begin{tabular}{|l|l|l|}
\cline { 2 - 3 } \multicolumn{1}{c|}{} & \multicolumn{2}{c|}{ Decision outcomes } \\
\cline { 2 - 3 } \multicolumn{1}{c|}{} & \multicolumn{1}{c|}{ Successful outcome } & \multicolumn{1}{c|}{ Unsuccessful outcome } \\
\hline $\begin{array}{l}\text { Effective risk assessment process } \\
\text { informing the decision process or } \\
\text { model (rational or system 2 } \\
\text { thinking) }\end{array}$ & $\begin{array}{l}\mid c \\
\text { Good risk assessment process } \\
\text { contributing to desired outcomes or } \\
\text { achievement of objectives }\end{array}$ & $\begin{array}{l}\text { Despite an effective risk assessment } \\
\text { process, the desired outcomes or } \\
\text { objectives are, through bad luck, not } \\
\text { achieved }\end{array}$ \\
\hline $\begin{array}{l}\text { Ineffective decision process or } \\
\text { model (experiential or heuristics- } \\
\text { based thinking) }\end{array}$ & $\begin{array}{l}\mid c \\
\text { Despite a poor risk assessment process, } \\
\text { the desired outcomes or objectives are, } \\
\text { through good luck, achieved }\end{array}$ & $\begin{array}{l}\text { A poor risk assessment process leads to } \\
\text { failure to achieve the desired outcomes } \\
\text { or objectives }\end{array}$ \\
\hline
\end{tabular}

Source: adapted from Falconer (2002)

\subsection{The purpose of risk assessments}

Formal risk assessments are a relatively recent management technique used with varying degrees of success, requiring design and implementation (National Research Council, 2009, pp. 65-66), and validation through some quality assurance mechanism to avoid assessments being considered "fortune-telling" (Rae \& Alexander, 2017, p. 157). They ought to be a "game-changing" information technology (Goble \& Bier, 2013, p. 1942) because the purpose of an effective risk assessment is to discover, contextualise and reliably communicate risk information in an understandable representation to inform decisions and aid achievement of 
objectives (Taylor \& Van Every, 2000). This should engender stakeholder trust in subsequent decisions, improve productivity and facilitate adaptation and experimentation by decision makers and risk managers, rewarding better-managed businesses with greater market share.

This might especially be the case in organisations viewing "management-as-a-technology" (Bloom, Raffaella, \& Van Reenen, 2016, p. 1) and investing accordingly. There is, however, a need to address the lack of information about "cross-organisational variations in risk management" (Smallman, 1996, p. 260) and risk assessments.

When conducted in-house, risk assessments for occupational health and safety (OHS) were more successful than if conducted by a third party (Morillas, Rubio-Romero, \& Fuertes) and (Karageorgiou et al, 2000) might be hypothesised as "key methods".

Ineffective risk assessments, possibly due to inadequate management competence, can act as a constraint in management generally (Bloom, Sadun, \& Van Reenen, 2012) and, possibly, New Zealand management (Green et al, 2010). They may also explain some highprofile failures, including the failure of some projects (Mullen, 2007) to achieve forecast benefits, and show the need to improve risk assessment practices (Beasley, Branson, \& Hancock, 2015; Bloom et al, 2012; Flyvbjerg et al, 2003; Green et al, 2010; Jack \& Weavers, 2013; Miller et al, 2015).

Such ineffective risk assessments and management may arise due to poor or absent knowledge of the conduct of effective risk assessments (KPMG International, 2013). Findings from the literature (including reports on major adverse events), supported by experience as a consultant and while running professional development courses for managers, suggest that:

- strategic and day-to-day decision making is often informed by no, or ineffective, risk assessments

- there are low levels of knowledge of structured risk assessment processes and common techniques (eg, PESTLE and SWOT analyses), let alone more structured techniques.

For example, an Independent Taskforce, appointed by the New Zealand Government after the Pike River disaster that killed 29 men, found that tertiary-educated managers lacked training in occupational health and safety (Jager et al, 2013). Experience suggested this includes training in risk assessments. These findings highlighted a need to identify a consistent process for risk assessments based on best practice and internationally agreed definitions. 
Based on interviews with 36 executive managers from a range of sectors, Birkinshaw \& Jenkins (2010) argued that effective management of risk requires personal accountabilities (the goals or objectives of managers) and formalised risk assessment systems, processes and techniques capable of providing good quality information to decision makers.

\section{Critical success factors for effective risk assessments}

There is little research evidence describing the critical success factors (CSF) for a risk assessment other than the credibility of risk assessment [CORA] framework (Wiedemann et al, 2013) and an analysis of common risk assessment errors (Gadd et al, 2003) making it difficult to judge the effectiveness of a risk assessment. Further, the wide range of definitions of risk, risk-related terms and concepts in academic and "grey" literature may compound this problem, with different stakeholders in a risk assessment possibly using different definitions of risk - the very subject of the assessment. While the most widely used guidance documents follow a broadly similar approach they use different numbers of stages, often with different names, potentially causing confusion within and between organisational users and possibly contributing to sub-optimal risk assessments and management.

The origins of this research are therefore in practice-based problems arising from risk assessments that were intended to provide decision makers with the "best available information" or "weight of evidence". Such assessments lead to pragmatic consideration of "alternative futures that inform present actions" (Simpson, 2009, p. 1338) and then to decisions about "what we have to do today to be ready for an uncertain tomorrow" (Drucker, 1973, p. 125) and may lead to abductive reasoning (section 3.1.1).

\subsection{Legislation and standards}

During this research the New Zealand Health and Safety at Work Act (2015) came into force, setting out general duties to be complied with "so far as is reasonably practicable". Analysis of this phrase concluded it created an implied requirement to carry out a risk assessment and implement the findings before workers or "other persons" are harmed (Peace, 2017b). Section 44 of the Act requires "officers" (directors and some senior managers) to "gain an understanding of the nature of the operations of the business ... and risks", implying some understanding of assessed risks (Peace, Mabin, \& Cordery, 2017). Section 44 gives no guidance on when officers can rely on risk assessment findings from employees or consultants, but section 138 of the New Zealand Companies Act (1993) empowers directors to rely on reports from an employee believed by a director to be reliable and competent in relation to the matters concerned, or a professional advisor or expert who a director believes on reasonable grounds to be competent. 
Late in this research ISO31000(2018) Risk management: guidelines, ISO45001(2018) Occupational health and safety management systems and IEC/ISO31010(2019) Risk assessment techniques were published. None of these affected the findings of this research but all referencing to ISO31000 and IEC/ISO31010 in this thesis is to the 2009 editions unless otherwise stated.

\subsection{Research timeline}

The research described in this thesis was conducted part time over 6 years, initially as a Master of Commerce by Thesis starting in 2013, and converted into a PhD in 2015. For the Master's project, an online survey was conducted in 2014. The survey methodology (section 3.3) broadly followed the risk management process in ISO31000 to explore the processes and risk techniques being used in practice (chapter 4). On conversion to the $\mathrm{PhD}$, the research question and sub-questions (section 2.9) were expanded to explore the critical success factors and necessary conditions for an effective risk assessment, whether they could be combined in a goal tree, and how any constraints might be overcome. This opened up the opportunity to structure the online survey data analysis using the same goal tree. Five case studies were investigated in 2015-2016 and the ontology and epistemology of the goal tree was researched in 2017-2018.

\subsection{Summary}

This introduction has shown that effective risk assessments add value to organisations, with commercial, legal and social reasons for improving their practice. The next chapter, the literature review, examines relevant literature, finding problems with the selection of risk definitions and risk techniques before showing that organisational goals and objectives can be used to develop a tentative goal tree that will aid data analysis. The literature review concludes with a statement of the revised research question and sub-questions. 


\section{Literature review}

The title of this research is "The effectiveness of risk assessments in informing decision makers". The literature review therefore first considers what risk is before exploring risk assessors and how a risk assessment might be structured. The preferred definition of risk leads to a discussion of critical success factors (CSF) and necessary conditions (NC) for the goal of an effective risk assessment, and then to objectives or goals. This in turn leads to an exploration of the goal tree (GT), one of the tools in the Theory of Constraints (TOC). The review closes with a brief consideration of risk assessors, decision makers and decision making models.

Risk assessments are "practices-in-use" (Jarzabkowski, 2004, p. 529) - organisational phenomena - forming a unit of analysis that allow examination of one characteristic of management activities. They are widely discussed in the academic and "grey" literature such as international and national standards and generally reliable but non-academic sources such as major consultancy firms (Saunders, Lewis, \& Thornhill, 2007, p. 64). All such literature has been considered in this literature review.

\subsection{Definitions of risk: in search of a Goldilocks definition}

Any assessment of risk in an organisational setting (and thus understanding of the effectiveness of risk assessments in informing decision makers) requires understanding what risk is. Ideally, a definition of risk would be broadly acceptable to lay people, decision makers, practitioners and academics. However, definitions of risk seem, invariably, to result in controversy and debate (eg, Leitch et al, 2016). Here, the literature review considers some of the definitions and asks whether it is possible to arrive at a "Goldilocks definition" of risk one that is "just right".

\subsubsection{Definitions from academic literature}

While many have attempted to define risk there is no commonly agreed definition of risk within, let alone between, academic disciplines (Aven \& Renn, 2009). Different people, disciplines, groups and cultures perceive and define risk differently - a problem that has been discussed by many authors - and this may contribute to frequent mismatches between the findings of risk assessors and the needs of decision makers and other stakeholders. Indeed, an extensive review of the definitions of risk (Boholm, Möller, \& Hansson, 2016) concluded the word carries so many quantitative and qualitative meanings that it is difficult to define the word in any single way that is acceptable to most, let alone all, users.

Some seemingly objective definitions of risk are based on how risk is measured (eg, probability, size of loss, variance of the distribution of all possible consequences) but remain estimates of uncertainty (Alcock, MacGillivray, \& Busby, 2011; Walker, Shenkir, \& Barton, 
2003; Warner, 1983). Other definitions consider subjective or objective perceptions of risk showing the distinct differences between "social scientists" and "engineers" (Douglas \& Wildavsky, 1982; Warner, 1992, p. 2; Wynne, 1992). For some authors the social and subjective dimensions of risk are more important than considerations of the technical content (Zinn \& Taylor-Gooby, 2006) although a few have pragmatically attempted to deconstruct the notion that the subjective and objective are independent and antithetical concepts (Bourdieu, 1977).

March \& Shapira (2011) reviewed managerial perspectives on risk as a factor in decision making. They noted that classical decision theory saw risk as variations in possible outcomes, their likelihoods, and their subjective values: a risky outcome being one where negative variance is large or uncertain. Their review of empirical studies showed managers pay less attention to uncertainty about positive outcomes and that decision makers may define risk differently from academic writers. Similarly, Sitkin \& Pablo (1992, p. 10) defined risk in relation to decision making as:

...the extent to which there is uncertainty about whether potentially significant and/or disappointing outcomes of decisions will be realised.

Jüttner, Peck, \& Christopher (2003, p. 200) defined supply chain-related risk as "the variation in the distribution of possible supply chain outcomes, their likelihood, and their subjective values". Reference to "variation" and "subjective" suggest uncertainty.

For sociologists the "dominant discourse of risk" has been summarised as being a body of knowledge represented by a range of documents such as articles, textbooks and standards (including ISO31000, 2009) that bring "risk" as a subject into existence (Hardy \& Maguire, 2016, p. 81). This may be used by actors such as risk assessors who determine and report on the nature and level of risk so that others can respond to their findings.

A review of the epistemology of risk covered definitions used in mathematics and logic, science and medicine, economics, sociology, the arts, philosophy and theology, and concluded (Althaus, 2005, p. 580):

If risk is defined as the application of some form of knowledge to the unknown in an attempt to confront uncertainty and make decisions, then each discipline can be said to apply its own forms of knowledge to uncertainty that uniquely "creates" varying types of risk.

Inclusion of "the application of some form of knowledge" in a risk definition was unusual in such a review but reference to uncertainty confirmed the key role this plays in approaches to risk in many disciplines. While Althaus' inclusion of sociology, the arts, philosophy and theology acknowledged differences between subjective and objective risk it left unanswered 
how those differences might be reconciled (Douglas \& Wildavsky, 1982; Perrow, 1999). Hansson (2010, p. 236) succinctly summarised some of those differences suggesting:

... an accurate and reasonably complete characterisation of a risk must refer both to objective facts about the physical world and to (value) statements that do not refer to objective facts about the physical world.

This aligned with "the need for awareness of both the factual and the value dimensions of problems, and of the complexities in both" (Funtowicz \& Ravetz, 1992, p. 253) capturing the duality of subjective and objective risk, the need to take account of the tangible and intangible character of risk and of the articulated and unarticulated concerns of stakeholders.

\subsubsection{Uncertainty and risk}

Knight (1921, pp. 19-20) attempted an early definition of risk, arguing it sometimes means "a quantity susceptible of measurement" (ie, objective) while at other times there was such uncertainty that risk was not measurable. This led Knight to see risk and uncertainty as two distinct concepts: "if you don't know for sure what will happen, but you know the odds, that's risk, and if you don't know the odds, that's uncertainty", a view that has prevailed in some disciplines. However, uncertainty now forms part of many definitions of risk and may be ontological (incapable of reduction by further investigation) or epistemic (capable of reduction by better data collection and structural understanding). This might be done by establishing a common framework for discussion leading to different actors gaining an appreciation of alternative points of view. However, although each may have access to the same data they may reach different conclusions (as was subsequently found when testing the risk canvas - section 7.4).

Bammer et al (2008) summarised uncertainty about knowledge, arguing there are three types of unknowns, while Evans (2012) suggested a fourth combination of knowns and unknowns as summarised in Figure 1.

Figure 1. Known/unknowns matrix

\begin{tabular}{|c|c|c|c|}
\hline & & \multicolumn{2}{|c|}{ Meta level (do I have the relevant data?) } \\
\hline & & Yes & No \\
\hline \multirow{2}{*}{$\begin{array}{c}\text { Primary level } \\
\text { (Am I aware this } \\
\text { data is relevant?) }\end{array}$} & Yes & $\begin{array}{l}\text { Known knowns } \\
\text { Information largely complete but some } \\
\text { uncertainty about specifics related to } \\
\text { the content }\end{array}$ & $\begin{array}{l}\text { Known unknowns } \\
\text { Tacit knowledge, denial of information }\end{array}$ \\
\hline & No & $\begin{array}{c}\text { Unknown knowns } \\
\text { Conscious ignorance, questions have } \\
\text { not been answered }\end{array}$ & $\begin{array}{l}\text { Unknown unknowns } \\
\text { Meta-ignorance, questions have not } \\
\text { been identified let alone answered }\end{array}$ \\
\hline
\end{tabular}

Sources: Bammer, Smithson, \& Goolabri Group (2008) and Evans (2012 table 5) 
Uncertainty has now been researched by many academics, including Ale (2002) (who argued that only some uncertainties can be assessed using structured techniques and that uncertainty pervades all stages in risk assessments) and Aven (2011a) (who, discussing uncertainty in the application of the precautionary principle, showed why uncertainty may not be fully understood by some risk practitioners or decision makers).

Haimes (1998, pp. 238-252) summarised some of the many sources of epistemic uncertainty shown in Figure 2 (expanded to include the work of other authors) leading to the conclusion that uncertainty is part of risk and so should form part of all risk assessments. In Haimes' basic taxonomy (green in Figure 2), there may be variability across time, geography and the individuals who are the subject of a risk assessment. The knowledge used to inform a risk assessment may be selected inappropriately due to, for example, the biases of assessors or model designers and there may be gaps in data. Poor design of a risk assessment may result in uncertainty and the assessors may not have been trained in or know of relevant risk techniques. The National Research Council (2009) report also suggested areas of uncertainty (pink in Figure 2) as did other authors (not colour coded).

Figure 2. A taxonomy of some sources of epistemic uncertainty in risk assessments

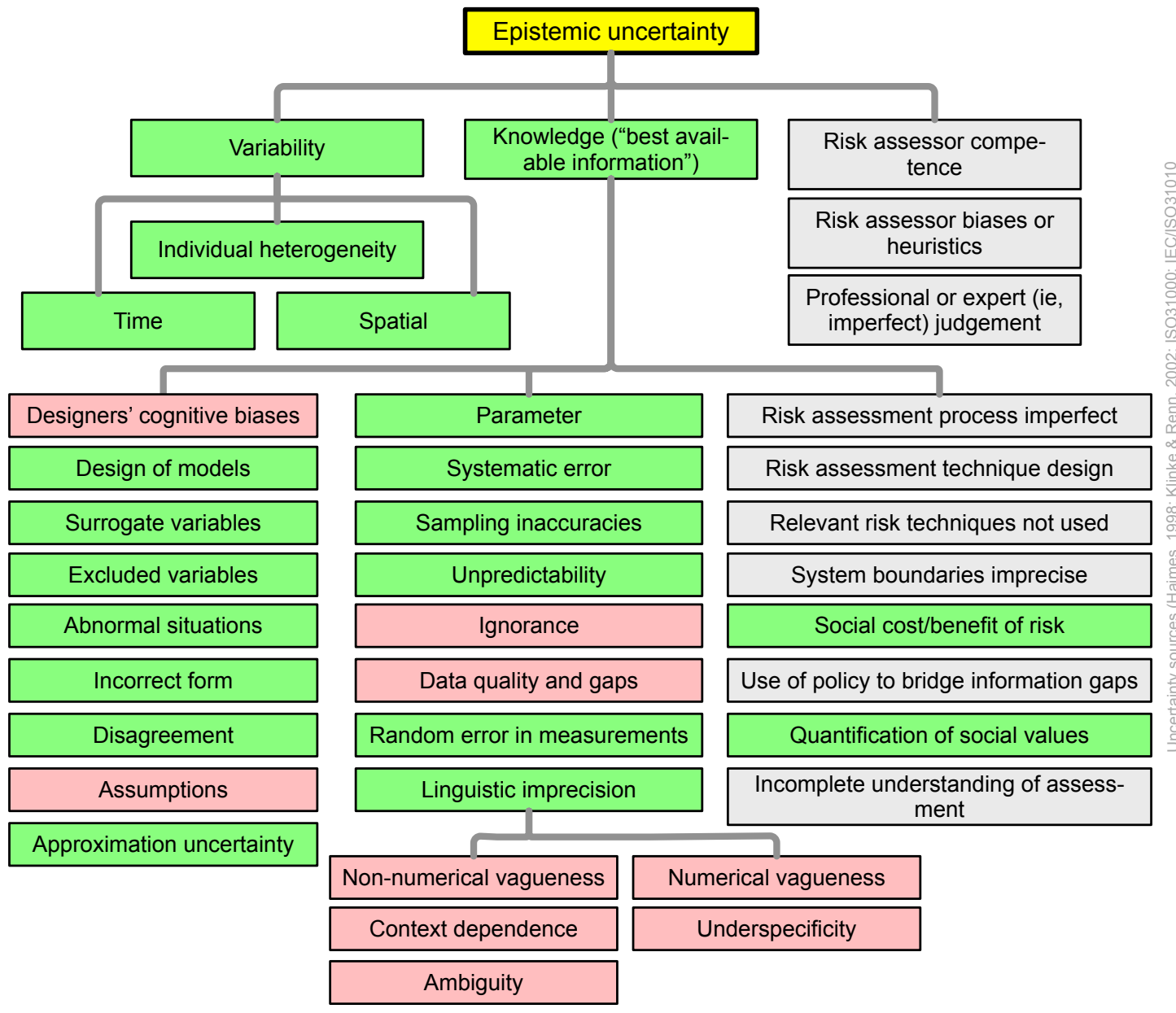

Sources: adapted by the author from Haimes (1998), Kasperson (2008), Morrison \& Morgan (1999b), National Research Council (2009) and Regan, Colyvan \& Burgman (2002), 
As Figure 2 shows, there are so many variables that no risk assessment can claim to respond to them all accurately and even an "expert judgement" based on the best available information may be inaccurate (Fischhoff et al, 1980). Thus, results of expert or professional judgement (discussed in more detail in section 6.5.2) should be expressed in confidence ranges (Burgman, 2016).

Finally, definitions of risk might matter little provided they are clearly stated in any risk assessment or risk management activity (Aven, 2013). This enables some rational discussion about risk but may not respond to the concern that control of the definition of risk "is an thus an exercise in power", capable of swaying the results of a risk assessment (Slovic, 1999, p. 699).

In summary, in the objectivist academic literature, risk is often defined as either:

- the effect of uncertainty on something of human value (eg, personal or organisational objectives), or

- the combination of probability of a consequence or, sometimes, the probability of an event (a way of measuring risk, not defining it).

Subjectivists see risk more as the intangible concerns of stakeholders. Thus, for the purposes of this research, inclusion of uncertainty (and its effects on something of value) and subjective elements are important components of the definition of risk.

\subsubsection{Definitions from legislation, standards and guidance documents}

One of the drivers for this research was the change in occupational health and safety legislation in New Zealand in 2013-2016. When the Transport and Industrial Relations Committee (2015, p. 5) reported the Health and Safety Reform Bill (2014) back to the New Zealand House of Representatives it said:

We prefer the common meanings of "risk" and "hazard", to encourage people to consider what risk means to them, in their particular circumstances.

Given the nature of the duties of care set out for different actors under the Health and Safety at Work Act (2015) this was an unfortunate decision as each duty-holder in a workplace might define risk differently, with potentially conflicting results of assessments.

Standards, codes and guidance on risk management appear to be dominated by (Dali et al, 2012):

- ISO31000 (2009) Risk management: guidelines

- Committee of Sponsoring Organizations of the Treadway Commission (COSO, 2004, 2016) Enterprise Risk Management 
- Project Management Institute's Project Management Body of Knowledge (PMBoK) (PMI, 2013)

- Food and Agriculture Organization/World Health Organization Procedural Manual (FAO/WHO, 2013) ${ }^{1}$

- World Organization for Animal Health Terrestrial Animal Health Code $\left(\right.$ WOAH, 2014) ${ }^{2}$

- Secretariat of the International Plant Protection Convention (IPPC, 2004) Pest risk analysis for quarantine pests including analysis of environmental risks and living modified organisms ${ }^{3}$.

ISO31000, COSO and PMBoK seem to be the most commonly used standards in the corporate sector. The FAO/WHO, WOAH and IPPC documents are widely used in relation to trade, food safety and animal health, and the Society for Risk Analysis glossary (SRA, 2015) provides several qualitative and quantitative definitions of risk, emphasising variations in how practitioners might use the word. These definitions are analysed in Table 3.

During the development of ISO31000 difficulties in defining "risk" were experienced by the multinational team of 40 experts, one of whom reported (G. Purdy 2019, email 5 May) "When we decided on 'the effect of uncertainty on objectives' at the ISO RM WG in Vienna, we were clear that the 'objectives' were the highest level rationale for the organisation to exist". This succinct definition was unclear to some people and had to be elaborated on by five notes. Other standards give different definitions of risk (eg, the "combination of the probability of occurrence of harm and the severity of that harm" (Safety of Machinery ISO12100, 2010)) while ISO45001(2018, p. 5) OHS management systems contains two definitions of risk:

occupational health and safety risk: combination of the likelihood of occurrence of a work-related hazardous event or exposure(s) and the severity of injury and/or ill health that can be caused by the event or exposure(s)

risk: effect of uncertainty

The first defines risk in terms of how it is measured, not what it is, and is not consistent with the second definition, taken from ISO/IEC Annex SL that is close to the ISO31000 definition but does not include objectives. Such definitions describe how to measure risk, not what it is, and imply the probability and severity of harm are certain when they rarely are.

\footnotetext{
${ }^{1}$ The 2018 edition of the manual was published near the end of this research but with no substantive change.

${ }^{2}$ The 2017 edition of the code contained no substantive change.

${ }^{3}$ The 2017 edition of the document contained no substantive change.
} 
Table 3. Summary of definitions of risk from standards, codes and guidance

\begin{tabular}{|c|c|c|c|c|c|}
\hline & $\begin{array}{l}\text { ISO31000 } \\
\text { (2009) }\end{array}$ & $\begin{array}{c}\text { COSO ERM } \\
(2004,2016)\end{array}$ & $\begin{array}{c}\text { PMBoK (PMI, } \\
\text { 2013) }\end{array}$ & $\begin{array}{l}\text { SRA (2015) } \\
\text { (seven } \\
\text { qualitative and } \\
\text { six quantitative } \\
\text { definitions) }\end{array}$ & $\begin{array}{c}\text { FAO/WHO (2013) } \\
\text { WOAH (2014) }\end{array}$ \\
\hline Risk is ... & $\begin{array}{l}\text { effect of } \\
\text { uncertainty on } \\
\text { objectives }\end{array}$ & $\begin{array}{l}\ldots \text { the } \\
\text { possibility that } \\
\text { events will } \\
\text { occur and } \\
\text { affect the } \\
\text { achievement } \\
\text { of strategy } \\
\text { and business } \\
\text { objectives }\end{array}$ & $\begin{array}{l}\ldots \text { an uncertain } \\
\text { event or } \\
\text { condition that, if } \\
\text { it occurs, has a } \\
\text { positive or } \\
\text { negative effect } \\
\text { on one or more } \\
\text { project objectives } \\
\text { such as scope, } \\
\text { schedule, cost, } \\
\text { and quality }\end{array}$ & $\begin{array}{l}\text {... possibility of } \\
\text { an unfortunate } \\
\text { occurrence } \\
\text { potential for } \\
\text { realisation of } \\
\text { unwanted, } \\
\text { negative } \\
\text { consequences } \\
\text { of an event } \\
\ldots \text { exposure to } \\
\text { a proposition ... } \\
\text { of which one is } \\
\text { uncertain } \\
\ldots \\
\text { consequences } \\
\text { of the activity } \\
\text { and associated } \\
\text { uncertainties }\end{array}$ & $\begin{array}{l}\ldots \text { a function of } \\
\text { the probability of } \\
\text { an adverse health } \\
\text { effect and the } \\
\text { severity of that } \\
\text { effect, } \\
\text { consequential to } \\
\text { a hazard(s) in } \\
\text { food }\end{array}$ \\
\hline An effect & $\begin{array}{l}\text { Explicitly } \\
\text { included }\end{array}$ & $\begin{array}{l}\text { Explicitly } \\
\text { included }\end{array}$ & $\begin{array}{l}\text { Explicitly } \\
\text { included }\end{array}$ & $\begin{array}{l}\text { Not specifically } \\
\text { mentioned }\end{array}$ & Explicitly included \\
\hline Objectives & $\begin{array}{l}\text { Explicitly } \\
\text { included and } \\
\text { examples given }\end{array}$ & $\begin{array}{l}\text { Explicitly } \\
\text { included and } \\
\text { examples } \\
\text { given }\end{array}$ & $\begin{array}{l}\text { Explicitly } \\
\text { included and } \\
\text { examples given }\end{array}$ & $\begin{array}{l}\text { Not explicit but } \\
\text { refers to human } \\
\text { safety and } \\
\text { damage to } \\
\text { assets }\end{array}$ & $\begin{array}{l}\text { Not explicit but } \\
\text { other documents } \\
\text { refer to the } \\
\text { objective of } \\
\text { human health }\end{array}$ \\
\hline $\begin{array}{l}\text { Positive or } \\
\text { negative }\end{array}$ & Both included & Negative only & Both included & Mostly negative & Negative only \\
\hline $\begin{array}{l}\text { Multiple } \\
\text { potential } \\
\text { causes }\end{array}$ & $\begin{array}{l}\text { Multiple causes } \\
\text { are included via } \\
\text { the definition of } \\
\text { "event" }\end{array}$ & $\begin{array}{l}\text { Not } \\
\text { mentioned }\end{array}$ & $\begin{array}{l}\text { Multiple causes } \\
\text { explicitly } \\
\text { included }\end{array}$ & Not mentioned & Not mentioned \\
\hline $\begin{array}{l}\text { Potential } \\
\text { events }\end{array}$ & $\begin{array}{l}\text { Explicitly } \\
\text { included in note } \\
3\end{array}$ & $\begin{array}{l}\text { Explicitly } \\
\text { included }\end{array}$ & $\begin{array}{l}\text { Explicitly } \\
\text { included }\end{array}$ & Not mentioned & Not mentioned \\
\hline $\begin{array}{l}\text { Multiple } \\
\text { potential } \\
\text { consequences }\end{array}$ & $\begin{array}{l}\text { Consequences } \\
\text { as plural } \\
\text { included in note } \\
3\end{array}$ & $\begin{array}{l}\text { Not } \\
\text { mentioned }\end{array}$ & $\begin{array}{l}\text { Multiple } \\
\text { consequences } \\
\text { explicitly } \\
\text { included via use } \\
\text { of the word } \\
\text { "impacts" }\end{array}$ & $\begin{array}{l}\text { Several } \\
\text { definitions refer } \\
\text { to multiple } \\
\text { consequences }\end{array}$ & $\begin{array}{l}\text { Implies single } \\
\text { effects }\end{array}$ \\
\hline $\begin{array}{l}\text { Combination of } \\
\text { consequences } \\
\text { and their } \\
\text { likelihood (as } \\
\text { distinct from } \\
\text { likelihood of an } \\
\text { event) }\end{array}$ & $\begin{array}{l}\text { Included in note } \\
4\end{array}$ & $\begin{array}{l}\text { Not } \\
\text { specifically } \\
\text { stated }\end{array}$ & $\begin{array}{l}\text { Not specifically } \\
\text { stated }\end{array}$ & $\begin{array}{l}\text { Examples refer } \\
\text { to the } \\
\text { magnitude of } \\
\text { the damage }\end{array}$ & $\begin{array}{l}\text { Uses the } \\
\text { probability of an } \\
\text { adverse } \\
\text { consequence }\end{array}$ \\
\hline Uncertainty & $\begin{array}{l}\text { Explicitly } \\
\text { discussed in } \\
\text { note } 5 \text { and } \\
\text { applicable to } \\
\text { context, } \\
\text { causes, events } \\
\text { or } \\
\text { consequences }\end{array}$ & $\begin{array}{l}\text { Implied by } \\
\text { use of the } \\
\text { word } \\
\text { "possibility" }\end{array}$ & $\begin{array}{l}\text { Explicitly } \\
\text { included }\end{array}$ & $\begin{array}{l}\text { Eight } \\
\text { descriptions of } \\
\text { uncertainty }\end{array}$ & $\begin{array}{l}\text { Implied by use of } \\
\text { the word } \\
\text { "probability" }\end{array}$ \\
\hline
\end{tabular}


Definitions used in guidance documents have increasingly referred to uncertainty as part of risk. In the definitions of risk summarised in Table 3 this is either plainly stated or implied. Thus, any risk assessment is an uncertain estimate of future outcomes and how they will affect objectives, the personal accountabilities of managers (Birkinshaw \& Jenkins, 2010) or some human values. This is especially clear in ISO31000 (which envisages uncertainty existing in relation to objectives) and PMBoK, and least clear in the WHO/FAO guidance.

\subsubsection{Summary}

This brief review shows there is no Goldilocks definition of risk - one that is "just right". The wide range of definitions of risk demonstrates as much about the origins and disciplines of authors as the definitional differences and, in some situations, this might require negotiation of an agreed definition. Failure to understand differences in definitions of risk may result in failure to communicate and consult adequately with stakeholders, including decision makers, each of whom may have different definitions and perceptions of risk.

While the above suggest a risk assessor should define risk in the context of their work and make clear to stakeholders how the word is being used, the analysis in Table 3 suggests ISO31000 provides an adequate definition of risk ("effect of uncertainty on objectives") in the context of this research as it links objectives - what organisations exist to achieve - and uncertainty, as further explored in Section 2.6.

This view is supported by the COSO and PMBoK definitions which also refer to objectives. Inclusion of uncertainty in the ISO31000 definition is highly relevant here because there is never certainty about achievement of organisational objectives unless and until they have been achieved. Such causal uncertainties need to be identified as part of a risk assessment.

\subsection{Risk assessors and sophistication of risk assessments}

Here the implications of risk assessor competence are briefly explored in relation to the complexity of a risk assessment and available risk techniques.

Funtowicz \& Ravetz (1992, pp. 251-273) described three levels of risk assessment sophistication scaled from applied science (eg, using simple but reliable techniques), through work by a professional consultancy, to "post-normal science" ("a dialogue among all the stakeholders in a problem, regardless of their formal qualifications or affiliations"). Ford et al (2008) developed a similar three-level approach to risk assessments from simple, to standard, to model-based that has been combined with the Funtowicz \& Ravetz model to create Figure 3. This includes a fourth level - codes, standards, standard operating procedure, and other documented responses to risk - that suggests levels of risk assessor 
competence (from lay person to practitioner, professional and "scientist"), and sophistication of risk assessment (from application of published codes to highly sophisticated using models).

Figure 3. Risk assessment sophistication

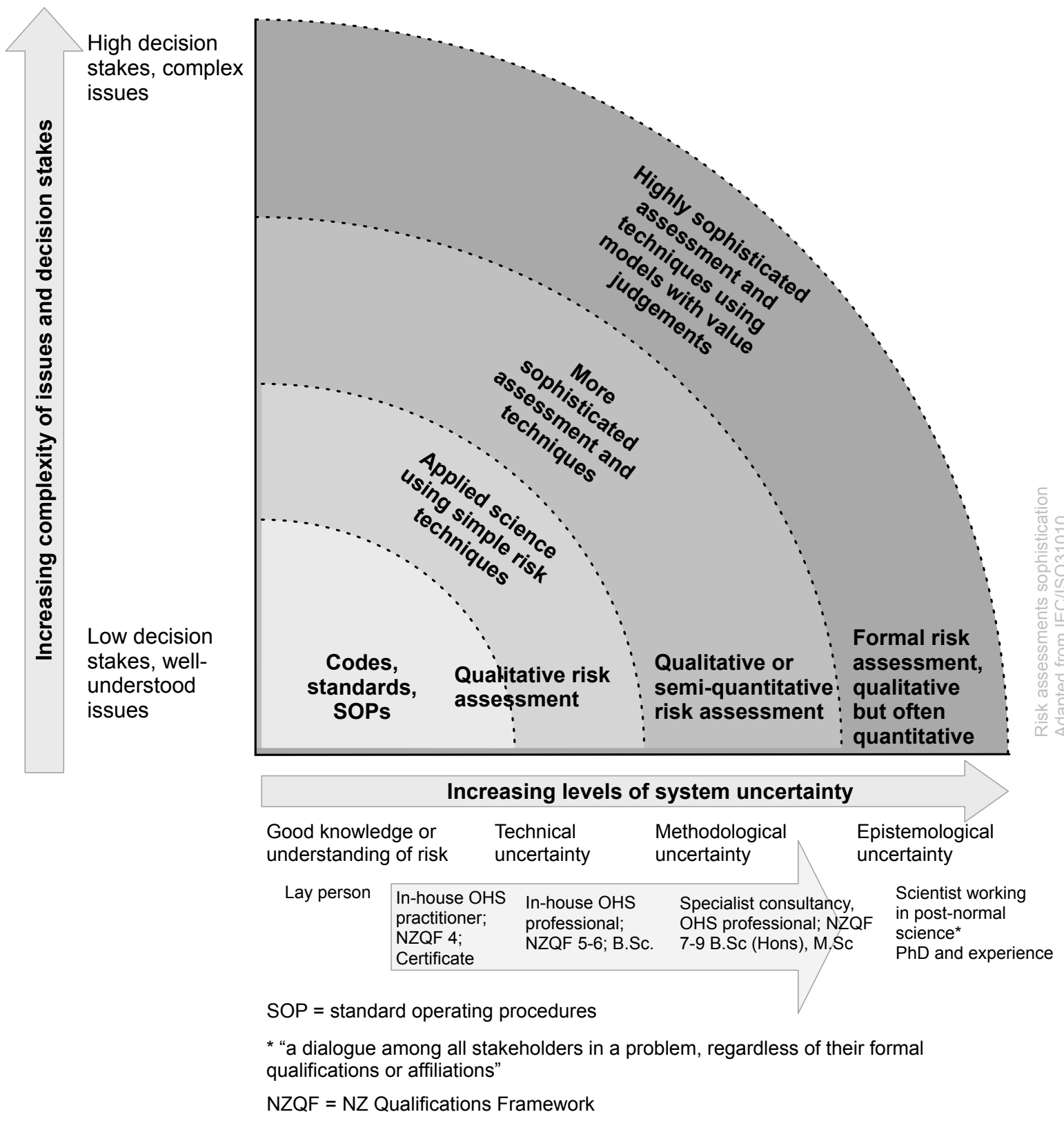

Adapted from Ford et al (2008), Funtowicz \& Ravetz (1992, pp. 251-273) and INSHPO (2017, pp. 10-11) with additions by author

In Figure 3, written codes, standards, and standard operating procedures (SOPs) should be such that workers and line managers can apply them in low-complexity, well understood "if/then" circumstances. As uncertainty and complexity increase, simple risk assessments using qualitative techniques should be carried out by trained 'practitioners' who have the competence to apply relevant techniques. Higher levels of uncertainty or greater complexity 
would require qualitative (sometimes quantitative) work by an in-house 'professional' or specialist consultancy, while highly complex risks with high uncertainty may require formal qualitative and often quantitative work by scientists.

The online survey included a question (section 4.3.10) exploring the codes, standards, etc used by respondents.

The terms 'practitioner' and 'professional' in Figure 3 have been adapted from the International Network of Safety and Health Practitioner Organizations (INSHPO, 2017, pp. 10-11) guidance that also sets out three levels of OHS practitioner qualifications under the Australian National Qualifications Framework (AQF 4-6) and three levels of professional (AQF 7-9) (comparable to the New Zealand and European Qualifications Frameworks (https://www.nzqa.govt.nz/)). While intended for those working in OHS the guidance might also be applicable to other people carrying out risk assessments in an organisational context. External professionals might also act as peer reviewers for in-house practitioners.

The online survey included questions about qualifications (section 4.3.3) and the results and issues associated with professional judgement are discussed in section 6.5.2.

\subsection{Risk assessments}

\subsubsection{Purpose of risk assessments}

All decisions are about or include risk and so should be supported by some form of risk assessment to assess the effect of uncertainty on objectives. The output from a risk assessment might range from the informing a simple "GO/NO GO" decision or a more nuanced strategic decision. The more significant the decision to be made, the more detailed and independent the risk assessment should be (Miller et al, 2015). Thus, the purpose of risk assessments is to discover and contextualise knowledge about uncertainty in risk "pictures" (Aven, 2003, p. 88), communicated by a credible person, that aids rational decisions (Taylor \& Van Every, 2000). Risk assessments should follow a structured and systematic process (Gerstein et al, 2016) to help provide a consistent approach to risk management (Mullen, 2007), and qualitative analysis should precede quantitative analysis (Aven, 2008). However, research in the UK (Gadd et al, 2000) and Germany (Lenhardt \& Beck, 2016) suggested that risk assessments may not be carried out, even when a legal requirement (Karageorgiou et al, 2000) or financially beneficial (Ernst \& Young, 2012). However, very little research into organisational risk assessments and their effectiveness (especially in New Zealand) was found. 
The larger or more complex the decision to be made the more it may require several, even many, risk assessments (Flyvbjerg et al, 2003, pp. 80-81). However, if each risk assessment is carried out by different assessors using different definitions, models or approaches there may be confusions, overlaps or gaps between the risk assessments, so increasing uncertainty for decision makers. Decision makers and stakeholders in major projects may be routinely inadequately informed - even misled - about risks (Flyvbjerg et al, 2003). The same issues emerged from the Royal Commission on the Pike River Coal Mine Tragedy (2012, pp. 52-54).

While enterprise or organisational risk assessments may not be science (Cumming, 1981) they ought to be reproducible, impartial and as accurate as possible, so providing the best available information to decision makers (Aven, 2017, 2018). Any risk assessment requires consideration of low probability events and their consequences (Burgman, 2005, p. 2) and, as summarised in Figure 2, should include discussion of uncertainty and comment on issues such as the reliability, quality and quantity of available data, use of assumptions, incomplete understanding and judgements or use of policy positions that were employed to bridge information gaps. However, such discussion may be incomplete or absent due to the competence, biases or heuristics of the risk assessors (Kahneman, Slovic, \& Tversky, 1982; MacGillivray, 2013) and a risk assessment may be ineffective if an assessor (Chance \& Brooks, 2010; Morrison \& Morgan, 1999b):

- uses a deficient risk assessment process or model that incorrectly frames the risk assessment

- uses no, or inappropriate, risk techniques

- incorrectly describes or measures risk

- fails to adequately address uncertainty

- uses complex statistical analyses prone to incorrect results

- inadequately communicates the results to decision makers.

Also, as with definitions of risk, there is controversy about the language of risk assessment (Leitch, 2010) and, together, these factors may contribute to risk management failures (Gadd et al, 2003; Simon, 1979; Stulz, 2008). However, despite such issues, some organisations do carry out risk assessments that provide high confidence in their effectiveness and trust in the risk assessors (Earle, 2010).

\subsubsection{Risk assessment processes}

Many risk assessment processes are available (including those discussed here), often using differently defined terms, so giving rise to conflicts between and within different academic and professional groups. For example, different risk assessment processes may be followed 
within an organisation depending on whether the assessment is carried out for strategic or operational purposes and ISO/IEC Annex SL (2012) (which provides a framework for all management system standards) places risk assessment in clause 6 (Planning) or 8 (Operation).

These variations were underlined by a Scientific Steering Committee $(2000$, p. 6) report to the European Union (EU) on harmonising risk assessment processes for human health and environmental impacts that included the comment that "... it is recognised that total harmonisation of risk assessment processes in the EU is not achievable in the short to medium term".

Although an OECD expert group was reported (Ale, 2002, p. 124) as saying that "efforts to map out the steps in the risk assessment process and the approaches/methodologies used therein" would "aid mutual understanding of risk assessment" it was reported as concluding that "standardisation of the risk assessment process, and approaches/methodologies used in each step of the process is neither desirable nor feasible". Neither the EU nor the OECD report commented on the earlier risk assessment guidance published by the FAO, WHO and WOAH but these are included here as they have a wide user base in regulatory agencies. Subsequently, Yaraghi \& Langhe (2011) argued that all available standards either lacked sufficient clarity or were limited to a small range of business types.

\section{Standards and documents for review}

Despite such reservations ISO31000 was published in 2009 (and revised and re-issued in 2018) and achieved wide international usage other than in African countries (Global Institute, 2015), although controversy about its language and construction remained (eg, Aven, 2011b; Leitch, 2010; Purdy, 2010). Evidence in favour of ISO31000 was provided in a critical review of the standard (Lalonde \& Boiral, 2012) where it was argued the standard provides a generic framework for managing any type of risk in any type of organisation, although a proposed research agenda for management system standards (Heras-Saizarbitoria \& Boiral, 2013) did not include ISO31000 or the other documents reviewed here.

A survey by Dali et al $(2012$, p. 33) allowed multiple selections to the question "which of the following standards/guidelines are used in your organisation?". Of the 1338 responses, three broadly similar standards ISO31000 (2009), AS/NZS4360(2004) and ISO27005(2011) were cited by $70 \%$ of respondents $(36 \%, 13 \%$ and $21 \%$ respectively). Respondents selected Committee of Sponsoring Organizations of the Treadway Commission (COSO) enterprise risk management (18\%), Project Management Body of Knowledge (PMBoK) (17\%), and Basel Committee on Banking Supervision (11\%). Respondents also selected "in-house 
documents" $(40 \%)$. While it is not possible to know what these contained they may have been based on source documents such as COSO or ISO31000.

Raz and Hillson (2005) reviewed six international or national standards and three professional standards. One (IEEE1540-2001) related to software lifecycle processes and is ignored here as being too narrow in focus. While four of the documents related to project risk management all but one (PMBoK) were ignored as they have been superseded or could not be accessed. The others were either derived from AS/NZS 4360 or very similar to that standard. The International Risk Governance Council (IRGC) White Paper on Risk Governance (Renn, 2008b) was included here because it appeared to represent an emerging, research-based European model.

The Terrestrial Animal Health Code (WOAH, 2014) uses a different process and language to those in ISO31000. However, based on work by Pharo (2002, 2004), Biosecurity New Zealand (2006), and a review of biosecurity risk analyses used by the Australian Department of Agriculture (Peace, 2013) it is evident that some biosecurity-related risk assessments include the stages set out in ISO31000.

Nothing has been found in the literature comparing the World Organization for Animal Health (WOAH), World Health Organization (WHO) or Food and Agriculture Organization (FAO) processes with ISO31000, IRGC or COSO. This is somewhat surprising given the importance attached to human health and biosecurity risks in the global and New Zealand economies and the self-regulatory control that private sector organisations are now expected to exert over such risks (Parker, 2002, pp. 31-61).

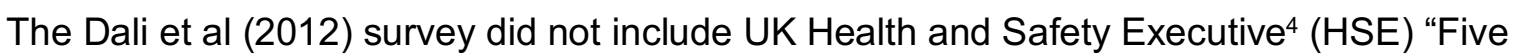
Steps" guidance on risk assessments (HSE, 1998) although more than 3.3 million copies had been downloaded up to 2006 (Neathey et al, 2006) since when it has been revised to the fourth edition (HSE, 2014a) making it one of the most widely used guides on risk assessments.

The above documents are summarised in Table 4, each representing a school of thought about how risk should be assessed and where column 1 (in key definitions and concepts) suggests that a risk assessment is a System 2 thinking process (Kahneman, 2011) requiring identification and evaluation of data in what may be a dynamic business process. This is true for even the simplest risk assessment process. As complexity and uncertainty increase, the risk assessment activity will need to be more structured and use appropriate techniques if relevant data is to be gathered, evaluated and reported effectively.

\footnotetext{
${ }^{4}$ The HSE is the UK regulatory agency for industrial and major risks
} 
Table 4. Comparison of common risk management processes

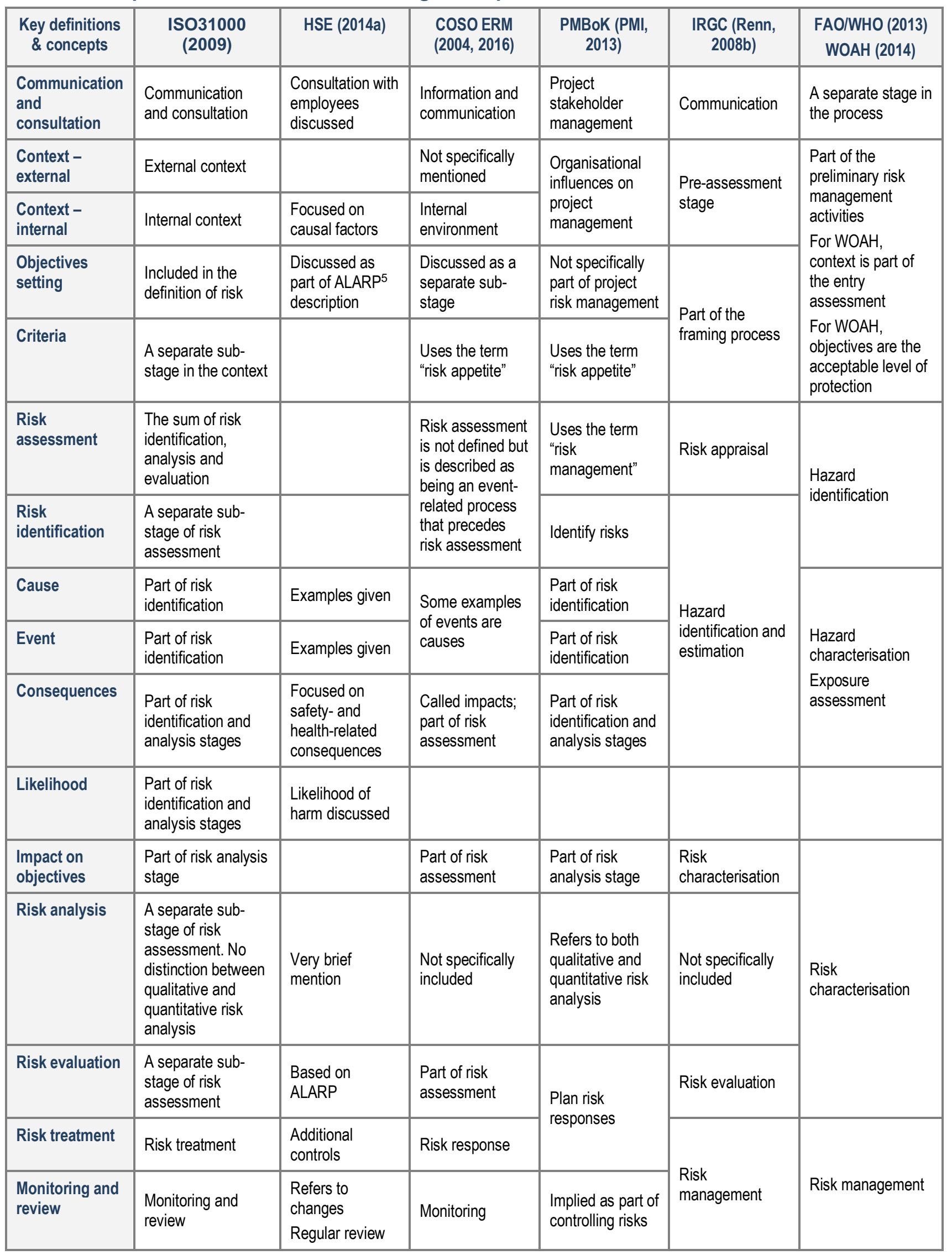

\footnotetext{
${ }^{5} \mathrm{ALARP}=$ as low as is reasonably practicable, a legal test, derived from English common law
} 
While the above analysis and Table 4 led to the conclusion that the ISO31000 risk management process describes the most effective risk assessment process, a difficulty with the standard is that risk assessment (the "overall process of risk identification, risk analysis and risk evaluation") is described as being part of the risk management process even though other stages in the risk management process are key to a risk assessment. In this research, risk assessment includes communicating, consulting, establishing the context, and identifying, analysing, evaluating, treating, monitoring and reviewing risk because research has shown these to be important for an effective risk assessment. This made it necessary to include each such stage in the Key definitions and concepts list, and contributed to the subsequent development of the tentative goal tree (section 3.2) and a conference paper on risk terminology (Peace, 2017a).

\section{Summary}

Each of the standards analysed in Table 4 are pragmatic, simplified models of processes (Morrison \& Morgan, 1999b) that enable communication between members of a community of actors, and so provide mediated access to the world (Fleetwood, 2005), thus creating uncertainty due to the simplifications it requires.

While this review shows ISO31000 conflicts with other approaches (especially the $\mathrm{FAO} / \mathrm{WHO}$ /WOAH approach) in both structure and language, it suggests that ISO31000 sets out the stages for an effective risk assessment in "a single concise and practical model" (Lalonde \& Boiral, 2012, p. 293), aligned with decision making about objectives and goals, that is suitable for all organisations and any risk.

\subsection{Risk techniques}

Section 2.2 showed the need for risk techniques to gather information about increasing levels of system uncertainty as issues and decision stakes become increasingly complex. However, reliable outcomes from the use of techniques may require a selection process and development of competence in their application. For example, Chinniah et al (2011) identified and assessed 31 qualitative risk techniques used in machinery safety risk assessments and found significant differences between them when applied to the same situations. That is, risk may be technique dependent, potentially leading to biased or incorrect results. This important finding has been little researched.

A further problem was reliability of quantitative data for use in quantitative risk analyses (Hopkins, 2004; HSE, 1989), suggesting such analyses may be unreliable. 


\subsubsection{Identification of risk techniques}

A technique is "a specific activity that has a clear and well-defined purpose within the context of a methodology" (Mingers \& Brocklesby, 1997, p. 491) or an "an instrument which conveys some advantage to its user in the execution of a task" (Frei et al, 2003, p. 1).

This section reviews the literature on risk techniques that might aid purposeful informationgathering activities, when and why they might be used, how they might be selected, and how they might fit with the maturity of organisations. The purpose of risk techniques is therefore to enable discovery of the best available information (section 3.5) about the effects of uncertainty on the achievement of organisational objectives. Techniques identified in this section were then used in the online survey (chapter 4 ) and the risk canvas (section 7.4). The literature review found 160 articles identifying possible risk techniques and an internet search using Google Scholar yielded a further 51 potential sources of techniques. While some articles reviewed single techniques, others identified or reviewed two or more (Ammar, Berman, \& Sataporn, 2007; Baker, Ponniah, \& Smith, 1998, 1999; Cagliano, Grimaldi, \& Rafele, 2015; Curtis \& Carey, 2012; Gould, Glossop, \& loannides, 2005; Hillson, Grimaldi, \& Rafele, 2006; Miller et al, 2015; Papazoglou et al, 1984; Rafele, Hillson, \& Grimaldi, 2004; Raz \& Michael, 2001; Williams, 1995).

Ten books (Aven, 2008; Chapman, 2011; Cooper et al, 2005; Haimes, 1998; Modarres, 2006, 2017; Stewart \& Melchers, 1997; Swallom, Lindberg, \& Smith-Jackson, 2003; Turney \& Pitblado, 1996; Woods, 2011, p. 34) provided corroboration for the techniques found in the above articles. Reviews of techniques and models used in process safety (Khan, Rathnayaka, \& Ahmed, 2015) and information systems (ENISA, 2006) described many variations on risk techniques while a taxonomy of risk techniques prepared for NASA by Goldberg et al (1994) gave the greatest number and descriptions of techniques. It was anticipated the online survey and case studies might identify other risk techniques. Some techniques were found to be common to other areas of management (eg, Proctor, 2009), including strategic, marketing, quality, environmental and project management, and software development and engineering design and production. However, some standard texts on financial risk management (eg, Chance \& Brooks, 2010) made no mention of risk assessment or risk techniques.

Some techniques are documented in international standards including:

- IEC/ISO31010 (2009) Risk management - Risk assessment techniques (this edition listing 29 techniques was used in this research but was likely to be replaced by a 2019 edition listing 41 techniques; the additional 12 techniques were identified in other sources cited above) 
- ISO 17776 (2016) Petroleum and natural gas industries - Offshore production installations - Major accident hazard management during the design of new installations describes 15 techniques of relevance to the offshore sector

- IEC1025 (2008) Fault tree analysis

- IEC60812 (2008) Failure modes and effects analysis

- IEC61882 (2016) Hazard and Operability (HAZOP) Studies.

\section{Risk techniques for further review}

If a risk technique was named at least three times in the literature it was selected for further review and (using guidance in IEC/ISO31010 (2009)) grouped under one or more of the stages in the ISO31000 risk management process (the "systematic application of management policies, procedures and practices to the activities of communicating, consulting, establishing the context, and identifying, analysing, evaluating, treating, monitoring and reviewing risk").

The grouped techniques were then discussed with two experienced risk practitioners and two focus groups of practitioners forming part of the pre-testing of the online survey (chapter 4). As a result, some techniques were added to the groups and some were removed.

"Professional judgement" was raised in one of the focus groups by one person who argued strongly it was widely used and should be included in the list of risk techniques. It was later included in the online survey despite difficulties with defining its meaning.

\section{Grouping risk techniques}

In Figure 4 the ISO31000 risk management process stages have been numbered 1-10 and risk assessment techniques grouped, numbered 1-10 and linked to the stages. Figure 4 was subsequently published in Peace (2017b) and later formed the basis of Figure A.1 in the international standard (IEC/ISO31010, 2019).

The grouped techniques later formed the basis for questions in the online survey (section 3.3).

\section{Human factors}

Identification and analysis of human or performance shaping factors (Rasmussen, 1982) that affect the dependability of any system or activity should form part of any risk assessment but are often overlooked, even in some safety-related assessments (Gadd et al, 2000), perhaps due to a lack of training of designers and risk or safety practitioners. Human reliability techniques described by Smith (2011) and other authors have been included in Figure 4 and 
some guidance on human aspects of dependability is readily available (HSE, 1999;

IEC62508, 2015).

\section{Figure 4. Risk techniques in the risk management process}

This graphic is based on the ISO 31000 risk management process diagram. Possible risk techniques are shown in boxes with solid lines and curved corners to indicate where they might be used. Note that some techniques can be used in several stages of the process.

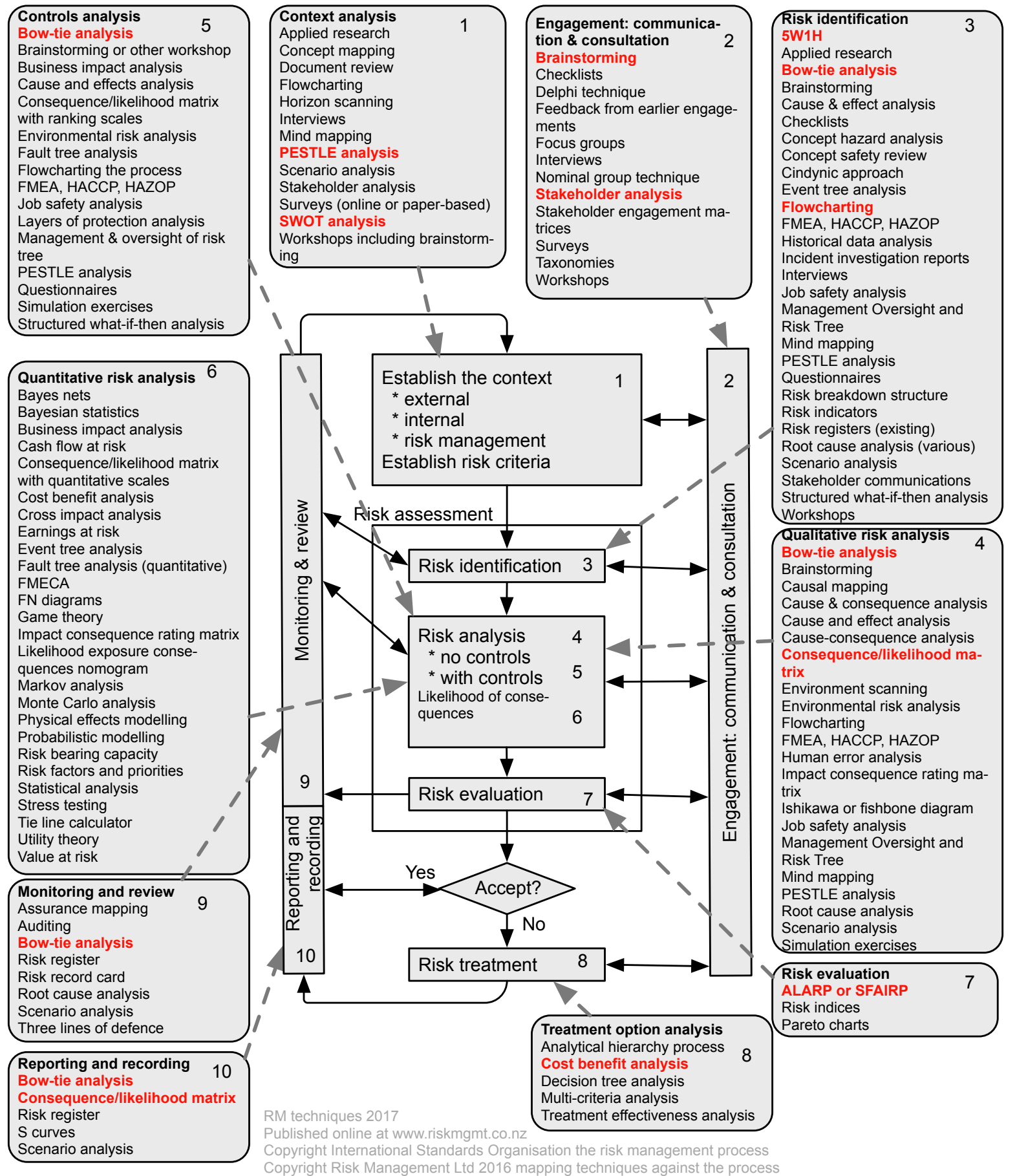

Source: adapted from Peace (2017b)

Figure 4 shows a composite set of techniques developed from the literature, that subsequently helped to select a suite of risk techniques (marked in red) for use in training courses and then to development of the risk canvas (section 7.4) and is read as follows. 
- Box 1 lists techniques that could be used to help research the context of an organisation or activity.

- Box 2 lists techniques that could be used to engage, communicate or consult with stakeholders in a risk assessment.

- Box 3 lists techniques that aid identification of risk.

- Box 4 lists techniques that aid qualitative analysis of risks that have been identified.

- Box 5 lists techniques that aid analysis of controls.

- Box 6 lists techniques that aid quantitative analysis of risks that have been identified and then analysed qualitatively.

- Box 7 lists techniques that aid evaluation of risks that have been analysed.

- Box 8 lists techniques that aid analysis of risk treatment options if a risk has been evaluated as unacceptable as is.

- Box 9 lists techniques that aid monitoring and review of the context, risks, controls, and treatments that are work in progress.

- Box 10 lists techniques that aid reporting on risks that have been assessed.

Dashed lines then link the lists to relevant stages in the risk management process adapted from ISO31000. This grouping aided development of the online survey (section 3.3.1) and review of the techniques used in the case studies (section 6.5).

\section{Bowtie analysis}

Bowtie analysis (https://www.cgerisk.com/knowledgebase/The history of bowtie) was developed in 1979 by $\mathrm{ICl}^{6}$ and came into wider use internationally after the Piper Alpha oil rig disaster in 1988. When the literature review was carried out in 2014 , bowtie analysis was described in IEC/ISO31010 (2009) as consisting of: a hypothesised event; possible causal factors (to the left of the event) that might lead to the event; and possible consequences (listed to the right of the event). A bowtie diagram can be expanded to include further information about sources of risk, knock-on consequences, the probability of such consequences, and possible actions to change risk if not already acceptable.

A bowtie can help carry out qualitative analyses of risk (ICMM, 2015), engage with workers in a group risk assessment (Trbojevic, 2008), identify simplified human factors (Targoutzidis,

\footnotetext{
${ }^{6}$ Imperial Chemical Industries, a UK chemicals manufacturer 1926-2008
} 
2010), and show the location and effectiveness of controls (McLeod \& Bowie, 2018) (AICHEME, 2013). While a bowtie can be quantified (Cherubin, Pellino, \& Petrone, 2011), a qualitative diagram often yields the best available information. It was therefore selected as part of a suite of risk techniques to be taught during training courses.

Although respondents to the online survey subsequently reported little use of the technique (section 4.3.16), anecdotally, bowtie analysis may now be in wider use in New Zealand and it is now described as a widely used "diagrammatic way of describing the pathways from source of risk to outcomes" (IEC/ISO31010, 2019).

\subsubsection{Quality assurance in risk assessments}

Anecdotal evidence suggested (and was subsequently confirmed by the results of the online survey, chapter 4) that risk and safety practitioners tend not to use formal, structured techniques in a structured process such as that depicted in Figure 4 due, for example to lack of knowledge of techniques, or their place in the risk assessment process, or both. This can result in mis-measurement of risk leading to uncertainty about results (Chinniah et al, 2011; Gadd et al, 2003; Stulz, 2008).

It might be thought necessary "in dealing with the richness of the real world, to go beyond using a single methodology to always combining methodologies, in whole or in part, and possibly from different (even incommensurate) paradigms to make the most of dealing with the richness of the real world" (Mingers \& Brocklesby, 1997, p. 489) rather than use a simple, perhaps single, generic approach to risk assessment. However, experience suggests that risk and safety practitioners use only one or two techniques but most rely on the consequence/likelihood matrix.

Quality assurance in, and reproducibility of, risk assessments should include recording why a technique was selected in a given assessment (Arunraj \& Maiti, 2007; Cantrell \& Clemens, 2009; Chapman, 1998; Goerlandt, Khakzad, \& Reniers, 2017; Lathrop \& Ezell, 2017; Pinto, Ribeiro, \& Nunes, 2013; Rae \& Alexander, 2017; Schrader et al, 2010; Suokas \& Rouhiainen, 1993; Williams, 1985).

\subsubsection{Risk techniques identification key and maturity modelling}

Research (Ernst \& Young, 2012; MacGillivray et al, 2007; Oliva, 2016) suggests that increasing sophistication and use of risk techniques is an indicator of the maturity of organisational risk management, performance and capability management. For example, an organisation with the lowest level of maturity might have no formal risk management process, using, at best, professional judgement (section 6.5.2) and the consequence/likelihood matrix, whereas an organisation with a high level of maturity might 
use a formal process supported by a range of techniques selected to help provide the best available information about uncertainty and its effects on objectives.

Finding and applying such techniques may therefore indicate overall organisational maturity and might require use of a taxonomy, a "fundamental mechanism for organising knowledge" (Nickerson, Varshney, \& Muntermann, 2013, p. 337), so enabling more "appreciation of the problem", "analysis of the underlying structure", "assessment of the situation", and appropriate "action" (Mingers \& Brocklesby, 1997, p. 494).

A further problem is that different risk techniques have been developed by people with different backgrounds, sometimes leading to: different names being used for the same concept, stage or process; the same name being used for different concepts, stages or processes, resulting in confusion between risk assessors or decision makers (Peace, 2017a).

Such differences may have been influenced by what people were taught during tertiary education or vocational training and may result in risk analyses whose results cannot be readily compared. For some such techniques, there is now a substantial body of practice (including commercial training courses) that might increase resistance to change of nomenclature. Furthermore, definitions may conflict with those in major dictionaries, perhaps explaining why technical language used by risk practitioners may be misunderstood.

Hazard and operability analysis (HAZOP) provides one example of such a standalone technique. Developed by Imperial Chemical Industries Ltd (ICI) in the late 1960s and early 1970 s as part of a response to several high-profile events, it has become an industrystandard technique in the petrochemical industry (Swann \& Preston, 1995) and other sectors. However, the language used in HAZOP studies is different from the language used in other techniques, giving rise to a potential mismatch of findings and responses to risk.

At least two taxonomies of risk techniques are in use (Goldberg et al, 1994; IEC/ISO31010, 2009; 2017b) and provide descriptions of available techniques, while Figure 4, a form of taxonomy, shows where techniques might be used in a risk assessment. Each is useful but none gives authoritative selection guidance (Gould et al, 2005) and there are variations in descriptions, thus requiring assessors to choose between techniques that might aid an assessment. Further, users cannot select a specific technique if they do not know how or when to apply it.

Although uninformed use of taxonomies should be rejected as they might "lead to an uncritical or unwitting limiting of method choice" (Davies, Mabin, \& Balderstone, 2005, p. 507 ) a risk techniques taxonomy might aid education and training of risk assessors, selection of appropriate techniques and reproducibility of assessment results. Unfortunately, 
none of the taxonomies was developed using generally agreed attributes to ensure it would be concise, robust, comprehensive, extendable and explanatory (Nickerson et al, 2013). These, together with other criteria (Zijp et al, 2015) have been used to review the taxonomies (Table 5), showing that none is directly useful to a risk assessor seeking guidance on selection of appropriate techniques within a given risk assessment.

Table 5. Review of risk techniques taxonomies

\begin{tabular}{|c|c|c|c|}
\hline Attribute & IEC/ISO31010:(2009) & Goldberg et al (1994) & Peace (2017b) \\
\hline Concise & $\begin{array}{l}\text { The } 2009 \text { edition has } 90 \text { pages } \\
\text { and sets out the risk } \\
\text { management process with } \\
\text { guidance on selecting } 29 \\
\text { techniques. The } 2018 \text { edition is } \\
\text { likely to be } 125 \text { pages long with } \\
\text { guidance on } 42 \text { techniques }\end{array}$ & $\begin{array}{l}306 \text { pages setting out } 55 \\
\text { techniques and methodologies } \\
\text { in a design process for systems } \\
\text { engineers }\end{array}$ & $\begin{array}{l}\text { Single page diagram framed on } \\
\text { the ISO31000 (2009) risk } \\
\text { management process diagram, } \\
\text { cross references to the } 29 \\
\text { techniques in IEC/ISO } 31010 \text { : } \\
2009\end{array}$ \\
\hline Robust & $\begin{array}{l}\text { Developed by an international } \\
\text { committee }\end{array}$ & $\begin{array}{l}\text { Six authors in the USA with } \\
\text { others providing input }\end{array}$ & Single author \\
\hline Comprehensive & $\begin{array}{l}\text { Limited to techniques deemed } \\
\text { relevant to risk assessment }\end{array}$ & $\begin{array}{l}\text { Covers a wide range of } \\
\text { techniques deemed relevant to } \\
\text { engineering }\end{array}$ & $\begin{array}{l}\text { Includes many techniques } \\
\text { deemed relevant in each stage } \\
\text { of the risk management process, } \\
\text { some are repeated }\end{array}$ \\
\hline Extendable & $\begin{array}{l}\text { More techniques could be added } \\
\text { but the cost of the final } \\
\text { document would probably be } \\
\text { exorbitant }\end{array}$ & $\begin{array}{l}\text { Not revised or extended since } \\
1994\end{array}$ & $\begin{array}{l}\text { More techniques could be added } \\
\text { to the diagram but it would } \\
\text { become unwieldy }\end{array}$ \\
\hline Explanatory & Each technique is explained & Each technique is explained & $\begin{array}{l}\text { No explanations given, relies on } \\
\text { further research by a reader }\end{array}$ \\
\hline $\begin{array}{l}\text { Supply or } \\
\text { demand driven }\end{array}$ & Supply & Supply & Supply \\
\hline $\begin{array}{l}\text { How techniques } \\
\text { are organised }\end{array}$ & $\begin{array}{l}\text { Described based on a selection } \\
\text { of criteria }\end{array}$ & $\begin{array}{l}\text { Described based on a selection } \\
\text { of criteria }\end{array}$ & Graphical layout with no criteria \\
\hline
\end{tabular}

Criteria for selection of risk techniques are set out in IEC/ISO31010:(2009, 2019) Risk assessment techniques and methodologies for assessing techniques for specific applications have been suggested, including project risk techniques (Forbes, Smith, \& Horner, 2008, 2010), IT-related techniques (Raspotnig \& Opdahl, 2013), risk-based management techniques (Arunraj \& Maiti, 2007), and root cause analysis techniques (Doggett, 2005). Forbes et al (2010) showed how some of these limitations could be overcome by using case-based reasoning. However, this would require a practitioner to build a database of cases or practice precedents that could be interrogated to identify appropriate techniques for use in a new but similar case. Few practitioners are likely to have the necessary resources to build such a database.

Although Figure 4 summarises when many commonly-used risk techniques can be used it gives no guidance on which would be appropriate in a given context. Furthermore, the above 
review and section 2.4.1 suggests the need to develop a risk techniques identification key (a printed or computer-aided device that aids the identification of entities

(https://en.wikipedia.org/wiki/ldentification key)) for risk techniques. However, no proposal for or research on an identification key of risk techniques has been found in the literature that would enable a user to identify techniques relevant to a risk assessment. Such an identification key might act as a mechanism to improve selection of appropriate risk techniques used in risk assessments (Chinniah et al, 2011), an aid for quality assurance (Lathrop \& Ezell, 2017; Raspotnig \& Opdahl, 2013), and as an organisational performance indicator.

See section 7.3.1 for further discussion of these mechanisms.

Problems associated with risk terminology contributed to the development of a conference paper (Peace, 2017a) and a subsequent conference paper on a risk techniques identification key (Peace \& Mabin, 2019).

\subsection{Critical success factors for risk assessments}

While every risk assessment will be at least marginally different, it was posited that there will be common features that determine the effectiveness of any risk assessment. These can be regarded as the critical success factors (CSF) in informing decision makers (Pellow \& Wilson, 1993).

The origins of critical success factor thinking appear to be with Daniel $(1961$, p. 116) who thought that "[i]n most industries there are usually three to six factors that determine success in management activities; these key jobs must be done exceedingly well for a company to be successful". Rockart (1979, p. 87) identified five CSF limited to the industry level, including "temporal factors ... or areas of activity that are significant for the success of an organisation for a particular period of time because they are below the threshold of acceptability". Subsequent authors (Caralli, 2004; Gates, 2010) expanded on the work of Daniel (1961) and Rockart (1979), suggesting that success factors could differ between and within organisations, and introduced the concept of critical success factors that might cascade through the organisation. CSF are therefore the few key areas where 'things must go right' for an organisation or manager to succeed (Boynton \& Zmud, 1984; Bullen \& Rockart, 1981), and that may form performance measures (Yaraghi \& Langhe, 2011).

Dettmer (2003, pp. 63-77) called such features "necessary conditions" (NC). He recognised that some NC were "few but critical" - if one was missing and resulted in failure to achieve a goal it might be considered a CSF - but later (Dettmer, 2007, p. 80) argued that NC may be 
quantifiable, measurable outcomes of specific activities or they may be qualitative outcomes - "yes" or "no" conditions. Dettmer tabulated these characteristics, shown here as Table 6.

Table 6. Characteristics of necessary conditions

\begin{tabular}{|l|l|l|}
\hline \multicolumn{1}{|c|}{ Absolute } & \multicolumn{2}{c|}{ Magnitudinal } \\
\hline \multicolumn{1}{|c|}{ "Zero-or-one" } & \multicolumn{1}{c|}{ "Satisficed" } & \multicolumn{1}{c|}{ "Continuously Improvable" } \\
\hline $\begin{array}{l}\text { A "yes-or-no" condition. Only } \\
\text { two states: either it's present or } \\
\text { it's absent. Presence is } \\
\text { required for the system to } \\
\text { benefit }\end{array}$ & $\begin{array}{l}\text { A modified "yes-or-no" condition. Some minimum } \\
\text { threshold required. May be increased (or } \\
\text { decreased) with benefit to the system until some } \\
\text { threshold is reached. After that, increasing or } \\
\text { decreasing results is of no further benefit to the } \\
\text { system } \\
\text { May be a quantifiable, measurable outcome of } \\
\text { specific activities }\end{array}$ & $\begin{array}{l}\text { No theoretical limit (though } \\
\text { probably a practical one). Can be } \\
\text { continuously increased or } \\
\text { decreased and produce incremental } \\
\text { improvements in system benefits }\end{array}$ \\
\hline
\end{tabular}

Source: Dettmer (2003, pp. 63-77; 2007, p. 80)

Table 6 shows CSF and some NC might be a "zero-or-one" condition while other NC could have magnitudes of necessity for an activity (such as a risk assessment) to initiate and complete. This is further explored in section 3.2.

In explaining when a NC might be considered to be a CSF Dettmer (2007) later called CSF "the show-stoppers" that were (Dettmer, 2011, p. 2):

[t]he limited number of high-level terminal outcomes without which the system's goal cannot be achieved - the few necessary conditions which, if satisfied, represent goal attainment. There are usually no more than three to five of such [critical success] factors

while NC were the:

lower order factors necessary for achievement of critical success factors.

Dettmer's (2011, p. 2) description and a subsequent email to this author (W. Dettmer 2019, 13 April) emphasised necessity logic in that CSF must be satisfied if the goal is to be achieved. In contrast, in his 2003 work, at least some lower-level NC could be sufficiently achieved to allow higher level NC or CSF to be fulfilled. If CSFs and NCs are found to be "True ideas ... that we can validate, corroborate and verify", (James, 2011, p. 80) their use might help answer concerns about risk assessment reproducibility (Haas, 2016); trustworthiness (Earle, 2010); and reliability and validity (Busby \& Hughes, 2006; Goerlandt et al, 2017); and help risk assessors review and report on their own performance (Tetlock, 2006).

However, the literature suggests little work on CSF and NC for effective risk assessments, and suggests such management research might be what Cherry (2010, pp. 9-17) calls a "white space". 


\section{Common features of risk assessments: CSF and NC}

The limited literature included, in early work, seven desirable qualities for a risk assessment (Fischhoff et al, 1980, pp. 53-59). These were adapted into the criteria for a "good risk assessment" (Haimes, 1998, pp. 35-36), summarised in Figure 5. (Although Haimes (1998) and Mirzaei (2016) used the term "criteria" instead of "factor", this research will use the goal tree and TOC nomenclature, including CSF.)

Subsequently, two reports described failure factors in safety-related risk assessments (Gadd et al, 2003; Gadd et al, 2000). These and lessons from the 2007 global financial crisis (Stulz, 2008) and other failures of risk management (Hubbard, 2009) have been adapted for this research to suggest necessary conditions for success.

Figure 5. Possible criteria for a "good" risk assessment

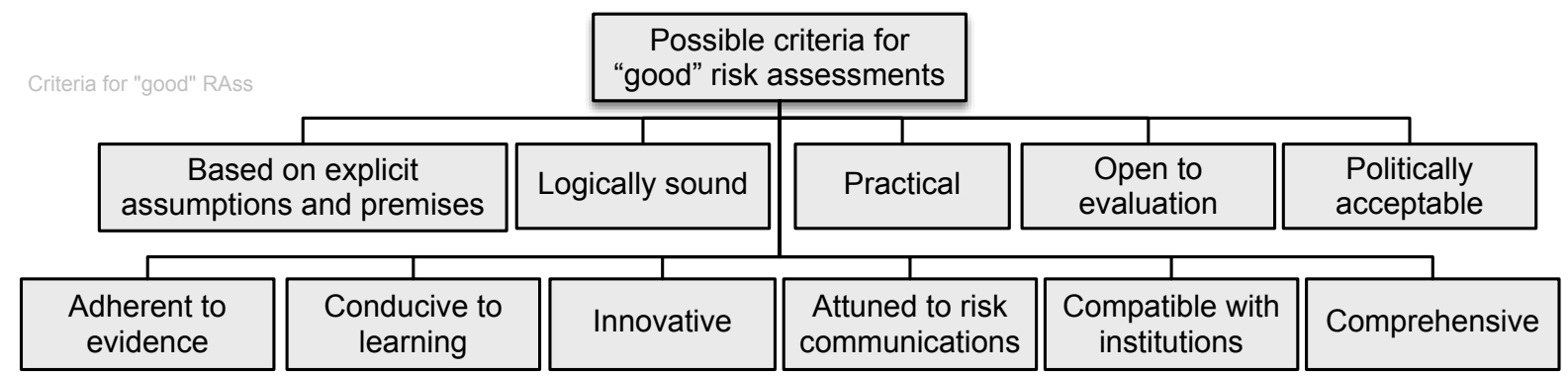

Source: adapted from Fischhoff et al (1980, pp. 53-59) and Haimes (1998, pp. 35-36)

The credibility of risk assessments (CORA, Wiedemann et al, 2013) approach established 18 criteria to help non-experts judge the credibility of science-based risk assessments. Other work (Durodié, 2017; Hillson \& Simon, 2007; ISO31000, 2009; Mullen, 2007; Petty \& Cacioppo, 1986; SAS Institute Inc, 2012) identified the following as conditions for an effective and trustworthy risk assessment:

- assessor competence and trustworthiness

- a relevant level of infrastructure and mechanisms to support appropriate level of implementation

- an integrated toolkit, both internally coherent and interfacing with other business tools and systems

- use by the organisation of a consistent and structured approach to risk assessment

- assessor competence (ie, relevant qualifications and experience) in the selected methods, mechanisms and techniques and trustworthiness.

These NC were collated in an iterative process. Two that appeared to be "show stoppers" were selected as CSF, with the other 13 being NC, as shown in the following list. 
- Risk assessment appropriately communicated to decision makers (CSF 01).

- All relevant factors including controversies and uncertainty fully and correctly evaluated (CSF 02).

- Literature or document review fairly sets out data (NC 01).

- Terms of reference for risk assessment are clear (NC 02).

- Relevant qualifications and experience stated or available (NC 03).

- Impartiality in terms of funding and mandate (NC 04).

- Stakeholders and risk assessors have a shared understanding of risk (NC 05).

- Appropriate engagement with stakeholders (NC 06).

- Competent or impartial risk assessor or team leader (NC 07).

- Risk is correctly framed (NC 08).

- Criteria for risk evaluation (NC 09).

- Appropriate language, graphics and layout (NC 10).

- Systematic hazard or risk identification (NC 11).

- Appropriate risk analysis techniques used (NC 12).

- Appropriate risk evaluation techniques used (NC 13).

It was postulated that risk assessors needed to use relevant techniques to elicit the best available information, de-bias their work (MacGillivray, 2013; Montibeller \& von Winterfeldt, 2015) and so help inform decision makers (Wiedemann et al, 2013), thus forming NC 11, 12 and 13. Meeting these $\mathrm{NC}$ might mean that risk assessment reports generally and, for occupational health and safety (OHS) specifically (Peace et al, 2017), might be relied on by directors. Risk communication was included as a CSF because an otherwise effective risk assessment can fail to communicate findings to decision makers having a short attention span (Mintzberg, 1971, 1990) if it is not presented in a relevant and "easily digestible" form (Trainor et al, 2002).

\subsection{Organisational objectives and goals}

The preferred definition of risk, the "effect of uncertainty on objectives", was discussed in section 2.1 and uncertainty explored in section 2.1.2. Here, the implications of "objectives" are explored, leading to discussion of the goal tree (GT) as a means of relating CSF and NC to each other, other than as a list. 
Objective is the goal or aim (Concise Oxford Dictionary, 2009), or the "result to be achieved" although words with a "similar meaning (eg, aim, goal or target)" (ISO/IEC Annex SL, 2012, p. 144) can also be used. While goals or objectives may be set at an organisational level they can have different aspects such as financial, health and safety, and environmental goals, and can apply at different levels such as strategic, organisation-wide, project, product, and process. Dettmer (2011, p. 2) described "goal" as:

The ultimate purpose for which the system exists (or was created) - the end to which a system's collective efforts are directed. In human systems or organizations, this is the outcome that the owners say is the preeminent or paramount objective of the system.

Knowing the organisational objectives or goals is key to planning, delivery of goods or services, and development of a shared organisational purpose (Dettmer, 2007; Drucker, 1973 p. 400). The overarching goal may be an abstract, high-level outcome but is achieved through a "system of interrelated activities" (Weick \& Roberts, 1993, p. 364), representing "the sum of a significant number of functional tasks or activities" (Dettmer, 2011), including risk assessments. Moreover, "to ensure safety, it is common to use a hierarchy of goals ..." (Aven, Vinnem, \& Roed, 2006, p. 119) or organisational objectives that are supported by subordinate goals, objectives, priorities or accountabilities for managers, workers, systems and activities and management at all levels should be involved in setting such goals and objectives and guiding the organisation to their achievement (Aven et al, 2006). This was described by Drucker (1954) as management by objectives.

\subsubsection{Goal-setting and goal orientation theory}

Vandewalle, Nerstad, \& Dysvik (2019) reviewed 40 years of goal orientation and showed that orientation away from performance goals and towards learning goals resulted in skills gains, improved decision making in complex situations, improved cognitive strategies (including using diagrams and charts), greater willingness to seek or accept feedback, and more ethical behaviours.

Reviewing 35 years of research into goal-setting, Locke \& Latham (2002, p. 714 ) concluded that "goal-setting theory is among the most valid and practical theories of employee motivation in organisational psychology" and that goal-setting works at the organisational and individual levels. They identified four performance mechanisms affected by goals, including that goals direct attention to relevant activities and away from irrelevant activities. Provided workers have necessary resources and training, task-relevant knowledge and strategies can be applied to achievement of performance goals to "create constructive discontent with ... present performance". This can lead to self-improvement efforts that can be amplified by feedback during and on completion of tasks, resulting in a sense of 
accomplishment (Latham \& Locke, 2006). These findings suggested that objective or goal setting (including its absence) might form part of a risk assessment and that CSF and NC might be combined in a goal tree to aid achievement of goals.

\subsubsection{Origins and philosophical foundations of the goal tree (GT)}

Aven et al (2006), Drucker (1954) and Locke and Latham (2002) did not describe a process by which objectives or goals might be achieved but Dettmer (2007) evolved the GT from the Intermediate Objectives Map, part of the Theory of Constraints (TOC), to link critical success factors and necessary conditions. This section summarises that work and an apparent problem with the GT.

\section{Theoretical foundations of the Theory of Constraints (TOC)}

The TOC is a pragmatic methodology originally developed in the late 1970 s by Eliyahu Goldratt (a physicist) for quality management and process improvement. It "seeks to identify what needs to change; what to change to; and how to bring about that change" (Davies et al, 2005, p. 508). Reviews of its evolution (Kim, Mabin, \& Davies, 2008; Watson, Blackstone, \& Gardiner, 2007) from hard science to management philosophy have demonstrated its theoretical foundations, while Naor, Bernardes, \& Coman (2012, p. 551) considered TOC satisfied "the overall requirements of a good theory", being "creative, useful and scientific" ( $p$. 546). Berry \& Smith (2005) concluded that TOC incorporates aspects of system theory, performance measurement and culture-based change management.

TOC is now widely used to help identify and overcome constraints in systems and activities (Dettmer, 2007, 2011; Scheinkopf, 1999) and is seen by some as an operational research and management science methodology (Davies \& Mabin, 2001; Mabin et al, 2016). It has been applied across all management domains with diverse applications including analysis of an aircrash (Zotov, Wright, \& Hunt, 2007), and resource and service issues in a hospital (Mabin et al, 2018).

\section{Origins of the $G T$}

Early work by Goldratt on an "Intermediate Objectives Map" (IO Map) in the mid-1990s was continued by Dettmer (1998; 2003, pp. 62-77; 2007, pp. 67-88; 2010, pp. 560-563; 2011) over a 15-year period. He renamed it the goal tree (Dettmer, 2011) to emphasise its place as a distinct logic tool that forms part of and shares the logic basis of TOC, and that is used to analyse the steps to achieve a goal. The GT has been used to help structure research into, for example, consensus building in reforms for sustainable water supply systems (Moore, 2009; Moore \& Mabin, 2018), the quality of higher education in Kenya and New Zealand (Kimani, 2015), and different aims in project management (Mirzaei, 2016). 
A GT depicts "what should be happening if a system is to succeed" (Dettmer, 2007, p. 68) by showing relationships between CSF and NC, not as a list but as a hierarchical tree, where a lower order NC underpins higher level NCs and CSFs. Each GT may be nested in a hierarchy of functional tasks or activities within the overall system boundary such that processes or activities (including risk assessments) have goals that are designed to support overarching organisational objectives.

Dettmer (2007, p. 75) thought there might "common elements" within the GT for a whole organisation but later specifically said it was possible to develop a generic GT for the same activity carried out in different organisations (Dettmer, 2011, pp. 6-7). As this might include risk assessments, it was decided that, as part of the research methodology, a tentative GT for an effective risk assessment - "what should be happening if a [risk assessment] system is to succeed" - would be developed using the CSF and NC as the "common elements" from section 2.5. Development of the tentative GT for risk assessments is described in section 3.2 as it formed part of the research methodology.

The tentative GT would be used to (1) help test the validity of those CSF and NC; (2) help test the validity of such a generic GT; and (3) facilitate analysis of data.

While not directly relevant to this research, some publications documenting the use of the GT/IO Map have been listed after the references to illustrate other contexts in which the GT has been used as part of a TOC study by other researchers. Relatively few have been published as articles in journals, and in most cases the use of the GT/IO map has been no more prominent than the other TOC tools. Exceptions to this include Moore (2009) and Moore \& Mabin (2018), where an iteratively developed IO Map played a major role in a single case context.

\subsection{Decision making and decision makers}

This research is about the effectiveness of risk assessments in informing decision makers. This section of the literature review therefore briefly considers the nature of decisions to be made and the decision makers. Organisations and the societies in which they function make decisions that may include complex political, economic, social, technological, legal or environmental issues. Decision maker needs for the best available information and the uncertainty of such information should be recognised so they can be better informed and use such information rationally (Abt et al, 2010). 


\subsubsection{Who are decision makers?}

In a seminal work on the acceptability of risk, Lowrance (1976) discussed issues associated with judging safety as part of risk taking and gave as examples of decision makers:

purchasers of products, legislators, scientific advisors and regulatory agencies. To these might be added a host of people who, in work situations, must decide on matters of minor, moderate, major or strategic importance to organisations, other stakeholders in organisations and the societies in which organisations (including governments) operate.

Thus, for the purposes of this research, a decision maker is any person who consciously or subconsciously weighs evidence and then makes a decision in an organisational context leading to some action or inaction about or involving risk.

\subsubsection{Decision making processes}

If the outcomes of decisions are reviewed retrospectively they should be judged on whether the best available information was found using an effective risk assessment (Falconer, 2002). Kahneman (2011) and Epstein et al (1992) summarised research on systems of thinking (Table 7) with Epstein stating there is "no dearth of evidence in everyday life that people apprehend reality in two fundamentally different ways" - experiential and rational. Kahneman called these system 1 and system 2. An experiential or system 1 approach with adverse consequences (eg, harm to people, or investment failures) might be regarded as irrational - even irresponsible.

Table 7. Summary of research on two decision making processes

\begin{tabular}{|c|l|c|l|}
\hline \multicolumn{2}{|c|}{ Epstein et al (1992) findings } & \multicolumn{1}{c|}{ Kahneman (2011) findings } \\
\hline Name & \multicolumn{1}{|c|}{ Description } & Name & \multicolumn{1}{c|}{ Description } \\
\hline Experiential & $\begin{array}{l}\text { Intuitive, automatic, natural, nonverbal, } \\
\text { narrative } \\
\text { Efficient aid to decision making } \\
\text {-prone if a decision is not based on } \\
\text { best available information } \\
\text { Judgement based }\end{array}$ & System 1 & $\begin{array}{l}\text { Shortcut or heuristics-based } \\
\text { Operates automatically and quickly with no sense } \\
\text { of voluntary control } \\
\text { Efficient aid to decision making } \\
\text { Error-prone if a decision is based on the wrong } \\
\text { heuristic or poor information }\end{array}$ \\
\hline Rational & $\begin{array}{l}\text { Analytical, deliberative, verbal, and } \\
\text { rational } \\
\text { Slower decision making, less error- } \\
\text { prone }\end{array}$ & System 2 & $\begin{array}{l}\text { Allocates attention to mental activities that demand } \\
\text { effort, including complex computations } \\
\text { Considered and reflective approach } \\
\text { Inputs from risk assessment and decision analysis }\end{array}$ \\
\hline
\end{tabular}

Risk assessments based on a well-constructed process should better inform decision makers than assessments based on more limited information (Aven, 2009; EPA, 2011; Forbes et al, 2008; Frost, 2003; Marhavilas, Koulouriotis, \& Gemeni, 2011). However, Mintzberg (1971) found busy managers prefer to work on issues that are current, specific and ad hoc, giving only cursory attention to reports (perhaps because they prefer immediate rather than delayed results) while Carson \& Snowden (2011) concluded it was hard to 
specify how managers might be persuaded to exercise rational behaviour. Drucker (1973, pp. 511-512) argued:

The main goal of a management science must be to enable business to take the right risk. Indeed, it must be to enable business to take greater risks - by providing knowledge and understanding of alternative risks and alternative expectations; by identifying the resources and efforts needed for desired results; by mobilizing energies for contribution; and by results against expectations, thereby providing means for early correction of wrong or inadequate decisions.

Reviewing Drucker's work, Crockford (1976, p. 7) concluded: "in short, all management is risk management". However, both Drucker and Crockford left unanswered what risk and risk management are. A New Zealand Ministry of Economic Development (MED, 2007, p. ii) report followed this argument, saying that:

Management and leadership skills impact substantially on organisational performance. Skilled managers create an environment where innovation and skill development can flourish.

Poor management skills, perhaps including risk assessment skills, may be a contributory factor for the economic underperformance of New Zealand and, if decision makers are inadequately informed about risks, it is less surprising that decisions fail to deliver expected results, risks eventuate to result in negative consequences, and opportunities arising from risks are not taken.

\subsubsection{Risk behaviour of decision makers}

Risk-taking is decision making about risk and was defined by Trimpop (1994) as a behaviour with uncertain outcomes that may result in positive or negative effects. Different people have different perceptions of risk and, depending on the situation, they may take or avoid risks differently; some may deny the existence of uncertainty (Bradley, Hirt, \& Smit, 2018), or overestimate or underestimate risks (Sitkin \& Pablo, 1992). Coleman (2007, p. 531) emphasised the need for a greater understanding of decision maker attributes and organisational context while Sitkin \& Pablo (1992) further described organisational social influences as dominated by an organisation's culture - the "tone from the top" (Schwartz, Dunfee, \& Kline, 2005).

Heuristics and biases, influenced by the wider experiences and needs of an organisation, pervade perceptions of risk and expert assessments potentially leading to poor decision making (MacGillivray, 2013; Nutt, 2002; Russo, Schoemaker, \& Hittleman, 2002). They may form the basis of, for example, "if-then" rules and include a poor understanding of good practice (Baker, 2002). MacGillivray's (2013) work aligns with the three-level knowledge- 
rules-skills framework for operational decision making proposed by Rasmussen \& Jensen (1974) who suggested that, in novel situations, stored knowledge is used in conscious, analytical processes leading to decisions. The knowledge-rules-skills model was subsequently applied to "human error" by Reason (1990), later extended to include "necessary violations" of rules (Reason, 1998, p. 304).

Over time, habituation of individual decision making and risk-handling practices can result in inappropriate responses to risk. A poor outcome history may result in unsuccessful decision makers changing their approach to try to find a better strategy and, if a new strategy is more successful, inertia may again set in, with each new success reinforcing how risk is handled and that strategy becoming embedded as part of the manager's skills. This may also result in problem domain familiarity and standardised responses leading decision makers (and expert advisors) to interpret novel situations using their familiar responses. Again, as experience accumulates, decision makers may rely increasingly on earlier successes and their abilities rather than looking for "weak signals" in contextual differences (Weick \& Sutcliffe, 2007). Individual risk preferences influence the behaviours of individuals but these may be mediated by organisational preferences.

Decision makers may reject conflicting or divergent information (Frimer, Skitka, \& Motyl, 2017 ) in the form of risk assessments if it might cause cognitive dissonance with strongly held views and harm to relationships with the risk assessors. Such strongly held views may be difficult to change (Kaplan, Gimbel, \& Harris, 2016) or result in selective use of the best available information (Kahan et al, 2012). Furthermore, top management homogeneity can result in mutual support and consensus being valued above rational debate and the quality of decisions.

Waterman, Peters, \& Phillips (1980) referred to the "limited capacity of decision makers to process information and reach what we usually think of as 'rational' decisions" (p.15), and suggested that "organisations learn and adapt very slowly" (p.25), engaging in "satisficing" (Simon, 1976), despite the need to state clear objectives or goals (Drucker, 1973). While risk assessments may help to counter such biases, overconfidence or desire for certainty in decision makers may create a further layer of uncertainty arising from the competence of the risk assessors or the effectiveness of the process used. Indeed, professional or expert judgement used by risk assessors is itself suspect (Slovic, Fischhoff, \& Lichtenstein, 2000), further suggesting the need for a structured approach to risk assessments (Fischhoff et al, 1980) and their validation (Lathrop \& Ezell, 2017).

Each organisation is faced by an almost infinite range of factors in its business environment and it may be impossible to do more than agree by consensus that only "certain possibilities, 
issues and contingencies are important and relevant to organizational decision making" (Turner \& Pidgeon, 1997, p. 166), while others are ignored. This is a form of bounded rationality (Simon, 1979) or capacity for processing information (Miller, 1994) that may subsequently be found to have contributed to the failure of a decision or, as Turner \& Pidgeon show, a disaster. It confirms the need for the terms of reference for risk assessments and the techniques used to reflect the nature of the decision to be made. However, Suter et al. (2007, p. 531) concluded pessimistically that "decision makers consider the information concerning risks, benefits, and costs, they may consult with stakeholders, they may pay particular attention to legal and regulatory constraints and precedents, then they test the political winds, consult their gut, and make a decision".

\subsubsection{Decision making models}

Decision making is a time machine in which decisions made now may come to fruition at some future time (Drucker, 1973, p. 125). Thus, decision making models should require the design of possible responses to some predicted future state. Four decision making models and the ISO31000 risk management process that can be used to help develop such responses are set out in Table 8 and compared with the risk management process in ISO31000 (2009).

The Predict/Act model (also called idea imposition) may give optimal results under conditions of low uncertainty (Franz \& Kramer, 2010; Hallegatte et al, 2012) but, as uncertainty increases, a more reflective learn, act, learn, revise model is needed to allow adaptation to unexpected or unpredicted conditions. Nutt (2002) distinguished the ideaimposition process (often associated with failed decisions) and discovery process (often associated with successful decisions) and Garvin \& Roberto (2001) referred to advocacy and inquiry processes. Other decision process models have three-, four- or five-stage processes or include consultation or debate (Coleman, 2007; Russo et al, 2002) or emphasise personal or organisational characteristics.

Work on rational decision making (Simon, 1979; Waterman et al, 1980) led Conlisk (1996, p. 672 ) to conclude "people are capable of a wide variety of substantial and systematic reasoning errors" and that bounded rationality is a necessary extension of apparently rational reasoning. 
Table 8. Comparison of some decision making and risk management stages

\begin{tabular}{|c|c|c|c|c|}
\hline $\begin{array}{l}\text { Risk management } \\
\text { process stage } \\
\text { ISO31000 (2009) }\end{array}$ & $\begin{array}{l}\text { Risk-based process } \\
\quad \text { (Aven, 2003) }\end{array}$ & $\begin{array}{c}\text { Discovery process } \\
\text { (Garvin \& Roberto, 2001; Nutt, } \\
\text { 2002) }\end{array}$ & $\begin{array}{l}\text { Four-stage process } \\
\text { (Russo et al, 2002) }\end{array}$ & $\begin{array}{l}\text { Predict/Act process } \\
\text { (Hallegatte et al, } \\
\text { 2012) }\end{array}$ \\
\hline $\begin{array}{l}\text { Establish the external, } \\
\text { internal and risk } \\
\text { management contexts } \\
\text { Communication and } \\
\text { consultation with } \\
\text { stakeholders }\end{array}$ & $\begin{array}{l}\text { Define decision } \\
\text { problem } \\
\text { Define decision } \\
\text { alternatives } \\
\text { Engage with } \\
\text { stakeholders to define } \\
\text { their goals, criteria and } \\
\text { preferences }\end{array}$ & $\begin{array}{l}\text { Identify events or trends } \\
\text { Understand and reconcile } \\
\text { claims and need for action } \\
\text { Attend to social and political } \\
\text { issues } \\
\text { Frame the decision }\end{array}$ & \multirow[t]{2}{*}{$\begin{array}{l}\text { Frame the decision } \\
\text { and develop criteria }\end{array}$} & \multirow[t]{2}{*}{$\begin{array}{l}\text { Learn about } \\
\text { current issues }\end{array}$} \\
\hline $\begin{array}{l}\text { Set criteria derived } \\
\text { from the context }\end{array}$ & $\begin{array}{l}\text { Risk assessment and } \\
\text { decision analyses }\end{array}$ & $\begin{array}{l}\text { Direction setting } \\
\text { Establish desired results }\end{array}$ & & \\
\hline Risk identification & $\begin{array}{l}\text { Analyses and } \\
\text { evaluations } \\
\text { Check with } \\
\text { stakeholders }\end{array}$ & \multirow[t]{2}{*}{$\begin{array}{l}\text { Search for and analyse ideas } \\
\text { Quantify analyses as much as } \\
\text { possible and present } \\
\text { graphically where possible }\end{array}$} & \multirow[t]{2}{*}{$\begin{array}{l}\text { Intelligence } \\
\text { gathering }\end{array}$} & \multirow[t]{2}{*}{ Predict } \\
\hline $\begin{array}{l}\text { Risk analysis } \\
\text { (qualitative or } \\
\text { quantitative) }\end{array}$ & & & & \\
\hline $\begin{array}{l}\text { Risk evaluation } \\
\text { Determine if the risk is } \\
\text { acceptable "as is" } \\
\text { Communication and } \\
\text { consultation }\end{array}$ & $\begin{array}{l}\text { Review and judgement } \\
\text { by decision maker(s) } \\
\text { Check with } \\
\text { stakeholders }\end{array}$ & $\begin{array}{l}\text { Evaluate ideas } \\
\text { Avoid intuition-based } \\
\text { decisions about risk } \\
\text { Evaluation should test } \\
\text { multiple alternatives and } \\
\text { assumptions, use well- } \\
\text { defined criteria in a process of } \\
\text { dissent and debate and so } \\
\text { achieve perceived fairness }\end{array}$ & $\begin{array}{l}\text { Coming to } \\
\text { conclusions }\end{array}$ & \\
\hline $\begin{array}{l}\text { Risk treatment } \\
\text { Communication and } \\
\text { consultation }\end{array}$ & Decision & $\begin{array}{l}\text { Select course of action } \\
\text { Implementation of the } \\
\text { preferred idea }\end{array}$ & & Act \\
\hline Monitoring and review & $\begin{array}{l}\text { Check with } \\
\text { stakeholders }\end{array}$ & & $\begin{array}{l}\text { Learning from } \\
\text { experience }\end{array}$ & Learn and revise \\
\hline
\end{tabular}

\section{Summary}

Based on the foregoing review, it is argued the risk management process in ISO31000 (2009) is also a decision making process, providing a model within which decision problems can be assessed and options tabled for decision making. The preferred definition of risk ("effect of uncertainty on objectives") then leads to the setting of objectives and goals as part of any decision making activity, suggesting the need to know the CSF and NC for the decision to succeed. These can be combined in a GT. 


\subsection{Overall conclusions}

Organisations may conduct risk assessments for a range of reasons but if decision makers are to rely on the results, risk assessors should:

- define risk in the context of the organisational decision to be made

- use a structured and generally accepted risk assessment model, supported by relevant techniques, to elicit the best available information

- discuss and describe uncertainties about the data, process and risk techniques used to support elicitation of the best available information.

Stakeholders in decisions and their supporting risk assessments might then regard the process as fair, even if they disagree with the findings.

Analysis of the terminology used in risk assessments has shown there is a range of overlapping and conflicting terms. This has the potential to confuse risk assessors and decision makers, especially if a risk assessment is carried out or used by a multidisciplinary team. This finding supports issues found in this author's practice and while running nonacademic training courses, where difficulties can be found in selecting appropriate risk techniques relevant to the work in hand, confirming this is a research "white space" - an area where data and knowledge are either limited or ambiguous and conflicting (Cherry, 2010, pp. 9-17).

There is a need for a structured process (an identification key, section 7.3.1) to help nonspecialists choose relevant risk techniques and help give assurance to decision makers that a risk assessment is effective. However, no such generic method has been developed and the time required meant the work had to be deferred for further research.

\subsection{Research questions}

The Research Committee approval for this research was for the following research question: $R Q$. What critical success factors and necessary conditions can be derived from the literature and case studies that would help decision makers and risk assessors to evaluate the effectiveness of risk assessments before they are used to aid a decision? 
The literature review has partially answered the first part of the question but led to the possibility that a generic goal tree for an effective risk assessment might be developed. The research question was therefore modified as follows.

$R Q$. Can a generic goal tree, populated with critical success factors and necessary conditions derived from the literature and case studies, be developed that would help decision makers and risk assessors to evaluate the effectiveness of risk assessments before they are used to aid a decision?

The following two research sub-questions were approved by the Research Committee and remain unchanged.

SQ 1. What processes and methods are currently being used for risk assessments? SQ 2. What mechanisms (in addition to a goal tree) could facilitate or improve risk assessments to provide support for strategic decisions in an organisational setting? A methodology for responding to these questions is developed in the next chapter. 


\section{Research methodology and methods}

\subsection{Introduction}

As noted in section 1.7, this research originated as a Master of Commerce by Thesis and was converted to a PhD before that thesis was submitted. The initial intention was to investigate problems found in practice but, on conversion, that research formed part of a research journey from praxis to theory and that also led to the development of possible solutions for the original problem. Thus, the research question and sub-questions are derived from practitioner problems but require an approach that is founded in theory yet pragmatic.

This chapter builds on the literature review (especially the development of goal-setting and the development of the goal tree (GT)), explores pragmatism (the philosophy of this research), abductive reasoning as a key part of the research approach, and mixed methods research (MMR) as the selected methodology. Development of a tentative GT to be used to structure the data analysis is then described, before setting out how the online survey and case studies were conducted, and any ethical issues managed.

\subsubsection{Ontology, epistemology and Pragmatism}

Pragmatism was originally conceived as the application of experimental methodologies to elicit the best understanding of a problem by researchers and so aid decision making (Jacobs, 2010). Resulting ideas may have been derived from one or more studies exploring organisational phenomena and so regarded as "true ideas ... that we can validate, corroborate and verify" (James, 2011, p. 80) but remain provisional as they rely on the imperfect evidence at hand (the "truth we can get today" (Peirce, 1931, p. 87)). Management "practices-in-use" are such a phenomena and form a unit of analysis " (Jarzabkowski, 2004, p. 529) that allows examination of one characteristic of management activities (here, risk assessments that inform decision making).

Pragmatism helps to clarify thinking by clearing away obstacles and diversions along the pathway of meaningful enquiry (Elkjaer \& Simpson, 2011) using abductive reasoning. Its results are cumulative and remain incomplete and provisional, rather than absolute and fixed (Jacobs, 2010). The case study as part of mixed methods research is central to pragmatism to gather the "weight of evidence" (Weed, 2005, p. 1545) to corroborate a theory but, in common with Popperian philosophy (Popper, 1959) and critical realism, pragmatism rejects the idea that research findings can ever be proved in an objective sense. Rather, closure can be achieved pragmatically when there is increasing convergence between theoretical concepts and empirical observations (Modell, 2009), or when additional corroborative evidence provides incrementally less improvement in theory (Eisenhardt, 1989a, p. 545; 
Tetlock, 2006). Pragmatism therefore relates the meaning of a concept or proposition to its practical consequences (Geroy \& Wright, 1988, p. 20).

Thus, the research here can be corroborated by empirically applying it to real-world situations to ascertain if it corroborates the CSF and NC in the tentative GT (section 3.2), acting as a "provisional conjecture" (Popper, 1959, p. 33 and 265) that merits further testing. Such testing will also show if the thesis meets Popper's (1959, p. 39) requirements that it represents a possible world, a possible experience, and our world of experience. Popper (1959) called such a judgement an appraisal and regarded it as acceptable as corroborating evidence. In this case, the CSF and NC identified in the literature review and the tentative GT (sections 2.5 and 3.2) linking them might enable predictions about the effectiveness of risk assessments. Such evidence might be quantitative or qualitative in mixed methods research and would help explore the research question and sub-question 1:

$R Q$. Can a generic goal tree, populated with critical success factors and necessary conditions derived from the literature and case studies, be developed that would help decision makers and risk assessors to evaluate the effectiveness of risk assessments before they are used to aid a decision?

SQ 1: What processes and methods are currently being used for risk assessments?

The results of this research were expected to suggests answers to sub-question 2 :

SQ 2. What mechanisms (in addition to a goal tree) could facilitate or improve risk assessments to provide support for strategic decisions in an organisational setting?

\subsubsection{Research approach and process used}

Kovács \& Spens (2005, p. 133) defined the research approach as "the way of conscious scientific reasoning" while the research process is the sum of the sequential steps the researcher engages in that are necessary for following the path of a specific research approach. This and the research question iteratively influence research method selection and reflect organisational, historical, political, ethical, evidential, and personal influences (Buchanan \& Bryman, 2007) - the researcher's "personal odyssey" (Denzin, 2008, p. 322).

\section{Personal odyssey}

My "personal odyssey" with a variety of research methods and, subsequently, mixed methods research (MMR) projects started when carrying out monitoring of atmospheric smoke and sulphur dioxide in London 1969-1970 and curiosity about whether reductions in their concentrations affected mortality in some exposed populations. Plotting before-andafter concentrations of these pollutants against mortality rates suggested a correlation with reduced deaths in people aged over 65 . 
A subsequent undergraduate project using a sound level meter, simple descriptive statistics and mapping to monitor environmental noise in a mixed rural and urban environment showed the dominant noise source was road traffic (Peace, 1974), an issue for urban planning. Later, field experience leading to a literature review suggested workers using hazardous substances in non-industrial small and medium businesses (SMEs) in the City of Bristol might suffer chronic harm to health as a result of their exposure. The research used semi-structured interviews in 87 SMEs handling or wholesaling such chemicals. The research found a general lack of (1) consistency in content, layout and presentation of information provided by manufacturers to users and, (2) understanding of the hazards due to chemicals by employers and employees (Peace, 1980).

Later work monitoring the exposure of museum curators to dust from bird and mammal specimens required observations, specimen and air sampling, and suggested (but did not demonstrate) a probable cause for ill health (Muir, Lovell, \& Peace, 1981). A case studybased research project at Master's level investigated statutory examinations of plant and equipment and found many needless examinations that did little to diminish workplace risk (Peace, 1996). These projects each started with a field problem, led to a literature review, and then used a range of techniques to measure or analyse data about exposures.

\section{Abductive reasoning}

Abductive reasoning links academic theorising with practical experiences (here, in risk assessments) and follows the "turn to practice" in organisational studies (Simpson, 2009, p. 1329). It is aligned with the chosen definition of risk (the "effect of uncertainty on objectives") which is placed pragmatically between objective definitions based on measurement of risk and those that are purely subjective. Risk assessment can then be seen as a pragmatic method of discovering alternative futures to inform present actions (Drucker, 1973; Simpson, 2009).

Kovacs \& Spens (2005) compared abductive reasoning in research with purely deductive and purely inductive research and noted that deductive research moves from theory to hypotheses or propositions, to empirical testing, and to corroboration or rejection of theory (Figure 6(a)), whereas inductive research moves from observations to propositions and their generalisation (Figure 6(b)). Abductive reasoning moves from real-life observations that deviate from theory and seeks to match them to a rule or theory to yield a new insight or general rule (Figure 6(c)) and enables opportunity to be taken from serendipitous discoveries during research (Farjoun et al, 2015) or to explain some surprising fact (Aven, 2015, p. 86). 
(a) Purely deductive research process

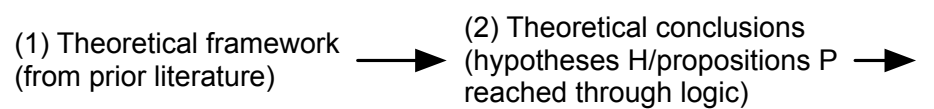

(3) Testing of conclusions
(4) Final conclusions (corroborating/abandoning theory; accepting/discarding $\mathrm{H} / \mathrm{P}$ )

(b) Purely inductive research process

(0) Existing theoretical knowledge from prior research
(1) Real-life observations

(2) (Final) theoretical conclusions (framework) (c) Abductive research process

(0) Prior theoretical knowledge in the literature and guidance documents (eg, ISO31000 and IEC/ISO31010)

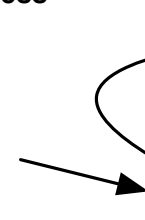

(2) Theory matching

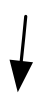

(1) Deviating real-life observations (observations during consultancy work, running short courses and facilitating workshops)

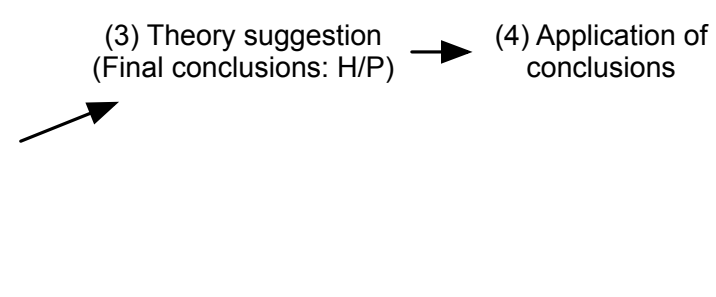

Adapted from Kovacs \& Spens (2005)

The abductive reasoning used in this research follows from observations during consultancy projects and short training courses that risk assessments are not always effective in informing decision makers. It uses the (GT, sections 2.6.1 and 3.2) one of the Theory of Constraints (TOC) tools (Dettmer, 2007; Kim et al, 2008; Rahman, 1998) to act as a model of the hierarchy of CSF and NC required for an effective risk assessment. It also acts as a mediator to help explain the empirical observations (Modell, 2009) of the "key inconsistencies" (Goldratt \& Cox, 2004, introduction) between theory (the stages in a risk assessment as summarised in Table 4) and practice (how risk assessments are carried out in the empirical world).

\section{Mixed methods research (MMR) process}

Organisational research is subject to widening boundaries, a multi-paradigmatic profile and methodological inventiveness, often applied by pragmatists (Burke Johnson, Onwuegbuzie, \& Turner, 2007) who may be "connoisseurs" of qualitative or quantitative methods relevant to the research problem (Teddlie \& Tashakkori, 2012) and where "qualitative data may enrich and substantiate causal explanations suggested by statistical co-variations in the same empirical setting" (Modell, 2009).

Abduction is frequently identified as a pragmatist process that uses mixed methods research to gather, analyse and interpret data (Dubois \& Gadde, 2002). The research here uses methods within MMR that "work" (Teddlie \& Tashakkori, 2012) with the "socially negotiated vehicles of knowledge formation" (Modell, 2009, p. 210) to aid triangulation of data (Manab, Othman, \& Kassim, 2012; Mathison, 1988), and so improve the reliability of results (Mingers, 2003, p. 560). 
Current controversies and debates about process, methods and language in pragmatism and MMR (Teddlie \& Tashakkori, 2012) bear a striking resemblance to concerns about risk assessment and management (Aven \& Zio, 2013) and confirm the need to use a reproducible process and methods that elicit the "weight of evidence" (Weed, 2005) or "best available information" (ISO31000, 2009, p. 7; 2018, p. 3) to support "warranted assertions" (Dewey, 1929) or corroborate a provisional conjecture (Popper, 1959).

\subsubsection{Selected methodology}

The research question asks "Can a generic goal tree, populated with critical success factors and necessary conditions derived from the literature and case studies, be developed that would help decision makers and risk assessors to evaluate the effectiveness of risk assessments before they are used to aid a decision?" and thus predetermines the use of case study methodology, among others.

Sub-question 1 "What processes and methods are currently being used for risk assessments?" could also be answered using case studies but the evidence gathered might be small and of uncertain value, whereas more data can be gathered using an anonymous online survey.

While this could lead to a conflict between interpretive and positivist methodologies (Farquhar, 2012), it draws on the pragmatist ontology applying abduction to qualitative data from the case studies and then seeking to find further meanings in the quantitative survey data and vice versa, to develop the best explanation for case study observations and survey data. This iterative approach to the research question and sub-questions (Tashakkori \& Teddlie, 1998), uses MMR, including (Creswell, 2009; Saunders et al, 2007; Yin, 2009):

- an online survey of a large group of respondents to gather data using a predetermined set of questions

- case studies to gather rich data from a small number of respondents and sources using document reviews, interviews, case-specific literature reviews

- SPSS for analysis of survey data and NVivo for analysis of case study data, with the structure provided by the tentative GT

- the goal tree (part of the TOC) to structure and analyse data, using necessary condition logic implicit in the GT.

This exploratory, practice-based research is summarised in Figure 7. The possible CSF and $\mathrm{NC}$ for an effective risk assessment were identified in section 2.5 and, based on these, a tentative GT developed (section 3.2) to structure analysis of data from the anonymous online survey and case studies. 
Figure 7. Summary of planned mixed methods methodology

\section{Abductive Reasoning in this research}

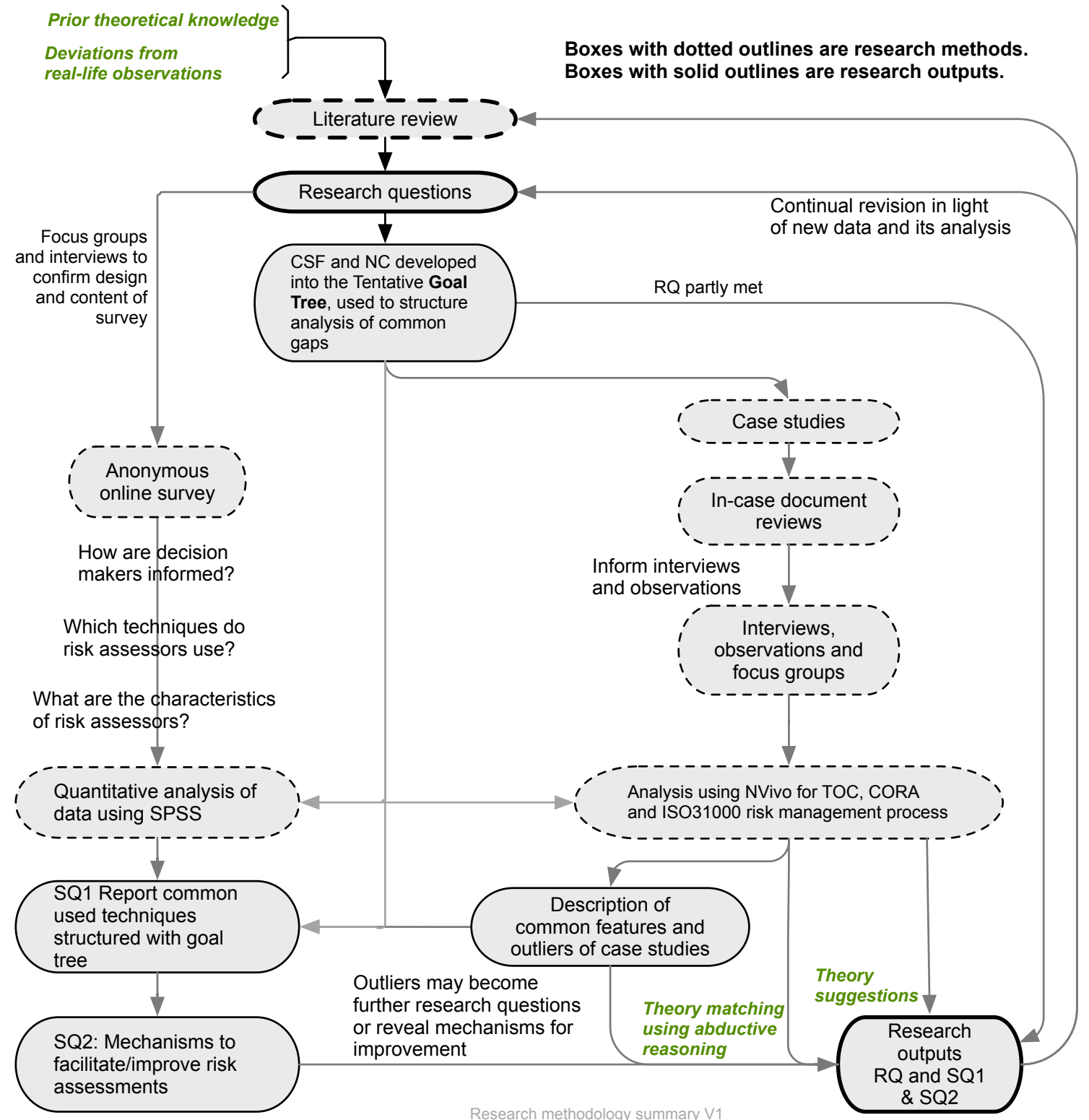

$\mathrm{RQ}=$ research question; $\mathrm{SQ}=$ research sub-question; $\mathrm{TOC}=$ Theory of Constraints; CORA = credibility of risk assessments

Figure 7 includes reference to abductive reasoning (italicised green text) resulting from reallife observations deviating from prior theoretical knowledge (top left and bottom right, in italics) raising questions about the effectiveness of risk assessments, leading to the research problem and literature review. Theory matching and theory suggestions are then shown in italics in the bottom right corner. The research therefore alternates between theory and practice. 


\section{Summary}

The pragmatic approach used in this research applied abductive reasoning to compare and contrast the empirical findings of the literature review, online survey and case studies and apply the GT and the TOC as the mediator to help explain "key inconsistencies" between risk assessment theory and practice. Use of a GT carries assumptions about its underlying ontology and the epistemology. This places a greater reliance on theory than induction yet is removed from deduction, calling for an abductive approach to "everyday language and concepts" (Dubois \& Gadde, 2002, p. 555).

\subsection{Tentative GT}

As noted in section 2.6, a generic GT, populated with critical success factors and necessary conditions derived from the literature and later the survey and case studies, was to be developed that would help decision makers and risk assessors to evaluate the effectiveness of risk assessments before they are used to aid a decision. The process for development of a GT was summarised Dettmer (2007, p. 86), shown here in Figure 8.

\section{Figure 8. Process for constructing a goal tree}

\section{Define the system}

Decide on the system boundary (international, national,

organisational, business unit, etc)

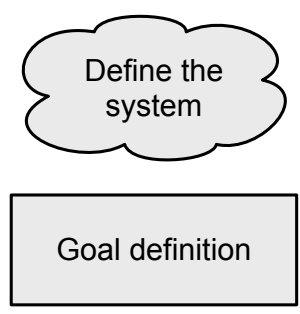

\section{Determine the system goal}

What is the single outcome for which the system exists?

What does the system owner define it as?

Obtain a consensus if others are responsible for setting it

3. Determine the critical success factors

What are the 3-5 high-level conditions that must be satisfied

for the goal to be achieved?

Ensure that they are the last milestones to be achieved

before the goal can be declared satisfied

CSF identification

(3-5 only)

\section{Determine the key necessary conditions} What key activities or tasks are required to realise the CSFs? (No more than 3-5 per CSF)

Limit the NCs to no more than two layers in the final GT

\section{Arrange the goal tree components}

Goal at the top

CSFs below the goal

$\mathrm{NC}$ below the CSF

6. Connect the goal, CSFs and NCs

Use single arrows (no ellipses or AND symbols)

Connect vertically

Connect horizontally as dictated by the situation

\section{Verify the connections}

Use necessity logic, not sufficiency

Cross-check finished connections with intuition

8. Enlist outside scrutiny of the entire goal tree Identify and insert any missing CSFs

Identify and insert any missing NCs

Identify and attach any missing connections

Rearrange entities to minimise cross-overs

Trim off any low-level NCs that would be better addressed in execution planning

Obtain outside scrutiny when the goal tree appears complete 
As summarised in Figure 8, the CSFs and NCs from section 2.5 posited to be necessary for an effective risk assessment were arranged into a tentative GT for the goal or objective of an effective risk assessment (Figure 9). It was tested informally against real-world risks from this author's experience and revised six times before the version used here was selected as adequate to more formally test risk assessments.

Figure 9. Tentative goal tree for effective risk assessments

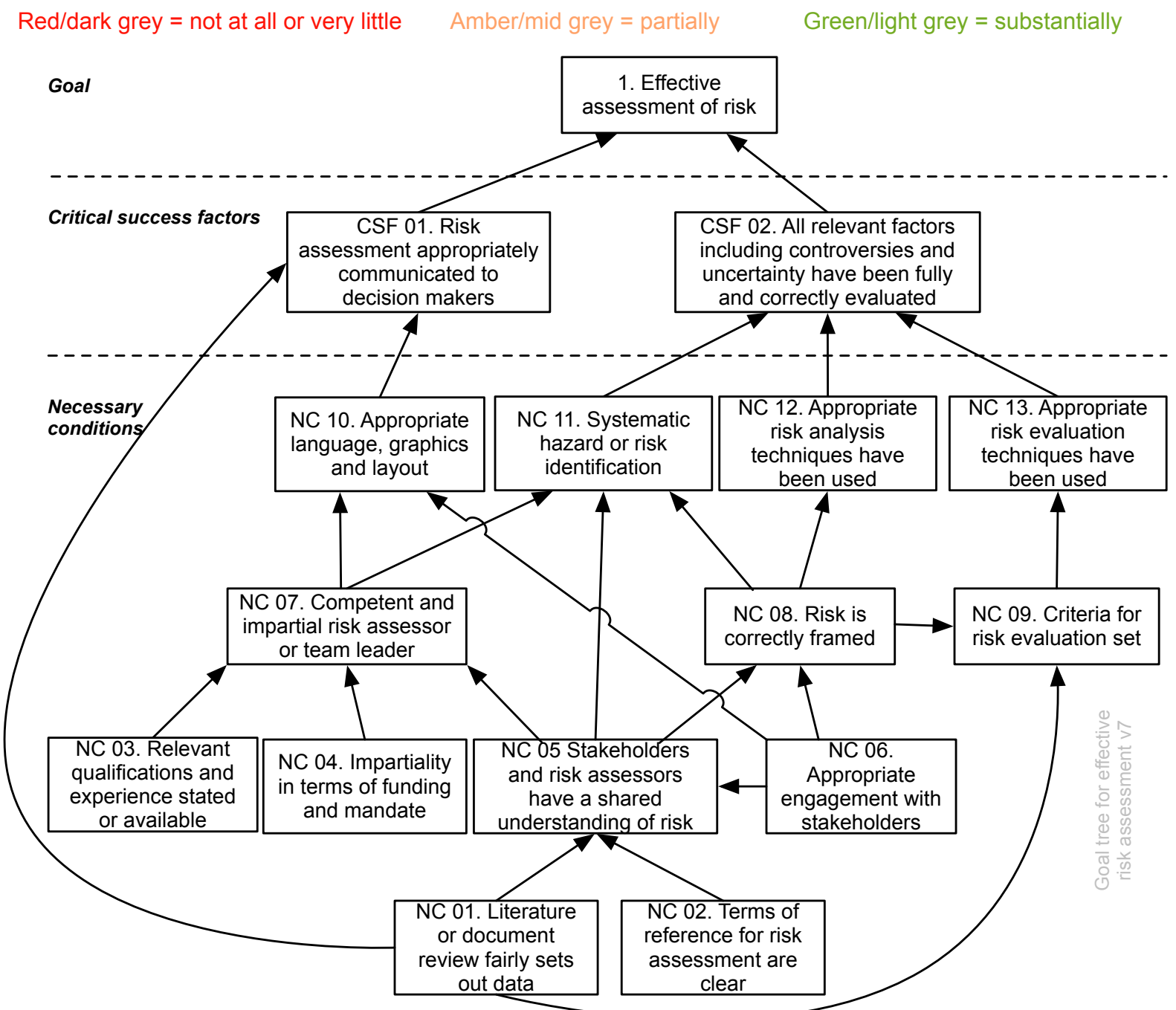

Source: developed by the author from Gadd et al (2003; 2000), Hubbard (2009), Stulz (2008) and Wiedemann et al (2013) using Dettmer's (2007) GT framework

This application of the GT is different from application to individual organisations (Kimani, 2015; Mirzaei, 2016) in that it is closer to application of CSF within sectors

and the same GT was used to aid analysis across several case studies and the online survey.

The GT uses necessity logic requiring a "yes-or-no" condition (Dettmer, 2003, pp. 65-67) expressed more fully as "in order to ... we must ... because ..." format (Dettmer, 2007, p. 
59), so meeting the requirement that a "good" risk assessment must be logically sound (Fischhoff et al, 1980, pp. 53-59), as summarised earlier in Figure 5.

\subsubsection{Necessity logic in NC}

Necessity logic may be impossible to meet at the start of a risk assessment. For example, the best available information may be required as part of $\mathrm{NC} 01$ but no document or literature review has been carried out. Dettmer (2003, pp. 65-67) anticipated this problem describing strict and "magnitudinal" NC (reproduced here in Table 6, section 2.5). The planned forensic review in the case studies was anticipated to require judgement of the magnitude to which a NC was "satisficed" in the case study risk assessments. To improve transparency in the assessment, Table 9, a colour coding scheme following Hohmann (2014), was developed to aid judgement the "minimum necessary conditions" and give a qualitative visual representation of "substantially" (green), "partially" (amber) or "not at all or very little" (red) complete, as shown at the top of the tentative GT.

Table 9. Rating scales for colour coding

\begin{tabular}{|l|}
\hline Evidence shows the CSF or NC was achieved: \\
\hline Substantially: $67-100 \%$ \\
\hline Partially: $34-66 \%$ \\
\hline Not at all or very little: up to $33 \%$ \\
\hline Not applicable for stated reasons \\
\hline
\end{tabular}

Hohmann argued that, at the start of a project or activity, a GT would have a predominance of reds but, as NC developed they would become amber and, when achieved, green. Hohmann noted that dominance of "autumnal colours" (red and amber) showed the goal was far from achievement while "spring colours" showed the goal was close to achievement. When applied in a GT, the necessity logic of the colours of the lowest NC should dictate the colour of higher level NC or CSF.

For example, in Figure 9 (and using the colour coding) in order to substantially achieve NC 05 (... shared understanding of risk) NC 01 we must substantially provide the best available information and NC 02 must substantially state clear terms of reference.

However, the GT and colour coding will be used to report the level of achievement as found in each NC and CSF to help test the if the design of the tentative GT is correct. Whether the necessity logic in the tentative GT should be strict or magnitudinal will be further discussed after analysis of the data.

Figure 9 also diverged from normal usage in that the weight of the connecting lines could be used to indicate the strength of a connection, determined by qualitative judgement. 


\subsubsection{Preliminary test of the tentative goal tree}

A preliminary test of the tentative GT was carried out using the risk assessment that preceded the crash of an ex-military Hawker Hunter aircraft on 22 August 2015 during the Shoreham Air Show in the UK, resulting in multiple fatalities and injuries. As part of its investigation, the UK Air Accident Investigation Branch (AAIB) asked the Health and Safety Laboratory (HSL, part of the UK Health and Safety Executive) to review the Shoreham Air Show Air Display Risk Assessment apparently completed on 14 August 2015. The HSL report was published as an appendix in the AAIB report (2017).

\section{Analysis using the goal tree}

A risk assessment covering the "airside" operation of a high-powered, ex-military jet aircraft at a public display adjacent to a busy main road and built-up area should be anything but formulaic, and should apply multiple methodologies, including engagement with stakeholders (Durodié, 2017). The HSL report revealed many shortcomings in the risk assessment as listed below that have been cross-referenced to the tentative GT. These included to "not at all or very little":

- review risk assessments from 2013 and 2014 to identify any changes in the context or the nature of risks and learn from incidents or near-hits at previous air shows (NC 01)

- include a map of the vicinity to help understand the context of the air show and what lay "over the boundary fence" (NC 01)

- follow official guidance published by the regulatory agency (the UK Civil Aviation Authority) or give an explanation for using a different approach (NC 01)

- record the qualifications and experience of the risk assessors (NC 03)

- ensure that all stakeholders had a shared understanding of risk (NC 05) or engage with all relevant stakeholders (NC 06)

- apply safety assessment criteria (NC 09)

- $\quad$ systematically develop a comprehensive list of hazards (NC 11) ${ }^{7}$

- go beyond a simplistic risk matrix (Peace, 2017c) and risk register, and to explain why quantitative risk analysis was not possible (NC 12)

\footnotetext{
${ }^{7}$ During the final revision of this thesis the pilot flying the Hawker Hunter was acquitted of manslaughter by gross negligence, having successfully "claimed he experienced 'cognitive impairment' while at the controls, brought on by hypoxia possibly due to G-force" (Anon, 2019). The HSL report appended to the AAIB (2017) report showed that "Loss of control due to pilot disorientation" was identified as a hazard in the risk assessment. It was analysed in terms of adverse weather and excessive radio traffic and did not consider pilot impairment, confirming that NC 11 was met "Not at all or very little".
} 
- apply the reasonably practicable test to identify "practicable" actions and assess whether they were "reasonable" (Peace, 2017b) (NC 13)

- effectively communicate the risks to decision makers (CSF 01)

- fully set out and correctly evaluate all relevant factors, including controversies and uncertainty (CSF 02).

The risk assessment was reported by HSL to have substantially included:

- the purpose of, or terms of reference for, the risk assessment (NC 02)

- a claim that the risk assessor had a "wealth of flying experience in general and display related experience in particular" that was not necessarily the same competence in risk assessments (NC 07).

The Shoreham air show GT in Figure 10 was colour coded using the scales in Table 9 to aid judgement about the magnitude of achievement of the CSFs and NCs identified from the HSL report.

Figure 10. The goal tree and the risk assessment from the Shoreham air show crash Red/dark grey $=$ not at all or very little Amber/mid grey = partially Green/light grey $=$ substantially

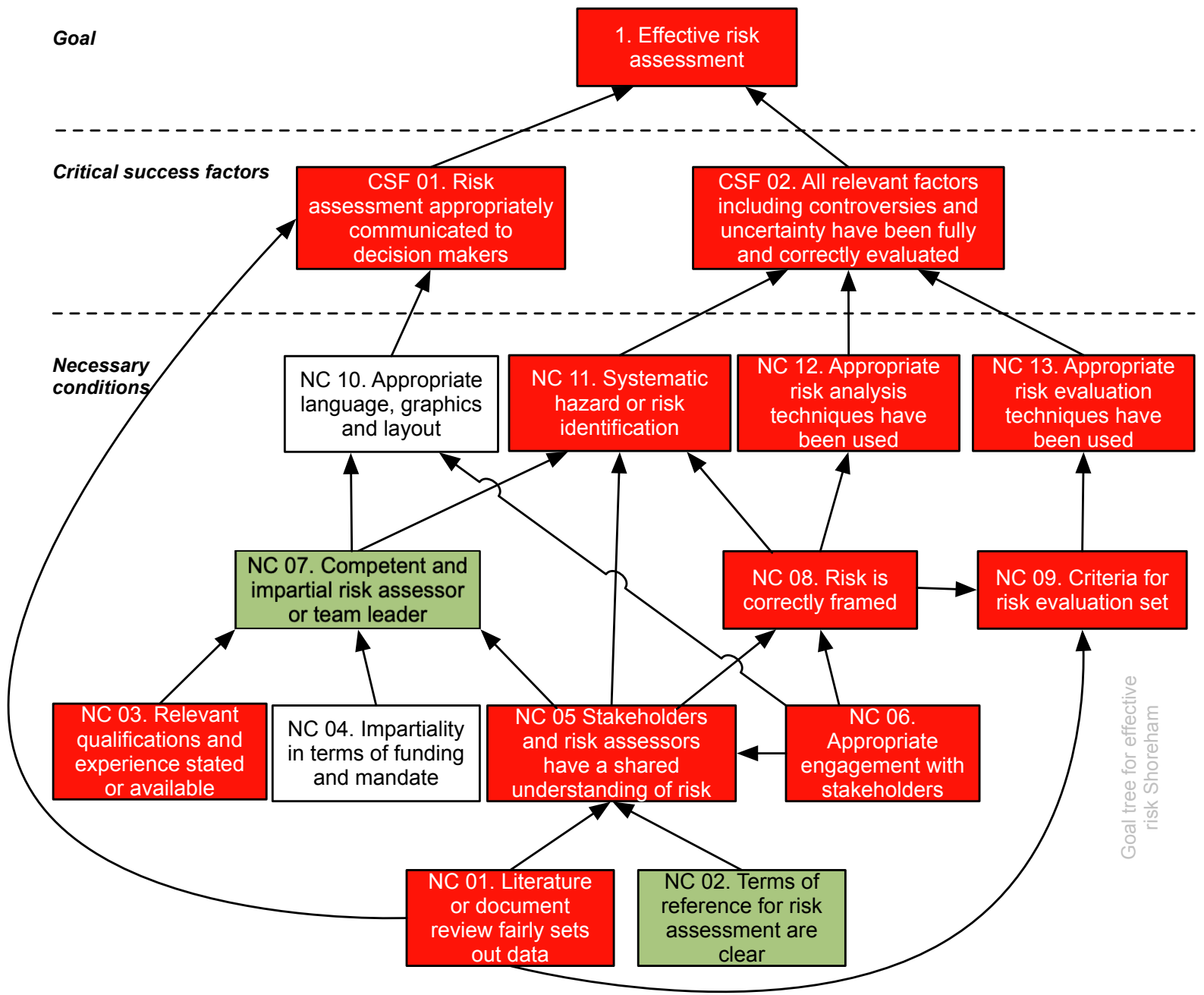


The GT shows a predominance of not at all or very little ("autumn colours") and only two substantial, suggesting the risk assessment was largely ineffective in identifying causal factors of a crash and the its consequences (potentially including fatalities, property damage) and "near hits".

\section{Conclusions from this test}

This test corroborated the tentative GT as a "provisional conjecture" (Popper, 1959, p. 33) that could be used to relate the CSF and NC in a model and that would aid analysis of data from the online survey and the case studies. It might also assist individual managers who carry risk assessments to assess if they have met the goal of an effective risk assessment. When used to analyse the Shoreham case (and subsequently the data collected in the online survey and case studies), it was used "bottom up" (ie, reverse) order. This showed that the objective or goal (section 2.6) of a risk assessment that would inform decision makers effectively was not met because so many CSF and NC (section 2.5) were not achieved. The test aligned with the conclusion of the HSL review that (AAIB, 2017, p. 317): the 2015 Shoreham Airshow Air Display Risk Assessment is not fit for the purpose of identifying and mitigating the risks and hazards to the public from the air display activities of the Airshow.

\section{Summary}

The GT (Dettmer, 2007, 2011) is a tool developed from the Intermediate Objectives Map in the Theory of Constraints (Davies et al, 2005) that provides a link between goal- or objectives-setting (Aven et al, 2006; Drucker, 1954), goal-setting theory (Latham \& Locke, 2006; Locke \& Latham, 2002) and goal orientation theory (Vandewalle et al, 2019). Thus, the tentative GT for an effective risk assessment provides a pragmatic model that sets out CSF and NC and sits between theory and practice (Morrison \& Morgan, 1999a) in risk assessments. It has been tested and appears to help structure predictions, acting to explain using necessity logic the process by which one risk assessment variable causes uncertainty or change in another. It was judged by this researcher to provide a tool to facilitate analysis of data from the planned online survey and case studies.

The CSF and NC were tabulated (Appendix A. NVivo codes based on goal tree CSF and $\mathrm{NC}$ ) to form NVivo nodes and sub-nodes to aid subsequent qualitative analysis of the online survey and case studies. 


\subsection{Online survey methodology}

\subsubsection{Survey design}

The online survey (initially part of a Master's research project) was designed as an exploratory, web-based survey. The survey instrument used Qualtrics (http://www.qualtrics.com/) and included (Bethlehem \& Biffgnandi, 2011):

- a welcome screen and assurance of anonymity

- a progress line

- forward and back arrows

- generic language that tried to avoid any assumption of prior knowledge of ISO31000 or other risk assessment processes

- a closing "thank you" screen.

The survey was in three parts covering: 1 . a decision made at least 12 months earlier; 2 . risk techniques respondents used when carrying out risk assessments; 3. demographic information. Survey questions in part 2 were structured around the risk assessment sections of the risk management process in ISO31000 (2009) and the COSO (2016) framework (section 2.3.2); derived from the analysis of risk techniques (section 2.4); with some demographic questions were derived from section 2.2.

The set of questions were reviewed and revised through seven versions over a period of two weeks and then tested with two focus groups of risk practitioners and two experienced colleagues.

A majority of the questions offered respondents a list of options and asked them to "choose no more than three". This limitation was intended to reduce the time required to complete the survey. Pre-testing suggested practitioners might select different techniques depending on the context of a risk assessment so, in such questions, no ranking was required.

The survey instrument was over 30 pages long and so in lieu of a full listing, the questions have been incorporated into chapter 4 Online survey: results and analysis.

\subsubsection{Respondent invitations}

Potential respondents (who remained anonymous and self-selecting) were contacted and invited to participate as follows.

- A brief outline of the survey objectives and link to the survey was posted to 16 Linkedln groups (https://www.linkedin.com/).

- Short articles outlining the survey of objectives and giving the link to the survey were published in a small number of electronic newsletters and magazines. 
- Six New Zealand professional bodies agreed to email their members with a brief statement of the survey objectives and the link to the survey.

- An outline of the survey objectives and link to the survey was posted in an online forum for UK safety practitioners.

- Emails were sent to professional contacts $(\mathrm{N}=15)$ in Australia, New Zealand and the UK with an outline of the survey objectives and link to the survey.

In each case the communication outlined the nature and purpose of the research and emphasised that participation was voluntary. While it was not possible to control the times of delivery or reading of the invitations it was likely they would be seen when potential respondents were checking for items of interest and might respond. It therefore was hoped the invitations might reach in excess of 1000 potential participants.

\subsubsection{Survey errors}

Online surveys can be controversial research tools as they can give rise to the range of errors summarised in Figure 11 that can lead to a mismatch between the survey population and the underlying population and, ultimately, flawed survey results (Bethlehem, 2010, p. 165).

Figure 11. Summary of potential survey errors

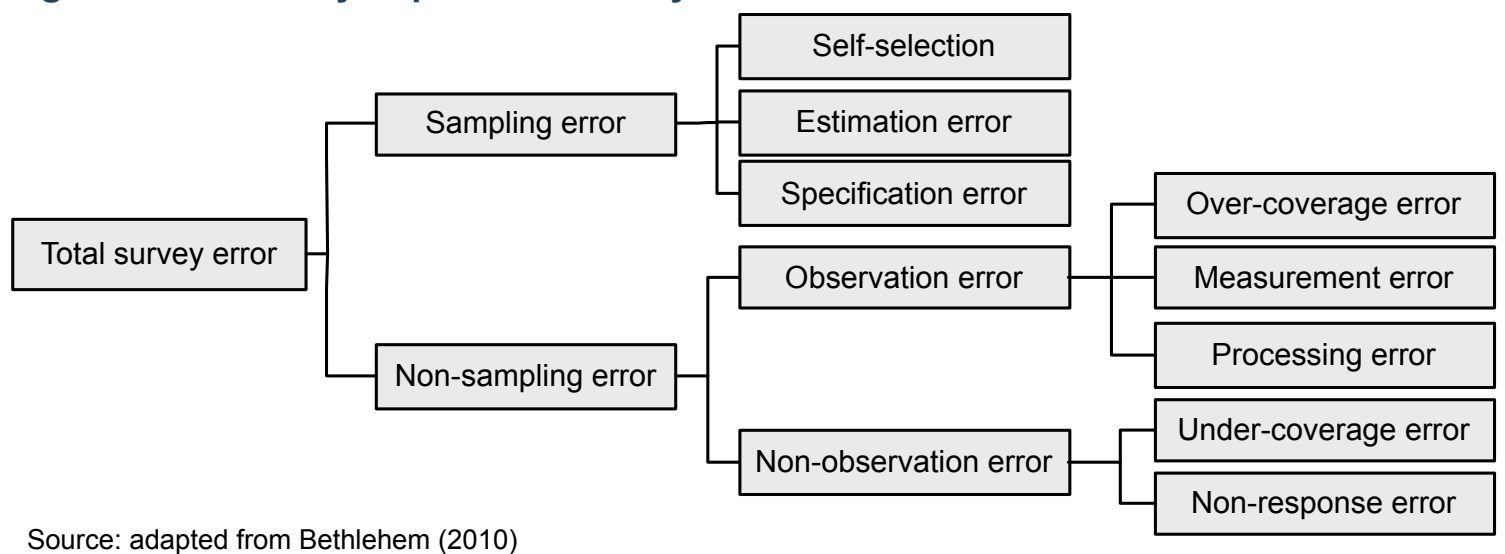

Sampling errors in online surveys include under-coverage (eg, self-selection), estimation error (the effect of the sample size) and specification error (unidentified multiple occurrences of survey elements).

Non-sampling errors arise from obtaining and recording responses and include overcoverage (survey elements are included but do not belong there), measurement errors (respondents give erroneous answers or the interviewer records the answer erroneously) and processing errors (those made during data entry or analysis), which are collectively reported as observation errors. 
Non-observation errors arise from under-coverage (eg, some intended respondents do not have access to the internet or have unreliable internet access), or non-response errors (some intended respondents do not respond to online survey requests): that is, a significant group of people might be non-respondents.

\section{Limitation of errors}

Survey errors were reduced by: designing the survey structure and questions so they reflected as wide a range of risk management processes and risk assessment models as possible and were therefore inclusive for likely respondents; using as many communication channels as possible to reach as many and as diverse a range of potential respondents as possible.

The Qualtrics survey software limited possible measurement errors but could not prevent errors where, for example, a respondent selected the wrong answer or misspelled their response to an "other" option. Some processing errors may have arisen due to the need to combine some data and so achieve a minimum sample of 30 respondents in any subgroup.

Under-coverage due to lack of access to the internet has been discounted, as potential respondents were professionals with workplace or domestic internet access. However, an uncertain level of under-coverage has undoubtedly arisen if target respondents did not receive an invitation to participate. Also, some respondents who could have provided additional insights might not be familiar with risk assessment processes or techniques. People working in the finance sector were invited via a Linkedln group, however, that resulted in no responses.

\section{Data analysis}

The software package SPSS was used for quantitative analysis of the data and the tentative GT (section 3.2) provided the qualitative framework for reporting the analysed survey data.

\subsection{Case study methodology}

In the pragmatist ontology, case studies can be used to investigate real-life problems in context (Toffel, 2016), or to explore questions or practice in an unexplored area (Cherry, 2010, pp. 9-17), or to help propose or test hypotheses of potential relevance to practice (Edmondson \& McManus, 2007; Eisenhardt \& Graebner, 2007), or to refute existing theory (Farquhar, 2012). Each case can form a unique experiment representing the context in which they exist. For example, an investigation of risk management in four named cases in the UK (Woods, 2011) showed similarities and contrasts and their individual contributions to theory (Woods, 2009), confirming the utility of case studies as a research methodology. Similarly, an investigation using four case studies of risk management practices in Australian 
and English local authorities showed the need for a pluralist approach to explain differences (Collier \& Woods, 2011).

Case study research may simply be "rich descriptions of events" with no explanations, or may provide "partial support of particular theories or frameworks", or may be multiple cases that rely on "some notion of statistical generalisation" (Easton, 1995). However, here, the case study research allowed the "systematic combining" of theory (using the GT from TOC), "explanatory power of case studies"(Yin, 2009), and an online survey "to provide a broad overview of the research domain and to guide more in-depth explanatory studies: in a word to provide something to explain" (Easton, 1995, p. 379). The cases also:

- provided empirical investigations in depth and in context (Farquhar, 2012) of the phenomenon of risk assessments informing decision makers about risk at the time the risk assessment report was submitted

- formed a critical case that illustrated practice (Flyvbjerg, 2006; Voss, Tsikriktsis, \& Frohlich, 2002) in risk assessments

- extended understanding of relationships (Farquhar, 2012) between decision making and risk assessments

- used a form of forensic, retrospective analysis requiring care to overcome researcher hindsight bias (Kahneman et al, 1982)

- showed in detail various approaches and the models and techniques used (Flyvbjerg, 2006) here, in risk assessments, and so corroborating or refuting the suggested critical success factors and necessary conditions that then can be generalised across sectors.

Analysis of the data was an iterative process where early conclusions were revisited in the light of later findings. This was "time consuming, creative and fascinating" (Marshall \& Rossman, 2006, p. 154), helping to bring order and structure to the analysis of the data by use of the tentative GT.

One of the problems in understanding how best to manage risk is a lack of detailed examples of real-world practice. Woods (2011) used an integrated case study approach to research how risk was managed in four UK organisations but gave little detail about how risk was assessed in them. This research therefore complements her broader work.

Here, the abduction uses an iterative approach between the empirical observations in the cases, the online survey and theory (the TOC and goal-setting theory) using the GT to provide a framework, as summarised Figure 12. 
Figure 12. Systematic combining

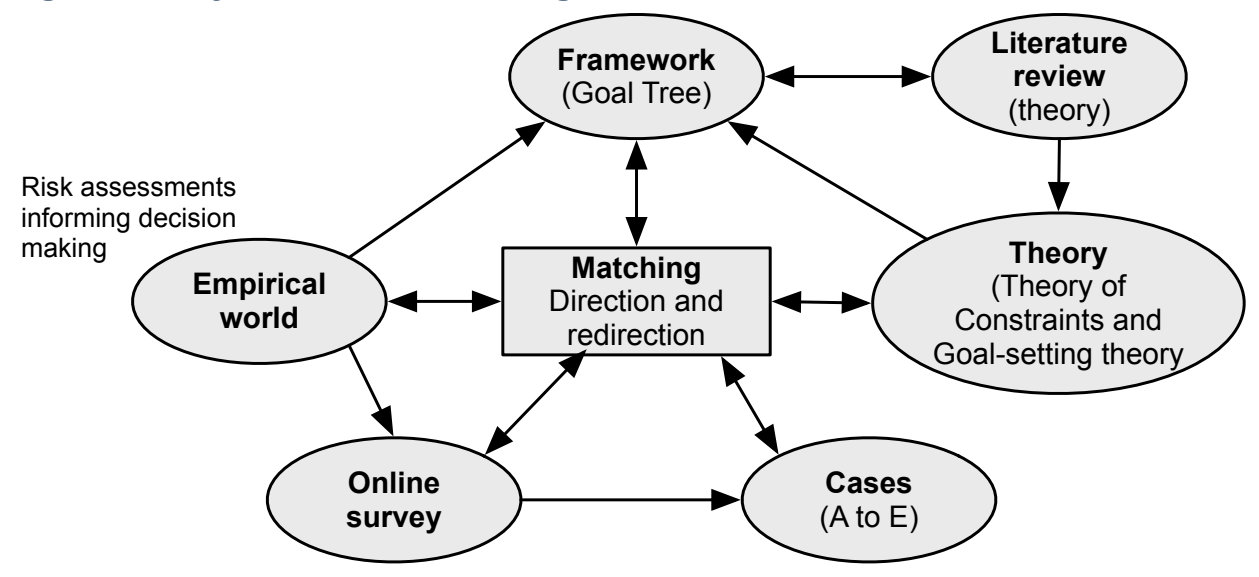

Adapted from Dubois \& Gadde (2002); Easton (1995)

\subsubsection{Case study methods}

\section{Document reviews}

During negotiations for access to each case, a set of background documents were identified using input from the case host and knowledge of the sector to help refine interview questions about decision outcomes and issues with the supporting risk assessments (Russell, 2008; Saunders et al, 2007). These documents were requested in electronic form so they could be analysed using NVivo. However, in some cases the available documents were very limited for a range of reasons, including that background papers or minutes of meetings had not been written or retained. Where possible, identified documents (including case study websites) were read before any site visits. As part of writing up each case, a further background literature review was carried out to help ascertain if the case had used the best available information.

\section{Interviews}

The interviews required a considerable investment in researcher and respondent time (eg, question design, scheduling interviews, transcription of interviews, paraphrasing responses). However, they provided a unique opportunity to uncover information, opinions, insights and memories from individuals that might not otherwise be obvious from documents (Cavana, Delahaye, \& Sekaran, 2001). Interviews were conducted on site using prepared questions previously circulated to respondents. Interviewees were asked the prepared questions listed in Table 10, followed by graphic elicitation using the tentative GT to help respondents build rich pictures to describe what might otherwise be difficult to describe in words alone (Anderson, 1993; Bagnoli, 2009; Crilly, Blackwell, \& Clarkson, 2006; Meier, 2007; Proctor, 2009). Any case-specific issues found in the document reviews were then discussed. With 
the consent of the participants all interviews were recorded and later transcribed. Interviews were thematically coded and analysed using NVivo to help link responses in different ways.

Table 10. Interview questions

\begin{tabular}{|l|l|}
\hline \multicolumn{1}{|c|}{ Decision makers were asked: } & \multicolumn{1}{c|}{ Risk assessors were asked: } \\
\hline What was your role in the decision? & What was your role in that risk assessment? \\
\hline How would you characterise the decision? & How would you characterise the decision? \\
\hline How and when was the risk assessment requested? & How and when was the risk assessment requested? \\
\hline $\begin{array}{l}\text { How well did the risk assessment inform you about the } \\
\text { risks? }\end{array}$ & $\begin{array}{l}\text { How well did the risk assessment inform the decision } \\
\text { makers about the risks? }\end{array}$ \\
\hline What makes a good risk assessment? & What makes a good risk assessment? \\
\hline Did you give any feedback on the risk assessment? & Did you receive any feedback on the risk assessment? \\
\hline $\begin{array}{l}\text { What do you generally want to know about risks before } \\
\text { making a decision? }\end{array}$ & $\begin{array}{l}\text { What do decision makers generally want to know about } \\
\text { risks before making a decision? }\end{array}$ \\
\hline $\begin{array}{l}\text { For this decision, are there any other documents I should } \\
\text { read to help me better understand this decision and the } \\
\text { related risks? }\end{array}$ & $\begin{array}{l}\text { For this decision, are there any other documents I } \\
\text { should read to help me better understand this decision } \\
\text { and the related risks? }\end{array}$ \\
\hline $\begin{array}{l}\text { For this decision and the related risks, is there anyone } \\
\text { else I should talk to? }\end{array}$ & $\begin{array}{l}\text { For this decision and the related risks, is there anyone } \\
\text { else I should talk to? }\end{array}$ \\
\hline
\end{tabular}

These qualitative, semi-structured interview questions were used to gather rich, multidimensional risk assessment experiences, and act as a guide if an interview went off-topic (Mason, 2006).

\section{Graphic elicitation}

The tentative GT (section 3.2) was also to act as a framing device or prop (Crilly et al, 2006; Varga-Atkins \& O'Brien, 2009) to complement the questions and enable further discussion.

After all the questions in the interview had been answered, each interviewee was asked to review and comment on the tentative GT.

Each diagram was coded to the interviewee and any changes they suggested recorded.

\subsubsection{Gap analysis - McKinsey 7-S}

Case studies A and B used gap analysis as part of their risk assessments, necessitating a review of relevant literature on gap analysis. A gap analysis is required to identify uncertainties in the move from the current state to some desired future state. Following an analysis, strategies are developed and implemented to close identified gaps. While gap analysis is often mentioned in reports and articles, no authoritative literature other than Krause (2009) (application of gap analysis to work health, safety and environmental management) has been found in relation to its use in risk assessments. However, internet sources refer to the McKinsey 7-S model (Structure, Systems, Strategy, Skills, Style, Staff, 
Shared values) as a gap analysis technique that originated from dissatisfaction with thenconventional approaches to organisational effectiveness (Peters \& Waterman, 1982;

Waterman et al, 1980). The original 7-S diagram was developed by Waterman et al who argued the model showed the interconnectedness and complexity of the seven factors and need to consider all seven even if planning to change only one. The 7-S model is shown in Figure 13 with some additional diagnostic questions posed by this researcher for risk assessments in particular.

Figure 13. McKinsey 7-S model with questions

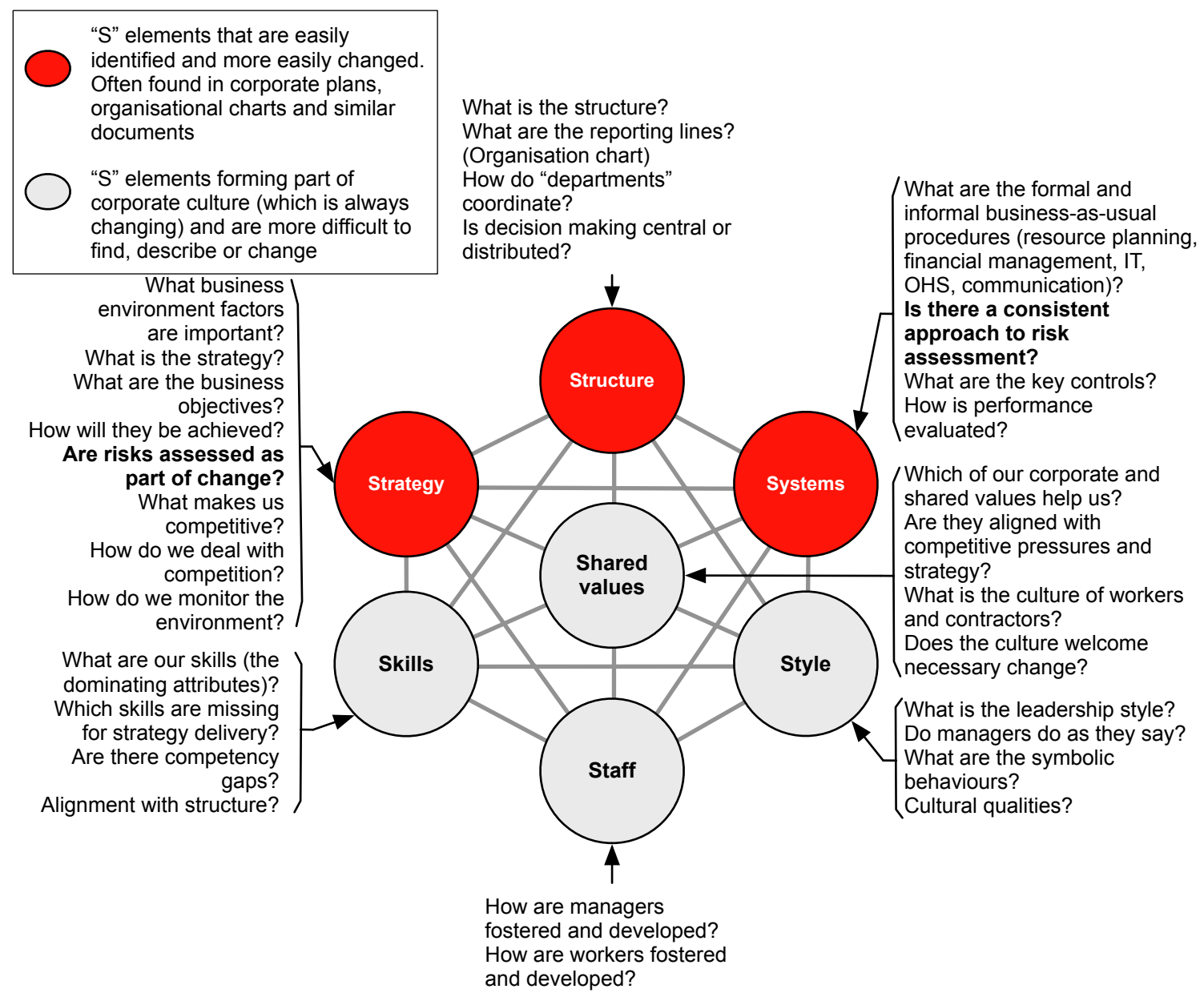

Source: base diagram adapted from Peters \& Waterman (1982) and Waterman et al (1980).

The seven factors suggest possible explanations for successes and failures of strategies, decisions and risk assessments if managers or risk assessors fail to adequately consider all seven factors in combination. Strategy and Systems appear to be aligned with ISO/IEC Annex SL (2012) (which provides a framework for all management system standards) and places risk assessment either in clause 6 (Planning) or clause 8 (Operation). The 7-S model was therefore used to investigate the gap analyses in case studies $A$ and $B$. 


\subsection{Use of the best available information}

This research was planned to investigate, via an online survey, how practitioners were conducting risk assessments generally and then (informed by the survey results) how case studies had carried out risk assessments. The survey questions asked if respondents used a "document review" and it was thought likely the cases would have based some of their input data on a document review of published material to yield the "best available information" (BAI, ISO31000, 2009) or the "weight of evidence" (WOE, Weed, 2005). While either might help overcome the availability bias - "what you see is all there is" (WYSIATI (Kahneman, 2011, pp. 85-88)) - their differences are explored and clarified here, along with what might be expected in practice.

ISO31000 (2009, p. 7) states that inputs to risk management should include the best available information based on "historical and current information, as well as future expectations". The information should be "timely and clear", "made available to relevant stakeholders" (NC 05 in the GT), together with any "limitations and uncertainties associated with such information and expectations" and should include "human and cultural factors including human behaviour and culture". The standard also refers to "the availability and reliability of information" and the "quality of the information". While this guidance at least superficially resembles good research practice, no epistemological basis for these descriptions or guidance is given in ISO31000 about how such information should be gathered in a document review, whether it should be weighted for quality, and how it should be made available.

Weed (2005) reviewed the WOE concept and methods mentioned in 92 articles reporting science-based risk assessments and suggested it is used in three general ways, each including a literature review.

\section{Metaphorical}

Provided a summary interpretation or synthesis of the evidence. No description or definition of WOE was given.

\section{Methodological}

All available evidence was examined and interpreted. The article might report the "strength of evidence" based on statistical evidence.

\section{Theoretical}

Used meta-analysis and narrative reviews to show where the WOE lay. Some journals require authors to state how they went about a review. 
The reliability and relevance of sources includes whether the source (Booth, Colomb, \& Williams, 2008, pp. 77-80):

- was published by a reputable press

- was peer reviewed

- was a reputable author

- is up to date

- has been frequently cited by others

- (if online only) is sponsored by a reputable organisation

- (if a book) has notes and a bibliography

- (if a book) has been well reviewed

- (if a website) includes bibliographic data

- (if a website) approaches its topic in a balanced manner.

Prior to the field work it was uncertain if any of the above guidance was followed. The above list was therefore to be used when considering if NC 01 ("Literature or document review fairly sets out data") had been achieved.

\subsection{Data analysis}

The tentative GT for an effective risk assessment (section 3.2) provided a framework for analysis of data from the interviews, document reviews, and related case study documents. The GT contained two CSF and 13 NC. These were used in a "bottom up" (ie, reverse) order when reporting on data collected in the interviews and document reviews.

To enable analysis within and between the cases, data from each case was coded for the:

- organisation

- document sources

- interviewee (name, position at the time of the risk assessment or decision, length of time in that position at the time of the risk assessment or decision, highest qualification, professional memberships).

Data was coded for analysis with NVivo using codes and sub-codes developed from the tentative GT set out in full in Appendix A. NVivo codes based on goal tree CSF and NC and further sub-codes developed as analysis progressed. This enabled clustering of data within and between cases to better understand the risk assessment phenomena (Miles, 1984). Data was compared with the tentative GT to corroborate or refute (Popper, 1959, p. 33) the 
posited CSF and NC, and identify constraints to effective risk assessments and suggest how they might be overcome (Dettmer, 2007; Zotov et al, 2007).

It was intended that each case study would include a qualitative influence diagram, based on researcher judgement for the design and layout, to illustrate how the risk assessment influenced the decision and subsequent outcomes. However, insufficient data was available to develop a diagram in Case Study E.

A 2x2 matrix comparing the effectiveness of each risk assessment with the decision outcome was developed. This was used in four of the case studies to judge qualitatively if the risk assessments aided the risk assessments. Insufficient data was available to develop a matrix in Case Study E. To minimise researcher biases, the effectiveness of each case study risk assessment was assessed using a combination of:

- responses from decision makers interviewed (which indicated their level of satisfaction with the risk assessment)

- reviews of records (which aided retrospective evaluation of the process and techniques used)

- $\quad$ matching data with the tentative GT

Care was taken to decouple the favourability of the decision outcome from the quality of the associated risk assessment.

\subsection{Ethical issues}

The research criteria listed below for selection of case studies were specified by the School of Management Research Committee and were intended to limit potential cases to those organisations with stable decision makers and good records of their risk assessments. Each of the cases:

- included a risk assessment that informed a strategic decision made in an organisational context at least 12 months, but not more than 36 months, before starting the field work

- was a large organisation

- related to potential occupational health and safety or environmental effects

- was an organisation willing to give access to adequate records for the document review and stakeholders willing to be interviewed

- was selected to further aid development of the tentative GT and other practical aids. 
These requirements acted to delimit the cases by time and scope, while the tentative GT acted to delimit possible variables.

It was anticipated that some risk assessments in the case studies might be found to be deficient, leading to the potential for harm to people, the environment, or tangible or intangible assets. Therefore, before starting the case studies, a full protocol, approved by the Victoria University Human Ethics Committee, was developed and set out in a memorandum of understanding signed by the researcher and a senior manager in each case study.

The protocol required that if a risk assessment was deemed to expose people or assets to harm the contact person would be advised to seek appropriate independent professional advice. In practice, each case had been completed at least 12 months before inclusion in the research and such risks eliminated.

Appendix B. Human Ethics Committee Approvals, shows approvals for the:

- $\quad$ online survey, reference number 20644; approved 6 May 2014

- case study research, reference number 22338: approved 21 September 2015

- Risk canvas research, reference number 23249: approved 16 June 2016.

No conflicts of interest were identified with the case studies.

\subsection{Summary and responses to the research questions}

This pragmatic research methodology is founded on the literature review (especially the development of goal-setting and the development of the GT). Using a mixed methods research approach to data collection, analysis and interpretations, this research moves from personal experience in the field, through the literature review and an online survey, to case studies.

In doing so it responds to the research gaps between the theory and practice of (1) risk assessments informing management decision making and (2) how risk assessors and decision makers judge the effectiveness of such risk assessments. The research methodology was expected to provide triangulation of data (section 8.2) and meet researcher preferences for (1) qualitative data showing the big picture for risk and its assessment in organisations and (2) some quantitative data to support the big picture (Denzin, 2008).

The next chapter reports the results of the online survey using the qualitative structure of the GT. 


\section{Online survey: results and analysis}

\subsection{Overview and research questions}

This chapter introduces the online survey data and its analysis before mapping the data into the tentative GT.

The structure of the online survey reported here was based on the literature review sections for risk assessment processes and techniques. When printed, the survey instrument was more than 30 pages long and so the questions have been incorporated into the tables and charts in this chapter. Statistical analysis of the data was carried out using SPSS and reporting of the results has been organised using the tentative GT structure (section 3.2) and the survey findings respond to sub-question SQ 1.

What processes and methods are currently being used for risk assessments?

While a response rate of $11 \%$ or less is normal for online surveys (Saunders et al, 2007), the parent population of respondents to this survey was unknown and therefore a response rate for this survey cannot be calculated. However, a sample size of between 30 and 500 respondents seems generally to be acceptable for online survey samples and sub-samples (Alreck \& Settle, 1995; Hill, 1998; Sue \& Ritter, 2012). In this survey, over 500 people looked at the start of the survey and 326 answered the first question; responses to subsequent questions varied in a range of 197 to 326 with a mean response per question of 239 .

\subsection{Demographic and general data}

The survey was run between May 2014 and January 2015.

The demographic questions showed that:

- $57 \%$ of the respondents lived in New Zealand

- $15 \%$ of the respondents lived in the UK and Eire

- $40 \%$ of the respondents worked in health and safety

- $23 \%$ of the respondents worked in risk management.

Part of the survey asked about the nature of a decision made at least 12 months earlier and whether it was supported by a risk assessment. Results are cross-tabulated in Table 11 showing that:

- safety-related objectives, activities or programmes (23\%) and strategy or transformational activities or programmes (23\%) dominated the responses

- $84 \%$ of safety-related decisions were supported by risk assessments compared with $70 \%$ of strategy-related decisions. 
Table 11. Nature of decision and whether supported by a risk assessment

\begin{tabular}{|l|r|r|r|}
\hline \multirow{2}{*}{$\begin{array}{l}\text { Thinking about a decision that was significant in your organisation at least } 12 \\
\text { months ago, did the decision mainly relate to (choose one) }\end{array}$} & \multicolumn{3}{|c|}{ Was the decision supported by a risk } \\
\cline { 2 - 4 } & \multicolumn{1}{|c|}{ Yessessment? } & \multicolumn{1}{|c|}{ No } & \multicolumn{1}{c|}{ Total } \\
\hline Safety-related objectives, activities or programmes & $62(84 \%)$ & $12(16 \%)$ & $74(23 \%)$ \\
\hline Strategy or transformational activities or programmes & $52(70 \%)$ & $22(30 \%)$ & $74(23 \%)$ \\
\hline Project or change management activities or programmes & $40(74 \%)$ & $14(26 \%)$ & $54(17 \%)$ \\
\hline Operational objectives & $22(52 \%)$ & $20(48 \%)$ & $42(13 \%)$ \\
\hline Financial objectives & $13(45 \%)$ & $16(55 \%)$ & $29(9 \%)$ \\
\hline Quality-related objectives, activities or programmes & $9(56 \%)$ & $7(44 \%)$ & $16(5 \%)$ \\
\hline Response to external events & $8(61 \%)$ & $5(39 \%)$ & $13(4 \%)$ \\
\hline Sales- or marketing-related objectives, activities or programmes & $8(61 \%)$ & $5(39 \%)$ & $13(4 \%)$ \\
\hline Stakeholder management activities & $4(50 \%)$ & $4(50 \%)$ & $8(2 \%)$ \\
\hline $\begin{array}{l}\text { Environmental- or sustainability-related objectives, activities or } \\
\text { programmes }\end{array}$ & $3(100 \%)$ & & $3(1 \%)$ \\
\hline Totals & $221(68 \%)$ & $105(32 \%)$ & 326 \\
\hline
\end{tabular}

Some $32 \%$ of respondents said the decision was not supported by a risk assessment, possibly confirming that lack of information about risks (King \& Crewe, 2013) contributes to the more than $50 \%$ of decisions that fail (Lovallo \& Sibony, 2010; Nutt, 2002; Nutt \& Wilson, 2010). Not all of the decisions will have had equal weight but these results corroborate the research problem (section 1.7) that risk assessments often fail to inform decision makers in this case, due to the absence of risk assessments.

The possible effectiveness of the risk assessments is partially shown by responses to subsequent questions.

\subsection{Reporting using the tentative goal tree CSF and NC}

\subsubsection{Literature or document review fairly sets out data (NC 01)}

To help achieve a shared understanding of the context of risk, assessors need to read background documents (section 3.5). Such documents can be identified using a range of techniques. Respondents were asked if they established the context or business environment as part of the risk assessment. Respondents answering "yes" (89\%) were then asked which three of 13 techniques (with an "other" option) they most often used to help understand the context or business environment. Responses are summarised below. 
Table 12. Risk techniques used in establishing the context

\begin{tabular}{|l|c|}
\hline \multicolumn{1}{|c|}{ Name of technique } & Number of respondents choosing this technique \\
\hline Professional judgement & 108 \\
\hline Workshops including brainstorming & 105 \\
\hline Scenario analysis & 64 \\
\hline Strengths, Weaknesses, Opportunities and Threats (SWOT) analysis & 64 \\
\hline Document or literature review & 62 \\
\hline Applied research & 42 \\
\hline Flowcharting & 36 \\
\hline PESTLE or PEST analysis & 34 \\
\hline Mind mapping & 28 \\
\hline Surveys (online or paper-based) & 21 \\
\hline Concept mapping & 15 \\
\hline Horizon scanning & 11 \\
\hline I rely on another person or group in my organisation to do this & 6 \\
\hline
\end{tabular}

The question was aimed at discovering how respondents elicited information about the context, including reviewing documents. The dominance of "professional judgement" suggested a lack of structure to their approach, explored further in chapter 5 , the case studies, and section 6.5.2.

"Other" responses included alternative names for those given in the survey and were categorised accordingly. "General discussion" was added to "Workshops including brainstorming" and the following were included in "document review and analysis":

- "data and other forms of records"

- "objectives"

- "documented objectives and business plan".

"Other" responses also included "LMSCARVER"(a technique that seems to have been mentioned in one book (Sikich, 2003)) and "tieline calculator" (a nomogram linking probability, exposure and consequences to give a dimensionless number (Dowell Solutions, 2011; Naval Weapons Centre, 1976)). Each was cited once and so disregarded.

\subsubsection{Terms of reference for risk assessment are clear (NC 02)}

In the survey, it was not possible to ascertain if the terms of reference for a decision and associated risk assessments were clear; this was reviewed in the case studies. 


\subsubsection{Relevant qualifications and experience stated or available (NC 03)}

The survey asked respondents about their highest qualifications and length of experience in their jobs. Their responses showed most were well qualified and experienced (see Table 13, Table 15 and Figure 14).

Of those working in risk management, $71 \%$ held a Bachelor's or Master's degree (Table 14) and almost all had at least one year in their job (Table 15). Similarly, of those working in safety management, 55 (55\%) of safety respondents held a Bachelor's or Master's degree and almost all had at least one year in their job.

Table 13. Cross tabulation of highest qualification and time in current role

\begin{tabular}{|l|c|c|c|c|c|}
\hline \multirow{2}{*}{ What is your highest educational qualification? } & \multicolumn{5}{|c|}{ How long have you worked in your current role? } \\
\cline { 2 - 6 } & $0-1$ years & $1-5$ years & $5-10$ years & $>10$ years & Total \\
\hline Certificate & 1 & 12 & 3 & 8 & $24(10 \%)$ \\
\hline Diploma & 1 & 18 & 8 & 18 & $45(18 \%)$ \\
\hline Bachelor's degree & 7 & 31 & 20 & 20 & $78(32 \%)$ \\
\hline Master's degree & 4 & 23 & 19 & 32 & $78(32 \%)$ \\
\hline PhD & 0 & 4 & 0 & 10 & $14(6 \%)$ \\
\hline None & 0 & 3 & 0 & 2 & $5(2 \%)$ \\
\hline Totals & $13(5 \%)$ & $91(37 \%)$ & $50(20 \%)$ & $90(37 \%)$ & 244 \\
\hline
\end{tabular}

Figure 14. Cross tabulation of highest qualification and time in current role

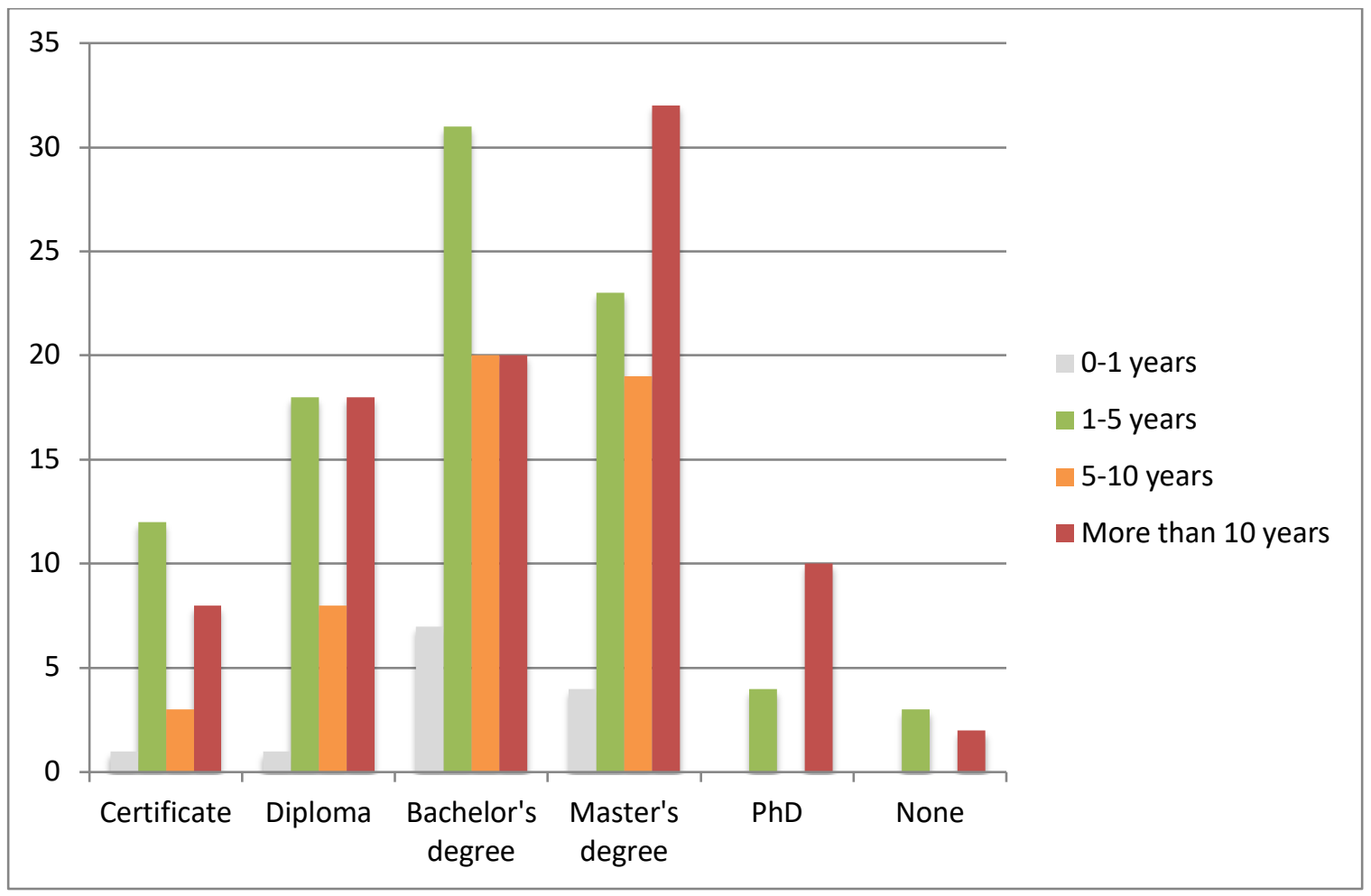


Table 14. Cross tabulation of jobs and highest qualifications

\begin{tabular}{|c|c|c|c|c|c|c|c|}
\hline \multirow{2}{*}{$\begin{array}{l}\text { Which one of the following } \\
\text { best describes your job or } \\
\text { area of employment? }\end{array}$} & \multicolumn{7}{|c|}{ What is your highest educational qualification? } \\
\hline & Certificate & Diploma & $\begin{array}{l}\text { Bachelor's } \\
\text { degree }\end{array}$ & $\begin{array}{l}\text { Master's } \\
\text { degree }\end{array}$ & $\mathrm{PhD}$ & None & Total \\
\hline Director & 2 & 4 & 6 & 5 & 4 & 0 & $21(9 \%)$ \\
\hline Executive manager & 0 & 3 & 10 & 12 & 1 & 0 & $26(11 \%)$ \\
\hline Corporate risk manager & 3 & 10 & 20 & 21 & 3 & 1 & $58(24 \%)$ \\
\hline $\begin{array}{l}\text { Project manager (employee or } \\
\text { consultant) }\end{array}$ & 1 & 0 & 4 & 3 & 1 & 0 & $9(4 \%)$ \\
\hline $\begin{array}{l}\text { Business continuity manager } \\
\text { (employee or consultant) }\end{array}$ & 1 & 1 & 1 & 2 & 0 & 1 & $6(2 \%)$ \\
\hline Corporate safety manager & 14 & 24 & 27 & 25 & 3 & 2 & $96(4 \%)$ \\
\hline Internal auditor & 3 & 2 & 9 & 3 & 2 & 1 & $20(8 \%)$ \\
\hline Regulatory or enforcement & 0 & 1 & 1 & 4 & 0 & 0 & $6(2 \%)$ \\
\hline Total & $24(10 \%)$ & $45(19 \%)$ & $78(32 \%)$ & $76(31 \%)$ & $14(6 \%)$ & $5(2 \%)$ & 242 \\
\hline
\end{tabular}

Figure 15. Comparison between jobs and highest qualifications

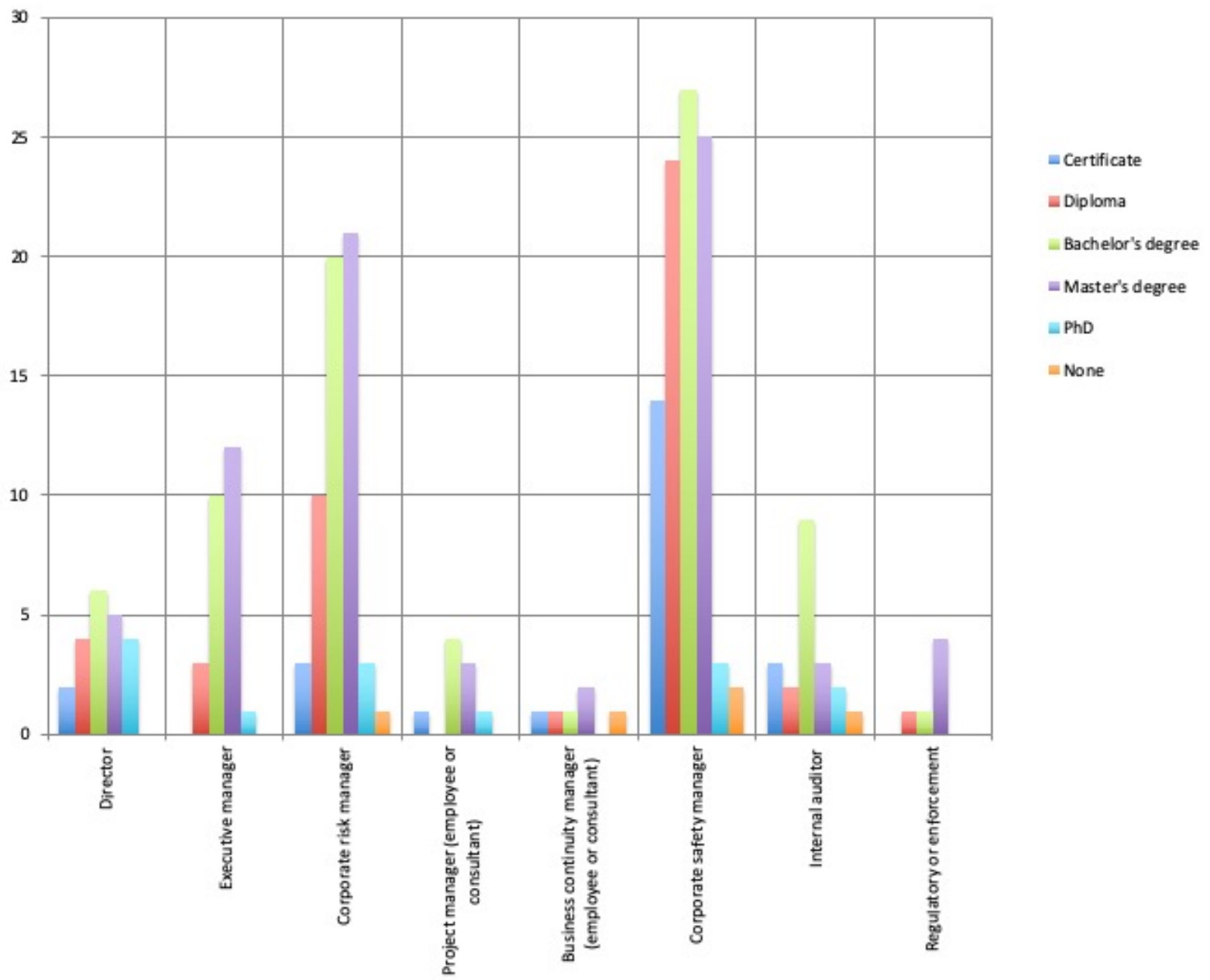


Table 15. Cross tabulation of jobs and time in current role

\begin{tabular}{|l|r|r|r|r|r|}
\hline \multirow{2}{*}{$\begin{array}{l}\text { Which one of the following best describes your job or area } \\
\text { of employment? }\end{array}$} & \multicolumn{5}{|c|}{ How long have you worked in your current role? } \\
\cline { 2 - 7 } & $0-1$ years & $1-5$ years & $5-10$ years & $>10$ years & Total \\
\hline Director & 0 & 3 & 4 & 14 & $21(9 \%)$ \\
\hline Executive manager & 2 & 7 & 4 & 13 & $26(11 \%)$ \\
\hline Corporate risk manager & 5 & 27 & 11 & 15 & $5824 \%)$ \\
\hline Project manager (employee or consultant) & 0 & 4 & 3 & 2 & $9(4 \%)$ \\
\hline Business continuity manager (employee or consultant) & 1 & 1 & 0 & 4 & $6(2 \%)$ \\
\hline Corporate safety manager & 3 & 39 & 24 & 29 & $96(40 \%)$ \\
\hline Internal auditor & 2 & 7 & 2 & 9 & $20(8 \%)$ \\
\hline Regulatory or enforcement & 0 & 1 & 1 & 4 & $6(2 \%)$ \\
\hline Total & $13(5 \%)$ & $89(37 \%)$ & $50(21 \%)$ & $90(37 \%)$ & 242 \\
\hline
\end{tabular}

Figure 16. Comparison between jobs and time in current role

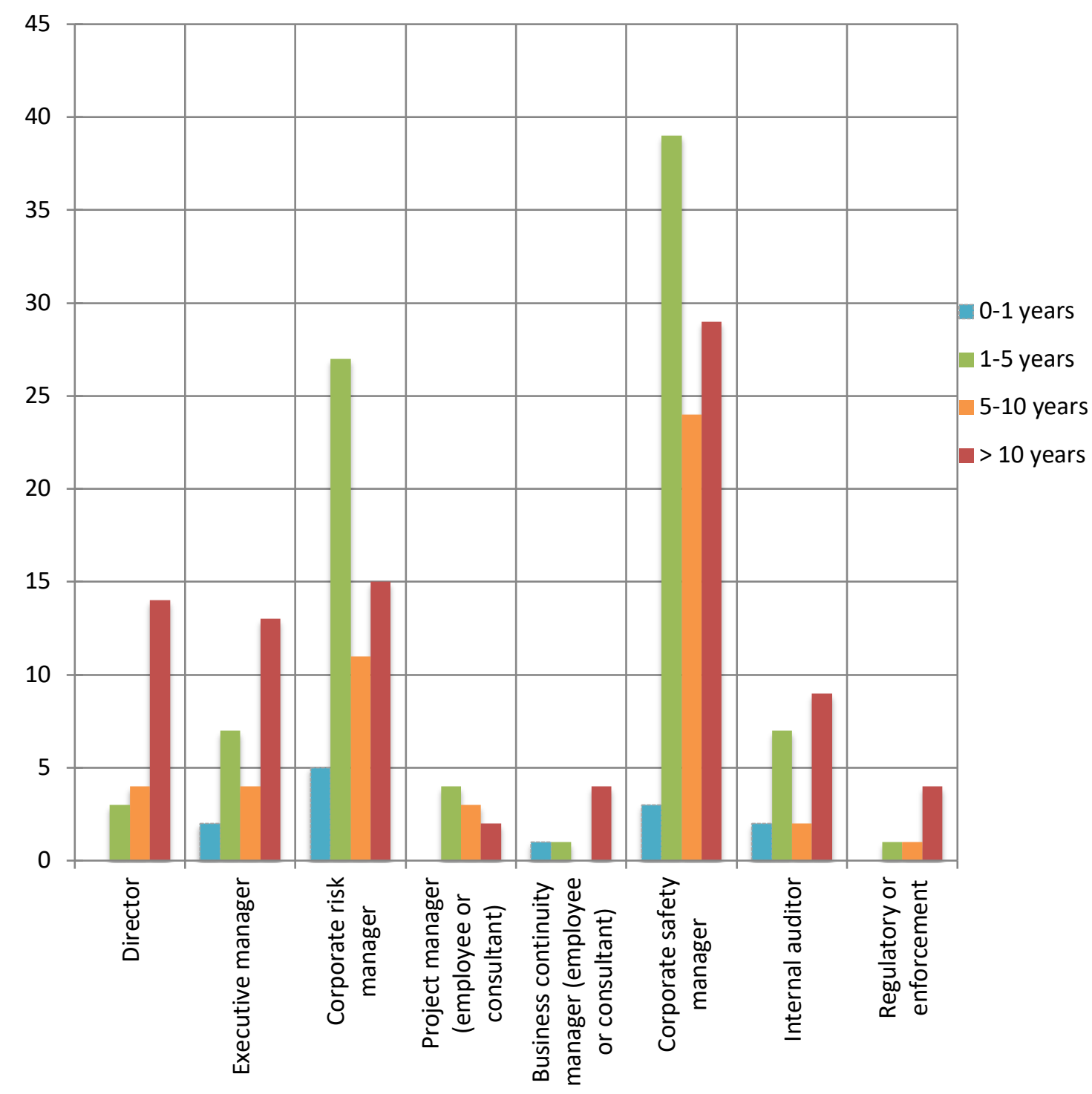


Table 16. Level of qualifications of respondents by country of respondent

\begin{tabular}{|l|c|c|c|c|}
\cline { 2 - 5 } \multicolumn{1}{c|}{} & New Zealand & Australia & $\begin{array}{c}\text { United Kingdom of } \\
\text { Great Britain and Eire }\end{array}$ & USA and Canada \\
\hline Certificate & $18(13 \%)$ & $1(1 \%)$ & $2(4 \%)$ & $1(4 \%)$ \\
\hline Diploma & $34(25 \%)$ & $52(73 \%)$ & $26(46 \%)$ & $4(17 \%)$ \\
\hline Bachelor's degree & $52(38 \%)$ & $8(11 \%)$ & $8(14 \%)$ & $4(17 \%)$ \\
\hline Master's degree & $26(19 \%)$ & $5(7 \%)$ & $18(32 \%)$ & $13(54 \%)$ \\
\hline PhD & $4(3 \%)$ & $5(7 \%)$ & $1(2 \%)$ & $2(8 \%)$ \\
\hline None & $4(3 \%)$ & 0 & $1(2 \%)$ & 0 \\
\hline Totals & 138 & 71 & 56 & 24 \\
\hline
\end{tabular}

\section{Memberships of professional bodies}

Competence may also be gained by membership of a professional body, perhaps enabling attendance at professional development meetings and courses. The names of individual professional bodies across different countries could not be anticipated so respondents were asked to select the type of professional body they were a member of. Many respondents picked at least two (Table 17) with the types most frequently selected being "risk management-related" ( $\mathrm{N}=110)$ and "occupational health and safety-related" $(\mathrm{N}=105)$.

Table 17. Focus of professional bodies

\begin{tabular}{|l|c|}
\hline \multicolumn{1}{|c|}{ Focus of professional organisation } & $\begin{array}{c}\text { Number of respondents choosing } \\
\text { this professional organisation focus }\end{array}$ \\
\hline Risk management-related & 110 \\
\hline Occupational safety- or process safety-related & 105 \\
\hline Health- or occupational health-related & 43 \\
\hline Environment management-related & 33 \\
\hline Management-related, including audit & 31 \\
\hline Project management-related & 27 \\
\hline Emergency management-related & 26 \\
\hline $\begin{array}{l}\text { Administration-related (including education and human } \\
\text { resources) }\end{array}$ & 24 \\
\hline Business continuity-related & 23 \\
\hline Other management-related & 22 \\
\hline Quality management-related & 18 \\
\hline Director-related & 17 \\
\hline Engineering-, science- or technology-related & 16 \\
\hline Accountancy-related & 10 \\
\hline Total & $\mathbf{5 0 5}$ \\
\hline
\end{tabular}




\section{Summary of qualifications and experience}

These results suggested respondents were well qualified in terms of degrees (especially safety managers - see Table 14 and Figure 15) and experienced. They were also likely to be members of professional bodies that might set entry requirements and to offer some form of updating service. They therefore might be expected to meet NC08. However, 30 (12\%) had a certificate or diploma and 5 years or less experience potentially diminishing their ability to exercise professional judgement (section 6.5.2). It is also acknowledged that some qualifications may be out of date or in areas unrelated to risk analysis, making them of little practical value in informing risk assessments

\subsubsection{Impartiality in terms of funding and mandate (NC 04)}

It was not possible to ascertain if funding of the risk assessments was impartial but it is most likely that funding was from within the organisations. This was reviewed in the case studies.

\subsubsection{Stakeholders and risk assessors have a shared understanding of risk (NC 05)} A shared understanding of risk will be achieved, in part, through engagement with stakeholders, and may also be key to the acceptance of risk assessments as effective and inclusive. (eg, Abt et al, 2010; Earle, 2010; McDermott \& Davies, 2008; Wiedemann et al, 2013).

\subsubsection{Appropriate engagement with stakeholders (NC 06)}

Respondents were asked if a risk assessment that supported a decision had included consultation with stakeholders. Table 18 shows responses cross-tabulated against the nature of decision made. 
Table 18. Whether stakeholders were consulted in the risk assessment

\begin{tabular}{|l|r|r|r|r|}
\hline \multirow{2}{*}{$\begin{array}{c}\text { Thinking about a decision that was significant in your } \\
\text { organisation at least } 12 \text { months ago, did the decision mainly } \\
\text { relate to: }\end{array}$} & \multicolumn{3}{|c|}{ Were stakeholders consulted about or as part of the risk } \\
\cline { 2 - 5 } assessment?
\end{tabular}

In some areas (eg, safety), engagement may be mandatory and the results showed $93 \%$ of safety-related responses included such engagement. In other sectors responses were lower but none were less than $80 \%$.

Such high engagement with stakeholders was confirmed when respondents were asked "when carrying out a risk assessment do you normally communicate or consult with stakeholders?". Responses (summarised in Table 19) showed a similarly high level of engagement, regardless of sector or respondent background.

Table 19. Do you consult with stakeholders?

\begin{tabular}{|c|c|c|}
\hline Response & Number & Percent \\
\hline Yes & 252 & $94 \%$ \\
\hline No & 16 & $6 \%$ \\
\hline Total & 268 & $100 \%$ \\
\hline
\end{tabular}

A "yes" response to this question led to the question "when carrying out a risk assessment which of the following do you most often use to help identify stakeholders in a risk assessment? Choose no more than three". Responses received from 248 people are summarised in Table 20. 
Table 20. Risk techniques used to identify stakeholders in a risk assessment

\begin{tabular}{|l|c|}
\hline \multicolumn{1}{|c|}{ Name of technique } & $\begin{array}{c}\text { Number of respondents } \\
\text { choosing this technique }\end{array}$ \\
\hline Personal knowledge of stakeholders & 153 \\
\hline Professional judgement & 148 \\
\hline Brainstorming & 107 \\
\hline Interviews with other stakeholders & 86 \\
\hline Workshops with other stakeholders & 67 \\
\hline Existing database of stakeholders & 59 \\
\hline I rely on another person or group in my organisation to do this & 7 \\
\hline
\end{tabular}

Respondents selected "personal knowledge" and "professional judgement" most often with no discernible difference in experience, qualifications or job. Both are prone to availability bias and over-confidence (Montibeller \& von Winterfeldt, 2015; Slovic et al, 2000). Identification of stakeholders may be straightforward (eg, the relevant people are the team asked to carry out some activity) or complex (eg, a wide cross-section of society needs to be engaged). The more complex the activity, the more structured the stakeholder identification should be.

The next question asked "when carrying out any risk assessment, which techniques do you most often use to determine how and how much to communicate or consult with stakeholders in a risk assessment? Choose no more than three". Responses are summarised in Table 21 and show the two most popular ways of deciding how, and how much, to communicate or consult with stakeholders were professional judgement and feedback from earlier consultations. This latter is significant because risk is in the future, not the past, and may require different consultation.

Stakeholder matrices are imperfect but do help de-bias consultation and communication by helping to ensure appropriate engagement (Anon, 2012; Department of Sustainability and Environment, 2009). Some "other" responses showed that some regulatory agencies require specific forms of consultation. 
Table 21. Techniques used to decide how to consult or communicate

\begin{tabular}{|l|c|}
\hline \multicolumn{1}{|c|}{ Name of technique } & $\begin{array}{c}\text { Number of respondents } \\
\text { choosing this technique }\end{array}$ \\
\hline Professional judgement & 187 \\
\hline Feedback from earlier consultation & 147 \\
\hline Brainstorming & 98 \\
\hline Stakeholder importance/influence matrix or similar & 84 \\
\hline I rely on another person or group in my organisation to do this & 11 \\
\hline Legal requirements or guidance & 3 \\
\hline
\end{tabular}

Cross tabulation of this data showed communication and consultation with stakeholders was carried out by:

- $93 \%$ of safety and risk managers or consultants

- $88 \%$ of project managers and internal auditors.

Level of education showed no significance in the extent of communication and consultation.

Further cross-tabulation showed high levels of engagement in all sectors (see Table 22). 
Table 22. Whether risk assessors communicate or consult in each sector

\begin{tabular}{|l|c|c|c|}
\hline \multirow{2}{*}{$\begin{array}{c}\text { Which sector do you work in or mostly provide consultancy } \\
\text { services in? }\end{array}$} & \multicolumn{3}{|c|}{$\begin{array}{l}\text { When carrying out a risk assessment do you normally } \\
\text { communicate or consult with stakeholders? }\end{array}$} \\
\cline { 2 - 4 } & Total & \multicolumn{2}{|c|}{ Yes } \\
\hline Manufacturing & 33 & 32 & $97 \%$ \\
\hline Public administration and safety & 26 & 26 & $100 \%$ \\
\hline Construction & 20 & 17 & $85 \%$ \\
\hline Professional, scientific and technical services & 17 & 17 & $100 \%$ \\
\hline Other services & 17 & 16 & $94 \%$ \\
\hline Financial and insurance services & 16 & 15 & $94 \%$ \\
\hline Electricity, gas, water and waste services & 14 & 13 & $93 \%$ \\
\hline Not elsewhere included & 13 & 12 & $93 \%$ \\
\hline Health care and social assistance & 13 & 11 & $5 \%$ \\
\hline Education and training & 10 & 8 & $80 \%$ \\
\hline Mining & 9 & 9 & $100 \%$ \\
\hline Transport, postal and warehousing & 8 & 7 & $88 \%$ \\
\hline Agriculture, Forestry and Fishing & 5 & 5 & $100 \%$ \\
\hline Arts and recreation services & 4 & 4 & $100 \%$ \\
\hline Accommodation and food services & 3 & 3 & $100 \%$ \\
\hline Information media and telecommunications & 3 & 3 & $100 \%$ \\
\hline Retail trade & 3 & 2 & $67 \%$ \\
\hline Rental, hiring and real estate services & 2 & 2 & $100 \%$ \\
\hline Administrative and support services & 2 & 2 & $100 \%$ \\
\hline Wholesale trade & 1 & 1 & $100 \%$ \\
\hline Total & 205 & $94 \%$ \\
\hline
\end{tabular}

\subsubsection{Competent or impartial risk assessor or team leader (NC 07)}

It was not possible to ascertain from the survey whether risk assessors were impartial. However, questions related to NC 03 suggested many were at least qualified and experienced, factors that may contribute to competence. 


\subsubsection{Risk is correctly framed (NC 08)}

Understanding the context or business environment of organisations and their risks can be key to correctly framing the risk and an effective risk assessment (Gould-Williams \&

Gatenby, 2010).

Overall, $86 \%$ of respondents reported their risk assessments did consider the context. The effectiveness of risk assessments carried out by the $14 \%$ who did not consider the context could not be estimated by the online survey and will be explored in the case studies.

Table 23. Whether the risk assessment included discussion of the context

\begin{tabular}{|l|r|r|r|r|}
\hline \multirow{2}{*}{$\begin{array}{l}\text { Thinking about a decision that was significant in your organisation } \\
\text { at least } 12 \text { months ago, did the decision mainly relate to: }\end{array}$} & \multicolumn{3}{|c|}{$\begin{array}{c}\text { Did the risk assessment include discussion of the context } \\
\text { or business environment? }\end{array}$} \\
\cline { 2 - 5 } Safety-related objectives, activities or programmes & Total & Yes & No & $1(2 \%)$ \\
\hline Strategy or transformational activities or programmes & 57 & $49(86 \%)$ & $7(12 \%)$ & $4(9 \%)$ \\
\hline Project or change management activities or programmes & 47 & $39(82 \%)$ & $4(9 \%)$ & 0 \\
\hline Operational objectives & 35 & $29(83 \%)$ & $6(17 \%)$ & 0 \\
\hline Financial objectives & 19 & $17(89 \%)$ & $2(11 \%)$ \\
\hline Quality-related objectives, activities or programmes & 10 & $10(100 \%)$ & 0 & 0 \\
\hline Sales- or marketing-related objectives, activities or programmes & 9 & $9(100 \%)$ & 0 & 0 \\
\hline Response to external events & 8 & $8(100 \%)$ & 0 & 0 \\
\hline Environmental- or sustainability-related objectives, activities or & 7 & $5(71 \%)$ & $2(29 \%)$ & 0 \\
\hline programmes & 3 & $2(67 \%)$ & $1(33 \%)$ & 0 \\
\hline Stakeholder management activities & 2 & $1(50 \%)$ & $1(50 \%)$ & 0 \\
\hline Total & 197 & $169(86 \%)$ & $21(11 \%)$ & $7(3 \%)$ \\
\hline
\end{tabular}

\subsubsection{Criteria for risk evaluation set (NC 09)}

Risk criteria (sometimes called risk appetite) are used to help decide if a risk is acceptable "as is". If criteria are not set by an organisation, risk assessors may use their own preferences for risk and incorrectly determine the acceptability of risks to the organisation. A question asked if such criteria were used as part of a risk assessment that had been used to aid a decision.

Overall, respondents reported that criteria were used in $65 \%$ of decisions, with $26 \%$ saying criteria were not used, a ratio of about 2:1. Table 24 and Figure 17 show responses crosstabulated with the nature of the decisions. Figure 17 only uses data where the number of responses totalled 10 or more. The table indicates criteria were most used in safety-related decisions. 
Table 24. Whether the risk assessment used predefined risk criteria or risk appetite

\begin{tabular}{|c|c|c|c|c|}
\hline \multirow{2}{*}{$\begin{array}{c}\text { Thinking about a decision that was significant in your } \\
\text { organisation at least } 12 \text { months ago, did the decision mainly } \\
\text { relate to: }\end{array}$} & \multicolumn{4}{|c|}{ Did the risk assessment use predefined risk criteria or risk appetite? } \\
\hline & Total & Yes & No & Unsure \\
\hline Safety-related objectives, activities or programmes & 57 & $39(69 \%)$ & $10(17 \%)$ & $8(14 \%)$ \\
\hline Strategy or transformational activities or programmes & 47 & $29(62 \%)$ & $15(32 \%)$ & $3(6 \%)$ \\
\hline Project or change management activities or programmes & 35 & $23(66 \%)$ & $12(34 \%)$ & 0 \\
\hline Operational objectives & 19 & $11(58 \%)$ & $6(32 \%)$ & $2(10 \%)$ \\
\hline Financial objectives & 10 & $7(70 \%)$ & $2(20 \%)$ & $1(10 \%)$ \\
\hline Quality-related objectives, activities or programmes & 9 & $6(67 \%)$ & $2(22 \%)$ & $1(11 \%)$ \\
\hline $\begin{array}{l}\text { Sales- or marketing-related objectives, activities or } \\
\text { programmes }\end{array}$ & 8 & $3(38 \%)$ & $4(50 \%)$ & $1(12 \%)$ \\
\hline Response to external events & 7 & $4(57 \%)$ & $1(14 \%)$ & $2(29 \%)$ \\
\hline $\begin{array}{l}\text { Environmental- or sustainability-related objectives, } \\
\text { activities or programmes }\end{array}$ & 3 & $3(100 \%)$ & 0 & 0 \\
\hline Stakeholder management activities & 2 & $2(100 \%)$ & 0 & 0 \\
\hline Total & 197 & $127(64 \%)$ & $52(26 \%)$ & $18(9 \%)$ \\
\hline
\end{tabular}

Figure 17. Percentages of decision types that used predefined risk criteria

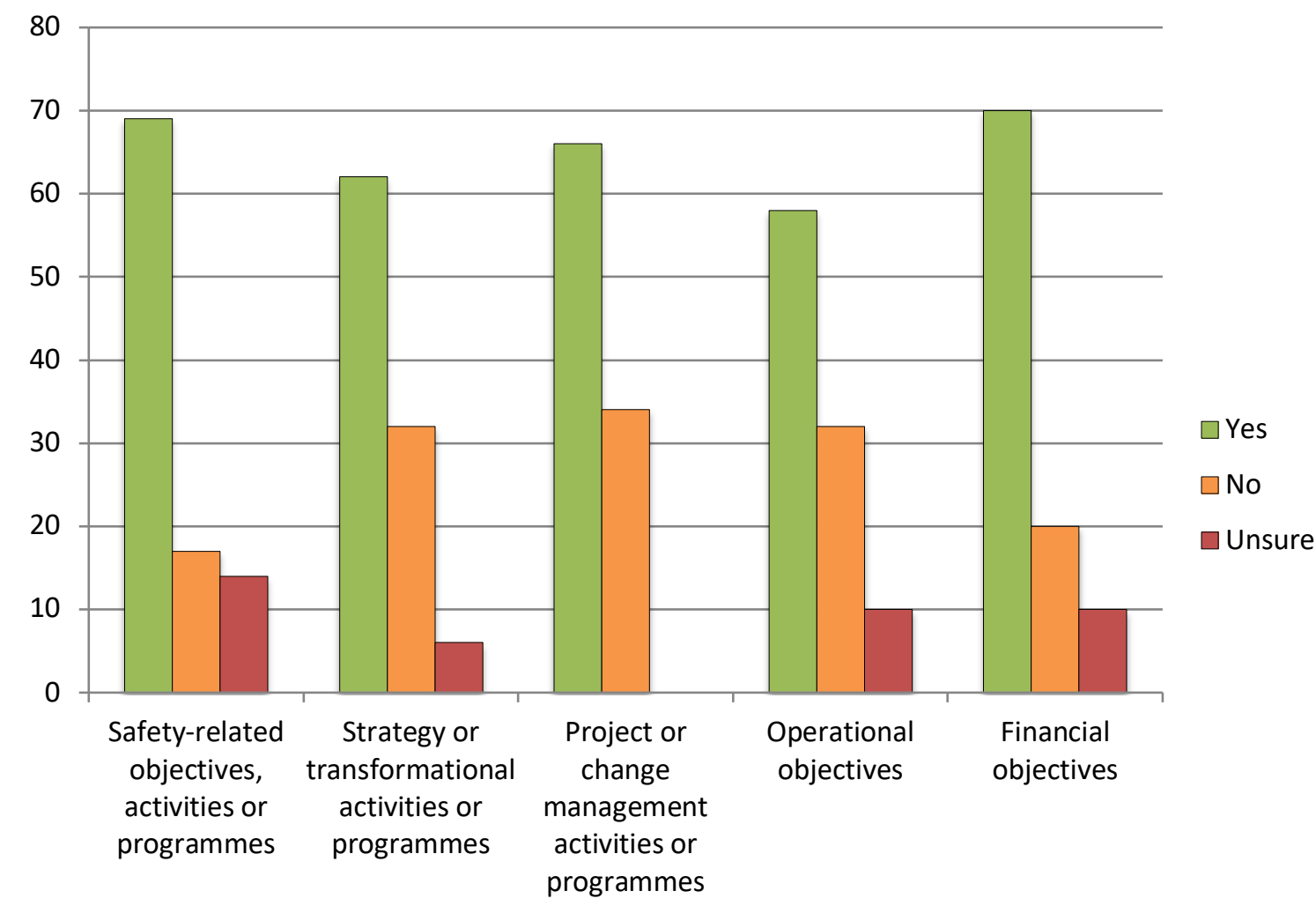




\subsubsection{Appropriate language, graphics and layout (NC 10)}

Effective communication of risk assessments requires use of appropriate language, graphics and layout. This could not be evaluated in the online survey and was to be reviewed in the case studies.

However, the guidance document on which risk management activities are based can influence the language, layout and conduct of risk assessments and subsequent management of risk. Respondents were asked "please identify the documents you refer to most often in your risk management work. Choose no more than three". Responses are summarised in Table 25. Some of the "other" responses have been consolidated into the table if they were clearly duplicates, leaving a list of 23 documents or sources nominated once each.

Many respondents $(\mathrm{N}=107)$ selected ISO31000 as their reference document. However, experience suggests it is common for an organisation to develop in-house guidance or procedures that may be based on a published standard and it was not surprising that 141 people selected this option.

"None - I use my professional judgement" was selected by $17(8 \%)$ respondents, suggesting they had no clear basis for their risk management-related work.

The responses to this question were broadly aligned with a 2011 survey carried out by Dali et al (2012). An earlier survey of 87 people in North America asking which risk management documents they most referred to had a $50 \%$ response rate (Fraser, Schoening-Thiessen, \& Simkins, 2008), showing the then-current joint standard (AS/SNZ4360, 2004) was in the top 11 selected, together with a handbook that supported the standard. 
Table 25. Risk management documents most frequently referred to by respondents

\begin{tabular}{|l|c|}
\hline \multicolumn{1}{|c|}{ Document title } & $\begin{array}{c}\text { Number of respondents choosing } \\
\text { this document (N=224) }\end{array}$ \\
\hline In-house or proprietary guidance or procedures & 141 \\
\hline ISO31000: 2009 "Risk management - Principles and guidelines" & 107 \\
\hline AS/NZS 4801 "Occupational health and safety management systems" & 46 \\
\hline OHSAS 18001 "Occupational health and safety management systems" & 31 \\
\hline ISO 9001 "Quality management systems" & 28 \\
\hline $\begin{array}{l}\text { IEC/ISO31010: 2009 "Risk management - risk assessment techniques" or SA/NZ } \\
\text { Handbook HB89 "Risk management - risk assessment techniques" }\end{array}$ & 30 \\
\hline $\begin{array}{l}\text { ISO 14001 "Environmental management systems - specification with guidance } \\
\text { for use" }\end{array}$ & 23 \\
\hline Other & 23 \\
\hline $\begin{array}{l}\text { SA/NZS HB436 "Risk management guidelines: a companion to AS/NZS } \\
\text { ISO31000" }\end{array}$ & 22 \\
\hline $\begin{array}{l}\text { Project Management Institute "Project management Body of knowledge" or } \\
\text { Association for Project Management "Body of Knowledge" }\end{array}$ & 18 \\
\hline COSO "Enterprise Risk Management - integrated framework" & 17 \\
\hline None - I use my professional judgement & 17 \\
\hline UK Health and Safety Executive documents or legislation & 13 \\
\hline AS/NZS 5050 Business continuity: management of disruption-related risks" & 9 \\
\hline ISO 22301 "Societal security - business continuity management systems" & 6 \\
\hline Codex Alimentarius, OIE or IPSM documents & 3 \\
\hline International Risk Governance Council White Paper "Risk Governance" & 3 \\
\hline
\end{tabular}

One of the Fraser et al (2008) survey questions asked if respondents used the qualitative and quantitative techniques set out in an application guide (COSO, 2004) to gain a composite assessment of risk. Nearly $49 \%$ said seldom, perhaps confirming "mismeasurement of known risks" as one explanation for the subsequent global financial crisis (Stulz, 2008) and suggesting other findings of the current research are long-standing.

\subsubsection{Systematic hazard or risk identification (NC 11)}

The literature review had shown a wide range of risk techniques that can be used to aid risk identification. Respondents were offered a list of 23 risk identification techniques plus "other - please specify" and asked which three they most often used. Responses are summarised in Table 26. 
Table 26. Risk techniques used in risk identification

\begin{tabular}{|c|c|}
\hline Name of technique & Number of respondents choosing this technique $(\mathrm{N}=252)$ \\
\hline Workshops, brainstorming and similar & 81 \\
\hline Professional judgement & 70 \\
\hline Risk registers (existing) & 63 \\
\hline Job hazard analysis or task analysis & 60 \\
\hline Incident investigation reports & 54 \\
\hline Root cause analysis & 48 \\
\hline Cause and effect analysis & 47 \\
\hline Interviews & 43 \\
\hline Scenario analysis & 38 \\
\hline Risk indicators & 31 \\
\hline Applied research & 27 \\
\hline HAZOP & 25 \\
\hline Failure modes and effects analysis & 22 \\
\hline Stakeholder communication to you or your organisation & 21 \\
\hline SWOT analysis & 18 \\
\hline Risk breakdown structure & 16 \\
\hline Questionnaires & 14 \\
\hline HACCP & 9 \\
\hline Mind mapping & 9 \\
\hline PESTLE or PEST analysis & 9 \\
\hline Flowcharting & 8 \\
\hline It's not my job to identify risks & 2 \\
\hline Bowtie analysis & 1 \\
\hline Checklists or trigger lists & 1 \\
\hline Event tree analysis & 1 \\
\hline MORT & 1 \\
\hline Structured what-if-then analysis (SWOT) analysis & 1 \\
\hline
\end{tabular}

Respondents named a range of "other" techniques, some with different names for those already given in the survey. These were added into the results but "other" responses included:

- activities and values matrix and foresighting

- Hierarchical Holographic Modelling

- LMSCARVER
- $\quad$ site observations

- tieline calculator

- HAZID

- financial implications

- "most of the above". 


\subsubsection{Appropriate risk analysis techniques have been used (NC 12)}

The next question offered respondents a list of 24 commonly used qualitative risk analysis techniques plus "other - please specify" and asked which three they most often used.

Responses are summarised in Table 27.

Table 27. Risk techniques used in qualitative risk analysis

\begin{tabular}{|l|c|}
\hline \multicolumn{1}{|c|}{ Name of technique } & $\begin{array}{c}\text { Number of respondents choosing this technique } \\
(\mathrm{N}=249)\end{array}$ \\
\hline Consequence likelihood matrix with ranking scales & 87 \\
\hline Professional judgement & 70 \\
\hline Brainstorming or other workshop & 59 \\
\hline Job hazard analysis & 52 \\
\hline Bowtie analysis & 47 \\
\hline Root cause analysis & 44 \\
\hline Cause and effect analysis & 37 \\
\hline Scenario analysis & 37 \\
\hline Impact consequence rating matrix with ranking scales & 26 \\
\hline HAZOP & 24 \\
\hline Failure modes and effects analysis & 21 \\
\hline Risk mapping & 21 \\
\hline Fault tree analysis (qualitative) & 19 \\
\hline I don't use qualitative techniques & 14 \\
\hline Structured what-if-then analysis (SWOT) analysis & 14 \\
\hline Flowcharting & 13 \\
\hline Questionnaires & 13 \\
\hline Environmental risk analysis & 12 \\
\hline HACCP & 7 \\
\hline Mind mapping & 7 \\
\hline PESTLE or PEST analysis & 6 \\
\hline Environment scanning & 5 \\
\hline Simulation exercises & 5 \\
\hline MORT & 21 \\
\hline It's not my job to analyse risks & 7 \\
\hline & 21 \\
\hline
\end{tabular}


"I don't use qualitative analysis" was selected by 14 people, suggesting that quantitative risk analyses are not always preceded by some form of qualitative assessment to enable understanding of the nature of risk before quantifying the level of risk.

"Other" included "Risk score equals severity times likelihood plus severity"; "web search similar organisations"; LMSCARVER; "We use most of the items as listed above"; and "national risk and costs averages for each incident".

The consequence likelihood matrix and professional judgement were frequently selected and are reviewed in more detail later. Structured qualitative techniques (eg, cause and effect analysis, HAZOP and PESTLE analysis) were less frequently selected even though they might give credible results and some assessment of uncertainty in the risk being assessed. It is therefore concluded that qualitative risk analyses may often be based on unstructured approaches, giving uncertain results.

\section{Evaluation of risk controls}

Risk assessments should identify existing controls and may show the effectiveness of control to be acceptable "as is" or unacceptable. Two questions asked about evaluation of risk controls as part of risk analysis. The first asked respondents if they identified controls as part of analysis of a risk; 235 (95\%) said "yes" and were then asked "When carrying out a risk assessment do you take into account the effectiveness and efficiency of existing controls as part of risk analysis?"; 229 (97\%) said "yes" and were then offered a question about control evaluation techniques. If respondents had answered "no" to these questions they were taken to a question about quantitative risk analysis.

The question about risk control techniques asked "When carrying out any risk assessment which techniques do you most often use to help identify or analyse the effectiveness and efficiency of existing controls? Choose no more than three". Responses are summarised in Table 28. 
Table 28. Judging the effectiveness of controls

\begin{tabular}{|l|c|}
\hline \multicolumn{1}{|c|}{ Name of technique } & Number of respondents choosing this technique (N=232) \\
\hline Professional judgement & 112 \\
\hline Brainstorming or other workshop & 86 \\
\hline Consequence likelihood matrix with ranking scales & 77 \\
\hline Job hazard analysis & 55 \\
\hline Bowtie analysis & 47 \\
\hline Root cause analysis & 38 \\
\hline Failure modes and effects analysis & 33 \\
\hline Cause and effect analysis & 31 \\
\hline Questionnaires & 21 \\
\hline Flowcharting or mapping the recommended & 20 \\
\hline process & 20 \\
\hline HAZOP & 18 \\
\hline Simulation exercises & 17 \\
\hline Layers of protection analysis & 12 \\
\hline SWOT analysis & 10 \\
\hline Environmental risk analysis & 3 \\
\hline MORT & 3 \\
\hline PESTLE or PEST analysis & 2 \\
\hline HACCP & \\
\hline
\end{tabular}

"Other" responses included:

- document research

- Delphi

- Control tests

- LMSCARVER and

- Examination of existing systems or processes and assurance outcomes of those elements.

This group of questions indicated that risk analyses are very likely to include consideration of current controls and their effectiveness but that effectiveness is most often evaluated using professional judgement, brainstorming and the consequence/likelihood matrix - all prone to personal and design biases - and so contributing to uncertainty in risk analysis results.

New Zealand respondents were marginally more likely to use professional judgement and the matrix and somewhat less likely to use brainstorming or other workshops, suggesting New Zealand respondents may work alone rather than in groups. This was explored in the case studies. 


\section{Quantitative risk analysis techniques}

Respondents were asked "When carrying out any risk assessment which quantitative techniques do you most often use to help analyse risks? Choose no more than three". Responses are summarised in Table 29.

Table 29. Risk techniques used in quantitative risk analysis

\begin{tabular}{|c|c|}
\hline Name of technique & Number of respondents choosing this technique ( $\mathrm{N}=249$ ) \\
\hline Consequence likelihood matrix with numerical scales & 103 \\
\hline Business impact analysis & 55 \\
\hline Risk factors and priorities & 51 \\
\hline Cost benefit analysis & 48 \\
\hline Impact consequence rating matrix with numerical scales & 35 \\
\hline Statistical analysis & 32 \\
\hline I don't use quantitative techniques & 31 \\
\hline Likelihood exposure consequences nomogram & 25 \\
\hline Failure modes, effects and consequences analysis & 22 \\
\hline Probabilistic modelling & 22 \\
\hline Monte Carlo analysis & 20 \\
\hline Fault tree analysis (quantitative) & 19 \\
\hline Event tree analysis & 17 \\
\hline Value at risk & 12 \\
\hline Cash-flow at risk & 8 \\
\hline Earnings at risk & 7 \\
\hline Physical effects modelling & 7 \\
\hline Stress testing & 5 \\
\hline Utility theory & 3 \\
\hline
\end{tabular}

Quantitative risk analyses require good quality data but even the process of gathering lower quality data can provide insights into the level of risk.

"I don't use quantitative techniques" was selected by 31 respondents, suggesting the other 218 respondents might use such techniques.

Nearly half of those saying they do use quantitative techniques $(\mathrm{N}=103)$ selected "Consequence likelihood matrix with numerical scales". Care had been taken to distinguish this quantitative matrix from the version which uses qualitative ranking. However, its popularity suggests many respondents may regard the two forms of matrix as being identical (Peace, 2017c). 
"Other" responses included:

- bowtie analysis, which was named twice, is a qualitative technique suggesting two respondents had either made a mistake or did not know the difference between qualitative and quantitative techniques

- QRAs, an abbreviation for quantitative risk analysis, leaving open which technique the respondent meant

- LMSCARVER was reported by this respondent for almost all questions about techniques

- risk equals severity times likelihood plus severity, a technique not found in the risk techniques literature.

\subsubsection{Appropriate risk evaluation techniques have been used (NC 13)}

The next question asked "When carrying out any risk assessment which techniques or concepts do you most often use to help evaluate a risk to decide if it is acceptable with its current characteristics or at its current level? Choose no more than three". Results are summarised in Table 30.

Table 30. Risk techniques used in risk evaluation

\begin{tabular}{|l|c|}
\hline \multicolumn{1}{|c|}{ Name of technique } & Number of respondents choosing this technique (N=234) \\
\hline Risk criteria developed by my organisation & 119 \\
\hline As low as is reasonably practicable (ALARP) & 110 \\
\hline Professional judgement & 109 \\
\hline Benchmarking against internal or external standards & 94 \\
\hline Risk appetite statement developed by my organisation & 49 \\
\hline Heat mapping & 33 \\
\hline Best available technology not entailing excessive cost & 33 \\
\hline Precautionary principle & 21 \\
\hline It's not my job to do this & 6 \\
\hline Cost benefit analysis & 3 \\
\hline
\end{tabular}

The term "as low as is reasonably practicable" is derived from English common law and safety legislation and was offered to enable New Zealand, Australian, UK and other safety practitioners to select it. However, cross-tabulation showed it was also selected by other groups. The term requires some form of risk assessment and then investigation of possible further action to determine if any additional actions are practicable (ie, capable of being done) and, if so, would be reasonable in terms of time, cost or other resources (Peace, 2017b). 
Professional judgement was nominated by 109 respondents, suggesting they judge the acceptability of risks using their own criteria rather than those established by their employer, legislation or a regulatory agency. "Other" responses included:

- "Regulatory Standards US FAA Dept of Defense etc"

- "LMSCARVER"

- "Tieline calculator"

- "Postural analysis tool"

- Refuse to use concept of acceptable risk since it is invalid.

Each was nominated by one person.

\subsubsection{Risk assessment appropriately communicated to decision makers (CSF 01)} How and how well risk assessments are communicated is critical to decision makers understanding and using them as part of decisions (Wiedemann et al, 2013). The tentative GT suggests necessary conditions for this, including the competence of risk assessors, how they understand the needs of decision makers, and discussion of uncertainty. The survey explored some aspects of competence and uncertainty.

Taking qualifications and length of experience as indicators of competence, $60 \%$ of respondents held a certificate, diploma or degree (although it was not known if that was relevant) and 58\% had five years or more experience in their job (Table 13 and Table 15). This level of education suggested they should be competent to communicate risk assessments to decision makers.

\subsubsection{All relevant factors including controversies and uncertainty have been fully and correctly evaluated (CSF 02)}

\section{Whether earlier risk assessments discussed uncertainty}

For this study, risk is defined as the "effect of uncertainty on objectives" so an assessment and discussion of uncertainty might be expected to form part of a risk assessment and subsequent decisions using the assessment.

In relation to the decision made at least 12 months earlier, respondents reported (Table 31):

- "uncertainty was not mentioned" in $14 \%$ of the cases

- "uncertainty was mentioned but not in detail" in $40 \%$ of the cases

- "considerable discussion of uncertainty" in $48 \%$ of the cases 
- "uncertainty was mentioned but not in detail" in $39 \%$ of decisions about strategy

- "uncertainty was mentioned but not in detail" in 35\% of decisions about safety.

The qualitative nature of "considerable" and other words left to respondents how to respond.

However, the overall picture is that uncertainty may be inadequately discussed in many decisions and risk assessments.

Table 31. Whether uncertainty was discussed in relation to the decision

\begin{tabular}{|c|c|c|c|c|c|}
\hline \multirow{2}{*}{$\begin{array}{l}\text { Thinking about a decision that was } \\
\text { significant in your organisation at least } 12 \\
\text { months ago, did the decision mainly relate } \\
\text { to (choose one) }\end{array}$} & \multicolumn{5}{|c|}{$\begin{array}{l}\text { To what extent did the risk assessment consider uncertainty and how it might affect } \\
\text { achievement of the objectives of the decision or the organisation? }\end{array}$} \\
\hline & Total & $\begin{array}{l}\text { Uncertainty was } \\
\text { not mentioned }\end{array}$ & $\begin{array}{c}\text { Uncertainty was } \\
\text { mentioned but } \\
\text { not in detail }\end{array}$ & $\begin{array}{l}\text { Considerable } \\
\text { discussion of } \\
\text { uncertainty }\end{array}$ & Unsure \\
\hline $\begin{array}{l}\text { Safety-related objectives, activities or } \\
\text { programmes }\end{array}$ & 60 & $12(20 \%)$ & $21(35 \%)$ & $25(41.6 \%)$ & $2(3.3 \%)$ \\
\hline $\begin{array}{l}\text { Strategy or transformational activities or } \\
\text { programmes }\end{array}$ & 49 & $4(8 \%)$ & $19(39 \%)$ & $25(51 \%)$ & $1(2 \%)$ \\
\hline $\begin{array}{l}\text { Project or change management } \\
\text { activities or programmes }\end{array}$ & 37 & $1(3 \%)$ & $15(41 \%)$ & $19(51 \%)$ & $2(5 \%)$ \\
\hline Operational objectives & 22 & $6(27 \%)$ & $6(27 \%)$ & $9(41 \%)$ & $1(5 \%)$ \\
\hline Financial objectives & 11 & $2(18 \%)$ & $1(9 \%)$ & $8(72 \%)$ & 0 \\
\hline $\begin{array}{l}\text { Quality-related objectives, activities or } \\
\text { programmes }\end{array}$ & 9 & $2(22 \%)$ & $2(22 \%)$ & $3(33 \%)$ & $2(22 \%)$ \\
\hline $\begin{array}{l}\text { Sales- or marketing-related objectives, } \\
\text { activities or programmes }\end{array}$ & 8 & $1(12 \%)$ & $4(50 \%)$ & $3(37 \%)$ & 0 \\
\hline Response to external events & 7 & $1(14 \%)$ & $2(28 \%)$ & $3(42 \%)$ & $1(14 \%)$ \\
\hline $\begin{array}{l}\text { Environmental- or sustainability-related } \\
\text { objectives, activities or programmes }\end{array}$ & 3 & 0 & $1(33 \%)$ & $2(66 \%)$ & 0 \\
\hline Stakeholder management activities & 3 & 0 & 0 & $3(100 \%)$ & 0 \\
\hline Total & 209 & $29(14 \%)$ & $71(40 \%)$ & $100(48 \%)$ & $9(4 \%)$ \\
\hline
\end{tabular}

\section{Uncertainty in risk assessments carried out by respondents}

A subsequent question asked "when carrying out any risk assessment, to what extent do you include the effect of uncertainty?". Responses were cross-tabulated with answers to the question reported above and are shown in Table 32 and Figure 18. The results show some discord between personal conduct of risk assessments and how others had carried out risk assessments. 
Table 32. Uncertainty in risk assessments

\begin{tabular}{|l|r|r|r|r|r|r|}
\cline { 3 - 8 } \multicolumn{2}{c|}{} & \multicolumn{6}{|c|}{ When carrying out any risk assessment, to what extent do you include the effect of } \\
uncertainty?
\end{tabular}

Figure 18. Uncertainty in risk assessments

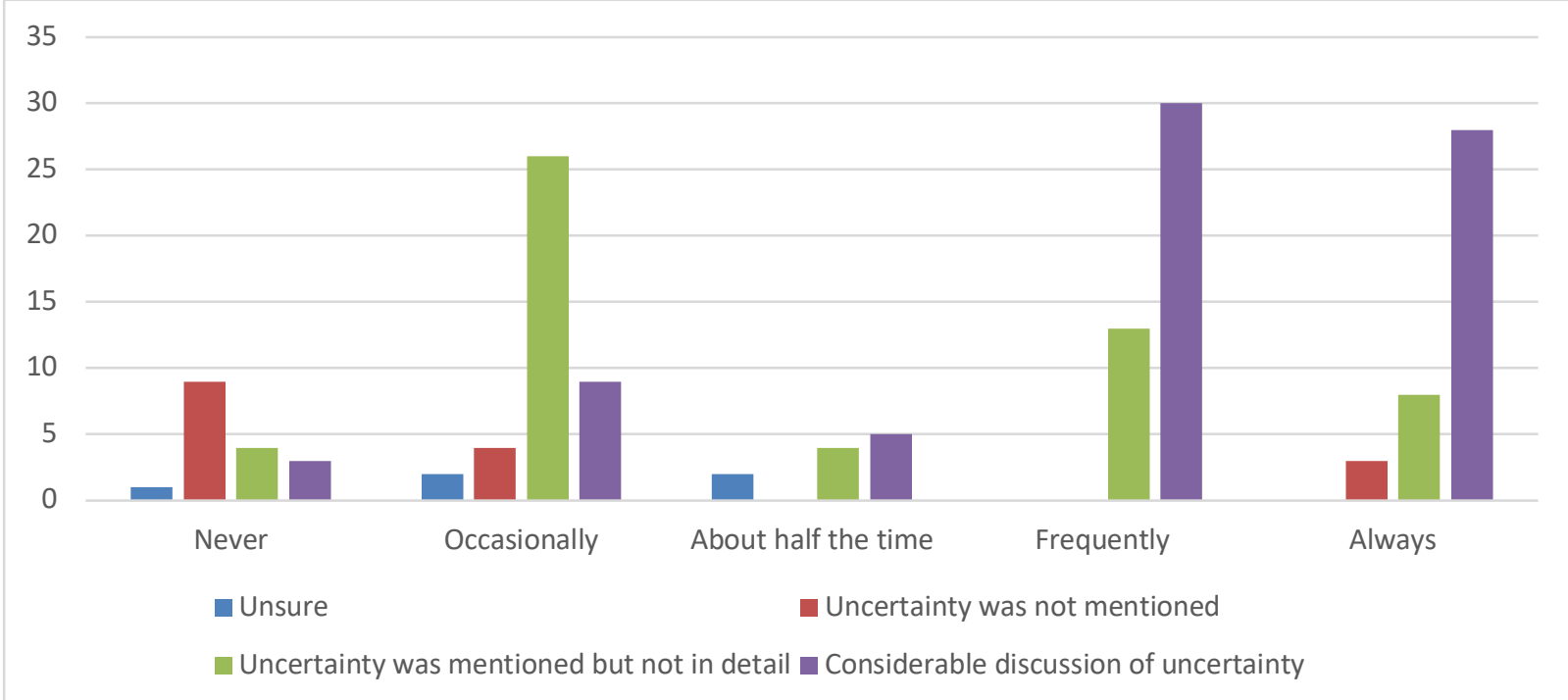

There was some difference in the two questions ("considered" versus "include the effect") but this apparent discord suggested an area for investigation in the case studies as it is not clear how much uncertainty is explicitly discussed in risk assessments.

\section{Nature of the decision and whether the risk assessment used named techniques}

The survey provided information about whether risk assessments used named techniques (as a way of minimising biases and increasing reliability) and discussed uncertainty. In ISO31000 (2009) risk assessment is defined as the "overall process of risk identification, risk analysis and risk evaluation".

Cross-tabulation of reported use of named risk assessment techniques or methods against the nature of the decisions showed some variation, with $61 \%$ saying such techniques were used (see Table 33 and Figure 19). The highest proportions of reported usage were in safety-related decisions and project activities. 
Table 33. Whether the risk assessment used named techniques or methods

\begin{tabular}{|c|c|c|c|c|}
\hline \multirow{2}{*}{$\begin{array}{l}\text { Thinking about a decision that was significant in your } \\
\text { organisation at least } 12 \text { months ago, did the decision } \\
\text { mainly relate to: }\end{array}$} & \multicolumn{4}{|c|}{ Did the risk assessment use named techniques or methods? } \\
\hline & Total & Yes & No & Unsure \\
\hline Safety-related objectives, activities or programmes & 57 & $42(74 \%)$ & $10(17 \%)$ & $5(9 \%)$ \\
\hline Strategy or transformational activities or programmes & 47 & $22(47 \%)$ & $20(42 \%)$ & $5(11 \%)$ \\
\hline Project or change management activities or programmes & 35 & $27(77 \%)$ & $6(17 \%)$ & $2(6 \%)$ \\
\hline Operational objectives & 19 & $10(53 \%)$ & $8(42 \%)$ & $1(5 \%)$ \\
\hline Financial objectives & 10 & $6(60 \%)$ & $3(30 \%)$ & $1(10 \%)$ \\
\hline Quality-related objectives, activities or programmes & 9 & $4(44 \%)$ & $4(44 \%)$ & $1(11 \%)$ \\
\hline $\begin{array}{l}\text { Sales- or marketing-related objectives, activities or } \\
\text { programmes }\end{array}$ & 8 & $4(50 \%)$ & $3(38 \%)$ & $1(12 \%)$ \\
\hline Response to external events & 7 & $3(43 \%)$ & $2(3 \%)$ & $2(3 \%)$ \\
\hline $\begin{array}{l}\text { Environmental- or sustainability-related objectives, } \\
\text { activities or programmes }\end{array}$ & 3 & $2(67 \%)$ & 0 & $1(33 \%)$ \\
\hline Stakeholder management activities & 2 & $1(50 \%)$ & $1(50 \%)$ & 0 \\
\hline Total & 197 & $121(61 \%)$ & $57(29 \%)$ & $19(9 \%)$ \\
\hline
\end{tabular}

Figure 19. Reported use of a technique cross-tabulated against decision nature

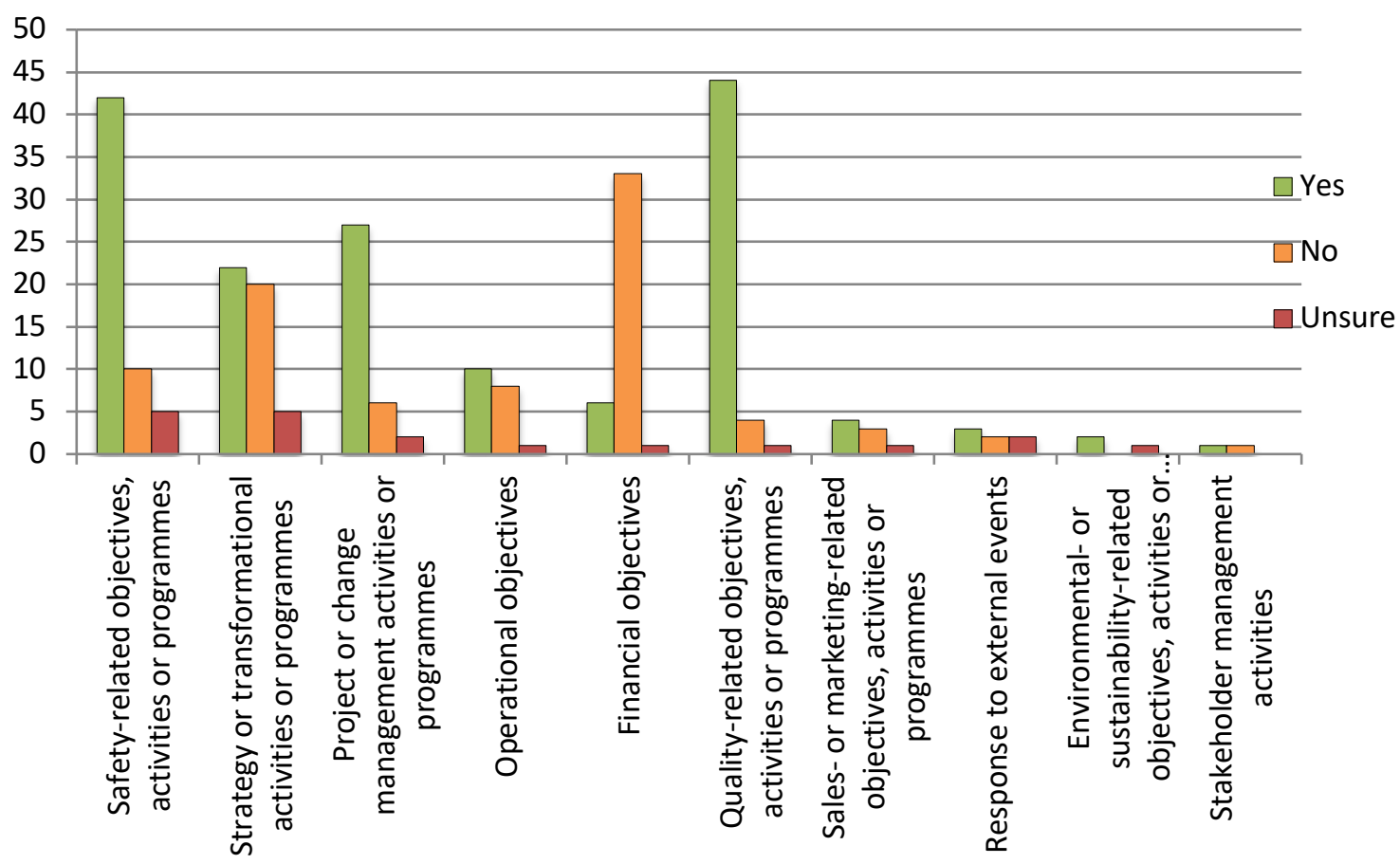

\subsubsection{Risk identification, analysis and evaluation techniques}

The variations in numbers and percentages of reported usage of risk techniques confirmed the need to explore the data in more detail in a series of questions covering each risk management sub-stage (risk identification, analysis and evaluation).

The range of techniques available required calculation of an index for each technique by dividing the number of selections for each risk technique by the total number of respondents 
to each question. The index numbers were totalled and ranked (see Table 34) and 23 techniques with 0.4 or greater in the sum of the index scores graphed in Figure 20.

Table 34 lists the techniques offered to respondents in the survey. Many are at least superficially the same or closely related. For example, bowtie analysis is based on fault tree analysis and event tree analysis and strongly resembles cause and effect analysis but without identifying an event, while root cause analysis is a collection of techniques that can include fault tree analysis (IEC62740, 2015). Individual variations made it necessary to name most common techniques to help ensure respondents found familiar techniques, so minimising reporting of large numbers of "other" techniques.

Figure 20. Most frequently selected risk assessment techniques

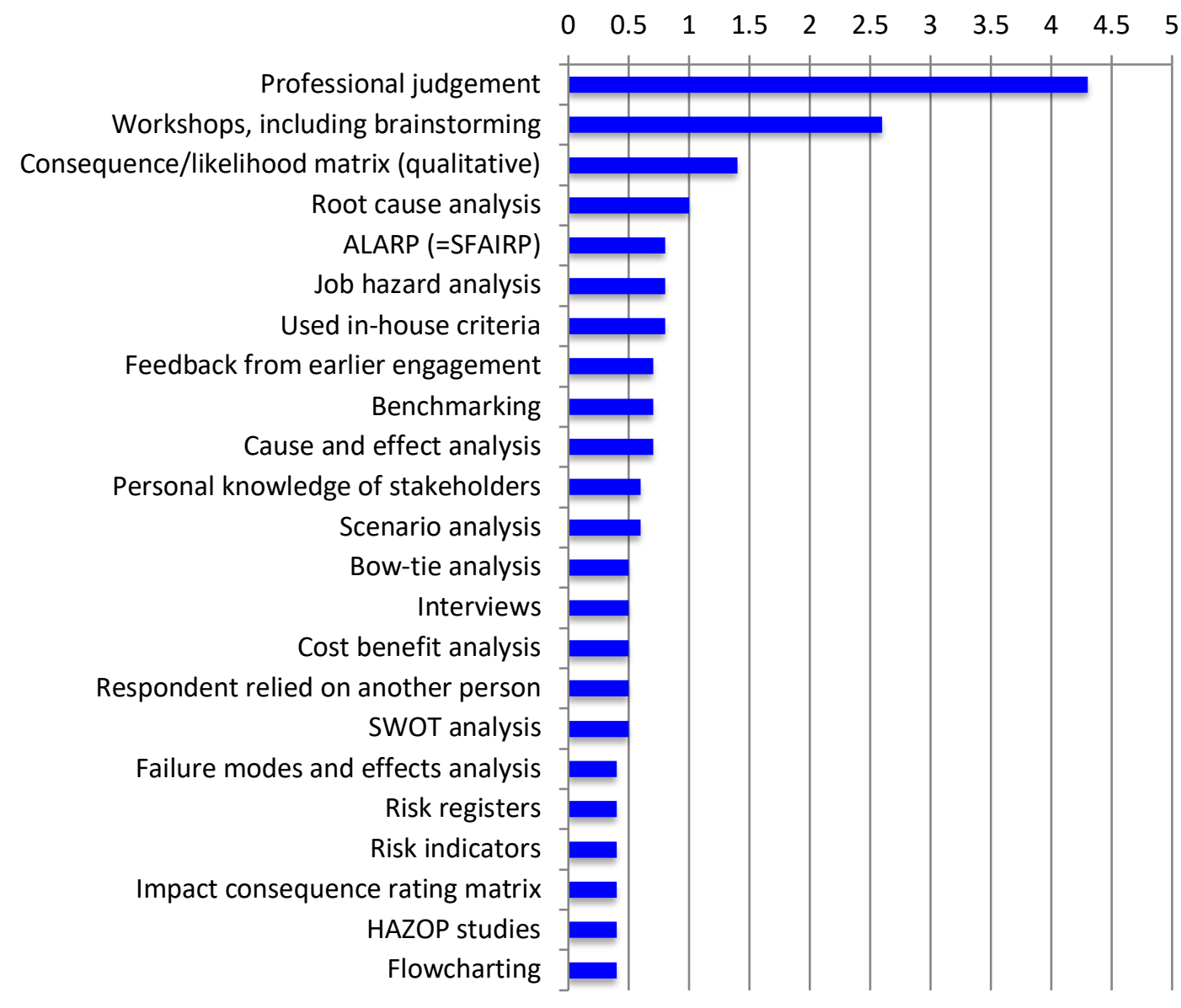


Table 34. Summary of reported usage of risk techniques

\begin{tabular}{|c|c|c|c|c|c|c|c|c|c|c|c|c|}
\hline & 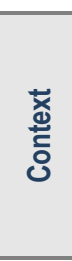 & 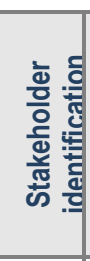 & 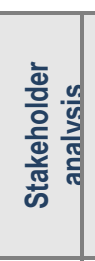 & 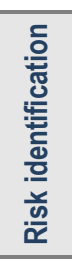 & 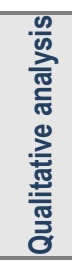 & 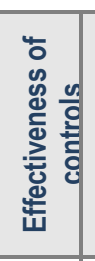 & 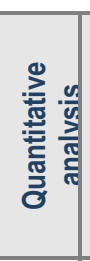 & 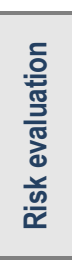 & 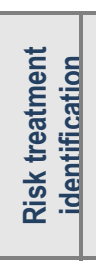 & 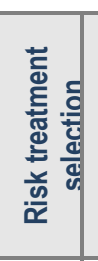 & 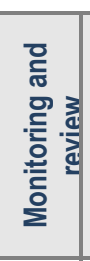 & 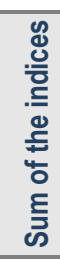 \\
\hline Professional judgement & 0.47 & 0.60 & 0.76 & 0.27 & 0.28 & 0.45 & & 0.46 & 0.43 & 0.40 & 0.24 & 4.3 \\
\hline Workshops, including brainstorming & 0.44 & 0.42 & 0.40 & 0.31 & 0.23 & 0.36 & & & 0.39 & & & 2.6 \\
\hline Consequence/likelihood matrix & & & & & 0.35 & 0.33 & 0.43 & & & 0.31 & & 1.4 \\
\hline Root cause analysis & & & & 0.19 & 0.17 & 0.16 & & & 0.17 & & 0.33 & 1.0 \\
\hline ALARP = SFAIRP & & & & & & & & 0.46 & & 0.37 & & 0.8 \\
\hline Job hazard analysis & & & & 0.24 & 0.20 & 0.24 & & & 0.14 & & & 0.8 \\
\hline Respondent used in-house risk criteria & & & & & & & & 0.51 & & 0.25 & & 0.8 \\
\hline Feedback from earlier engagement & & & 0.59 & & & & 0.09 & & & & & 0.7 \\
\hline Benchmarking & & & & & & & & 0.40 & & 0.16 & 0.10 & 0.7 \\
\hline Cause and effect analysis & & & & 0.17 & 0.14 & 0.13 & & & 0.23 & & & 0.7 \\
\hline Personal knowledge of stakeholders & & 0.62 & & & & & & & & & & 0.6 \\
\hline Scenario analysis & 0.28 & & & 0.15 & 0.15 & & & & & & & 0.6 \\
\hline Bowtie analysis & 0.00 & & & 0.00 & 0.19 & 0.20 & 0.01 & & 0.14 & & & 0.5 \\
\hline Interviews & & 0.35 & & 0.17 & & & & & & & & 0.5 \\
\hline Cost benefit analysis & & & & & & & 0.20 & & & 0.32 & & 0.5 \\
\hline $\begin{array}{l}\text { Respondent relied on another person } \\
\text { for this stage in the process }\end{array}$ & 0.01 & 0.02 & 0.03 & & & & & 0.02 & 0.03 & 0.04 & 0.35 & 0.5 \\
\hline SWOT analysis & 0.28 & & & 0.07 & 0.06 & 0.05 & & & 0.00 & & & 0.5 \\
\hline Failure modes and effects analysis & & & & 0.09 & 0.08 & 0.12 & 0.09 & & 0.06 & & & 0.4 \\
\hline Risk registers (existing) & & & & 0.25 & & 0.16 & & & & & & 0.4 \\
\hline Risk indicators & & & & 0.12 & & & & & & & 0.27 & 0.4 \\
\hline Impact-consequence rating matrix & & & & & 0.10 & & 0.15 & & & 0.13 & & 0.4 \\
\hline HAZOP & & & & 0.10 & 0.09 & 0.09 & & & 0.09 & & & 0.4 \\
\hline Flowcharting & 0.16 & & & 0.03 & 0.05 & 0.09 & & & 0.03 & & & 0.4 \\
\hline $\begin{array}{l}\text { Stakeholder importance/influence } \\
\text { matrix }\end{array}$ & & & 0.34 & & & & & & & & & 0.3 \\
\hline BATNEEC & & & & & & & & 0.14 & & 0.15 & & 0.3 \\
\hline Applied research & 0.18 & & & 0.10 & & & & & & & & 0.3 \\
\hline Questionnaires & & & & 0.05 & 0.05 & 0.09 & & & & & 0.06 & 0.3 \\
\hline Existing database of stakeholders & & 0.25 & & & & & & & & & & 0.3 \\
\hline Document or literature review & 0.25 & & & & & & & & & & & 0.2 \\
\hline Layers of protection analysis & & & & & & 0.24 & & & & & & 0.2 \\
\hline Control self-assessment & & & & & & & & & & & 0.24 & 0.2 \\
\hline Business impact analysis & & & & & & & 0.23 & & & & & 0.2 \\
\hline External advice & & & & & & & & & 0.15 & 0.08 & & 0.2 \\
\hline PESTLE analysis & 0.15 & & & 0.04 & 0.02 & 0.01 & & & & & & 0.2 \\
\hline Risk factors \& priorities & & & & & & & 0.22 & & & & & 0.2 \\
\hline Incident investigation reports & & & & 0.21 & & & & & & & & 0.2 \\
\hline Risk appetite statement & & & & & & & & 0.21 & & & & 0.2 \\
\hline Heat mapping & & & & & & & & 0.14 & & 0.05 & & 0.2 \\
\hline
\end{tabular}




\begin{tabular}{|c|c|c|c|c|c|c|c|c|c|c|c|c|}
\hline & 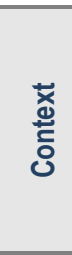 & 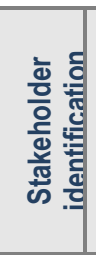 & 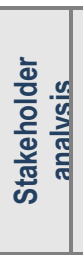 & 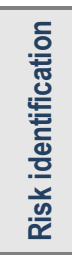 & 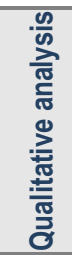 & 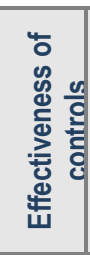 & 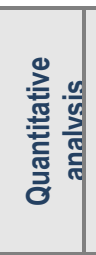 & 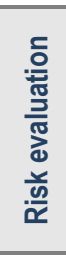 & 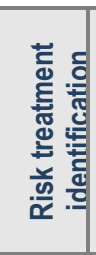 & 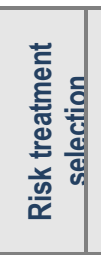 & 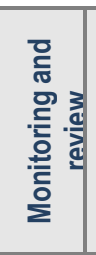 & 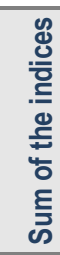 \\
\hline Risk mapping & & & & & 0.08 & & & & 0.10 & & & 0.2 \\
\hline Simulation exercises & & & & & 0.02 & 0.08 & & & 0.08 & & & 0.2 \\
\hline Mind mapping & 0.12 & & & 0.00 & 0.03 & & & & & & & 0.2 \\
\hline Focus groups & & & & & & & & & & & 0.14 & 0.1 \\
\hline Statistical analysis & & & & & & & 0.14 & & & & & 0.1 \\
\hline Precautionary principle & & & & & & & & 0.09 & & 0.04 & & 0.1 \\
\hline Risk breakdown structure & & & & 0.06 & & & & & 0.06 & & & 0.1 \\
\hline Tie line calculator & 0.00 & 0.00 & & 0.00 & & & 0.09 & 0.00 & 0.00 & 0.00 & & 0.1 \\
\hline Similar risks & & & & & & & & & 0.11 & & & 0.1 \\
\hline Checklists & & & & & & & & & 0.10 & & & 0.1 \\
\hline Probabilistic modelling & & & & & & & 0.09 & & & & & 0.1 \\
\hline Environmental risk analysis & & & & & 0.05 & 0.04 & & & & & & 0.1 \\
\hline Surveys & 0.09 & & & & & & & & & & & 0.1 \\
\hline HACCP & & & & 0.04 & 0.03 & 0.01 & & & 0.01 & & & 0.1 \\
\hline Analytical hierarchy process & & & & & & & & & & 0.08 & & 0.1 \\
\hline Stakeholder communication & & & & 0.08 & & & & & & & & 0.1 \\
\hline Monte Carlo analysis & & & & & & & 0.08 & & & & & 0.1 \\
\hline Legal advice & & & & & & & & & & 0.08 & & 0.1 \\
\hline Causal analysis & & & & & & & & & 0.07 & & & 0.1 \\
\hline Complaints analysis & & & & & & & & & & & 0.07 & 0.1 \\
\hline Event tree analysis & & & & & & & 0.07 & & & & & 0.1 \\
\hline Concept mapping & 0.07 & & & & & & & & & & & 0.1 \\
\hline Environment scanning & & & & & 0.02 & & & & 0.03 & & & 0.1 \\
\hline Value at risk & & & & & & & 0.05 & & & & & 0.1 \\
\hline Horizon scanning & 0.05 & & & & & & & & & & & 0.0 \\
\hline Capacity for change analysis & & & & & & & & & & 0.04 & & 0.0 \\
\hline Treatment effectiveness analysis & & & & & & & & & & 0.04 & & 0.0 \\
\hline Fault tree analysis & & & & & & & & & 0.04 & & & 0.0 \\
\hline Cash flow at risk & & & & & & & 0.03 & & & & & 0.0 \\
\hline Earnings at risk & & & & & & & 0.03 & & & & & 0.0 \\
\hline Physical effects modelling & & & & & & & 0.03 & & & & & 0.0 \\
\hline MORT & & & & 0.00 & 0.01 & 0.01 & & & 0.00 & & & 0.0 \\
\hline Constraints analysis & & & & & & & & & & 0.02 & & 0.0 \\
\hline Stress testing & & & & & & & 0.02 & & & & & 0.0 \\
\hline Utility theory & & & & & & & 0.01 & & & & & 0.0 \\
\hline Planned reviews & & & & & & & & & & & 0.55 & 0.0 \\
\hline Variance monitoring & & & & & & & & & & & 0.07 & 0.0 \\
\hline
\end{tabular}

Notes to the table

The index values are rounded to two decimal places but the sum of the indices has been rounded to one decimal place. 


\section{Overall results}

Across all stages in the risk management process, the techniques most frequently selected were professional judgement, workshops (including brainstorming) and consequence/ likelihood matrix with ranking scales. Given the popularity of these techniques, they were reviewed in more detail together with techniques commonly used in the case studies (section 6.5). Many simple, qualitative techniques capable of structuring gathering of information had a low ranking, raising doubts about the training or experience or both of respondents (despite the demographic data).

\subsection{Summary of the online survey results}

\subsubsection{Results mapped into the tentative goal tree}

The results from the online survey were analysed using SPSS and summarised using the CSFs and NCs in the tentative GT (section 3.2), where the strength of the evidence from the data enabled to colour coding the GT to represent the composite results (Figure 21). However, it is not possible to make any deductions about the logical connections so the arrows have been faded out.

Figure 21. Online survey results mapped into the goal tree

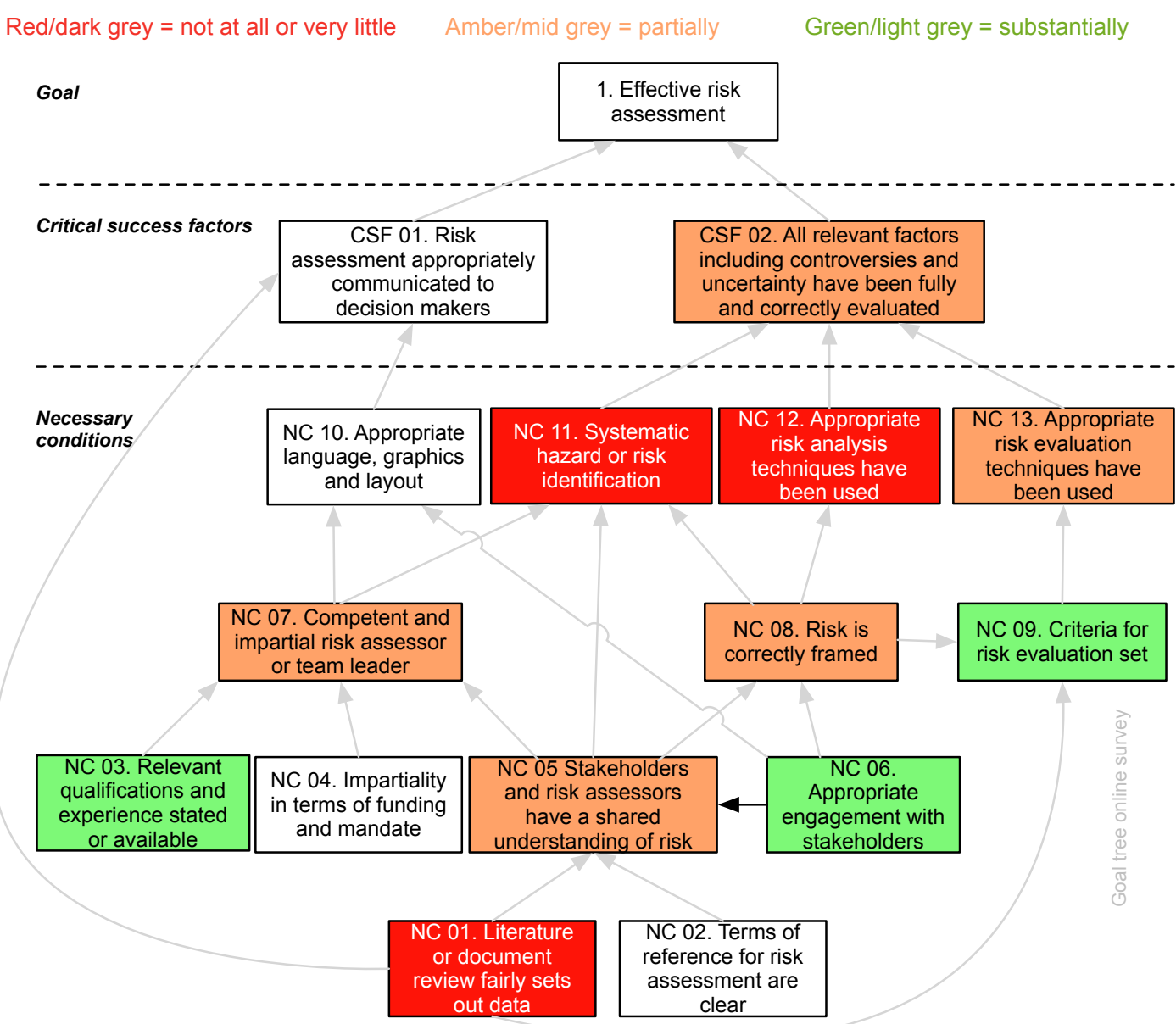


From the GT summary it can be seen that survey respondents often:

- were substantially well qualified and experienced (NC 03), substantially engaged with stakeholders (NC 06) and substantially used risk criteria (NC 09)

- had a partial shared understanding of risk (NC 05) and partially framed risk correctly (NC 08)

- used literature or document reviews, relevant risk identification, analysis and evaluation techniques (NC 01,11, 12 and 13) not at all or very little.

As a result, all relevant factors (CSF 02) were likely to be partially reported. Using Hohmann's (2014) description, this GT suggests autumnal colours predominate leading to the following comments.

\subsubsection{Engagement with stakeholders}

Respondents reported strong engagement with stakeholders, especially in safety-related risk assessments and decisions. There was also better than expected consideration of the context of the organisation. However; there were wide variations in whether risk assessments used named techniques or methods, with similar results for the use of predefined risk criteria.

\subsubsection{Qualitative and qualitative techniques}

A risk may have qualitative or quantitative factors that should be drawn out in a risk assessment and so enable decisions about the acceptability of the risk. The analysis should clearly state the qualitative nature of the risk, the quantitative level of risk (if calculated), and the uncertainties in the risk assessment and selected techniques (Wiedemann et al, 2013).

In the current study, the majority of respondents reported using qualitative techniques but 14 (6\%) selected "I don't use qualitative techniques". Somewhat more respondents $(31,12 \%)$ selected "I don't use quantitative techniques". However, some respondents may not have distinguished quantitative from qualitative techniques, opting for similarly named techniques, while some nominated qualitative techniques as quantitative techniques.

While qualitative risk analysis techniques may be supported by quantitative analyses decision makers may not trust precise probability estimates of defined consequences (March \& Shapira, 1987). The survey found that the reported use of highly subjective techniques made it unlikely that risk assessments could be more than estimates prone to considerable misunderstandings by decision makers (Budescu, Broomell, \& Por, 2009; Evans, 2012; Tetlock, 2006). 
Although bowtie analysis was selected as a risk technique that could be used for training (section 2.4.1) there were few reports of its use by survey respondents. Nonetheless, it was incorporated in the risk canvas (section 7.4) because anecdotal evidence suggested it helped course participants to see the big picture.

\subsubsection{ALARP and SFAIRP}

The survey was designed and run before the New Zealand Health and Safety Reform Bill (2014) was published, containing the "so far as is reasonably practicable" (SFAIRP) test, almost identical to the "as low as is reasonably practicable" test offered in the survey. For health and safety-related risks, reasonably practicable requires that potentially practicable (ie, capable of being implemented) options be identified and, if reasonable (in time, cost or other resources) implemented (Peace, 2017b).

Respondents were offered a number of risk evaluation techniques or options including "as low as is reasonably practicable" (ALARP) and this was selected by 110 people (47\%), suggesting they might have a health and safety background.

\subsubsection{Outliers and errors}

Two respondents consistently identified as their "other" techniques the "tieline calculator" and "LMSCARVER".

Some respondents selected "other" and then identified risk techniques that might be inappropriate or difficult to use. For example, two named bowtie analysis as a quantitative analysis technique.

The survey provided no named techniques for identification or analysis of risk involving human factors. However, several respondents selected "other" and named task analysis and TRIPOD.

\subsubsection{Uncertainty}

It is noteworthy that uncertainty was not mentioned in risk assessments about half the time, and not in detail about a third of the time suggesting assessors give little consideration to this key part of a risk assessment.

Safety-related decisions were often claimed to be supported by a risk assessment. However, uncertainty was either not mentioned or not mentioned in detail in $55 \%$ of these risk assessments. Uncertainty was more likely to be discussed in strategy or project related risk assessments but, overall, there was "considerable discussion of uncertainty" in only $48 \%$ of cases. Such variable results suggest many respondents do not include uncertainty and its effects on objectives in their real-life risk assessments, potentially a key cause of ineffective risk assessments. 


\subsubsection{Conclusions from the online survey and research questions}

No one technique will give reliable results in all business environments or for all risks (E. Lewis 2013, email). Some risks might not be assessable with techniques currently available, while some risk assessors might not be able to apply the techniques that are available (Jones \& Razin, 2013). However, design of the survey offered a range of techniques ranging from simple to complex in application but that all provide some structure to a stage within the risk management process.

Responses to the survey showed a strong preference for professional judgement, workshops and use of the consequence/likelihood matrix, suggesting that many respondents work at the novice or practitioner/technician level (section 2.2) and might benefit from a risk identification key (section 2.4.1) and a structured process for the use of basic risk techniques (the risk canvas, section 7.4).

It was surprising to this researcher that so many respondents selected professional judgement, workshops and the qualitative consequence/likelihood matrix as risk techniques. Such preferences are unlikely to reduce uncertainty in risk assessment results but may give a veneer of reliability to risk assessments, potentially leading to ill-founded decisions and may provide an explanation for risk assessments that are not effective in informing decision makers. Professional judgement is discussed in more detail in section 6.5.2 and the matrix in section 6.5.3.

If such problems are to be overcome risk assessors need to know and apply a wider range of techniques, and decision makers need to understand the results of those techniques. This might require, for example,

- development of a risk technique selection identification

- simple workshop engagement techniques, including use of Post-it notes and flipcharts.

These and other options are reported in chapter 7, Mechanisms that might facilitate or improve risk assessments.

This chapter has substantially answered sub-question SQ 1 "What processes and methods are currently being used for risk assessments?". The next chapter reports on risk assessments in the case studies. 


\section{Case studies: results and analysis}

\subsection{Overview and research questions}

This study investigated the effectiveness of risk assessments in informing decision makers using mixed methods research. This chapter describes an in-depth study of four full and one partial case studies to help respond to the research question and sub-question 1:

$R Q$. Can a generic goal tree, populated with critical success factors and necessary conditions derived from the literature and case studies, be developed that would help decision makers and risk assessors to evaluate the effectiveness of risk assessments before they are used to aid a decision?

SQ 1. What processes and methods are currently being used for risk assessments?

\section{Number of case studies}

Whilst nearly 40 organisations were approached only four agreed to help, with one providing two cases. This may indicate that, in New Zealand, formal risk assessments are not routinely carried out, not fully documented, or that organisations lacked confidence in their risk assessments.

The case organisations that were prepared to share their risk assessments comprised a mix of public and private sector entities and risk assessments mostly relating to health and safety-related decisions. One organisation provided a full case study (D) and a partial case study $(E)$ that gave insights into risk assessment practice in a medium-sized, privately held company. The five cases are summarised in Table 35.

Table 35. Summary of case studies characteristics

\begin{tabular}{|c|l|l|}
\hline $\begin{array}{c}\text { Case study } \\
\text { code }\end{array}$ & \multicolumn{1}{|c|}{ Industry sector } & \multicolumn{1}{c|}{ Brief summary of decision } \\
\hline A & Construction & $\begin{array}{l}\text { What form the new occupational health and safety (OHS) management } \\
\text { system should take, given likely changes in OHS legislation }\end{array}$ \\
\hline B & Office building occupier & $\begin{array}{l}\text { What actions should be carried out post-2013 earthquakes to minimise } \\
\text { damage to assets and disruption of activities as a result of a similar or greater } \\
\text { event affecting Wellington }\end{array}$ \\
\hline C & Land management & $\begin{array}{l}\text { Whether the level of work health and safety risk associated with use of quad } \\
\text { bikes was acceptable }\end{array}$ \\
\hline D & Primary food sector & Whether to proceed with production of a new product \\
\hline E & Primary food sector & Whether to proceed with redevelopment of an existing site \\
\hline
\end{tabular}

Each case includes a summary of the context, the decision to be made and a further, short literature review to aid understanding of the risks being considered. The data is analysed using the tentative GT structure. 


\subsection{Methodology}

The methodology used was described in section 3.4.1. The five cases reported here:

- provided opportunities to further test the critical success factors (CSF), necessary conditions (NC) and tentative GT

- provided empirical investigations in depth and in context (Farquhar, 2012) of the phenomenon of risk assessments informing decisions at the time the risk assessment was completed

- formed "critical cases" that illustrate practice in risk assessments

(Flyvbjerg, 2006; Voss et al, 2002)

- extended understanding of the relationships between decision making and risk assessments

- showed in detail various approaches to risk assessments and the models and techniques used, so testing the suggested CSF and NC between sectors

- applied forensic, retrospective analyses but avoided researcher hindsight bias by using: pre-set questions; pre-set NVivo codes; and the same tentative GT to bring order and structure to analysis of the cases and aid interpretation of the data. 


\subsection{Case Study A data and analysis}

\subsubsection{Business environment of the decision}

Case study organisation $A$ is an established national construction company, a sector that has had the second highest occupational injury rate in New Zealand (Driscoll et al, 2004) due to work at heights, in excavations, with hazardous substances, and with a wide range of hand and powered equipment. Depending on workload, the case study company employs many hundreds of employees, contractors and subcontractors and now is a party in major joint ventures.

A new chief executive joined the company in 2012 and concluded that a number of changes needed to be made to the company, including restructuring and implementation of a company-wide occupational health and safety (OHS) management system integrated into the overall business systems.

This objective for improved OHS was also suggested by some members of the board for ethical reasons and was strongly influenced by the Pike River mine disaster (Macfie, 2013) and subsequent enquiries (MBIE, 2013; Royal Commission on the Pike River Coal Mine Tragedy, 2012; Shanks \& Meares, 2013). These enquiries pointed to the need for new and more stringent health and safety legislation (now the Health and Safety at Work Act 2015). Some members of the executive management team also saw the need to make changes in anticipation of the likely new legislation.

As a result of these commitments, the position of National Safety, Health and Environmental (SHE) Manager, was created in 2013 and a person with international and New Zealand experience engaged. His first major task in late 2013 was to conduct a gap analysis covering current and best practice. Fieldwork took about three months, engaging with many line managers and workers, and showed gaps between then-current practices and four comparison documents (see over for details).

As the results emerged and drafts of the Review Report circulated, senior management support for development of a new OHS management system grew, resulting in a straightforward decision to proceed with development and implementation of the HS\&E Project Management Plan and Manual in 2014 that set out how the OHS management system was to be implemented. A high level of implementation success has since been shown by three independent audits.

A timeline for the case from 2010 to 2016 is shown below, with key events in bolded borders and external events in dashed lines. 
Figure 22. Timeline of the Case Study A decision, risk assessment and documents
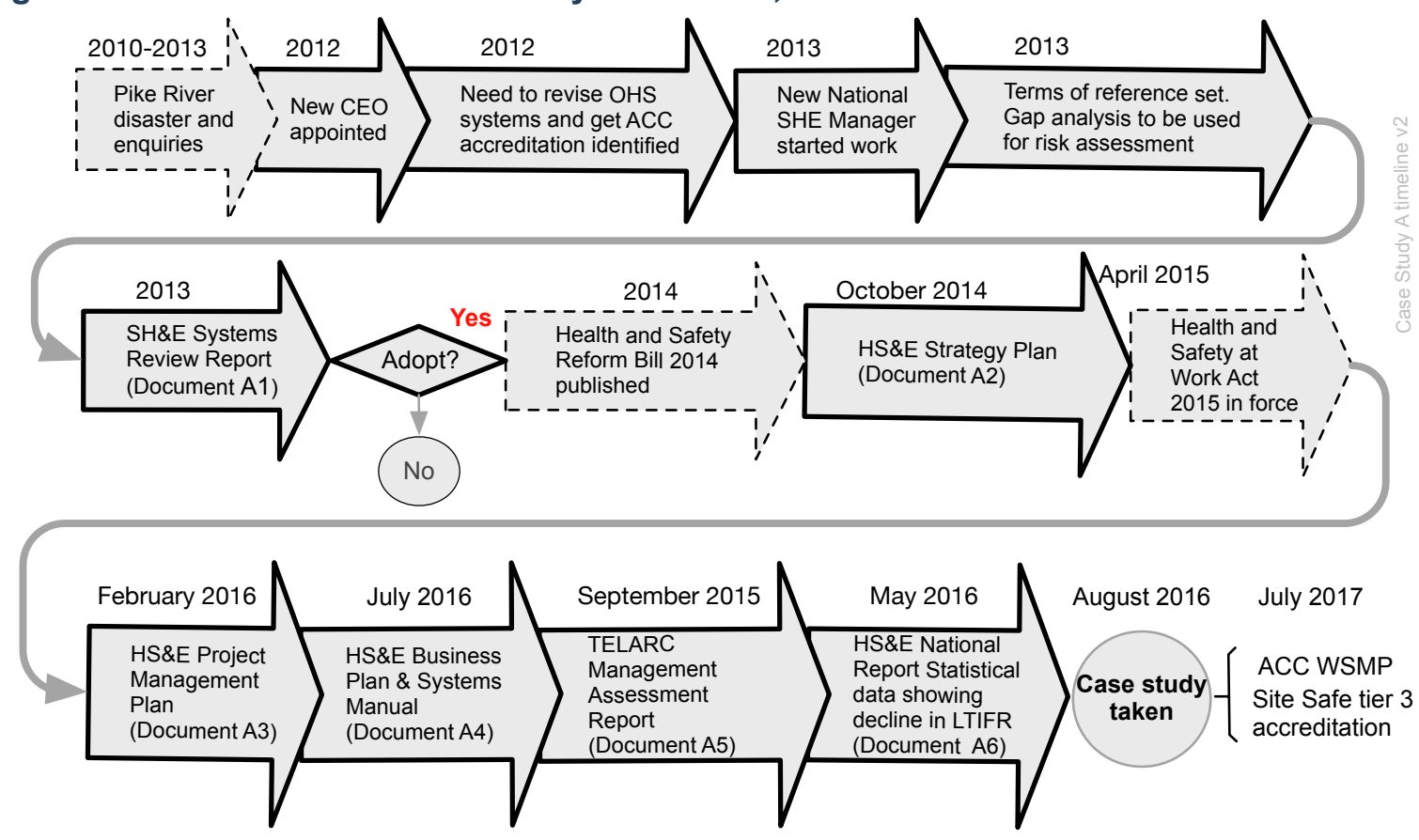

\subsubsection{Case study documents and interviewees}

\section{Comparison documents}

The risk assessment used a gap analysis comparing the status of OHS management with four documents representing at least good practice.

- AS/NZS4801: (2001) Occupational Health and Safety Management Systems

- Health and Safety in Employment Act (1992)

- Accident Compensation Corporation ${ }^{8}$ (ACC, 2002) Workplace Safety Management Practices ("WSMP") audit tool

- ISO31000 (2009) Risk management: principles and guidelines.

\section{Outcome documents}

The documents in Table 36 include the 2013 Review Report and five that post-date that document. Two set out how the gaps were to be, or had been, closed. All were provided by the SHE Manager and reviewed. The Safety Health \& Environmental Systems Review Report (the "Review Report") was the key risk assessment/gap analysis report. It and other internal documents were rated as usually reliable and probably true as there was no way of personally verifying them. The Management Assessment Report was written by TELARC, an

\footnotetext{
${ }^{8}$ The Accident Compensation Corporation is the state-owned monopoly insurer of accidents offering $24 / 7$ cover
} 
accredited audit company. The subsequent Site Safe and ACC WSMP audit reports postdated the case being taken and were not used.

Table 36. Documents reviewed in Case Study A

\begin{tabular}{|l|c|c|}
\hline \multicolumn{1}{|c|}{ Case study document title } & $\begin{array}{c}\text { Year } \\
\text { published }\end{array}$ & $\begin{array}{c}\text { Code } \\
\text { number }\end{array}$ \\
\hline Safety Health \& Environmental Systems Review Report & 2013 & A1 \\
\hline HS\&E Strategy Plan & 2014 & A2 \\
\hline HSE Project Management Plan & 2016 & A3 \\
\hline HS\&E Business Plan \& Systems Manual & 2016 & A4 \\
\hline Management Assessment Report (TELARC) & 2016 & A5 \\
\hline Statistical data (HS\&E National Report May) & 2016 & A6 \\
\hline
\end{tabular}

\section{Interviewees}

The participants noted in the table below were interviewed in their offices using the previously circulated questions.

Table 37. People interviewed in Case Study A

\begin{tabular}{|c|l|c|c|l|l|l|}
\hline $\begin{array}{c}\text { Person } \\
\text { code }\end{array}$ & \multicolumn{1}{|c|}{ Job title } & $\begin{array}{c}\text { Decision } \\
\text { maker } \\
\text { (Y/N) }\end{array}$ & $\begin{array}{c}\text { Risk } \\
\text { assessor } \\
\text { (Y/N) }\end{array}$ & $\begin{array}{c}\text { Highest } \\
\text { qualification }\end{array}$ & $\begin{array}{l}\text { Years in current or } \\
\text { similar role }\end{array}$ & $\begin{array}{c}\text { Professional } \\
\text { body } \\
\text { membership }\end{array}$ \\
\hline CEO & $\begin{array}{l}\text { Chief Executive } \\
\text { Officer }\end{array}$ & $\mathrm{Y}$ & $\mathrm{N}$ & Master's degree & $\begin{array}{l}4 \text { years in current } \\
\text { role }\end{array}$ & CPEng \\
\hline $\mathrm{AB}$ & $\begin{array}{l}\text { Divisional } \\
\text { Manager 1 }\end{array}$ & $\mathrm{Y}$ & $\mathrm{N}$ & $\mathrm{BE}$ (Hons) & $\begin{array}{l}6 \text { years in current } \\
\text { role }\end{array}$ & None \\
\hline $\mathrm{AC}$ & $\begin{array}{l}\text { Divisional } \\
\text { Manager 2 }\end{array}$ & $\mathrm{Y}$ & $\mathrm{N}$ & $\begin{array}{l}\text { Certificate in } \\
\text { Construction }\end{array}$ & $\begin{array}{l}16 \text { years in } \\
\text { current role }\end{array}$ & None \\
\hline $\begin{array}{c}\text { SHE } \\
\text { Manager }\end{array}$ & $\begin{array}{l}\text { National HS\&E } \\
\text { Manager }\end{array}$ & $\mathrm{N}$ & $\mathrm{Y}$ & $\begin{array}{l}\text { Advanced Dip } \\
\text { OHS }\end{array}$ & $\begin{array}{l}2 \text { years 10 } \\
\text { months in current } \\
\text { role }\end{array}$ & None \\
\hline
\end{tabular}

\subsubsection{Decision to be made}

The decision to be made was what form the new OHS management system should take, given likely changes in OHS legislation. The risk assessment should therefore be a gap analysis between current and best practices.

\section{Background to construction sector risk}

The construction sector in New Zealand has long been known to have a poor record of occupational injuries and ill health (Driscoll et al, 2004). While the frequency of injuries is skewed towards small sites and sole traders, large companies usually have many employees $(\mathrm{N} \geq 100)$ working on large sites with higher levels of risk due to work on multistorey structures and deep excavations, and short-term employment of tradespeople. These 
factors result in the sector remaining one of the four worst performing employment sectors (the others are fishing, forestry and farming) in New Zealand.

As noted above, the 2010 Pike River disaster resulted in three significant enquiries, pointing to the need for new OHS legislation ultimately derived from a report to the UK government (Lord Robens et al, 1972) that led to the Health and Safety at Work Act 1974 and, subsequently, other legislation in the Commonwealth. This included the Robens-style Model Work Health and Safety Bill, developed by the Australian Federal Government in response to the need to reduce trade barriers between each of the States. It was agreed to be a good model but required adaptation to New Zealand legal traditions and practice. A Reform Bill was tabled in 2014 and the Health and Safety at Work Act 2015 (HSWA) came into force in April 2016.

Robens-style legislation is distinguished from earlier standards-setting legislation by creating general duties derived from English common law (Ford, 2002) and implies requirements for development of management systems.

In 2012, in the aftermath of Pike River and the enquiries showing underfunding of the regulatory agency and outmoded legislation, the government set a target for a $25 \%$ reduction in work-related fatalities and serious injury by 2020 (MBIE, 2013). This, together with the new legislation, created a framework of requirements that would be difficult for employers to ignore.

Section 36 of the HSWA set out an overarching general duty and seven specific requirements for OHS that could be interpreted as a statutory requirement for some components of a risk management framework. Compliance would thus provide opportunity as well as obligation and so complemented the business plans of the new Chief Executive Officer.

\subsubsection{Case study data}

The tentative GT for an effective risk assessment (section 3.2) provided a framework for analysis of data from the interviews, reports and interviews. The GT, CSF and 13 necessary conditions NC are reported on, as before, in a "bottom up" (ie, reverse) order..

\section{Literature or document review fairly sets out data (NC 01)}

The Review Report and interviews confirmed the:

... current application of SHE systems and management were reviewed using AS/NZS 4801, ACC Partnership Programme Audit Standards and New Zealand Legislation as benchmarking tools. 
The ACC Partnership standards were originally based on AS/NZS4801: 2001 (at the time of the gap analysis the standard was overdue for review and revision). The Health and Safety in Employment Act (1992) had also been recognised as out of date (especially in relation to workplaces such as construction sites that are shared by several employers). While these comparison documents represented some aspects of good practice they could have been supported or contrasted with more up-to-date sources giving the best available evidence on OHS interventions (Van Eerd, 2019). For example, prior to conduct of the gap analysis, at least 20 research reports and guidance documents relevant to OHS in the construction industry were available online, including those summarised in Box 1.

\section{Box 1. Literature relevant for Case Study A: OHS management}

Conventional guidance on construction site safety had been published in Australia (NOHSC, 2005) and professional health and safety practitioner guidance for contractor health and safety "good practice" was published by the UK Institution of Occupational Safety and Health (IOSH \& ASSE, 2010). IOSH had also published guidance on the application of technology in the construction sector (Whyte et al, 2013)

Improvement of governance oversight of high consequence, low likelihood risks in the construction sector (Gilbertson et al, 2011), and the competence, commitment and leadership of managers, their access to competent OHS advice, and face-to-face worker engagement or oral communication (Cameron, Hare, \& Duff, 2007), often of an informal nature (Cameron et al, 2006) had been identified as critical success factors for work health and safety. These might be supported by training, structured to avoid repetition of subjects.

Crucially, the importance of "respect, trust, clarity, pre-emption, challenge, consistency, collaboration, motivation, empowerment, communication, openness, fairness and assurance" (Bolt et al, 2012) in a supportive environment (Conchie \& Moon, 2010) was emphasised in relation to behaviour change (Lunt et al, 2008; McDonald et al, 2002). This should include raising awareness of health-related risks and encouragement of relationships with construction clients to require inclusion of OHS in projects (Brabazon, Tipping, \& Jones, 2000; Cheyne et al, 2012; Crosthwaite \& Langdon, 2007).

Differences in national (and perhaps regional) cultures as underlying causes of adverse consequences had been investigated (Bomel Ltd, 2006a) and attempts made to identify risks common to construction sites (Bomel Ltd, 2006b) that might facilitate development of a companywide management system.

All these document were freely accessible and might have provided the "best available information" (ISO31000, 2009) or greater "weight of evidence" (Weed, 2005) for the gap analysis results. Their absence perhaps confirmed that "good practice is not consistently understood by industry" (Baker, 2002, p. v) or that published research is not widely accessed 
by practitioners (Van Eerd et al, 2017). This proved to be a consistent problem in the case studies and the results of the online survey (see section 6.4 for a summary of data).

\section{Terms of reference for the risk assessment are clear (NC 02)}

Failure to establish terms of reference for a risk assessment can result in risk assessors carrying out work that was not wanted by decision makers. Here, the terms of reference for the risk assessment project were stated in the Review Report (emphasis added):

... one of the main objectives of this process is to eventually develop and apply an improved 'risk based' framework of systems for pending changes in New Zealand legislation, and gain ISO accreditation with an integrated approach to SH\&E (and $\underline{\text { Risk Management) and to ensure that leadership and commitment is demonstrated }}$ and achieved throughout all levels of management, employees and stakeholders within the business.

One of the senior managers was very clear about the terms of reference when he commented in his interview:

I am a member of the executive, we hired [SHE Manager] on the basis that there was a gap in our management, how we managed health and safety. When [he] came on board he was given the task of reviewing our health and safety management systems, to do a gap analysis and, coming out of that, what the health and safety systems should look like. [Manager AC].

The resulting Review Report was a:

... full SH\&E system (gap analysis) ... carried across the current ... business regions and projects.

During his interview the SHE Manager said:

My role was given to me by [CEO] in November 2013. I said I would carry out a pretty thorough gap analysis. ... We knew the new legislation was coming at us and was broadly in line with what I was used to in the UK.

The stated objectives showed the company had set terms of reference for the gap analysis, but the following three unstated objectives were also identified from the case study documents and interviews:

- improve risk assessments

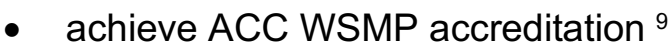

\footnotetext{
${ }^{9}$ The workplace safety management practices scheme operated by the government monopoly insurer, Accident
} 
- reduce the lost time injury frequency rate (LTIFR).

Their inclusion could have led to "scope creep" (Kerzner, 2014) but because they were aligned with the stated objectives and work was closely monitored by the CEO work was completed on time. A further positive outcome was identified after completion of the case study fieldwork: the company had gained a further award for its management system from Site Safe.

\section{Qualifications and experience of assessors stated or available (NC 03)}

The SHE Manager was named as the Review Report author and, although his qualifications were not stated, they were known to those who might read the report.

\section{Impartiality in funding and mandate (NC 04)}

The funding and mandate for the risk assessment was evidently from the management team and board and was not cited in the Review Report. This NC was probably of little relevance as readers of the report were likely to be limited to the management team and board.

\section{Stakeholders and risk assessors have a shared understanding of risk (NC 05)}

Feedback has been identified as part of an effective risk assessment (Lekka et al, 2017; Tetlock, 2006; Tetlock \& Gardner, 2015) and, during the interviews, emerged strongly as a means of gaining a shared understanding of risk.

There was quite a lot of feedback. Some of it was site-based, some high-level. A lot of communication. [Manager $A B$ ]

The [SHE Manager] gave me feedback on complications with site managers and project managers and forms of feedback and sign-off. [CEO]

Perhaps crucially:

There was quite a bit of dialogue with [SHE Manager] and I through the whole process that then culminated in presentation of the report to the whole team. I went through the gap analysis and all his recommendations with [SHE Manager] first and then the team gave [SHE Manager] feedback. [CEO]

This process of wide engagement between stakeholders and the risk assessor was highly effective and was summarised in the Review Report as leading to a shared understanding of risk that:

... involved contributors from a cross section of [case study] personnel and other interested parties including: Senior and Operational management, Project and Site

Compensation Corporation, provided rewards for an occupational health and safety management system 
Management, Human Resources, Health and Safety Management and Regional Health and Safety (H\&S) Reps and Sub Contractors.

However, the SHE Manager (who had worked in London) identified a problem of many topic specialists who work alone: he lacked a competent peer reviewer (see section 2.2).

I think the only issue I had with my work was that I didn't have somebody to pass over it to give a sense check because there was no one at the level I was for health and safety in the business. I had someone in London who I could bounce stuff off. I didn't even have the opportunity to go outside to an outside consultant or another safety practitioner.

Peer review as part of continuing professional development forms part of the requirements for many professional bodies, including the New Zealand Institute of Safety Management and UK Institution of Occupational Safety and Health and acts to help maintain professional standards.

Engagement feedback and feed forward flows are summarised in Figure 23, with the lack of a peer reviewer for the SHE Manager shown as a dashed line.

Figure 23. Feedback flows in the risk assessment

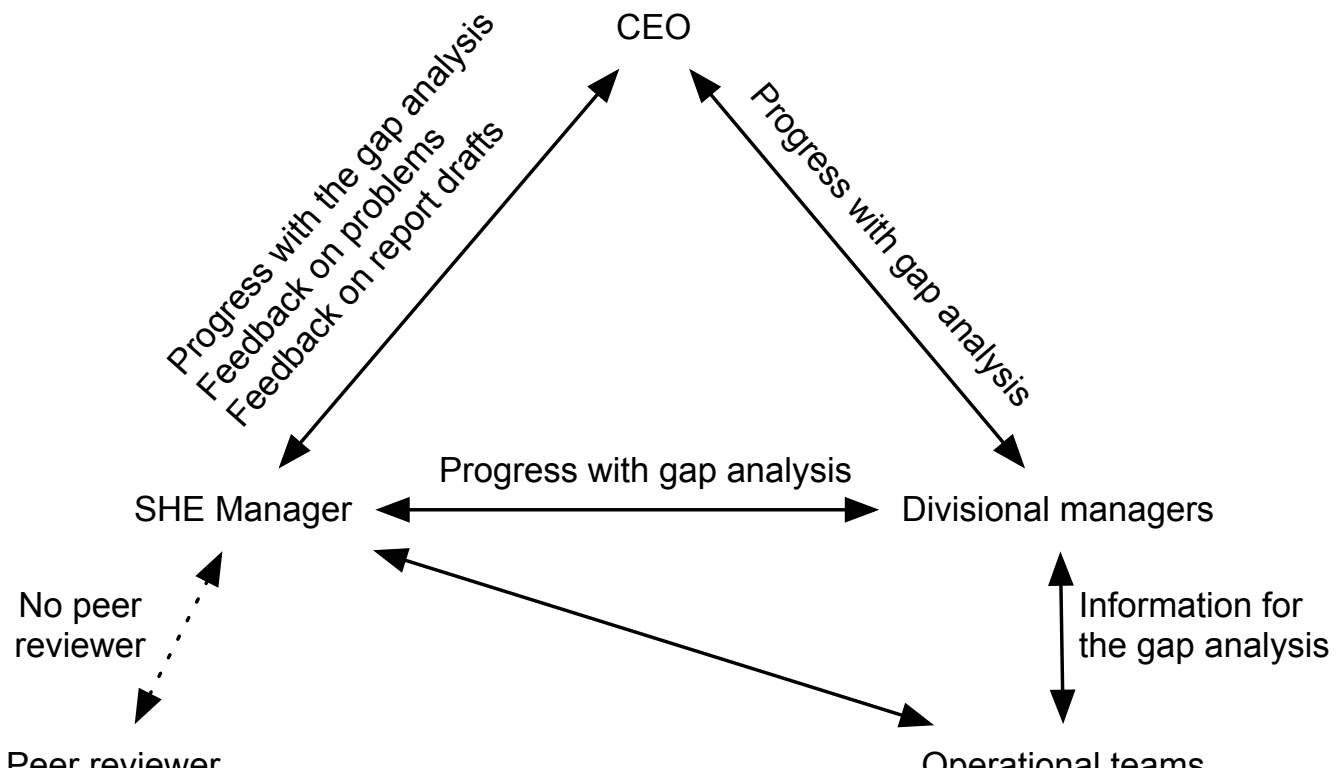

Peer reviewer

Operational teams

After the Review Report had been accepted engagement (NC 05) continued, now about the proposed systems, and again resulting in good outcomes.

I'm responsible to test run some of the new systems and give feedback from my team. [Manager AC] 
Implementation of the OHS management system succeeded because it was founded on a shared understanding of risk and risk controls.

\section{Appropriate engagement with stakeholders (NC 06)}

The Review Report clearly described the close engagement with executive and line managers and workers. This was supported by interviewees; for example, at the start of the gap analysis process.

I spoke to the exec team and the workers and asked them what they wanted. [SHE Manager]

There was a fair bit of engagement in this risk assessment - senior managers, workers on the tools. [SHE Manager]

Thus, engagement during the gap analysis and subsequent development of the project plan included a wide range of stakeholders. Inclusion of "the workers" helped build consensus about the findings and was key to permanent workers and junior managers supporting the subsequent proposals:

Yes, [SHE Manager] came down. We reviewed all the documents and sat down and worked through them on a real-life project. For example, working at height was discussed, we needed it to be a bit more robust. How might a new person pick things up, that was quite important. [Manager AC]

It's [the gap analysis findings and proposed management system] that got stakeholder engagement - that gets people who are coming on site and the risks they will be exposed to. [Manager $A B]$

Such practicable solutions that would be reasonable to implement (ie, required as a result of the reasonably practicable test in the HSWA) had been readily available for many years but might not have been used due to cost, project timing, lack of client support, etc.

The SHE Manager also made the point that his work needed a tangible connection through the management team to the board, giving feedback about the culture change.

I've been saying to these guys, go back to Pike River and the issue was what the board didn't know but the management people did know. [SHE Manager]

The work of the SHE Manager:

... culminated in a high level report that went to the board. Like at a high level you've got different forms of approval and feedback. [CEO] 
While such governance-level engagement has since been made a statutory requirement in section 44 HSWA (Peace et al, 2017) it also seems to have become a given within the company.

Obviously, directors have responsibility in terms of health and safety and personal compliance. [Manager AC]

There was no public consultation or participation in this risk assessment and no special procedures for addressing controversies were reported (Wiedemann et al, 2013) as the project was not controversial: the management team knew it was required by the CEO and, through him, the board.

Engagement with stakeholders was generally good across the survey case study data (section 6.4).

\section{Competent and impartial risk assessor or team leader (NC 07)}

This NC was developed from Busby \& Hughes (2006) which most often applies to science research that informs societal risk assessments. In that context, the risk assessor should evidently be competent and impartial. Codes of conduct set by professional bodies for OHS and other risk practitioners also require such characteristics (eg, the UK IOSH, 2013).

Inclusion of this in the GT was agreed to be necessary:

Yes, number five's [NC 07] good. The people doing the risk assessment, their competences. [Manager $A B]$

The SHE Manager held an Advanced Diploma in Occupational Health and Safety and was highly regarded for his expertise as he:

... brought with him lots of experience in health and safety in a number of key organisations. He was aware of the UK market and the regulations there, and what's happening in Australia. [Manager AC]

Risk is correctly framed (NC 08)

The Review Report clearly set out the business environment of the case study, including comments such as:

... current work activities ranging from remediation, telecommunications, earthquake strengthening and repair, residential and commercial construction. 
The four interviewees were asked how they would characterise the decision or risk assessment. Initially, it appeared to be narrowly framed as a decision about improving OHS management but the SHE Manager framed the decision both widely and narrowly.

Building a bigger picture, seeing the business environment ... and it has to depend on the worker. [SHE Manager]

The CEO said:

The decision was characterised by a combination of things but mostly health and safety being good business practice.

Reference to "good business practice" echoed research findings about sharing good practices (Baker, 2002) but other interviewees also saw the decision as relating to businessas-usual, with financial or strategic implications.

Well I think there was certainly an element of strategic in terms of the key objectives of the organisation. We operate in the construction industry; our projects are measured by a number of success factors. Health and safety is one of those that is important, and to a lesser extent there is legislation, and then there's marketing to demonstrate that you've got what it takes - robust health and safety systems in place. So, it's certainly got strategic but also its every day. Prior to SHE Manager coming on board the new chief executive thought the health and safety systems were insufficient, that there was a gap, so it was certainly strategic to raise the standards. [Manager AC]

Table 38 below summarises how three decision making senior managers characterised the decision objectives and risk assessment, with OHS being but one of several in this large company. Such characterisation of this gap analysis as being about more than either OHS or compliance objectives generally agrees with other work that found adoption of good OHS 
practices often has drivers other than legal requirements, including ethical considerations and commercial benefits (Baker, 2002; Nielsen \& Parker, 2012).

Table 38. Character of the decision

\begin{tabular}{|l|c|}
\hline $\begin{array}{c}\text { Possible objectives of the decision } \\
\text { or risk assessment }\end{array}$ & $\begin{array}{c}\text { Whether this objective was } \\
\text { mentioned in Case Study A }\end{array}$ \\
\hline Business as usual & $\checkmark$ \\
\hline Compliance & $\checkmark$ \\
\hline Decision making & X \\
\hline Delivery of goods or services & $\checkmark$ \\
\hline Environmental & $\checkmark$ \\
\hline Equipment fit for purpose & $X$ \\
\hline Financial & $\checkmark$ \\
\hline Good practice & $\checkmark$ \\
\hline $\begin{array}{l}\text { Occupational health and safety } \\
\text { (including welfare) }\end{array}$ & $\checkmark$ \\
\hline Project management & $\checkmark$ \\
\hline Reputation & $\checkmark$ \\
\hline Strategic & $\checkmark$ \\
\hline Sustainability & $\mathrm{X}$ \\
\hline
\end{tabular}

\section{Criteria for risk evaluation set (NC 09)}

Development and use of an agreed benchmark against which risk can be compared or assessed is a key part of a risk assessment and subsequent risk control. The Review Report discussed the implications of the likely change from all practicable steps in the Health and Safety in Employment Act 1992 to reasonably practicable in the proposed legislation (now the HSWA). This included:

... what was reasonably able to be done ... [after] weighing up all relevant matters including the likelihood of the hazards or the risk concerned occurring and the degree of harm that might result from the hazard or risk.

The report made clear there was more that could be done that was both practicable and reasonable, and that project-specific risk assessments should precede identifying how best to manage OHS in projects.

A number of other benchmarks are in general use (Peace, 2017a); those defined in ISO Guide 73 (2009) are risk appetite, attitude, aversion, criteria, and tolerance but a search of the case study documents found no definition of these terms or concepts other than key critical risks. The search also found that: 
- appetite was used by Manager AC (we would compare where that risk sits with the appetite of the company) and the CEO ("so we would be looking at the risk appetite, what it should be, once we've looked at the controls in place")

- attitude was used in a cultural sense in the message to all employees and as part of OHS and environmental risk management (eg, "an employee's awareness of Senior Managers attitudes")

- aversion was not used in any sense

- criteria was used in the 2016 Business Plan \& Systems Manual in relation to pre-engagement of contractors and audit criteria

- tolerance was used in the 2016 Project Management Plan relation to zero tolerance for drug and alcohol use and by Manager AC ("If the company had a low tolerance for health and safety [injuries] or for regulatory areas")

- key critical risks were introduced as part of the management system and refer to activities giving rise to a greater chance of harm.

As the case study did not have formal benchmarks prior to development of the OHS management system it is assumed managers were using their professional judgement.

Appropriate language, graphics and layout (NC 10)

While the Review Report used no graphics, it did contain a brief, plain language summary, and was presented in a simple layout. Several drafts had preceded the final version, enabling discussion of technical language and concepts.

The report was written in what was initially assessed to be non-technical language but when two samples of the text were run through an online readability tool at http://www.readabilityformulas.com/ that used the SMOG readability algorithm (Arkin et al, 2004 ) it was assessed as "college graduate" level. As the management team held tertiary or professional qualifications this was probably not an issue.

\section{Systematic hazard or risk identification (NC 11)}

While the Review Report did not identify risks, the interviews made clear that management was well aware of the need to improve performance before there was a change in legislation that might create compliance-related risk. 
The identification stage started with interviews and was:

... carried out across the business regions and projects using a structured process of interviews with the CEO, internal directors and business unit leaders, followed by a series of site visits to view and observe systems and procedures and the safety culture in action. [Review Report]

It included "safety walkarounds" by the SHE Manager and, subsequently, the CEO. These have been shown to be a predictor of injuries in the Danish construction industry (Cournoyer et al, 2011; Mikkelsen, Spangenberg, \& Kines, 2010).

Interviews and observations are established research techniques (Saunders et al, 2007) that are also used by practitioners for task analysis (Kirwan \& Ainsworth, 1992) and injury prevention in the construction industry (Mikkelsen et al, 2010). Here, the observations and site visits provided insights that could not be gained by a desktop gap analysis:

Yes, that's the experience I'm talking about, you can't sit in a room. [SHE Manager] Risk in construction projects due to uncertainties in design was identified four times in the Review Report and commented on by one manager.

Doing a good risk assessment in construction means you've got to know what your design is. [Manager $A B]$

Such uncertainty can arise if the design is not completed until after a bid has been tendered, leaving uncertainties about constructability as a major source of safety-related risk (see, for example, Weinstein, Gambatese, \& Hecker, 2005). The Review Report showed this risk source could be managed by project-specific risk assessments, structured around risk criteria.

As discussed in NC 01, by the time of the gap analysis a body of applied research had been published and could have added weight to the qualitative analysis.

Appropriate risk analysis techniques have been used (NC 12)

The SHE Manager was asked How did you carry out the gap analysis? and responded:

... it was not a question of sitting on your own using a risk matrix. It was more farreaching than that. I spoke to the exec team and the workers and asked them what they wanted.

The risk matrix is widely used to compare levels of risk after the nature of a risk has been determined, to aid ranking of risks for attention and was used by this organisation.

You've probably got to look at the consequence, what could go wrong. So, I quite like the idea of the risk matrix. [Manager AC] 
The CEO alluded to the matrix but did not mention it specifically.

What are the consequences or their likelihood of something happening to the business. [CEO]

Assessing the effectiveness of controls as part of a risk analysis emerged strongly in the interviews.

... how our [risks are] currently managed or not managed [CEO]

Maybe looking at what are our controls. We would be looking at what they are, identifying them. We'd be looking at the effectiveness of those controls. And then taking account of the controls, what is the residual risk. [Manager AC]

The final draft Review Report was accepted as providing adequate qualitative information to demonstrate where there were gaps.

The risk assessment may well show you where there are gaps and that would help you make the decision? [CP]

Yes [Manager AC]

These findings align with the online survey results showing that professional judgement and the risk matrix are the two most commonly used risk analysis techniques.

In Case Study A, there was a strong interest in the effectiveness of occupational health and safety (OHS) using the obsolete joint Australia/New Zealand standard Occupational Health and Safety Management Systems (SA/SNZ4801, 2001) being used to aid the gap analysis. The McKinsey 7-S model (section 3.4.2) was used as part of this research to investigate any missing issues of importance. Headings from the standard are shown in the amber-shaded rectangular boxes in Figure 24. 


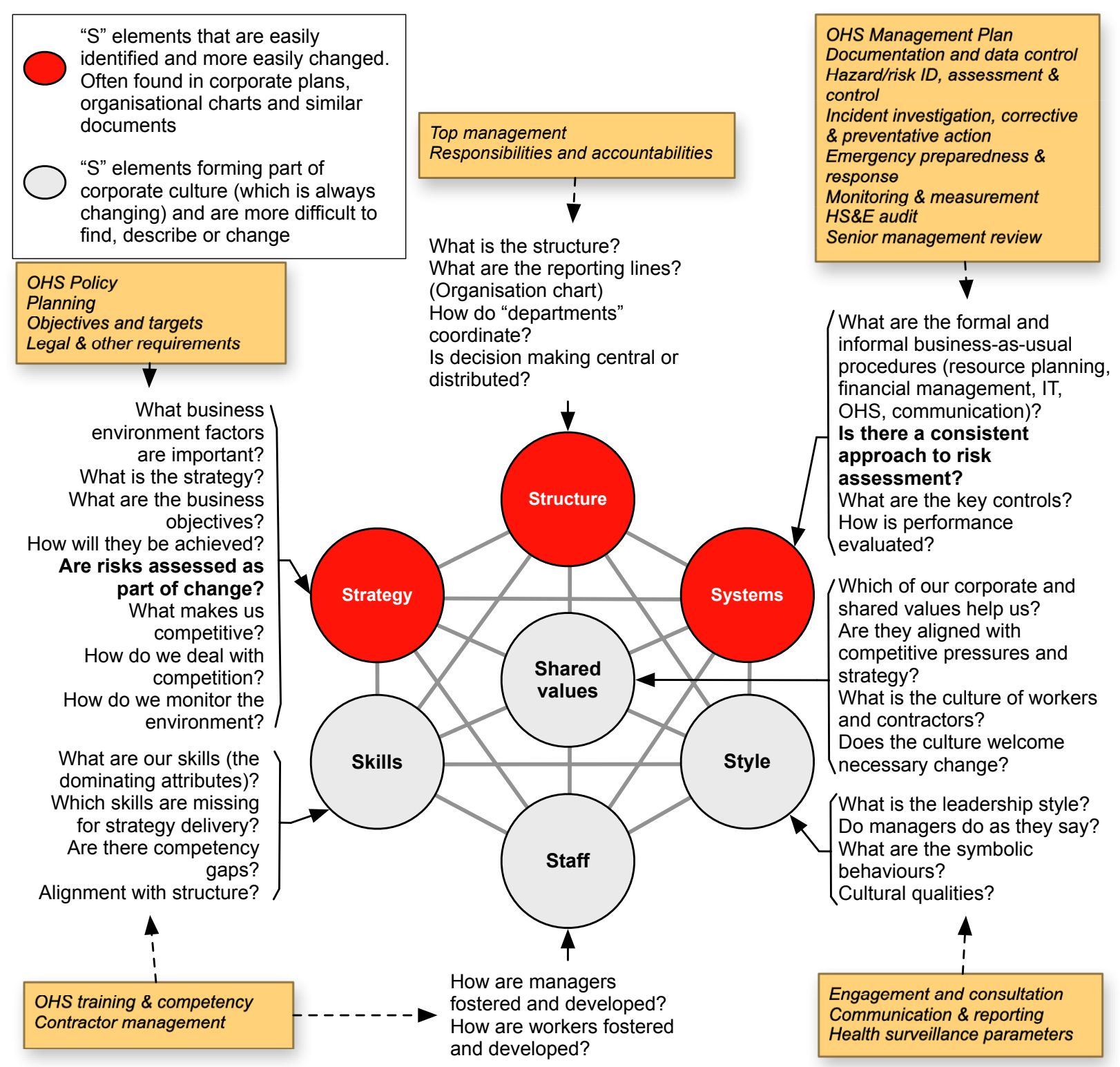

Source: base diagram adapted from Peters \& Waterman (1982), Waterman et al (1980) with additions from AS/NZS4801

Superficially, AS/NZS4801 aligns with all 7-S elements except shared values. These can be critical to successful implementation of an occupational health and safety management system and Case Study A overcame this by strong leadership from the CEO. Closer review of the other 7-S elements suggests areas that are not covered by AS/NZS4801, making the gap analysis against the standard incomplete.

(Two years after completion of this case study the company went into receivership, corroborating the need to take a wide view in any gap analysis to ensure all relevant issues are addressed.) 


\section{Appropriate risk evaluation techniques have been used (NC 13)}

The Review Report summary did not refer to the reasonably practicable test (or other criteria), instead evaluating identified gaps using professional judgement. In his interview the CEO showed a clear understanding of the use of criteria and the need to adjust the management of risks through additional controls.

So, we would be looking at the risk appetite, what it should be, once we've looked at the controls in place. If there is a bit of a difference and what the residuals were, then we'd want to make sure that we control those risks.

\section{Risk assessment appropriately communicated to decision makers (CSF 01)}

As work proceeded, drafts of the Review Report were circulated for comment

Yes, I can certainly remember some of the early gap analysis reports [Manager AC] While the Review Report was based on a gap analysis it did not contain a table showing "as is" (in 2013) with "desired" but met the needs of the decision makers in terms of the findings, content and language. It at least touched on areas that were the subject of some controversy and provided sufficient evidence for the decision to proceed with development of a management system:

... there was obviously a bit of a gap and he put forward a strategic plan [Manager $A C]$

No assumptions were stated in the Review Report and none were identified during the interviews. The report noted the limitation that not all regions, projects and sites were visited.

\section{All relevant factors including controversies and uncertainty have been fully and correctly evaluated (CSF 02)}

The preceding analysis of NCs suggests that all relevant factors were evaluated but that the following aspects could have been given more weight.

\section{Controversies}

The interviewees and Review Report discussed a number of controversies but, by the time the report was finalised, many appear to have been resolved by the engagement.

I can certainly remember some of the early gap analysis reports. [Manager AC]

Earlier research had shown that "greater project manager experience" and "lower project staff turnover" were associated with projects exhibiting superior OHS performance (Cameron et al, 2007, pp. 46-49). However, such effects (and those due to project management methodologies) were not discussed beyond noting 
variations in the:

... way in which each division and project approached SH\&E Management through planning, implementation, monitor and evaluation.

Absence of safety by design is a pervasive source of risk in the construction industry (Weinstein et al, 2005) and, in New Zealand, may take many years to overcome as necessary skills are developed. It was mentioned briefly in the Review Report as:

Senior management and site management responsibilities are well defined [in the policy] ... but no other management is mentioned such as ... Commercial, Design, Tendering and Programming.

One controversy raised by employees during the gap analysis had been:

... the outcomes of ... incident reports 'not' finding the true underlying causation of serious harm and serious near miss incidents.

Such controversies may arise if management believes employees are using incident investigations as a means to gain additional benefits beyond health or safety, while employees may believe management wants to avoid remedying systemic problems. In the case study, this may have been connected with the appointment of safety representatives by management:

... and where the safety rep has no real influence or incentive to carry out their roles and with no formal H\&S training. It should be noted that the role of a safety rep is to represent employees on health and safety matters, not for implementing and reviewing health and safety programmes as detailed in our current H\&S plans. [Review Report]

This has now been overcome by making safety representatives independent of management.

\section{Uncertainty and risk}

ISO31000 was one of the comparison documents. It sets out a definition of risk ("effect of uncertainty on objectives") that should be very influential in any assessment of risk as it implies understanding organisational objectives, how uncertainty might affect achievement of those objectives and what the effects, positive or negative, of such uncertainty might be.

The case study had defined its objectives for OHS but the Review Report did not explicitly discuss uncertainty in achieving them, although implementation of ISO31000 in the case study was recognised as: 
... a great opportunity for the ... business to be recognised as an industry leader ... [Review Report]

It is argued below that higher performance in OHS has had positive effects beyond such recognition.

As the Review Report was completed before publication of the draft legislation on 10 March 2014, a key uncertainty would have been the forthcoming statutory requirements. However, the objectives of the changes included best practice, possibly making compliance of lesser importance. That the business environment would change and the new health and safety legislation impose higher requirements was well understood by the interviewees, including a degree of uncertainty:

Then there's the new legislation although this was very early days and it was beginning to appear on the horizon. [CEO]

We knew the new legislation was coming at us and was broadly in line with what I was used to in the UK. [SHE Manager]

Gaps giving rise to uncertainty were identified in the report. For example: ... many of these procedures are somewhat light and perhaps overstated, and some are not functional due to missing and essential templates and H\&S documentation.

In summary, no completed and/or up-to-date training analysis or employee training matrixes were sighted during the review process, and it would appear that some new employees are located on to a project without any real assessment of their previous SH\&E competency.

\section{Treatment options}

The Review Report set out a range of options to bridge the identified gaps. After approval of the Review Report a series of project implementation plans were developed and implemented, including actions to be taken by the Senior Leadership Team.

\subsubsection{Case Study A outcomes}

\section{Gap analysis objectives}

The outcomes of the gap analysis were next evaluated to see if it helped achieve the objectives. The case study website was reviewed on 23 July 2017 and further substantiated some of the following stated and unstated objectives to:

- develop and apply an improved "risk based" framework of systems for pending changes in New Zealand legislation 
- gain ISO accreditation with an integrated approach to SH\&E (and Risk Management)

- ensure that leadership and commitment is demonstrated and achieved throughout all levels of management, employees and stakeholders within the business

- (as a result of the new systems to) improve risk assessments, achieve ACC WSMP accreditation, and reduce the lost time injury frequency rate (LTIFR).

Figure 25 is a qualitative influence diagram showing the estimated strength of relationships between the risk assessment and outcomes and including the unplanned outcomes identified during analysis of the case study data. The thickness and direction of the lines represents estimated strengths of influence.

Figure 25. Case Study A qualitative influence diagram

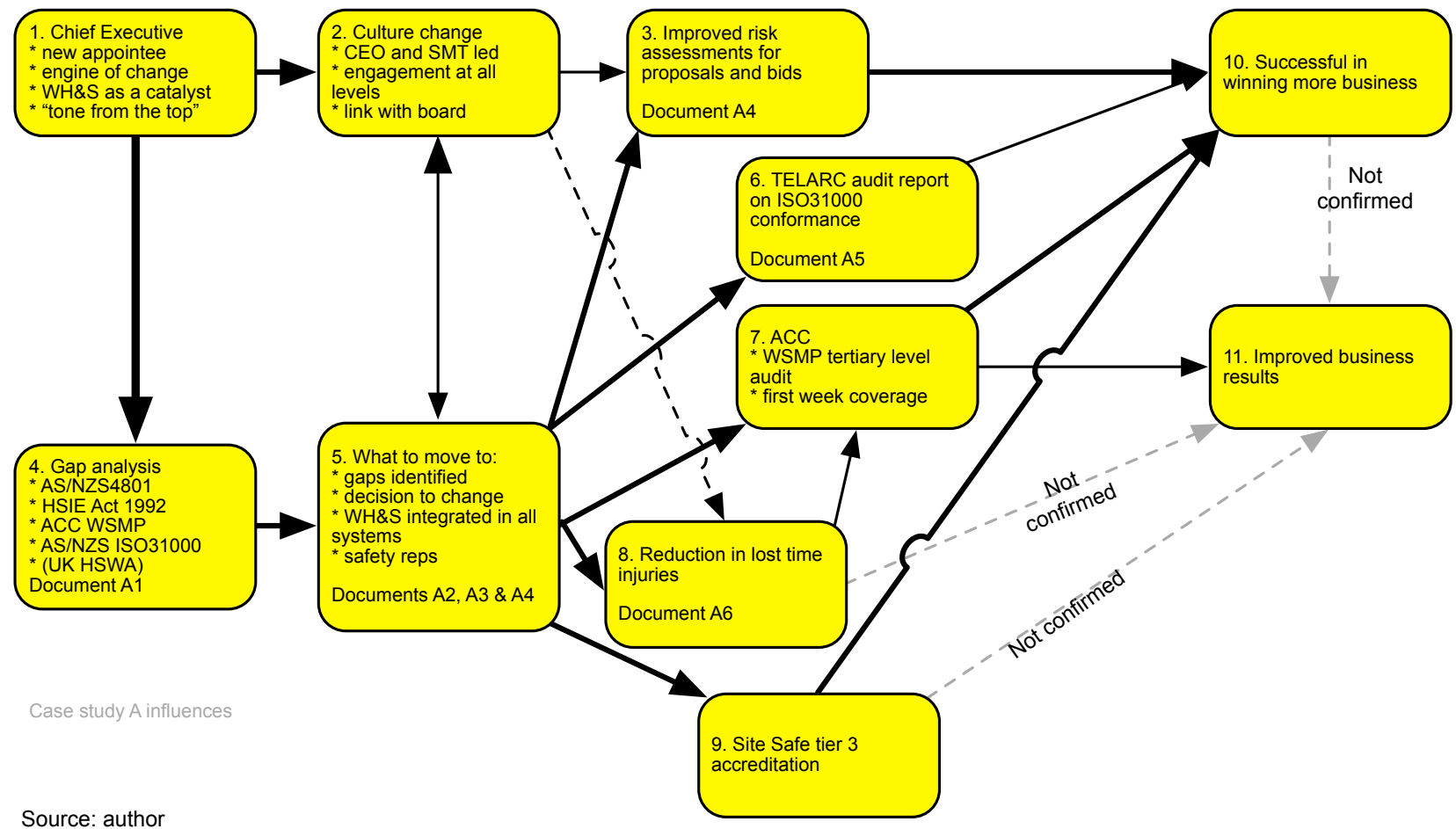

Research in the UK (Baker, 2002) found no examples of organisations that had moved from average OHS performance to sector leaders in the way that Case Study A did, perhaps due to the leadership of the CEO. 


\section{Role of the CEO}

The new CEO recognised a need for structural and cultural change, and that improved OHS management can act as a driver for organisational change (box 1, Figure 25).

We could improve and use health and safety as an organisational catalyst for improvement.

He was an engine for change, who set the "tone from the top" (Schwartz et al, 2005), and who:

... wanted to see health and safety performance improved and from experience in other organisations I knew that performance could be improved.

Prior to completion of the gap analysis the CEO somewhat influenced a culture change in OHS but was highly influential in driving the gap analysis (box 4, Figure 25), seeking and revising versions of the draft report as work proceeded.

There was quite a bit of dialogue with [SHE Manager] and me through the whole process that then culminated in presentation of the report to the whole team. [CEO]

\section{OHS management system}

The HS\&E project management plan was strongly influenced by the findings from the gap analysis recorded in the Review Report (box 5, Figure 25). Although not stated, the UK HSWA and associated regulations (eg, the Construction Design and Management Regulations) may have influenced this work.

[SHE Manager] was aware of the UK market and the regulations there ... [Manager $A C]$

The new system closed gaps and aimed for integration in the company management system, so meeting this objective.

\section{TELARC audit}

The subsequent TELARC audit (box 6, Figure 25) was commissioned by ACC and Case Study A and carried out in September 2015. It was also in the form of a gap analysis comparing the-then status with guidance in ISO31000. The findings strongly supported the new management systems and, in the summary, the report stated the company:

... showed excellent 'compliance' to the guidelines within ISO31000 and thus no concerns specifically raised.

One concern expressed in the report was that the company ... is not being consistently followed (in principle) by other major construction companies and thus contractors go from [case study] sites to other work sites that 
have less rigid controls (or none) thus there is a lots of confusion out in this area. Different companies, different standards.

This, and other comments in the report independently demonstrated that Case Study A had become a leader in OHS performance in its industry sector.

\section{Culture change}

This sought-after change (box 2 in Figure 25) was strongly influenced by the CEO and the gap analysis. The SHE Manager commented:

One of the more positive aspects of the review was an obvious commitment from the business to further improve SHE performance; and a Senior Management team who want SH\&E to become a management function and be fully integrated into [Case Study A] business.

It was not possible to measure the culture during the case study work and no baseline study had been carried out before the organisational changes in 2014-2016 but the CEO stated:

If I walk out onto a project site and I feel safe then it is a well-run site with happy staff and happy clients. That's the number one thing.

As further evidence for a positive leadership change:

- the TELARC audit report commented on the level of training of staff and supervision of contractors

- the company now publishes HSE Knowledge Share leaflets describing "what good looks like" based on examples from company projects

- a monthly statistical report on a range of leading and lagging indicators also suggests (but does not confirm) that the company is monitoring its own performance.

The case study has subsequently become involved with other national and regional risk management initiatives.

This is in contrast to earlier work in the UK that found there were "no real sector leaders who set the benchmark in health and safety practices for others to follow" (Baker, 2002), whereas this case study showed the converse - the company became an industry leader.

\section{Improved risk assessments}

Improved risk assessments following introduction of the new management system (corroborated by the TELARC report) drew many comments from interviewees (box 3 , Figure 25) and was a further unplanned outcome leading to another unplanned outcome commercial benefits (see below). 
The OHS management system now includes a systematic approach to hazard or risk identification for specific projects and workshops for project implementation. Training in risk assessments acted to enable company managers and workers to talk about what they already knew.

We did the risk management training. We asked them what do you think, is this a critical risk? And nine times out of 10 they knew, they knew this was critical. They could see how this could impact on the business. [SHE Manager]

Risk assessment workshops developed as part of the management system now assess risks a project might pose to the company.

In our company there is a Gateway system that works right from day one. Our marketing team and myself would review a contract, give it effectively a risk-based score. Is it a project that suits our skills and capabilities? If it does, do we go after the project or not. So that's where it starts. [Manager AB]

If a bid is successful these are followed by pre-start risk workshops:

Yes, you pull in a team who will run the project and they workshop everything. ... before we start a project we have a 1-2 day risk workshop. The guys who are on the job are part of the workshop. A lot of that will be health and safety, environmental ... and behind that there is a project risk management. There might be a lack of workers in the market - what effect will that have on this project? [Manager $A B]$

Some risk assessments now are simple but effective:

Within health and safety those key elements of that, and again we would rank those elements what's the consequence, what's the likelihood. That would give us the inherent risk, what are the inherent risks. Maybe looking at what are our controls. We'd be looking at what they are, identifying them. We'd be looking at the effectiveness of those controls. And then taking account of the controls, what is the residual risk. [Manager $A B]$

Arising from such workshops more detailed risk-aware planning is carried out.

This is a specific risk assessment on a job [pointing to a file]. This is a full 70-80 page health and safety project management plan. Every project has one. It covers all our systems. All our people, the organisational structure for the site. [Manager $A B]$

As a result of such workshops:

... the risk assessments we are putting in give us a lot more data. [Manager $A B]$ 
The overall effect has been more confidence within the company.

We've got the data and people can see the results, what they're doing has a cultural effect on risk. [Manager $A B]$

\section{ACC WSMP status}

The revised management system was subsequently independently audited by ACC for workplace safety management practices purposes and the company was awarded tertiary status (box 7 , Figure 25 ), resulting in a $20 \%$ reduction in ACC levies and contributing to a further unplanned outcome - improved business results (box 11, influence diagram).

\section{Prevention of harm to workers}

By May 2016 the lost time injury frequency rate (box 8, Figure 25) had reduced from 3.2 to 1.47 with a target of less than 1.0. This helped reduce liability for the first week of wages under the ACC scheme and contributed to improved business results.

\section{Site Safe audit}

Site Safe also audited the company and awarded it Tier 3 accreditation (box 9, Figure 25) the highest level in the Construction Safety Charter Accreditation programme and one of only two construction companies to achieve this status. This unplanned outcome was achieved after the case study was taken and so no independent documentation for this has been seen.

\section{Commercial and organisational benefits}

The improvements in risk assessments have acted as "a game-changing information technology" and are serving as "a platform for constructive discussion among parties that hold different values" (Goble \& Bier, 2013, p. 1942). This has enabled more information to be provided in bids to prospective clients. Further, the ACC, Site Safe and TELARC audits may have provided valuable but intangible assurances to prospective clients that the case study would contribute to compliance with the range of duties set out in part 2(2) of the Health and Safety at Work Act 2015.

We are seeing a lot more clients asking, especially government, asking for more technical data. [Manager $A B]$

These successes may have resulted in the company winning more business but this fell outside the case study work and has not been confirmed. However, it is postulated that the successful outcomes noted above have led to success in winning more business (box 10 , Figure 25), again leading to better business results (box 11). 
The SHE Manager asked rhetorically:

Was it business-as-usual? Not really, it's a step change ...

\subsubsection{Summary of Case Study A risk assessment and outcomes}

Despite some deficiencies in the gap analysis, the web of planned and unplanned outcomes in the influence diagram were all positive and therefore the weight of evidence in this case study suggests the risk assessment/gap analysis (Figure 26):

- was effective in informing the CEO and management team about the decision to be made

- contributed information necessary for a successful outcome

- could have been strengthened by a substantially better literature review.

Figure 26. Effectiveness of the risk assessment compared with outcomes

\section{Decision outcome}

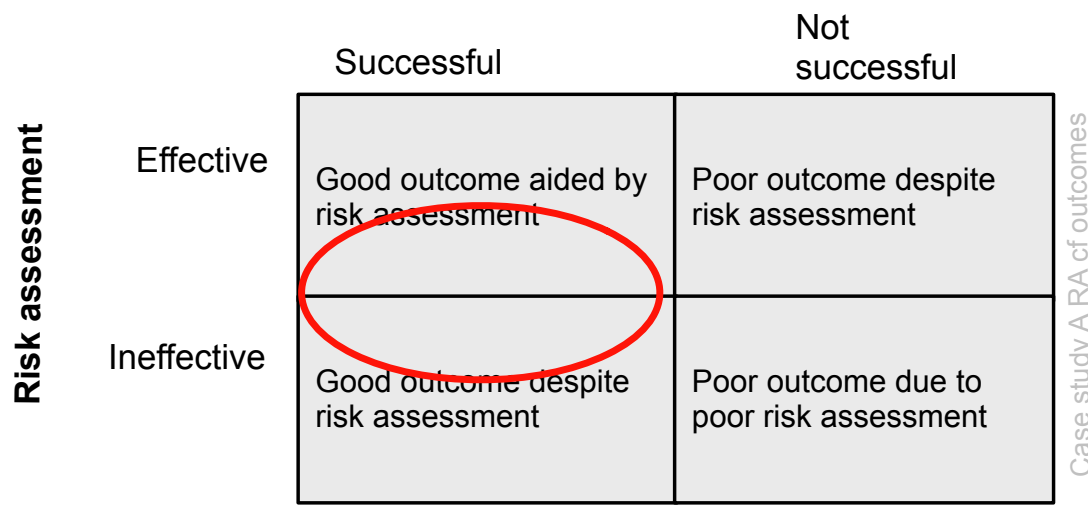

The decision to improve OHS management was made in January 2014 and pre-dated the Health and Safety Reform Bill 2014 (published in March 2014) and the Health and Safety at Work Act 2015 (which came into force in April 2016).

As a result:

Now, people are starting to say [SHE Manager] and [CEO], you know, they were ahead of the game. [Manager $A B]$

In contrast with the UK where there may be few or no sector leaders for OHS (Baker, 2002), Case Study A may be a sector leader setting a benchmark for other construction companies.

\subsubsection{Evaluation of Case Study A risk assessment using the goal tree}

The tentative GT (section 3.2) postulated 13 NCs and two CSFs for a risk assessment to be considered effective. To summarise the findings and indicate the magnitude of "satisficing" (Dettmer, 2003, p. 66) these have been colour shaded in Figure 27 to show if they were met substantially, partially, or not at all/very little. NC 04 is left clear as it was judged not relevant in case $A$. 
The GT colour is half amber, half green. Although stakeholders received a partial document review (NC 01) they achieved a substantial shared understanding of the risks. The terms of reference (NC 02) were substantially met.

Figure 27. The goal tree and the risk assessment in Case Study A

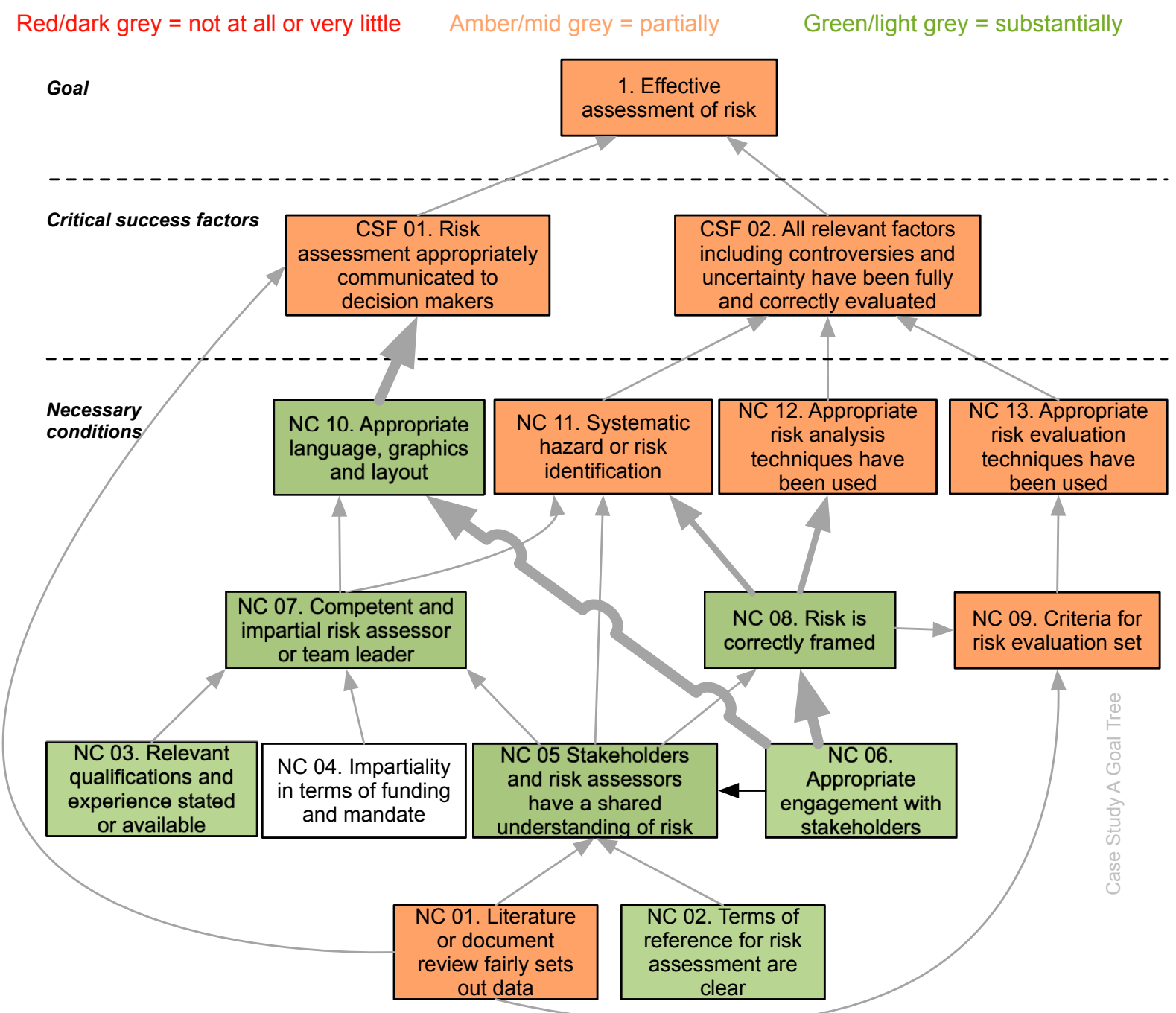

The link between NCs 05 and 07 was very weak, suggesting a tentative GT design error. However, engagement with stakeholders (NC 06) was substantial and a key NC, contributing indirectly (thick grey-shaded arrows) to both CSFs. Such engagement has been found to be of importance by other researchers (eg, Cameron et al, 2007; Durodié, 2017; Pashorina-Nichols, 2016).

Relevant qualifications and experience (NC 03) were not stated but were substantially available and the risk assessor was competent and impartial so NC 07 was substantially met. 
Risk identification (NC 11) was partial - a formal gap analysis approach was needed. Risk analysis techniques (NC 12) were partial (qualitative comment on the gaps found during interviews and site visits).

Criteria for risk evaluation (NC 09) were partial, a weakness that was overcome by oversight from the CEO and management team during development of the Review Report, leading to their professional judgement being applied in the risk evaluation (NC 13).

The report was used appropriate language and was circulated to the management team (CSF 01) but did not include all relevant factors (eg, comment on the reasonably practicable test or the need to develop an integrated management system) issues that should have emerged from NCs 11, 12 and 13. It was rated as partial.

\section{Interviewee comments}

The following quotes have been annotated to identify NCs mentioned by the CEO who said a risk assessment should help understand (emphasis added):

... the current state [NC 05], what are the risks [NC 11], the issues [NC 05], how are they currently managed or not managed [NC 13]. What are the consequences or their likelihood of something happening to the business [NC 12]. So, for me that's the first part, that gives me a feel for whether it's a real issue or not [CSF 02], whether it is worth spending time on or not.

And that the risk assessment should also describe the context and provide options for improvement:

If you've got the basic framework [NC 08] in front of you, you are well aware of the issues confronting you - what might happen if you do nothing, what the options are to improve [CSF 02], the costs and benefits [NC 12], then you're in the position of making an informed decision. [CEO]

And:

Building a bigger picture seeing the business environment [CSF 02]... And how our competitors were behaving. [SHE Manager]

The other interviewees also referred to the context or environment:

So that gives us a robust picture of the initial factors... Depends on the context. [NC 08] [Manager AB]

The three NCs of risk identification, analysis and evaluation were strongly identified by Manager AC (emphasis added): 
There is really a risk framework, it generally starts with what are the risks [NC 11], what's the risk appetite for the business, so we have some sort of structure to it. That will look at different aspects of the project [NC 12], and whether it's health and safety [NC 12] or the staff. It could be financial [NC 12], there's a number of elements to that. We go through that and ... What are the things that could go wrong? ... What could go wrong [NC 12] and what is the likelihood [NC 12]. If it does happen what's going to be the impact? Would that be acceptable [NC 13]? What's going to be the cost to overcome that [NC 13]? Is it reasonable [NC 13] to spend that many dollars to address that risk? And from there, some of the specifics that fit in the framework.

Thus, the risk assessment should provide enough information for managers to place a risk in the business environment, know "whether it's a real issue or not, whether it's worth spending time on or not", and provide information about how to deal with the risk if it is of concern.

From the perspective of the CEO, the gap analysis worked:

Very well, [it] followed a structured process for the first three months. [the SHE Manager] went out and got familiar with the business, what was working well or not working well.

From the SHE Manager there was the sense that the gap analysis was effective:

It must have been well received because it's happened!

\section{Deficiencies in the GT}

The commitment to change and strong leadership of the CEO suggested the need for a third critical success factor in the GT - Ownership of the risk assessment at an appropriate management level. This was also touched on by Manager AC when looking at the GT:

Have you got risk owners in there?

These comments are further discussed in chapter 7. 


\subsection{Case Study B data and analysis}

\subsubsection{Business environment of the decision}

Case Study B is a knowledge-intensive consumer services organisation characterised by intangibility, heterogeneity, inseparability, and perishability (Xin et al, 2013) that operates in the New Zealand public sector. In 2013 it occupied a main site, four satellite sites and two off-site locations in Wellington, each having a range of buildings occupied with seasonal variations, and over extended hours, by employees, contractors, large numbers of customers and members of the public.

The 2010 and 2011 Canterbury earthquakes (Cubrinovski et al, 2011; Cubrinovski et al, 2010) prompted many organisations to reassess seismic risks and associated response plans. In accordance with existing policy, Case Study B staff responded to these earthquakes by carrying reconnaissance visits to Canterbury, reviewing reports of damage from similar organisations, and revising response plans.

On 21 July and 23 August 2013 two relatively shallow earthquakes near Seddon in the north-east of the South Island of New Zealand were widely felt in central regions, causing damage to land, buildings and contents over a wide area (McClure et al, 2016; Wikipedia, 2013, 2017), including some owned or occupied by Case Study B. Its staff carried out a gap analysis using data from the 2010-2011 Canterbury and 2013 Seddon earthquakes and then revised its plans taking into account its own experiences from the earthquakes. The top row of the timeline (Figure 28) shows Case Study B responses to the Canterbury earthquakes.

Figure 28. Timeline of the Case Study B decision, risk assessment and documents

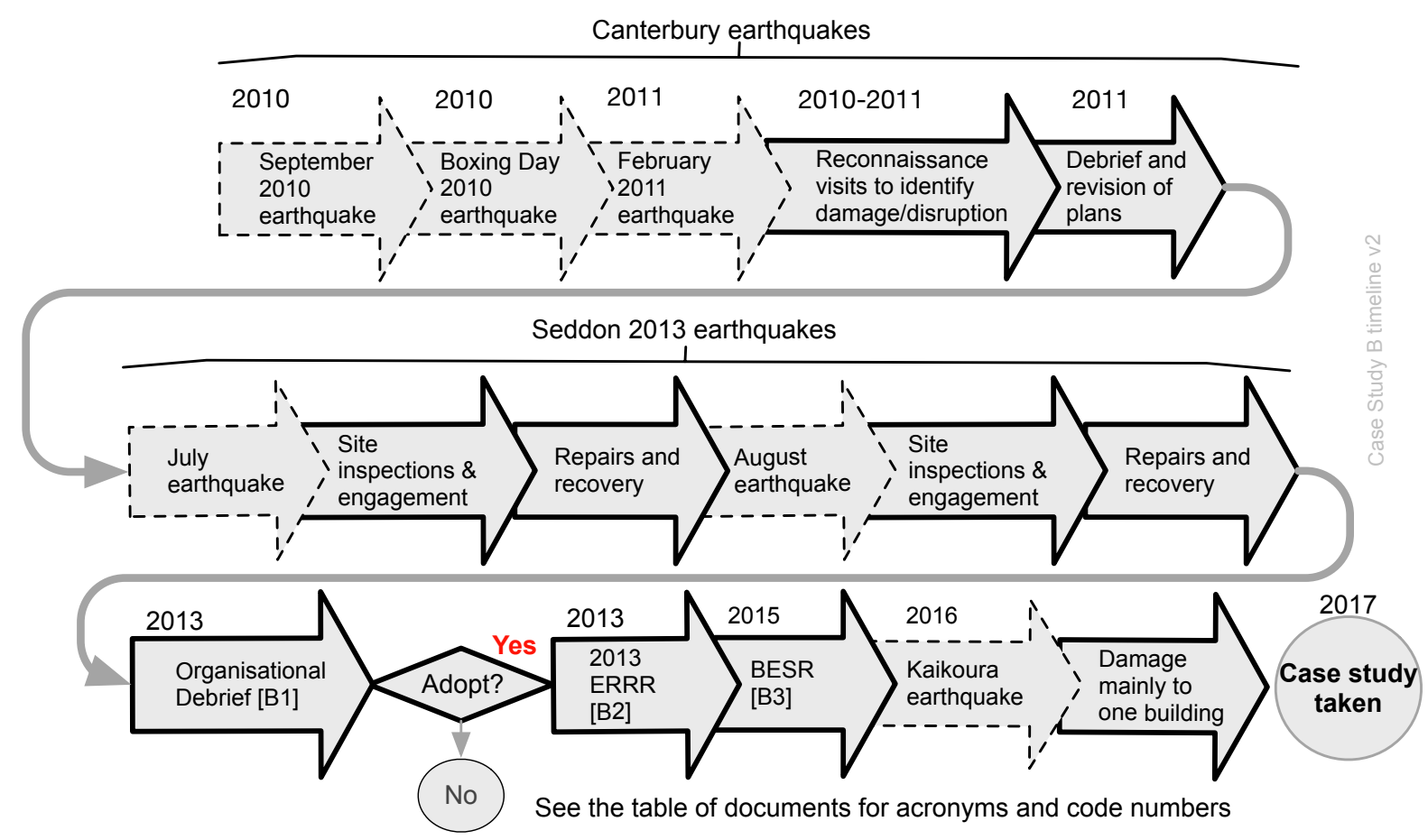


The middle row and left-hand end of the bottom row show the effects of, and response to, the Seddon earthquakes, including the decision to adopt the 2013 Review. Subsequent to that decision, the 2016 Kaikoura earthquake damaged some case study assets, providing the opportunity to assess the effectiveness of 2013 review. The right-hand side of the bottom row of the timeline identifies some effects of the Kaikoura earthquake.

\subsubsection{Decision to be made}

The decision to be made was what actions should be carried out post-2013 earthquakes to minimise damage to assets and disruption of activities as a result of a similar or greater event affecting Wellington.

\subsubsection{Case study documents and interviewees}

The background documents listed in Table 39 formed part of the case study. The Benchmarking and Self-Review report enables judgement of the extent to which the case study had closed gaps found in its 2013 report. the Ministry of Civil Defence and Emergency Management (MCDEM) and New ZealandS4104 documents were available but not used by the case study.

Table 39. Documents reviewed in Case Study B

\begin{tabular}{|l|c|}
\hline \multicolumn{1}{|c|}{ Case study document title } & $\begin{array}{c}\text { Code } \\
\text { number }\end{array}$ \\
\hline $\begin{array}{l}\text { Organisational Debrief: Earthquakes of Sunday 21 July and Friday 16 August } \\
2013\end{array}$ & B1 \\
\hline 2013 Earthquake Response and Recovery Review (2013 Review) (ERRR) & B2 \\
\hline Benchmarking and Self-Review 2015 (BESR) & B3 \\
\hline Risk Management Procedure (2016 edition) & B4 \\
\hline MCDEM 4Rs website & B5 \\
\hline NZS4104:1994 Seismic restraint of building contents & B6 \\
\hline
\end{tabular}


The participants noted in Table 40 were interviewed in their offices or meeting rooms using the previously circulated questions.

Table 40. People interviewed in Case Study B

\begin{tabular}{|c|c|c|c|c|c|c|}
\hline $\begin{array}{l}\text { Person } \\
\text { code (all } \\
\text { managers) }\end{array}$ & De-identified role & $\begin{array}{c}\text { Decision } \\
\text { maker } \\
(\mathrm{Y} / \mathrm{N})\end{array}$ & $\begin{array}{c}\text { Risk } \\
\text { assesso } \\
\text { r (Y/N) }\end{array}$ & $\begin{array}{l}\text { Highest } \\
\text { qualification }\end{array}$ & $\begin{array}{l}\text { Years in current or } \\
\text { similar role }\end{array}$ & $\begin{array}{l}\text { Professional } \\
\text { body } \\
\text { membership }\end{array}$ \\
\hline $\mathrm{BA}$ & Director Site Services & Y & $\mathrm{N}$ & & & \\
\hline $\mathrm{BB}$ & Consultant Planner & $\mathrm{N}$ & Y & BA & 25 & None \\
\hline $\mathrm{BC}$ & Asset Manager & $\mathrm{N}$ & Y & & & \\
\hline $\mathrm{BD}$ & $\begin{array}{l}\text { Manager Customer } \\
\text { Services }\end{array}$ & $\mathrm{N}$ & Y & $\begin{array}{l}\text { PG Cert [sector] } \\
\text { Administration }\end{array}$ & 8 & $\begin{array}{l}\text { Association of } \\
\text { [sector] } \\
\text { Managers }\end{array}$ \\
\hline $\mathrm{BE}$ & $\begin{array}{l}\text { Senior Advisor: Safety, } \\
\text { Risk Assurance }\end{array}$ & $\mathrm{N}$ & Y & $\begin{array}{c}\text { Level } 2 \text { Dip. } \\
\text { Safety, Risk \& } \\
\text { Environment }\end{array}$ & 3 & None \\
\hline
\end{tabular}

\section{Background to seismic risk in Wellington}

The coincidence of the Wellington CBD and urban area with the highly active, surface rupturing Wellington earthquake fault creates the worst-case seismic risk in New Zealand with the potential for tens or hundreds of fatalities, thousands of injuries and billions of dollars of damage (Ansell \& Taber, 1996; Clarke, 1998; Cousins, Spence, \& So, 2006). This has been evidenced by, for example, the 1855 earthquake that severely damaged the newly founded city (Grapes, 2000) and the 1942 earthquake that damaged more than 20,000 houses in Wellington (Downes, 1995).

This level of threat led to the 1991 Wellington Earthquake Lifelines project that examined the threat to lifeline utilities (water, gas, electricity, transport, etc). It included a methodology and damage assessment chart to aid estimation of damage to building services or "equipment not fixed or fittings not designed for seismic codes" (Hopkins, 1991, pp. 21-26). The report provided a further analysis for building services, including water supplies, and crosstabulated 14 lifeline utilities to suggest interdependencies that could render an otherwise undamaged or lightly damaged building unusable because of denial of access or failure of key utilities (Ho \& Hastak, 2010).

\section{6 event}

The 2016 Kaikoura earthquake occurred at 00:02 on 14 November 2016 and behaved in ways not previously identified (Hamling et al, 2017), resulting in damage to infrastructure (Market Economics Ltd, 2017), and with several buildings in Wellington central business district (CBD) being demolished or requiring extensive repairs. One of the Case Study 
Buildings in the CBD suffered no structural damage but extensive disruption due to damage to the fittings and contents. Some furniture, storage shelves, equipment, etc were thrown about violently. Some plumbed-in water coolers were torn from their fittings, resulting in water running across floors, damaging records and resources that had to be disposed of. This damage resulted in complete closure of the building for several weeks followed by progressive reopening as clean-up and repairs progressed. Essential business activities were conducted in alternative locations but were severely disrupted.

\subsubsection{Case Study B data}

The tentative GT for an effective risk assessment (section 3.2) provided a framework for analysis of data from the interviews, reports and interviews. The GT, CSF and 13 NC are reported on, as before, in a "bottom up" (ie, reverse) order.

\section{Literature or document review fairly sets out data (NC 01)}

Within this case study, three types of document were used: comparison documents drawn from the experiences of comparable organisations in the Canterbury earthquakes, existing internal documents, and external sources.

Two University of Canterbury reports (Seville, Hawker, \& Lyttle, 2011, 2012) were used for comparison by the organisation. These described the impacts of a series of earthquakes on an organisation having several sites, many buildings, and diverse activities, some of which were similar to the case study, including access by members of the public.

The 2015 BESR report [B3] used the Seville et al reports to help identify any "lessons and provide a report for the senior leadership team and the Board about the status of the [organisation] compared with all of those" and "gaps they had identified" [BB]. It summarised "the findings from a review of the organisation's emergency management, recovery, and business continuity planning processes, particularly with regard to the University of Canterbury's experiences and learnings ..." (see below) and recommended that the information in the report be noted. This report provided a measure of the success of the 2013 reports in identifying actions considered necessary.

As part of this review a short literature review of earthquake-related risk is summarised in Box 2. Some of the documents are academic references and are not readily accessible to lay people; several are from the Bulletin of the New Zealand Society of Earthquake Engineers, a journal that is itself not widely accessible in academic libraries. Thus, all might have been helpful as background but might not be accessible by non-academics. 


\section{Box 2. Literature relevant for Case Study B: Earthquake-related risk}

The 1997 Edgecumbe and 2007 Gisborne earthquakes caused damage to infrastructure, buildings and building contents (Butcher, Andrews, \& Cleland, 1998; Powell, 2010), with the Gisborne event providing an opportunity to review for the first time in many years the effects of a major earthquake on a New Zealand city.

Damage to lifeline utilities in the 2010 and 2011 Canterbury earthquakes has been summarised (Billings \& Charman, 2011; Davey, 2010; Giovinazzi et al, 2011; Massie \& Watson, 2011) showing that buildings may be structurally undamaged but unusable due to the lack of water, wastewater, electricity, transport and other services. This supported earlier work on Engineering Lifelines in Wellington (Hopkins, 1991) and Christchurch (Christchurch Engineering Lifelines Group, 1997).

Dhakal (2010) reported that overturning of display racks/shelves in the 2010 Christchurch earthquake caused impact damage to contents while contents stored on floors often suffered water damage. Dhakal (p. 411) also identified good practice in the use of filing cabinets and non-industrial storage shelves to help avoid such damage. One of the Seville et al reports cited this article noted:

... many organisations throughout Canterbury suffered business disruption because of nonstructural damage; fallen equipment, broken glass, tipped shelving/storage units, etc (Seville et al, 2011, p. 40)

Dowrick (2003) identified risks associated with shops' stock stored at a high level that was not seismically restrained and the Canterbury Earthquakes Royal Commission: Low-damage building technologies (2012, p. 35) report provided evidence that:

"fix, fasten and forget" is a simple but effective way to lessen the non-structural and contents damage to a building (evidence from Dr. Richard Sharpe)

More widely, the effects of the Canterbury earthquakes were summarised as including voluntary and compulsory evacuation of the central business district with, for some organisations, an inability to continue operating, while others were compelled to change from "bricks and mortar" operation to online trading (Stevenson et al, 2011).

The University of Canterbury teaches civil engineering with a special interest in earthquake engineering. It therefore took an active and early interest in reporting on the effects of the 2010 and 2011 earthquakes on its own buildings and activities (as reported by Seville et al (2011)) but Deam, Comerio, \& Clendon (2010, p. 368) showed that "three quarters [of the university's buildings] had contents damaged; filing cabinets overturned, books off shelves, shelves overturned ...".

Noting the damage to many shelves and racking systems in the Canterbury earthquakes, the BESR reported "There is no current Standard for seismic design of shelving and racking systems". However, New Zealand standard, NZS4104:(1994) Seismic Restraint of Building Contents was available and would have given good guidance. 
This literature review suggested that larger organisations carrying out a major risk assessment need to look beyond "what you see is all there is" - (Kahneman, 2011, pp. 8588 ) - if the risk assessment is carried out in-house.

The people interviewed did report that they routinely identify reports on major events of interest in similar organisations and engage in continuing professional development.

Yes, so in our team, they are constantly attending seminars, searching literature and bringing to light any that are particularly worth reading [BA]

The consequences of Hurricane Katrina were mentioned $[\mathrm{BA}]$ as showing how a major event could affect a large city, and not just individual organisations (Corey \& Deitch, 2011). This included issues such as disruption of public and private transport infrastructure; previously this had been identified by the organisation as critical, leading to a detailed response plan developed that was based on:

the data and the transport surveys done by the [organisation] because, obviously, getting here is a key part in ... how our business works. [BB]

The organisation also used "a suite of planning tools" [B2] including the Risk Management Procedure [B4]. However, only the 2016 edition of this was available when the case study was taken.

\section{Terms of reference for risk assessment are clear (NC 02)}

Within this case study, no formal terms of reference were set for the 2013 gap analysis but it was routine to review any significant events that directly affected the organisation or that were relevant to its business activities ("we ... automatically do a debrief report for an event like that" $[\mathrm{BA}]$ ) and so this "was automatically triggered" $[\mathrm{BB}]$. Similar reviews had taken place in the 12 months to October 2013 for a severe weather event (which disrupted regional transport and infrastructure) and a fire (which had closed two contiguous Case Study Buildings [B1]).

The organisational debrief held on September 52013 enabled 16 senior managers (including most of the senior leadership team but not the CEO) to:

- learn from summaries of the localised debriefings that had already occurred

- communicate their own experiences of the 2013 earthquake events

- share other key organisational learnings.

The report on this meeting included a high-level summary of proposed actions to be taken and enabled senior managers to confirm them [B1]. 
The 2013 Review [B2] outlined for the two 2013 Seddon earthquakes:

... the response and recovery stages ... summarises post-earthquake stakeholder engagement activities and highlights key themes and business improvements that have been, and continue to be, undertaken to strengthen our crisis management capabilities.

The 2013 Review "was essentially identifying what happened in the 2013 earthquakes and how the organisation could do better next time" $[\mathrm{BA}]$ and captured a body of knowledge used in the organisational debrief report [B1] to senior managers.

\section{Relevant qualifications and experience stated or available (NC 03)}

NC 08 was derived from the credibility of risk assessment framework (Wiedemann et al, 2013) which advocates "the report discloses the names and affiliations of the experts who conducted the assessment". The qualifications of the interviewees or other staff were not stated in any of the reports but were shown in seismic risk assessments provided by professional engineers. This resulted in an apparently contradictory situation: internal staff were presumed to be qualified and have relevant experience but consultants had to state their credentials if they were to be regarded as credible.

The staff want to know who has made an assessment of a building, what's their experience and qualifications, can we trust them, do we need a second opinion. ... And that's something I don't think the [organisation] had appreciated until now. [BD] This apparent contradiction could be explained by the assumption that staff are employed because of their qualifications and expertise. Thus, NC 08 may only be relevant to publicly available or consultancy reports. However, some case study staff may have been operating outside their normal roles in areas not covered by their qualifications or experience. On balance, reports about major risks should carry evidence of the competence of their authors, regardless of their status.

In this case, one of the interviewees had resigned from a UK professional body because there seemed little relevance to maintaining membership when resident in New Zealand. Credibility of professional advisors in a large organisation such as Case Study B might require that such evidence of competence be maintained.

\section{Impartiality in funding and mandate (NC 04)}

The funding and mandate for the risk assessment was evidently from the management team and Board but was not cited in any of the reports. 
Stakeholders and risk assessors have a shared understanding of risk (NC 05)

When the 2013 organisational debrief [B1] was completed it was presented to the Board and the Audit and Risk Committee, providing necessary information about seismic risk:

... the senior leadership team had quite a comprehensive debrief and it included some really good discussion about how to respond [BB]

This interviewee responding to the question "what do decision makers want to know about risk" said emphatically:

The stakeholders - they want to know the stakeholders. If a risk is only going to impact on a small number of people versus it's going to impact on quite a substantial number of stakeholders [BB]

In this case, seismic risk impacted on all stakeholders, internal and external, and the level of engagement drove a shared understanding of seismic risk for buildings ("we certainly never had any lack of engagement" [BB]). However, as the 2016 earthquake showed, this understanding was not complete in relation to the contents of one building, an issue that might have been overcome by better risk identification and analysis. Nonetheless, the report contributed to a shared understanding of seismic risk in relation to the activities of the organisation because:

It was distributed to everyone who contributed to it, so anyone who had given feedback got the response and it went to the highest level of the organisation. [BB]

NC 05 hypothesised that feedback would help create a shared understanding of risk between risk assessors and decision makers. Interviewees were asked if they received any feedback on the 2013 Review [B2]; they responded:

Yes, we got [verbal] feedback through senior managers but there were also a couple of emails that were sent around thanking people for the work they did. [BE] Yes, there was from the [CEO]. We had an email saying "thank you" and it [B2] was very well received by the [Board]. [BB]

From the 2013 earthquake? No. From the 2016 earthquake? Definitely yes. I think over that period of time they'd realised the need to consider the impact of disasters on the staff. [BD]

Interviewees were encouraged by this feedback as it showed their senior managers had understood the importance of their work - an area that may rarely be demonstrated as key to organisational survival. That feedback may have praised the work done but the technical content of the work was found to have been partly lacking when the 2016 earthquake damaged the contents of one building. 


\section{Appropriate engagement with stakeholders (NC 06)}

Following the 2013 Seddon earthquakes there were a "number of immediate debriefings ... conducted on all sites primarily focused on building safety and evacuation procedures" [B2]. These used the Ministry of Civil Defence and Emergency Management guidance on debriefing after major events (MCDEM, 2006). Subsequent engagement used consensus findings in the form of "localised de-briefs" to aid development of a number of business improvement plans. Many action points were "captured through the debriefing process [and] integrated into existing improvement plans and specific projects" [B1].

The engagement process did not just rely on face-to-face meetings: "a process was put in place for stakeholders to report concerns about buildings by emailing photographs of damage with locations and notes to a dedicated earthquake email address" [B2]. This acted as a means for damage to be identified that might otherwise have been missed by building inspectors (although it did not directly aid forecasting what might happen in any future earthquake). Many such emails were received from across the organisation [BB], providing a low-cost form of engagement.

The Seville et al $(2011,2012)$ reports had shown the need for executive management to be well-informed, an issue confirmed by the ERRR [B2] as a key learning:

Share as much information as possible with senior staff immediately after an event The interviewees were asked about engagement with a diverse range of people outside their own unit and considered this to be very important. For example, "sometimes fresh eyes" $[B D]$ help identify issues that had been overlooked.

The organisational debrief summarised these and other findings and presented the "broader issues and themes that arose from both earthquakes" [B1].

When we did our debrief we went to all of the responder groups, a senior leadership team debrief meeting, and we asked staff for feedback as well. [BB]

The engagement and feedback flows are summarised in Figure 29. There appeared to be no strong influences beyond the professionalism of the facilities and risk management staff and the diffuse concerns of staff and customers. 
Figure 29. Feedback and engagement in the risk assessment

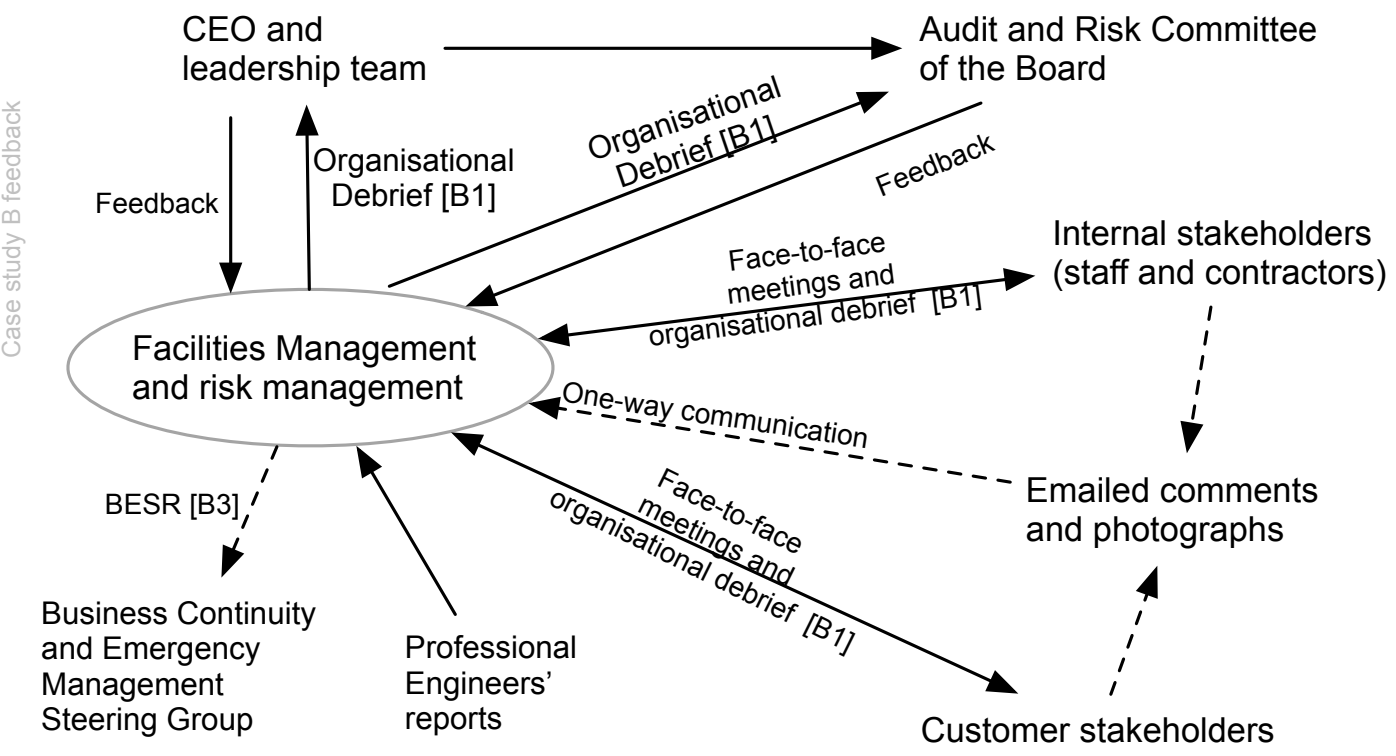

The success of engagement was at least in part due to "the director [who] owns and drives that particular piece of work and would be seen as the champion in that area of work" [BC], suggesting that for a risk assessment for major risks to be effective it needs to be championed by a senior manager or member of the leadership team. Personal experience suggests this high level of consultation was unusual and contributed to the successful outcomes discussed later.

\section{Competent and impartial risk assessor or team leader (NC 07)}

The Facilities Management and Risk Management teams held some risk-related qualifications and had diverse experience. Professional engineers were engaged for their special skills and would have complied with the then-current IPENZ Code of Ethics (2005).

\section{Risk is correctly framed (NC 08)}

One interviewee stated emphatically that, for the Board and executive management team, "... first and foremost, it's about safety" [BA] of staff, customers and contractors. However, the reports and other interviewees described a wide range of objectives of the decision and risk assessment. Table 41 summarises how the interviewees characterised the objective and risk assessment, showing the decision and risk assessment had wide-ranging characteristics (Baker, 2002; Nielsen \& Parker, 2012). 
Table 41. Character of the decision

\begin{tabular}{|l|c|}
\hline $\begin{array}{c}\text { Possible objectives of the decision or } \\
\text { risk assessment }\end{array}$ & $\begin{array}{c}\text { Whether this objective was mentioned } \\
\text { in Case Study B }\end{array}$ \\
\hline Business as usual & $\checkmark$ \\
\hline Compliance & X \\
\hline Decision making & $\checkmark$ \\
\hline Delivery of goods or services & $\checkmark$ \\
\hline Environmental & X \\
\hline Equipment fit for purpose & X \\
\hline Financial & $\checkmark$ \\
\hline Good practice & $\checkmark$ \\
\hline $\begin{array}{l}\text { Occupational health and } \\
\text { safety (including welfare) }\end{array}$ & $\checkmark$ \\
\hline Project management & $\checkmark$ \\
\hline Reputation & $\checkmark$ \\
\hline Strategic & $\checkmark$ \\
\hline Sustainability & $X$ \\
\hline
\end{tabular}

\section{Criteria for risk evaluation set (NC 09)}

The organisation has a large portfolio of buildings and has invested in "a medium term structural improvement plan to bring all buildings above $67 \%$ of New Building Standard (NBS)". [B2] ${ }^{10}$ This was taken to be the structural risk criterion but no criteria had been set for stability of building contents.

Comerio (2005) researched potential disruption of a multi-building, multi-site organisation straddling the San Andreas fault in California and suggested that a criterion of not more than 30 days disruption following a major earthquake might be relevant. Such a criterion might have complemented the Seville et al $(2011,2012)$ reports and the plan to exceed $67 \%$ NBS. Legal requirements can also form risk criteria. Given the numbers of staff, customers and contractors working in or visiting the sites, the requirement of the Health and Safety in Employment Act 1992 to "take all practicable steps" to avoid harm might have been used as a criterion in reports [B1] and [B2]. In January 2015 (when the BESR [B3] was completed) the Health and Safety at Work Act 2015 requirement to avoid harm "so far as is reasonably practicable" had come into force and replaced the earlier requirement and should have been reported as a relevant risk criterion for safety.

\footnotetext{
${ }^{10}$ The "New Building Standard" is set under the New Zealand Building Act 2004 and Building (Specified Systems, Change the Use, and Earthquake-prone Buildings) Regulations and prescribes the earthquake resistance of new buildings (https://www.building.govt.nz/). Existing buildings must be at or brought up to an approved standard within specified timeframes.
} 


\section{Appropriate language, graphics and layout (NC 10)}

\section{Organisational debrief [B1]}

The Organisational Debrief [B1] contained two graphics showing how the crisis management team operated relative to organisation management. It was written in what was initially assessed to be non-technical language but when two samples of the text were run through an online readability tool http://www.readabilityformulas.com/ that used the SMOG readability algorithm (Arkin et al, 2004) it was assessed as "college graduate" level. As the management team held tertiary or professional qualifications this was probably not an issue.

\section{Review [B2]}

The 2013 Review report [B2] was 41 pages long and used only a few graphics and these were illustrations of equipment rather than processes. The introduction stated it:

- outlines the [organisation]'s actions in the response and recovery stages for each earthquake event,

- summarises post-earthquake stakeholder engagement activities, and

- highlights key themes and business improvements that have been, and continue to be, undertaken to strengthen our crisis management capabilities.

The complexities of the events led to the report being somewhat complex in layout. It too was written in what was initially assessed to be non-technical language but was assessed by the online tool (http://www.readabilityformulas.com/) as "college graduate" level.

\section{Benchmarking and Self Review [B3]}

The Benchmarking and Self Review report [B3] was structured around the Seville et al $(2011,2012)$ reports and considerable thought had been put into how information would be presented $[\mathrm{BB}]$. Each Canterbury learning was reported against, and the status of the case organisation in relation each learning was colour coded (as shown in Table 44). This seemed to be helpful to readers ("they liked the traffic light presentation") but readers were also provided with succinct summaries of urgent work ("these are the three things we need to take action on now").

So, it was a one pager with all the key bits so you could cut to the chase really quickly with everything else they wanted attached.

This comment was reminiscent of reference to "the one-page memo" (Peters \& Waterman, 1982, p. 150) and the ability to "handle a little bit of information at one time", perhaps derived from the "Magical Number Seven, Plus or Minus Two" 
(Miller, 1994) describing how much information a person can handle.

This report was also assessed as "college graduate" level language.

\section{Systematic hazard or risk identification (NC 11)}

Analysis of the consequences and their likelihood must be explained so they "stack up" and "'fit together"'; there should be "a broad range of controls, and also assurance - do we have assurance that the controls work?" [BE].

\section{Risk techniques used in 2013}

The following risk identification techniques were used in 2013.

\section{Document review}

The principal risk identification methodology for the 2013 BESR [B3] was a document review of Seville et al $(2011,2012)$.

Inspections and walk-through surveys

After the July and August 2013 earthquakes, case study facilities management staff walked through the buildings making observations and recording damage to gain "an understanding of the situation" [BD] and enabling access by the structural engineers $[B C]$. The need to see the nature and level of damage personally was important [BC].

Inspections are a well-established approach or response to a possible or actual event and may be carried out before or after an event to identify high-risk conditions (eg, the Federal Emergency Management Administration guidance on Rapid Visual Screening (Rojahn \& Scawthorn, 2002)) or in more detail (eg, as part of hazard inspecting, surveying and mapping (Wood, 2003)).

The extent to which the inspections conformed with such protocols was not ascertained. No research has been found that investigates the effectiveness of such inspections or any information-gathering procedures forming part of an inspection, but observations have been shown to aid injury prevention (Mikkelsen et al, 2010).

\section{Self-reporting}

Engagement in the 2013 gap analysis was successful because self-reporting included so many people in:

... a process [that] was put in place for stakeholders to report concerns about buildings by emailing photographs of damage with locations and notes to a dedicated earthquake email address. This also enabled requests for seismic securing of furniture to be processed. [B2]

The scale of damage and disruption was such that this system was needed to 
enable facilities management staff to log requests, deal with other post-earthquake issues and try to deal with business-as-usual issues.

\section{What If analysis}

"What if" analysis was used by some people [BD], although the process was not structured and the results were not always challenged critically.

\section{What could have been used}

\section{Related hazards}

The 2013 review [B2] briefly mentioned evacuation from a possible tsunami but did not elaborate. Work by Geological and Nuclear Sciences has identified areas in Wellington that are prone to tsunami (Berryman, 2005; Power, 2013) and included at least four of the organisation's buildings.

Liquefaction following the 2013 earthquake was the most extensive to affect Wellington CBD generally since the 1855 and 1942 earthquakes (Hancox et al, 2013) and some was close to three buildings occupied by the organisation.

Table 42 is adapted from Dowrick \& Rhoades (2005) and shows an estimate for casualties due to overturning of building contents in a major earthquake affecting the Wellington central business district at different times.

Table 42. Casualties due to building contents in a Wellington earthquake

\begin{tabular}{|c|c|c|c|c|c|c|}
\hline \multicolumn{2}{|c|}{} & \multicolumn{3}{c|}{ Earthquake occurs at 1100 on a weekday } & \multicolumn{3}{c|}{ Earthquake occurs at 0200} \\
\cline { 2 - 7 } & Deaths & Severe injuries & $\begin{array}{c}\text { Moderate } \\
\text { injuries }\end{array}$ & Deaths & Severe injuries & $\begin{array}{c}\text { Moderate } \\
\text { injuries }\end{array}$ \\
\hline $\begin{array}{c}\text { Contents, etc } \\
\text { overturning }\end{array}$ & $\approx 100$ & $\approx 100$ & $\approx 150$ & Few $\approx 3$ & $\approx 7$ & $\approx 18$ \\
\hline
\end{tabular}

Source: adapted from Dowrick \& Rhoades (2005)

Such data had been reported in the media and could have been linked with the legal requirements noted earlier for the safety of staff, contractors and customers visiting the sites.

\section{Available guidance documents}

The Lifelines in Wellington report (Hopkins, 1991, pp. 21-26) mentioned the:

Seismic restraint of plant and equipment including housekeeping items, storage shelves and appliances in accordance with New ZealandS4219 [1983, Specification for seismic resistance of engineering systems in buildings].

New ZealandS4219 did not specifically apply to building contents weighing less than $300 \mathrm{~kg}$ but was complemented in 1994 by NZS4104 Seismic restraint of building contents which had been withdrawn. NZS4104 "specifie[d] requirements to reduce risk of injury to people and damage to the contents of buildings during 
earthquake shaking, and to ensure maintenance of the means of access into and from a building after earthquake". Availability of and following the guidance in NZS4104 in 2013 might therefore have prevented some damage reported in the 2016 earthquake.

\section{Bowtie analysis as a risk identification and analysis technique}

Bowtie analysis could have been used in 2013 to produce a simplified analysis for loss of use of a building following an earthquake such as that shown in Figure 30.

Figure 30. Simple bowtie analysis for loss of use of a building due to an earthquake

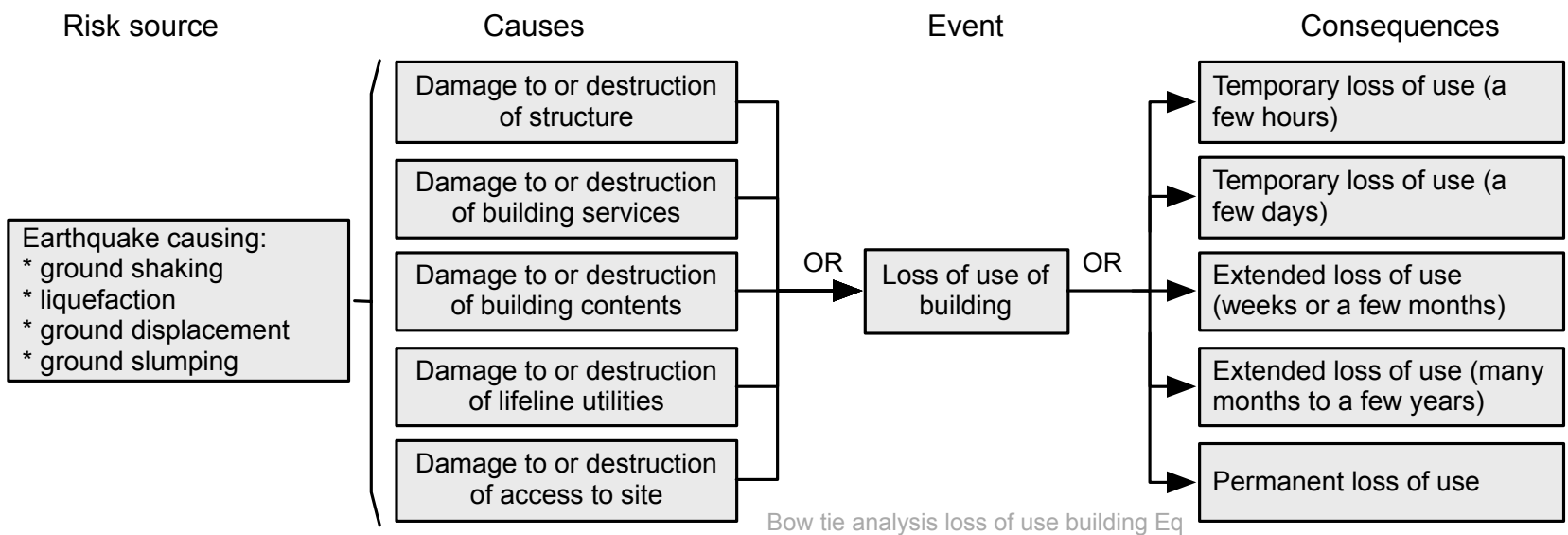

As described in section 2.4.1, this bowtie could have been expanded to include further information about sources of risk, causes, knock-on consequences, the probability of such consequences, controls and their effectiveness, and possible actions to change the risk if not already acceptable.

Had the risk assessment included this technique as part of engagement with stakeholders it might have identified causes of loss of use arising from an earthquake, including overturning furniture and water coolers (a significant source of loss in 2016).

\section{Appropriate risk analysis techniques were used (NC 12)}

\section{General}

As noted, historical data from reports about the experiences of the University of Canterbury was used (Seville et al, 2011, 2012). The data was analysed as a gap analysis between the Canterbury learning and the status of the case study organisation in 2013.

The "traffic lights" colour coding scheme with descriptive text in Table 43 was developed by case study staff to enable greater consistency in professional judgement when rating the extent to which the organisation conformed with Seville et al learnings. 
Table 43. "Traffic lights" coding scheme

\begin{tabular}{|c|l|}
\hline Green & $\begin{array}{l}\text { Point noted and any risk mitigated to the extent that it can be at this stage, but ongoing } \\
\text { refresh and enhancement is needed }\end{array}$ \\
\hline Amber & $\begin{array}{l}\text { Plans under way but not fully implemented, reasonable level of preparedness, risk } \\
\text { mitigated to large extent, prioritised for enhancement }\end{array}$ \\
\hline Red & Low preparedness, risk still of concern, included in 2015 planning \\
\hline
\end{tabular}

Source: BESR [B3]

\section{Buildings}

Risk associated with the building structures was assessed by consulting engineers. Their reports were written in technical terms and described any damage or vulnerabilities they had discovered and the likelihood of the buildings withstanding another earthquake, including "the performance capacity of the buildings, and any need to do some further investigation" $[\mathrm{BC}]$. These reports were regarded as a critical success factor in the response phase [B2].

Although there was some damage to the buildings in the 2013 earthquakes the main issue for most staff and customers was damage to lifts in buildings on the main site (some needing repair). However, the upper levels of one CBD high-rise building occupied by the case study:

... experienced greater accelerations due to the earthquakes. Flooding occurred to upper levels from a roof top water tank, and unsecured bookshelves, filing cabinets and furnishings had been displaced [B2]

This building suffered further damage to contents in the 2016 earthquake as some contents were not secured for a range of reasons explored later.

\section{Financial services}

The BESR [B3] also set out a more detailed analysis of the effects of a major event on the financial services business unit of the organisation. This hypothesised three major event scenarios (summarised in Table 44 below). The lower third of the table provides supporting evidence for restoration times in the case study. 
Table 44. Case Study B scaled major events

\begin{tabular}{|c|c|c|}
\hline Localised event & Major event in Wellington region & Catastrophic event - Wellington region \\
\hline $\begin{array}{l}\text { Severe damage to a } \\
\text { localised area of the } \\
\text { [organisation] eg, fire, flood, } \\
\text { explosion }\end{array}$ & $\begin{array}{l}\text { Significant property damage and casualties but } \\
\text { relatively quick recovery of systems, } \\
\text { telecommunications and power. This scenario } \\
\text { would describe the [effects on Wellington } \\
\text { buildings of the] Christchurch earthquakes. These } \\
\text { were very damaging and very costly but essential } \\
\text { services and IT infrastructure were re-established } \\
\text { within several days }\end{array}$ & $\begin{array}{l}\text { Widespread property damage across } \\
\text { Wellington, significant loss of life, } \\
\text { major damage to roading, rail and } \\
\text { port infrastructure, loss of power and } \\
\text { essential services for at least two } \\
\text { weeks }\end{array}$ \\
\hline \multicolumn{3}{|l|}{ Resilience assessment } \\
\hline Green & Amber & Red \\
\hline $\begin{array}{l}\text { Recovery, operating within } \\
1-3 \text { days }\end{array}$ & $\begin{array}{l}\text { IT systems up within } 1-5 \text { days } \\
\text { Skeleton staff available } 1-3 \text { days }\end{array}$ & $\begin{array}{l}\text { IT systems down until power restored } \\
\text { Long wait to restore facilities } \\
\text { Organisation may be financially } \\
\text { unsustainable for a considerable } \\
\text { period }\end{array}$ \\
\hline \multicolumn{3}{|c|}{ Estimates based on data in Brunsdon \& Mowll (2012) and Mowll et al (2013) } \\
\hline Localised event & Major event in Wellington region & $\begin{array}{c}\text { Catastrophic event - Wellington } \\
\text { region }\end{array}$ \\
\hline \multirow[t]{2}{*}{$\begin{array}{l}\text { Modified Mercalli } 7 \text { event, } \\
\text { 30-year return period }\end{array}$} & Modified Mercalli 8 event, 120-year return period & $\begin{array}{l}\text { Modified Mercalli } 10 \text { event, } 1,500- \\
\text { year return period }\end{array}$ \\
\hline & $\begin{array}{l}\text { Power restoration } \leq 50 \text { days } \\
\text { Water restoration } \leq 40 \text { days }\end{array}$ & $\begin{array}{l}\text { Power restoration } 60-95 \text { days } \\
\text { Water restoration } 55 \text { days }\end{array}$ \\
\hline
\end{tabular}

Sources: upper 2/3 BESR [B3], estimates in lower 1/3 from Brunsdon \& Mowll (2012) and Mowll et al (2013)

The nature of the consequences for each level of severity was then estimated by the case study against the following [B3].

People

Availability of knowledgeable staff to operate financial processes post event.

\section{Systems}

There is almost a complete reliance on e-systems and IT infrastructure to undertake virtually all financial tasks. No systems, no recovery.

Office space and equipment

With modern mobile systems and technology businesses can increasingly operate independently of office facilities. However, access to IT equipment (desktop, laptop and notebook PCs) and telecommunications is critical.

\section{Adequate financial resources (cash)}

It is estimated that the organisation will require access to cash or bank reserves of at least $\$ X$ million per week to sustain normal and recovery operations.

This provided a professional judgement of possible consequences for the case 
study with more detail than in the other reports ([B1] and [B2]). This part of the BESR [B3] report seemed to give no direct consideration to customers and the effects that a protracted outage might have on customer retention. No other analyses were reported to senior management in the BESR.

\section{Controls assessment}

The effectiveness of safety-related risk controls was reviewed by [BE] to ascertain if these were standalone or part of a suite of controls.

The gap analysis was not just about the integrity of buildings and their contents but also in terms of building evacuation ("where are the open spaces"?). The 2013 earthquakes revealed two issues not previously identified.

- Whereas the standard earthquake life-safety response was to "drop, cover and hold" this was not possible in some buildings due to the configuration of the furniture $[B A]$.

- In an earthquake it might be safer to stay in "an internal safe space unless you're not sure if it is safe!" [BA]. This was a national issue, not just for the case study, and led to a public information campaign distinguishing between fire evacuation (leave the building) and earthquake evacuation (stay unless it is unsafe).

\section{Business impact analysis}

Earlier work $[B A]$ had analysed the importance of key Case Study Business functions using business impact analysis (IEC/ISO31010, 2009) but was not discussed in any of the reports [B2, B1, B3].

\section{Consequences, likelihood and the risk matrix}

It is well established that people find it hard to judge the scale of the consequences of a future event and their likelihood due to lack of knowledge or experience of comparable risks (Kahneman \& Lovallo, 1993; Slovic et al, 2000). In relation to seismic risk, this may be especially difficult to judge if there has been a long interval since the last damaging earthquake (as was the case in Wellington until 2013), leaving many people with no relevant personal experience (McClure et al, 2016). In the case study this is addressed by annual peer reviews of risk assessments. Sometimes people ... only focus on the consequence not the likelihood. We just check that they've got an appropriate measure of how likely this is to occur. ... people don't know how likely something is to occur. Do they have the proper experience to inform that? We also look at people assessing something similar. Colleagues, or from other institutions. That's really valuable. [BB] 
The organisation has a risk matrix (documented in the risk management procedure [B4]) that was derived from AS/NZS4360 (1999, withdrawn in 2004). This was not cited in the reports or reported by the interviewees as being used although one interviewee mentioned use of the risk matrix to provide "some way of judging how the risk has been assessed".

\section{Case Study B gap analysis}

The risk assessment in this case study was a form of gap analysis, as described in Case Study A. Case Study B interviewees said they used the Ministry of Civil Defence and Emergency Management (MCDEM) Reduction, Readiness, Response and Recovery model (4Rs) as the basis for their risk assessment. The Ministry website (MCDEM, n.d.) describes the 4 Rs thus.

The New Zealand integrated approach to civil defence emergency management can be described by the four areas of activity, known as the '4Rs'.

The $4 R$ s are:

Reduction: Identifying and analysing long-term risks to human life and property from hazards; taking steps to eliminate these risks if practicable, and, if not, reducing the magnitude of their impact and the likelihood of their occurring.

[Emphasis added, and Readiness, Response and Recovery not reported as they were not relevant here]

A further literature review showed the $4 \mathrm{Rs}$ and similar approaches have been described as in need of updating and full documentation (Crondstedt, 2002) and out of date (Rogers, 2011).

When mapped into Figure 31 (based on Figure 13, section 3.4.2, the McKinsey 7-S model) it becomes evident the 4Rs model (the amber-shaded box) only addresses the 7-S Systems factor in a limited way and does not include organisational objectives (Durodié, 2017) which would have shown the high dependence on non-structural assets and occupation of the building.

Had Case Study B also used 7-S, the structure, strategy, skills, staff, style and shared values topics might have shown issues associated with satellite sites and problems associated with distributed management might have emerged more clearly. 


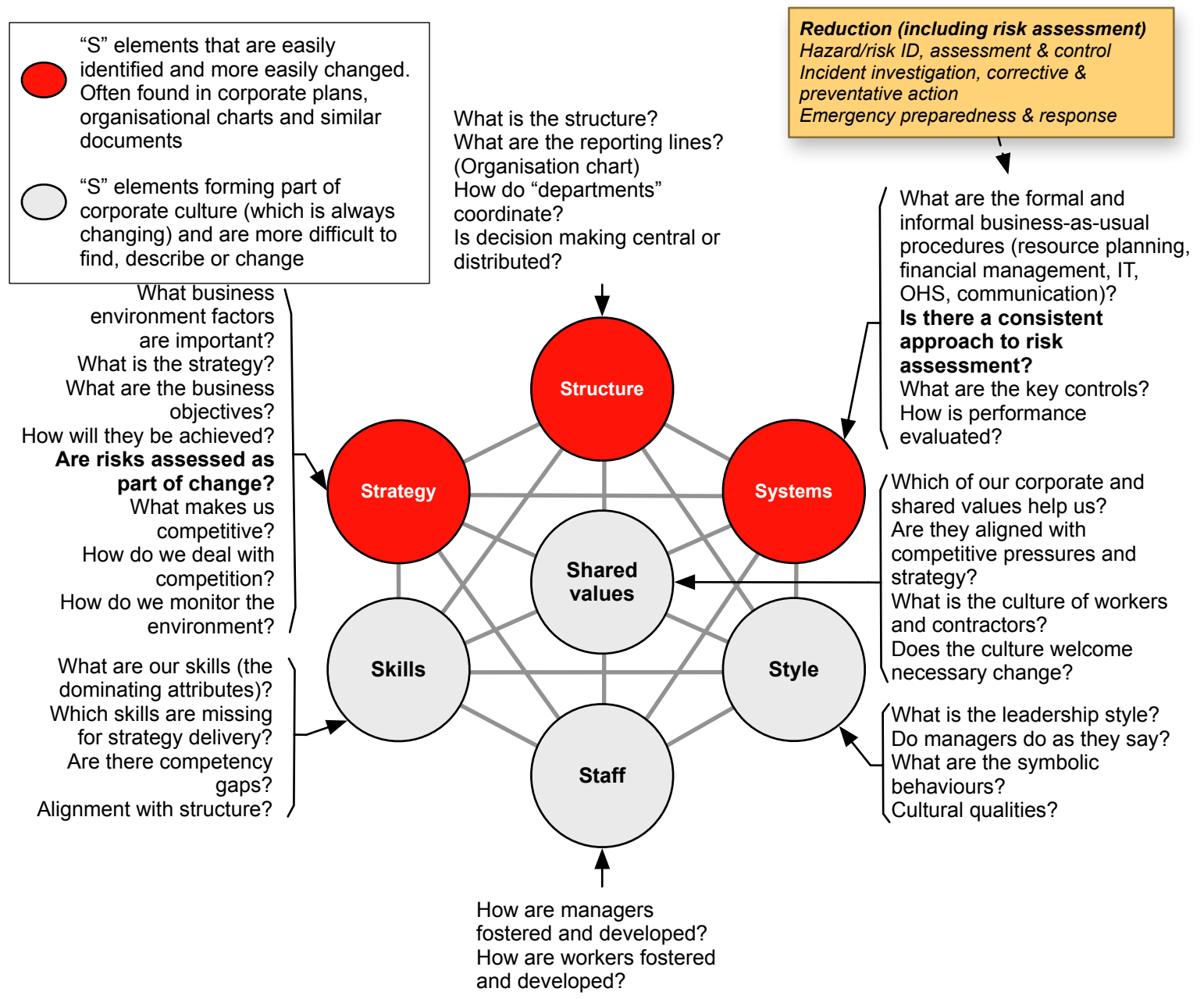

Source: basic diagram adapted from Peters \& Waterman (1982), Waterman et al (1980) with additions from MCDEM (n.d.).

As none of the other 7-S elements are analysed the 4Rs cannot be regarded as a valid gap analysis or risk technique, making likely these key issues might be overlooked.

\section{Appropriate risk evaluation techniques have been used (NC 13)}

The near absence of stated risk criteria made difficult the evaluation of seismic risks across the organisation. Neither of the 2013 reports referred to the requirement of the Health and Safety in Employment Act 1992 to take "all practicable steps" to prevent harm, and nor did the 2015 BESR report refer to the Health and Safety at Work Act (enacted but not due to come into force for 15 months). Discussion of these requirements in the context of a legal criterion might have raised concerns about potential harm due to displaced furniture.

\section{Appropriate communication to decision makers (CSF 01)}

Each situation is unique and so the risk assessment should include "how the factors around the risk were identified and then assessed": a "cut and paste" assessment would not provide the necessary information $[\mathrm{BC}]$. Decision makers should be given a report setting out "the 
showstoppers and what they mean to them" so that they could understand if "the organisation would be able to fulfil its functions".

Many people (including decision makers) may lack experience of the outcomes of an earthquake and so be unable to imagine what it would be like. This can be overcome in an emergency management context:

... where someone has really thought through the scenarios of what could possibly happen and linked ... what are the important things for the services [with] what could go wrong $[B A]$

This could have been done by cross-tabulation of engineering lifeline utilities and case study dependencies (Hopkins, 1991).

The three reports (B1, B2 and B3) did set out a substantial body of information derived from debriefs and the Seville et al $(2011,2012)$ reports but did not describe the differences between Christchurch and Wellington, the age and distribution of buildings, and the proximity of reclaimed land that might be prone to liquefaction.

The reports were presented to the Board, the Audit and Risk Committee and the Business Continuity and Emergency Management Steering Group, prompting further discussion. One interviewee said that at the governance level:

... they were interested in what other people were doing, whether there was a standard around it, whether there were any guidelines. [BB]

\section{All relevant factors including controversies and uncertainty have been fully and} correctly evaluated (CSF 02)

No controversies emerged from the interviews or the three reports.

Uncertainty was only mentioned once in the reports ("there was a level of uncertainty around the safety of buildings" [B2]). This specific uncertainty was managed by engaging consulting engineers to inspect the buildings.

There were and remain considerable uncertainties about the size and timing of major earthquakes and how future earthquakes might damage buildings and their contents. The main 2010 and 2011 Canterbury earthquakes were quite different in characteristics and severity and, while the 2013 report mentioned the "... aftershock sequence of each earthquake differed ..." [B2], this uncertainty could have been emphasised in relation to the business objectives of the case study.

The learnings from the two 2013 Seddon earthquakes and the Canterbury earthquakes were well-described, as were treatment options and plans with "a full action list ... attached as 
Appendix 5" [B2]. This provided "an improvement plan, our position against these risks" [BB]. These were implemented, many by 31 October 2013, when the organisational debrief was issued.

However, Seville et al (2011) reported that the University of Canterbury suffered considerable non-structural damage including:

Substantial damage and disruption from overturned furniture and more than one million books off library shelving

The 2013 Review [B2] and Seville et al (2011) noted that many older style shelves and racking systems collapsed in the Canterbury earthquake, creating significant life-safety hazards, and that "there is no current Standard for seismic design of shelving and racking systems". None of the case study organisation's reports mentioned New ZealandS4104 which was highly relevant to the "need to seismically secure furniture ... as part of Health and Safety strategies" [B2]. This was an omission that may have contributed to adverse consequences following the 2016 Kaikoura earthquake.

The BESR report did state that "seismic securing requirements for new assets are included in Facilities Management tender documents" [B3]. However, there remain significant assets that were not seismically secured; for example, a personal visit to one satellite site in October 2017 found unsecured items stored on shelving systems that could overturn and that did not conform with the guidance in New ZealandS4104.

In some cases such conditions might be "normal violations" of rules because conformance is not possible due to the rigidity of the rules or the local conditions (Reason, 1998), but they might also be evidence of budgetary under-resourcing.

\subsubsection{Summary of Case Study B outcomes and gap analysis}

The BESR report [B3] provided an overview of work carried out up to 20 January 2015 and the data is summarised in Table 45.

Table 45. Summary of actions from lessons learned

\begin{tabular}{|c|c|c|c|}
\cline { 2 - 4 } \multicolumn{1}{c|}{} & \multicolumn{3}{c|}{ Status as at 20 January 2015 } \\
\hline Source & $\begin{array}{c}\text { Risk is largely } \\
\text { mitigated }\end{array}$ & $\begin{array}{c}\text { Plans under way, not } \\
\text { fully implemented }\end{array}$ & $\begin{array}{c}\text { Low preparedness, } \\
\text { still of concern }\end{array}$ \\
\hline Seville et al (2011) & 25 & 6 & 1 \\
\hline Seville et al (2012) & 27 & 12 & 1 \\
\hline 2013 Review & 9 & 8 & 1 \\
\hline Total & 61 & 26 & 3 \\
\hline
\end{tabular}

This data seems to suggest that the response to the 2013 earthquakes was very effective. However, they were "heavily focused on readiness [the second stage of the 4Rs] recognising 
the impact preparation has on the organisation's overall ability to respond" [B2]. Further action was needed to ensure the response stage would be effective, but no mention was made of the reduction stage or any need for building or activity risk assessments.

Risk assessments that follow the guidance in ISO31000 will consider the context or business environment, recognising that this is subject to "normal chaos" (Lauder \& Marynissen, 2018). For example, changes in the physical environment the organisation operates in and the characteristics of staff and customers will change the outcomes of risk assessments generally and seismic risk assessments specifically.

Figure 32 is a qualitative influence diagram showing the estimated strength of relationships between the risk assessment and decision outcomes. It also includes other factors discussed below that may have influenced events, including luck that the 2016 earthquake was at midnight and not during work hours.

The Canterbury earthquakes (cloud symbols 1 and 2 in Figure 32) had some influence on management and the risk assessors because they led to the Seville et al $(2011,2012)$ reports that were subsequently used to structure the BESR [B3] report. Reconnaissance visits to Canterbury were mentioned in interviews but not in the three reports and so are seen as of uncertain influence.

Cloud symbol 3 represents the range of structural damage and damage to building services, racking, silos and storage tanks that followed the 1987 Edgecumbe earthquake (Butcher et al, 1998) and 2007 Gisborne earthquake (Sharpe \& Watt, 2007). In the Gisborne event, nonstructural damage and damage to stock were the most prevalent (Powell \& Harding, 2009) with only $15 \%$ of respondents securing furniture to a wall (Powell, 2010), and almost all of the public library shelves overturning. These events seem not to have informed Case Study $\mathrm{B}$, with some of the data being publicly accessible.

Given the higher level of seismic risk in Wellington it might be thought that such events would enable Wellington people to relate such consequences to the need to act (Wachinger et al, 2013) but there seems to be a need for a large enough reinforcing event for action to be taken (Dillon, Tinsley, \& Burns, 2014). This may have been provided by the 2010-2011 Canterbury earthquakes, followed by the 2013 Seddon earthquakes, leading people in a study (McClure et al, 2016) to perceive seismic risk as "more real, plausible and important after those earthquakes". 
Figure 32. Case Study B qualitative influence diagram

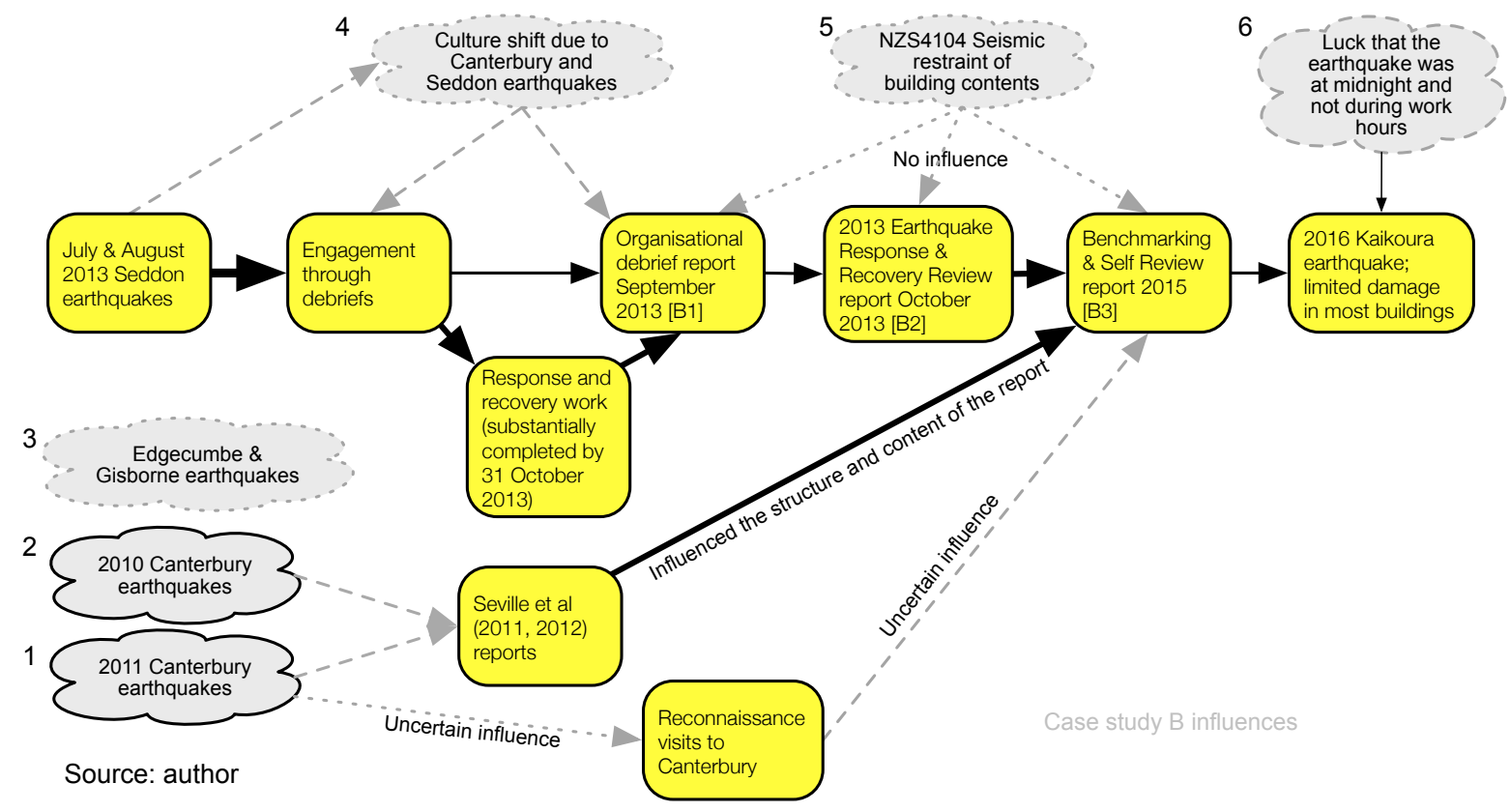

It is therefore conjectured (cloud 4, Figure 32) there may have been some influence on action in the organisation from the Seddon earthquakes but not the earlier Edgecumbe and Gisborne earthquakes (shown as grey dashed lines). This cultural shift seems to have made far easier establishing a business case for reduction and readiness work as part of the 4Rs.

One interviewee said:

Quite often what we don't do is take seriously what we have learned ... We are very good at resolving a thing immediately but we don't think beyond that [BD].

In this case, the imperatives created by the Seddon earthquakes seem to have influenced longer-term thinking and action but only by a gap analysis with earlier earthquakes whose effects might not be repeated in Wellington. Due to deficiencies in the gap analysis, outcomes in the influence diagram were a mixture of positive and negative, and therefore the weight of evidence in this case study suggests the risk assessment/gap analysis:

- was not very effective in informing the CEO and management team about some of the decisions to be made

- enabled sharing of information necessary for some successful outcomes

- failed to correctly identify uncertainties about the then future earthquakes that might result in unusual consequences.

Most of the successful outcomes were achieved because of intense engagement (NC 06) and despite the work lacking full data and an effective risk assessment. There was a strong element of luck that the 2016 earthquake occurred just after midnight when buildings were largely unoccupied other than by cleaners, security staff and some who were working late. 
This element of luck was mentioned in Seville et al (2011) in relation to the 2011 earthquake following the 2010 earthquakes.

At 12.51pm on Tuesday 22 February 2011 luck ran out for the city of Christchurch when an earthquake measuring 6.3 caused significant damage to the Central Business District and Eastern suburbs of Christchurch.

Thus, in Figure 33, the risk assessment has been rated as ineffective in preventing the unsuccessful outcomes.

Figure 33. Effectiveness of a risk assessment compared with outcomes

\section{Decision outcome}

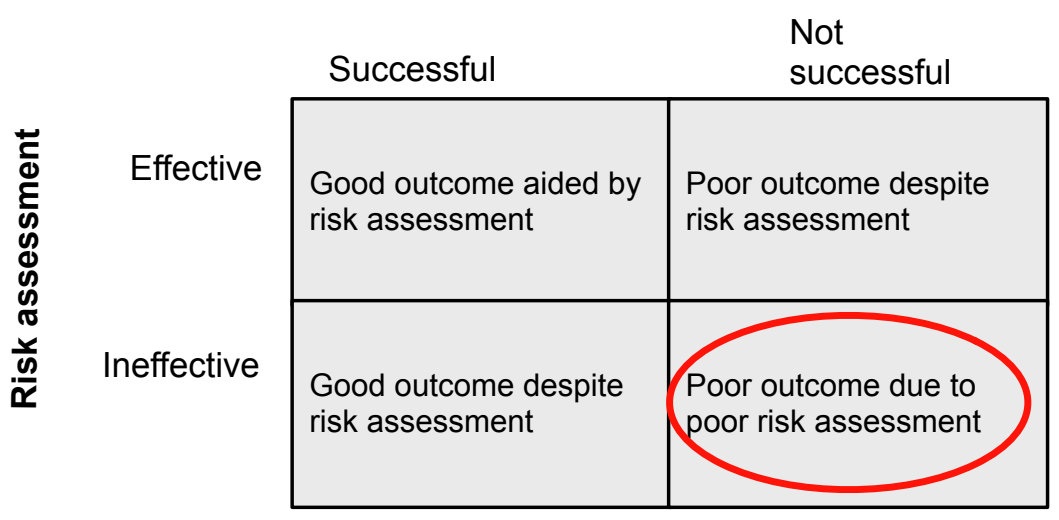

Why damage occurred in 2016

Table 46 summarises information from the three reports and interviews about the level of damage in one high-rise building owned by the case study organisation. The table should be read taking into account the stated need to

... seismically secure furniture [that] needs to be continually refreshed as part of Health and Safety strategies [B2, B3]

and

Promote seismic securing of furniture needs as part of Health and Safety strategies [B2] 
Table 46. Damage in one high-rise building in the 2013 and 2016 earthquakes

\begin{tabular}{|c|c|c|}
\hline 2013 damage & 2016 damage & Comments \\
\hline $\begin{array}{l}\text { Overall, damage was quite minor } \\
\text { despite the upper floors } \\
\text { experiencing greater } \\
\text { accelerations [B2] } \\
\text { Cracking in plaster }\end{array}$ & $\begin{array}{l}\text { Regarded as far more extreme } \\
\text { [BC] }\end{array}$ & $\begin{array}{l}\text { Seismic securing requirements for new assets are } \\
\text { included in Facilities Management tender } \\
\text { documents [B3] }\end{array}$ \\
\hline $\begin{array}{l}\text { Some filing cabinets, bookcases, } \\
\text { etc fell over [B2] }\end{array}$ & $\begin{array}{l}\text { A substantial number of filing } \\
\text { cabinets, bookcases, etc fell over, } \\
\text { especially on upper floors [BD] }\end{array}$ & $\begin{array}{l}\text { When people changed offices their filing cabinets } \\
\text { and bookcases might be changed but these were } \\
\text { not always seismically restrained } \\
\text { Absence of checking on restraints [BD] }\end{array}$ \\
\hline $\begin{array}{l}\text { Water coolers were large bottles } \\
\text { with limited capacity mounted on } \\
\text { a case containing the cooling } \\
\text { system [BD] }\end{array}$ & $\begin{array}{l}\text { Water coolers had been plumbed } \\
\text { in by external contractors without } \\
\text { cut-off valves and without seismic } \\
\text { restraints [BD] }\end{array}$ & $\begin{array}{l}\text { Prior to } 2016 \text {, water damage was limited to a small } \\
\text { area. The } 2016 \text { earthquake caused plumbed-in } \\
\text { water coolers to fall over, breaking pipes and so } \\
\text { allowing water to run for } 5-6 \text { hours from level } 11 \text { to } \\
\text { the ground floor [BD] causing major damage }\end{array}$ \\
\hline $\begin{array}{l}\text { "Sloshing" in a header tank } \\
\text { caused some water damage to } \\
\text { upper floors [B2] }\end{array}$ & $\begin{array}{l}\text { No mention of further water } \\
\text { damage from this tank }\end{array}$ & \\
\hline
\end{tabular}

The gaps noted in the two grey-shaded cells of the table were due to a lack of process, audit and "enforcement" by management, due in part to the organisational culture. However, following the damage in 2016 management said:

... enough is enough, we are mandating this, there isn't a discussion. You'll get bungee cords installed throughout the building and filing cabinets screwed back to the wall. You'll get a chance to decide if you want your office moved around and then it will be fixed [BC]

This would still leave the need to lock closed filing cabinets to prevent their flying open - a risk control that is likely to fail over time as controls come to be seen as interfering with daily work ("necessary violations" (Reason, 1998, p. 304)). In October 2017, during a visit by this researcher to another satellite site, furniture (including shelving systems) was not seismically restrained, suggesting remedial works were incomplete and, in some instances, poorly maintained 11 months after the Kaikoura earthquake and four years after the Seddon earthquakes.

\subsubsection{Evaluation of Case Study B risk assessment using the goal tree}

The tentative GT (section 3.2) postulated 13 NCs and two CSFs for a risk assessment to be considered effective. To summarise the findings and indicate the magnitude of "satisficing" (Dettmer, 2003, p. 66) these have been colour shaded in Figure 34 to show if they were met substantially, partially, or not at all/very little. NC 04 is left clear as it was again judged not relevant in this case. 
The dominant colour is red. There was very little use of open access literature to inform NC 01 and show a "big picture" that might be different from the Canterbury University reports.

Stakeholders and risk assessors had very little shared understanding of risk (NC 05) beyond what happened in Christchurch. Executive management input to the terms of reference (NC 02) was, at best, partial; greater input might have led to a prospective rather than a retrospective risk assessment.

Figure 34. The goal tree and the risk assessment in Case Study B

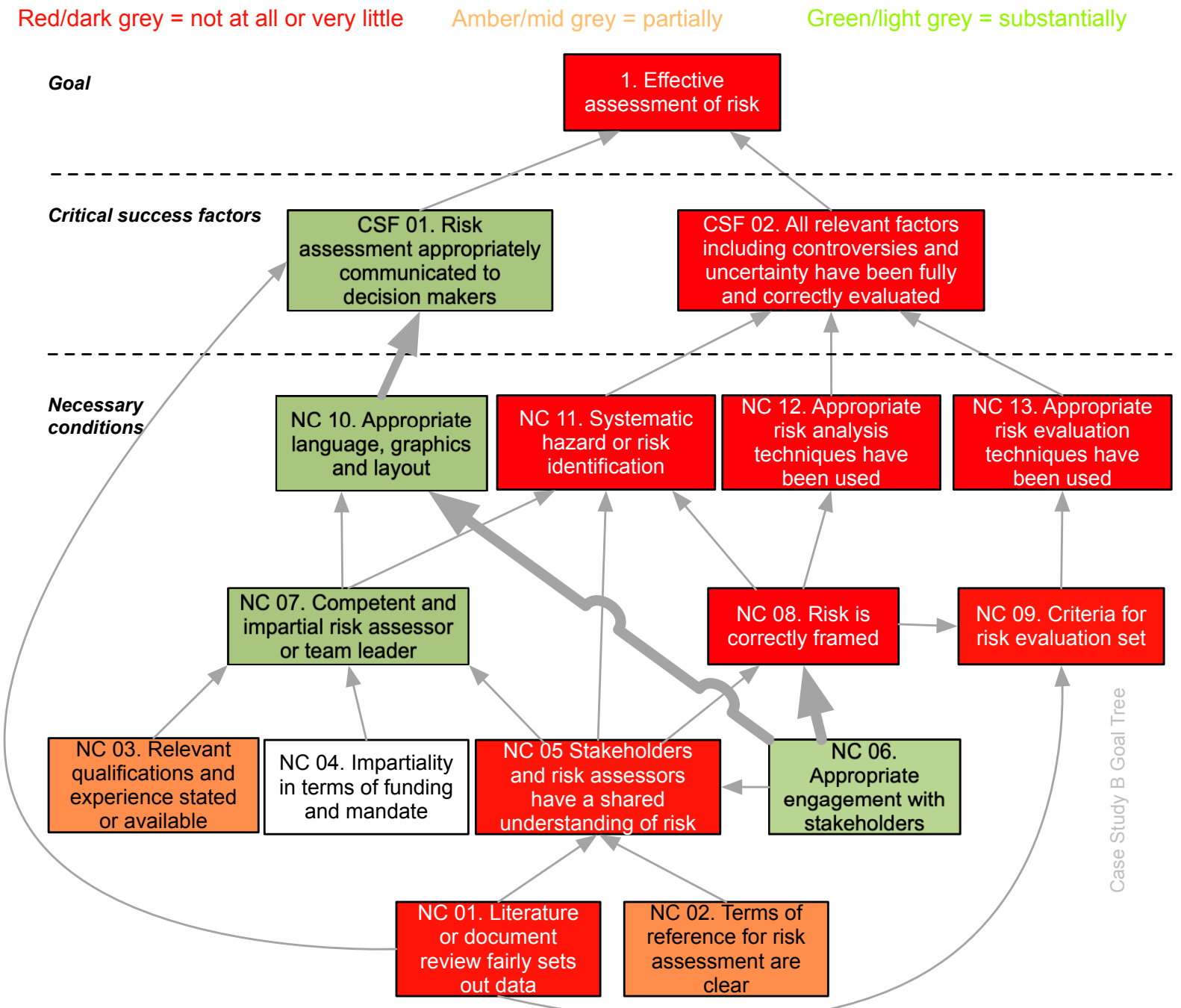

Engagement with all stakeholders (NC 06) was substantial and a key NC, contributing indirectly (thick grey-shaded arrows) to both CSFs. However, the risk was not at all or very little correctly framed (NC 08) and NC 11, NC 12, NC 13 and CSF 02 were also rated as not at all or very little met.

Although, the report was substantially communicated to stakeholders (CSF 01) and used substantially appropriate language (NC 10) it did not include all relevant factors and 
uncertainty (CSF 02). The risk assessors were partially qualified (NC 03) and substantially competent (NC 07)

\section{Interviewee comments}

Interviewees generally approved of the GT (eg, "looks pretty comprehensive to me" and "seems to cover everything for me") but emphasised some necessary conditions ("I think that impartiality is very important" NC 07). The importance of the critical success factors was emphasised as "what the senior leadership team is looking for" [BB]. The need to make the risk assessment real was stressed ("this fits into your NC 02" [BB]). However, it was important to describe "your scenarios in business terms". This might be achieved by: ... getting a visual of the risk, going to the site and seeing the factors, getting an understanding of the situation. Understand the dynamics of what you are working with as well $[B C]$

Another interviewee stressed the need to identify to the decision makers who the stakeholders were, especially where there might be reputational impacts:

... they are very keen on that and that feeds into the financial risk [BD]

Therefore NC 06 should be amended to "Identification of and appropriate engagement with key stakeholders". Interviewees suggested adding to the GT the risk owner ("the budget holder"), or a mechanism for identifying that person [BE]. As discussed in Case Study $A$, this might form part of a third critical success factor, "management involvement".

The need for standardisation of language and graphics (specifically including "the risk matrix") was important to one interviewee so "there is no point having to interpret language", especially in large organisations [BC]. This issue has also been identified in other research (Budescu et al, 2009; Ho et al, 2015; Kent, 2007) as a potential source of uncertainty in decision making. 


\subsection{Case Study C data and analysis}

\subsubsection{Business environment of the decision}

This case study is a land management organisation with a wide range of land-use activities on all types and conditions of land, in all regions of New Zealand. Workers and at least some contractors were using all-terrain vehicles - ATVs (also known as quad bikes) - to help transport people and materials to work sites but were known to be prone to loss of control events that might result in death, serious harm or minor injuries. On a day-to-day basis workers, contractors and visitors might be on such land but workers using ATVs might not know who would be present or where they might be. ATVs were almost entirely used by workers in the operations group of the organisation. The timeline of the risk assessment is shown in Figure 35.

Figure 35. Timeline of the Case Study $\mathrm{C}$ decision, risk assessment and documents
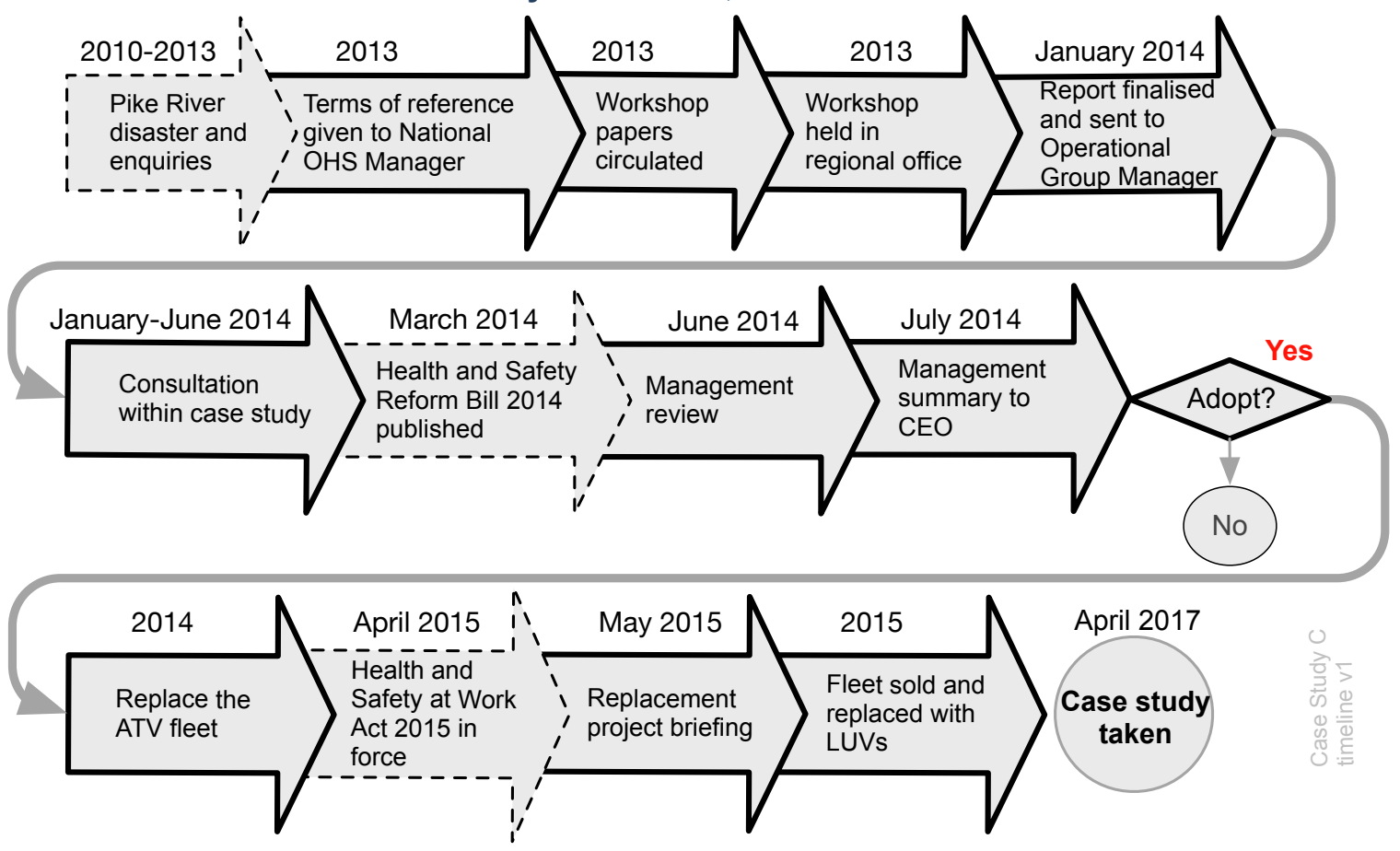

By late 2013 it was clear that new occupational health and safety (OHS) legislation would replace the earlier Health and Safety in Employment Act 1992 and would probably be based on the Australian Model Work Health and Safety Bill (Model Work Health and Safety Bill, 2011), in turn based on the UK HSWA (1974). The New Zealand Health and Safety at Work Act was enacted in 2015 and sets out duties for every "person having control of a business or undertaking" - a PCBU - as defined in section 17 of the Act. Section 36 requires, in summary, that a PCBU ensure, so far as is reasonably practicable, the health and safety of workers who work for the PCBU or who might be influenced or directed by the PCBU. The duty extends to "other persons" (eg, visitors to land) who must not be put at risk from the work of the PCBU. 
The history of the use of ATVs from three-wheeled in the 1980s to four-wheeled in the 2000s has been marked by numerous fatalities and severe injuries, with claims that some manufacturers attempted to block change (Lower, 2013) in the same way that tobacco and asbestos companies derided evidence of harm from their products (Oreskes \& Conway, 2010).

ATVs were originally developed for private, off-road use but had become widely used in rural work generally. However, they have a poor safety record in New Zealand, Australia, the USA and UK (and possibly other countries). As such, their continued use in New Zealand would need to be justified by a risk assessment showing that (Peace, 2017b):

- all that was practicable to prevent harm had been considered

- anything that was practicable and found to be reasonable would be done.

In 2013 the case study National OHS Manager was tasked with carrying out such a risk assessment and reporting the results to the operational group manager. The report was intended to facilitate discussion about options for use or replacement of the fleet of ATVs with light utility vehicles (LUVs).

\subsubsection{Case study documents and interviewees}

The documents listed in Table 47 formed part of the case study.

Table 47. Documents reviewed in Case Study C

\begin{tabular}{|l|c|c|}
\hline \multicolumn{1}{|c|}{ Case study document title } & $\begin{array}{c}\text { Year } \\
\text { published }\end{array}$ & $\begin{array}{c}\text { Code } \\
\text { number }\end{array}$ \\
\hline Organisation Chart, Management Team & 2015 & C1 \\
\hline Organisation Chart, Operations Group & n.d. & C2 \\
\hline Task assignment & 2013 & C3 \\
\hline Quad bike use (the initial risk assessment report) & 2014 & C4 \\
\hline Draft memorandum to CEO & 2014 & C5 \\
\hline Final memorandum to CEO & 2014 & C6 \\
\hline Briefing notes for managers' use & 2015 & C7 \\
\hline Q\&A Quad bike replacement project notes for staff & 2015 & C8 \\
\hline
\end{tabular}


The participants noted in Table 48 were interviewed in their offices using the previously circulated questions.

Table 48. People interviewed in Case Study C

\begin{tabular}{|c|l|c|c|l|l|c|}
\hline $\begin{array}{c}\text { Person } \\
\text { code }\end{array}$ & \multicolumn{1}{|c|}{ Job title } & $\begin{array}{c}\text { Decision } \\
\text { maker } \\
\text { (Y/N) }\end{array}$ & $\begin{array}{c}\text { Risk } \\
\text { assessor } \\
\text { (Y/N) }\end{array}$ & $\begin{array}{c}\text { Highest } \\
\text { qualification }\end{array}$ & $\begin{array}{c}\text { Years in } \\
\text { current or } \\
\text { similar role }\end{array}$ & $\begin{array}{c}\text { Professional } \\
\text { body } \\
\text { membership }\end{array}$ \\
\hline $\mathrm{CA}$ & Director & $\mathrm{Y}$ & $\mathrm{N}$ & $\begin{array}{l}\text { University } \\
\text { Entrance }\end{array}$ & 3.5 years & $\mathrm{N}$ \\
\hline $\mathrm{CB}$ & $\begin{array}{l}\text { National OHS } \\
\text { Manager }\end{array}$ & $\mathrm{N}$ & $\mathrm{Y}$ & $\begin{array}{l}\text { Grad. Dip. } \\
\text { OHS }\end{array}$ & 16 & $\mathrm{~N}$ \\
\hline $\mathrm{CC}$ & $\begin{array}{l}\text { Operations } \\
\text { Group } \\
\text { Manager }\end{array}$ & $\mathrm{Y}$ & $\mathrm{Y}$ & $\begin{array}{l}\text { Bachelor of } \\
\text { Forestry } \\
\text { Science }\end{array}$ & 2 & $\mathrm{~N}$ \\
\hline $\mathrm{CD}$ & Supervisor & $\mathrm{N}$ & $\mathrm{Y}$ & None & 1.5 years & $\mathrm{N}$ \\
\hline
\end{tabular}

\subsubsection{Decision to be made}

In 2013 the executive manager [CA] accountable for operations responded to an earlier report on injuries due to use of ATVs [CB] and asked for:

... a report on quad bike use ... including an analysis of incidents, recent research, and recommendations

This was to be used as the basis for a decision about the future of ATVs by the organisation. The assessment "was quite a substantial piece of work, so it probably took a full six months" [CA], the report was submitted in January 2014, and a summary report submitted to the CEO in July 2014. While each report left open the continued use of ATVs, the decision was made to cease their use and to replace some with "light utility vehicles" (LUVs).

\section{Background to ATV risk}

The US Consumer Product Safety Commission (CPSC) defines an ATV as an "off-road, motorized vehicle having three or four low-pressure tires, a straddle seat for the operator and handlebars for steering control". In the 24 years between 1985 and 2009, ATV loss of control events (LCEs) in the USA killed between 10,561 and 13,617 people and injured hundreds of thousands of riders (Myers, 2016; Myers \& Cole, 2016). More than $60 \%$ of LCEs in the USA resulted in death, typically due to overturning. Three-wheel bikes were inherently unstable and the CPSC issued rules between 1985-1988, ultimately prohibiting their sale. However, they continued to be imported to New Zealand (possibly until 2011), resulting in a continuing number of claims made to the Accident Compensation Corporation (ACC). 


\subsubsection{Case Study C analysis}

As before, the tentative GT for an effective risk assessment (section 3.2) provided a framework for analysis of data from the reports and interviews. The GT, CSF and 13 NC are reported on, as before, in a "bottom up" (ie, reverse) order.

Literature or document review fairly sets out data (NC 01)

The 2014 report [C4] cited:

- work showing the nature and level of risk due to use of ATVs in New Zealand (Shulruf \& Balemi, 2010) and Australia (Lower, 2013; Lower \& Temperley, 2016)

- an internal report Evaluation of ATV Quad Bikes used within [Case Study $C]$ analysing case study-specific risk factors

- unpublished work (not followed up on here) carried out in Australia that included work by State Government agencies, and several reports from New Zealand state sector organisations; work on ATVs in Australia (Tasmania specifically) was mentioned as being influential.

While not mentioned in the main report [C4], the WorkSafe (2014) guidance had been used to inform an earlier revision of the ATV standard operating procedure (SOP).

The main report [C4] was summarised in a draft memorandum [C5] that included some additional material. The main report was circulated for consultation with stakeholders and their comment. This was followed by the three-page final report to the CEO [C6] that gave only the essential information. Together the reports gave a balanced picture suggesting that ATVs could be used subject to stricter controls but that they could be replaced, perhaps over a few years. Each report gave statistical data from within the Case Study And some data from other sources, but none cited external research evidence that might have made the case for replacement irrefutable.

It was known that the safety legislation would change and be more risk-based but "it made no difference which legislation we were under" [CB].

As part of the review of this case study a short literature review of ATV safety was carried out. This showed the best available evidence that would have been available (Van Eerd, 2019) for a quad bike intervention and is summarised in Box 3. 


\section{Box 3. Literature relevant for Case Study C: ATV safety}

At an individual level, harm following an ATV loss of control event (LCE) can appear unique but a broader, population-based study can show such incidents form part of an epidemic. A New Zealand study of admissions to Waikato Hospital between February 2007 and March 2011 (Wood, Duijiff, \& Christey, 2013) identified 101 patients with ATV-related injuries, including deaths, from a database of 13,400 patients. It found those affected were typically male with a mean age of 38.8 years and often had suffered from head injuries. Admission data showed a $42 \%$ increase from 2009 to 2010 , resulting in increased hospital bed occupancy and Waikato hospital ATV-related costs projected to increase in 2012 to nearly New Zealand $\$ 1.5$ million.

Another study of ATV use identified New Zealand farmers' "propensity for risk-taking, unrealistic optimism, and fatalism as risk factors" (Clay et al, 2015, p. 12) and, in another major study, it was estimated there were about 70,000 ATVs in use in the agriculture sector (Moore, 2007) with an average of seven deaths per year since 1997. As a result, ACC paid more than $\$ 3.6$ million compensation for ATV-related claims in 2003-4. In a threepart project, the use of ATVs by workers in a corporate farm and staff in a regional council showed their use was often limited to 1-2 hours per day (Paterson, Mora, \& Thomas, 2013) and contrasted the typically flat land the farm workers drove on with the wider range of geography that Council staff might cover.

In an Australian study a total of 220 fatalities due to ATV LCEs were recorded in Australian farming between 2001 and 2015 (Lower \& Temperley, 2016). A subsequent comparison of Australian and New Zealand fatal injuries associated with ATV use found 101 cases between July 2007 and June 2012, with 69 in Australia and 32 in New Zealand (Lilley, Lower, \& Davie, 2017), an apparently high ratio when compared with respective country populations. Common factors were male farm workers, failure to wear helmets, and the LCE involving a rollover, typically resulting in crush injuries to the head or thorax. The economic cost of an ATV fatality was estimated to be between $A \$ 2.4$ and $A \$ 4.3$ million (Lower, Pollock, \& Herde, 2013).

Options identified in these studies included:

- improved farm management and work organisation

- regulation

- improved ATV design and modification

- behaviour-based interventions, including rider awareness and training

- use of tested crush prevention devices

- labelling and education programmes

- use of personal protective equipment (specifically helmets, but only $46 \%$ cases in the Waikato study used them)

- a "first alert" system to trigger an alarm at "home base" when a near hit or actual incident is identified

- feedback to the rider if the ATV is being operated outside its safe envelope

- speed limiters matched to specific locations

- replacement of ATVs with safer vehicles.

Advice from the New Zealand regulatory agency in 2012 (then the Department of Labour) mentioned an average of five farm deaths per year and gave some useful injury prevention guidance (DoL, 2012), including selecting the best vehicle for a specific task. Unfortunately, the 20-page booklet was not as user-friendly as earlier more succinct guidance (OSH, 2002), although it was reissued in an improved form in 2014 (WorkSafe NZ, 2014). Advice in a UK HSE (2014b) information sheet on safe use of ATVs shows differences in risk between the UK and Australia and New Zealand due to geography, climate and usage, reinforcing the need for a risk assessment to be contextualised. 
Some of the above would have aided development of the best available information but are academic references and might not be easily accessed by non-academics.

\section{Terms of reference for risk assessment are clear (NC 02)}

The terms of reference were set in 2013 as "a report on quad bike use in [Case Study C], including an analysis of incidents, recent research, and recommendations .... This report should be used as the basis of robust discussion on the future use of quad bikes" [C4, CB]. At this stage it was not clear that the CEO was inclined to withdraw all ATVs from use (NC 07).

Not including the cover sheet and contents page, the 20-page report met each of these requirements. It also included a description of tests on crush protection devices and rollover protection devices, clearly distinguishing between them, and discussing respective advantages and disadvantages.

Relevant qualifications and experience of assessors stated or available (NC 03) Although none of the reports gave the qualifications or experience of assessors, they were known to the decision makers and, during the interviews, it became obvious that each workshop attendee brought contributory expertise (section 6.5.2) to the risk assessment. The track record of at least two of the participants (CB and $C D$ ) was well-known and respected.

\section{Impartiality in terms of funding and mandate (NC 04)}

The funding and mandate for the risk assessment was from the management team and was not cited in the reports.

\section{Stakeholders and risk assessors have a shared understanding of risk (NC 05)}

As a result of this engagement there was a shared understanding of the nature and level of risk. The workshop meant that each person doing the risk assessment had their "eyes open - it meant I really understood what we were talking about" [CC].

After the decision had been made, briefing notes were published on the intranet and used in face-to-face meetings to explain the decision and its implications. While not forming part of the risk assessment or decision, this aided general understanding and implementation of the decision.

\section{Appropriate engagement with stakeholders (NC 06)}

The 2013 workshop included representatives of senior and line managers and field staff from across the organisation $[\mathrm{C} 5, \mathrm{CB}]$ and was a major contributor to the risk assessment as it elicited their knowledge and experience and enabled a shared understanding. These people 
were identified in the subsequent workshop report [C4] that was widely consulted on and then summarised to the CEO and management team [C5, C6]. Thus, before the decision was made, there had been wide consultation with other stakeholders who were not present in the workshop.

\section{Competent and impartial risk assessor or team (NC 07)}

The composition of the workshop group was outlined in the initial report [C4] and referred to in the two summary reports [C5, C6]. While criteria for judging expertise usually include credentials, experience and track record in a given field, greatest emphasis should be put on track record (Collins \& Evans, 2007).

It was not possible to fully judge the competence of the risk assessment team as a whole, but the National OHS Manager had 30 years' experience in the organisation (including 16 years in his position) and held a relevant qualification. He wrote the main report, including interpretation of the supporting documents. One field worker [CD] had nine years' experience in the organisation (including 18 months in his position) using quad bikes for "about $30 \mathrm{~km}$ a day, for about three days a week. I suppose at least $20 \mathrm{~km}$ a day". The senior manager who led the workshop had two years' experience and a Bachelor's degree in Forestry Science.

These workshop participants are regarded as competent by qualification and experience, with a good track record relative to ATVs, and so were able to make significant contributions to the workshop.

\section{Risk is correctly framed (NC 08)}

Interviewees were asked how they characterised the objectives of the risk assessment. Each report, and the briefing notes, were also reviewed for characterisation comments, summarised in Table 49. While OHS was the most frequently named, other characteristics were also named, agreeing with earlier work (Baker, 2002; Nielsen \& Parker, 2012).

While CC's comment that "Knowing that five people per year die in ATV incidents in New Zealand" made clear this risk assessment was about the safety of operational staff, other objectives listed in the table (business-as-usual, service delivery and financial) were also mentioned. In addition, the initial report [C4] stated "these machines provide an important and efficient way for staff to transport themselves and equipment to often remote locations where access would otherwise be difficult", although it was "questionable as to whether the bikes were being used within the manufacturers' specifications". 
Table 49. Decision objectives

\begin{tabular}{|l|c|}
\hline \multicolumn{1}{|c|}{ Possible objectives of the decision or risk assessment } & Whether this objective was mentioned in Case Study C \\
\hline Business as usual/operational & $\mathrm{X}$ \\
\hline Compliance & $\mathrm{X}$ \\
\hline Decision making & $\checkmark$ \\
\hline Delivery of goods or services & $\mathrm{X}$ \\
\hline Environmental & $\checkmark$ \\
\hline Equipment fit for purpose & $\checkmark$ \\
\hline Financial & $\mathrm{X}$ \\
\hline Good practice & $\checkmark$ \\
\hline Occupational health and safety (including welfare) & $\mathrm{X}$ \\
\hline Project management & $\mathrm{X}$ \\
\hline Reputation & $\mathrm{X}$ \\
\hline Strategic & $\mathrm{X}$ \\
\hline Sustainability & \\
\hline
\end{tabular}

The cost of replacing the ATVs (subsequently estimated to be $\$ 1$ million) was considerably less than A\$2.3 million, the estimated cost of a fatality due to a quad bike (Lower et al, 2013) in Australia, or the New Zealand Social Cost of Road Crashes (MoT, 2013), estimated to be approximately New Zealand $\$ 4.5$ million. Such simple valuations would have shown it was reasonable in terms of the 1992 OHS legislation in force at the time of the decision to change from ATVs to LUVs.

\section{Criteria for risk evaluation set (NC 09)}

Interviewees made clear the CEO had talked with senior managers in other organisations that used ATVs. Some had already stopped using them or were moving to eliminate them and, given the injury and near-hit data in monthly reports, the "CEO's tolerance for more ATV injuries was pretty low. The tolerance for the on-going injury rate was not acceptable and level of risk, the background risk, was just too high" [CA].

Subsequently, it became clear that the risk criterion was implied to be zero serious harm or fatalities from the use of ATVs, a very difficult criterion to meet and making almost certain that use of ATVs had to cease.

\section{Appropriate language, graphics and layout (NC 10)}

The executive summary was written in what was initially assessed to be non-technical language, although when a sample from the executive summary was run through an online readability tool at http://www.readabilityformulas.com/ that used the SMOG readability 
algorithm (Arkin et al, 2004) it was assessed as "tenth grade", ie about 15-16 years of age, "fairly difficult to read", but probably acceptable for the intended audience.

The initial report [C4] used charts and photographs to illustrate points and, for data, trends over time.

\section{Systematic hazard or risk identification (NC 11)}

ATV-related risk factors were identified in a workshop that was well-planned, with prereading circulated to participants. It met the criteria described in the review of workshops (section 6.5.3) and was judged to be successful because "risk assessments should be done in a team" [CB] to facilitate open sharing of knowledge. The success of the workshop was confirmed by comparing the results with section 6.5.3, showing it was a loose process with a flexible agenda, providing a learning opportunity with a narrow focus on ATV-related risks, controls and treatment options.

\section{Background research}

As shown in this case study report, there is a substantial body of research showing ATV LCEs are a major cause of occupational fatalities and serious harm. A briefing paper summarising such academic research could have been commissioned and circulated to workshop participants to facilitate understanding and discussion of the nature and level of risk in the organisation.

\section{Appropriate risk analysis techniques have been used (NC 12)}

\section{Consequence/likelihood matrix}

During the workshop a $5 \times 5$ consequence/likelihood matrix commonly used in the organisation was applied and helped participants see the effect of controls.

We spent a lot of time on that and used the matrix. What would happen if we did this, would it make a difference to that particular incident? Would that have changed things? [CD]

\section{Human factors}

The initial report [C4] found that "if the controls are in place the risk reduces, however it is only the likelihood that is reducing, not the consequence. And this assumes that all of the controls are in place, something we cannot always rely upon. The risk of ATV use remains a fatal risk no matter what protection is offered". Put another way, it was viewed as just a matter of time before a worker suffered serious harm or was killed in an ATV loss of control event. The initial report [C4] also noted "of concern were the high number of incidents that involved loss of control by the rider, nearly $50 \%$. This would indicate issues around skills, experience, training and local knowledge". These two quotations suggested that a 
human factors-led approach to the risk assessment might have shown that use of ATVs was untenable. This would have been especially clear knowing they were used in diverse locations and conditions with the most immediate management of risk being under the control of the worker and, to a lesser extent, their supervisor. A report for the UK HSE noted (Gadd et al, 2003, p. 42):

It is important to ensure that there is adequate consideration of human factors at each stage of the risk assessment process. In carrying out the assessment, it may be helpful at each stage to consider explicitly the task, the individual and the organisational factors.

Figure 36 summarises such factors under the headings organisation, job and individual workers. These are then used to re-group some of the findings in the reports and interviews.

Figure 36. Human and performance-shaping factors

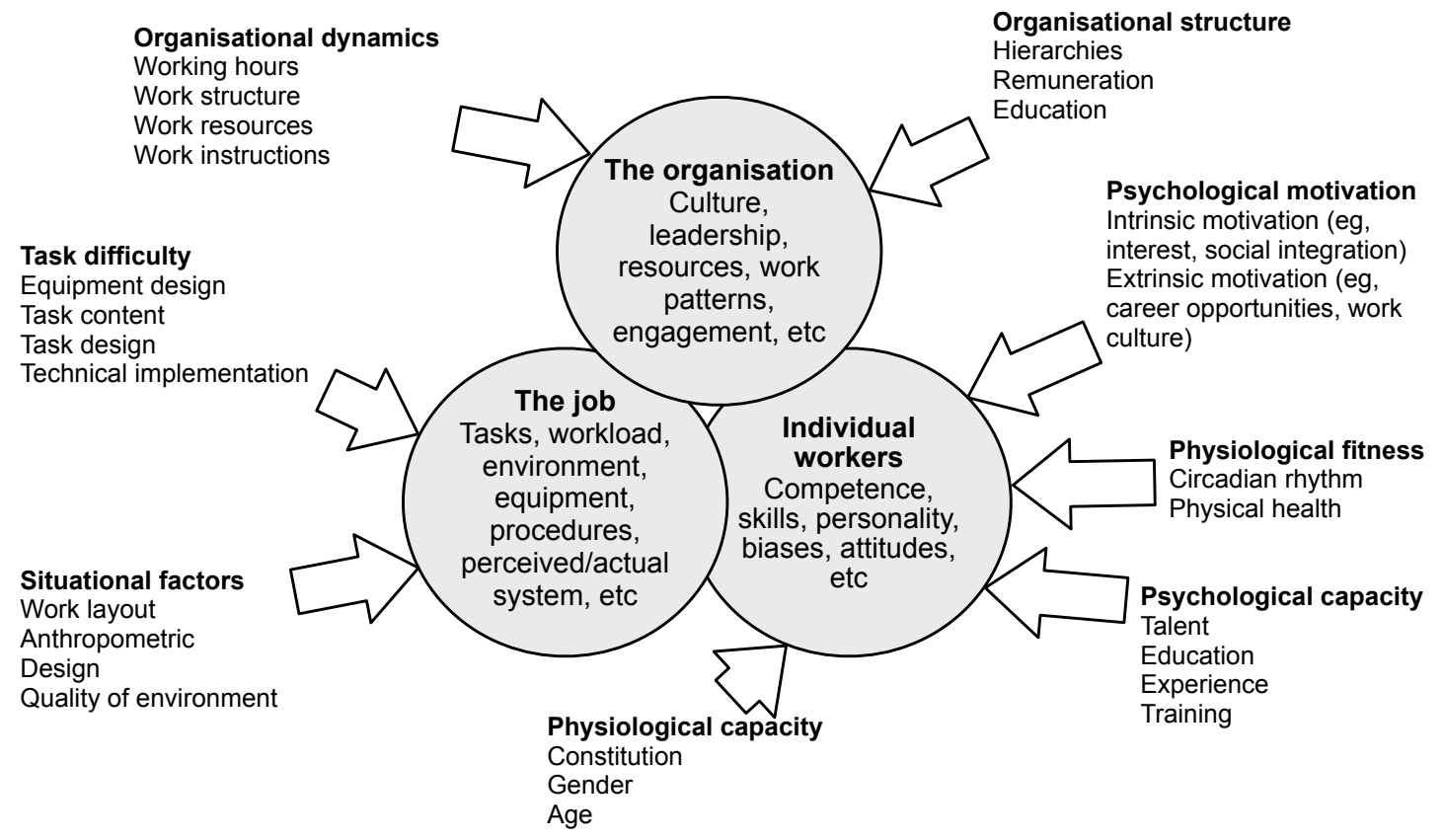

Adapted from HSE (1999) and IEC 62508 (2015)

Use of ATVs provides an example of "normal chaos" (Lauder \& Marynissen, 2018), where apparently identical activities will always be at least subtly different due to the range of job- and worker-related variables (summarised in Figure 36). In the case of ATV operation, those variables are highly dependent on the skill of a driver and, to a lesser extent, their supervisor who signs off an activity requiring use of an ATV. Even in a well-managed organisation (the third major area in Figure 36) with a low tolerance of workplace injuries, normal chaos can give rise to unacceptable risk. Some of the human factors touched on in the diagram and its sources were 
identified in case study reports $\mathrm{C} 4, \mathrm{C} 5$ and $\mathrm{C} 6$.

Organisational issues included: uncertainty about the number of certified operators ("there are approximately 400-500 trained operators" [CB]; the numbers of near-hit and injury reports (see Table 50); the general culture in the organisation that included "a very high commitment to getting the work done" [CC] potentially tempting workers to allow "necessary violations" (Reason, 1998, p. 304); "both positive and negative drivers of our safety culture with quads" identified by the review team.

Job issues included: the probable ineffectiveness of rollover and crush protection devices ("manufacturers are unlikely to change their stance and admit that CPDs [crush protection devices] are necessary because of the risk of litigation from the families of the 11,000 people who have been killed in quad bike accidents in the USA from 1982 to 2010" (Lower, 2013)); uncertainty about the number of ATVs actually in the fleet ("the fleet manager believes there are about 170 ..." [CB]. Individual worker issues included: probable ineffectiveness of training (the "judgement of users appears to be lacking and some staff take unnecessary risks"); controls and their effectiveness ("there is evidence that our [standard operating procedures] in many cases simply are not being read, despite many being just one page”); the range of people using ATVs (“... used by staff, contractors and at times trained volunteers for transport of people and equipment") the approach to ATV safety was "built around training and gaining competency for users".

Thus, if ATV-related risk is framed as a human factors issue, changing some or all ATV-specific factors still leaves considerable uncertainty about an operator loss of control event with potentially fatal consequences.

\section{Appropriate risk evaluation techniques have been used (NC 13)}

The initial report made six recommendations, including further consideration of whether ATVs "continue to be used ... or phased out over time" [C4]. None of the reports or interviewees mentioned the "reasonably practicable" test that underpinned the Health and Safety in Employment Act 1992, the legislation in force at the time of the risk assessment and decision. This required that "all practicable steps be taken to achieve the result that it is reasonably practicable to take in the circumstances".

The reasonably practicable test has been subject to legal interpretation many times but, perhaps most notably, in an English case that determined it meant the employer had to decide before any harm occurred if there was anything that could be done that was practicable and, if so, whether it would be reasonable to implement it (Asquith LJ., 1949). 
Had "reasonably practicable" been discussed in the workshop and the subsequent reports it might have been obvious that it would be both practicable to stop using ATVs and that the cost would almost certainly be seen by the courts as reasonable (Venning J, 2008).

"Reasonably practicable" was touched on in the interviews, for example:

They certainly want to know about the level of risk in relation to the mitigations we have recommended. They want to see that the investment they are going to put in actually does reduce the risk" [CB])

There was a consensus that it would be practicable and reasonable to reduce the risk by revising the relevant standard operating procedure and limiting the use of ATVs but this option was not acceptable to the CEO for whom, as described by [CA]:

The level of risk, the background risk, was just too high.

Had the risk assessment used the value of a statistical life (Access Economics, 2008; Ale, Hartford, \& Slater, 2015) as part of a cost benefit analysis it would have become clear that it would be reasonable to spend up to about $\$ 4.5$ million to prevent one fatality (MoT, 2013).

\section{Risk assessment appropriately communicated to decision makers (CSF 01)}

The subsequent decision to stop using ATVs needed support from internal stakeholders and, (potentially) others in the sector, those who benefited from the activities of the organisation, and those accountable for such activities. This required a well-developed and written risk assessment that would be accepted by stakeholders. The three reports (C4, C5 and C6) were communicated to decision makers but lacked documented information from Australia, although the CEO had "also been informed by his colleagues in Australia who each run their own similar organisations" [CC]. This informal communication between CEOs was similar to two of Mintzberg's (1971, pp. 100-101) CEO characteristics

4 The manager sits between his organisation and a network of contacts

5 The manager demonstrates a strong preference for the verbal media.

\section{All relevant factors including controversies and uncertainty have been fully and correctly evaluated (CSF 02)}

Controversies about frontline workers' preferences for ATVs without their having trialled alternatives were fully reported, as were the considerable controversies about fitting rollover protection or crash protection devices (Lower \& Temperley, 2016).

The initial report [C4] discussed uncertainty about: off-road use of ATVs, especially variables in use (eg, spray tanks that could range from full to empty in a working day, so changing the centre of gravity unpredictably) $[C D]$; the effectiveness of training $[C B]$; the fear of reduced to 
carry out business-as-usual activities if it did not use ATVs, leading to risk about the achievement of business objectives [CA]. However, as it transpired:

There have been no detrimental effects on operations overall, and we have adjusted well to life after quads [CB]

Indeed, it was found to be possible to do without ATVs - "you can do without the things you thought were absolute must-haves" [CB].

Dispensing with ATVs was not considered in depth as the workshop attendees had not fully understood the attitude of the CEO to ATVs [CA]. Adaptations of ATVs were discussed at length $[C D]$, and alternative transport types identified including walking, four-wheel drive vehicles, helicopters, two-wheel motorbikes and mountain bikes [C4]. Using light utility vehicles (LUVs) was discussed but, as these were not in wide use, they were not included in reports $\mathrm{C} 4, \mathrm{C} 5$ or $\mathrm{C} 6$, although subsequently:

Another team was put together to select the type of LUV we wanted. We were looking for robustness with good service backup. [CB]

\subsubsection{Summary of the risk assessment and outcomes}

\section{Case Study C outcomes}

The initial risk assessment objectives [C4] were "a report on ATV use in [case study], including an analysis of incidents, recent research, and recommendations". This report and the two summary reports ( $\mathrm{C} 5$ and $\mathrm{C} 6$ ) provided much background information for consultation with stakeholders that responded to this objective. However, they were not adequate to provide the evidence sought by the CEO "and he wanted us to look again with more rigour and it was then pretty clear that LUVs were the better option" [CC].

This may have indicated a need for more practicable options to be identified and priced to help decide if they were reasonable. Given the evidence from other organisations in New Zealand and Australia, this "wasn't a radical idea" [CD]. As a result:

What seemed like a difficult decision was probably one of the simplest the leadership team has made. [CB]

In this instance, rigorous application of the reasonably practicable test to evaluate the risk would have shown ATVs to pose an unacceptable level of risk and that there were practicable alternatives that were reasonable.

\section{Incident data}

The organisation uses an online system for reporting incidents. Table 50 shows data for reported potential consequences of incidents for the 36 months ending 31 December 2014 (ie, while using ATVs) compared with data from the 12 months ending 28 February 2017 
(while using LUVs), again for potential consequences. While the data is limited and relies on self-reporting, it suggests a marked shift away from potentially major consequences to minor or insignificant consequences.

Table 50. ATV and LUV reported incidents

\begin{tabular}{|l|c|c|c|c|}
\cline { 2 - 5 } \multicolumn{1}{c|}{} & \multicolumn{2}{c|}{$\begin{array}{c}\text { Potential consequences due to ATV } \\
\text { use in Case Study C }\end{array}$} & \multicolumn{2}{c|}{$\begin{array}{c}\text { Potential consequences due to LUV } \\
\text { use in Case Study C }\end{array}$} \\
\hline Potential level of harm & \multicolumn{1}{c|}{ 1 January 2012 - 31 December 2014 } & \multicolumn{2}{c|}{ 1 March 2016 - 28 February 2017 } \\
\hline $\begin{array}{l}\text { Major (serious harm or single } \\
\text { fatality) }\end{array}$ & 10 & $30 \%$ & 0 & $0 \%$ \\
\hline Moderate (disability) & 10 & $31 \%$ & 2 & $4 \%$ \\
\hline Minor (medical treatment) & 5 & $15 \%$ & 10 & $9 \%$ \\
\hline Insignificant & 4 & $12 \%$ & 9 & $45 \%$ \\
\hline Totals & 33 & & 22 & $41 \%$ \\
\hline
\end{tabular}

The data in Table 50 was described thus [CB]:

When we have an incident - any sort of incident - it's given a risk potential score in a report. Not what did happen but what could have happened. If you look at this report [columns 2 and 3] you will see we had no injuries but a high number of fatal risk incidents. Now, of course, those have disappeared because we don't have ATVs. There hasn't been an incident with a LUV that had a fatal risk component [columns 4 and 5]. There is no doubt in my mind that if we haven't prevented a fatality, we have at least prevented serious injuries".

The data from Table 50 is presented in Figure 37 to show the mean reports per year 20122014 and actual reports for 2016-2017.

Figure 37. ATV and LUV reported incidents

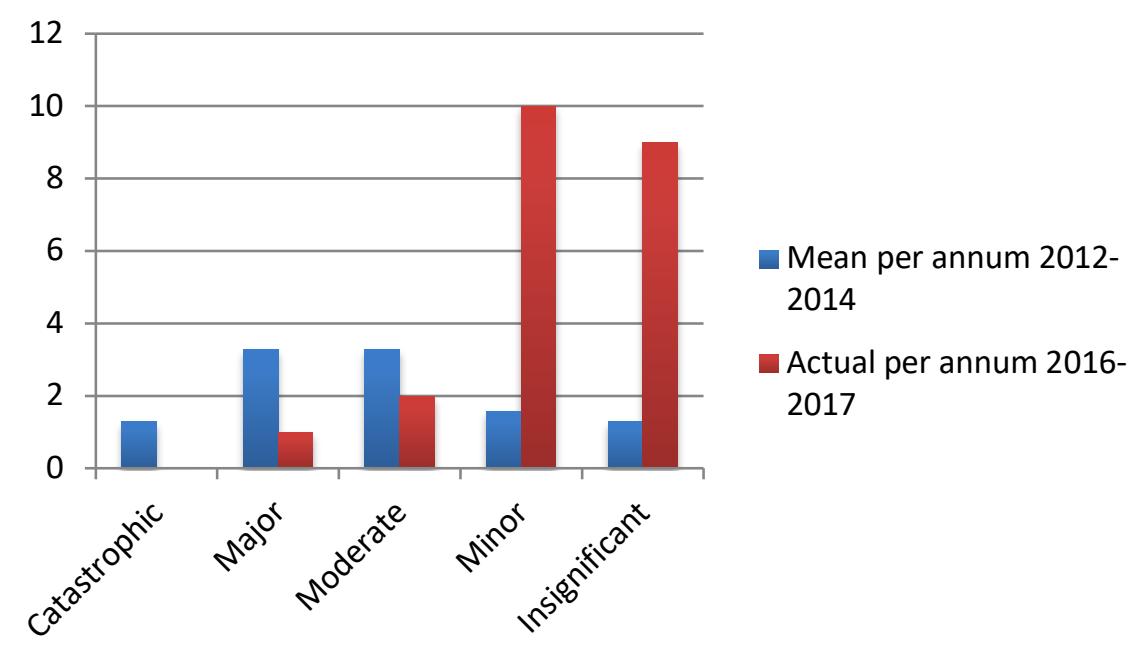


Comparing reported $\$ 1$ million to replace the ATVs with the $\$ 4.5$ million value of a statistical life showed and taking into account this incident data shows the decision to stop using ATVs was a success for occupational health and safety in the organisation. While no other outcomes have been considered in this research it was reported that organisational objectives were not adversely affected. ATVs "were never designed as a work bike, they were a recreational vehicle. But they've become a bit of a workhorse" [CB].

The Influence diagram Figure 38 shows the estimated strength of relationships between the risk assessment and outcomes. The thickness of the lines represents the strengths of influence (estimated by this researcher) including the dashed line leading to no adverse effects on operational performance.

Figure 38. Case Study $\mathrm{C}$ qualitative influence diagram

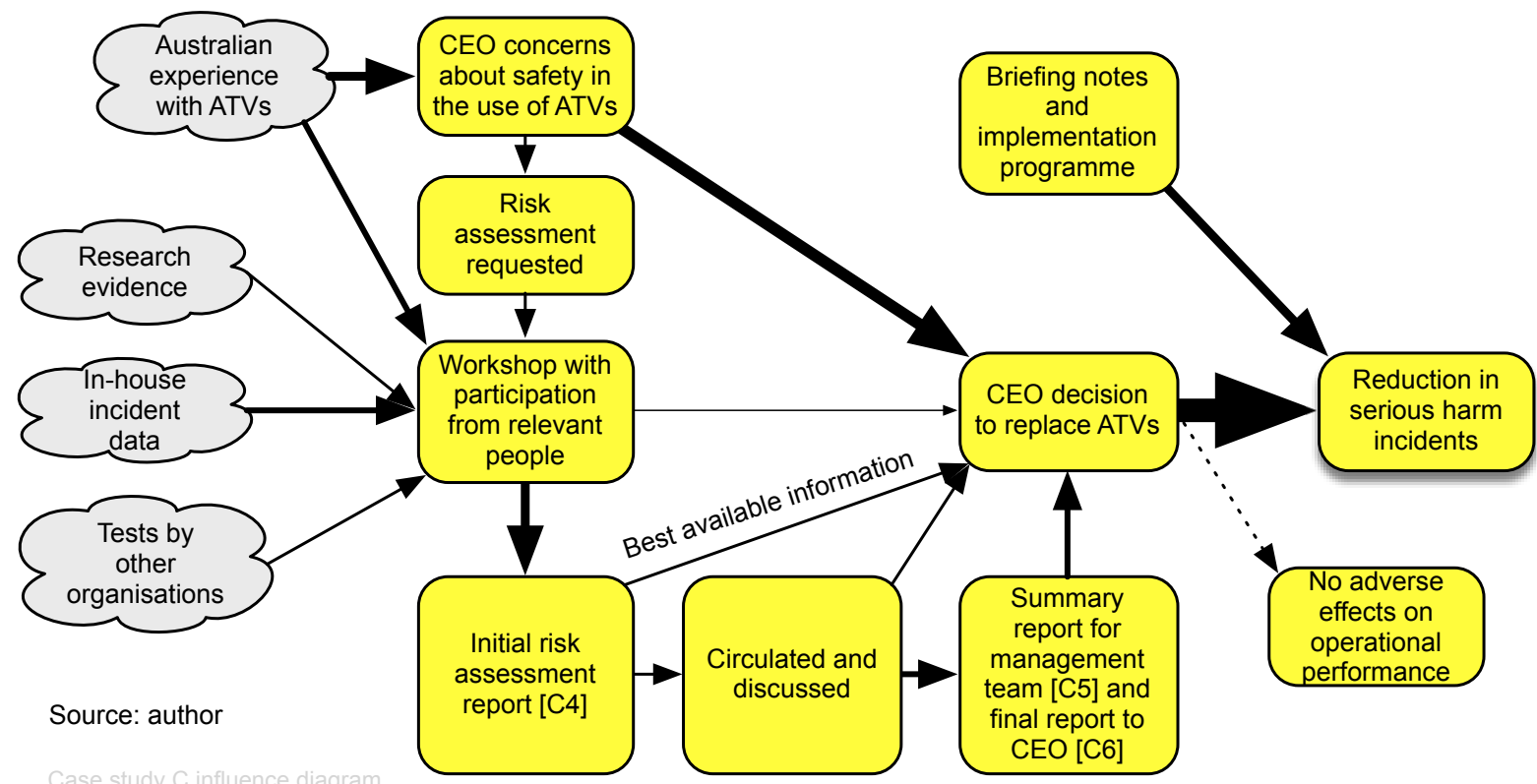

The documents and interviews strongly suggested the CEO was influenced by Australian organisations (as found by Mintzberg (1971, p. 100), a CEO "sits between his organization and a network of contacts"). He learned that analysis of ATV use in one Australian State showed "their use has driven up costs for facilities development with a negative result on visitors' experiences through wider and less walking friendly tracks" [C3] while "those who had gone away from ATVs to LUVs were reporting huge improvements in safety stats" [CB].

The workshop report [C4] met the terms of reference for the risk assessment and was undoubtedly influential in getting the conversation started and shaping opinions. However, it did not fully respond to the needs of the CEO. The strongest influence to his decision to replace ATVs was from the Australian experience, supported by reports C4, C5 and C6. This, combined with the briefing notes and implementation programme, led to the reduction in potential serious harm incidents summarised in Table 50. 


\section{Improved risk assessments}

In 2016 the organisation started using bowtie analysis (section 2.4.1) in workshops for risk assessments associated with on-road driving, helicopters, and other significant risk sources. These are "showing us where there are [control] gaps" [CB]. Also, by early 2017 risk assessments were forming a large component of business cases [CB].

Despite deficiencies in the risk assessment, the planned and unplanned outcomes in the influence diagram were all positive. The weight of evidence in this case study strongly suggests the risk assessment:

- contributed information necessary for consultation but was not at all effective in informing the CEO and management team within the original terms of reference

- could not, and did not, respond to the incompletely expressed objectives of the CEO.

Thus, the final outcome was successful despite the risk assessment, as summarised in Figure 39.

Figure 39. Effectiveness of the risk assessment compared with outcomes

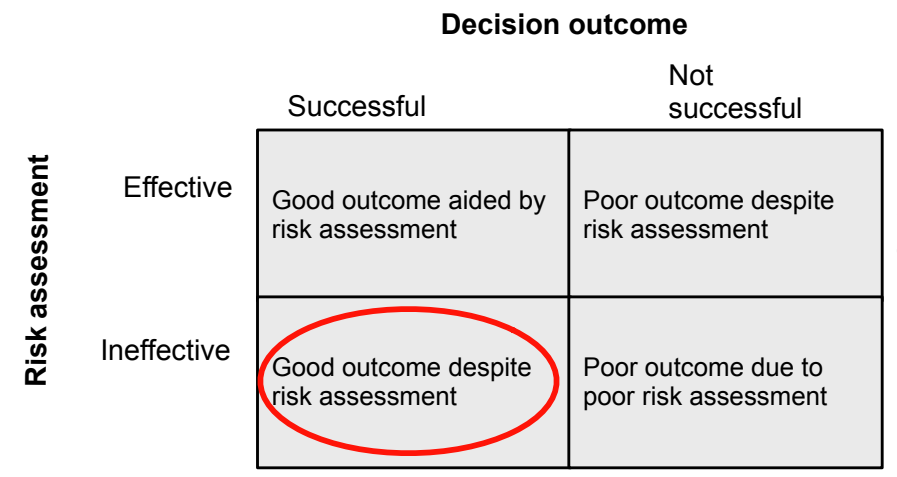

\subsubsection{Evaluation of Case Study C risk assessment using the goal tree}

The tentative GT (section 3.2) postulated 13 NCs and two CSFs for a risk assessment to be considered effective. To summarise the findings and indicate the magnitude of "satisficing" (Dettmer, 2003, p. 66), these have been colour shaded in Figure 40 to show if they were met substantially, partially, or not at all/very little. NC 04 is left clear as it was again judged not relevant in this case.

The GT is predominantly "Autumn Colours". Had the document review (NC 01) been more than very little, more evidence (perhaps as summarised in Box 3 ) might have been found showing that ATVs are inherently high risk machines, requiring their elimination "so far as is reasonably practicable" (Health and Safety at Work Act, 2015). NC 01 has a necessity arrow 
directly connecting it to CSF 01 suggesting that such evidence might have quickly led to the conclusion that Case Study C should eliminate use of ATVs.

The assessors were substantially competent (NC 07) and qualified (NC 03). The report used substantially appropriate language and graphics (NC 10).

Figure 40. The goal tree and the risk assessment in Case Study C

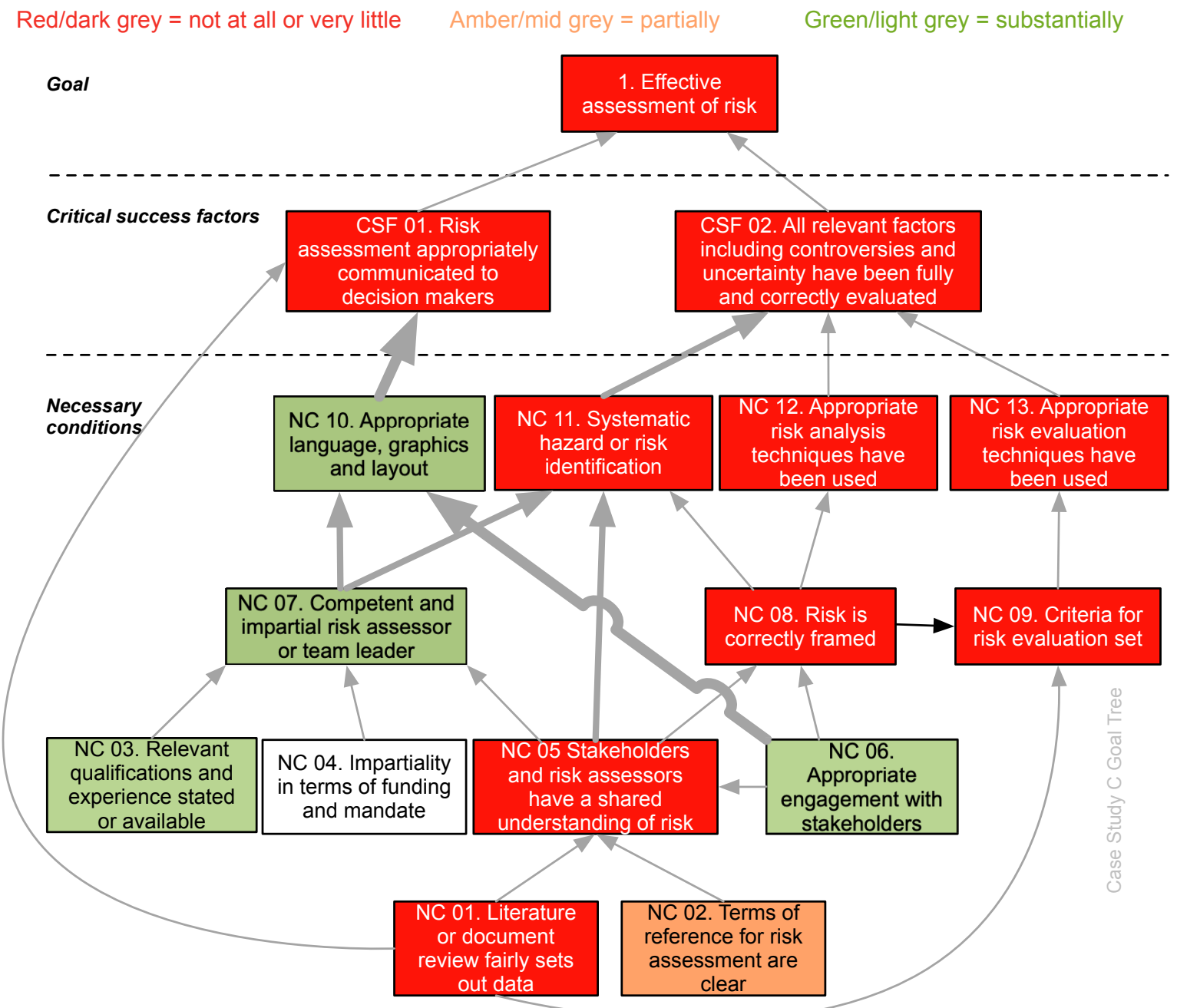

The linkages between NC 06 and NC 10 and between NC 10 and CSF 01 were very strong.

The terms of reference (NC 02) were partial leading to the assumption that controls could be improved. The risk assessors and CEO had very little shared understanding of the risks (NC 05).

Engagement with all stakeholders (NC 06) was substantial and a key NC, again contributing indirectly to both CSFs, but did not overcome the bias towards minimising the risk by improving the controls instead of eliminating the risk. Despite this substantial engagement, the risk was not at all correctly framed (NC 08) to include human and performance-shaping factors. NC 11 was rated as not at all met (the wrong risk was 
identified) and possible controls (starting with elimination) not at all correctly analysed (NC 12).

The CEO's unstated criterion (eliminate ATV use) in NC 09 was not at all/very little met and application of the reasonably practicable test in NC 13 not at all used, resulting in failure to show that replacement of ATVs might be both practicable and reasonable.

This analysis demonstrates the importance of setting clear terms of reference (NC 02) and criteria (NC 09) and basing a risk assessment on a broad document review (NC 01).

\section{Interviewee comments}

Respondents were positive about the GT - it "has everything we went through" [CD]. A very thoughtful response that related to NC 13 was:

At first it looked like a very busy diagram. Can't see anything that is missing. I like the impartial risk assessor [NC 07]. What about elevating risk to an appropriate level [of management]? A risk in [a rural area] is not necessarily going to be a risk in [head office]. [CB]

Three of the interviewees asked for a copy of the GT because it showed necessary conditions they had not previously considered, further suggesting that the GT was helpful.

\subsubsection{Subsequent publications and actions}

The CEO of Case Study C followed best practices derived from his Australian land management counterparts. They acted as Australasian sector leaders and may have influenced other New Zealand organisations. For example, OSPRI is a not-for-profit company engaged in bovine tuberculosis control in the agricultural sector across all regions of New Zealand (https://www.ospri.co.nz/). In early 2017 OSPRI published requirements for the safer use of ATVs by contractors (OSPRI, 2017b); this included challenging whether an ATV was the most appropriate vehicle for an activity. Subsequently, the company prohibited use of ATVs in its contract work (OSPRI, 2017a).

Conversely, a farm safety consultant (G. Neate 2018, email 3 March) working for a company with about 1500 New Zealand farmer clients and with good knowledge of ATV use in organisations did not "know how many organisations had stopped using quad bikes" but thought there was a "general move away from quad bikes on farms to side-by-sides [LUVs]. However, to date these have also had their share of fatalities". He is "an advocate of rollover protection on quad bikes". This respondent provides "SOPs and competency checklists and assists with carrying out risk assessments" and considered "risk assessments on farms are very entry level". 


\subsection{Case Study D data and analysis}

\subsubsection{Business environment of the decision}

Case Study D is a long-established food producer. In 2016, management investigated whether growing oyster mushrooms for sale into the New Zealand food retail sector would be commercially viable and compliant with legislation. A timeline for the activity is shown in Figure 41.

Figure 41. Timeline for mushroom trial

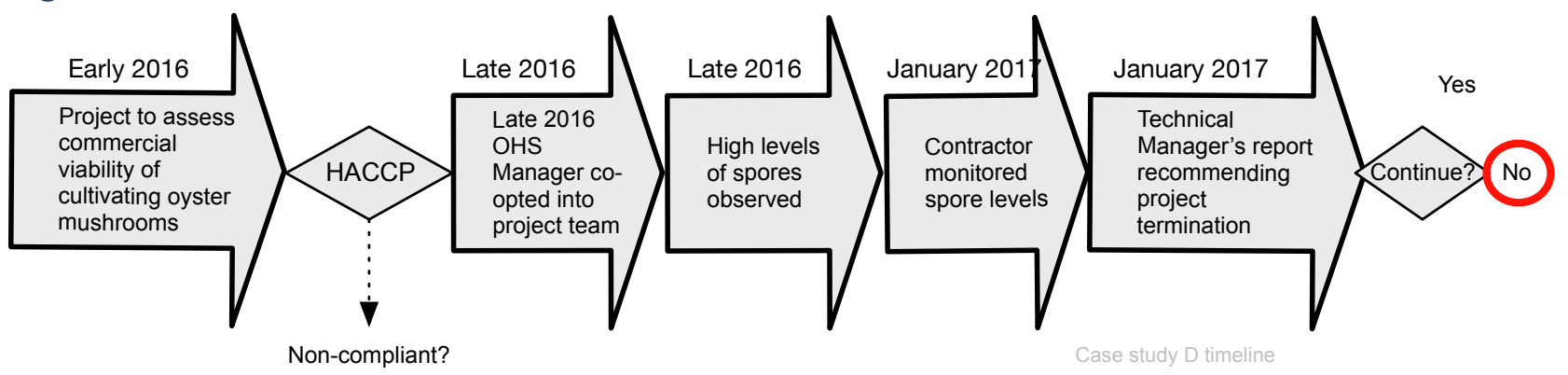

In early 2016 a pilot growing room was set up with tables on which bought-in bags of compost seeded with oyster mushroom spores were placed. Hazard analysis and critical control points analysis (HACCP) is a standard food safety risk analysis technique (ISO22000, 2005; Lee, 2012) required to be used under the Food Act 1981, and a HACCP analysis in 2016 showed production would comply with this Act.

In the trials 16 bags per day yielding about $2.5 \mathrm{~kg}$ of mushrooms per bag were harvested by three workers standing or sitting in front of the tables. Workers hand-picked the mushrooms and trimmed off the stems, sending these to waste and the fruiting bodies for weighing. No mushrooms were for sale at this stage. The trials went well and the case study had arranged the necessary retail packaging, labels and distribution when, in late 2016, it was noted that mushrooms being harvested were giving off large numbers of spores. Spores from some species of fungi are known allergens (Newman Taylor, 1994), and a specialist occupational hygiene monitoring consultancy was asked to monitor spore levels and report. They used air sampling pumps connected to spore traps in prepared cassettes for personal monitoring of workers. The spore traps were sent for analysis by a specialist microbiological laboratory.

The contractor's February 2017 report showed spore levels were in excess of 240,000 spores per cubic metre of air, more than 250 times greater than known exposures of workers in common mushroom growing. The report [D1] noted "there is no current exposure standards [sic] for mushroom spores, however due to the high measurements obtained during monitoring, recommendations have been made in reference to the following factsheet". That eight-page factsheet (Molde, 2011) published by the UK regulatory agency, the Health and Safety Executive (HSE) was freely available on the internet. Staff in the case 
study had carried out a HACCP analysis for food safety purposes but had not identified an occupational health risk, so this result was a surprise to management.

The case study Technical Manager reported the results to the CEO with a strong recommendation to halt the trial and not proceed with production. This recommendation was accepted, although records were kept of the pilot plant configurations should a further trial be carried out.

\subsubsection{Case Study Documents and interviewees}

Only one document [D1] was available for review; others mentioned by interviewees could not be found but have been recorded in Table 51 for completeness.

Table 51. Documents reviewed in Case Study D

\begin{tabular}{|l|c|c|}
\hline \multicolumn{1}{|c|}{ Case study document title } & $\begin{array}{c}\text { Year } \\
\text { published }\end{array}$ & $\begin{array}{c}\text { Code } \\
\text { number }\end{array}$ \\
\hline Science report prepared by the Technical Manager & 2016 & \\
\hline Hazard analysis and critical control points report & 2016 & \\
\hline Configuration of the trial prepared by the Specialty Grower & 2016 & \\
\hline Fungal Spore Monitoring (contractor's report) & 2017 & D1 \\
\hline Close out report from Technical Manager to CEO & 2017 & \\
\hline
\end{tabular}

The three people interviewed are reported in Table 52; the Technical Manager, a key person, was on leave and not available.

Table 52. People interviewed in Case Study D

\begin{tabular}{|c|l|c|c|l|c|c|}
\hline $\begin{array}{c}\text { Perso } \\
\mathrm{n} \text { code }\end{array}$ & \multicolumn{1}{|c|}{ Job title } & $\begin{array}{c}\text { Decision } \\
\text { maker (Y/N) }\end{array}$ & $\begin{array}{c}\text { Risk } \\
\text { assessor } \\
\text { (Y/N) }\end{array}$ & Highest qualification & $\begin{array}{c}\text { Years in } \\
\text { current or } \\
\text { similar role }\end{array}$ & $\begin{array}{c}\text { Professional body } \\
\text { membership }\end{array}$ \\
\hline DA & CEO & Y & N & BSc & 6 & $\mathrm{~N}$ \\
\hline DB & $\begin{array}{l}\text { Health \& Safety } \\
\text { Manager }\end{array}$ & N & Y & $\begin{array}{l}\text { MSc Environmental } \\
\text { Management }\end{array}$ & 3 & $\begin{array}{l}\text { New Zealand Institute } \\
\text { of Safety Management }\end{array}$ \\
\hline DC & $\begin{array}{l}\text { Specialty } \\
\text { Grower }\end{array}$ & N & Y & $\begin{array}{l}\text { Tertiary degree, } \\
\text { ecology \& biosecurity }\end{array}$ & 4 months & $\mathrm{N}$ \\
\hline
\end{tabular}




\subsubsection{Decision to be made}

In 2016, management investigated whether growing oyster mushrooms for sale into the New

Zealand food retail sector would be commercially viable and compliant with legislation.

\section{Background to growing mushrooms}

As summarised in Figure 42, cultivation of the common mushroom in New Zealand for production of button, cup and flat mushrooms is a well-established cyclical process, comparable with practices in the UK (Molde, 2011) and USA [DA].

Figure 42 Cultivation cycle for common mushroom

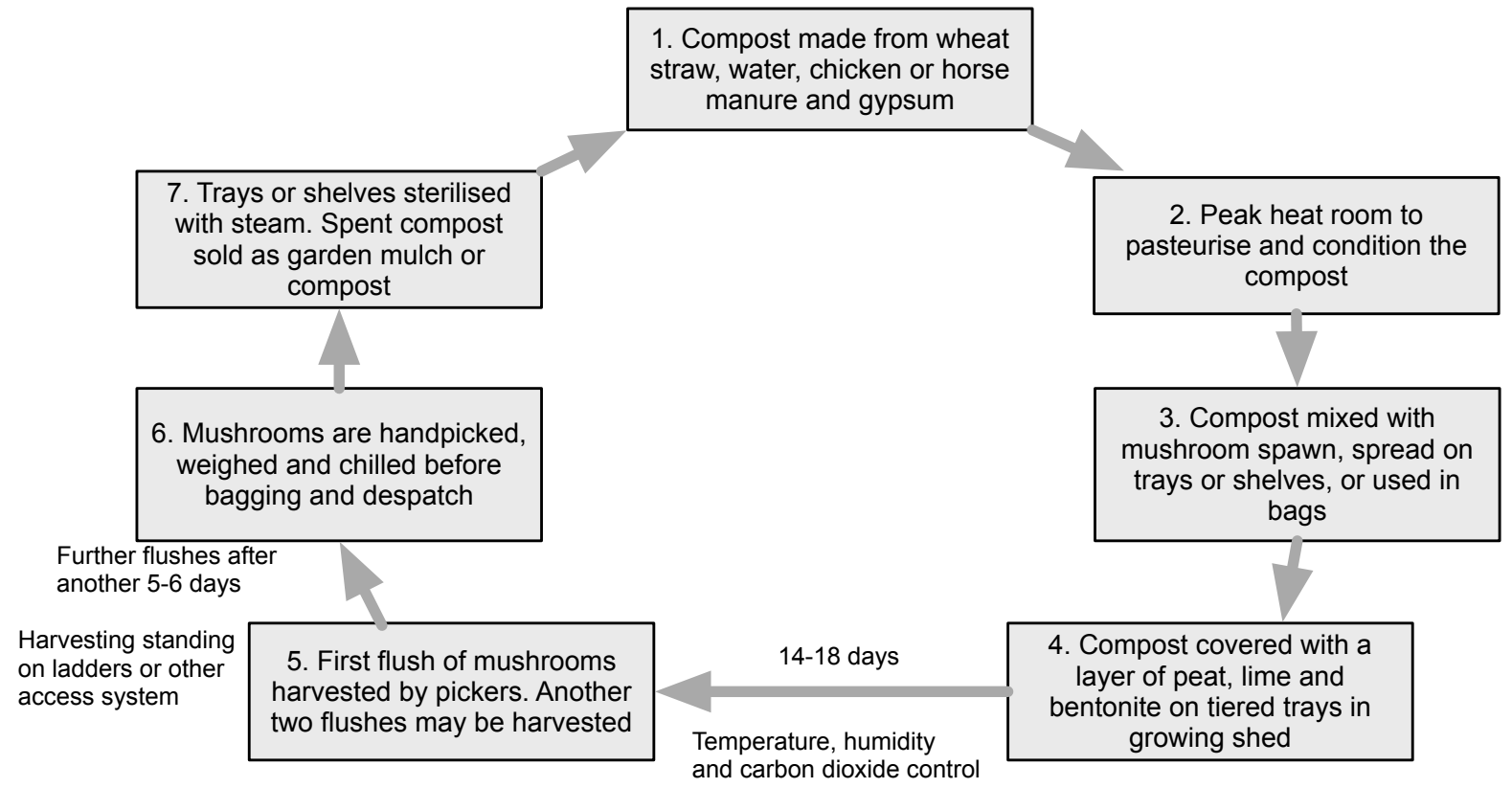

Adapted from Buchanan \& Barnes (n.d.) and Mushroom Growers Federation New Zealand Ltd (n.d.)

\section{Growing oyster mushrooms}

Oyster mushrooms are claimed to have greater nutritional value and health benefits and their scarcity and taste make oyster mushrooms a higher value mushroom than the common mushroom (Agaricus bisporus) (Anon, 2018).

The oyster mushroom (Pleurotus ostreatus) is an exotic species in New Zealand and not approved for importation under the Hazardous Substances and New Organisms Act (Buchanan \& Barnes, n.d.). Buchanan \& Barnes reported limited experience growing $P$. pulmonarius (the endemic species) at a small scale by a few New Zealand growers since 1994. Thus, it is conjectured, any associated occupational health problems may not have been noticed in New Zealand.

Growing oyster mushrooms in New Zealand (see Figure 43) is reported to use bags of wood shavings prepared offsite and placed on tables or shelves in a room with temperature and humidity control (Buchanan \& Barnes, n.d.) and [D2]. 
Figure 43. Cultivation cycle for oyster mushrooms

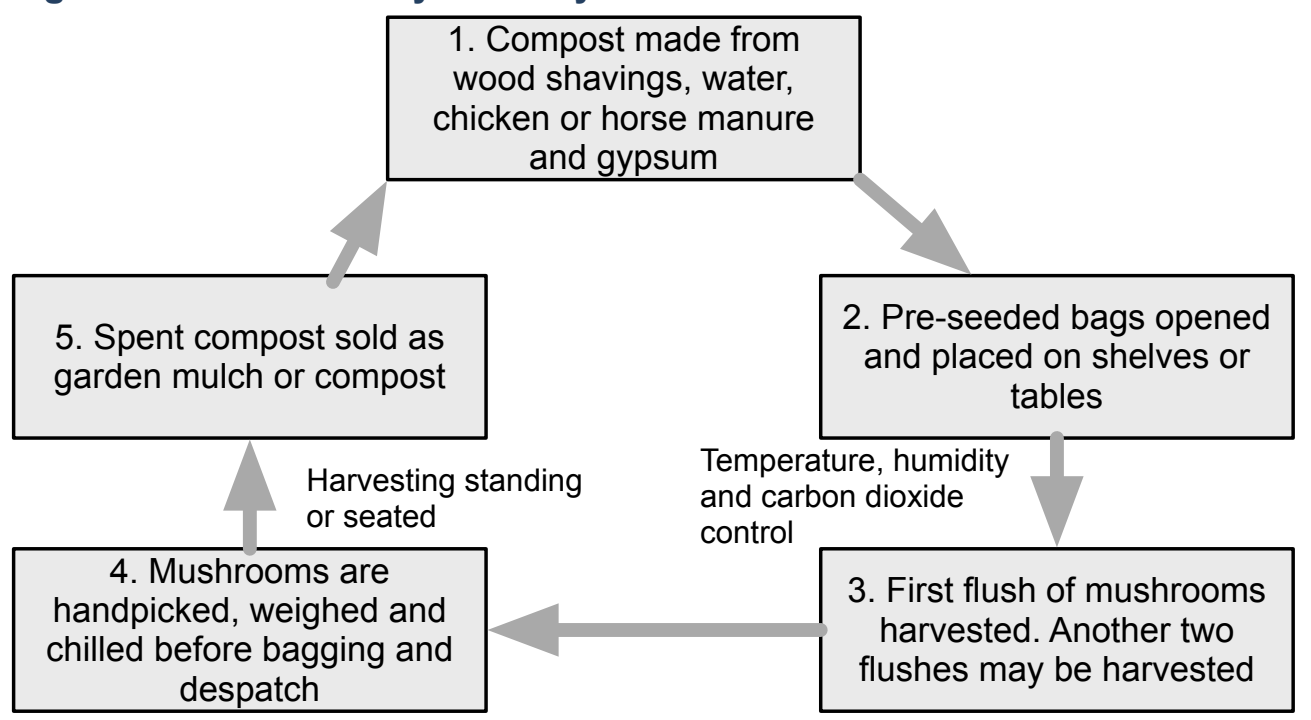

Source: author

For this trial, the case study "bought the bags just for the trials and grew them" in a room roughly $3 \times 3 \times 2$ metres [DB]. The trial had 16 bags at a time maturing with about 67 bags in the room; each bag was about $30 \times 70 \mathrm{~cm}$. Harvesting would take about 3 hours [D1]. During that time:

The spores, you could really see them coming off from the mushrooms. That was an indicator for everybody that we had to be very careful doing this. [DB]

Molde (2011, p. 1) similarly noted that oyster mushrooms are species "that may spore heavily prior to and during harvesting". Thus, workers standing or sitting alongside bags while harvesting them will have been exposed to potentially high levels of spores.

\subsubsection{Case study analysis}

The tentative GT for an effective risk assessment (section 3.2), CSF and $13 \mathrm{NC}$ are again used in a "bottom up" (ie, reverse) order as a framework for analysis of data from the interviews, reports and interviews.

\section{Literature or document review fairly sets out data (NC 01)}

The Technical Manager "had done a scientific paper as part of a review of anything relating to this particular species and had not found anything to give us at least a warning" [DA]. The interviews suggest it may have contained a preliminary hazard analysis and critical control points (HACCP), a food safety technique. Use of HACCP appears to have framed risks as being those to food safety and production and not to occupational health. When the Health and Safety Manager was co-opted into the project team, monitoring the spores was suggested [DB]. A more detailed HACCP study, reported as being carried out during the pilot project, contained flowcharts and detailed records of hazards and critical control points [DB]. 
As only one document was available from the case, a short literature search was carried out by this author and is summarised in Box 4 .

\section{Box 4. Literature relevant for Case Study D: OHS in mushroom growing}

A Google Scholar search for "oyster mushroom lung disease", yielded three relevant articles (Cox, Folgering, \& van Griensven, 1988; Mori et al, 1998; Senti et al, 2000) that could not be read without buying them or having access to the relevant databases but the abstracts gave sufficient information to raise concerns about occupational health. A search of the HSE website for documents that contained "mushroom" or "bioaerosol" also found relevant reports. In addition, a brief literature search was carried out that identified seven articles of relevance from which further articles about oyster mushrooms were identified. Relevant search results were grouped as below with preference given to publicly available reports and academic articles used to support them. Common occupational health and safety hazards in commercial mushroom cultivation include: work at heights on ladders or from access platforms; heat; humidity; exposure to excess carbon dioxide in enclosed spaces; exposure to bioaerosols, fungal spores and other allergens, also in enclosed spaces.

Early reports of respiratory disease in mushroom workers in the 1950s related to the common mushroom causing mushroom worker's lung and mushroom grower's lung (Bringhurst, Byrne, \& Gershon-Cohen, 1959; Newman Taylor, 1994; Stewart, 1974). Stewart (p. 252) described the disease as "due to the inhalation of organic dust particles derived from either the mushrooms, their spores or the compost in which the mushrooms are grown". A textbook on diseases of occupations described farmer's lung and mushroom worker's lung as two distinct forms of extrinsic allergic alveolitis (Newman Taylor, 1994) that might be diagnosed as occupational asthma ("... symptoms of wheezing, chronic coughing, shortness of breath resembling those of asthma, attributable to occupational exposure to allergens that cause true asthma, or to dusts, fumes, or suspended atmospheric particles" (Senti et al, 2000; Tanaka et al, 2002)). Molde (2011) described occupational health hazards (including "mushroom worker's lung" and "mushroom picker's lung") associated with cultivation of the common mushroom (Agaricus bisporus), but noted that few cases were reported in the UK. Exotic species such as the oyster mushroom (Pleurotus osteatus) "may spore heavily prior to and during harvesting" but is not found in New Zealand. Another species, P. pulmonarius, is endemic and has been cultivated overseas and locally (Buchanan \& Barnes, n.d.); it was the subject of the pilot project [D1]. Work on $P$. osteatus spores identified allergic reactions under experimental conditions (Schachter et al, 2011) and in mushroom workers (Cox et al, 1988; Mori et al, 1998; Vereda et al, 2007).

Aerosols containing spores, organic dusts (including from compost) and other particulate matter have been found to cause occupational asthma (Crook, Easterbrook, \& Stagg, 2008; Lacey \& Dutkiewicz, 1994; Stagg et al, 2010; Swan et al, 2003); three of these references are publicly accessible research reports and mention mushroom compost. A 13-year longitudinal study found a higher rate of coughs in compost workers and those who had left the industry when compared with a control group (van Kampen et al, 2016).

The reports in Box 4 would have provided background information relevant to the risk assessment and helped to move it from characterised as a food safety assessment to include occupational health. Consideration of some of the human factors shown in Figure 36 might also have signalled the need to consider job-related factors. 


\section{Terms of reference for risk assessment are clear (NC 02)}

The terms of reference for this risk assessment are not clear but in late 2016 at least some project team members were verbally "co-opted into the group to look at the health and safety parts of it" [DB] because the company was "about to ramp up the harvesting and test run". Up to that point, the Technical Manager had been doing the test runs with the participation of harvesting staff and shipping departments to see if the quality of the crop could be improved. The increased project team was working with them to arrange schedules for shipping to market [DC].

Three reports were issued at the end of the pilot project. The reports from the Technical Manager and Specialty Grower [DC] could not be found but the report from the consultancy that monitored the spores has been used [D1].

\section{Relevant qualifications and experience stated or available (NC 03)}

The key reports were not available for review so it is unknown if the qualifications and experience of the assessment team were stated.

\section{Impartiality in terms of funding and mandate (NC 04)}

The funding and mandate for the risk assessment was evidently from the management team and board and was not cited in the Review Report.

\section{Stakeholders and risk assessors have a shared understanding of risk (NC 05)}

The extent to which there was a shared understanding of the occupational health risk due to oyster mushroom spores is not clear. After he was co-opted into the project team, the Health and Safety Manager "was looking at the safety, how they pick, working inside the growing room, how high are the racks, the safety parts of that. At the same time, suggesting the measurement of spores exposure" when he observed the clouds of spores.

\section{Appropriate engagement with stakeholders (NC 06)}

Engagement within the project team and with other stakeholders included interviews, workshops, and one-on-one with people; "we have been doing these things for some time after health and safety incidents and I think the company is quite good at bringing together people who are involved in whatever the process was and workshopping it, looking at ways to minimise the risk" [DA]. The clouds of spores and their occupational health issues were not noticed or commented on initially.

\section{Competent and impartial risk assessor or team (NC 07)}

The Technical Manager (“a very capable person" [DA]) was leading a project team that, by late 2016, included the Health and Safety Manager, Packaging Manager, Harvesting 
Manager, Occupational Health Nurse (a contractor), and a Specialty Grower [DB, DC]. The job titles are assumed to indicate relevant expertise. In addition, the Health and Safety Manager reported having an MSc and the nurse held at least two nursing qualifications and a current practicing certificate (https://www.nzohna.org.nz/membership/).

\section{Risk is correctly framed (NC 08)}

The project "was a mix of health and safety, financial, environmental. It was more the business-as-usual, more on the food safety part of it" [DB].

The table below summarises how the decision-makers and risk assessors characterised the objectives of the decision and risk assessment, with OHS being but one among others. Such characterisation of this risk assessment as being about more than either OHS or compliance generally agrees with other work that found adoption of good OHS practices often has drivers other than legal requirements, including ethical considerations and commercial benefits (Baker, 2002; Nielsen \& Parker, 2012). Food safety was not mentioned.

Table 53. Character of the decision

\begin{tabular}{|l|c|}
\hline $\begin{array}{c}\text { Possible objectives of the decision } \\
\text { or risk assessment }\end{array}$ & $\begin{array}{c}\text { Whether this objective was } \\
\text { mentioned in Case Study D }\end{array}$ \\
\hline Business as usual & X \\
\hline Compliance & X \\
\hline Decision making & $X$ \\
\hline Delivery of goods or services & $\checkmark$ \\
\hline Environmental & $X$ \\
\hline Equipment fit for purpose & $\checkmark$ \\
\hline Financial & $X$ \\
\hline Good practice & $\checkmark$ \\
\hline $\begin{array}{l}\text { Occupational health and safety } \\
\text { (including welfare) }\end{array}$ & $\checkmark$ \\
\hline Project management & $\checkmark$ \\
\hline $\begin{array}{l}\text { Quality management (fit for } \\
\text { purpose) }\end{array}$ & $\checkmark$ \\
\hline Reputation & $X$ \\
\hline Strategic & $\checkmark$ \\
\hline Sustainability & $\checkmark$ \\
\hline
\end{tabular}

\section{Criteria for risk evaluation set (NC 09)}

Because the reports were not available for review it is not known if they included risk criteria or wider terms of reference. 


\section{Appropriate language, graphics and layout (NC 10)}

The key reports were not available and so their language, graphics and layout could not be judged.

\section{Systematic hazard or risk identification (NC 11)}

The food safety assessment was about the room, the equipment, the boxes that bags of mushrooms were placed into, and the chiller used to transfer from the growing building to the packing building [DB], and used HACCP as legally required under New Zealand legislation (Food Act, 1981) and the international Codex Alimentarius (FAO, 2003). The HACCP analysis (IEC/ISO31010, 2009; ISO22002, 2009; Lee, 2012) used flowcharts [DB] to develop an "appropriate food safety programme". No preliminary hazard analysis (Aven, 2008) was reported as being carried out that might have identified spores as a risk to occupational health.

This weight of legal requirements for a food producer may have led to an imbalanced risk assessment with attention skewed towards food safety and insufficient emphasis on occupational health and safety. Here, this meant there could be a very low level of food safety risk but a high level of occupational health risk [DB].

Both the Health and Safety Manager [DB] and Specialty Grower [DC] only became involved in the project after it had started and then raised concerns about spores [DB].

Perhaps with hindsight:

For this type of mushroom [peak spore release] is when they are just about to be ready, it's pretty close to the peak in terms of the flushes: first, second, third flush. If you wait a little while they can come again. First fruiting is the highest: when they are just coming up to harvesting they are high, very high" [DC]

Preliminary research by the case study had not identified cause for concern and smaller New Zealand companies growing oyster mushrooms were not know to have found problems with high spore concentrations.

The CEO gave an anecdotal account of visiting a farm in the USA that was growing oyster mushrooms in two rooms. "A lady I talked to had been doing it for 15 years and she was wearing a half mask with a filter in it, but only when the mushrooms were sporing. In their 'infant' stage they are not producing spores. If you were to plot it, they go exponential and it was only when there were spores in higher numbers that they would wear this mask". The species of oyster mushroom being grown was not stated. 
As a result, spore control was believed to be "definitely manageable" for case study staff had "never come across anything telling us you needed anything other than a filter mask to work in this environment" [DB].

\section{Appropriate risk analysis techniques were used (NC 12)}

Had the spore hazard been known before the trial started, a low-cost technique using a dust lamp could have been used to qualitatively identify the presence of fine particulate matter (HSE, 2015). The dust lamp is a high intensity torch shone through a cloud of dust or fume and the beam viewed slightly to one side as it to illuminates the dust. The cloud can be photographed or videoed and provides qualitative evidence of the problem. This might have demonstrated the health hazard earlier in the trial, enabling a change of approach or termination of the trial.

The air sampling approach used by the contractor was carried out near to the end of the trial when the project team "did know it could be a problem, the amount of spores in the harvesting room. It could be a problem so a report was commissioned to do a count of the spores" $[D C]$. The sampling met good practice and trapped spores, dust, pollen and bacteria from the breathing zone of the worker being monitored. Although subsequent tests did not include culturing fungi or other organisms, they did enable identification of fungi species and counting spores, pollen, dust and any non-viable fungi spores (these can also cause an allergic response in susceptible people) [D1]. Test certificates of the equipment were available

\section{Appropriate risk evaluation techniques have been used (NC 13)}

Only one worker engaged in oyster mushroom harvesting was monitored once, but the contractor considered it likely that manual handling of oyster mushrooms on the packing line would also generate substantially higher concentrations of airborne spores than handling of common mushrooms (Agaricus bisporus) [D1]. Taken alone, this single test might not be seen as providing the "best available information" (ISO31000) or "weight of evidence" (Weed, 2005) on which to base the decision, but there was already observational evidence about the spores [DB].

It is also likely the link in the contractor's report [D1] might have been followed by management to the report by Molde (2011) so providing further evidence of a significant occupational hazard.

The legal requirement (2015) to eliminate or reduce occupational health and safety-related risks "so far as is reasonably practicable" was indirectly applied in that a range of risk treatment options were considered to be practicable but most would require more 
investigation. The contractor noted that "extremely high concentrations of oyster mushroom spores were recorded ... where harvesting took place" [D1] and that this required an increased level of respiratory personal protective equipment. This was practicable and financially reasonable but unacceptable to the workers.

The risk evaluation took "a fairly risk averse approach, although other companies might not be so concerned ... We are aware of some small - and larger - enterprises that are growing this mushroom without the precautions that we would require if we were to do it" [DA].

The CEO also made clear his personal aversion to the risk:

Speaking outside my expertise here, but if one in a hundred or one in a thousand people react it could result in a serious loss of lung function. To the extent that if this person was sensitised and came across these mushrooms while preparing a meal they would immediately have to leave. It could be a very serious reaction. [DA]

This emphasised the link between workers workplace exposure (which could be controlled) and their domestic exposure (which could not be directly controlled).

\section{Risk assessment appropriately communicated to decision makers (CSF 01)}

The Technical Manager's report was not available so it was not possible to judge how well it communicated the outcome to the CEO as the decision maker. Given comments by the CEO quoted above it is evident he trusted her judgement and technical advice, although he "was a little bit surprised" by the content of the report.

\section{All relevant factors including controversies and uncertainty have been fully and correctly evaluated (CSF 02)}

The report from the Technical Manager to the CEO was reported as including reference to the findings in the contractor's report and recommendation of a high level of respiratory personal protective equipment [D1]. It made a very strong recommendation to not proceed with the project because there was no confidence the spore-related risk could be managed properly, so "we decided to pass" [DA].

Treatment options that were discussed included:

- "can we grow in the open" [DC] (although scaling might be a problem and "we couldn't [grow] in an open space") [DB]

- investigation of administrative controls, including training and the correct mushroom picking technique [D1]

- "switching to a different species or variety of oyster mushrooms that would produce less spores" [DC] 
- altering the growing conditions to reduce the number of spores [DC]

- use of aspirated respiratory protective equipment [D1] (but not a preferred option of the health and safety manager)

- import of a different species that produces fewer spores and so reduces the risk (this would require consent under the Hazardous Substances and New Organisms Act and might take two or three years) [DC].

The Specialty Grower [DC] wrote a report to the Technical Manager suggesting:

... recommendations on possible ways to alleviate the problem with spores and ensure that people could work in the safest possible manner

... how to reproduce the production of oyster mushrooms in those conditions and with the resources of staff, and engineering, growing packing, shipping; how you could set it up again and possibly go into full-time production

... how [production] could get back up and running as quickly as possible.

\subsubsection{Summary of the risk assessment and outcomes}

The CEO "decided to pass", meaning production did not proceed and the spore-related risk was eliminated. Thus, it is not possible to show how many workers harvesting or packing oyster mushrooms might have been harmed had full-scale production proceeded. The decision to not proceed was reported to the directors who "expressed huge disappointment about this project being stopped but they didn't put undue pressure on anyone" [DA].

\section{Risk assessment objectives}

As the risk assessment objectives were not available it is not possible to comment on whether they were achieved. What can be said is there may have been a possible confusion between the HACCP analysis required by the Food Act 1981 for food safety purposes and the apparently less obvious need for a risk assessment that met the reasonably practicable test under the Health and Safety at Work Act (Peace, 2017b).

In box 1, Figure 44 (a qualitative influence diagram) the project was started by the Technical Manager who carried out the legally required HACCP study (box 3 ) for food safety purposes. The lack of a wide document review (box 4) contributed to the pilot study being well established (box 5) when the when the Health and Safety Manager and Specialty Grower were co-opted onto the project team (boxes 6 and 8). They commented on excessive spores (box 7), leading to engagement of the specialist consultancy (box 9), supported by a specialist laboratory. The consultancy report strongly influenced both the health and safety and technical managers who, in turn, strongly influenced the CEO (box 10). He then decided the project should halt and not proceed to commercial production of oyster mushrooms. 
Figure 44. Case Study D qualitative influence diagram

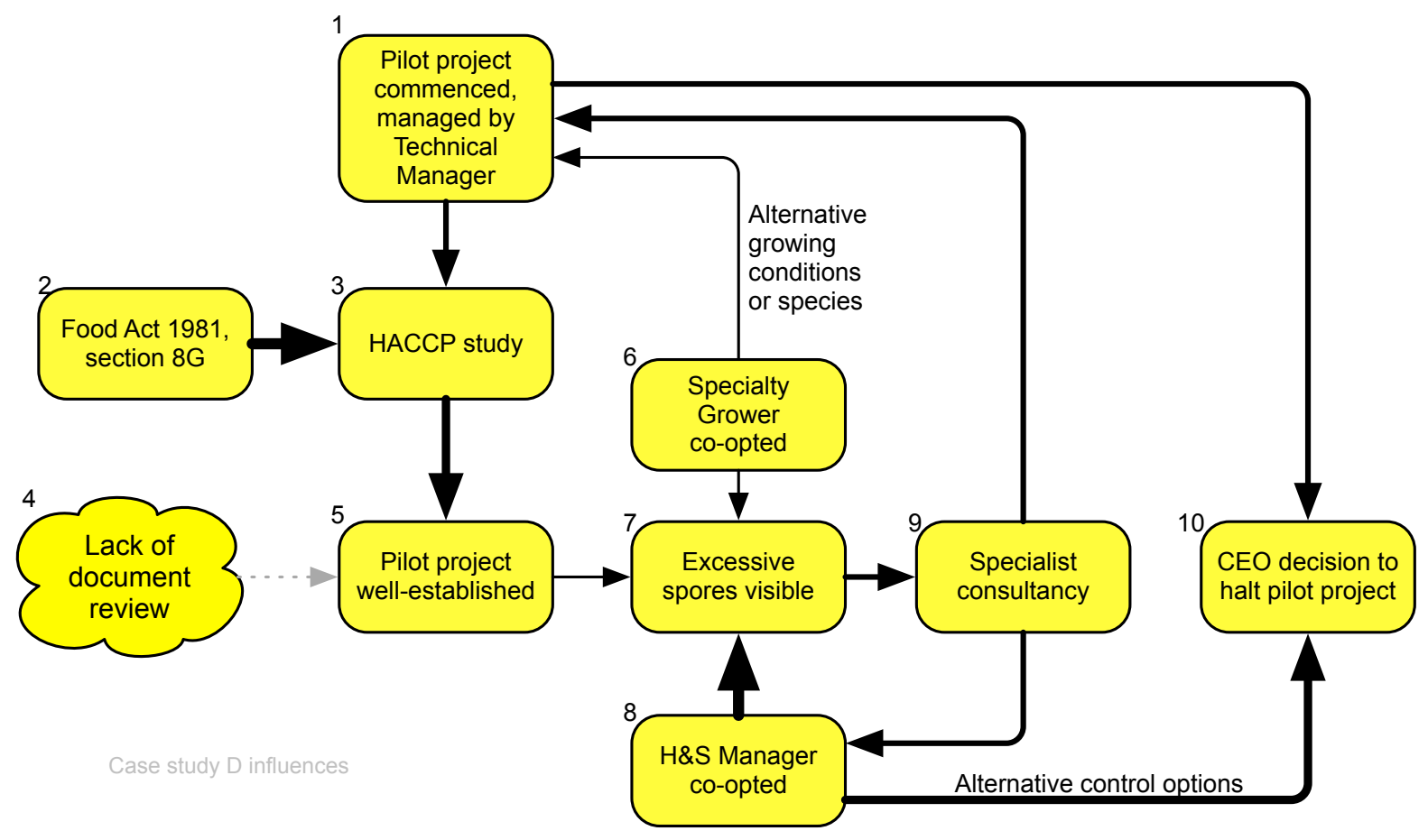

\section{Summary of the outcomes}

The weight of evidence in this case study strongly suggests the HACCP study in early 2016 was not effective for OHS-related risks but the early 2017 assessment was effective in informing the CEO about the decision to be made and contributed information necessary for a successful outcome (cancellation of the project). Figure 45 reflects this evaluation in that the decision had a successful OHS outcome (workers were not needlessly exposed to a serious long- or short-term risk to their health) even though there was a poor commercial outcome. Such an overall outcome confirmed the need for early engagement with all stakeholders to help ensure their concerns are heard and responded to.

Figure 45. Effectiveness of a risk assessment compared with outcomes

\section{Decision outcome}

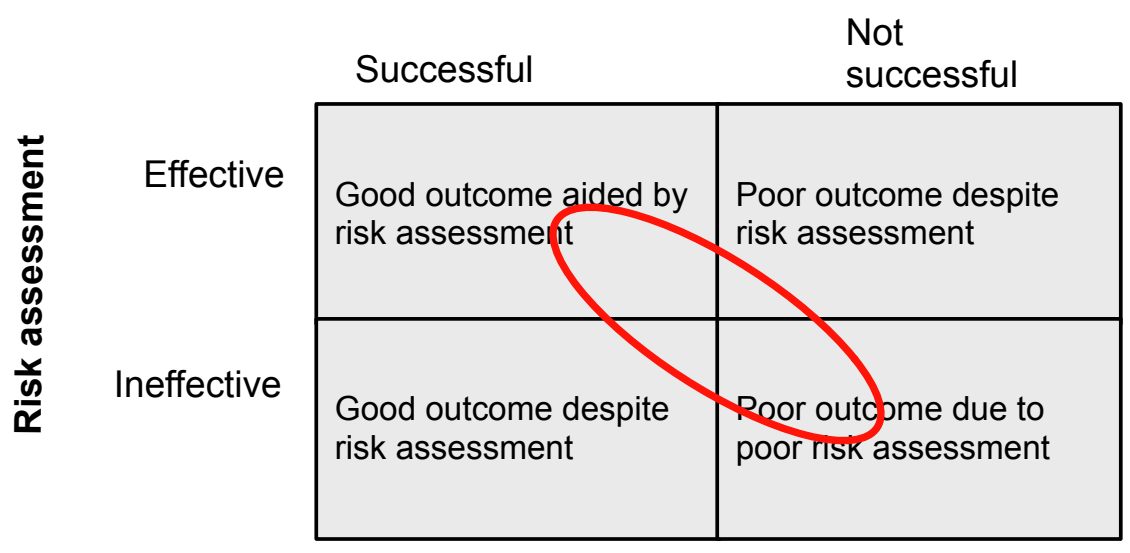


The Technical Manager's initial report (one component of NC 01) was not available and may have covered issues such as the different allergenic properties of common and oyster mushrooms spores, a key issue in the later risk assessment. It might also have explored whether the species of oyster mushroom seen being cultivated in the USA by the CEO was Pleurotus osteatus (not found in New Zealand), P. pulmonarius (endemic in New Zealand) or some other species with different allergenic properties.

\subsubsection{Evaluation of Case Study D risk assessment using the goal tree}

The tentative GT (section 3.2), postulated 13 NCs and two CSFs for a risk assessment to be considered effective. To summarise the findings and indicate the magnitude of "satisficing" (Dettmer, 2003, p. 66) these have been colour shaded in Figure 46 to show if they were met substantially, partially, or not at all/very little. NC 03 is green because the qualifications of the risk assessors were substantially known. NC 04 is left clear as it was judged not relevant in case D. NC 07 and 10 are also clear as no evidence was available.

Figure 46. The goal tree and the risk assessment in Case Study D

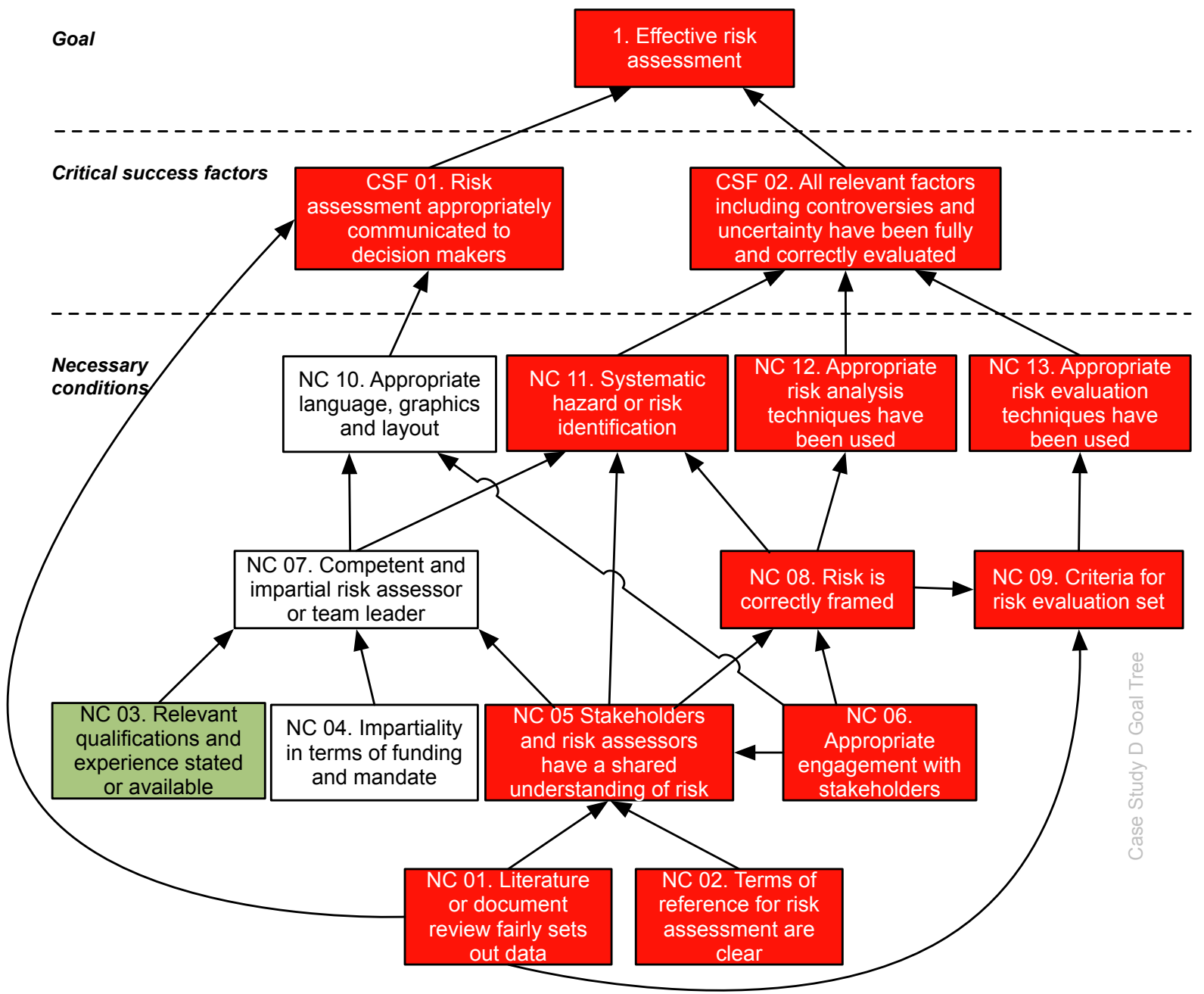


The linkages between the NC and CSF were weak, showing a general lack of engagement. The document review (NC 01) and terms of reference (NC 02) were not at all met. Correct criteria (NC 09) were not at all established; stakeholders had very little shared understanding of risk (NC 05); the risk was not at all framed correctly (NC 08); and stakeholders were not at all engaged until late in the pilot study.

Human health risks (NC 11) due to spore inhalation by pickers were not at all identified or analysed until late in the project despite guidance to "generate a comprehensive list of risks ... because a risk that is not identified at this stage will not be included in further analysis" (ISO31000, 2009, p. 17). In NC 12, HACCP was the legally required risk analysis technique for food-related risks but only partially applicable to OHS-related risk (IEC/ISO31010). A workshop-based hazard and operability study (HAZOP) study (IEC61882, 2016) would have required use of guide words such as More, Less, As well as, Other than, and Compatibility that might have defined possible variations in the atmosphere when comparing common and oyster mushrooms. The evidence suggests a "what you see is all there is" or WYSIATI assessment (Kahneman, 2011, pp. 85-88) up to late 2017.

\section{Interviewee responses}

Interviewees were asked to review and comment on the GT. The CEO said "nothing strikes me as particularly missing" and the Health and Safety Manager similarly could not "see anything to add" but did ask whether "the sponsor should be at the beginning?".

The Specialty Grower also thought "it looks pretty complete" but asked for clarification of critical success factor 02 - "all controversies and so on". In the ensuing discussion he thought "there's always going to be uncertainty, I think we are trying to minimise uncertainty. Would you say that was the goal, the best sort of risk assessment, you're trying to get everything?".

The Specialty Grower then concluded that the risk assessment for oyster mushrooms "would be correctly evaluated by this [pointing to GT] ... The right decision was made based on this diagram, the necessary condition about impartiality, that would be nice but is not necessary". 


\subsection{Case Study E data and analysis}

This case study is based on an interview with the CEO alone and hence is only partial. It has been included despite the paucity of data to illustrate more fully the range of risk assessments that may be carried out as part of organisational decision making. It revealed a case where the risk assessment was a progressive iteration over a 12-month period that focused on the production site and distant market without considering transport corridors that might be catastrophically disrupted.

\subsubsection{Business environment of the decision}

Case Study $\mathrm{E}$ is a long-established primary food production business, originally owned by two families. In 2003, following a buy-out by one family, a new General Manager began investigating replacement of the fully depreciated and obsolete production assets. In 2008 this led to a strategic plan for the progressive replacement of old buildings, plant and equipment with modern assets. These were based on a new technology developed in Holland that would provide a safer and more efficient working environment. The project was planned to be in two stages with the first stage completing in 2011 , having replaced about half of the old assets. The company then spent five years learning how to best exploit the new technology. The General Manager was promoted to Chief Executive Officer in 2011 and led planning for the second stage. In 2016, after consideration of options and risks, the decision was made to start the second stage on the existing main site on the South Island. Subsequently, the Kaikoura earthquake damaged key transport links to expanding markets.

A timeline for the case from 2003 to 2017 is shown in Figure 47.

Figure 47. Timeline of the Case Study E decision

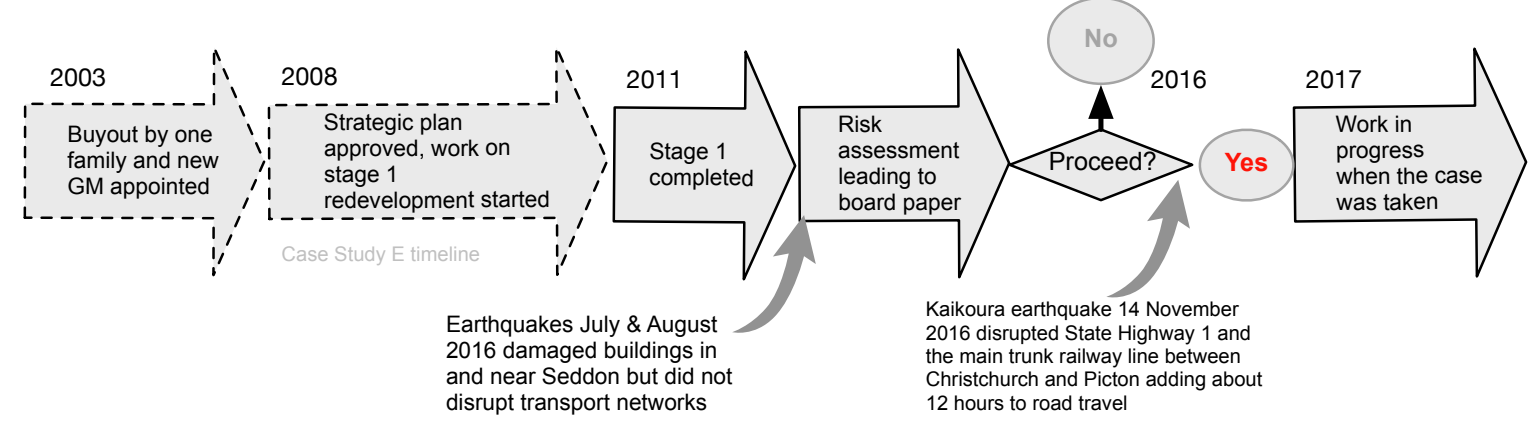

\subsubsection{Case study documents and interviewees}

No documents were provided by the case study. Details of the CEO are in Table 54. 
Table 54. People interviewed in Case Study E

\begin{tabular}{|c|l|c|c|c|c|c|}
\hline $\begin{array}{c}\text { Person } \\
\text { code }\end{array}$ & Job title & $\begin{array}{c}\text { Decision } \\
\text { maker } \\
(\mathrm{Y} / \mathrm{N})\end{array}$ & $\begin{array}{c}\text { Risk } \\
\text { assessor } \\
\text { (Y/N) }\end{array}$ & Highest qualification & $\begin{array}{c}\text { Years in current } \\
\text { or similar role }\end{array}$ & $\begin{array}{c}\text { Professional body } \\
\text { membership }\end{array}$ \\
\hline EA & CEO & $\mathrm{Y}$ & $\mathrm{Y}$ & $\mathrm{BSc}$ & 6 & $\mathrm{~N}$ \\
\hline
\end{tabular}

\section{Decision to be made}

The decision to be made was whether to complete redevelopment of the main production site on the South Island or open a new production site on the North Island near to growing markets in Auckland.

\section{Background to the sector}

The case study had implemented new technology making it highly competitive with others in its sub-sector but it was distant from an expanding market in and around Auckland. Some small competitors were making niche products but lacked the resources to compete with its three main products. Due to the nature of its products there was little threat of import substitution.

\subsubsection{Case study analysis}

The tentative GT for an effective risk assessment (section 3.2) provided a framework for analysis of data from the interview. The GT, CSF and $13 \mathrm{NC}$ are reported on, as before, in a "bottom up" (ie, reverse) order.

\section{Literature or document review fairly sets out data (NC 01)}

No documents were available for review because no records had been kept in an accessible place. No literature review was reported by the CEO even though this was a major capital expenditure project, highly dependent on timely delivery of a perishable product to markets more than $1100 \mathrm{~km}$ distant in Auckland. A brief literature review was therefore carried out as part of this research and is reported below. 
Box 5. Literature relevant for Case Study E: transport corridor vulnerability

The New Zealand transport network is typically long and narrow with relatively little redundancy outside the main centres. A Google Scholar search found limited open-source research on disruption of these highways. A Master's thesis that focused on the Kaikoura District road network (Clydesdale, 2000) accurately described the vulnerabilities of parts of SH1on the South Island. A New Zealand Transport Agency (NZTA) strategic case for the Picton to Christchurch section of State Highway 1 (James, 2016), noted that "the freight route from Picton along the east coast of the South Island is the primary freight route in the South Island" and that "SH1 has sections that are prone to closure from natural events (extreme rainfall, sea surge, earthquakes)". It was published nearly three years after the Seddon earthquake and six months before the Kaikoura earthquake caused major blockages of the SH1.

This data was difficult to find but did indicate the subsequent consequences of the Kaikoura earthquake - both State Highway 1 and the main trunk railway were blocked, resulting in goods traffic being diverted for nearly two years and considerable economic disruption (Market Economics Ltd, 2017). Two experienced business continuity practitioners were asked what data they would have accessed before that earthquake to support consultancy work. Both thought the risks were analogous to State Highway 1 north of Wellington but neither could identify authoritative grey literature that would have been of assistance.

Terms of reference for risk assessment are clear (NC 02)

No terms of reference were stated by the CEO but "the plan was always to follow through and convert all of the old technology to the new technology" requiring careful assessment of risks, some of which were new or had changed since the first stage was completed.

\section{Relevant qualifications and experience stated or available (NC 03)}

The CEO provided his qualifications and experience in the consent form.

Impartiality in terms of funding and mandate (NC 04)

The funding and mandate for the risk assessment was evidently from the board.

\section{Stakeholders and risk assessors have a shared understanding of risk (NC 05)}

The objective was to rationalise production sites and cater better for the growth market. The uncertainties were, "to work out from a strategic point of view where we wanted to put this investment" [EA].

\section{Appropriate engagement with stakeholders (NC 06)}

The CEO spoke at length about engagement with the board and line and technical management about the proposal. He emphasised that "the company is quite good at 
bringing together people who are involved in whatever the process was and workshopping it, looking at ways to minimise the risk".

\section{Competent and impartial risk assessor or team (NC 07)}

The CEO was the primary risk assessor with support of other managers but no further information about the team was available.

\section{Risk is correctly framed (NC 08)}

Risk was framed in terms of uncertainties of access to raw materials and the new production facility. The CEO was asked to characterise the risks and he described all characteristics listed in Table 55 except risk associated with decision making, illustrating the "tone from the top", his values and the values of the shareholders. Sustainability has become a more important objective since one family took control in 2003. However, "delivery of goods or services" (Table 55) was not described as being vulnerable to disruption of the transport corridor between Christchurch and Picton.

Table 55. Decision objectives - case study E

\begin{tabular}{|l|c|}
\hline \multicolumn{1}{|c|}{ Possible objectives of the decision or risk assessment } & Whether this objective was mentioned in Case Study D \\
\hline Business as usual & $\checkmark$ \\
\hline Compliance & $\checkmark$ \\
\hline Decision making & $\checkmark$ \\
\hline Delivery of goods or services & $\checkmark$ \\
\hline Environmental & $\checkmark$ \\
\hline Equipment fit for purpose & $\checkmark$ \\
\hline Financial & $\checkmark$ \\
\hline Good practice & $\checkmark$ \\
\hline Occupational health and safety (including welfare) & $\checkmark$ \\
\hline Project management & $\checkmark$ \\
\hline Quality management & $\checkmark$ \\
\hline Reputation & $\checkmark$ \\
\hline Strategic & $\checkmark$ \\
\hline Sustainability & $\checkmark$ \\
\hline
\end{tabular}

\section{Criteria for risk evaluation set (NC 09)}

No written criteria were stated but "We've gone to what we think is best practice in the industry" for operational risk (including occupational health and safety) and for financial risk "I call it the peak debt, managing the company's debt level".

Appropriate language, graphics and layout (NC 10)

The report was not available for review. 


\section{Appropriate systematic hazard or risk identification (NC 11)}

Because risk identification was "very much building on the previous work" [EA], it was possible that an emerging source of risk might be missed, although "next week we are going to have an external review of our risk management. We haven't done that before - used an external agency to help us benchmark ourselves. But that's what we're doing, for the first time". The outcome of that workshop does not form part of this research.

Risk identification did not include offsite causes such as disruption of transport routes to the major markets in the North Island. This might have been done by flowcharting the business as a supply chain from suppliers to customers and asking "what if" questions. When analysed this might have shown a human factors issue with longer driving times and requirements for breaks.

\section{Appropriate risk analysis techniques were used (NC 12)}

A critical raw material is primarily produced in the region near the main site and the analysis appears to have been essentially qualitative, comparing and contrasting the availability of raw materials and production locations, including:

- raw material produced in the region near the main site and used at the main site

- raw material produced in the region near the main site and transported to a new production site near Auckland

- raw material produced in the Auckland region and used at a new production site near Auckland.

The analysis included transport costs and "was probably more a continuation of the strategic reviews conducted over the years" that update the 10-year strategic plan and included "where do you produce the [raw material] if you've got a production base in the North Island?". The plan was updated every 1-3 years and covers many of the risks in the strategic reviews "so it's very much building on the previous work", perhaps an unstructured form of scenario analysis (IEC/ISO31010, 2009; Schwartz, 1996; Stulz, 2008).

Data for the reviews came from "interviews, workshops, and one-on-one with people". It was analysed using the "risk management document with the severity and likelihood and those sort of things, so that we end up with a priority list".

\section{Appropriate risk evaluation techniques have been used (NC 13)}

No information about techniques was given other than discussion of board meetings when the issues were workshopped. 


\section{Risk assessment appropriately communicated to decision makers (CSF 01)}

The report was not available for review but the oral descriptions suggested it was probably appropriately communicated to the board.

\section{All relevant factors including controversies and uncertainty have been fully and correctly evaluated (CSF 02)}

The report was not available for review but the oral descriptions suggested it did cover all relevant factors.

\subsubsection{Summary of the risk assessment and outcomes}

The risk assessment evolved over a protracted period (perhaps 12 months) with board feedback and questions driving further analysis. It led to the decision to replace them all old buildings on the main site and with modern buildings and new technology. Total production capacity was only increased by about $10 \%$ but the changes led to greater efficiencies, improved occupational health and safety, compliance with resource consents, and greater sustainability. Transport costs of product to the expanding market were deemed acceptable but disruption of key transport routes (as happened in the Kaikoura earthquake) was not assessed. When redevelopment of the main site was completed and production increased, such disruption might have a detrimental effect on product quality due to the temporary increased travel times to North Island markets.

The lack of any documents to review and the above led to the risk assessment being only partially effective.

Figure 48. Effectiveness of a risk assessment compared with outcomes

\section{Decision outcome}

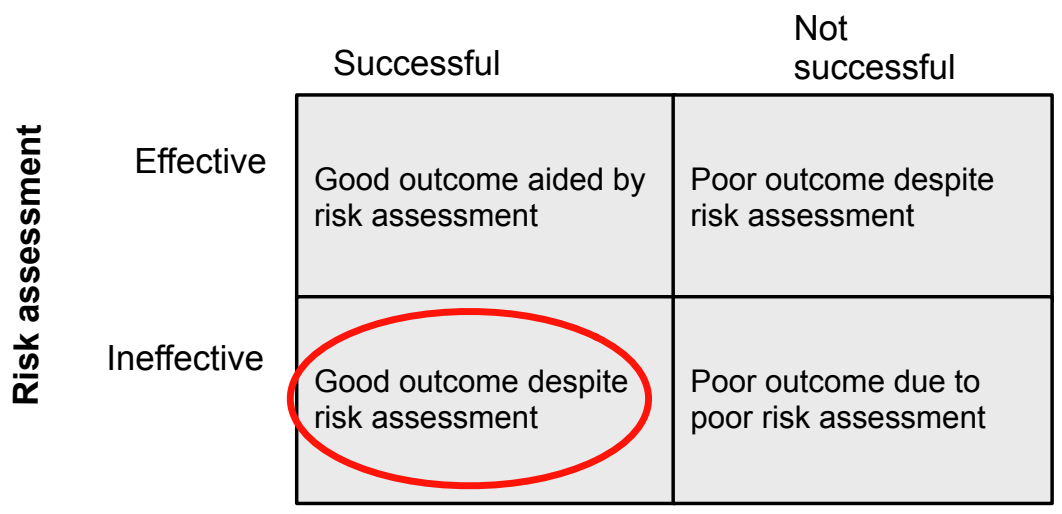

\subsubsection{Evaluation of Case Study E risk assessment using the goal tree}

The tentative GT (section 3.2), postulated 13 NCs and two CSFs for a risk assessment to be considered effective. To summarise the findings and indicate the magnitude of "satisficing" (Dettmer, 2003, p. 66), these have been colour shaded in Figure 49 to show if they were met 
substantially, partially, or not at all/very little. NC 04 is left clear as it was again judged not relevant in this case.

The absence of any document review or board papers and the interview with the CEO showed board or management consideration of the security of transport links was not at all or very little (NC 01). This suggested the need for a wide-ranging and independent risk assessment to complement business cases.

The board appears to have had a partially shared understanding of risk NC 05 (supported by substantial engagement, NC 06); they knew much about production and sales but not transport. The terms of reference, NC 02 , were not at all stated .

NC 08 was partially correctly framed in relation to production but not to external factors that might disrupt delivery.

Figure 49. The goal tree and the risk assessment in Case Study E

Red/dark grey $=$ not at all or very little Amber/mid grey = partially $\quad$ Geen/light grey = substantially

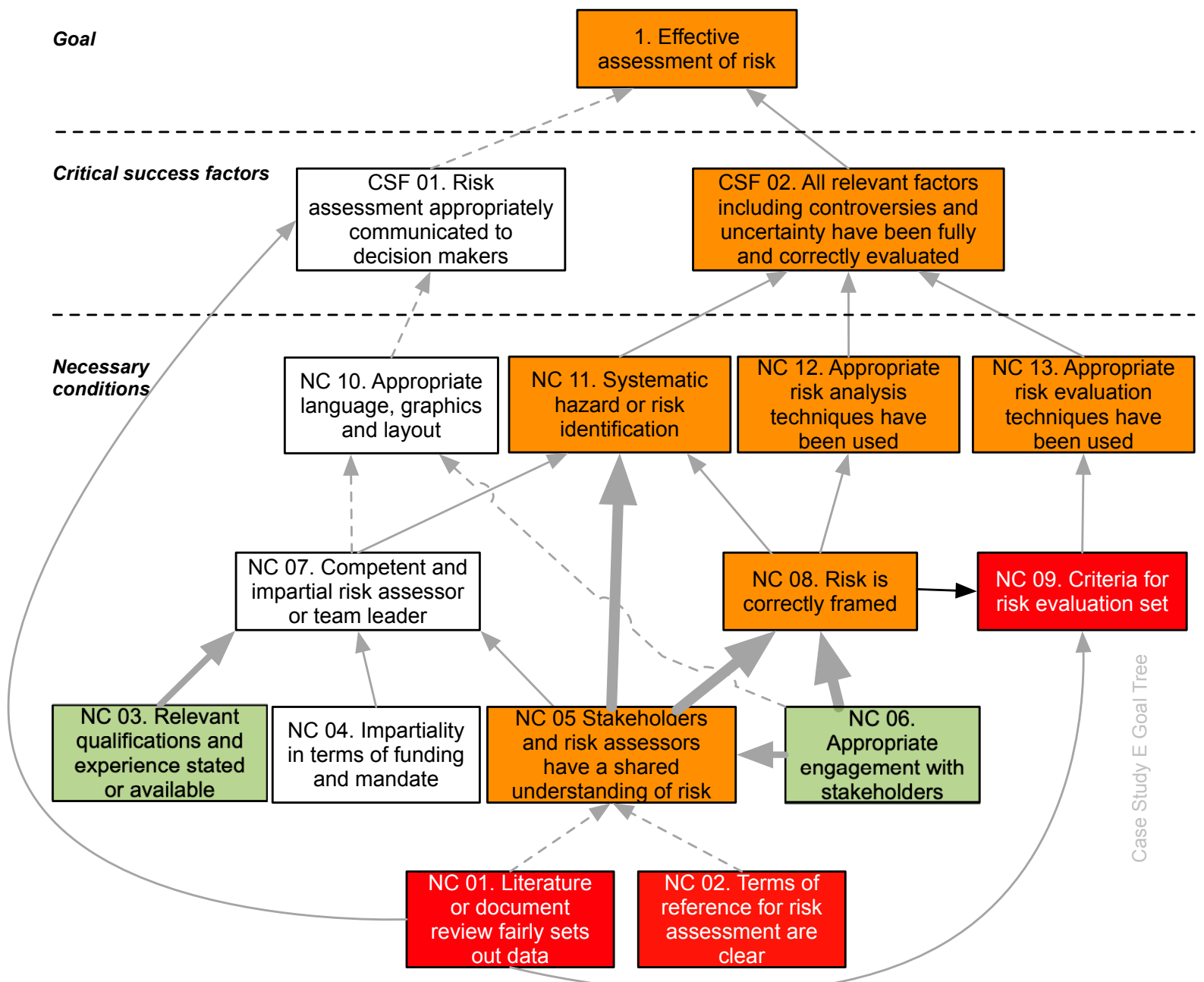

The linkages between NC 06 and NC 08 and between NC 05 and NCs 08 and 11 were very strong but the magnitudinal achievement of nine NC was partial or not at all. 
All "significant" risks should be considered (ISO31000) but risks were not systematically identified by the case, instead being taken from several iterations of the strategic plan. Major disruption of $\mathrm{SH} 1$ was an unidentified, major risk, that eventuated after the decision to proceed and that caused major disruption of road and rail routes to key North Island markets. NC 11 "systematic hazard or risk identification" was therefore partially met; NC 12 (risk analysis) and NC 13 (risk evaluation) could not respond to the missed risk, and CSF 02 was partially met because relevant factors on the transport routes was not included.

NC 10 is clear as the report giving rise to CSF 01 (also left clear) was not seen.

\section{Interviewee response}

The CEO was asked to review and comment on the GT and thought it covered most issues.

\subsubsection{Case study E discussion}

This partial case study provided an interesting example of a risk assessment that had "evolved" over a 12-month period as a series of board meetings with the CEO. Little or no relevant literature (NC 01) was available but the case organisation could have taken external advice and might have been advised that the transport corridor was vulnerable to a single major event. Such vulnerability has been well known for many years in relation to the transport corridors north of Wellington. After the Canterbury earthquakes this would have been a prudent step but was not taken by management and the board did not press, let alone consider, the issue.

\subsection{Case study chapter summary}

This chapter has reported the data from four full and one partial case study. Analysis of the data from each case has shown individual deficiencies.

Case studies A and B used a form of gap analysis but both had a narrow approach to the obvious issues without investigating how other or external factors might affect the organisation. Case study $E$ also failed to consider external factors in the form of threats to the transport corridor near Kaikoura and may also have failed to consider the corridor north of Wellington. Case study $C$ provided a good but incorrect risk assessment (improve the standard operating procedure and continue to use quad bikes) when the CEO was concerned about the risk of a worker fatality while using a quad bike. Case study $D$ also provided an example of using the wrong terms of reference (carry out a food safety risk assessment) when the greater risk was harm to worker health.

Common themes were:

- lack of literature or document reviews 
- unclear terms of reference

- absence of clear criteria for risk evaluation

- lack of a structured risk assessment process

- lack of systematic risk identification.

The next chapter provides a full comparison between, and comparison of, the case studies and the online survey. 


\section{Comparison between, and discussion of, the case studies and survey}

\subsection{Overview}

The previous two chapters have reported data from the online survey and analysis of that data. This chapter compares responses from interviewees to the standard questions and discusses common features in the data from the online survey and case studies.

\subsection{Case study limitations and summaries}

Despite initial hope that case studies would be easy to negotiate, more than 40 promising cases did not come fruition, perhaps due to the lack of effective risk assessments or records of risk assessments (Gadd et al, 2000; Lenhardt \& Beck, 2016), the embarrassment this might cause, or failure to identify the value of risk assessments (Goble \& Bier, 2013).

The five case studies are summarised in Table 56.

Table 56. Summary of case studies characteristics

\begin{tabular}{|c|c|c|c|c|}
\hline $\begin{array}{l}\text { Case } \\
\text { study } \\
\text { code }\end{array}$ & $\begin{array}{l}\text { Industry } \\
\text { sector }\end{array}$ & Brief summary of decision & $\begin{array}{l}\text { Risk assessment } \\
\text { characteristics }\end{array}$ & Decision outcome \\
\hline$A$ & Construction & $\begin{array}{l}\text { What form the new occupational health } \\
\text { and safety (OHS) management system } \\
\text { should take, given likely changes in } \\
\text { OHS legislation }\end{array}$ & $\begin{array}{l}\text { A gap analysis } \\
\text { comparing then-current } \\
\text { practices with } \\
\text { AS/NZS4801: } 2001\end{array}$ & $\begin{array}{l}\text { Good outcome partially } \\
\text { aided by the risk } \\
\text { assessment }\end{array}$ \\
\hline B & $\begin{array}{l}\text { Office building } \\
\text { occupier }\end{array}$ & $\begin{array}{l}\text { What actions should be carried out } \\
\text { post-2013 earthquakes to minimise } \\
\text { damage to assets and disruption of } \\
\text { activities as a result of a similar or } \\
\text { greater event affecting Wellington }\end{array}$ & $\begin{array}{l}\text { A gap analysis } \\
\text { comparing then-current } \\
\text { practices with two } \\
\text { reports on damage and } \\
\text { disruption in Canterbury } \\
\text { University following the } \\
2010-2011 \text { earthquakes }\end{array}$ & $\begin{array}{l}\text { Poor outcome due to poor } \\
\text { risk assessment }\end{array}$ \\
\hline C & $\begin{array}{l}\text { Land } \\
\text { management }\end{array}$ & $\begin{array}{l}\text { Whether the level of work health and } \\
\text { safety risk associated with use of quad } \\
\text { bikes was acceptable }\end{array}$ & $\begin{array}{l}\text { A workshop informed by } \\
\text { readily available } \\
\text { information and a risk } \\
\text { matrix }\end{array}$ & $\begin{array}{l}\text { Good outcome despite the } \\
\text { flawed risk assessment }\end{array}$ \\
\hline D & $\begin{array}{l}\text { Primary food } \\
\text { sector }\end{array}$ & $\begin{array}{l}\text { Whether growing oyster mushrooms for } \\
\text { sale into the New Zealand food retail } \\
\text { sector would be commercially viable } \\
\text { and compliant with legislation }\end{array}$ & $\begin{array}{l}\text { The assessment had } \\
\text { the wrong terms of } \\
\text { reference but was } \\
\text { informed by an external } \\
\text { analysis of mushroom } \\
\text { spores }\end{array}$ & $\begin{array}{l}\text { Poor outcome for the } \\
\text { commercial activity due to a } \\
\text { poor initial risk assessment } \\
\text { but a good outcome for } \\
\text { OHS aided by the later risk } \\
\text { assessment }\end{array}$ \\
\hline$E$ & $\begin{array}{l}\text { Primary food } \\
\text { sector }\end{array}$ & $\begin{array}{l}\text { Whether to complete redevelopment of } \\
\text { the main production site on the South } \\
\text { Island or open a new production site on } \\
\text { the North Island near to growing } \\
\text { markets in Auckland }\end{array}$ & $\begin{array}{l}\text { An iterative process } \\
\text { between the CEO and } \\
\text { board }\end{array}$ & $\begin{array}{l}\text { Good outcome despite the } \\
\text { risk assessment failing to } \\
\text { consider an external cause } \\
\text { (earthquake) disrupting } \\
\text { transport links }\end{array}$ \\
\hline
\end{tabular}




\section{Limitations}

The five case studies provided data that was voluntarily disclosed but with no opportunity to corroborate it. They were diverse organisations, employing between several hundred and a few thousand employees in urban and rural settings on fixed and temporary worksites.

Although data made available in Case Study E was very limited it provided insights into a risk assessment in a medium-size business.

\subsection{Interviewees in the case studies}

The interviewees were asked a set of standard questions and their responses are summarised in this section.

\section{Demographic data}

Data about the interviewees is analysed in Table 57. Eight of the interviewees were decision makers and 11 were risk assessors with one (the CEO in Case Study E) having both roles.

Table 57. People interviewed in the five case studies

\begin{tabular}{|c|c|c|c|c|c|c|}
\hline $\begin{array}{l}\text { Person } \\
\text { code }\end{array}$ & Job title & $\begin{array}{c}\text { Decision } \\
\text { maker } \\
\text { (Y/N) }\end{array}$ & $\begin{array}{c}\text { Risk } \\
\text { assessor } \\
\text { (Y/N) }\end{array}$ & Highest qualification & $\begin{array}{l}\text { Years in current or } \\
\text { similar role }\end{array}$ & $\begin{array}{l}\text { Professional } \\
\text { membership }\end{array}$ \\
\hline$A A$ & Chief Executive Officer & $\mathrm{Y}$ & $\mathrm{N}$ & Master's degree & 4 years & CPEng \\
\hline$A B$ & Divisional Manager 1 & Y & $\mathrm{N}$ & BE (Hons) & 6 years & None \\
\hline$A C$ & Divisional Manager 2 & Y & $\mathrm{N}$ & $\begin{array}{l}\text { Certificate in } \\
\text { Construction }\end{array}$ & 16 years & None \\
\hline$A D$ & National HS\&E Manager & $\mathrm{N}$ & Y & Advanced Dip OHS & 2 years 10 months & None \\
\hline $\mathrm{BA}$ & Director Site Services & Y & $\mathrm{N}$ & & & \\
\hline BB & Consultant Planner & $\mathrm{N}$ & Y & BA & 25 years & None \\
\hline$B C$ & Asset Manager & $\mathrm{N}$ & Y & & & \\
\hline $\mathrm{BD}$ & $\begin{array}{l}\text { Manager Customer } \\
\text { Services }\end{array}$ & $\mathrm{N}$ & Y & $\begin{array}{l}\text { PG Cert [sector] } \\
\text { Administration }\end{array}$ & 8 years & $\begin{array}{l}\text { Association of } \\
\text { [sector] Managers }\end{array}$ \\
\hline $\mathrm{BE}$ & $\begin{array}{l}\text { Senior Advisor: Safety, } \\
\text { Risk Assurance }\end{array}$ & $\mathrm{N}$ & Y & $\begin{array}{l}\text { Level } 2 \text { Dip. Safety, } \\
\text { Risk \& Environment }\end{array}$ & 3 years & None \\
\hline CA & Director & Y & $\mathrm{N}$ & University Entrance & 3.5 years & None \\
\hline $\mathrm{CB}$ & National OHS Manager & $\mathrm{N}$ & Y & Grad. Dip. OHS & 16 years & NZISM \\
\hline $\mathrm{CC}$ & $\begin{array}{l}\text { Operations Group } \\
\text { Manager }\end{array}$ & Y & Y & $\begin{array}{l}\text { Bachelor of } \\
\text { Forestry Science }\end{array}$ & 2 years & None \\
\hline$C D$ & Supervisor & $\mathrm{N}$ & Y & None & 1.5 years & None \\
\hline DA & CEO & Y & N & BSc & 6 years & None \\
\hline DB & Health \& Safety Manager & $\mathrm{N}$ & Y & $\begin{array}{l}\text { MSc Environmental } \\
\text { Management }\end{array}$ & 3 years & NZISM \\
\hline $\mathrm{DC}$ & Specialty Grower & $\mathrm{N}$ & Y & Tertiary degree & 4 months & None \\
\hline EA & CEO & Y & Y & BSc & 6 & $\mathrm{~N}$ \\
\hline
\end{tabular}


Due to the small sample size $(\mathrm{N}=14)$ no conclusions are drawn from Table 57 other than to note how few interviewees were members of a professional body $(\mathrm{N}=4)$, with one having resigned from a risk-related professional body, and that half of the interviewees appeared to have less than five years' experience in their role, indicating a lack of training for conducting risk assessments. This is contrasted with respondents in the online survey (section 4.3.3) almost all of whom held some qualifications, were members of a professional body and had at least five years' experience (even though some of these qualifications may have been old or irrelevant to risk assessments).

\subsubsection{Character of the decision to be made}

Table 58 summarises case study interviewee responses to the question "How would you characterise the decision?" and includes online survey data in Table 23. The online survey column is the number of people responding "yes" to the question "did a decision include such characteristics". In some case study interviews characteristics were mentioned during answers to different questions. The total column is sorted in descending order but only represents how interviewees responded, not the number of responses.

Table 58. Character of the decision or risk assessment

\begin{tabular}{|c|c|c|c|c|c|c|c|}
\hline \multirow[b]{2}{*}{$\begin{array}{c}\text { Possible objectives of the decision or risk } \\
\text { assessment }\end{array}$} & \multicolumn{6}{|c|}{ Whether this objective was mentioned in case study: } & \multirow[b]{2}{*}{$\begin{array}{l}\text { Online } \\
\text { survey }\end{array}$} \\
\hline & A & B & C & D & E & Total & \\
\hline Business-as-usual or operational activities & $\checkmark$ & $\checkmark$ & $\sqrt{ }$ & $\checkmark$ & $\checkmark$ & 5 & 19 \\
\hline Financial & $\checkmark$ & $\checkmark$ & $\sqrt{ }$ & $\sqrt{ }$ & $\sqrt{ }$ & 5 & 10 \\
\hline $\begin{array}{l}\text { Occupational health and safety (including } \\
\text { welfare) }\end{array}$ & $\sqrt{ }$ & $\sqrt{ }$ & $\sqrt{ }$ & $\sqrt{ }$ & $\checkmark$ & 5 & 57 \\
\hline Strategic & $\checkmark$ & $\sqrt{ }$ & $x$ & $\sqrt{ }$ & $\sqrt{ }$ & 4 & 47 \\
\hline Delivery of goods or services, or sales & $\sqrt{ }$ & $\sqrt{ }$ & $\sqrt{ }$ & $\mathrm{x}$ & $\mathrm{x}$ & 3 & 8 \\
\hline Good practice & $\checkmark$ & $\checkmark$ & $x$ & $x$ & $\checkmark$ & 3 & $\mathrm{~N} / \mathrm{A}$ \\
\hline Project management & $\sqrt{ }$ & $x$ & $x$ & $\sqrt{ }$ & $\sqrt{ }$ & 3 & 35 \\
\hline Quality management (fit for purpose) & $x$ & $x$ & $\sqrt{ }$ & $\sqrt{ }$ & $\sqrt{ }$ & 3 & 9 \\
\hline Reputation & $\checkmark$ & $\checkmark$ & $x$ & $x$ & $\checkmark$ & 3 & $\mathrm{~N} / \mathrm{A}$ \\
\hline Compliance & $\checkmark$ & $x$ & $x$ & $x$ & $\checkmark$ & 2 & $N / A$ \\
\hline Environmental & $\sqrt{ }$ & $\mathrm{x}$ & $x$ & $\sqrt{ }$ & $\sqrt{ }$ & 2 & $\mathrm{~N} / \mathrm{A}$ \\
\hline Equipment fit for purpose & $x$ & $x$ & $\sqrt{ }$ & $x$ & $\checkmark$ & 2 & $\mathrm{~N} / \mathrm{A}$ \\
\hline Decision making & $x$ & $\checkmark$ & $x$ & $\mathrm{x}$ & $x$ & 1 & $N / A$ \\
\hline Sustainability & $x$ & $x$ & $x$ & $x$ & $\sqrt{ }$ & 1 & 3 \\
\hline Response to external events & $\mathrm{N} / \mathrm{A}$ & $\mathrm{N} / \mathrm{A}$ & $\mathrm{N} / \mathrm{A}$ & $\mathrm{N} / \mathrm{A}$ & $\mathrm{N} / \mathrm{A}$ & $\mathrm{N} / \mathrm{A}$ & 7 \\
\hline Stakeholder management activities & $\mathrm{N} / \mathrm{A}$ & $\mathrm{N} / \mathrm{A}$ & $\mathrm{N} / \mathrm{A}$ & $\mathrm{N} / \mathrm{A}$ & $\mathrm{N} / \mathrm{A}$ & $\mathrm{N} / \mathrm{A}$ & 2 \\
\hline
\end{tabular}


Business-as-usual, financial and OHS were mentioned in each case study, even though case studies A, C and D were predominantly about OHS, suggesting that changes in OHS practices may be based on compliance or good practice but other drivers can be as important (Baker, 2002). Compliance was mentioned in two case studies ( $A$ and $E$ ), with manager $A B$ seeing commercial advantage in an early change to comply with forthcoming OHS legislation:

I sit on the executive team for the company and I am interested in bringing our health and safety systems up to standard for the new health and safety legislation that came into force in April. I guess that's what drove it. Better to get it sorted earlier rather than later $[A B]$

Conversely, the CEO of Case Study E stated "because we have so many resource consents, we have always been very mindful of complying fully, to take a very responsible stance to that".

\subsubsection{How and when the risk assessment was requested}

In cases $A, C$ and $E$ the risk assessment was requested the risk assessment verbally. In case studies $B$ and $D$, the work was a standard response to a major event (case $B$ ) or new product (case D).

\subsubsection{How well the risk assessment informed about the risks}

In Case Study A the risk assessment clearly informed decision makers effectively: "Very well, he followed a structured process for the first three months" and "I think it was fairly clear what the risks were, what the gaps were" [CEO]. Similar comments were given in the other cases.

\subsubsection{What makes a good risk assessment?}

Before they were shown the tentative goal tree the risk assessors and decision makers who were interviewed were asked what makes a good risk assessment. Their collective responses, related to NC in the GT are summarised as:

- how the process engaged with the people affected by the risk (including their importance and influence) (NC 06)

- the issues, current state or context and what has or may have changed (NC 05)

- known causal factors and the full range of possible consequences and their probability or likelihood (NC 11 and 12)

- the nature and level of the uncontrolled risk (NC 12) 
- the current controls covering the consequences and their probability, including whether they form a set or suite of controls, and assurance that the controls work (NC 12)

- the options/opportunities to improve (including a cost benefit analysis), so an informed decision can be made (NC 12)

- a practical, unbiased report that is short and to the point, giving an unflinching look at the process or activity (CSF 01 and NC 13)

- the report should contain complete information, before, during and after, possibly including scientific or engineering data from specialists (CSF 01 and NC 12).

Senior decision makers (eg, directors and the management team) were especially interested in "the showstoppers and what they mean to them" (CSF 02), including legal obligations, to aid with reporting requirements (eg, Financial Markets Authority, 2018; Peace et al, 2017). These responses were considered when developing the mechanisms in chapter 7 , including revision of the GT.

\subsubsection{Did you give or receive any feedback on the risk assessment?}

Feedback to risk assessors is an important way for risk assessors to know how well they have met the needs of decision makers (Tetlock \& Gardner, 2015, pp. 180-185; Thaler \& Sunstein, 2008, pp. 82-83, 99-100).

In Case Study A the CEO "went through the gap analysis and all the recommendations with $[A B]$ first and then the team gave $[A B]$ feedback". This culminated in a high level report that went to the board because "at a high level you've got different forms of approval and feedback" [AA]. In this case study there was a lot of feedback. "Some of it was site based, some high-level" [AB].

It was common for feedback to include verbal or emailed thanks for work done. In some cases this was preceded by a debate about the risk assessment report (eg, Case Study C) or came after a meeting with the CEO to discuss what action to take (eg, Case Study D). The case studies suggested that feedback on a risk assessment was increasingly limited the further a person was removed from the CEO or other decision maker.

In a major investment decision such as in Case Study E, feedback was incorporated in "an iterative process drilling down on these particular areas" that included being "asked for more detail with future projections out over 20 years" [CEO]. 


\subsection{Summary of the goal tree data}

Table 59 uses the same red/amber/green colour coding shown in Table 9 (section 3.2.1) to summarise the GTs for the Shoreham air crash, online survey and five case studies. It strongly portrays Hohmann's (2014) autumnal colours, indicating the inadequacies of the risk assessments in the case studies and Shoreham air crash.

The colour coding is shown as found, not using necessity logic. If necessity logic is used more of the results change to partially or not at all or very little.

Table 59. Summary of the effectiveness of each goal tree

\begin{tabular}{|c|c|c|c|c|c|c|c|}
\hline & & & \multirow{2}{*}{\multicolumn{5}{|c|}{ Case study }} \\
\hline & & & & & & & \\
\hline CSF or NC $\downarrow$ & $\begin{array}{c}\text { Shoreham } \\
\text { aircrash }\end{array}$ & $\begin{array}{l}\text { Online } \\
\text { survey }\end{array}$ & A & B & C & D & E \\
\hline $\begin{array}{l}\text { Effectiveness of the } \\
\text { risk assessment }\end{array}$ & & NK & & & & & \\
\hline CSF 01 & & NK & & & & & NK \\
\hline \multicolumn{8}{|l|}{ CSF 02} \\
\hline \multicolumn{8}{|l|}{ NC 01} \\
\hline NC 02 & & NK & & & & & \\
\hline \multicolumn{8}{|l|}{ NC 03} \\
\hline NC 04 & & NR & NR & NR & NR & NR & NR \\
\hline \multicolumn{8}{|l|}{ NC 05} \\
\hline \multicolumn{8}{|l|}{ NC 06} \\
\hline NC 07 & & & & & & NK & NK \\
\hline \multicolumn{8}{|l|}{ NC 08} \\
\hline \multicolumn{8}{|l|}{ NC 09} \\
\hline NC 10 & NK & NK & & & & NK & NK \\
\hline \multicolumn{8}{|l|}{ NC 11} \\
\hline \multicolumn{8}{|l|}{ NC 12} \\
\hline NC 13 & & & & & & & \\
\hline
\end{tabular}

$\mathrm{NR}=$ Not Relevant

NK $=$ Not Known

As noted earlier, respondents in the case studies often had no professional qualifications or recent experience, suggesting a link to the dominance of not at all or very little in Table 59.

\subsubsection{Key NC and CSF}

In the tentative GT the "few but critical" NCs appear to have been:

- literature or document review fairly sets out data (NC 01) terms of reference for risk assessment are clear (NC 02)

- appropriate engagement with stakeholders (NC 06)

- competent and impartial risk assessor or team leader (NC 07). 
Applying necessity logic ("In order to ... we must ...") to NC 05 Stakeholders and risk assessors have a shared understanding of risk yields the following statement:

In order for Stakeholders and risk assessors [to] have a shared understanding of risk we must provide a Literature or document review [that] fairly sets out data and Terms of reference for risk assessment [that] are clear.

\subsubsection{General comments on the tentative GT}

\section{Risk assessment appropriately communicated to decision makers (CSF 01)}

The reports in cases A, B and C appropriately communicated the results, even though the results were, at best, partially effective, and in cases $B$ and $C$ incorrect. The reports in case $\mathrm{B}$ communicated a retrospective gap analysis, not a prospective risk assessment.

\section{All relevant factors including controversies and uncertainty have been fully and correctly evaluated (CSF 02)}

The reports in cases $B$ and $C$ were based on incorrectly founded risk assessments and so did not describe controversies and uncertainties (eg, human factors in case C).

\section{Literature or document review fairly sets out background data (NC 01)}

The online survey showed that about $25 \%$ of respondents carried out a document review but gave no evidence for the quality of such work. The availability of relevant documents was confirmed by the simple literature reviews in the case studies (Boxes 1-5), although some documents might be hard to find. Due to the rarity of events of interest, such knowledge may be difficult to gain via personal experience, making the published work of others invaluable for risk assessors.

NC 01 was partially achieved in Case Study A and, applying necessity logic, made four higher NC and CSF partially achieved, even though assessed in isolation as substantially achieved (Table 59). This is to say that the lower level NC set the foundations for higher NC and the CSF. This, and similar findings, showed areas where application of Hohmann's (2014) colour coding (Table 9, section 3.2.1) would help identify how the tentative GT specifically (and GTs more generally) could be strengthened before starting an activity leading to the goal.

Case $\mathrm{E}$ did not consider major disruption of transport routes. An informal enquiry with this author's professional colleagues showed none could identify relevant literature and (as shown in Box 5) might have resorted to using their professional judgement (section 6.5.2). This suggests training in online literature searches should form part of training. 


\section{Terms of reference for risk assessment are clear (NC 02)}

In case $A$ the $C E O$ set and supervised the terms of reference but in cases $B, C, D$ and $E$ there was lack of clarity in setting the terms of reference, suggesting this may be a common issue. In case $C$ it resulted in the risk assessment answering the "wrong question".

Relevant qualifications and experience stated or available (NC 03)

Even though this forms part of the credibility of risk assessment framework (CORA, Wiedemann et al, 2013) it was of no significance in cases A, B, C and $E$ and may be more relevant for third party risk assessments that inform public policy. Online survey respondents held credentials and experience that might be stated in a risk assessment report. NC 03 should remain in the GT for those risk assessments in the public domain or those carried out by a third party where the credentials and integrity of assessors may be significant.

\section{Impartiality in terms of funding and mandate (NC 04)}

This too forms part of CORA (Wiedemann et al, 2013) but was of no significance in the five case studies. However, it should remain in the GT for risk assessments in the public domain or those carried out by a third party where the impartiality of assessors may be significant.

\section{Stakeholders and risk assessors have a shared understanding of risk (NC 05)}

With the exception of the Shoreham air crash and Case Study D, this NC was partially achieved and influenced higher NC and CSF. In Case Study D, achievement of NC 05 very little contributed to the project being cancelled once the occupational health risk was understood.

\section{Appropriate engagement with stakeholders (NC 06)}

Each of the case studies (except D) substantially achieved NC 06 and this was often the $\mathrm{NC}$ that enabled some success in the higher NC and CSF.

\section{Risk is correctly framed (NC 08)}

Correct framing leads to application of relevant risk identification, analysis and evaluation techniques. For example, in case $\mathrm{B}$, the framing was about conformance with response work carried out in Christchurch and led to a retrospective result when it should have been prospective. In Case Study D, framing the risk as relating to food safety led to failure to identify, analyse and evaluate OHS-related risks. Such incorrect framing was not recognised as an issue by most respondents. The online survey results suggested that respondents believe they frame risk correctly. 


\section{Criteria for risk evaluation set (NC 09)}

The absence of explicit risk evaluation criteria in the case studies made it difficult to determine if a risk was, or was not, acceptable "as was". Such criteria act as a benchmark against which the findings of a risk analysis are compared. In Case Study C stating a criterion of, for example, fatalities are not acceptable while using an ATV would have quickly made clear the analysed risk was not acceptable and so short-circuited the assessment.

\section{Appropriate language, graphics and layout (NC 10)}

Three of the case studies (A, B and C) provided copies of their reports and cases B and C contained graphics. In each, NC 10 was substantially achieved, despite being written in tertiary-level English.

\section{Systematic hazard or risk identification (NC 11)}

Case studies A and C systematically identified risk as per their terms of reference, whereas Case Study B assumed that what had happened in Christchurch in 2010-2011 was what might happen in a future major Wellington earthquake. (Case Study B also failed to monitor implementation of actions identified in the risk assessment.) Case Study D identified the obvious food safety-related risk but did not look further. Case Study E relied on the strategic plan that had been iteratively updated without actively asking what might have changed or overlooked. The online survey results showed that most respondents used workshops and professional judgement to identify risk.

\section{Appropriate risk analysis techniques have been used (NC 12)}

The online survey results suggested little use of risk techniques, with professional judgement (section 6.5.2) being the dominant approach used. In case studies A, B and C professional judgement was used to seek out data in a workshop, and (in case C) used an adapted consequence/likelihood matrix. In Case Study D, a hazard analysis and critical control points study was carried out but this was not relevant to occupational health. In Case Study E, workshops with the board provided data.

\subsection{Risk techniques in the case studies and online survey}

The most frequently selected risk techniques in the online survey were professional judgement, workshops (including brainstorming), and the consequence/likelihood matrix with ranking scales. These and other techniques were also being mentioned directly and indirectly in the case studies and will now be considered in more depth to respond further to sub-questions 1 and 2 . The use of document or literature reviews is also discussed here. 


\subsubsection{Literature or document reviews}

About $25 \%$ of survey respondents claimed to use document reviews, and only Case Study C effectively used a partial review of relevant literature, suggesting that (in New Zealand at least) there may be a lack of publicly accessible research data that can be used to inform risk assessments, an area for improvement and possibly confirming recent work on knowledge transfer in OHS (Van Eerd, 2019).

\subsubsection{Professional judgement}

Professional judgement was included in the survey in response to one of the focus groups where it was argued strongly it was widely used and should be included in the list of risk techniques. The online survey identified professional judgement as the most commonly selected risk technique and therefore this sub-section reviews some characteristics of professional judgement before considering how its use in risk assessments might be improved. It may be a valid technique in a risk assessment but requires a sufficient range of training, knowledge and experience, as shown in the following review.

Professional judgement is used in diverse areas and people possessing professional judgement are assumed to be experts having "well-learnt, highly-practised" skills (Bolger \& Wright, 1994, p. 2) applying previously learned processes and techniques to help gather and collate data about a problem and so enable forecasting (Tetlock, 2006; Tetlock \& Gardner, 2015) but if they have weak or non-existent supporting evidence (Burgman, 2016) may place undue confidence in their estimates and forecasts. Such forecasting also requires using knowledge prudently and acknowledging what is not known (Meacham, 1990). Thus, forecasting and professional judgement are a form of risk assessment requiring knowledge and expertise.

Figure 50 has been developed to summarise a range of research and models. In row 1 of that model, Collins \& Evans (2007) argued there are two forms of tacit knowledge ubiquitous and specialist.

As shown in row 2, knowledge is acquired from an early age through school, websites, books, TV programmes and other sources, leading to a popular understanding of many topics useful in everyday life. If people decide to enter a trade or profession they are initially taught knowledge from primary sources and rules for its application, so moving from ubiquitous tacit knowledge to specialist tacit knowledge. Such teaching may start with prepared notes, followed by a requirement to seek out relevant knowledge. A person having high expertise may develop "contributory expertise" that is made available to others in their trade or profession, perhaps in the form of textbooks, articles or practice notes. 
Figure 50. Knowledge, skills and judging competence

\begin{tabular}{|c|c|c|c|c|c|c|c|c|}
\hline \multicolumn{9}{|c|}{ Row } \\
\hline 1 & \multicolumn{2}{|c|}{ Ubiquitous tacit knowledge } & \multicolumn{6}{|c|}{ Specialist tacit knowledge } \\
\hline 2 & $\begin{array}{l}\text { "Beer mat" } \\
\text { knowledge }\end{array}$ & $\begin{array}{c}\text { Popular } \\
\text { understanding }\end{array}$ & \multicolumn{5}{|c|}{ Primary source knowledge } & $\begin{array}{l}\text { Contributory } \\
\text { expertise }\end{array}$ \\
\hline 3 & Dreyfus (2004) & $\begin{array}{l}\text { Lay person } \\
\text { having "special" } \\
\text { knowledge }\end{array}$ & Novice & $\begin{array}{l}\text { Advanced } \\
\text { beginner }\end{array}$ & \multicolumn{2}{|c|}{$\begin{array}{l}\text { Competent } \\
\text { practitioner }\end{array}$} & Proficient & Expert \\
\hline 4 & \multicolumn{2}{|c|}{ Fish \& Coles (1998) } & $\begin{array}{l}\text { Automaton or } \\
\text { "junior mechanic" }\end{array}$ & \multicolumn{2}{|c|}{$\begin{array}{l}\text { Practitioner as } \\
\text { Technician }\end{array}$} & \multicolumn{2}{|c|}{$\begin{array}{c}\text { Practitioner as } \\
\text { independent } \\
\text { (senior) technician }\end{array}$} & $\begin{array}{l}\text { Professional } \\
\text { applying expert } \\
\text { judgement }\end{array}$ \\
\hline 5 & \multirow{4}{*}{ 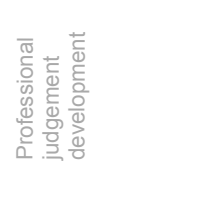 } & \multirow{4}{*}{ Meta criteria -} & & & & & \multicolumn{2}{|c|}{ Interactional expertise } \\
\hline 6 & & & & & \multicolumn{3}{|c|}{ Experience } & \\
\hline 7 & & & Credent & tials & \multicolumn{4}{|c|}{ Continuing professional development } \\
\hline 8 & & & & & & \multicolumn{3}{|c|}{ Track record } \\
\hline
\end{tabular}

Adapted from Collins \& Evans (2007), Dreyfus (2004), and Fish \& Coles (1998)

\section{Skill development}

Row 3 in shows a widely used five-stage process of skill development (Dreyfus, 2004). In relation to the work of risk and safety practitioners (and possibly other professions) it has been expanded to include lay people who may have special, but not specialist, tacit knowledge.

Row 4 shows a similar gradation developed by Fish \& Coles (1998). Rows 3 and 4 bear a resemblance to the range of people on the $X$ axis of Figure 3 (section 2.2) suggesting the range of credentials, experience and expertise that risk assessors may require in different types of risk assessments. A novice or "junior mechanic" in a trade or profession will learn from primary sources, progressively placing rules in the context of their knowledge and applying them mechanistically. A "practitioner as technician" begins to place real-world examples in that context and learn how to better apply rules and maxims. With more experience an emerging competent person recognises the very large number of situational elements they are exposed to and may learn and apply heuristics that enable them to cope. If the heuristics work well, they become additional rules but, if they fail, the person will seek alternative strategies that do work. These in turn may become rules.

Should a person stop here in the "safety of rules", they will not progress beyond competence and will remain in the early stages of independent but senior technician. A proficient person has learned principles and rules but these are progressively replaced by what Dreyfus (2004, p. 180) called "situational discriminations" that a truly independent senior technician can apply. However, they still need to think about what to do to achieve goals or objectives and may revert to application of rules or heuristics. 
A professional applying expert judgement is able to draw on a substantial body of experience to diagnose a problem and know how to achieve a goal. Their responses are intuitive and might be called professional judgement. However, few risk assessors have sufficient experience of all possible combinations in complex situations (La Porte, 1975) and rarely receive feedback on whether a risk assessment was accurate (Tetlock, 2006) or tested by some event. This may make it difficult for a person to form reliable, experiencebased professional judgement.

While rows 3 and 4 in Figure 50 appear to form a hierarchy, they should not be interpreted as such (Fish \& Coles, 1998). Rather, they are a spectrum of skills and judgements a practitioner or professional may move through in any given day or situation. In this spectrum, application of expert judgement is the highest form or level of professional reasoning. It is, however, ephemeral and prone to cognitive biases (Montibeller \& von Winterfeldt, 2015), perhaps even "necessary violations" (Reason, 1998, p. 304) giving rise to adverse unintended consequences.

\section{Interactional expertise}

Collins \& Evans (2007) also identified interactional expertise (row 5 in Figure 50). This expertise might be found in professionals investigating an area of practice, research or knowledge where they lack contributory expertise but know enough about it to be able to hold a conversation with a true expert. It is found in people who have a wide range of experiences.

\section{Expert status}

Conventionally, expertise is recognised by the credentials and experience of a person (rows 6 and 7 in Figure 50) (Bolger \& Wright, 1994; Tetlock, 2006). Although experience develops over time a person might be highly qualified with considerable experience but have a poor track record in their field (Collins \& Evans, 2007).

It has been argued that "expert performance" takes 10 years intense practice to achieve (Ericsson, Krampe, \& Tesch-Romer, 1993), sometimes described as 10,000 hours practice. Assuming a person practises their profession for 25 hours per week in a 48-week working year, it equates to about eight years with the balance spent on other activities. However, deliberate practice in a professional has been found to account for very little competence, with the majority being due to basic qualifications, supervised experience and continuing professional development (Macnamara, Hambrick, \& Oswald, 2014) along with "grit", perseverance and a passion for long-term goals (Duckworth et al, 2007). 


\section{Issues with professional judgement}

In the online survey (section 4.3.3, Table 13), $62 \%$ of respondents had up to 10 years' experience with $42 \%$ having up to 5 years' experience placing many as being (Figure 50 ) novices or advanced beginners having some primary source knowledge. They might be called a practitioner, perhaps working independently. When compared with Figure 3 , section 2.2 , this might place $62 \%$ of respondents as in-house practitioners or professionals but no higher. These results suggest an urgent need for training and mentoring of practitioners who may be called on to exercise professional judgement. The combination of low qualifications and experience of some respondents may make some professional judgements unreliable. It also may explain why some respondents did not use more structured techniques - they had not been trained in their use.

Expert-based approaches such as professional judgement include a spectrum of techniques from assertions-by-experts at one end (least accurate) to Delphi forecasts at the other (more accurate), with quality varying with the knowledge of the experts in relation to the subjects of interest (Sylvan \& Thorson, 1980). Individual experts vary in terms of their ability to cope with large numbers of interdependent variables, and, if such variables and interdependencies are not identified in a structured process, they may be overlooked. How well the forecast turns out depends on both the accuracy of the description of the context and of the assumptions made.

It is well-established that risk assessors answering questions such as "how safe is safe enough?" can suffer from a range of biases, including optimism bias, availability bias and overconfidence, and may take inside views instead of outside views that might improve the quality of the work (eg, Dube-Rioux \& Russo, 1988; Fischhoff et al, 1980; Kahneman, 2011; Kahneman \& Lovallo, 1993; Mandel \& Barnes, 2014; Montibeller \& von Winterfeldt, 2015; Slovic et al, 2000), with bounded rationality - the ability to process a limited amount of data acting as a further source of error (Miller, 1994; Simon, 1979). Thus, if results are obtained by judgement alone rather than through a structured process they should be reported as such (Ale, 2002).

\section{Can professional judgement be improved?}

Tetlock (2006, p. 69) used an analogy from a story by Isaiah Berlin about the hedgehog (which had one big idea) and the fox (which knew many things) to develop the model in Figure 51. A fox-like cognitive style reduces extreme views and hindsight bias and positively influences integrative complexity and openness to counterfactuals, making the forecaster more cautious about probability judgements. These characteristics enable better updating based on new evidence, leading to improved forecasting or risk assessment skills. In 
contrast, a hedgehog knows only one way to defend itself - roll up into a ball - and so is vulnerable to the fox which may have learned many ways of attacking.

Figure 51. Developing forecasting skill

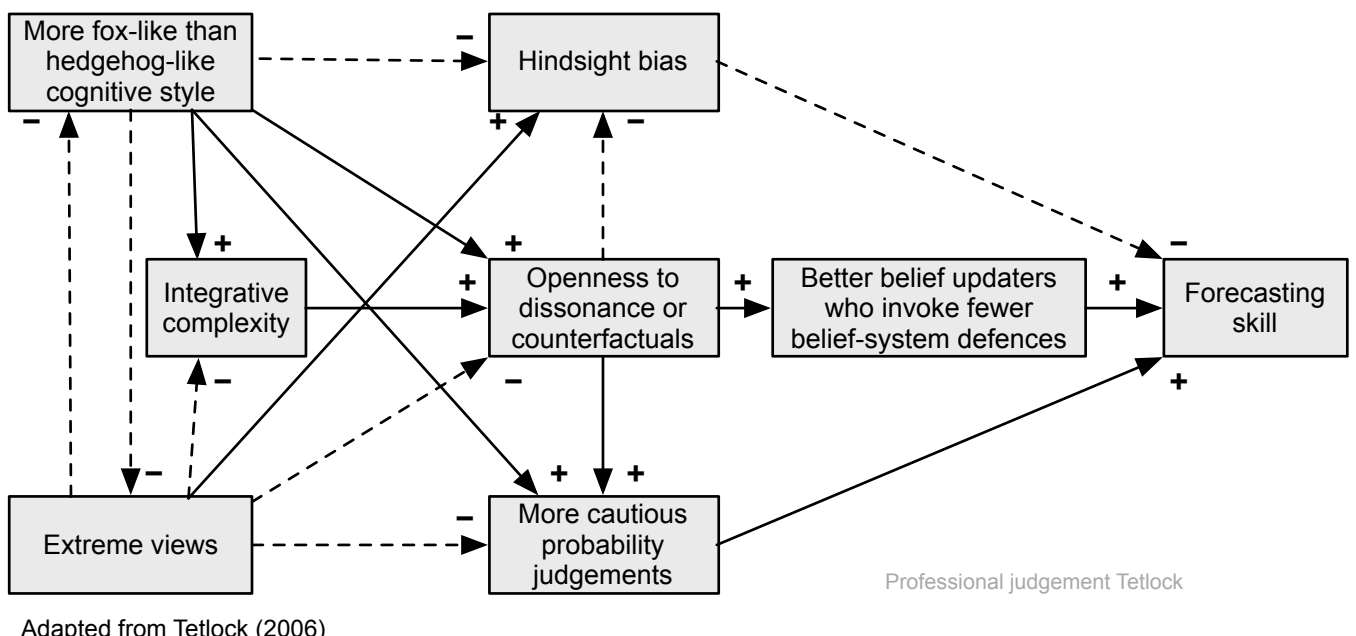

A "fox-like" behaviour involves constantly seeking the best available information through better data collection, fact-checking and attention to diverse sources of information to help overcome biases (Tetlock, 2006, p. 69), so helping to improve risk assessor performance (Owen, 2018). It can include engagement with a diverse range of people ("sometimes fresh eyes" [interviewee BD]) to help identify issues that had been overlooked. Conversely, hedgehog-like behaviour assumes that "what you see is all there is" (Kahneman, 2011, pp. 85-88) resulting in risk assessments being insufficiently informed about the current context of an organisation or activity.

The online survey and case studies showed that document or literature review as part of a risk assessment was not widely used, suggesting that some, perhaps many, risk assessments may be unsupported by published information (eg, applied research or "grey literature" from a reputable source). The five case studies supported this finding, with only one $(\mathrm{C})$ using some applied research and three others using, at best, publicly-available nonspecific documents to inform their work.

Encouraging a fox-like manner in an organisation will require a structured approach to finding and assembling data. However, the online survey suggested that many respondents did not use such processes or techniques.

\section{Discussion}

Professional judgement was included in the online survey in response to the strong views of professional colleagues, providing an interesting result and leading to this brief enquiry into professional development, judgement and expertise. Based on this enquiry, many risk 
assessments based on so-called "professional judgement" may be ill-founded and should be viewed sceptically. Professional judgement unsupported by a formal process or techniques or document review seems to be a pervasive approach by risk and safety practitioners to their work and may be at least a contributory cause of risk assessment ineffectiveness. Further work is needed to discover if many practitioners use a hedgehog-like approach to risk assessments rather than behaving like foxes to elicit rich data that would make their work more effective in informing decision makers.

\subsubsection{Workshops}

After professional judgement, workshops were the second most selected risk technique in the online survey and were used in various forms in each case study ("you pull in a team who will run the project and they workshop everything" $[A B])$. Case studies $A, B$ and $C$ used formal workshops to elicit information while Case Study $E$ used board meetings as a form of workshop to engage in a dialogue about future investment plans.

Workshops have been defined as a "structured, large-group conversation about future uncertainties" (Quail, 2010, p. 155) intended to enable efficient sharing of data ("unknown knowns" in Figure 1) and experiences that may also enable team building and continuous improvement (Cameron, 2005; Sutton, 2006).

To be effective, workshops should be well-planned, facilitated and structured (Niven, 2014; Quail, 2010), include diverse membership (Thaler \& Sunstein, 2008) and require appropriate facilities (Cross et al, 2001). Workshop participants should include subject matter experts for the systems or activities under assessment, supported by people who are risk assessment experts and others who have relevant knowledge (Landquist et al, 2013). Workshops can use some risk techniques (eg, PESTLE, SWOT, or HAZOP analysis) to frame or structure the activity. When planned and run in a structured manner workshops can provide good information and insights (Quail, 2010).

The survey and case studies did not show if use of workshops or brainstorming sessions by respondents met these criteria, and avoided confounding issues, including maintaining individual independence of thought of participants to avoid groupthink (Surowiecki, 2005). This left open whether respondents were reporting effective or ineffective workshops.

The risk canvas, a workshop tool that helps overcome some practical issues, is described in section 7.4.

\subsubsection{Consequence/likelihood matrix with ranking scales}

The matrix has become a widely used but much-criticised risk technique (Ale, Burnap, \& Slater, 2015; Cox, 2008; Franks et al, 2002; Hillson \& Simon, 2007; Julian, 2011; Middleton 
\& Franks, 2001; SA, 2012) requiring qualitative judgement in what may be assumed to be a quantitative process.

While risk matrices apparently provide a simple mechanism for analysing the level of individual risks they too often are poorly designed or incorrectly used (Peace, 2017c) and, when included in risk or safety management software packages, a matrix may be erroneously perceived as being "scientific" and capable of giving reliable results. Any such matrix represents an attempt to fit a wide range of dynamic risk levels into a narrow range of predefined cells, introducing uncertainty about the results.

Used alone as an analysis technique risk matrices are likely to give misleading, even wrong, results leading to false certainties or inappropriate allocation of resources. This can arise from well-intentioned but poor design decisions, as found in Case Study B:

Except we skewed it a bit in terms of high consequence low probability events as opposed to high probability low consequence events. But pretty much the same, the $5 \times 5$ matrix $[B B]$

A matrix should be used to report the findings of a risk analysis (the possible consequences of an event and the likelihood of those consequences) in a graphical form (IEC/ISO31010, 2009). The results should be treated as an indicative comparison between risks, to help distinguish those requiring urgent attention but sometimes a matrix helps identify consequences.

They use the tabular framework where they do the before and after likelihood and impact, they include what could go wrong. But I guess what's quite helpful is the headings. So, what could happen to people, reputation, facilities [BC]

In the survey (section 4.3.12) the consequence/likelihood matrix with qualitative ranking scales was selected by 87 respondents as one of their three qualitative risk analysis techniques, while matrices with quantitative scales was selected by 103 respondents as one of their quantitative techniques. The matrix can also be used to help judge the effectiveness of controls and 77 survey respondents chose it for this purpose. Similarly, the matrix can be used to help choose the best options for risk treatment and was selected by 70 respondents. The matrix was also used by case studies $B$ and $C$ to aid risk ranking ("Oh, certainly the matrix, some way of judging how the risk has been assessed"[AD]). However, in Case Study A, the National Health and Safety Manager deprecated its use ("it was not a question of sitting on your own using a risk matrix. It was more far-reaching than that"). These findings suggest the matrix is of limited value as a risk analysis technique, as has been argued elsewhere (Peace, 2017c). 


\subsubsection{What-if analysis}

Simply asking "What-if?" questions in a workshop can elicit useful data (Adedokun et al, 2006).

[BA] Yes, what-if ... What-if all our computers went down or we were locked out of the building. Okay, we would use computers elsewhere or laptops. Where are those computers or laptops? The answer is we have this wonderful plan that says we have these wonderful resources but no one has said these are the resources that are available and if they are not available, how would we source them?

What-if analysis can be strengthened by structuring the questions in a Structured What-If Then analysis (SWIFT) (Aven, 2008; Card, Ward, \& Clarkson, 2012; IEC/ISO31010, 2009). SWIFT was not reported as being used in Case Study B, suggesting the What-if analysis may have been less structured and hence less reliable.

\subsubsection{Human factors}

Human or performance-shaping factors would have been relevant in each case study (especially case C) but were not explicitly included in their risk assessments. This may have been due to a general lack of training and experience in human factors.

\subsubsection{Gap analysis}

Gap analysis had not been considered as a risk technique until after data collection in case studies A and B. Use of the McKinsey 7-S model showed weaknesses in those case studies, suggesting it could be used to identify areas of uncertainty about current and the proposed conditions. It is included in the next chapter as a mechanism that could facilitate or improve risk assessments for strategic decisions.

\subsection{Conclusions and research questions}

Analysis of the tentative GT showed where individual risk assessments were weak and where there were systemic opportunities for improvement. Decision makers could use the GT to review a risk assessment before using it to help inform a decision, or to develop actions to improve risk assessments generally.

The research question was therefore answered positively.

RQ. Can a generic goal tree, populated with critical success factors and necessary conditions derived from the literature and case studies, be developed that would help decision makers and risk assessors to evaluate the effectiveness of risk assessments before they are used to aid a decision? 
Sub-question 1 asked "What processes and methods are currently being used for risk assessments?". Professional judgement was found to dominate in the online survey and each case study (including Case Study A, where the base gap analysis document was an out-of-date standard) and so was discussed at length in this chapter. The risk matrix was also a popular risk technique, despite its weaknesses, and was found to be inappropriately used. There was generally a failure to use document reviews to search for the best available information. In each case the extent of engagement with stakeholders improved the risk assessment effectiveness. The case studies substantially confirmed the findings of the online survey, including that risk assessments are often largely unstructured and lack support from formal risk techniques even when carried out by risk specialists. As a result, risk assessments (recent or currently being conducted) may be unreliable guides for decision makers. The need for improvement is apparent.

The next chapter addresses sub-question 2.

SQ 2. What mechanisms (in addition to a goal tree) could facilitate or improve risk assessments to provide support for strategic decisions in an organisational setting? 


\section{Mechanisms that might facilitate or improve risk assessments}

\subsection{Overview and research questions}

This research has shown that respondents and interviewees have a preference for qualitative, unstructured risk assessment processes and techniques, typically lacking quality assurance and reproducibility, that potentially create or conceal uncertainty about the achievement of objectives. Sub-question SQ 2 asks "what mechanisms (in addition to a goal tree) could facilitate or improve risk assessments to provide support for strategic decisions in an organisational context?". This chapter further extends the main literature review and places mechanisms derived from research and practice in the revised GT.

\subsection{The revised goal tree}

Applying the logic of Popper (1959) that all research findings are provisional, the tentative GT (section 3.2) has been redrawn as the revised GT, Figure 52. Note that the tentative GT numbering has been retained even though some NC have been removed and the positions of others changed.

The number of NC has been reduced from 13 to 11 . NC 01, 02, 05 and 07 are "the few but critical" NC (Dettmer, 2003, pp. 63-77) and so key to the success of a risk assessment and are shown shadowed.

Two new NC are included in the bottom row as AA and BB.

The connector lines have been revised to reflect linkages supported by this research. Specifically, NC 02 now links to NC 01 to show that terms of reference will specify what a document review should address. NC 05 now links to NC 10 to show that the input of stakeholders will influence report format. As in the tentative GT, NC 01 links to NC 09 but also now links with NC 11 to show that risk identification techniques will be dictated by the background papers and terms of reference. NC 11 now links into NC 12 (risks cannot be analysed if they were not identified) and NC 12 to NC 13 (risks cannot be evaluated if they were not analysed).

\subsubsection{Organisational systems and the goal}

ISO/IEC Annex SL (2012) provides a framework for all management system standards and places risk assessment in clause 6 (Planning) or 8 (Operation). The Strategy and Systems factors in the McKinsey 7-S model, Figure 13, was expanded to ask in Strategy "Are risks assessed as part of change?", and, as part of Systems, "Is there a consistent approach to risk assessment?". These frameworks have been aligned the purposes of this research and 
placed in cloud symbols in Figure 52 with Strategy and Systems seen as system goals (Dettmer, 2007, p. 86), so providing a pragmatic link from this research to practice.

The goal has been revised to "Decision makers receive an effective risk assessment".

Figure 52. Revised goal tree for an effective risk assessment

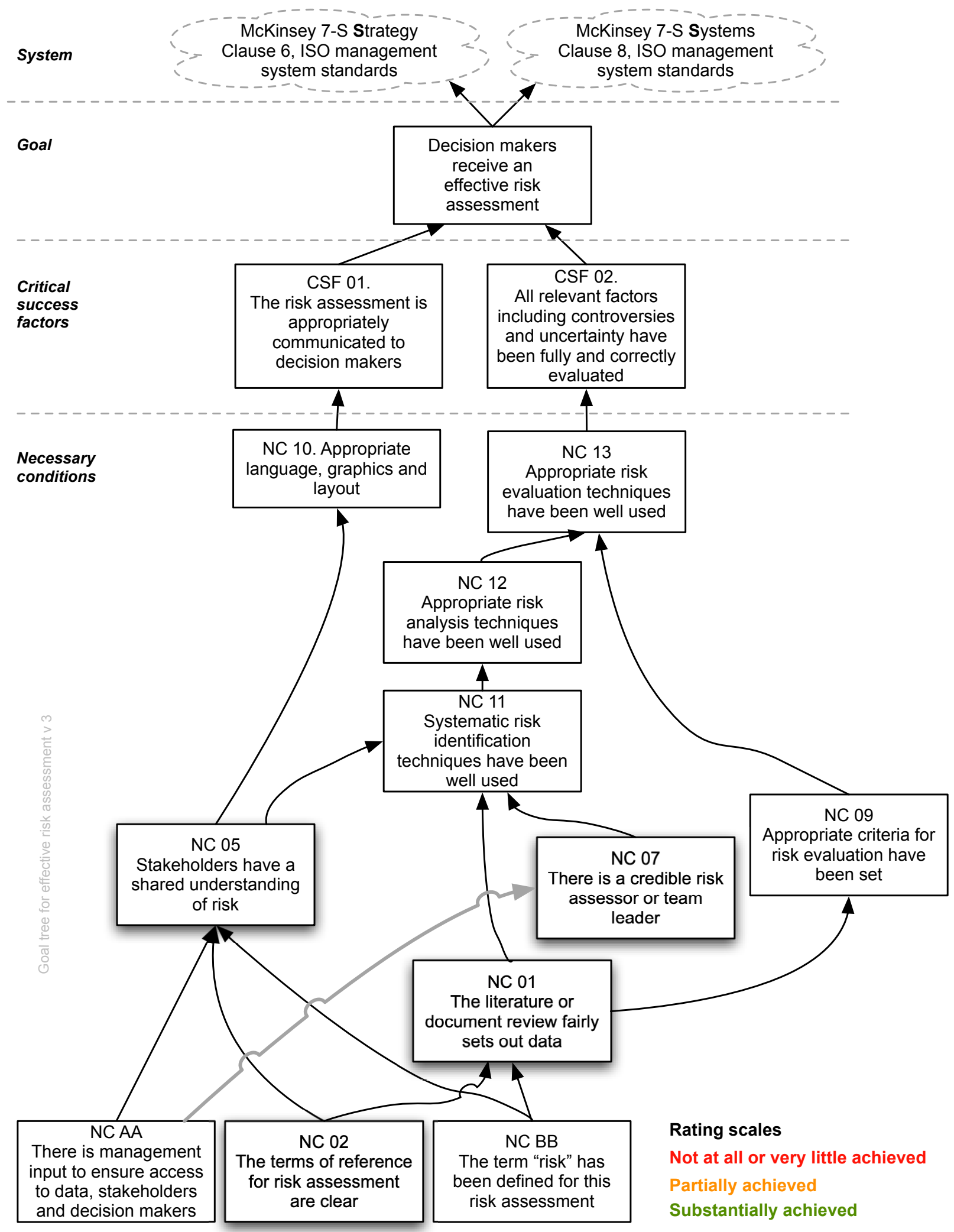




\subsubsection{Key alterations to the GT}

\section{Management input NC AA}

"Proactive and visible commitment from senior management" is a necessary condition for effective risk assessments and subsequent management responses (Trainor et al, 2002, p. 55 and 66 ) and, following comments from case study interviewees, management input has been added as NC AA.

\section{Definition of risk for this risk assessment NC BB}

While the need to define risk was identified in the literature review (section 2.1) it was not included in the tentative GT because it was not thought a necessary condition. However, as discussed in section 6.3 , interviewees frequently mentioned a range of objectives characterised in the risk assessments, suggesting the need to explicitly use the ISO31000 definition ("effect of uncertainty on objectives") or an alternative definition, helping focus on the purpose of the assessment - risk.

Care must be taken to use a broadly acceptable definition for "defining risk is ... an exercise in power" (Slovic, 1999, p. 699).

\section{Literature or document reviews NC 01}

This research suggests that risk assessments are dominated by professional judgement and, generally, lack of sources of "context dependent knowledge and experience [which is] at the very heart of expert activity" (Flyvbjerg, 2006, p. 222). The published work of others is helpful for risk assessors who need to know what has happened and its causes (Zardo \& Pryor, 2017) so providing the best available information (section 3.5) that might have improved case studies A, B, C and D, providing a weight of evidence for each decision. However, there was a general lack of use of document or literature reviews in the online survey and case studies, suggesting that risk assessors need guidance in online searching generally and knowledge of some of the major sources of free-to-access research sources, database and major consultancies. Use of such sources would at least partially respond to the criticism that "professional knowledge workers" are not aware of relevant research (Van de Ven \& Johnson, 2006, p. 802).

\section{Credible risk assessor NC 07}

The CORA model (Wiedemann et al, 2013) was used to help develop the GT and includes "impartiality in terms of funding and mandate". This was not found to be relevant in the case studies in this research because it was evident that funding followed the mandate which originated either from the board or CEO. NC 07 has been amended to include "credible" to 
reinforce the need for assessors to be trained, qualified, have relevant experience, and to be impartial.

\section{Shared understanding of risk}

NC 05 has been reworded to "Stakeholders have a shared understanding of risk" with input from new NC AA: "There is management input to ensure access to data, stakeholders and decision makers" and BB "The term 'risk' has been defined for this risk assessment".

\section{NC 11, 12 and 13}

NC 11, 12 and 13 have each include "well" to indicate the need to follow a structured process. They have also been rearranged to show that risk identification must precede risk analysis which in turn must precede risk evaluation. NC 11 has been renamed by deleting "hazard or" to encourage thinking beyond the OHS-related causal factors of risk, and by adding "systematic" to encourage use of structured risk identification.

Development of a risk techniques identification key (section 7.3.1) would enable better selection of techniques in NC 11, 12 and 13, and the risk canvas (section 7.4) provides a basic set of risk techniques.

\section{Feedback to risk assessor or team}

Although the revised GT does not use feedback several interviewees confirmed the benefits for them of feedback, and research (Tetlock \& Gardner, 2015) suggests it is an important way to improve risk assessment practice. Further, it is "an underpinning ontological assumption in the systems world that feedback occurs" (Cox, Mabin, \& Davies, 2005); the grey shaded line connecting NC 02 to 07 represents management to risk assessor feedback.

\section{Other comments}

Risk is defined in this research as the "effect of uncertainty on objectives". The revised GT will help demonstrate areas of uncertainty where NC have been achieved not at all or very little or partially, so providing a visual check that uses necessity logic to show "in order to ... we must ..." if a NC is to be substantially achieved. The guide words and their colour coding remain in the revised GT.

Dettmer (2007, p. 81) suggested an "arbitrary rule of thumb" that a GT should be limited to two layers of NC but also showed an example of a GT with five layers of NC. It was not possible to meet this guide and the revised GT now has six layers. However, the revised GT responds to the findings of the research, is more compact than the tentative GT, and is applicable to preparation for, or reviews of, risk assessments. 
During this research a number of mechanisms that might support this NC were identified and are outlined below.

\subsubsection{Training of risk assessors}

Competence of risk assessors (section 2.2) and the discussion of professional judgement (section 6.5.2) confirmed that there may be a weak relationship between risk management theory and practice (Smallman, 1996, p. 260) and led to the conclusion that practical and relevant training is needed in risk assessments. In that discussion reference was made to the International Network of Safety and Health Practitioner Organizations (INSHPO, 2017, pp. 10-11) guidance and Australian qualifications framework (broadly equivalent to the New Zealand framework). While this applies to OHS practitioners and professionals it might extend to others who carry out or use risk assessments. Training and education in risk assessment should be included in engineering, management, architecture and other undergraduate and trades courses (Care, Jary, \& Parnell, 2012; Copsey et al, 2010; Hinde \& Ager, 2003; Perrin et al, 2018; Schleyer et al, 2005; Taylor, 2015).

The relationship between management research, teaching and practice (Burke \& Rau, 2010) synthesis (Boyer, 2016) and government policy in New Zealand has been represented (Figure 53) as this author's perception of the current state of risk assessment and management teaching, research and practice in New Zealand.

Figure 53. Risk management research, teaching, practice and policy in New Zealand Red/dark grey $=$ not at all or very little Amber/mid grey $=$ partially Green/light grey $=$ substantially

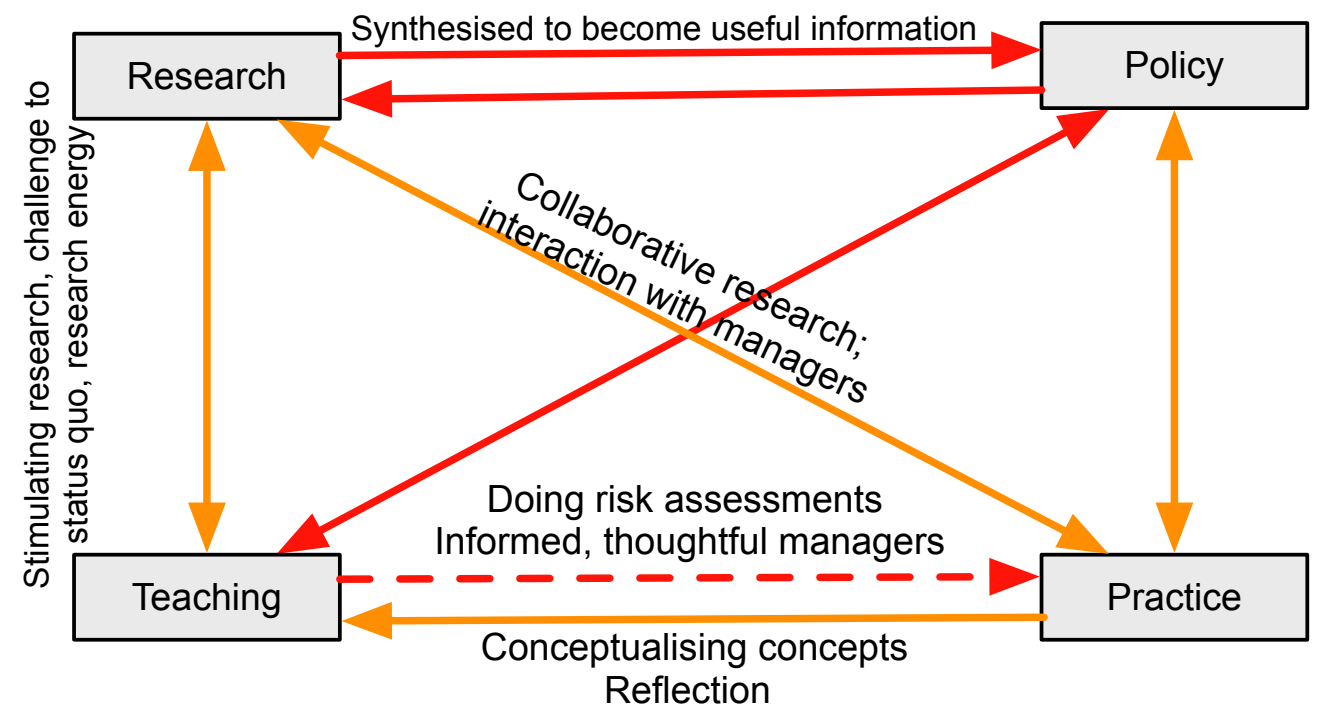

Source: adapted from Burke \& Rau (2010) and Boyer (2016)

The dashed lines and colour coding show little or no linkage between each of these areas despite risk management being a real-world subject with the potential to be a "game- 
changing technology" (Goble \& Bier, 2013, p. 1942) forming part of "management-as-atechnology" (Bloom et al, 2016).

This view is supported by Lamm (2018, 7 June email to Peace) who commented:

The fact is that while a risk assessment course (typically referred to as risk management) might be listed in the tertiary institutions' calendars (refer to Massey Uni and AUT), it does not mean that it is taught. Indeed it would be rare now to find a university that offers risk assessment/management as a standalone course. Yes, risk assessment may be covered in say accounting/finance, engineering, construction, emergency management etc. degrees, but only as a sub-,sub-, section of a paper which means that students would only get say an hour or two tuition on the topic.

Using Figure 53, more effective OHS prevention programmes (Case Studies A, C and D) may require better knowledge transfer and exchange from academics to practitioners (Van Eerd, 2019), forming another area for improvement. Practitioner training courses using the risk canvas (section 7.4) appears to result in better informed managers (at least in the short term), suggesting an area for further research.

A risk assessment may be effective but rejected by decision makers if it does not meet their beliefs (Benabou \& Tirole, 2016; Frimer et al, 2017) or biases (Bolger \& Wright, 1994; Montibeller \& von Winterfeldt, 2015). Thus, decision makers also need training in risk assessments if they are to judge whether a given risk assessment is informing them effectively.

\subsection{Additional mechanisms that might facilitate risk assessments}

\subsubsection{Risk techniques identification key}

The online survey and case studies showed a dominant preference for professional judgement, workshops and the consequence/likelihood matrix as risk techniques, suggesting a lack of knowledge of structured techniques. The literature review (section 2.4) identified the need for development of a demand-side risk technique identification key to help users know which techniques are available, when to use them, and which would give the best available information. It would also help demonstrate the validity of a technique choice. However, as noted in the limited literature on identification keys (Nickerson et al, 2013; Zijp et al, 2015), such work can require several years to identify key diagnostic features of 
interest and develop an identification key using those features. This improvement option is therefore noted as further work.

\subsubsection{Maturity models that include risk techniques}

Research by Ernst \& Young (2012), confirmed by Oliva (2016), seemed to suggest that increasing sophistication and standardisation of risk techniques was an indicator of organisational performance and capability and might be a mechanism to improve risk assessments as an organisational performance indicator. Maturity models usually describe a series of organisation development stages, each building on earlier stages, and may have four levels (Hillson, 1997) or five levels of maturity (Matsumoto \& Shirasaka, 2016; Oliva, 2016). They have been researched and widely publicised by the Software Engineering Institute of the Carnegie Mellon University (Curtis, Hefley, \& Miller, 2009) but only one mapping study reviewing 2019 articles has been found (Wendler, 2012) and this showed that most of the published maturity models lacked validation. This is also an area of further research in the use of risk techniques and how they help elicit information about risk.

\subsubsection{The goal tree as a risk technique}

Section 2.6.1 of the literature review led to development of the tentative GT (section 3.2) to frame analysis of the data and suggested the GT could also be used as a risk technique by establishing a hierarchy of GTs for key organisational goals (Caralli, 2004) to help explore uncertainties about achieving goals or objectives.

\subsubsection{McKinsey 7-S as a risk technique}

The McKinsey 7-S model (Figure 13) provided a qualitative framework to aid assessment of gap analyses carried out by case studies $A$ and $B$ and showed the need to consider the interrelationships between all parts of an organisation. The 7-S model is seen as having potential for use in the investigation of management systems and structures and has been linked with the GT in section 7.2. This potential was corroborated by work outside this research in 2018 when facilitating 16 introductory workshops on international standard ISO45001 (2018) Occupational health and safety management systems for members of the New Zealand Institute for Safety Management and showing how to carry out a gap analysis using the McKinsey 7-S model.

\subsubsection{Improved judgements of probability}

As described in section 7.4.2 users of the risk canvas had to judge the probability of consequences with no controls and then the probability of consequences with controls, taking into account the effectiveness of controls. The test showed users appeared to improve the reliability of the probability judgements but confidence in the answers was not 
judged. Burgman (2016, p. 90) suggested this might be done by use of the following three questions.

- $\quad$ "First, think about all the things that might lead you to pick a low value. With these in mind, realistically, what do you think is the lowest plausible number? Take a moment to write it down."

- Second, think about all the things that might lead you to pick a high value. With these in mind, realistically, what do you think is the highest plausible number? Take a moment to write it down.

- Finally, thinking of all the things that contribute to your estimates, on balance, what is your best estimate".

The answers can then be mapped into a diagram such as Figure 54 with the uncertainty range (lowest to highest) representing the confidence of the risk assessor

Figure 54. Three-point format for questions about probabilities

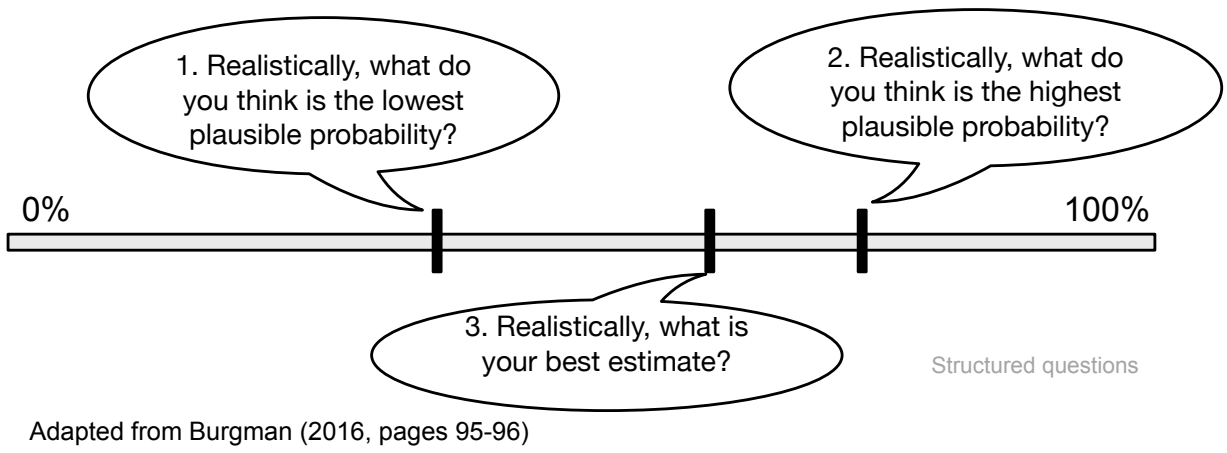

Such forecasts can be recorded and used to help risk assessors improve and calibrate future risk assessments.

This and similar techniques for expert elicitation (Tetlock, 2006) are an area for further practice-based research. 


\subsection{The risk canvas: evolution and testing}

The foregoing are standalone mechanisms that might improve risk assessments. However, the online survey (section 4.4), corroborated by the case studies and experience, suggested that risk assessors might not know how to select and use basic qualitative risk techniques (including those identified in section 2.4.1) in a structured process. Such techniques might enable systematic recording and communication of findings, and so enable reproducibility and trust in the risk assessment (Busby \& Hughes, 2006; Earle, 2010; Goerlandt et al, 2017).

There are many graphic elicitation methods that might help overcome such problems, including blank and prepared Post-it notes, timelines, mind maps, flowcharts, maps, charts, diagrams and visual metaphors that can be used as pragmatic tools to elicit risk information (Anderson, 1993; Bagnoli, 2009; Crilly et al, 2006; Eppler \& Aeschimann, 2009; Meier, 2007) or to provide access to shared or unique experiences and data (Fleetwood, 2005).

A combination of printed forms, Post-it notes and flip charts was initially used to teach basic risk techniques selected from Figure 4, (section 2.4.1) but the results were invariably messy "maps" of networks of knowledge (Petersen, 2017, p. 39) that failed to deliver consistent or reproducible results (Haas, 2016) or communicate the results. During a series of one-day training courses for managers and field technicians run by this author in 2015 , it was suggested ${ }^{11}$ that a large sheet be pre-printed with the suite of risk techniques being taught. When using abductive research such suggestions are supported by Farjoun et al (2015) and it was exploited to become the basis of the risk canvas.

Reservations about the reliability of input data for quantitative risk analysis (Hopkins, 2004; HSE, 1989), difficulties with subjective and objective risk and the frequent lack of training in risk assessments suggested the need to avoid teaching any but the most basic qualitative techniques. Initially, the consequence/likelihood matrix was used but subsequently found to create uncertainty in assessment results (Peace, 2017c) and has since been downgraded to a risk reporting technique (IEC/ISO31010, 2019).

The prototype risk canvas was about 1.8 metres wide and 1.2 metres high with the content being hand-drawn. Over several iterations this was simplified to an A1 sheet (Figure 55, a one eighth version) containing record sheets for data from the suite of selected techniques, including a grid to guide placement of $40 \mathrm{~mm}$ wide Post-it notes in a bowtie analysis. These provided space to summarise the results from the following suite of techniques.

Brainstorming and stakeholder analysis were selected to aid engagement ((Brugha \& Varvasovszky, 2000; Morgan, 2004; Proctor, 2009; Schmeer, 2001)). Stakeholder

\footnotetext{
${ }^{11}$ Ward M, Pers. Comm. email to Peace C (2015) Risk Canvas development
} 
identification and analysis, and development of an engagement plan are placed in box A.

Document review requiring identification of at least six documents for subsequent review led to identification of background papers that would inform the risk assessment. The results are placed in box $B$.

PESTLE (political, economic, social, technical, legal and environmental issues) and SWOT analysis and document review were selected to aid understanding issues external to an organisation while SWOT focused more on internal issues ((Bensoussan \& Fleisher, 2008; Forbes et al, 2008; Proctor, 2009)). PESTLE analysis results are summarised in box C. SWOT results are summarised in box D. The business objectives of the activity are recorded in box $E$.

Flowcharting (Best, 2011; Borthick, Schneider, \& Vance, 2010) and 5W1H (Who, What, Why, When, Where, and How) analysis were combined to help show where activities took place in a process and help identify risk.

After some experimentation, bowtie analysis was selected as the key risk identification and analysis technique (section 2.4.1). Development of a simple bowtie analysis (centred on the Event circle) therefore enables identification of causal factors and consequences, followed by placement and evaluation of controls, use of a risk velocity scale, and probability of the specified consequences. Administrative matters, including a pin symbol in the top left corner to indicate a place to attach additional worksheets or overflow from the main canvas.

The risk canvas was supported by a separate course handbook (Peace, 2017d, not part of this research) that gave details for the above techniques. This version included use of a $5 \times 5$ consequence/probability matrix despite its known limitations (Peace, 2017c).

Like any model, the risk canvas could clearly "lead to uncritical or unwitting limiting of method choice" but it was considered to "represent an opportunity to 'see, think and act' in a more systematic way in handling complexity" (as advocated by Davies et al, 2005, p. 507). 
Figure 55. Risk canvas 2.3 (one-eighth full-size)

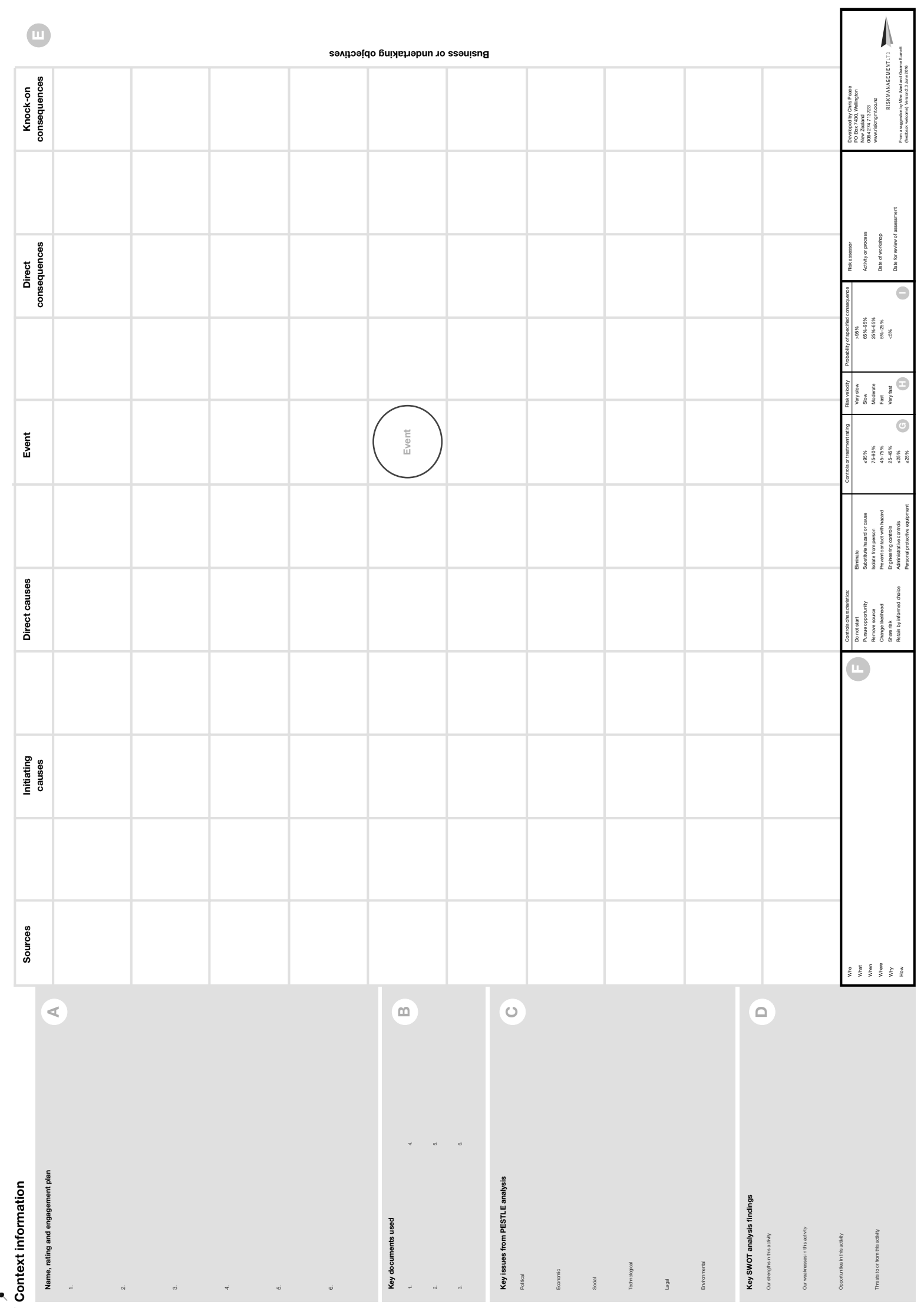




\subsubsection{Risk canvas test and results}

A Human Ethics Committee application to test the risk canvas during one- and two-day courses $(N=12)$ was approved in July 2016. Course participants varied from experienced construction managers and occupational health and safety practitioners to managers inexperienced in risk management. All participants were given a case study to read before their courses and to use during the courses. Each course was divided into small groups of 35 participants. At the end of each course the participants $(\mathrm{N}=95)$ were asked to complete an anonymous feedback sheet giving 11 questions and, for each, a Likert scale of five responses. A total of 70 participants completed the feedback sheets, giving a $74 \%$ response rate. Anonymous narrative feedback was also given by 25 of the participants. Observations of groups using the canvas were made and common problems with risk assessments noted.

\section{Document review}

In the online survey (section 4.3.1), document review was the third most frequently selected technique with 62 respondents (25\%) saying they used it. While the range of documents that might need to be reviewed can be considerable, reading those that are key documents can be critical to identifying causal factors of events and consequences as part of a risk assessment (Gadd et al, 2003; Toman, 2014). Part of a used risk canvas is shown in Figure 56.

Figure 56. Extract from the risk canvas - document review

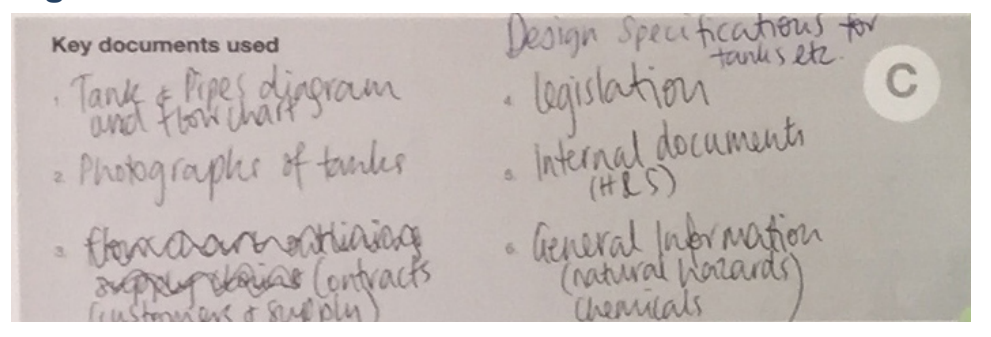

Question 3 asked participants if "having a space to record documents was helpful" and responses to the question are summarised in Figure 57.

Figure 57. Summary of responses

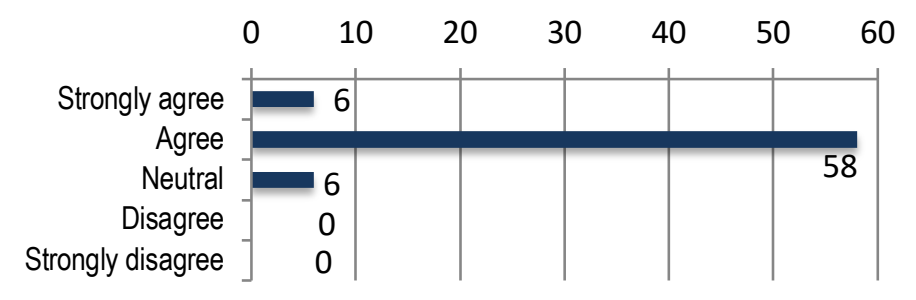

Although the documents identified in a workshop could quickly exceed the space provided, $91 \%$ agreed the space was helpful. A separate sheet, pinned to the risk canvas, would provide a longer working record if necessary. 


\section{Engagement with stakeholders (NC 06)}

Engagement with stakeholders is recognised as key to positive relationships, effective risk assessments and management of risks (see, for example, AccountAbility, 2015; Garnett et al, 2016) and may also disclose "weak signals" that had previously been missed (Weick \& Sutcliffe, 2007). Stakeholder engagement is sometimes mandatory (eg, as part of occupational health and safety management). Engagement was strongly supported in the online survey (section 4.3.6) and done well in the case studies. Part of a used risk canvas is shown in Figure 58.

Figure 58. Extract from risk canvas - engagement

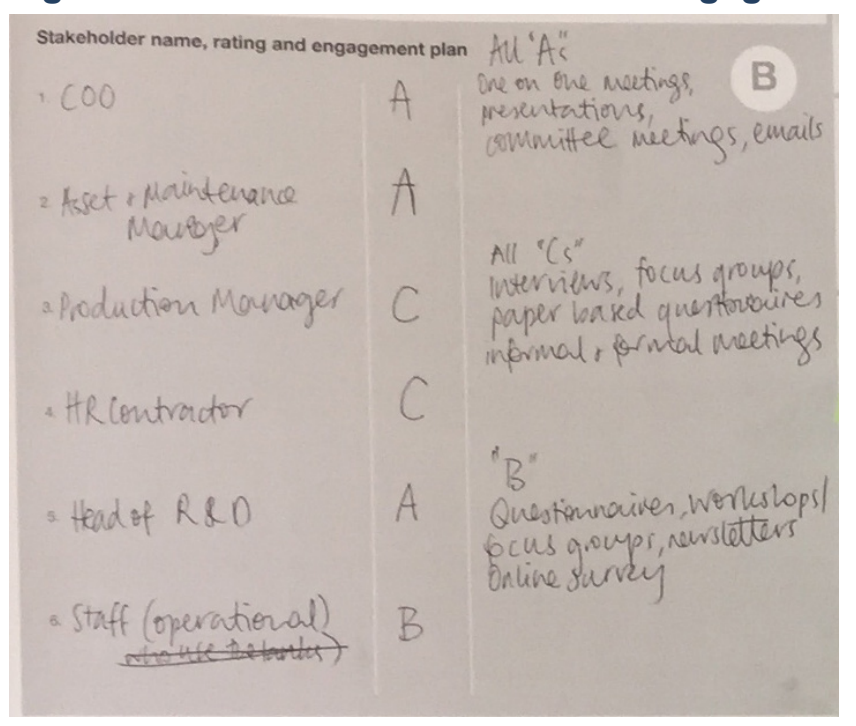

Question 2 asked participants if "having a space for an engagement plan was helpful" and responses to the question are summarised in Figure 59.

Figure 59. Summary of responses to space for the engagement plan

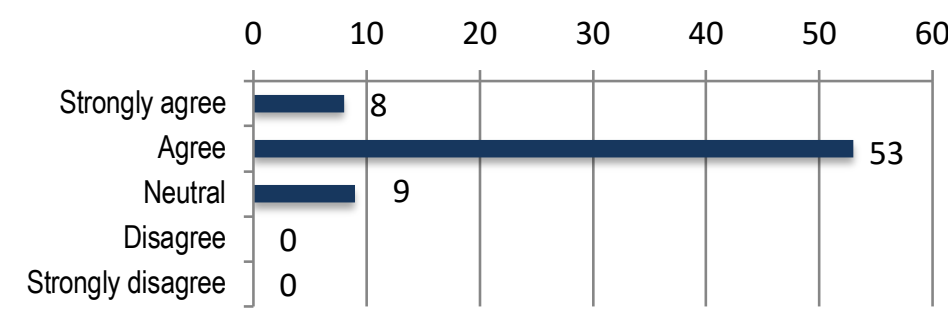

While space in the risk canvas was limited, 61 (87\%) respondents strongly agreed or agreed this was helpful. Observations during the courses showed that it enabled participants to brainstorm a small number of stakeholders, analyse them for their importance and influence and develop an outline engagement plan. This contrasted with use of personal knowledge and professional judgement selected by respondents to the online survey. In practice, there might be many stakeholders to be engaged with and a separate plan might be needed for each which can be pinned to the top-left corner. 


\section{PESTLE analysis (NC 08)}

PESTLE analysis is a widely used management technique that enables gathering of information about the business environment (Marhavilas et al, 2011; Proctor, 2009) and help avoid failure of a risk assessment.

PESTLE analysis was selected by 34 (14\%) people in the online survey and, over a five-year period, perhaps one-third of course participants have indicated by a show of hands that they have "heard of or use PESTLE analysis". These results and observations during training courses suggest that analysis of the business environment is not common, perhaps accounting for failure of some risk assessments. Part of a used risk canvas is shown in Figure 60.

Figure 60. Extract from the risk canvas - PESTLE analysis

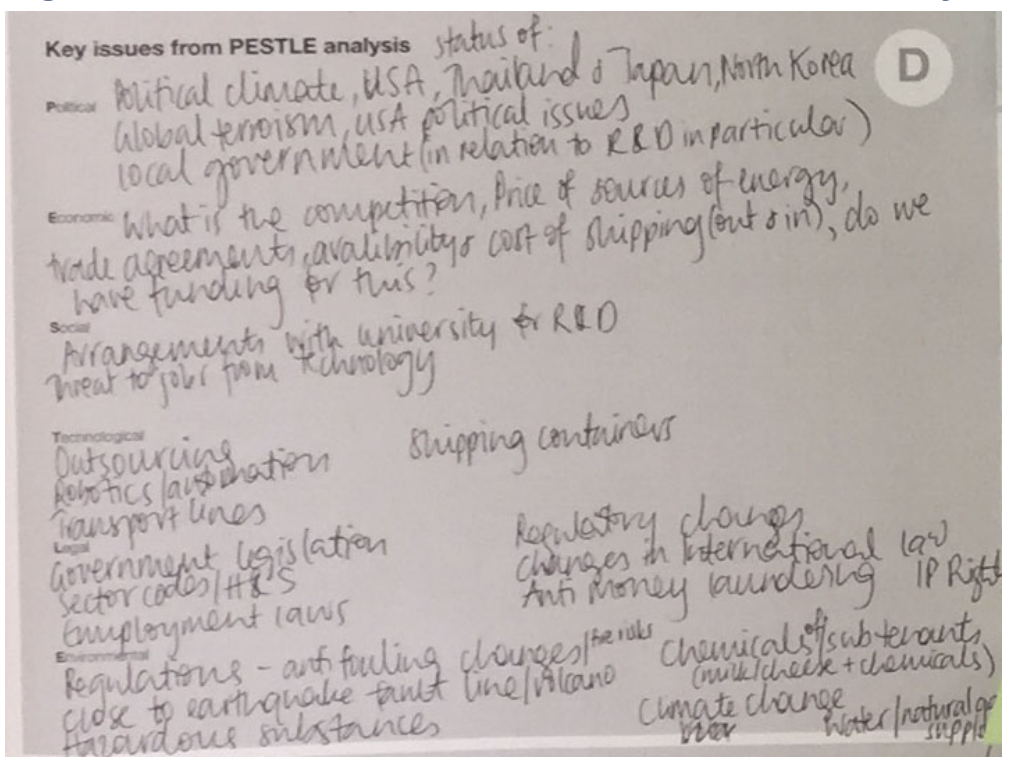

Question 4 asked participants was "having a space to record the results of a PESTLE analysis was helpful" and responses to the question are summarised in Figure 61.

Figure 61. Summary of responses to space to record a PESTLE analysis

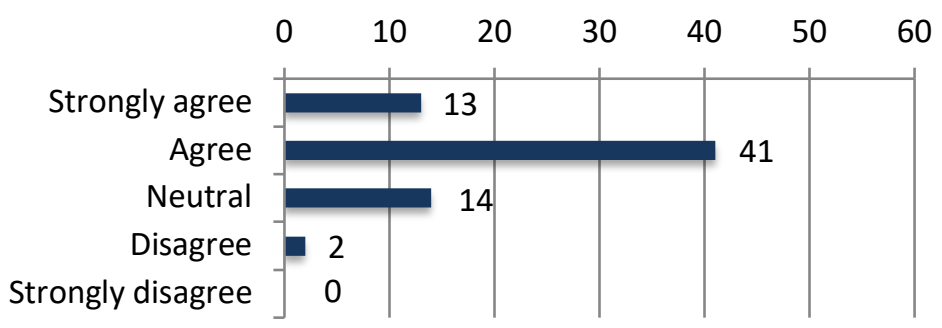

Recording a PESTLE analysis was helpful for $77 \%$ of participants but some people reported that understanding the PESTLE factors in the business environment was of little relevance and so were neutral about or disagreed with its use. This may reflect either the teaching or uncertainty about the need to understand the business environment. 


\section{SWOT analysis (NC 08)}

SWOT analysis is also widely used in management (Panagiotou, 2003; Proctor, 2009) and was selected by 64 people in the online survey and, while running workshops and training courses over a five-year period, perhaps one-quarter of course participants have indicated by a show of hands that they have "heard of or use SWOT analysis". These results and observations during training courses suggest that analysis of the business environment is not common, perhaps accounting for failure of some risk assessments. Part of a used risk canvas is shown in Figure 62.

Figure 62. Extract from the risk canvas - SWOT analysis

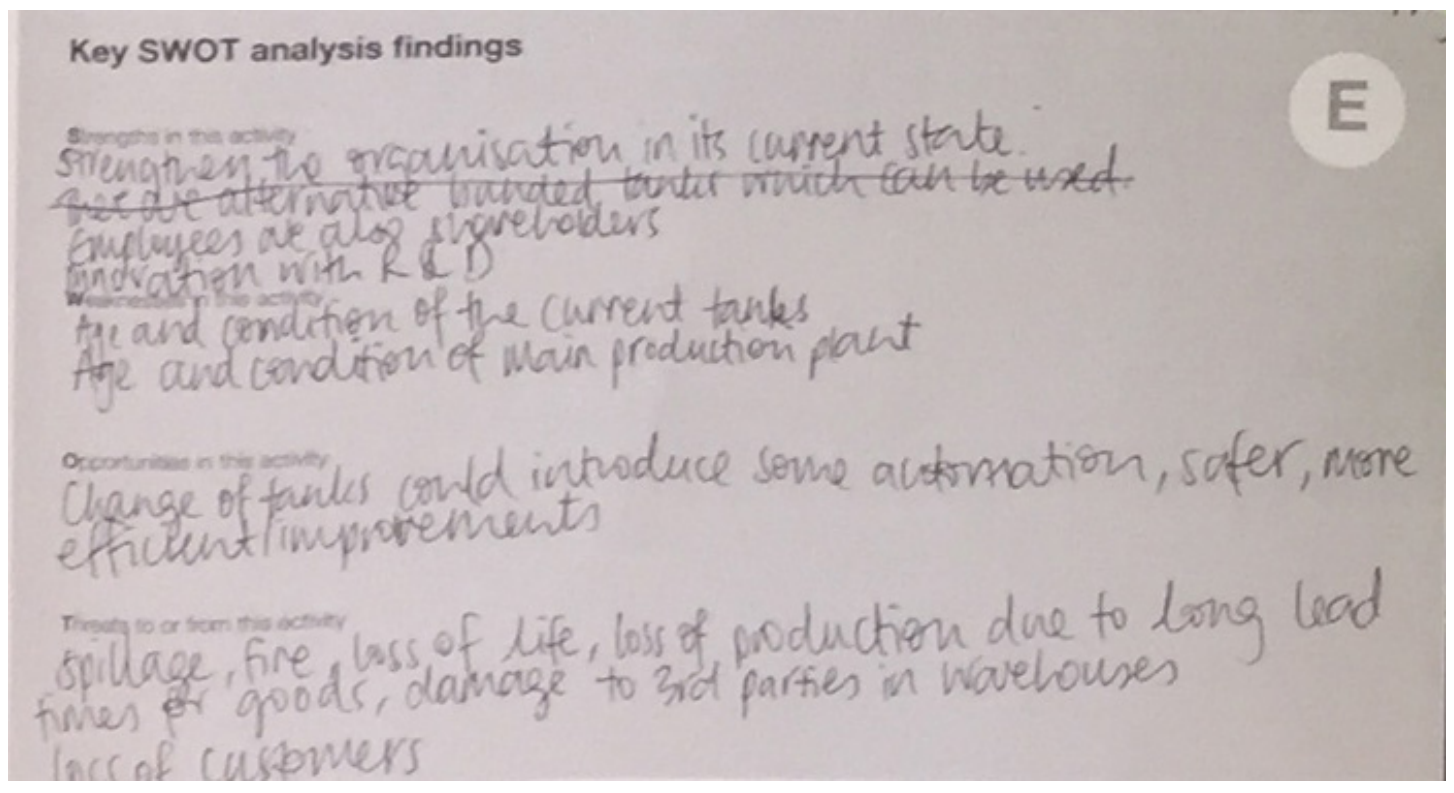

Question 5 asked participants if "having a space to record the results of a SWOT analysis was helpful" and responses are summarised in Figure 63

Figure 63. Summary of responses to space to record a SWOT analysis

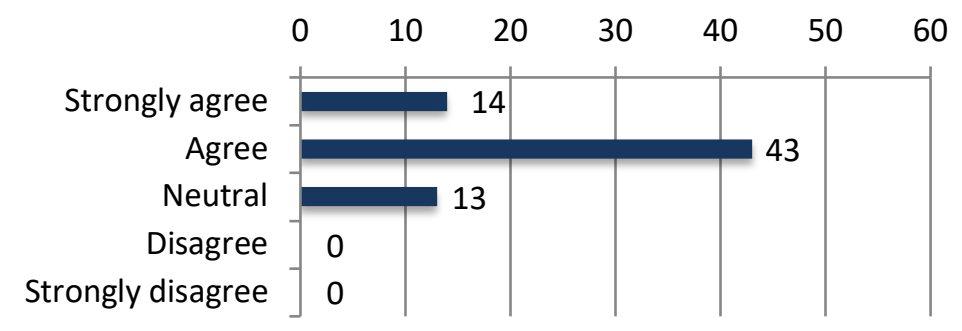

Recording a SWOT analysis was helpful for $81 \%$ of participants but others reported that understanding the SWOT factors in the business environment was of little relevance, perhaps resulting in the number who were neutral about recording a SWOT analysis. 


\section{Business and activity objectives (NC 08)}

Risk is defined in ISO31000 as the "effect of uncertainty on objectives", implying that the relevant organisational objectives must be stated and understood as part of framing a risk (section 2.6). Part of a used risk canvas is shown in Figure 64.

Figure 64. Extract from the risk canvas - objectives

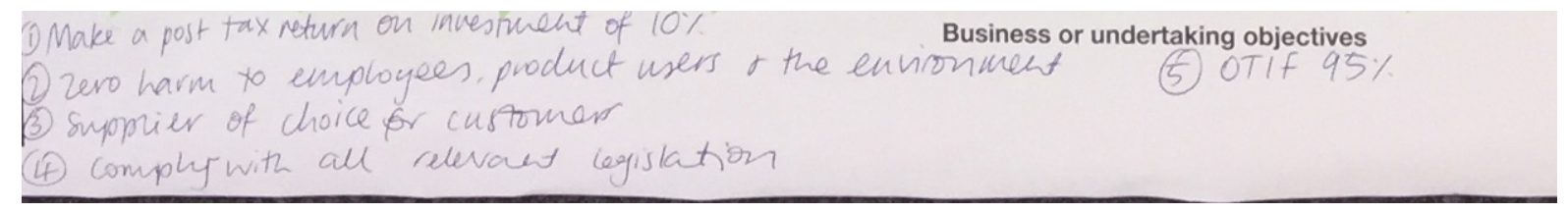

Question 6 asked participants if "having a space to record the business objectives was helpful" and responses are summarised in Figure 65.

Figure 65. Summary of responses to space to record objectives

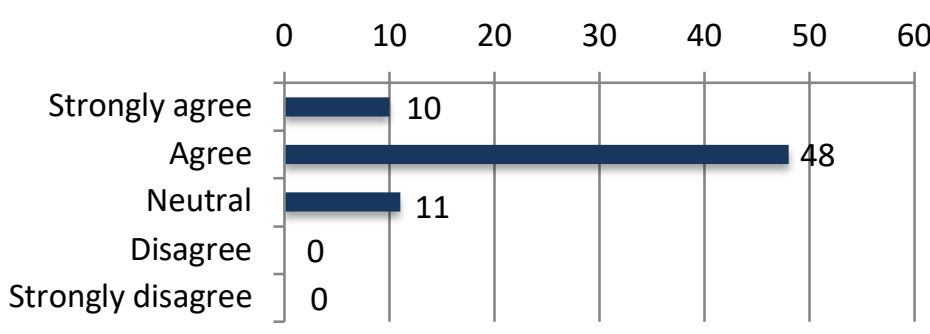

The course notes made clear that there may be a cascade of objectives from strategic to operational and that equipment can also be thought of as having objectives (eg, the objectives of a tank include containment of the contents). Some short course participants reported finding it difficult to define, understand or use business objectives during courses, but $83 \%$ found it helpful to have a space to record them. One wrote as part of their feedback that they would "Request to see company policies", suggesting, for them, a detachment of risk management from business objectives.

Although $86 \%$ of respondents to the online survey said their work considered business objectives as part of the context, these observations suggest some managers lack understanding of and guidance in their accountabilities for achieving organisational goals (perhaps the reason they were on a short course). 
Who, What, Why, When, Where, How analysis (NC 11)

A mind map of 72 questions based on Who, What, Why, When, Where, and How (5W1H) was developed in 2013 by this author as a response to some course participants apparently being unable to pose questions during risk assessments.

During the courses, participants were asked to draw a simple flowchart analysing an activity (Best, 2011) and then populate it with information elicited from the supplied case study material by using $5 \mathrm{~W} 1 \mathrm{H}$. No samples of this work were kept. Question 7 asked participants if "having a space to record the results of the $5 \mathrm{~W} 1 \mathrm{H}$ analysis was helpful". The responses are summarised in Figure 66.

Figure 66. Summary of responses to space to record key $5 \mathrm{~W} 1 \mathrm{H}$ results

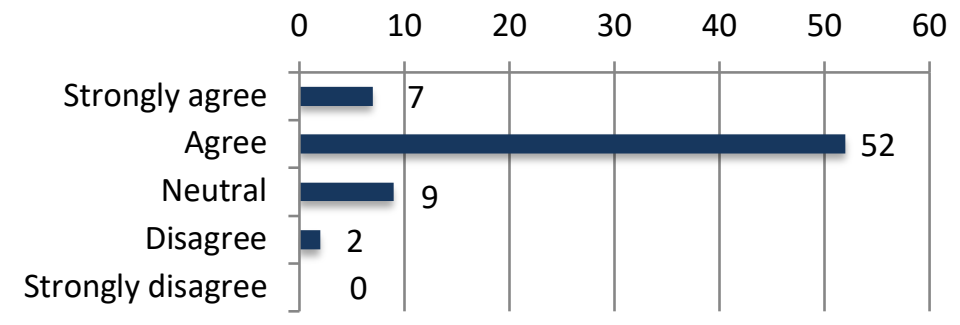

Some of the participants may have found that entering the information into a flowchart drawn on the back of the canvas provided the necessary record; one specifically wrote " $5 \mathrm{~W} 1 \mathrm{H}$ [space] too small to be effective" but $84 \%$ found it helpful to have a space to record their findings. 


\section{Bowtie analysis (NC 11)}

Online survey respondents said they frequently used bowtie analysis to analyse risks (ranked fifth in Table 27, section 4.3.12) or to aid evaluation of controls (ranked fifth in Table 28, section 4.3.12). The risk canvas sets out a grid with "event" pre-entered in a circle in the centre of the grid. Each cell in the grid provides room for a $40 \mathrm{~mm}$ wide Post-it note to be placed in it with a relevant entry. Use of Post-it notes allows errors to be easily corrected or incorrectly placed entries to be moved. Parts of a used risk canvas are shown in Figure 67 and Figure 68.

Figure 67. Part of the causal effects (left) side of a bowtie

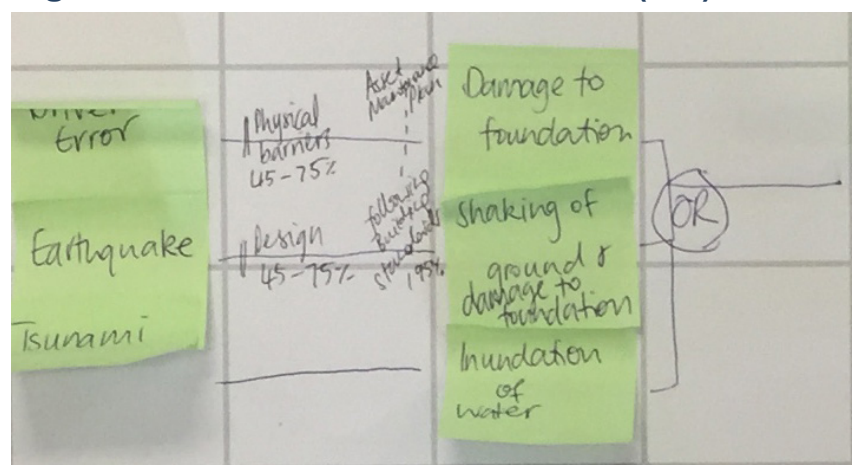

Figure 68. Part of the consequences (right) side of a bowtie

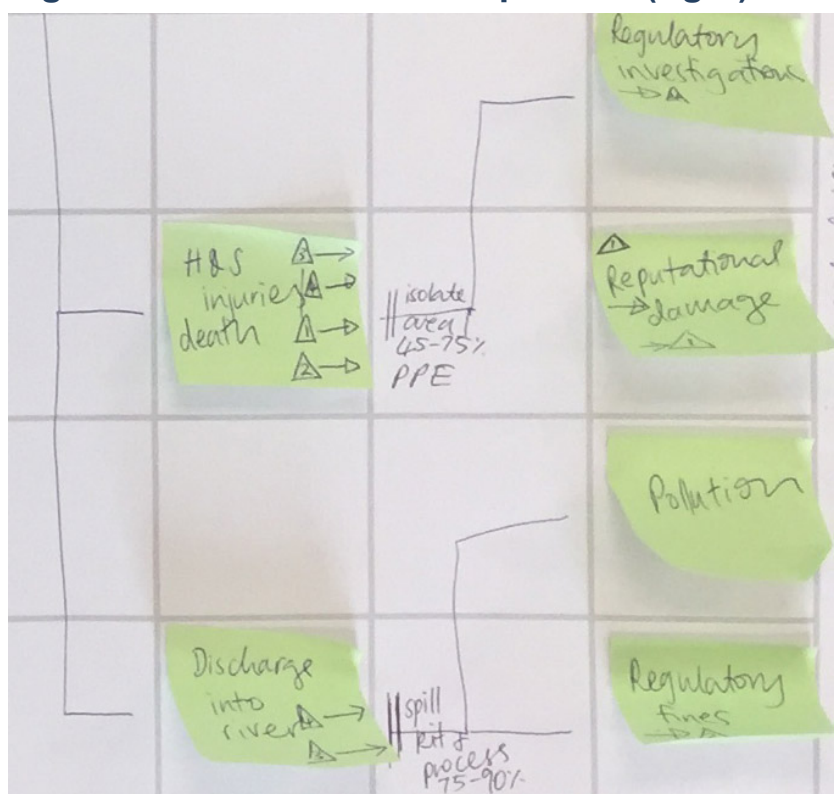


Responses to the question "was having a grid helpful" are summarised in Figure 69.

Figure 69. Responses to provision of a grid for the bowtie analysis

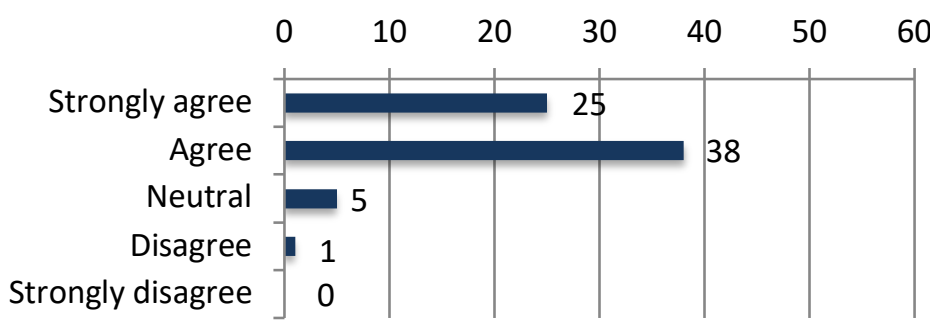

Overall, $90 \%$ of participants found the grid helpful but one group of safety and health practitioners $(\mathrm{N}=15)$ gave the widest spread of feedback for this and for the PESTLE and $5 \mathrm{~W} 1 \mathrm{H}$ techniques. It is not clear whether this was due to design of the risk canvas, this author's teaching, the supporting training notes, or the attendees backgrounds.

Bowtie analysis (section 2.4.1) appeared to offer promise as a technique that may be widely applicable to many risks but observations of groups in the trials showed a range of responses to it. Some groups quickly understood that it gave a left to right flow from risk sources to causes/hazards, and then to a defined event, and the consequences that might result from that event. Other groups initially struggled with the idea that an event could have many causes and many consequences, perhaps having previously learned about earlier single cause, single consequence models (Bird \& Loftus, 1976; Heinrich, 1931) that are now discredited.

Some groups found it difficult to portray complex situations because the available space on the risk canvas was insufficient but, often, the groups found they had shown where there were control gaps and deficiencies that were not otherwise obvious. Because each group was using the same training course case study, this also led to a previously unreported finding that many different bowtie diagrams might be developed from the same data, perhaps creating uncertainty about the "right" answer. 


\section{Probability of consequences (NC 12)}

The courses taught the use of probability ranges instead of guidance words such as "very high" that are open to diverse interpretations (Kent, 2007). The risk canvas offered five ranges to estimate the probability of the worst case consequences (Burgman, 2016, p. 90) and attendees were asked if being offered guidance on the probability of consequences was helpful; the results are summarised in Figure 70.

Figure 70. Responses to guidance on the probability of risk consequences

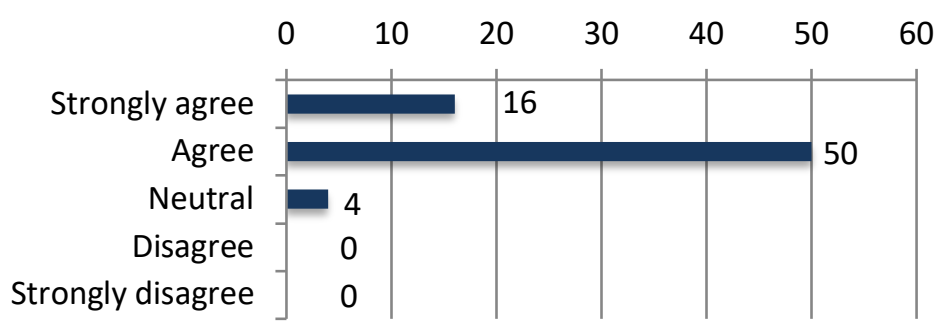

The guidance was helpful to $94 \%$ of participants but was observed to cause strong debate within groups and in open discussion, with some participants preferring to use words as descriptions. This is broadly aligned with online survey results where $229(97 \%)$ respondents said they took into account controls effectiveness and 112 said they used their professional judgement to do this. 


\section{Control characteristics and effectiveness (NC 12)}

If a risk cannot be avoided or eliminated it must be managed through the application of controls. However, the effectiveness of controls may vary widely so any risk assessment should identify both the controls characteristics and their effectiveness (Ellul \& Yerramilli, 2013; SA/IIA, 2010). However, the ability of risk assessors to accurately judge the effectiveness of controls is a recurring problem (Slovic, 1987), as is misinterpretation of words used to indicate effectiveness (Budescu et al, 2009; Burgman, 2016). The risk canvas attempts to overcome these problems by giving some control characteristics (Figure 71) and effectiveness ranges for controls (Figure 72).

Figure 71. Extract from the risk canvas - controls characteristics

\begin{tabular}{|ll|}
\hline \multicolumn{1}{|c|}{ Control characteristics } & \\
\hline Do not start & Eliminate \\
Pursue opportunity & Substitute hazard or cause \\
Remove source & Isolate from person \\
Change likelihood & Prevent contact with hazard \\
Share risk & Engineering controls \\
Retain by informed choice & Administrative controls \\
& Personal protective \\
& equipment \\
\hline
\end{tabular}

Figure 72. Extract from the risk canvas - controls effectiveness

\begin{tabular}{|c|}
\hline Controls or treatment rating \\
\\
$\leq 95 \%$ \\
$75-90 \%$ \\
$45-75 \%$ \\
$25-45 \%$ \\
$\leq 25 \%$ \\
$\leq 25 \%$
\end{tabular}

Question 9 asked if "having guidance on control characteristics and effectiveness was helpful" with responses summarised in Figure 73.

Figure 73. Responses to guidance on control characteristics

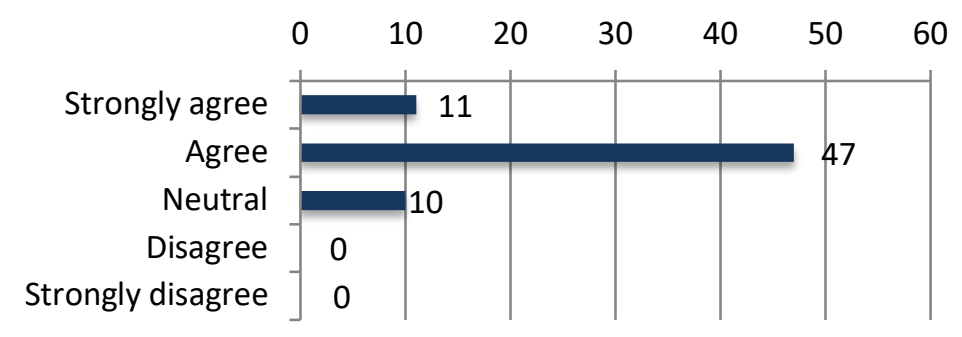

The results showed that such guidance was strongly helpful. 


\section{Guidance on risk velocity (NC 12)}

Risks may progress from causal factors to impact on objectives at different speeds (Tattam \& Esteban, 2013), requiring different management responses (Eisenhardt, 1989b).

Guidance on risk velocity was not included in the online survey but is part of the risk canvas and the relevant part of the risk canvas is reproduced in Figure 74.

Figure 74. Extract from the risk canvas - risk velocity

\begin{tabular}{|l|}
\hline \multicolumn{1}{|c|}{ Risk velocity } \\
Very slow \\
Slow \\
Moderate \\
Fast \\
Very fast \\
\hline
\end{tabular}

Question 11 asked if "having guidance on risk velocity was helpful". Responses summarised in Figure 75 showing $74 \%$ found the guidance on risk velocity helpful with $26 \%$ being neutral or disagreeing.

Figure 75. Responses to guidance on risk velocity

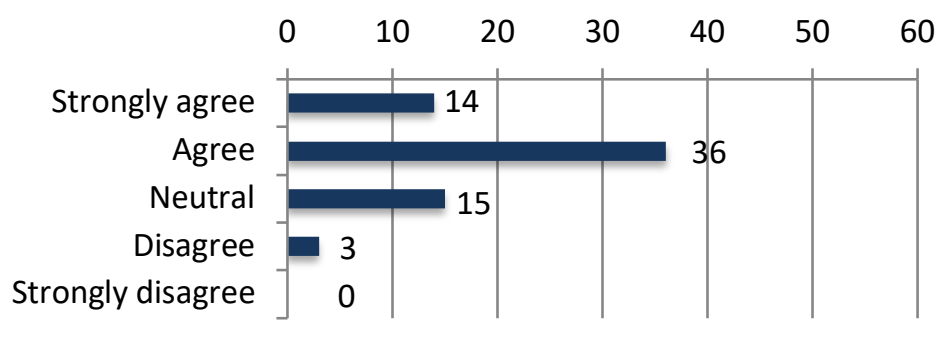




\section{Overall rating of the risk canvas (CSF 02)}

Course participants were asked "overall, was the risk canvas helpful in carrying out a risk assessment" The responses are summarised in Figure 76 and showed a high level of agreement with $91 \%$ strongly agreeing or agreeing and none disagreeing.

Figure 76. Summary of overall response to the risk canvas

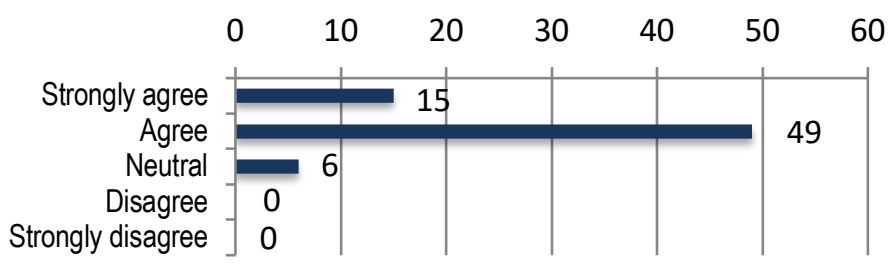

Participants were also asked for narrative comments on the canvas, with 26 giving the comments in Table 60. These and the level of agreement with "helpful in carrying out a risk assessment" suggest that the risk canvas facilitated learning how to assess and understand, and then manage risk. The negative comments suggest improvements in design, teaching and application.

Table 60. Narrative comments on the risk canvas

\begin{tabular}{|c|c|c|}
\hline Positive comments & Mixed or ambivalent comments & Negative comments \\
\hline $\begin{array}{l}\text { Interactive (the size [A1] makes } \\
\text { it group friendly) }\end{array}$ & $\begin{array}{l}\text { It would be good to have an example - an idea } \\
\text { of what the finished product should look like }\end{array}$ & $\begin{array}{l}\text { Good for bowtie and Post-it use, } \\
\text { duplication SWOT/PESTLE. Did } \\
\text { not help understanding on the } \\
\text { whole management process }\end{array}$ \\
\hline $\begin{array}{l}\text { Excellent process and totally } \\
\text { applicable to [name of } \\
\text { organisation] work }\end{array}$ & $\begin{array}{l}\text { Like the canvas, expect could get very large for } \\
\text { some work - electronic version probably a } \\
\text { must }\end{array}$ & $\begin{array}{l}\text { Difficult to use for an artificial } \\
\text { situation }\end{array}$ \\
\hline $\begin{array}{l}\text { Good way to learn, helped with } \\
\text { group discussion }\end{array}$ & $\begin{array}{l}\text { I will try to use this again - I don't think the } \\
\text { issues will be obvious until you are more } \\
\text { familiar with using it }\end{array}$ & $\begin{array}{l}\text { Useful but uncertain if any of my } \\
\text { clients would understand it }\end{array}$ \\
\hline $\begin{array}{l}\text { Yes, definitely felt that the } \\
\text { canvas held some positives. } \\
\text { Hands-on tactile way to problem } \\
\text { solve. Great tool, keep it going }\end{array}$ & $\begin{array}{l}\text { Produce it as a standalone tool, then gather } \\
\text { feedback }\end{array}$ & $\begin{array}{l}\text { More information about linkage of } \\
\text { output triangle }\end{array}$ \\
\hline A good tool for this course & $\begin{array}{l}\text { Understanding that it is more for the } \\
\text { element/event }\end{array}$ & Headings need more clarity \\
\hline $\begin{array}{l}\text { Very good. Brought up lots of } \\
\text { things I would otherwise have } \\
\text { not thought of }\end{array}$ & $\begin{array}{l}\text { Need to use it a couple of times before I could } \\
\text { answer }\end{array}$ & $\begin{array}{l}\text { Layout to improve the visibility and } \\
\text { therefore the importance of the } \\
\text { business objectives }\end{array}$ \\
\hline Love it & $\begin{array}{l}\text { Not sure, I might make a whiteboard version } \\
\text { once I had used it a few times and was happy } \\
\text { with the format }\end{array}$ & $\begin{array}{l}\text { Extra detail with headings to make } \\
\text { it clearer in what should go where }\end{array}$ \\
\hline $\begin{array}{l}\text { I thought it was key to carrying } \\
\text { out the process }\end{array}$ & $\begin{array}{l}\text { Brief instructions on how to use on the back of } \\
\text { the canvas }\end{array}$ & $\begin{array}{l}\text { Better distinction between } \\
\text { 'sources', 'initiating causes', and } \\
\text { 'direct causes' would be helpful }\end{array}$ \\
\hline All good & $\begin{array}{l}\text { I answered neutral for several questions above } \\
\text { because I have limited knowledge in applying } \\
\text { this information but sure as I progress/develop } \\
\text { risk assessment capability, all will become } \\
\text { clear }\end{array}$ & \\
\hline
\end{tabular}




\subsubsection{The risk matrix and the risk canvas}

Use of the risk matrix to rate the level of risk ("magnitude of any risk or combination of risks, expressed in terms of the combination of consequences and their likelihood" (ISO31000, 2009 , p. 6)) was taught during the sequence of training courses reported here but usually only after the risk canvas had been completed. However, after gaining Human Ethics Committee approval, construction sector managers $(\mathrm{N}=28)$ were asked during two courses to estimate the level of risk using a supplied $5 \times 5$ consequence/likelihood matrix both before and after development of the bowties. The event under analysis was loss of footing that might result in a personal injury (eg, after a fall). While each participant gave their own results, they were working in groups of 3-5 and all were using data from the same case study. The matrix they used was similar to many used to aid analysis of the level of risk in organisations and met design criteria suggested by Cox (2008). Analysis of their responses gave the following results:

- 16 people reduced the level of risk by one level after developing the bowtie, suggesting the "big picture" reduced their perception of the level of risk

- five people reduced the level of risk by two levels after developing the bowtie (ie, a substantial reduction in the level of risk)

- seven people considered developing the bowtie made no difference to their initial level of risk.

The individual data is shown in Figure 77 with respondents 1-28 on the $X$ axis and perceived level of risk on the $\mathrm{Y}$ axis $($ red $=$ initial, green $=$ final).

Figure 77. Changes in perception of the level of risk due to bowtie analysis

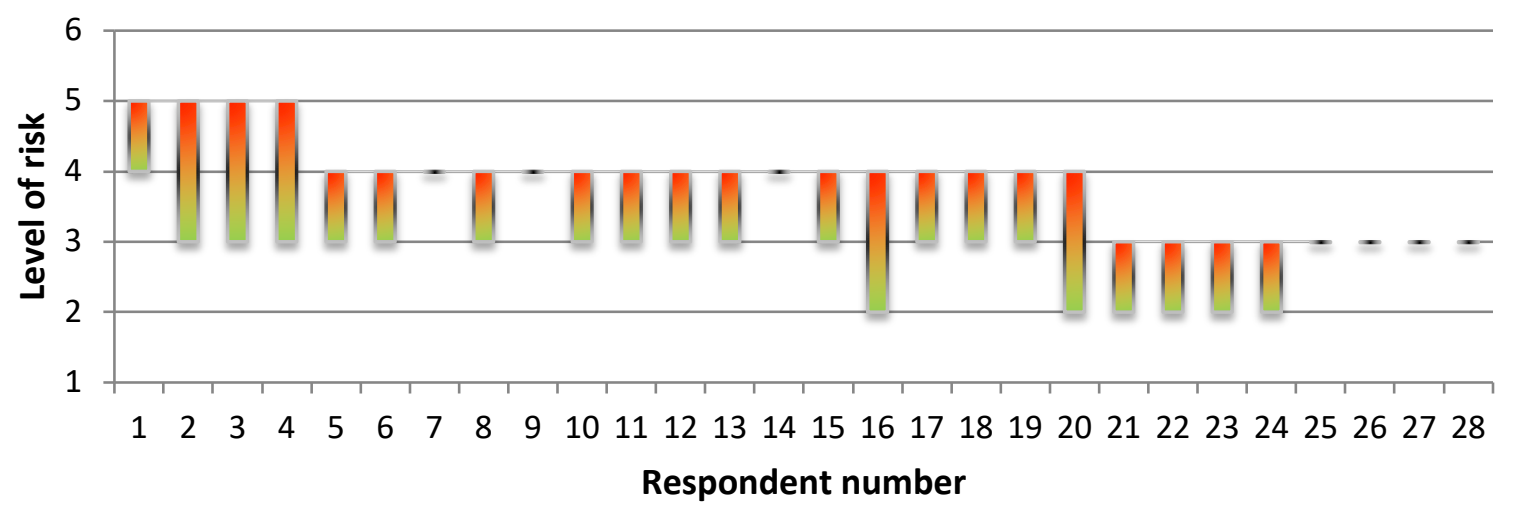

This test confirmed the matrix is a source of uncertainty (Ball \& Watt, 2013; Peace, 2017c) and (as used here) potentially mis-rated the level of risk by $20-40 \%$. This could be countered by using multimethodology (especially bowtie analysis) to build a "big picture" and minimise biases (Montibeller \& von Winterfeldt, 2015). If life-safety or investment decisions about unacceptable risk depended solely on such variable results it should be no surprise if they 
are found to be wrong. Other work similarly described examples of variability in expert judgements, showing the problem is widespread (Burgman, 2016; Rae \& Alexander, 2017).

\subsubsection{Observations during courses}

Observations suggested some groups were subject to "groupthink" (Janis, 1973) resulting in less assertive people withdrawing from discussions, indicating their risk assessments might have been less than effective (Arcus, 2015).

Some course participants found it challenging to accept that different causal chains could give rise to different consequences at different speeds or under slightly different conditions (perhaps the "normal chaos" proposed by Lauder \& Marynissen (2018)) while some argued for the now out-of-date domino theory with a single line of cause and effect (Bird \& Loftus, 1976; Heinrich, 1931). During the courses it was suggested to participants the risk canvas might be used to:

- aid engagement with stakeholders

- act as a record of the risk assessment

- structure and inform a report to decision makers, so giving assurance that an effective process had been followed (Wiedemann et al, 2013).

No clear feedback on these suggestions was discerned although some participants said they would think further about their outputs.

\subsubsection{Suggested changes to the risk canvas}

Course participants suggested the following changes to the canvas (in italics) to which this author's responses are noted (plain text).

\section{Bowtie analysis template design}

Grey-black out the squares that will not be used - was not until second day that our table [group] realised what it was going to be so had a lot of confusion where to write things, or take out horizontal lines in table (Post-its make these redundant) This will be pre-tested with some small groups. If found helpful, the canvas will be changed.

Sources and initiating causes was confusing. Simpler is better.

Use the "Why tree" technique to help identify causal factors (IEC62740, 2015).

Use of acronyms (PESTLE, SWOT and 5W1H)

Anagram [sic] meanings should be on sheet.

Some are already on the canvas but it will be revised to include them all. 


\section{Other suggestions}

As a programme or app

Make it more user friendly and simplified for all business aspects

These will be investigated.

\subsubsection{Risk canvas and the Shoreham Airshow risk assessment}

The risk canvas has emerged as a potentially successful training aid: would it be effective as a tool for a risk assessment in the field? If it been used to aid the Shoreham Airshow risk assessment it is conjectured it might have acted as a reminder to:

- seek out and engage with more stakeholders

- research background documents, including maps

- facilitated the conduct of a PESTLE analysis, perhaps reminding about local residents and roads, the technical condition of the aircraft, and legal requirements

- facilitated a SWOT analysis that might have led to consideration of 'weaknesses' or 'threats' such as human factors

- facilitated use of bowtie analysis, perhaps using the event "loss of control of aircraft" and identification of controls.

\subsubsection{Reliability when using the risk canvas}

When results must be reliable and reproducible, risk assessments should be carried out by trained risk assessors. Provided their work followed a generally accepted process (such as the risk management process in ISO31000), results might be expected to be reliable.

However, there is ample evidence that this is not the case (Ale, 2002; Goerlandt et al, 2017; Haas, 2016; Khastgir et al, 2017).

Here, the risk canvas caused intense engagement in some groups and was clearly a helpful learning tool but no group duplicated the work of another group - even if they worked in the same organisation. For many course attendees this did not matter as they identified key causal factors, consequences and control deficiencies requiring attention. For example, in another test the group members were from an International Electrotechnical Commission (IEC) technical committee meeting who needed to identify risk to their work. For about twothirds of the group ( $\mathrm{N}=35)$ English was their second language. They identified many causal factors and consequences that could be worked on to reduce uncertainty and its effect on their work. Although the groups produced overlapping findings none of the risk canvases were duplicated. 
As tested here, the risk canvas was a workshop tool that enabled a broad focus on learning a process and gathering the best available information under training course conditions.

Gerstein et al (2016) developed a risk-informed decision methodology for NASA that used structured qualitative judgements of seven "risk factors" and reporting with radar charts having seven matching axes. This has not been explored here but, conceptually, could be linked with the risk canvas to further aid reliability of risk assessment findings and is an area of further research.

\subsubsection{Risk canvas: summary and discussion}

The risk canvas provided a set of basic risk techniques thought to help inform decision makers with the best available information from a risk assessment. Overall, feedback on the risk canvas from 85 participants with diverse backgrounds on 11 courses (plus the findings from the IEC workshop) showed encouraging preliminary findings. Participants found the risk canvas "Brought up lots of things I would otherwise have not thought of" (respondent 54) and identified areas for improvement in design.

While the risk canvas helped some individuals who were learning how to conduct a risk assessment, it did not provide reproducible results. Results remained messy, albeit more organised in layout (as shown in photographed extracts).

The risk canvas confirmed the benefits of interactive work using what is essentially a groupgraphical technique group where members learned from each other. Demonstrating the long-term validity and usefulness of the risk canvas will require further research, including access to real-world risk assessments. 


\subsubsection{Risk canvas and the revised goal tree}

As shown in Figure 78, the risk canvas provides a framework to address the goal, CSF and NC in the revised GT. The solid red ellipses identify NC or CSF the risk canvas proactively assists and those with dashed ellipses identify NC the risk canvas assists partially, corroborating use of the risk canvas as a training aid.

Figure 78. Risk canvas and the revised GT

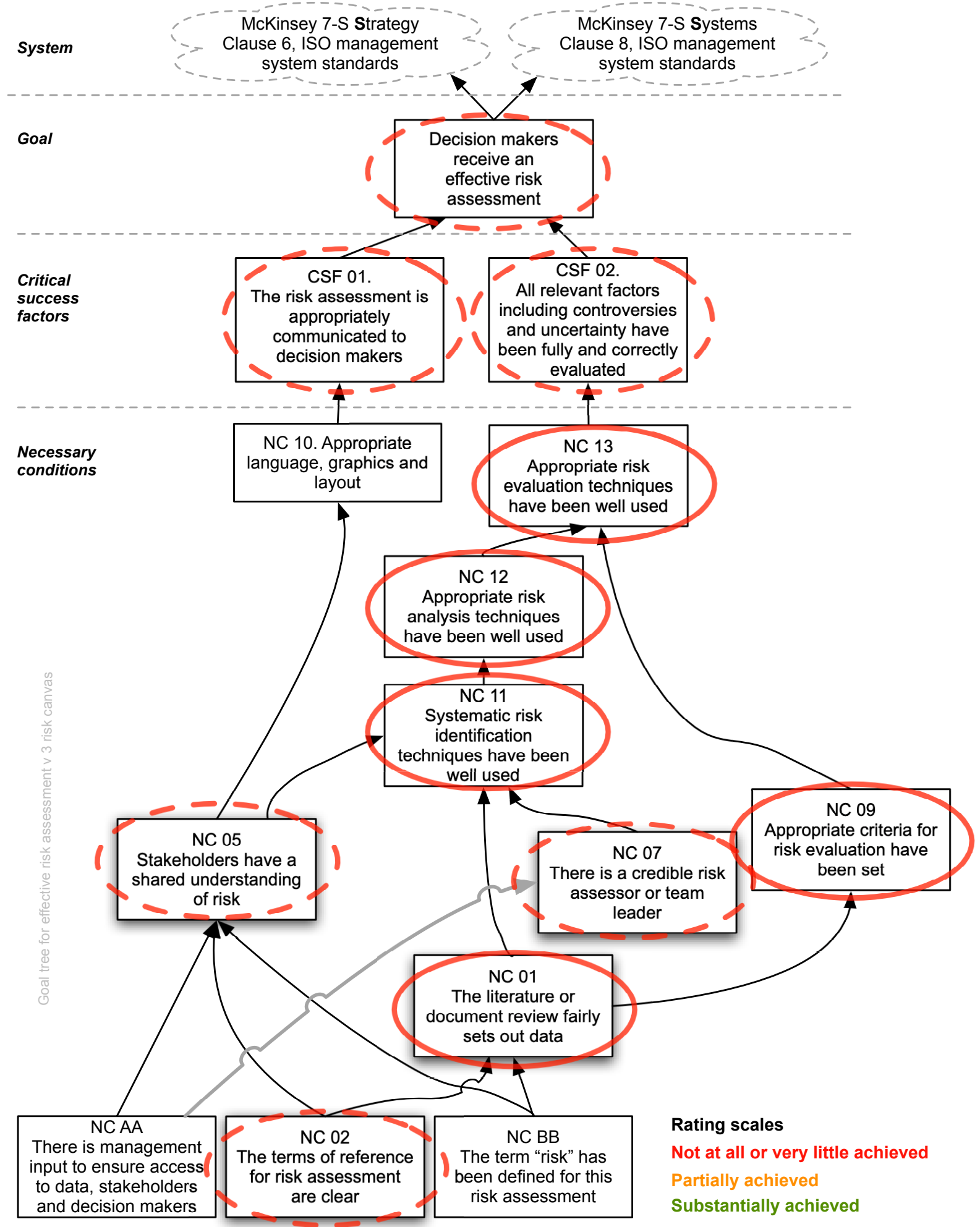




\subsection{Conclusions and research questions}

Each of the mechanisms discussed in this chapter would act to improve risk assessments.

- The revised GT offers potential for decision makers to judge the effectiveness of a risk assessment and for risk assessors to help plan a risk assessment or judge their own work.

- Training and education in the conduct of risk assessments is essential if they are to be effective and recognised as such by decision makers.

- Such training should include how to carry out and use a literature search.

- Development and publication of an identification key for risk technique selection will help assessors find techniques relevant to a given assessment.

- Development of a risk techniques maturity model suggesting how wider use of risk techniques may help reduce uncertainty in the risk assessment outcomes and effectiveness in informing decision makers.

- The GT itself is a management tool that helps reduce uncertainty in the achievement of goals - organisational objectives.

- Gap analysis using the McKinsey 7-S model similarly has the potential to be a risk technique should be researched and documented.

- Improving judgements of probability will reduce uncertainty about the occurrence of consequences.

- The risk canvas provides a useful workshop template with test results showing it provides a good structure for training and, possibly, practice.

\section{Research question}

Options for the improvement of risk assessments derived from the literature review, online survey and case studies were identified and discussed, so responding to sub-question 2 "what mechanisms could facilitate or improve risk assessments to provide support for strategic decisions in an organisational context?".

In the next chapter the findings of the literature reviews and research are discussed. 


\section{Discussion}

\subsection{Research overview, origins and questions}

In this chapter the origins of the research and the research questions are revisited as a prelude to exploring the research credibility, reliability and limitations. The survey and case study results are discussed before exploring the findings and two key themes arising from the research.

As originally planned (section 1.7), this research began as a Master of Commerce by thesis (later converted to this $\mathrm{PhD}$ ) intended to respond to observations that some, perhaps many, risk assessments are ineffective. This is despite claims they should be a "game-changing technology" (Goble \& Bier, 2013, p. 1942), forming part of management-as-a-technology (Bloom et al, 2016), that informs decisions, so providing organisational benefits (Table 1, section 1.4). The Master's research was to use an online survey to gather data from a large group of risk and safety practitioners and was also planned to include observations and focus groups. After conversion to a $\mathrm{PhD}$, the research question was initially:

$R Q$. What critical success factors and necessary conditions can be derived from the literature and case studies that would help decision makers and risk assessors to evaluate the effectiveness of risk assessments before they are used to aid a decision?

Following identification from the literature of CSF and NC and exploration of the goal tree, the research question was revised to ask:

RQ. Can a generic GT, populated with critical success factors and necessary conditions derived from the literature and case studies, be developed that would help decision makers and risk assessors to evaluate the effectiveness of risk assessments before they are used to aid a decision?

The tentative GT (section 3.2) was developed from the CSF and NC and used to structure analysis of the online survey data and qualitative data from the case studies, and for testing of the risk canvas, substantially answering the research question. This now leads to further consideration of the GT as both a research tool and risk technique in section 8.3.1.

Two research sub-questions asked:

SQ1. What processes and methods are currently being used for risk assessments? (answered in chapters 4 Online survey: results and analysis and 5 Case studies: results and analysis), 
SQ2. What mechanisms could facilitate or improve risk assessments to provide support for strategic decisions in an organisational context? (answered in chapter 7 , Mechanisms that might facilitate or improve risk assessments).

\subsection{Research credibility, reliability and limitations}

The research philosophy was Pragmatism (Elkjaer \& Simpson, 2011) which sees research and practice as activities on a continuum, where both are engaged in problem-solving and inquiry in a "complex, uncertain, and ever-evolving world" (Weick, 2016, p. 342). This encourages its practitioners to think and act recursively, enabling understanding of the effect of actions on both their contexts and themselves, perhaps explaining some surprising fact (Aven, 2015, p. 86) or enabling exploitation of serendipitous findings and effects (Farjoun et al, 2015). The interplay between prior theoretical knowledge (including research literature, grey literature and international standards), theory suggestions and real-life observations from consultancy and other work that diverged from theory is summarised in Figure 6 , section 3.1.1.

The phenomenon under study is risk assessments in an organisational context and their effectiveness. Modell (2009) showed that, in the social sciences, triangulation has come to include integration of mixed methods to provide complementary and converging insights that enable better understanding of phenomena. Figure 79 summarises how the data was triangulated in this research.

Figure 79. Triangulation of data and methods in this research

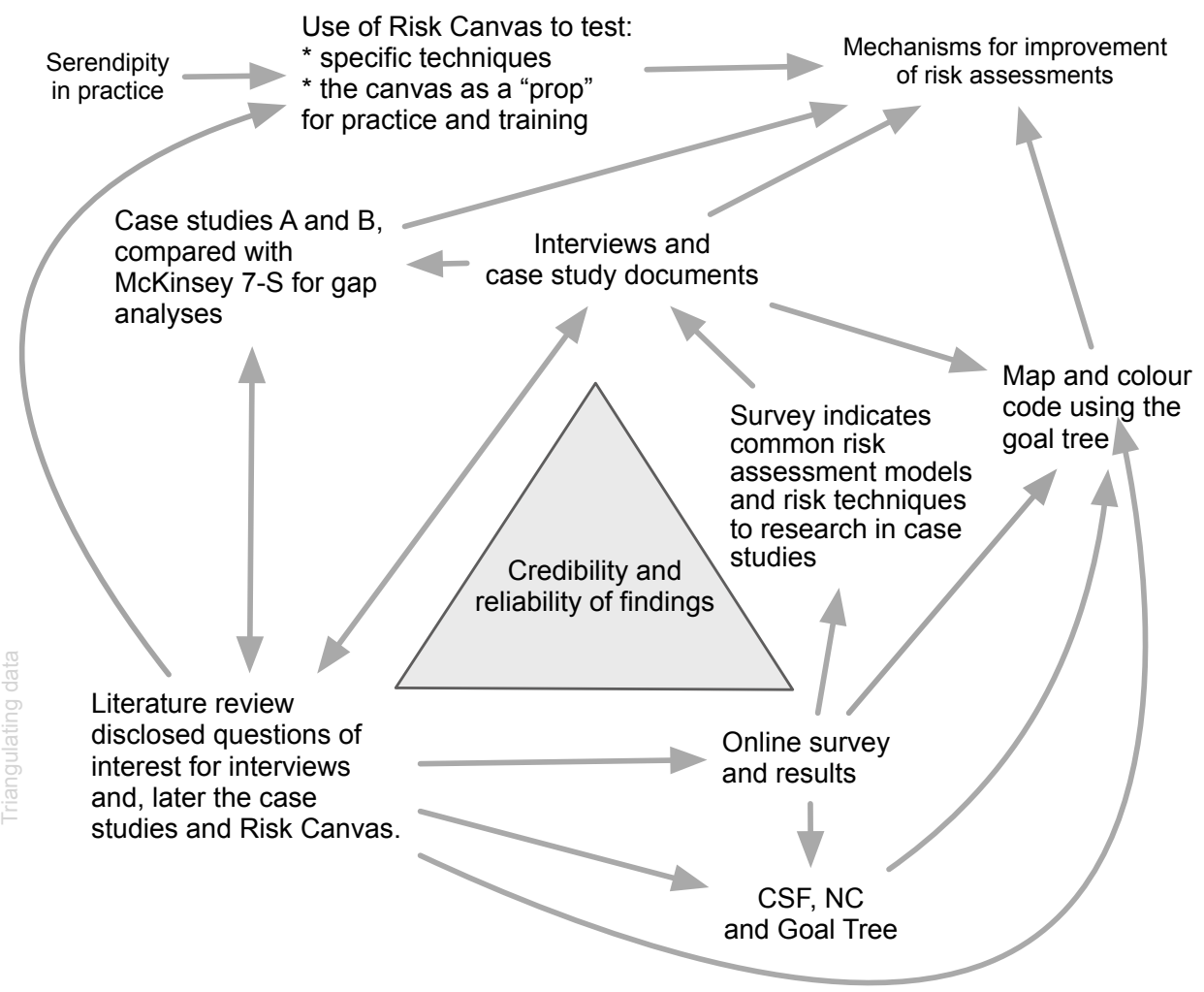


The literature review (including the CORA framework for science-based risk assessments) informed the survey and case study questions and identified CSF and NC that enabled development of the tentative GT and the NVivo codes. This GT was used to map, colour code, and then compare the CSF and NC with data from the survey, case studies and risk canvas, and to identify common issues that needed to be addressed. The online survey and case studies were investigated using the tentative GT, McKinsey 7-S and risk canvas. The risk canvas was tested separately and found to be an effective prop and aid to teaching specific techniques.

The data derived from the survey and case studies provided insights into practice. Such online survey data is fallible and remains provisional (Elkjaer \& Simpson, 2011) because, for example, survey respondents might later, based on more recent experience, choose different options in the questions. Similarly, case study interviewees might later have a changed perspective. However, each is treated here as 'true' at the time the data was collected.

More than 40 organisations were approached as possible case studies in this research but almost all either declined or failed to respond, perhaps because risk assessments were not carried out or were not very effective. This is a similar finding to research in the UK (Gadd et al, 2003), European Union (Karageorgiou et al, 2000), Germany (Lenhardt \& Beck, 2016), and USA (Beasley et al, 2015). One of the five case studies provided only partial information but this was sufficient to show some features of risk assessments led by a CEO and so was included in the research. Researching a greater number of cases might have added more credibility but, with the available resources, would have resulted in less depth (Easton, 1995).

In the five case studies a total of 25 documents were reviewed, 16 respondents interviewed and five supplementary literature reviews carried out. The number of case studies means the research was unrepresentative and findings remain fallible and provisional (Elkjaer \& Simpson, 2011) but, when combined with the results of the online survey, may be considered interlocking and complementary (Kovács \& Spens, 2005), so corroborating the perceived problem (section 1.7) that:

Risk assessments often fail to inform decision makers effectively about uncertainty in the form of causes of possible events, the consequences that might follow, the effectiveness of existing controls and the options for treating risk. 
The research achieved rigour (Vermeulen, 2005) within an abductive approach by applying a quantitative online survey, complemented by qualitative case studies, underpinned by the literature review to the phenomenon of organisational risk assessments.

\subsubsection{Literature review}

This research was an investigation of the effectiveness of risk assessments in an organisational context. Thus, the literature review included "grey literature" (Saunders et al, 2007 , p. 64) such as standards or practitioners' publications. International standards published by the International Standards Organization (ISO) and International Electrotechnical Commission (IEC) have a defined development process for their preparation, including exposure of drafts for public comment, and are regarded as reliable. Other grey literature published by major consultancies is also seen as reliable despite possible conflicts of interest. Academic literature was regarded as highly reliable if it was peer-reviewed or an academic text book.

The literature review concluded that effective decision making and risk assessment processes are similar; both require a good understanding of the context or business environment, engagement with stakeholders, and forecasting what might happen at some future point. The process described in ISO31000 (2009) provides a model that is widely (but by no means solely) used by practitioners (Dali et al, 2012).

The literature review also found there is inadequate guidance on risk technique selection, leading to a need to develop an identification key (section 7.3.1).

\subsubsection{Online survey results}

About 230 people responded to most of the survey questions, suggesting the results were reliable. Although the quantitative data from the survey only provided a "surface depiction" (Modell, 2009, p. 213) of the risk assessment phenomenon; however, when mapped into the GT (Figure 21), a richer picture emerged of CSF 02, and NC 01, 06, 11, 12, and 13 being, at best, partially achieved.

The survey showed a strong preference for use of professional judgement, workshops and the consequence/likelihood matrix, with some respondents apparently unable to distinguish between qualitative and quantitative techniques. New Zealand survey respondents were somewhat more likely to use professional judgement and the matrix, and somewhat less likely to use brainstorming or other workshops, possibly suggesting that New Zealand respondents either prefer to work alone rather than in groups or that this is a reflection of the country's population size and spread, and typical organisation size, giving reduced opportunities to work collaboratively. These results suggested a need for training in structured processes and risk techniques to help give more reliable results. 


\subsubsection{Case studies results}

The near absence of document reviews (NC 01) in the case studies was a foundational issue that might be due to (Geroy \& Wright, 1988) the lack of time for practitioners to gather data; out-of-date literature searching skills; failure to relate research skills to praxis; or the lack of practitioner training in searching for data (Zardo \& Pryor, 2017).

Overall, what might appear to be a good decision outcome was found to be not supported by effective risk assessments. For example, and using necessity logic, the risk assessment in Case Study A was partially effective because of supervision by the CEO; as a result, the outcome was very successful. A more substantial literature review would have resulted in more evidence for the changes.

Case Study B relied on a retrospective approach based on historical events that had happened elsewhere. A prospective "what if" assessment might have identified the potential for earthquake damage to non-structural elements to be causes of disruption and injury. As a result the risk assessment was not at all effective.

Misunderstanding the terms of reference in case $C$ resulted in a narrow risk assessment that was not at all effective because it led to the belief that improvement of the standard operating procedure would reduce the risk of worker harm. However, it failed to ask if ATVs as a source of OHS-related risk could be eliminated. A better literature review might have found the range of evidence to challenge the perceived terms of reference and so make the risk assessment effective. The decision outcome became successful because the CEO took alternative advice from others.

Case $D$ included two risk assessments. The first, for food safety, was not at all effective because the terms of reference were lacking in comprehensiveness and/or appropriateness. The second, for occupational health, was substantially effective using test results from consultants. Had the risk been correctly framed and supported by a substantial literature review with earlier engagement the risk assessment might have been very effective and avoided late cancellation of the pilot project.

The decision in Case Study $\mathrm{E}$ was positive in relation to proposed commercial benefits and supported by a risk assessment that evolved iteratively as a 12-month dialogue between the board and CEO. However, the lack of any reported literature review about or assessment of supply chain vulnerabilities meant it failed to consider disruption of supply chains from the proposed enlarged production site to the developing market and so was not at all effective.

In Case Study A (and possibly C), the decision appeared to be informed by a risk assessment but the decision makers had apparently already made the decision and needed substantiating evidence from the risk assessments. This was similar to the pitfall of "carrying 
out a risk assessment to attempt to justify a decision that has already been made" (Gadd et al, 2003, p. 7).

In cases $B$ and $E$ earthquakes were external causes of damage and disruption and so were outside the control of the organisations. However, the earthquakes had internal consequences that were controllable and could have been foreseen by an effective risk assessment.

Although not a case study, the Shoreham aircrash risk assessment was shown by using the GT to be poorly conducted, and provided misleading findings that failed to anticipate the disaster.

The GT showed document reviews, systematic risk identification, risk analysis, risk evaluation and description of relevant factors (including controversies and uncertainty) were, at best, partially achieved. There was, however, generally substantial engagement with stakeholders. These findings suggests that risk assessors may rely on their relationships with stakeholders and professional experience instead of the best available information in research and guidance documents. This issue has also been identified in the fire service in Australia (Owen, 2018), OHS in Great Britain (Van Eerd et al, 2017) and management research (Van de Ven \& Johnson, 2006).

Improvement of document or literature reviews might have improved inputs to NC $07,08,09$ and 10 and decision makers would have received a more effective risk assessments. For important decisions, the costs of such a document review might be small compared with the costs of decision failure (as was found in four case studies).

The cases showed various approaches to risk assessments and corroborated use of the critical success factors and necessary conditions in the tentative GT.

A process and outcomes matrix was used to portray the effectiveness of each risk assessment compared with the decision outcomes and is used here (Figure 80 ) to summarise the case study and Shoreham Airshow findings.

Figure 80. Process and outcomes matrix

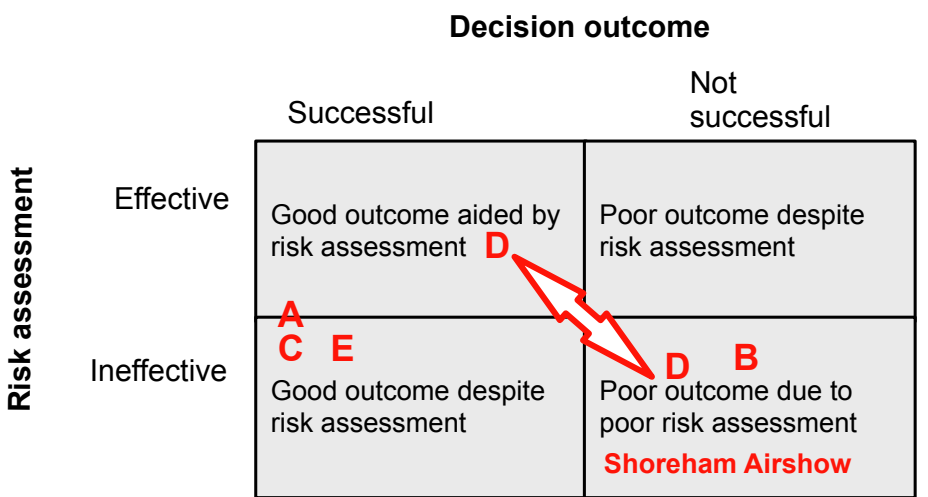


Each case study:

- formed a "critical case" that illustrated practice in risk assessments (Flyvbjerg, 2006; Voss et al, 2002)

- provided empirical investigations in depth and in context (Farquhar, 2012) of the phenomenon of risk assessments informing decisions at the time the risk assessment was completed

- extended understanding of the relationships between decision making and risk assessments.

Use of pre-set questions and NVivo codes, and the same tentative GT to structure the findings from each case study facilitated "the process of bringing order, structure, and interpretation to a mass of collected data [which often] is messy [and] ambiguous" (Marshall \& Rossman, 2006, p. 154).

\subsubsection{Key findings and themes of the research}

Sub-question 2 sought to identify mechanisms that could provide support for strategic decisions in an organisational context, distinguishing this research from science-based risk assessments that inform policy decisions. A range of relevant mechanisms has been identified, including the GT and risk canvas as two key outcomes and themes of the research.

The following are further important findings and themes:

- absence of risk definitions in risk assessments

- professional judgement as a pervasive problem

- survey and case study respondents

- lack of document reviews in case study risk assessments

- lack of structure in case study risk assessments

- risk techniques and an identification key

- use of McKinsey 7-S as a gap analysis technique.

These findings and themes are now discussed.

\subsection{Key outcomes and themes}

\subsubsection{The goal tree: philosophy and applicability as a research and practical tool}

The research findings showed that the GT was a useful research and practical tool but that it had not been fully explored in the literature. A detailed consideration of both aspects now follows. 
Dettmer (2007, pp. 60-62) argued that "logic trees [including the GT] are not flowcharts" because they use symbols and connection conventions missing from flowcharts. However, Recker et al (2009), who carried out a detailed analysis of business process models to show "the poor performance of flowcharts" despite "their historically high level of adoption in modelling practice", based some of their research on flowcharts using ANSI standard X3.5 (1970), now ISO5807 (1985). An alternative to flowcharts is fault tree analysis (IEC61025, 2008) which also has a standard symbol set. Comparison of the ISO5807,IEC61025 and TOC symbol sets shows some superficial similarities, confirming the origins of each for distinct purposes.

Objectives or goals in the definition of risk were linked (section 2.6.2) to management by objectives (Drucker, 1954), goal setting (Latham \& Locke, 2006), goal orientation theory (Vandewalle et al, 2019), and the GT, part of the Theory of Constraints (TOC) (Dettmer, 2007), which is an evolving management methodology (Kim et al, 2008).

The GT may be regarded as having theoretical and practical utility if it can represent some aspect of theory or the world (or both); enable learning through its construction and application (Morrison \& Morgan, 1999b); mediate between theory and the empirical world (Dubois \& Gadde, 2002); and/or function as a generalisable tool or instrument.

As noted in the literature review, the GT seems to have been regarded (Dettmer, 2007, p. $74 ; 2011)$ as unique to systems within organisations, while Moore (2009) and Moore \& Mabin (2018) progressively developed one GT during their research. Here, the tentative GT was used to aid analysis of the results of the online survey and risk assessments in five case studies, and the Shoreham aircrash. This is a previously unreported use of a single GT in different organisations and is a contribution to the TOC literature.

As the GT was not included by Davies et al (2005) in an analysis of philosophical assumptions underlying the TOC tools, these are explored here to support its use. Applying the Davies et al structure to the GT yields Table 61 which shows the ontological and epistemological basis of the GT, a contribution to the literature. 
Table 61. Philosophical assumptions underlying the TOC goal tree

\begin{tabular}{|c|c|c|c|c|c|c|c|}
\hline $\begin{array}{l}\text { Methodology/ } \\
\text { technique }\end{array}$ & $\begin{array}{l}\text { What it does } \\
\text { A system to } \\
\ldots\end{array}$ & $\begin{array}{l}\text { Ontology } \\
\text { What it } \\
\text { assumes to } \\
\text { exist }\end{array}$ & $\begin{array}{l}\text { Epistemology } \\
\text { Representation } \\
\text { by modelling } \\
\text {... }\end{array}$ & $\begin{array}{l}\text { Epistemology } \\
\text { Necessary } \\
\text { information }\end{array}$ & $\begin{array}{l}\text { Epistemology } \\
\text { Source of } \\
\text { information }\end{array}$ & $\begin{array}{l}\text { Axiology } \\
\text { Users }\end{array}$ & $\begin{array}{l}\text { Axiology } \\
\text { Purpose to ... }\end{array}$ \\
\hline TOC GT & $\begin{array}{l}\text {... identify } \\
\text { and relate } \\
\text { critical } \\
\text { success } \\
\text { factors and } \\
\text { necessary } \\
\text { conditions for } \\
\text { achievement } \\
\text { of a goal }\end{array}$ & $\begin{array}{l}\text { Desired } \\
\text { outcomes, } \\
\text { specific } \\
\text { factors and } \\
\text { conditions that } \\
\text { are needed for } \\
\text { achievement } \\
\text { of a goal }\end{array}$ & $\begin{array}{l}\text {... necessary- } \\
\text { condition logic } \\
\text { relationships of } \\
\text { the necessary } \\
\text { conditions and } \\
\text { their relationship } \\
\text { to the goal in } \\
\text { the form of a } \\
\text { tree }\end{array}$ & $\begin{array}{l}\text { Objective } \\
\text { facts, } \\
\text { subjective } \\
\text { opinions, } \\
\text { logic } \\
\text { relations, } \\
\text { judgements }\end{array}$ & $\begin{array}{l}\text { Observation } \\
\text { and } \\
\text { measurement } \\
\text { of the real } \\
\text { world, } \\
\text { judgement }\end{array}$ & $\begin{array}{l}\text { Decision } \\
\text { makers, } \\
\text { analysts, } \\
\text { advisors, } \\
\text { consultants, } \\
\text { facilitators and } \\
\text { implementers }\end{array}$ & $\begin{array}{l}\text {... show } \\
\text { relationships } \\
\text { between } \\
\text { critical success } \\
\text { factors and } \\
\text { necessary } \\
\text { conditions for } \\
\text { achieving the } \\
\text { goal }\end{array}$ \\
\hline
\end{tabular}

Addition to Davies et al (2005) framework by author

Davies et al (2005) also used a 3x4 grid developed by Mingers \& Brocklesby (1997) for mapping soft systems tools to map the TOC tools, but did not extend to this to the GT. Table 62 is a draft map for the GT that responds to this gap and follows the Mingers (2003) convention of grey shading to show the likely extent to which a method supports the activity in each cell of the grid.

Table 62. Mapping the philosophical foundations of the goal tree

\begin{tabular}{|c|c|c|c|c|}
\hline & Appreciation of ... & Analysis of ... & Assessment of ... & Action to ... \\
\hline $\begin{array}{l}\text { Three } \\
\text { dimensions of } \\
\text { problem } \\
\text { situations } \downarrow\end{array}$ & $\begin{array}{l}\text {... the problem situation } \\
\text { as experienced by the } \\
\text { agents involved }\end{array}$ & $\begin{array}{l}\ldots \text { the underlying } \\
\text { structure/constraints } \\
\text { generating the situation } \\
\text { as experienced }\end{array}$ & $\begin{array}{l}\text {... the ways in which } \\
\text { the situation could be } \\
\text { other than it is; of the } \\
\text { extent to which the } \\
\text { constraints could be } \\
\text { altered }\end{array}$ & $\begin{array}{l}\text {... bring about desirable } \\
\text { changes }\end{array}$ \\
\hline $\begin{array}{l}\text { Social world } \\
\text { Developed } \\
\text { through } \\
\text { evolution and } \\
\text { linguistically- } \\
\text { endowed } \\
\text { humans }\end{array}$ & $\begin{array}{l}\text { Social practices, power } \\
\text { relations }\end{array}$ & $\begin{array}{l}\text { Distortions, conflicts of } \\
\text { interest }\end{array}$ & $\begin{array}{l}\text { Ways of challenging \& } \\
\text { altering power } \\
\text { structures }\end{array}$ & $\begin{array}{l}\text { Generate empowerment } \\
\text { and enlightenment }\end{array}$ \\
\hline $\begin{array}{l}\text { Personal world } \\
\text { Our own } \\
\text { individual } \\
\text { thoughts and } \\
\text { experiences }\end{array}$ & $\begin{array}{l}\text { Individuals' beliefs, } \\
\text { meanings, emotions }\end{array}$ & $\begin{array}{l}\text { Different perceptions } \\
\text { and Weltanschaung }{ }^{12}\end{array}$ & $\begin{array}{l}\text { Alternative } \\
\text { conceptualisations and } \\
\text { constructions }\end{array}$ & $\begin{array}{l}\text { Generate } \\
\text { accommodations and } \\
\text { consensus }\end{array}$ \\
\hline $\begin{array}{l}\text { Material world } \\
\text { Outside and } \\
\text { independent of } \\
\text { human beings }\end{array}$ & Physical circumstances & $\begin{array}{l}\text { Underlying causal } \\
\text { structure }\end{array}$ & $\begin{array}{l}\text { Alternative physical and } \\
\text { structural arrangements }\end{array}$ & $\begin{array}{l}\text { Select and implement } \\
\text { best alternatives }\end{array}$ \\
\hline
\end{tabular}

Source: structure adapted from Davies et al (2005), Mingers (2003) with shading for the GT provided by author

\footnotetext{
${ }^{12}$ A particular philosophy or view of life; the world view of an individual or group (Oxford Online English Dictionary)
} 
The GT entity was found to:

- mediate between theory and practice, acting to explain the process by which one variable leads to uncertainty or change in another (Morrison \& Morgan, 1999a)

- enable structured predictions and analysis of research data

- enable visualisation of a hierarchy of organisational goals to be effected by organisational policies or standard operating procedures (Dettmer, 2007, p. 73; Drucker, 1973, pp. 262-263)

- $\quad$ show, using suitable colour coding (section 3.2.1), where a risk assessment has weaknesses and therefore what is needed to achieve the goal

- provide a visual representation for use when conducting a risk assessment or after a risk assessment has been completed but before submission to decision makers

- enable analysis of the different perceptions of interviewees of an effective risk assessment

- enable an assessment of the physical and structural arrangement of risk assessments

- enable selection and implementation of the mechanisms for improvement of risk assessments.

This analysis of the GT as an enquiry, representational and benchmarking process tool reflects its nature as a pragmatic technique that facilitates exploration of the personal and material worlds, aiding selection between alternatives and providing a focus on the satisfying factors that are needed to achieve the goal. As such, its use can be corroborated by empirically applying it to real-world situations to ascertain if it links the critical success factors (CSF) and necessary condition (NC). It also acts as a "provisional conjecture" (Popper, 1959, p. 33 and 265) that merits further testing to discover if it meets Popper's (1959, p. 39) requirements that it represents a possible world, a possible experience, and our world of experience.

\section{The GT as a practical tool}

The literature review (section 2.5) identified $15 \mathrm{NC}$, two of which were considered to be CSF - the "show-stoppers" (Dettmer, 2007). These were mapped into the tentative GT for risk assessments (section 3.2) and used to aid analysis of data from the online survey and case studies. 
Dettmer (2003, pp. 63-77; 2007, p. 80) described how necessity logic requires that NC and CSF be achieved either $100 \%$ or satisficed to an agreed or acceptable level (section 2.5). His 2003 work has not been further developed but it suggested some mechanism to indicate the development of NC or CSF may be of practical assistance. The colour coding system used in this research followed Hohmann (2014) (Table 9, section 3.2.1) to show how well the NC and CSF were achieved in the Shoreham Airshow risk assessment, online survey and case studies. These were then summarised in Table 59 where they vividly show most NC and CSF were not at all or very little achieved. This was novel research.

Using the GT to map the risk assessment process thus helps develop shared meaning and placement of the various pieces of data (Petersen, 2017, p. 41 and 48), makes explicit what was previously vague, and improves focus on the goal.

Whereas a checklist simply shows what has or has not been done, the GT shows, using necessity logic, how some incomplete action will affect other NC or CSF. For example, if the GT is used to monitor progress in a risk assessment, the risk assessor or team leader will be able to see where inadequacies in one or more NC would result in the goal of an effective risk assessment not being achieved. Also, a decision maker can quickly see where there are inadequacies and so gauge the reliability of a risk assessment. This is an application of the GT that has not previously been explored.

The GT for the test on the Shoreham aircrash data and case studies (Figure 27, Figure 34, Figure 40, Figure 46 and Figure 49) includes directional arrows linking the NC and CSF. In this research (but not the GT literature) the arrows have been qualitatively weighted to indicate the strength of effects. This helps show the importance of engagement (now CSF 01 ) that sometimes made an otherwise ineffective risk assessment somewhat effective. This is an application of the GT that has not previously been explored.

About half of the interviewees asked if they could keep a copy of the GT, suggesting many had not previously considered the importance of the design and conduct of risk assessments and that the GT has practical as well as theoretical benefits.

Section 137 of the New Zealand Companies Act (1993) requires directors and officers to "exercise the care, diligence, and skill" of a reasonable director and section 138 authorises directors to "rely on reports... and other information prepared or supplied, and on professional or expert advice". These requirements are underpinned by the Financial Markets Authority (2018) and New Zealand Stock Exchange (2017) guidance on corporate governance. Similar duties are in section 44 of the New Zealand Health and Safety at Work Act (2015). Directors and officers needing to comply with these duties may require training in what to expect in risk assessors' reports. Such risk assessments need to be substantially 
effective in their conduct for, as discussed in section 2.7.3, decision makers may be biased and unwilling to accept the results of risk assessments (Frimer et al, 2017; Kahan et al, 2012; Kaplan et al, 2016).

As part of setting the "tone from the top" the GT could be used by directors and senior managers to gauge if a risk assessment met all CSF and NC for an effective risk assessment. The GT can also be used to help map the necessary conditions for achievement of organisational goals and where there is uncertainty (ie, "risk") and therefore becomes a risk technique in itself.

The revised GT now includes NC 07a feedback from "management" to help risk assessors understand what might be expected. Such feedback might be given, for example, in a structured manner after completion of a major risk assessment or during annual performance reviews.

This work has extended earlier work on the GT (Dettmer, 2003, 2007, 2011; Hohmann, 2014) and refreshed and extended Dettmer's work on "magnitudinal" necessary conditions (Dettmer, 2003, p 65-66) that he had subsequently overlooked ${ }^{13}$.

\subsubsection{Risk canvas as a pragmatic training tool}

The risk canvas (section 7.4) was evolved from a pragmatic problem (how better to teach a suite of qualitative risk techniques (section 2.4.1) and then tested during 12 training courses with 95 participants. It was found to provide a structured approach that should provide reproducibility of process (a quality assurance issue (Lathrop \& Ezell, 2017)) but did not necessarily provide reproducibility of results (section 7.4 .7 ).

Further consideration of the risk canvas test results suggested there are at least three variables in a risk assessment: (1) quality and quantity of data, (2) experiences and characteristics of risk assessors, and (3) use of risk techniques.

The first two are independent qualitative variables that moderate the risk assessment results and that can be held constant by providing limited data (the training course case study) and techniques (the risk canvas and course handbook), leaving the variable experiences and characteristics of assessors uncontrolled.

${ }^{13}$ Email to author dated 13 April 2019 reporting "somehow I overlooked including that chart" 
Figure 81. Risk canvas as a moderator

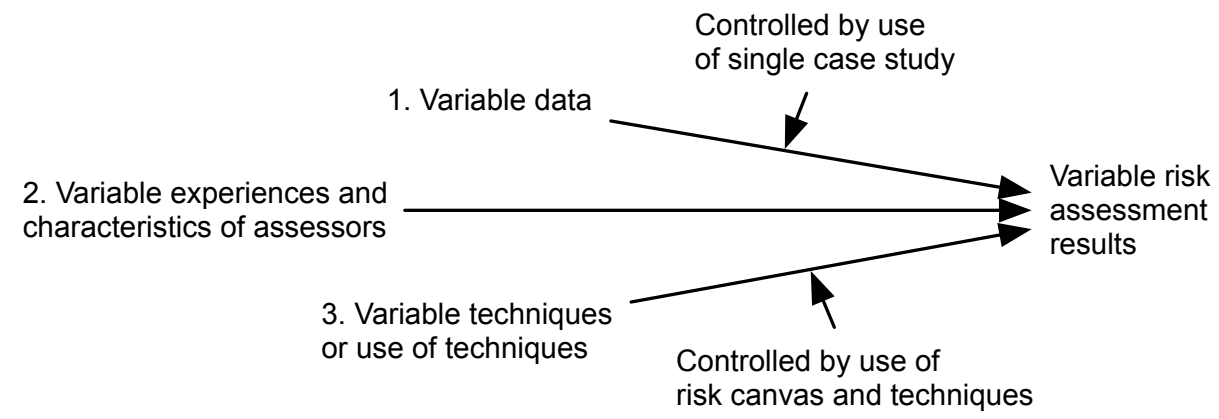

None of the groups on the training courses produced the same results, again suggesting this variable might require moderation through training and feedback.

This was especially pronounced in the bowtie analyses produced by the groups. Some bowties were qualitatively similar but none were identical, suggesting that the technique is helpful in engaging members of a group but may not produce reliable results, a result not previously reported in the literature.

The overall results were, on a smaller scale, comparable to an inter-country risk assessment exercise that concluded there was a need for harmonisation of risk assessment training and models, processes, language and results presentation (Contini, Amendola, \& Ziomas, 1991).

\subsection{Further findings and themes}

\subsubsection{Risk definitions in risk assessments}

A key finding in the literature review was that the definition of risk is contentious, but is often related to uncertainty (section 2.1.2). This led to the decision to use the definition "effect of uncertainty on objectives" in ISO31000 (2009) and thence to organisational objectives in section 2.6 which, in turn, led to use of the GT as a research tool and, potentially, a risk technique. While the selected definition of risk fitted with the research criterion of risk assessments in an organisational context, selection of an alternative definition might have led the research to different conclusions.

It was concluded that, as part of any risk assessment, the definition of risk should be negotiated with stakeholders (perhaps as part of the literature review) to avoiding imposing a definition on stakeholders, for "defining risk is ... an exercise in power" (Slovic, 1999, p. 699).

None of the case studies defined risk as part of their risk assessments, so missing an opportunity to explore the effects of uncertainty and ensure that organisational or risk assessment objectives had been set. Furthermore, about one-third of survey respondents 
never or rarely mentioned uncertainty in risk assessments (section 4.3.15). These results may indicate a high level of ill-founded optimism about assessment capabilities.

\subsubsection{Professional judgement as a pervasive problem}

Responses in the online survey showed that professional judgement was the most widely used "risk technique". A subsequent review of professional judgement (section 6.5.2) showed how misleading reliance on professional judgement may be if it is not based on interpretation of data derived from a structured process. Professional judgement can, however, be improved if assessors are taught how to seek out the best available information, perhaps using the risk canvas.

On the basis of the online survey and case studies, training and development is needed to help overcome issues identified in this research. These include over-reliance on the subjective nature of professional judgement (section 6.5.2) and failure to carry out a basic document review (section 6.5.1). There is a substantial body of relevant, low/no cost primary and secondary research (Zardo \& Pryor, 2017) that could be used to aid practice (Owen, 2018) and build wider professional knowledge (so avoiding single "big ideas" (Tetlock, 2006, p. 69)) but practitioners need training in accessing it. However, relationships between risk assessment research, policy, teaching and practice in New Zealand appear to be weak at a tertiary level (section 7.2.3). Risk assessment as a "game-changing technology" (Goble \& Bier, 2013) is unlikely to become part of management-as-a-technology in New Zealand (Bloom et al, 2016) if it is not taught and researched consistently at a tertiary level.

Development of tertiary level generic risk assessment and risk management courses might help remedy this and lead to the development of a research base in New Zealand. Such teaching might include: professional development courses for practitioners on selection of relevant techniques to be used within a structured process; and directors and officers training in when and what to expect in risk assessments as part of their Companies Act and HSWA duties (Jager et al, 2013; Peace, 2017b; Peace et al, 2017).

\subsubsection{Survey and case study respondents}

The online survey (section 4.3.3) showed that many respondents were well-qualified and experienced. The number of case study respondents was too small to draw conclusions that may be generalised but they may have been less qualified or experienced, perhaps leading to use of less structured risk techniques and effective risk assessments. This suggests they either had not been taught relevant techniques or received little feedback that might lead to their regular use.

Case studies $A$ and $C$ included two in-house professionals and in Case Study B one of the interviewees had resigned from a UK professional body because there seemed little 
relevance to maintaining membership when resident in New Zealand. Credibility of professional advisors in a large organisation such as Case Study B might require that such evidence of competence be maintained. These findings suggest many in-house risk assessors may generally be capable of straightforward qualitative risk assessments (section 2.2) but may not be aware of the skills they could call on from others with higher qualifications or skills.

None of the respondents was identified as a "scientist working in post normal science" (Funtowicz \& Ravetz, 1992, pp. 251-273); each of the case studies would have benefited from an external peer review by at least a specialist consultancy as noted by the National SHE Manager in case study A (section 5.3.4):

I think the only issue I had with my work was that I didn't have somebody to pass over it to give a sense check because there was no one at the level I was for health and safety in the business. I had someone in London who I could bounce stuff off. I didn't even have the opportunity to go outside to an outside consultant or another safety practitioner.

\subsubsection{Risk techniques and an identification key}

The low level of usage of structured techniques found in the online survey confirmed the need for an identification key identified in the literature review (section 2.4.3) and online survey conclusions (section 4.4.7) but the work required was found to be substantial (Nickerson et al, 2013; Zijp et al, 2015) and is a future project.

\subsubsection{Use of McKinsey 7-S as a gap analysis technique}

Use of the McKinsey 7-S model (Figure 13) helped identify areas where the gap analyses in in case studies $A$ and $B$ had missed issues subsequently found to be important. It is likely that risk and safety practitioners will be asked to develop or contribute to risk improvement plans requiring use of gap analysis. The McKinsey 7-S model (Figure 13) may help ensure that important issues are considered when developing such plans. The model requires further work to ensure it aids identification of key issues that are widely applicable.

\subsubsection{Revision of the CORA framework}

The CORA framework will be reviewed using the summarised findings of the GT (section 6.4 ) and an article submitted for publication suggesting changes that would strengthen it.

\subsection{Conclusions}

This research used a pragmatist approach (section 3.1.1) derived from observations that risk assessments often seemed to be ineffective in informing decision makers, and that 
practitioners seemed not to be using processes or techniques described in guidance literature.

Tentatively (and keeping in mind confirmation bias (Bolger \& Wright, 1994; Dube-Rioux \& Russo, 1988)), the results corroborate findings from the field that practitioners and decision makers lack training in the conduct of risk assessments.

No ethical issues were encountered in this research as the outcomes of the case study decisions were completed before the cases were taken.

This chapter has discussed the research findings, linking them to the research question and sub-questions, and confirmed that the research is "white space" - an area where data and knowledge are either limited or ambiguous and conflicting (Cherry, 2010, pp. 9-17).

The next chapter sets out research conclusions and possible future research. 


\section{Conclusions}

\subsection{Problem statement and research questions}

The problem statement was that:

Risk assessments often fail to inform decision makers effectively about uncertainty in the form of causes of possible events, the consequences that might follow, the effectiveness of existing controls and the options for treating risk.

The original $R Q$ was:

$R Q$. What critical success factors and necessary conditions can be derived from the literature and case studies that would help decision makers and risk assessors to evaluate the effectiveness of risk assessments before they are used to aid a decision?

The literature review substantially answered this RQ and led to adoption of the GT as a research tool, pragmatically providing the opportunity to look beyond the problem at hand by revising the $R Q$ and setting sub-questions as follows.

RQ. Can a generic goal tree, populated with critical success factors and necessary conditions derived from the literature and case studies, be developed that would help decision makers and risk assessors to evaluate the effectiveness of risk assessments before they are used to aid a decision?

SQ1. What processes and methods are currently being used for risk assessments? SQ2. What mechanisms could facilitate or improve risk assessments to provide support for strategic decisions in an organisational context?

\subsection{Findings and contributions}

\subsubsection{Contributions to management research}

In section 1.7, general questions about management research (Toffel, 2016; Wein, 2009) were posed and are now answered in relation to this research.

While there has been research into science-based risk assessments (including quantitative risk analyses), no research into organisational risk assessments in New Zealand was found in the literature. This research was therefore novel.

Similarly, the problem of effectiveness and quality assurance in risk assessments is being addressed internationally but not yet in New Zealand. With advances in technology where there may be a lack of experience or knowledge, the problem is important. The research question and this research are therefore of considerable relevance to practice, at both the local and international level. Successful conduct of risk assessments is highly relevant to risk 
assessors and the decision makers they report to and can provide substantial benefits (section 1.4); it may also form part of the "game-changing" skills of managers that should be seen as part of "management-as-a-technology".

This research was carried out rigorously using mixed methods research with Pragmatism as the research philosophy. Developing and designing the research in two stages (Master's thesis converted to this Doctoral thesis) was challenging. Despite early optimism that case studies would be easy to recruit, more than 40 organisations were approached as possible case studies but either declined or failed to respond, also making finding sufficient data challenging. However, the five case studies each contributed insights into the conduct of risk assessments in New Zealand organisations.

Using abductive reasoning and mixed methods research techniques, this research yielded data that has been analysed and triangulated in a conventional and rigorous manner.

The problem of inadequate or absent risk assessments has been partially addressed by policy makers who have set out expectations for risk assessments (eg, in legislation and guidance documents) but no evidence-based guidance on risk assessments has been published in New Zealand. This research has shown that, although risk assessments are always an estimate of future conditions and so can never be accurate, they should be informed by the best available information, follow a structured process to provide some insights into those conditions, and so be reliable enough to effectively inform decisions. While what was the best available information may subsequently be replaced by better information, the original process should not be open to criticism for failure to follow good practice.

\subsubsection{Contributions to the literature}

This research has made the following contributions to the literature in terms of theoretical and methodological insights.

\section{The goal tree}

As reported in section 2.5, little previous research for CSFs and NCs for an effective organisational risk assessment (as distinct from a science-based risk assessment) was found. When relevant CSF and NC were combined into the tentative GT (section 3.2) they became an analytical tool to probe "what should be happening if a system is to succeed". The ontological foundations and epistemological assumptions underpinning the GT process were explored (sections 2.6.2 and 8.4.2) and for example, confirmed the GT process as an appropriate epistemology for identifying and representing the relationships between CSFs and NCs. 
The tentative GT has enabled an assessment of alternative conceptualisations and constructions in the personal world and alternative physical and structural arrangements in the material world (Table 62). It also represents (section 3.1.1) what Popper called a possible world, a possible experience, and our world of experience.

As noted in section 2.6.2 a collection of conference papers that included the GT/IO Map have been collated at the end of the references as a contribution to future TOC and GT research.

Use tentative GT helped evaluate the results of the online survey and five case study risk assessments and provided the following novel and deeper insights into use of the GT.

- Previously, the GT was seen as unique to an organisation whereas in this research one GT has been used as a research tool to compare and contrast the case studies and online survey results.

- Use of colour coding of the CSF and NC together with necessity logic enabled judgement of the effectiveness of the risk assessments. Application of this magnitudinal approach showed clearly where work needed to be done for a risk assessment to be regarded as effective in informing decision makers.

- The GT might generate structured engagement about uncertainty in the objectives or goals of the system or activity, level of knowledge about the system, competence of risk assessors, and techniques used, leading to strengthening of the results of the assessment.

- The research found the GT was also a practical management and risk assessment tool that could be developed further. This work is also relevant to practitioners, as shown by several interviewees asking for a copy of the tentative GT.

- The tentative GT was used to test the risk assessment that preceded the aircrash at the 2015 Shoreham Airshow and suggested significant gaps in that assessment that may have contributed to the severe consequences.

- The five case studies similarly showed consistent deficiencies in New Zealand practice, suggesting that risk assessments need improvement if directors and officers are to rely on them under the New Zealand Companies Act and Health and Safety at Work Act.

- The final GT is a tool that can be further tested in future risk assessments. 
This research is therefore academically novel and has contributed by filling research gaps, providing quantitative evidence through the online survey, together with rich descriptions through the case study research.

\section{Communications}

Whilst undertaking this research the following conference papers and articles have been published:

Peace, C. (2014). How does Goldilocks find out about the bears? Currently-used risk processes and techniques. Paper presented at the conference Risk Beyond the Numbers, 26 August Palmerston North organised by Society for Risk Analysis.

Peace, C. (2014). Did Goldilocks use professional judgement before entering the woods? The place of professional judgement, expertise and intuition in risk assessments. Paper presented at the Joint NZSA + ORSNZ conference, Wellington.

Peace, C. (2017). The reasonably practicable test and work health and safetyrelated risk assessments New Zealand Journal of Employment Relations, 42(2), 61 78 (Figure 4 in section 2.2 was included in this article and has since been cited in a new version of the international standard IEC/ISO31010 (2019) becoming a contribution to risk assessment practice.)

Peace, C., Mabin, V., \& Cordery, C. (2017). Due diligence: a panacea for health and safety risk governance? Policy and Practice in Health and Safety, 15(1), 19-37. Peace, C. (2017). The risk matrix: uncertain results? Policy and Practice in Health and Safety, 15(2), 131-144.

Peace, C. (2017). Are you sure? Lexicological difficulties arising from risk terminology. Paper presented at the Risk in an Interconnected World, 20-23 November 2017 Melbourne organised by Society for Risk Analysis.

Peace, C., \& Mabin, V. (2019). The goal tree. Poster presented at the Risk and Decision Making conference, 13-14 November 2019 Wellington organised by Society for Risk Analysis.

Peace, C., \& Mabin, V. (2019). Risk techniques identification key. Paper presented at the Risk and Decision Making, 13-14 November 2019 Wellington organised by Society for Risk Analysis.

Toffel (2016) suggested research findings should be made available to practitioners; anecdotal evidence suggests that some practitioners in New Zealand would welcome communication of this research. It is anticipated that parts of this research will be 
communicated to practitioners via articles in magazines and newsletters, and meetings of professional organisations.

\subsubsection{Contributions to the practice of risk assessment}

\section{Effectiveness of risk assessments and uncertainty}

This research has shown that risk assessments are not as effective as needed to inform decision makers with the best available information and so minimise uncertainty about the achievement of objectives.

In Case Study $C$ the risk assessment was commissioned retrospectively to substantiate the decision rather than using the risk assessment prospectively to inform the decision. This poses a future research question: do managers often seek confirmation for their decisions through retrospective risk assessments?

\section{Definition of risk}

The literature review (section 2.1) found there are many definitions of "risk", each possibly requiring a different approach, and that risk assessors need to define risk as part of setting up a risk assessment. For the purposes of this research the definition in ISO31000 (the "effect of uncertainty on objectives") was selected as it drew attention to organisational objectives and where there might be uncertainty about their achievement. However, risk assessors should pragmatically agree with decision makers the definition to be used in their work or, at least, state the definition used in their report.

A contribution of this research is therefore that any risk assessment should start with agreement about the definition of risk to be used. Without such agreement, the assessors and users of the assessment may fail to agree on or value the findings.

\section{Literature reviews in the case studies}

The review of risk techniques (section 2.4) can be used by future researchers, so avoiding a substantial literature search. It will be expanded and submitted for publication.

Only $25 \%$ of the survey respondents claimed to carry out a document or literature review and such reviews were virtually non-existent or largely ineffective in the case study risk assessments. The cases showed significant failures to base risk assessments on the best available information using academic or reliable, freely available sources (section 3.5).

This finding highlighted the need to enable knowledge transfer and exchange systems. In each case study, important decisions could have been better supported had the risk assessments included an effective document review. 


\section{Professional judgement}

Professional judgement was included as a technique in the online survey following the advocacy of professional colleagues. The survey showed over-reliance on professional judgement (it was the principal technique for many respondents), confirmed in some case study interviews. This prompted a brief literature review and consideration of how it might be improved (section 6.5.2). Professional judgement is capable of improvement if assessors are trained in effective literature or document reviews (especially for major risk assessments) and the risk assessment process and techniques, and encouraged to adopt a "fox-like" approach of seeking out new or better information about risks (an issue for training and education).

\section{Risk canvas}

If decision makers are to accept the results of risk assessments, the assessments should meet high standards of practice. That requires effective engagement with stakeholders and as part of a structured process that is supported by structured techniques selected to elicit the best available information. The idea for the risk canvas (section 7.4) emerged from work to identify a suite of risk assessment techniques that might meet that need (section 2.4.1).

Version 2.1 of the risk canvas was developed and tested in this research, showing potential to improve simple risk assessments in practice and when teaching groups how to conduct a risk assessment. When tested using a supplied case study and course handbook it was generally well-received as a tool, and workshop participants interacted with each other in the learning process.

The risk canvas has now been widely used as part of short training courses run by this researcher and has evolved to version 4.3, providing further evidence for its effectiveness. An article describing its development, epistemology and usage is to be submitted for publication.

While the GT provides a planning and validation tool for risk assessment practice, the risk canvas provides a template for a basic assessment and for teaching that process.

\section{Probability judgement}

The survey and case studies research did not reveal a problem with poor judgement of probability, but when testing the risk canvas (section 7.4.2) it became evident that users changed probability judgements when they gained better available information. This corroborated other research and was an important finding for practice and further research on training risk assessors. The risk canvas training notes have been amended to include a methodology for improving probability estimates. 


\section{McKinsey 7-S}

The McKinsey 7-S model was initially identified as a practical technique (section 3.4.2) to help assess the effectiveness of gap analyses in case studies A and B (sections 5.3.6 and 5.4.5), but may be a useful tool to aid thinking beyond the obvious when carrying out a gap analysis. This potential was corroborated by work outside this research in 2018 when facilitating 16 introductory workshops on international standard ISO45001 (2018) Occupational health and safety management systems for members of the New Zealand Institute for Safety Management and showing how to carry out a gap analysis using the McKinsey 7-S model. The model will be further developed and submitted for publication.

\section{Risk assessments and risk assessors}

In section 2.2 earlier work by others was brought together to map the range of risk assessments against the competency and skills required of risk assessors, contributing to planning their training and education, and delivery of assessments. Similar mapping of knowledge, skills and competence in section 6.5.2 suggested parallel results. These findings will be expanded and submitted for publication.

\subsubsection{Future research}

\section{Risk techniques identification key}

Section 2.4 of the literature review identified a wide range of risk techniques that might be used in a risk assessment and suggested a need for a risk techniques identification key to help assessors select techniques relevant to a planned risk assessment. Developing such an identification key would help improve quality assurance in risk assessments but was found to be beyond the scope of this research, becoming an area of further work (section 7.3.1).

\section{Risk assessment research, policy, practice and teaching}

In an ideal national system, risk assessment research, policy, practice and teaching would inform each other (section 7.2.3). Practice ought to feed back into policy and forward into teaching to help ensure continuous improvement in standards and competence. In New Zealand this does not seem to be happening, perhaps predisposing some policy and practice initiatives to failure, an area for further research ${ }^{14}$.

\subsection{Summary}

The research problem was:

\footnotetext{
${ }^{14}$ Victoria University now offers a paper in hazard and risk as part of teaching occupational health and safety.
} 
Risk assessments often fail to inform decision makers effectively about uncertainty in the form of causes of possible events, the consequences that might follow, the effectiveness of existing controls and the options for treating risk.

This research marks a way point in a series of research journeys attempting to respond to this problem.

Within the work reported here, researching an appropriate definition of risk led to selection of the "effect of uncertainty on objectives" resulting in an appreciation of uncertainty due to data variability, knowledge and assessor competence (section 2.1.2). The journey through the literature review found a wide range of risk assessment processes and techniques that could be used to provide structured analyses of risk (section 2.4). Together with a generic structure for risk assessments, these formed the basis of the online survey for the Master's research.

Conversion of the Master's research to this Doctoral research required a more theoretical framework for analysis of the survey data and the planned cases studies. Objectives in the definition of risk (section 2.1) led to consideration of organisational objectives and goals. These in turn led to the GT (section 2.6) and development of the tentative GT (section 3.2) using the 15 possible necessary conditions for an effective risk assessment. These NC had already been found in the literature review (section 2.5) and two were thought to be "show stoppers" that could be designated critical success factors.

The tentative GT was tested on the Shoreham aircrash report and found to be a useful tool. It was then used to structure qualitative analysis of the data from the online survey and five case studies, further confirming it as a research and practical tool. This research therefore marks a stage in the investigation and development of the GT as an emerging research and practical tool in the Theory of Constraints (section 8.3.1).

Reviewing the literature on risk assessment processes and techniques informed the selection of the suite of techniques (section 2.4.1) that were then developed into the risk canvas (section 7.4). When tested under controlled conditions the risk canvas showed promise as a teaching and training tool but also showed that risk assessors from different backgrounds may assess a given risk differently.

The research questions (section 2.9) have been answered and have led to pragmatic contributions to overcome the issues identified in the research problem. The findings and contributions are directly applicable to research and practice and have shown areas where further research is needed. As with other pragmatist research, the results remain provisional. 
This research therefore marks a further stage in this researcher's "personal odyssey" (section 3.1.2) that started in 1969 and has passed through a range of applied research projects to commencement of a Master of Commerce by thesis that was converted to this Doctoral research. This research taking six years has strengthened for me what Boyer (2016, p. 86) described as "what it means to be a scholar - a recognition that knowledge is acquired through research, through synthesis, through practice, and through teaching".

\section{The future for risk assessments}

The current practice of risk assessments in New Zealand has been provisionally shown by the survey and case studies to be inadequate to inform decisions, often being based on professional judgement and the simplistic consequence/likelihood matrix. Neither can be considered adequate risk techniques to effectively inform decision makers about risk (the "effect of uncertainty on objectives") and, it is conjectured, may be one causal factor of the workplace injury and fatality rate and performance of businesses.

More effective risk assessments would help stakeholders have greater confidence in the ability of managers to assess and manage risk. The results of this work therefore have the potential to help improve the decision making of managers and policymakers.

During the course of this research the importance of risk assessments for occupational health and safety has been emphasised with the New Zealand Health and Safety at Work Act 2015 coming into force, bringing with it the implied requirement for risk assessments.

Risk assessments will face increasing challenges as new technologies are developed, creating risks for which there may be no or inadequate risk techniques or available information about the causes of harms or the nature or probability of such harms. It is hoped the contributions in this research will enable improvements in the training of risk assessors, validation of their results and the provision of tools that will facilitate their work. 


\section{References}

AAIB. (2017). Report on the accident to Hawker Hunter T7, G-BXFI near Shoreham Airport on 22 August 2015. Aircraft Accident Report 1/2017 Aldershot: Air Accident

Investigation Board. Retrieved from https://www.gov.uk/aaib-reports/aircraft-accidentreport-aar-1-2017-g-bxfi-22-august-2015

Abt, E., Rodricks, J., Levy, J. I., et al. (2010). Science and Decisions: Advancing Risk Assessment. Risk Analysis, 30(7), 1028-1036.

ACC. (2002). Workplace Safety Management Practices. Wellington: Accident Compensation Corporation. Retrieved from www.acc.co.nzl

Access Economics. (2008). The Health of Nations: The Value of a Statistical Life. Research Report Canberra.

AccountAbility. (2015). Stakeholder Engagement Standard. Standard AA1000AS London: AccountAbility Standards Board. Retrieved from http://www.accountability.org/

Adedokun, J., Woods, I., Boult, M., et al. (2006). A structured what if? analysis to identify risks in anaesthesia and perioperative care: A-974. European Journal of Anaesthesiology, 23, 251.

AICHEME. (2013). Guideline for Barrier Risk Management (Bow Tie Analysis). Retrieved 1 November 2013, from http://www.aiche.org/ccps/community/projects/project-237guideline-barrier-risk-management-bow-tie-analysis

Alcock, R., MacGillivray, B., \& Busby, J. (2011). Understanding the mismatch between the demands of risk assessment and practice of scientists - The case of Deca-BDE. Environment International, 37(1), 216-225.

Ale, B. (2002). Risk assessment practices in The Netherlands. Safety Science, 40(1), 105126.

Ale, B., Burnap, P., \& Slater, D. (2015). On the origin of PCDS - (Probability consequence diagrams). Safety Science, 72(0), 229-239.

Ale, B., Hartford, D. N. D., \& Slater, D. (2015). ALARP and CBA all in the same game. Safety Science, 76, 90-100.

Alreck, P., \& Settle, R. (1995). The survey research handbook (2nd ed.). Chicago, IL: Irwin.

Althaus, C. (2005). A disciplinary perspective on the epistemological status of risk. Risk Analysis, 25(3), 567-588.

Ammar, A., Berman, K., \& Sataporn, A. (2007). A review of techniques for risk management in projects. Benchmarking: An International Journal, 14(1), 22-36.

Anderson, J. V. (1993). Mind mapping: A tool for creative thinking. Business Horizons, 36(1), 41.

Anon. (2012). Consultation principles: guidance. Retrieved from https://www.gov.uk/

Anon. (2018). Mushrooms: the flavour heroes that pack a nutritional punch. Market Report Wellington: Moore Wilson. Retrieved from https://moorewilsons.co.nzl

Anon. (2019, 8 March). Shoreham airshow crash pilot cleared over deaths of 11 people, The Guardian.

Ansell, R., \& Taber, J. (1996). Caught in the Crunch. Auckland: Harper Collins.

Arcus, S. (2015, 18 October). Poor governance drives scandal, Sunday Star Times.

Retrieved from http://www.stuff.co.nz/sunday-star-times/

Arkin, E. B., Bauer, C., Burklow, J., et al. (2004). Making Health Communication Programs

Work. US Department of Health and Human Services. Retrieved from

https://www.cancer.gov/publications/health-communication/pink-book.pdf

Arunraj, N., \& Maiti, J. (2007). Risk-based maintenance - Techniques and applications. Journal of Hazardous Materials, 142(3), 653-661.

AS/SNZ4360:1999. Risk Management. Wellington: Standards New Zealand.

AS/SNZ4360:2004. Risk Management. Wellington: Standards New Zealand.

Asquith LJ. in Edwards -v- NCB (1949), Kings Bench, All ER 743 1;

Aven, T. (2003). Foundations of Risk Analysis: a knowledge and decision-oriented perspective. New York: Wiley. 
Aven, T. (2008). Risk analysis: Assessing uncertainties beyond expected values and probabilities. Chichester: John Wiley \& Sons, Ltd.

Aven, T. (2009). A new scientific framework for quantitative risk assessments. Int. J. Business Continuity and Risk Management, 1(1), 67-77.

Aven, T. (2011a). On Different Types of Uncertainties in the Context of the Precautionary Principle. Risk Analysis, 31(10), 1515-1525.

Aven, T. (2011b). On the new ISO guide on risk management terminology. Reliability Engineering \& System Safety, 96(7), 719-726.

Aven, T. (2013). On the meaning of a black swan in a risk context. Safety Science, $57(0)$, 44-51.

Aven, T. (2015). Implications of black swans to the foundations and practice of risk assessment and management. Reliability Engineering \& System Safety, 134(0), 8391.

Aven, T. (2017). What Defines Us as Professionals in the Field of Risk Analysis? Risk Analysis, 37(5), 854-860.

Aven, T. (2018). An Emerging New Risk Analysis Science: Foundations and Implications. Risk Analysis, 38(5), 876-888.

Aven, T., \& Renn, O. (2009). On risk defined as an event where the outcome is uncertain. Journal of Risk Research, 12(1), 1-11.

Aven, T., Vinnem, J., \& Roed, W. (2006). On the Use of Goals, Quantitative Criteria and Requirements in Safety Management. Risk Management: an international joumal, 8(2), 118-132.

Aven, T., \& Zio, E. (2013). Foundational Issues in Risk Assessment and Risk Management. Risk Analysis, 34(7), 1164-1172.

Bagnoli, A. (2009). Beyond the standard interview: the use of graphic elicitation and artsbased methods. Qualitative Research, 9(5), 547-570.

Baker, E. (2002). A survey of UK approaches to sharing good practice in health and safety risk management. Research Report CRR292 for Health and Safety Executive; Sudbury: HSE Books. Retrieved from http://www.hse.gov.uk/research/rrhtm/index.htm

Baker, S., Ponniah, D., \& Smith, S. (1998). Techniques for the analysis of risks in major projects. Journal of the Operational Research Society, 49(6), 567.

Baker, S., Ponniah, D., \& Smith, S. (1999). Risk response techniques employed currently for major projects. Construction Management and Economics, 17(2), 205 - 213.

Ball, D. J., \& Watt, J. (2013). Further Thoughts on the Utility of Risk Matrices. Risk Analysis, 33(11), 2068-2078.

Bammer, G., Smithson, M., \& Goolabri Group. (2008). The nature of uncertainty. In Bammer, G. \& Smithson, M. (Eds.), Uncertainty and Risk: Multidisciplinary Perspectives (pp. 289-304). London: Earthscan Publications Ltd.

Beasley, M., Branson, B., \& Hancock, B. V. (2015). Report on the Current State of Enterprise Risk Oversight: Update on Trends and Opportunities. Research Report 6th edition: North Carolina State University. Retrieved from www.erm.ncsu.edu

Benabou, R., \& Tirole, J. (2016). Mindful Economics: The Production, Consumption, and Value of Beliefs. Journal of Economic Perspectives, 30(3), 141-164.

Bennett, E., \& Gilbertson, A. (2006). The commercial case for applying CDM. Research Report 467 for Health and Safety Executive; Sudbury: HSE Books. Retrieved from http://www.hse.gov.uk/research/rrhtm/index.htm

Bensoussan, B. E., \& Fleisher, C. S. (2008). Analysis without Paralysis - 10 tools to make better strategic decisions. . New Jersey: Pearson Education Ltd.

Bernstein, P. (1996). Against the gods: The remarkable story of risk. New York: John Wiley \& Sons.

Berry, R., \& Smith, L. (2005). Conceptual foundations for the Theory of Constraints. Human Systems Management, 24, 83-94. 
Berryman, K. (2005). Review of Tsunami Hazard and Risk in New Zealand. Client Report 2005/104 for Ministry of Civil Defence \& Emergency Management; Lower Hutt: Institute of Geological \& Nuclear Sciences.

Best, B. (2011). The Whys and Hows of Flowcharting. Quality, 50(4), 23-25.

Bethlehem, J. (2010). Selection Bias in Web Surveys. International Statistical Review, 78(2), 161-188.

Bethlehem, J., \& Biffgnandi, S. (2011). Handbook of web surveys. Oxford: Wiley.

Billings, I., \& Charman, N. (2011). Christchurch City Council lifelines - performance of concrete potable water reservoirs in the February 2011 Christchurch earthquake. Bulletin of the New Zealand National Society for Earthquake Engineering, 44(4), 418424.

Biosecurity New Zealand. (2006). Risk Analysis Procedures. Wellington: Author. Retrieved from https://www.mpi.govt.nz/

Bird, F., \& Loftus, R. (1976). Loss Control Management. Georgia: Institute Press.

Birkinshaw, J., \& Jenkins, H. U. W. (2010). Making better risk management decisions. Business Strategy Review, 21(4), 41-45.

Bloom, N., Raffaella, S., \& Van Reenen, J. (2016). Management as a Technology? Working Paper 16-133: Harvard Business School. Retrieved from http://papers.ssrn.com/sol3/papers.cfm?abstract id=2788794

Bloom, N., Sadun, R., \& Van Reenen, J. (2012). Does Management Really Work? Harvard Business Review, 90(11), 76-82.

Boholm, A., Corvellec, H., \& Karlsson, M. (2012). The practice of risk governance: lessons from the field. Journal of Risk Research, 15(1), 1-20.

Boholm, M., Möller, N., \& Hansson, S. O. (2016). The Concepts of Risk, Safety, and Security: Applications in Everyday Language. Risk Analysis, 36(2), 320-338.

Bolger, F., \& Wright, G. (1994). Assessing the quality of expert judgment: Issues and analysis. Decision Support Systems, 11(1), 1-24.

Bolt, H., Haslam, R., Gibb, A., \& Waterson, P. (2012). Pre-conditioning for success: Characteristics and factors ensuring a safe build for the Olympic Park. Research Report RR955 for Health and Safety Executive; Sudbury: HSE Books. Retrieved from http://http://www.hse.gov.uk/research/rrhtm/index.htmrrhtm/

Bomel Ltd. (2006a). An analysis of the significant causes of fatal and major injuries in construction in Scotland. Research Report RR 443 for Health and Safety Executive; Sudbury: HSE Books. Retrieved from http://www.hse.gov.uk/research/rrhtm/index.htm

Bomel Ltd. (2006b). The global perspective in addressing construction risks. Research Report 458 for Health and Safety Executive; Sudbury: HSE Books. Retrieved from http://www.hse.gov.uk/research/rrhtm/index.htm

Booth, W., Colomb, G., \& Williams, J. (2008). The craft of research (3rd ed.). Chicago, IL: University of Chicago Press.

Borthick, A. F., Schneider, G. P., \& Vance, A. O. (2010). Preparing Graphical Representations of Business Processes and Making Inferences from Them. Issues in Accounting Education, 25(3), 569-582.

Bourdieu, P. (1977). Outline of a theory of practice. Cambridge: Cambridge University Press.

Bowden, J., \& Green, P. (2010). Relationality and the myth of objectivity in research involving human participants. In Higgs, J., Cherry, N., Macklin, R. \& Ajjawi, R. (Eds.), Researching Practice: A Discourse on Qualitative Methodologies (pp. 105-132). Boston, MA: Sense Publishers.

Boyer, E. L. (2016). Scholarship reconsidered : priorities of the professoriate. San Francisco, California: Jossey-Bass.

Boynton, A., \& Zmud, D. (1984). An assessment of critical success factors. Sloan Management Review, 25, 17-27.

Brabazon, P., Tipping, A., \& Jones, J. (2000). Construction health and safety for the new Millennium. Research Report CRR313 for Health and Safety Executive; Institution of 
Civil Engineers; Sudbury: HSE Books. Retrieved from

http://www.hse.gov.uk/research/rrhtm/index.htm

Bradley, C., Hirt, M., \& Smit, S. (2018). Strategy beyond the hockey stick: John Wiley \& Sons.

Bringhurst, L. S., Byrne, R. N., \& Gershon-Cohen, J. (1959). Respiratory disease of mushroom workers: Farmer's lung. Journal of the American Medical Association, 171(1), 15-18.

Brown, G. D., Corbet, S., McMullan, C., \& Sharma, R. (2015). Do industrial incidents in the chemical sector create equity market contagion? Journal of Safety Research, 55, 115-119.

Brown, R., \& Gørgens, T. (2009). Corporate governance and financial performance in an Australian context. Working Paper Canberra: The Treasury. Retrieved from http://www.treasury.gov.au/documents/1495/PDF/TWP 2009-02.pdf

Brugha, R., \& Varvasovszky, Z. (2000). Stakeholder analysis: a review. Health Policy and Planning, 15(3), 239-246.

Brunsdon, D., \& Mowll, R. (2012). Lifelines utility restoration times following a Wellington Fault earthquake. Report Wellington: Greater Wellington Council.

Buchanan, D., \& Bryman, A. (2007). Contextualizing Methods Choice in Organizational Research. Organizational Research Methods, 10(3), 483-501.

Buchanan, P., \& Barnes, J. (n.d.). The Mushroom Industry in New Zealand. Retrieved 25 February 2018, from http://www.isms.biz/articles/the-mushroom-industry-in-newzealand/

Budescu, D. V., Broomell, S., \& Por, H.-H. (2009). Improving Communication of Uncertainty in the Reports of the Intergovernmental Panel on Climate Change. Psychological Science, 20(3), 299-308.

Bullen, C., \& Rockart, J. F. (1981). A primer on critical success factors. Report CISR No. 69: Sloan School of Management. Retrieved from http://hdl.handle.net/1721.1/1988

Burgman, M. (2005). Risks and Decisions for Conservation and Environmental Management.

Burgman, M. (2016). Trusting Judgements: How to Get the Best out of Experts. Cambridge: Cambridge University Press.

Burke Johnson, R., Onwuegbuzie, A., \& Turner, L. (2007). Toward a Definition of Mixed Methods Research. Journal of Mixed Methods Research, 1(2), 112-133.

Burke, L. A., \& Rau, B. (2010). The Research-Teaching Gap in Management. Academy of Management Learning \& Education, 9(1), 132-143.

Busby, J., \& Hughes, E. (2006). Credibility in risk assessment: a normative approach. International Journal of Risk Assessment and Management, 6(4/5/6), 508-527.

Butcher, G., Andrews, L., \& Cleland, G. (1998). The Edgecumbe Earthquake: a review of the 2 March 1987 Eastern Bay of Plenty earthquake. Christchurch: Centre for Advanced Engineering.

Cagliano, A. C., Grimaldi, S., \& Rafele, C. (2015). Choosing project risk management techniques. A theoretical framework. Journal of Risk Research, 18(2), 232-248.

Cameron, E. (2005). Facilitation made easy: practical tips to improve meetings and workshops (3rd ed.). London: Kogan Page Ltd.

Cameron, I., Hare, W., \& Duff, R. (2007). Superior safety performance: OSH personnel and safety performance in construction. Research Report for Institution of Occupational Health and Safety; Leicester: IOSH Publishing Ltd. Retrieved from http://www.iosh.co.uk/safetyperform

Cameron, I., Hare, W., Duff, R., \& Maloney, W. (2006). An investigation of approaches to worker engagement. Research Report RR516 for Health and Safety Executive; Sudbury: HSE Books. Retrieved from http://www.hse.gov.uk/research/rrhtm/index.htm

Canterbury Earthquakes Royal Commission: Low-damage building technologies, (2012) Vol. 3 Christchurch, retrieved from http://canterbury.royalcommission.govt.nz/. 
Cantrell, S., \& Clemens, P. (2009). Finding All the Hazards. Professional Safety, 54(11), 3235.

Caralli, R. (2004). The Critical Success Factor Method: Establishing a Foundation for Enterprise Security Management. Technical Report CMU/SEI-2004-TR-010: Software Engineering Institute. Retrieved from https://resources.sei.cmu.edu/

Card, A. J., Ward, J. R., \& Clarkson, P. J. (2012). Beyond FMEA: The structured what-if technique (SWIFT). Journal of Healthcare Risk Management, 31(4), 23-29.

Care, L., Jary, D., \& Parnell, R. (2012). Healthy Design, Creative Safety - Approaches to health and safety teaching and learning in undergraduate schools of architecture. Research Report RR 925 for Health and Safety Executive; Sudbury: HSE Books. Retrieved from http://www.hse.gov.uk/research/rrhtm/index.htm

Carson, P. A., \& Snowden, D. (2011). Health, safety and environment metrics in loss prevention - part 2. Loss Prevention Bulletin(221), 12-17.

Cavana, R. Y., Delahaye, B. L., \& Sekaran, U. (2001). Applied business research: qualitative and quantitative methods. Milton, QLD: John Wiley \& Sons.

Chance, D., \& Brooks, R. (2010). An introduction to derivatives and risk management (8th ed.). Mason, $\mathrm{OH}$ : South-Western Cengage Learning.

Chapman, R. J. (1998). The effectiveness of working group risk identification and assessment techniques. International Journal of Project Management, 16(6), 333343.

Chapman, R. J. (2011). Simple tools and techniques for enterprise risk management (2nd ed.). Chichester: Wiley.

Cherry, N. (2010). Doing Qualitative Research in the White Spaces. In Higgs, J., Cherry, N., Macklin, R. \& Ajjawi, R. (Eds.), Researching Practice: A Discourse on Qualitative Methodologies (pp. 9-17). Boston, MA: Sense Publishers.

Cherubin, P., Pellino, S., \& Petrone, A. (2011). Baseline risk assessment tool: A comprehensive risk management tool for process safety. Process Safety Progress, 30(3), 251-260.

Cheyne, A., Hartley, R., Gibb, A., \& Finneran, A. (2012). Talk the talk - walk the walk: An evaluation of Olympic Park safety initiatives and communication. Research Report for Institution of Occupational Health and Safety; Wigston: IOSH Publishing Ltd.

Retrieved from http://www.iosh.co.uk/olympicpark

Chinniah, Y., Gauthier, F. o., Lambert, S., \& Moulet, F. (2011). Experimental Analysis of Tools Used for Estimating Risk Associated with Industrial Machines. Research Report R-684. Retrieved from http://www.irsst.qc.cal

Christchurch Engineering Lifelines Group. (1997). Risks \& Realities: a multidisciplinary approach to the vulnerability of lifelines to natural hazards. Research Report Christchurch: Centre for Advanced Engineering.

Clarke, M. (1998). The economic effects of a 1998 Wellington earthquake. Working Paper Wellington: NZIER. Retrieved from http://nzier.org.nz/

Clay, L., Hay-Smith, E. J. C., Treharne, G. J., \& Milosavljevic, S. (2015). Unrealistic Optimism, Fatalism, and Risk-Taking in New Zealand Farmers' Descriptions of QuadBike Incidents: A Directed Qualitative Content Analysis. Unrealistic Optimism, Fatalism, and Risk-Taking in New Zealand Farmers' Descriptions of Quad-Bike Incidents: A Directed Qualitative Content Analysis, 20(1), 11-20.

Clydesdale, J. (2000). The economic impact of road closures caused by natural hazards case study Kaikoura. (Master of Applied Science Thesis), Lincoln University, Lincoln, NZ. Retrieved from https://researcharchive.lincoln.ac.nz/handle/10182/2801

Coleman, L. (2007). Risk and Decision Making by Finance Executives. Retrieved from http://ssrn.com/abstract $=975133$.

Collier, P. M., \& Woods, M. (2011). A Comparison of the Local Authority Adoption of Risk Management in England and Australia. Australian Accounting Review, 21(2), 111123.

Collins, H. M., \& Evans, R. (2007). Rethinking expertise. Chicago: University of Chicago Press. 
Comerio, M. (2005). Downtime and Recovery: The Impacts of Institutional Closure, Rotorua, Centre for Advanced Engineering.

Companies Act 1993, Wellington. Available at http://www.legislation.govt.nz/

Conchie, S., \& Moon, S. (2010). Promoting active safety leadership: Identifying the individual and organisational antecedents of active safety leadership in construction supervisors. Research Report 10.2 Wigston, UK: Institution of Occupational Safety and Health. Retrieved from www.iosh.co.uk

Concise Oxford Dictionary. (2009)). Oxford: Oxford University Press Ltd.

Conlisk, J. (1996). Why bounded rationality? Journal of Economic Literature, 34(2), 669-700.

Contini, S., Amendola, A., \& Ziomas, I. (1991). Benchmark exercise on major hazard analysis. Research Report EUR 13386 EN Luxembourg: Commission of the European Communities. Retrieved from http://publications.jrc.ec.europa.eu/

Cooper, D., Raymond, G., Grey, S., \& Walker, P. (2005). Project risk management guidelines: managing risk in large projects and complex procurements. West Sussex: John Wiley \& Sons.

Copsey, S., Taylor, T., Debruyne, M., et al. (2010). Mainstreaming occupational safety and health into university education. Luxembourg: European Agency for Security and Health at Work. Retrieved from www.bookshop.europa.eu

Corey, C. M., \& Deitch, E. A. (2011). Factors Affecting Business Recovery Immediately after Hurricane Katrina. Journal of Contingencies and Crisis Management, 19(3), 169-181.

COSO. (2004). Enterprise Risk Management - Integrated Framework: Application techniques. Report Jersey City, NJ: Committee of Sponsoring Organizations of the Treadway Commission.

COSO. (2016). Enterprise Risk Management - Aligning Risk with Strategy and Performance. Report Jersey City, NJ: Committee of Sponsoring Organizations of the Treadway Commission.

Cournoyer, M. E., Kleinsteuber, J. F., Garcia, V. E., et al. (2011). Safety observation contributions to a glovebox safety program. Journal of Chemical Health and Safety, 18(5), 43-55.

Cousins, J., Spence, R., \& So, E. (2006). Wellington Areas Casualty Estimation 2006. Research Report for Accident Compensation Corporation; Wellington: GNS Science.

Cox, A., Folgering, H. T., \& van Griensven, L. J. (1988). Extrinsic allergic alveolitis caused by spores of the oyster mushroom Pleurotus ostreatus. European Respiratory Journal, 1(5), 466.

Cox, J., Mabin, V., \& Davies, J. (2005). A case of personal productivity: Illustrating methodological developments in TOC. Journal of Human Systems MAnagement, 24(1), 39-65.

Cox, L. (2008). What's Wrong with Risk Matrices? Risk Analysis, 28(2), 497-512.

Creswell, J. (2009). Research design : qualitative, quantitative, and mixed methods approaches (3rd ed.). Thousand Oaks, CA: Sage Publications Inc.

Crilly, N., Blackwell, A. F., \& Clarkson, P. J. (2006). Graphic elicitation: using research diagrams as interview stimuli. Qualitative Research, 6(3), 341-366.

Crockford, G. N. (1976). The Changing Face of Risk Management. Geneva Papers on Risk \& Insurance - Issues \& Practice, 30(1), 5-10.

Crondstedt, M. (2002). Prevention, Preparedness, Response, Recovery - an outdated concept? Australian Journal of Emergency Management, 17(2), 10-13.

Crook, B., Easterbrook, A., \& Stagg, S. (2008). Exposure to dust and bioaerosols in poultry farming: summary of observations and data. Research Report RR 655 for Health and Safety Executive; Sudbury: HSE Books. Retrieved from http://www.hse.gov.uk/research/rrhtm/index.htm

Cross, M., Davidson, W., \& Thornton, J. (1986). The Impact of Captive Insurer Formation on the Parent Firm's Value. The Journal of Risk and Insurance, 53(3), 471-483.

Cross, R., Parker, A., Prusak, L., \& Borgatti, S. P. (2001). Knowing what we know:: Supporting knowledge creation and sharing in social networks. Organizational Dynamics, 30(2), 100-120. 
Crosthwaite, D., \& Langdon, D. (2007). Health and safety in public sector: construction procurement. Research Report RR556 for Health and Safety Executive; Sudbury: HSE Books. Retrieved from http://www.hse.gov.uk/research/rrhtm/index.htm

Cubrinovski, M., Bradley, B., Wotherspoon, L., et al. (2011). Geotechnical aspects of the 22 February 2011 Christchurch earthquake. Bulletin of the New Zealand National Society for Earthquake Engineering, 44(4), 205-226.

Cubrinovski, M., Green, R., Allen, J., et al. (2010). Geotechnical reconnaissance of the 2010 Darfield (Canterbury) earthquake. Bulletin of the New Zealand National Society for Earthquake Engineering, 43(4), 243-320.

Cumming, R. (1981). Is Risk Assessment A Science? Risk Analysis, 1(1), 1-3.

Curtis, P., \& Carey, M. (2012). Risk assessment in practice. Committee of Sponsoring Organizations of the Treadway Commission.

Curtis, W., Hefley, W., \& Miller, S. (2009). People Capability Maturity Model. Technical Report CMU/SEI-2009-TR-003: Software Engineering Institute. Retrieved from http://www.sei.cmu.edu

Dali, A., Croke, P., Goy, J., et al. (2012). Global ISO 31000 survey 2011. PowerPoint Slide Show Paris: G31000. Retrieved from http://www.iso31000survey.com/Global Survey ISO 31000 English.pdf

Daniel, D. R. (1961). Management information crisis. Harvard Business Review, 39(5), 111121.

Davey, R. (2010). Damage to potable water reservoirs in the Darfield earthquake. Bulletin of the New Zealand National Society for Earthquake Engineering, 43(4), 429-431.

Davies, J., Mabin, V., \& Balderstone, S. J. (2005). The theory of constraints: a methodology apart? - a comparison with selected OR/MS methodologies. Omega, 33(6), 506-524.

Davies, J., \& Mabin, V. J. (2001). Knowledge management and the framing of information: a contribution to OR/MS practice and pedagogy. Journal of the Operational Research Society, 52(8), 856-872.

Davis, G. F. (2015). What Is Organizational Research For? Administrative Science Quarterly, 60, 179-188.

Deam, B., Comerio, M., \& Clendon, J. (2010). Preliminary observations of the Darfield (Canterbury) earthquake: University of Canterbury buildings. Bulletin of the New Zealand National Society for Earthquake Engineering, 43(4), 368-373.

Denzin, N. (2008). The new paradigm dialogs and qualitative inquiry. International Journal of Qualitative Studies in Education, 21(4), 315-325.

Department of Sustainability and Environment. (2009). Stakeholder Analysis. Retrieved 14 July, 2009, from http://www.dse.vic.gov.au/

Dettmer, H. W. (1998). Constraint Theory: A Logic-Based Approach to System Improvement. Monograph. Retrieved from http://www.goalsys.com/books/documents/HICSSPaper.pdf

Dettmer, H. W. (2003). Strategic navigation : a systems approach to business strategy Milwaukee, WI: ASQ Quality Press.

Dettmer, H. W. (2007). The logical thinking process: a systems approach to complex problem solving. Milwaukee, WI: American Society for Quality.

Dettmer, H. W. (2010). Strategy. In Cox, J. F. \& Schleier, J. G. (Eds.), Theory of constraints handbook (pp. 551-570). New York: McGraw-Hill.

Dettmer, H. W. (2011). Our goal is ... What is our goal? Monograph: Goal Systems International. Retrieved from http://goalsys.com/

Dewey, J. (1929). Experience and nature. Chicago: W W Norton \& Co.

Dhakal, R. (2010). Damage to non-structural components and contents in 2010 Darfield earthquake. Bulletin of the New Zealand National Society for Earthquake Engineering, 43(4), 404-411.

Dillon, R. L., Tinsley, C. H., \& Burns, W. J. (2014). Near-Misses and Future Disaster Preparedness. Risk Analysis, 34(10), 1907-1922.

Doggett, A. M. (2005). Root cause analysis. Quality Management Journal, 21(4), 34-45. 
DoL. (2012). Guidelines for the safe use of quad bikes. Guidance Note Wellington: Department of Labour.

Douglas, M., \& Wildavsky, A. (1982). Risk and Culture: University of California, Berkeley.

Dowell Solutions. (2011). Risk Score Calculator. Retrieved from http://www.dowellsolutions.com.au/wp-content/uploads/2011/06/Risk-ScoreCalculator.pdf.

Downes, G. (1995). Atlas of isoseismal maps of New Zealand earthquakes. Lower Hutt: Institute of Geological \& Nuclear Sciences.

Dowrick, D. J. (2003). Earthquake risk reduction actions for New Zealand. Bulletin of the New Zealand National Society for Earthquake Engineering, 36(4), 249-259.

Dowrick, D. J., \& Rhoades, D. A. (2005). Risk of casualties in New Zealand earthquakes. Bulletin of the New Zealand National Society for Earthquake Engineering, 38(2), 5372.

Dreyfus, S. (2004). The Five-Stage Model of Adult Skill Acquisition. Bulletin of Science, Technology \& Society, 24(3), 177-181.

Driscoll, T., Mannetje, A., Dryson, E., et al. (2004). The Burden of Occupational Disease and Injury in New Zealand. Technical Publication 0478280114 Wellington: National Occupational Health and Safety Advisory Committee. Retrieved from https://cohsr.aut.ac.nz/nohsac-reports

Drucker, P. (1954). The practice of management. New York: Harper \& Row.

Drucker, P. (1973). Management: tasks, responsibilities, practices. New York: Harper \& Row.

Dube-Rioux, L., \& Russo, J. E. (1988). An availability bias in professional judgment. Journal of Behavioral Decision Making, 1(4), 223-237.

Dubois, A., \& Gadde, L.-E. (2002). Systematic combining: an abductive approach to case research. Journal of Business Research, 55(7), 553-560.

Duckworth, A., Peterson, C., Matthews, M., \& Kelly, D. (2007). Grit: Perseverance and passion for long-term goals. Journal of Personality and Social Psychology, 92(6), 1087-1101.

Durodié, B. (2017). Theory informed by practice. Application informed by purpose. Why to understand and manage risk, cultural context is the key. Safety Science, 99, 244254.

Earle, T. C. (2010). Trust in Risk Management: A Model-Based Review of Empirical Research. Risk Analysis: An International Journal, 30(4), 541-574.

Easton, G. (1995). Case Research as a Methodology for Industrial Networks; A Realist Apologia. Turnbull, P., Yorke, D. \& Naudé, P. (Eds.), Interaction, Relationships And Networks: Past - Present - Future, pp 368-391 Manchester, University of Manchester. Retrieved from https://www.escholar.manchester.ac.uk/uk-ac-manscw:2n485

Edmondson, A., \& McManus, S. (2007). Methodological fit in management field research. Academy of Management Review, 32(4), 1155-1179.

Eisenhardt, K. M. (1989a). Building Theories from Case Study Research. Academy of Management Review, 14(4), 532-550.

Eisenhardt, K. M. (1989b). Making fast strategic decisions in high-velocity environments. Academy of Management Journal, 32(3), 543-576.

Eisenhardt, K. M., \& Graebner, M. E. (2007). Theory building from cases: opportunities and challenges. Academy of Management Journal, 50(1), 25-32.

Elkjaer, B., \& Simpson, B. (2011). Pragmatism: A lived and living philosophy. What can it offer to contemporary organization theory? Philosophy and Organization Theory (pp. 55-84).

Ellul, A., \& Yerramilli, V. (2013). Stronger Risk Controls, Lower Risk: Evidence from U.S. Bank Holding Companies. The Journal of Finance, 68(5), 1757-1803.

ENISA. (2006). Risk Management: Implementation principles and Inventories for Risk Management/Risk Assessment methods and tools. Report Heraklion: European 
Network and Information Security Agency. Retrieved from

http://www.enisa.europa.eu/

EPA. (2011). Decision Paths for making decisions under the HSNO Act. Protocol

Wellington: Environmental Protection Authority. Retrieved from www.epa.govt.nz

Eppler, M. J., \& Aeschimann, M. (2009). A systematic framework for risk visualization in risk management and communication. Risk Management: an international journal, 11(2), 67-89.

Epstein, S., Lipson, A., Holstein, C., \& Huh, E. (1992). Irrational Reactions to Negative Outcomes: Evidence for Two Conceptual Systems. Journal of Personality and Social Psychology, 62(2), 328-339.

Ericsson, A., Krampe, R., \& Tesch-Romer, C. (1993). The Role of Deliberate Practice in the Acquisition of Expert Performance. Psychological Review, 100(3), 363-406.

Ernst \& Young. (2012). Turning risk into results. Report AU1082: Author. Retrieved from www.ey.com

Evans, D. (2012). Risk intelligence: how to live with uncertainty. London: Atlantic Books.

Falconer, L. (2002). Management decision-making relating to occupational risks: the role of 'grey data'. Journal of Risk Research, 5(1), 23-33.

FAO. (2003). Hazard analysis and critical control point (HACCP) system and guidelines for its application. Guidance Note Rome: Food and Agriculture Organisation. Retrieved from http://www.fao.org/

FAO/WHO. (2013). Procedural Manual. Rome: Food and Agriculture Organisation. Retrieved from ftp://ftp.fao.org/

Farjoun, M., Ansell, C., \& Boin, A. (2015). Pragmatism in Organization Studies: Meeting the Challenges of a Dynamic and Complex World. Organization Science, 26(6), 17871804.

Farquhar, J. (2012). Case Study Research for Business. London: Sage Publications Ltd.

Fernández-Muñiz, B., Montes-Peón, J. M., \& Vázquez-Ordás, C. J. (2009). Relation between occupational safety management and firm performance. Safety Science, 47(7), 980991.

Financial Markets Authority. (2018). Corporate Governance In New Zealand. Principles and Guidelines: A Handbook for Directors, Executives and Advisors. Wellington: Author. Retrieved from http://www.fma.govt.nzl

Finneran, A., Hartley, R., Gibb, A., et al. (2012). Learning to adapt health and safety initiatives from mega projects: an Olympic case study. Policy and Practice in Health and Safety, 10(2), 81-102.

Fischhoff, B., Lichtenstein, S., Slovic, P., et al. (1980). Approaches to Acceptable Risk: A Critical Guide. Research Report NUREG/CR-1614: ORNL/S b-7656/: Oak Ridge National Laboratory.

Fish, D., \& Coles, C. (1998). Developing professional judgement in health care: learning through the critical appreciation of practice. Oxford: Butterworth-Heinemann.

Fleetwood, S. (2005). Ontology in Organization and Management Studies: A Critical Realist Perspective. Organization, 12(2), 197-222.

Flyvbjerg, B. (2006). Five Misunderstandings About Case-Study Research. Qualitative Inquiry, 12(2), 219-245.

Flyvbjerg, B., Bruzelius, N., \& Rothengatter, W. (2003). Megaprojects and Risk: an anatomy of ambition. Cambridge, MA: Cambridge University Press.

Food Act 1981, Wellington. Available at http://www.legislation.govt.nz/

Forbes, D. R., Smith, S., \& Horner, M. (2008). Tools for selecting appropriate risk management techniques in the built environment. Construction Management \& Economics, 26(11), 1241-1250.

Forbes, D. R., Smith, S., \& Horner, M. (2010). The selection of risk management techniques using case-based reasoning. Civil Engineering and Environmental Systems, 27(2), 107-121. 
Ford, E. P., Aven, T., Røed, W., \& Wiencke, H. S. (2008). An approach for evaluating and selecting methods for risk and vulnerability assessments. Journal of Risk and Reliability, 222(3), 315-326.

Ford, M. (Ed.). (2002). Redgrave's Health and Safety (4th ed.). London: Butterworths LexisNexis.

Franks, A., Whitehead, R., Crossthwaite, P., \& Smail, L. (2002). Application of QRA in operational safety issues. Research Report RR 025 for Health and Safety Executive; Sudbury: HSE Books. Retrieved from http://www.hse.gov.uk/research/rrhtm/index.htm

Franz, L., \& Kramer, M. (2010). The Dimensions of Decisions: A Conceptual and Empirical Investigation. In Nutt, P. \& Wilson, D. (Eds.), Handbook of decision making (pp. 517540). Chichester: Wiley.

Fraser, J., Schoening-Thiessen, K., \& Simkins, B. (2008). Who reads what most often? A survey of enterprise risk management literature read by risk executives. Journal of Applied Finance, 73-91.

Frei, R., Kingston, J., Koornneef, F., \& Schallier, P. (2003). Investigation Tools In Context. JRC/ESReDA Seminar, Petten, Joint Research Centre of the European Union. Retrieved from Downloaded from www.nri.eu.com

Frimer, J. A., Skitka, L. J., \& Motyl, M. (2017). Liberals and conservatives are similarly motivated to avoid exposure to one another's opinions. Journal of Experimental Social Psychology, 72(C), 1-12.

Frost, F. (2003). The use of strategic tools by small and medium-sized enterprises: an Australasian study. Strategic Change, 12(1), 49-62.

Funtowicz, S., \& Ravetz, J. (1992). Three types of risk assessment and the emergence of post-normal science. In Krimsky, S. \& Golding, D. (Eds.), Social theories of risk. Westport, CT: Praeger.

Gadd, S., Keeley, D., \& Balmforth, H. (2003). Good practice and pitfalls in risk assessment. Research Report RR 151 for Health and Safety Executive; Sudbury: HSE Books. Retrieved from http://www.hse.gov.uk/research/rrhtm/index.htm

Gadd, S., O'Hara, R., Dickety, N., \& Weyman, A. (2000). Good Practice by SMEs in Assessing Workplace Risks: Final Report. Research Report RAS/00/12 Sheffield: Health and Safety Laboratory. Retrieved from www.hse.gov.uk/research/

Garnett, K., Lickorish, F. A., Rocks, S. A., et al. (2016). Integrating horizon scanning and strategic risk prioritisation using a weight of evidence framework to inform policy decisions. Science of The Total Environment, 560-561, 82-91.

Garvin, D., \& Roberto, M. (2001). What You Don't Know About Making Decisions. Harvard Business Review, 108-116.

Gates, L. (2010). Strategic Planning with Critical Success Factors and Future Scenarios: An Integrated Strategic Planning Framework. Technical Report CMU/SEI-2010-TR-037: Software Engineering Institute. Retrieved from https://www.sei.cmu.edu/

Geroy, G. D., \& Wright, P. C. (1988). Evaluation Research: A Pragmatic, Program-Focused, Research Strategy for Decision-Makers. Performance Improvement Quarterly, 1(3), 17-26.

Gerstein, D., Kallimani, J., Mayer, L., et al. (2016). Developing a Risk Assessment Methodology for the National Aeronautics and Space Administration. Research Report RR1537 Santa Monica, CA: Rand Corporation. Retrieved from www.rand.org/t/RR1537

Gilbertson, A., Kappia, J., Bosher, L., \& Gibb, A. (2011). Preventing catastrophic events in construction. Research Report RR 834 for Health and Safety Executive; Sudbury: HSE Books. Retrieved from http://www.hse.gov.uk/research/rrhtm/index.htm

Giovinazzi, S., Wilson, T., Davis, C., et al. (2011). Lifelines performance and management following the 22 February 2011 Christchurch earthquake, New Zealand: highlights of resilience. Bulletin of the New Zealand National Society for Earthquake Engineering, 44(4), 402-417. 
Global Institute. (2015). Countries having adopted ISO 31000 as their official national risk management standard. Author. Retrieved from http://g31000.org/wpcontent/uploads/2015/04/High res word-map with table-17.pdf.

Goble, R., \& Bier, V. M. (2013). Risk assessment can be a game-changing information technology - but too often it isn't. Risk Analysis, 33(11), 1942-1951.

Goerlandt, F., Khakzad, N., \& Reniers, G. (2017). Validity and validation of safety-related quantitative risk analysis: A review. Safety Science, 99, 127-139.

Goldberg, B., Everhart, K., Stevens, R., et al. (1994). System Engineering "Toolbox" for Design-Oriented Engineers. Reference Publication 1358 Alabama: NASA. Retrieved from http://snebulos.mit.edu/

Goldratt, E., \& Cox, J. (2004). The Goal (3rd ed.). Aldershot: Gower Publishing Ltd.

Gould, J., Glossop, M., \& loannides, A. (2005). Review of hazard identification techniques. Research Report HSL/2005/58 for Health and Safety Executive; Sudbury: Health and Safety Laboratory. Retrieved from http://www.hsl.gov.uk/

Gould-Williams, J. S., \& Gatenby, M. (2010). The Effects Of Organizational Context And Teamworking Activities On Performance Outcomes. Public Management Review, 12(6), 759-787.

Grapes, R. (2000). Magnitude eight plus: New Zealand's biggest earthquake. Wellington: Victoria University Press.

Green, R., Agarwal, R., Van Ree, J., et al. (2010). Management Matters in New Zealand How does manufacturing measure up? Research Report for Ministry of Economic Development; The Treasury; Department of Labour; New Zealand Trade and Enterprise; Sydney: University of Technology Sydney. Retrieved from http://www.med.govt.nz/

Haas, C. N. (2016). Reproducible Risk Assessment. Risk Analysis, 36(10), 1829-1833.

Haimes, Y. Y. (1998). Risk modelling, assessment and management New York: John Wiley $\&$ Sons.

Hallegatte, S., Shah, A., Lempert, R., et al. (2012). Investment Decision Making Under Deep Uncertainty: Application to Climate Change. Working Paper 6193 Washington, DC: World Bank. Retrieved from http://elibrary.worldbank.org/

Hamling, I. J., Hreinsdóttir, S., Clark, K., et al. (2017). Complex multi-fault rupture during the 2016 Mw 7.8 Kaikōura earthquake, New Zealand. Science, 356(6334).

Hampel, R. (1998). Committee on Corporate Governance. London: Gee Publishing Ltd.

Hancox, G., Archibald, G., Cousins, W., et al. (2013). Reconnaissance report on liquefaction effects and landslides caused by the ML 6.5 Cook Strait earthquake on 21 July 2013, New Zealand Report 2013/42: GNS Science. Retrieved from www.gns.cri.nz

Hansson, S. O. (2010). Risk: objective or subjective, facts or values. Journal of Risk Research, 13(2), 231-238.

Hardy, C., \& Maguire, S. (2016). Organizing risk: discourse, power, and "riskification". Academy of Management Review, 41(1), 80-108.

Health and Safety at Work Act 1974, UK. Available at http://www.legislation.gov.uk/ukpga/1974/37

Health and Safety at Work Act 2015, New Zealand. Available at http://www.legislation.govt.nz/

Health and Safety in Employment Act 1992, Available at http://www.legislation.govt.nz/

Health and Safety Reform Bill 2014, New Zealand. Available at http://www.legislation.govt.nz/

Heinrich, H. (1931). Industrial Accident Prevention, A Scientific Approach: McGraw-Hill.

Hendricks, K. B., \& Singhal, V. R. (2003). The effect of supply chain glitches on shareholder wealth. Journal of Operations Management, 21(5), 501-522.

Hendricks, K. B., \& Singhal, V. R. (2005). An Empirical Analysis of the Effect of Supply Chain Disruptions on Long-Run Stock Price Performance and Equity Risk of the Firm. Production and Operations Management, 14(1), 35-52. 
Heras-Saizarbitoria, I., \& Boiral, O. (2013). ISO 9001 and ISO 14001: towards a research agenda on management system standards. International journal of management reviews, 15(1), 47-65.

Hill, R. (1998). What sample size is "enough" in internet survey research? Interpersonal Computing and Technology: An Electronic Journal for the 21st Century, 6(3-4).

Hillson, D. (1997). Towards a Risk Maturity Model. International Joumal of Project and Business Risk Management, 1(1), 35-45.

Hillson, D., Grimaldi, S., \& Rafele, C. (2006). Managing Project Risks Using a Cross Risk Breakdown Matrix. Risk Management, 8(1), 61-76.

Hillson, D., \& Simon, P. (2007). Practical Project Risk Management: the ATOM methodology. Vienna, VA: Management Concepts.

Hinde, A., \& Ager, R. (2003). Benchmarking the competent person in manufacturing and engineering sectors. Research Report RR 121 for Health and Safety Executive; Sudbury: HSE Books. Retrieved from http://www.hse.gov.uk/research/rrhtm/index.htm

Ho, E., Budescu, D., Dhami, M., \& Mandel, D. R. (2015). Improving the communication of uncertainty in climate science and intelligence analysis. Behavioural Science \& Policy, 1(2), 43-55.

Ho, E., \& Hastak, M. (2010). Impact Analysis of Natural Calamities on Infrastructure and Industries. Working Paper: Purdue University. Retrieved from http://www.irbnet.de/daten/iconda/CIB11539.pdf

Hohmann, C. (2014). What is a goal tree? Retrieved 23 August 2017, from https://hohmannchris.wordpress.com/2014/07/16/goal-tree-how-green-is-your-tree/

Hopkins, A. (2004). Quantitative risk assessment: a critique. Working Paper 25 Canberra: Australian National University. Retrieved from www.http://ohs.anu.edu.au/

Hopkins, D. (Ed.). (1991). Lifelines in Earthquakes: Wellington Case Study. Christchurch: Centre for Advanced Engineering.

Hoyt, R., Moore, D., \& Liebenberg, A. (2008). The Value of Enterprise Risk Management: Evidence from the U.S. Insurance Industry. Enterprise Risk Management Symposium, Chicago, IL, Society of Actuaries. Retrieved from http://www.soa.org/

HSE. (1989). Quantified risk assessment: its input to decision making. London: HMSO.

HSE. (1998). Five steps to risk assessment. Guidance Note INDG163: HSE Books.

HSE. (1999). Reducing error and influencing behaviour. Guidance Note HS(G) 48 Sudbury: HSE Books. Retrieved from http://www.hse.gov.uk/

HSE. (2014a). Risk assessment: A brief guide to controlling risks in the workplace. Guidance Note indg163 Sudbury, UK: HSE Books. Retrieved from www.hse.gov.uk/pubns/indg163.htm

HSE. (2014b). Safe use of all-terrain vehicles (ATVs) in agriculture and forestry. Information sheet 33: HSE Books. Retrieved from http://www.hse.gov.uk/pubns/ais33.pdf

HSE. (2015). The dust lamp: A simple tool for observing the presence of airborne particles. Guidance Note MDHS82/2 Sudbury: Health and Safety Executive. Retrieved from http://www.hse.gov.uk/pubns/mdhs/pdfs/mdhs82-2.pdf

Hubbard, D. (2009). The failure of risk management: Why it's broken and how to fix it: Wiley.

ICMM. (2015). Health and Safety critical control management: Good practice guide. London: International Council on Mining and Metals. Retrieved from www.icmm.com

IEC60812:2008. Analysis techniques for system reliability - Procedure for failure mode and effects analysis (FMEA). Geneva: International Electrotechnical Commission.

IEC61025:2008. Fault tree analysis. Geneva: International Electrotechnical Commission.

IEC61882:2016. Hazard and operability studies (HAZOP studies). Geneva: International Electrotechnical Commission.

IEC62508:2015. Human aspects of dependability. Geneva: International Electrotechnical Commission.

IEC62740:2015. Root cause analysis (RCA). Geneva: International Electrotechnical Commission. 
IEC/ISO31010:2009. Risk management - Risk assessment techniques. Geneva: International Standards Organization.

IEC/ISO31010 CDV:2019. Risk management - Risk assessment techniques. Geneva: International Electrotechnical Commission.

INSHPO. (2017). The Occupational Health and Safety (OHS) Professional Capability Framework: A Global Framework for Practice: Knowledge matrix mapped to the OHS Body of Knowledge. International Network of Safety and Health Practitioner Organizations. Retrieved from https://www.inshpo.org/

IOSH. (2013). Code of Conduct, Guidance and Disciplinary Procedure. Wigston: Author. Retrieved from https://www.iosh.co.uk/About-us/Regulating-the-profession.aspx

IOSH, \& ASSE. (2010). Global best practices in contractor safety. Wigston, UK: IOSH Services Ltd \& American Society of Safety Engineers. Retrieved from www.iosh.co.uk

IPENZ. (2005). Code of Ethics. Retrieved from https://www.ipenz.nz/.

IPPC. (2004). Pest risk analysis for quarantine pests including analysis of environmental risks and living modified organisms. Guidance Note Geneva: Secretariat of the International Plant Protection Convention. Retrieved from https://www.ippc.int/file uploaded/1146658377367 ISPM11.pdf

ISO5807:1985. Information processing -- Documentation symbols and conventions for data, program and system flowcharts, program network charts and system resources charts. Geneva: International Standards Organization.

ISO12100:2010. Safety of machinery -- General principles for design -- Risk assessment and risk reduction. Geneva: International Standards Organization.

ISO17776:2016. Petroleum and natural gas industries - Offshore production installations Major accident hazard management during the design of new installations. Geneva: International Standards Organization.

ISO22000:2005. Food Safety Management Systems - Requirements. Geneva: International Standards Organization.

ISO22002:2009. Prerequisite programmes on food safety -- Part 1: Food manufacturing. Geneva: International Standards Organization.

ISO27005:2011. Information technology: Security techniques: Information security risk management Geneva: International Standards Organization.

ISO31000:2009. Risk management - Principles and guidelines. Geneva: International Standards Organization.

ISO31000:2018. Risk management - Guidelines. Geneva: International Standards Organization.

ISO45001:2018. Occupational health and safety management systems: Requirements with guidance for use. Geneva: International Standards Organization.

ISO Guide 73:2009. Risk management - vocabulary - guidelines for use in standards. Geneva: International Standards Organization.

ISO/IEC Annex SL N157:2012. Directives, Part 1. Consolidated ISO Supplement Procedures specific to ISO. Geneva: International Standards Organization.

Jack, M., \& Weavers, M. (2013). Ministerial Inquiry into the Novopay Project. Ministerial Inquiry Wellington. Retrieved from http://www.minedu.govt.nz/theMinistry/NovopayProject/Ministeriallnquiry.aspx

Jacobs, D. (2010). Pragmatism. In Mills, A., Durepos, G. \& Wiebe, E. (Eds.), Encyclopedia of case study research. Thousand Oaks, Ca: SAGE Publications Ltd.

Jager, R., Cosman, M., Mackay, P., et al. (2013). Independent Taskforce on Workplace Health \& Safety. Report Wellington. Retrieved from www.hstaskforce.govt.nz

James, A. (2016). SH1 Picton to Christchurch (Ashley River Bridge) Strategic Case. Report Wellington: New Zealand Transport Agency.

James, W. (2011). Pragmatism's Conception of Truth. In Talisse, R. \& Aikin, S. (Eds.), The Pragmatism Reader: From Peirce through the Present (pp. 79-91): Princeton University Press. 
Janis, I. L. (1973). Groupthink and group dynamics: a social psychological analysis of defective policy decisions. Policy Studies Journal, 2(1), 19-25.

Jarzabkowski, P. (2004). Strategy as Practice: Recursiveness, Adaptation, and Practices-inUse. Organization Studies, 25(4), 529-560.

Jones, V., \& Razin, E. (2013). The emerging importance of managing risk in the boardroom. Retrieved from https://risk.thomsonreuters.com/sites/default/files/GRC00285.pdf.

Julian, T. (2011). What's right with risk matrices? A great tool for managers. Retrieved 26 July 2012, from http://31000risk.wordpress.com/article/what-s-right-with-riskmatrices-3dksezemiiq54-4/

Jüttner, U., Peck, H., \& Christopher, M. (2003). Supply chain risk management: outlining an agenda for future research. International Journal of Logistics: Research \& Applications, 6(4), 197-210.

Kahan, D., Peters, E., Wittlin, M., et al. (2012). The polarizing impact of science literacy and numeracy on perceived climate change risks. Nature Climate Change, 2(10), 732735.

Kahneman, D. (2011). Thinking fast and slow. London: Penguin Books Ltd.

Kahneman, D., \& Lovallo, D. (1993). Timid Choices and Bold Forecasts: A Cognitive Perspective on Risk Taking. Management Science, 39(1), 17-31.

Kahneman, D., Slovic, P., \& Tversky, A. (Eds.). (1982). Judgment under uncertainty: heuristics and biases. Cambridge, NY: Cambridge University Press.

Kaplan, J., Gimbel, S., \& Harris, S. (2016). Neural correlates of maintaining one's political beliefs in the face of counterevidence. Scientific Reports, 6(1).

Karageorgiou, A., Jensen, P. L., Walters, D., \& Wilthagen, T. (2000). Risk Assessment in Four Member States of the European Union. In Frick, K., Jensen, P. L., Quinlan, M. \& Wilthagen, T. (Eds.), Systematic Occupational Health and Safety Management: Perspectives on an International Development (pp. 1-16). Amsterdam: Pergamon, Elsevier Science.

Kasperson, R. (2008). Coping with deep uncertainty: challenges for environmental assessment and decision-making. In Bammer, G. \& Smithson, M. (Eds.), Uncertainty and Risk: Multidisciplinary Perspectives (pp. 337-348). London: Earthscan Publications Ltd.

Kent, S. (2007). Words of Estimative Probability. Retrieved 28 December, 2012, from https://www.cia.gov/library/center-for-the-study-of-intelligence/csi-publications/booksand-monographs/sherman-kent-and-the-board-of-national-estimates-collectedessays/6words.html

Kerzner, H. R. (2014). Project Recovery : Case Studies and Techniques for Overcoming Project Failure. Somerset, USA: John Wiley \& Sons, Incorporated.

Khan, F., Rathnayaka, S., \& Ahmed, S. (2015). Methods and models in process safety and risk management: Past, present and future. Process Safety and Environmental Protection, 98, 116-147.

Khastgir, S., Birrell, S., Dhadyalla, G., et al. (2017). Towards increased reliability by objectification of Hazard Analysis and Risk Assessment (HARA) of automated automotive systems. Safety Science, 99, 166-177.

Kim, S., Mabin, V. J., \& Davies, J. (2008). The theory of constraints thinking processes: retrospect and prospect. International Journal of Operations \& Production Management, 28(2), 155-184.

Kimani, S. (2015). Exploring Quality of Learning and Teaching Experiences in Higher Education using the Theory of Constraints : Kenya and New Zealand. (PhD Thesis), Victoria University of Wellington, Wellington.

King, A., \& Crewe, I. (2013). The Blunders of our Governments. London: Oneworld Publications.

Kirwan, B., \& Ainsworth, L. (1992). A Guide to Task Analysis. London: Taylor \& Francis. Kloman, F. (2010). A brief history of risk management. In Fraser, J. \& Simkins, B. (Eds.), Enterprise Risk Management - Today's Leading Research and Best Practices for Tomorrow's Executives (pp. 19-30). New Jersey: Wiley. 
Knight, F. (1921). Risk, uncertainty and profit (1957 reprint ed.). Boston, MA: Houghton Mifflin.

Knight, R., \& Pretty, D. (2002). Sudden increases and decreases in shareholder value and the implications for CEOs. Ernst \& Young. Retrieved from http://www.oxfordmetrica.com/public/CMS/Files/599/02RepComEY.pdf

Kovács, G., \& Spens, K. (2005). Abductive reasoning in logistics research. International Journal of Physical Distribution \& Logistics Management, 35(2), 132-144.

KPMG International. (2013). Global risk survey. Working Paper 121405a: Author. Retrieved from http://www.kpmg.com/global/en/issuesandinsights/articlespublications/riskmanagement-outpacing-capabilities/pages/default.aspx

Kramer, R. M. (1999). Trust and distrust in organizations: Emerging perspectives, enduring questions. Annual Review of Psychology, 50(1), 569.

Krause, T. (2009, June). Steps in Safety Strategy: The Gap Analysis \& Implementation Plan. EHS Today, 2, pp. 22 Retrieved from http://ehstoday.com/safety/news/steps-safetystrategy-9948

La Porte, T. R. (1975). Complexity and uncertainty: Challenge to action. In La Porte, T. (Ed.), Organised social complexity: Challenge to politics and policy (pp. 332-356). Princeton, NJ: Princeton University Press.

Lacey, J., \& Dutkiewicz, J. (1994). Bioaerosols and occupational lung disease. Journal of Aerosol Science, 25(8), 1371-1404.

Lalonde, C., \& Boiral, O. (2012). Managing risks through ISO 31000: A critical analysis. Risk Management, 14(4), 272-300.

Lamm, F., Massey, C., \& Perry, M. (2007). Is there a link between Workplace Health and Safety and Firm Performance and Productivity? New Zealand Journal of Employment Relations, 32(1), 72-86.

Landquist, H., Hassellöv, I. M., Rosén, L., et al. (2013). Evaluating the needs of risk assessment methods of potentially polluting shipwrecks. Journal of Environmental Management, 119, 85-92.

Larsson, T., Mather, E., \& Dell, D. (2007). To influence corporate OH\&S performance through the financial market. International Journal of Risk Assessment and Management, 7(2), 263-271.

Latham, G. P., \& Locke, E. A. (2006). Enhancing the Benefits and Overcoming the Pitfalls of Goal Setting. Organizational Dynamics, 35(4), 332-340.

Lathrop, J., \& Ezell, B. (2017). A systems approach to risk analysis validation for risk management. Safety Science, 99, 187-195.

Lauder, M. A., \& Marynissen, H. (2018). Normal chaos: A new research paradigm for understanding practice. Journal of Contingencies and Crisis Management, 26(2), 319-323.

Lee, J. (2012). Standardisation of Hazard Analysis and Critical Control Point (HACCP). Wellington: Ministry for Primary Industries. Retrieved from http://www.foodsafety.govt.nz/

Leitch, M. (2010). ISO 31000:2009 - The New International Standard on Risk Management. Risk Analysis, 30(6), 887-892.

Leitch, M., Chapman, C., Johnson, J., et al. (2016). Directing risk management in organizations: Guidance from the Centre for Risk Research. Southampton: Centre for Risk Research. Retrieved from http://www.southampton.ac.uk/risk

Lekka, C., Greaves, D., Healey, N., \& Mellor, N. (2017). Leadership and worker engagement in the ports industry. Research Report RR1089 for Health and Safety Executive; Sudbury: HSE Books. Retrieved from http://www.hse.gov.uk/research/rrhtm/index.htm

Lenhardt, U., \& Beck, D. (2016). Prevalence and quality of workplace risk assessments Findings from a representative company survey in Germany. Safety Science, 86, 4856. 
Lilley, R., Lower, T., \& Davie, G. (2017). Towards a harmonised approach to reducing quadrelated fatal injuries in Australia and New Zealand: a cross-sectional comparative analysis. Australian and New Zealand Journal of Public Health, 41(5), 524-529.

Locke, E. A., \& Latham, G. P. (2002). Building a Practically Useful Theory of Goal Setting and Task Motivation. American Psychologist, 57(9), 705-717.

Lord Robens, A., Beeby, G., Pike, M., et al. (1972). Safety and Health at Work: Report of the Committee, 1970-72. London: HMSO.

Lovallo, D., \& Sibony, O. (2010). The case for behavioural strategy. McKinsey Quarterly, (March). Retrieved from https://www.mckinsey.com.

Lower, A. (2013). Quad bikes: tobacco on four wheels. Australian and New Zealand Journal of Public Health, 37(2), 105-107.

Lower, A., Pollock, K., \& Herde, E. (2013). Australian quad bike fatalities: what is the economic cost? Australian and New Zealand Journal of Public Health, 37(2), 173178.

Lower, A., \& Temperley, J. (2016). Preventing death and serious injury caused by quad rollovers on Australian farms. Policy Paper Australian Centre for Agricultural Health and Safety Sydney: University of Sydney. Retrieved from https://sydney.edu.aul

Lowrance, W. (1976). Of Acceptable Risk: Science and the Determination of Safety. New York: Harvard University.

Lundgren, T., \& Olsson, R. (2010). Environmental incidents and firm value-international evidence using a multi-factor event study framework. Applied Financial Economics, 20(16), 1293-1307.

Lunt, J., Bates, S., Bennett, V., \& Hopkinson, J. (2008). Behaviour change and worker engagement practices within the construction sector. Research Report RR 660 for Health and Safety Executive; Sudbury: HSE Books. Retrieved from http://www.hse.gov.uk/research/rrhtm/index.htm

Mabin, V., Davies, J., Kimani, S., \& Mirzaei, M. (2016). TOC for Academic Research: Moving from common sense to common practice. TOCICO International Conference, Leesburg, VA,

Mabin, V., Yee, J., Babington, S., et al. (2018). Using the Theory of Constraints to resolve long-standing resource and service issues in a large public hospital. Health Systems, 7(3), 230-249.

Macfie, R. (2013). Tragedy at Pike River mine: how and why 29 men died. Wellington: Awa Press.

MacGillivray, B. H. (2013). Heuristics Structure and Pervade Formal Risk Assessment. Risk Analysis, 34(4), 771-787.

MacGillivray, B. H., Sharp, J. V., Strutt, J. E., et al. (2007). Benchmarking Risk Management Within the International Water Utility Sector. Part II: A Survey of Eight Water Utilities. Journal of Risk Research, 10(1), 105-123.

Macnamara, B. N., Hambrick, D. Z., \& Oswald, F. L. (2014). Deliberate Practice and Performance in Music, Games, Sports, Education, and Professions: A Meta-Analysis. Psychological Science, 25(8), 1608-1618.

Manab, N., Othman, S., \& Kassim, I. (2012). Enterprise-Wide Risk Management Best Practices: The Critical Success Factors. OIDA International Journal of Sustainable Development, 4(3), 87-96.

Mandel, D. R., \& Barnes, A. (2014). Accuracy of forecasts in strategic intelligence. Proceedings of the National Academy of Sciences, 111(30), 10984-10989.

March, J., \& Shapira, Z. (1987). Managerial perspectives on risk and risk taking. Management Science, 33(11), 1404-1418.

Marhavilas, P. K., Koulouriotis, D., \& Gemeni, V. (2011). Risk analysis and assessment methodologies in the work sites: On a review, classification and comparative study of the scientific literature of the period 2000-2009. Journal of Loss Prevention in the Process Industries, 24(5), 477-523. 
Market Economics Ltd. (2017). Economic impact of the 2016 Kaikoura earthquake. Report for Ministry of Transport; Takapuna: Market Economics Ltd. Retrieved from http://www.transport.govt.nz/assets/Uploads/Our-Work/Documents/KaikouraEarthquake-MERIT-Report.pdf

Marshall, C., \& Rossman, G. B. (2006). Designing qualitative research (4th ed. ed.). Thousands Oaks, Calif: Sage Publications.

Mason, J. (2006). Mixing methods in a qualitatively driven way. Qualitative Research, 6(1), 9-25.

Massie, A., \& Watson, N. (2011). Impact of the Christchurch earthquakes on the electrical power system infrastructure. Bulletin of the New Zealand National Society for Earthquake Engineering, 44(4), 425-430.

Mathison, S. (1988). Why Triangulate? Educational Researcher, 17(2), 13-17.

Matsumoto, Y., \& Shirasaka, S. (2016). Self - Evaluation Driven Improvement of Risk Management utilizing Risk Management Capability Maturity Model. INCOSE International Symposium, pp - 108, Retrieved from https://doi.org/10.1002/j.23345837.2016.00317.x

MBIE. (2013). Working Safer: A blueprint for health and safety at work. Report Wellington: Ministry of Business, Innovation and Employment. Retrieved from http://www.mbie.govt.nz/

McClure, J., Henrich, L., Johnston, D., \& Doyle, E. E. H. (2016). Are two earthquakes better than one? How earthquakes in two different regions affect risk judgments and preparation in three locations. International Journal of Disaster Risk Reduction, 16, 192-199.

MCDEM. (2006). Organisational Debriefing. Guidance Note IS6/06. Retrieved from http://www.civildefence.govt.nz/

MCDEM. (n.d.). The 4Rs: Reduction, readiness, response and recovery. Retrieved 6 July, 2017, from http://www.civildefence.govt.nz/cdem-sector/cdem-framework/the-4rs/

McDermott, P., \& Davies, G. (2008). Communicating Operational Risk Results to Senior Management. RMA Journal, 90(9), 50-53.

McDonald, N., Hrymak, V., Pérez-González, J. D., et al. (2002). Safety Behaviour in the Construction Industry. Research Report Dublin, Eire: Health and Safety Authority. Retrieved from http://www.elcosh.org/document/1435/d000055/Safety\%2BBehaviour\%2Bin\%2Bthe \%2BConstruction\%2BIndustry.html

McLeod, R. W., \& Bowie, P. (2018). Bowtie Analysis as a prospective risk assessment technique in primary healthcare. Policy and Practice in Health and Safety, 16(2), 177193.

McShane, M. K., Nair, A., \& Rustambekov, E. (2011). Does Enterprise Risk Management Increase Firm Value? Journal of Accounting, Auditing \& Finance, 26(4), 641-658.

Meacham, J. (1990). The loss of wisdom. In Sternberg, R. (Ed.), Wisdom: its nature, origins, and development. New York: Cambridge University Press.

MED. (2007). Economic Development Indicators. Report Wellington: Ministry of Economic Development. Retrieved from www.med.govt.nz/indicators

Meier, P. (2007). Mind-mapping: a tool for eliciting and representing knowledge held by diverse informants. Social Research Update, (52), Retrieved from http://sru.soc.surrey.ac.uk/SRU52.pdf

Middleton, M., \& Franks, A. (2001). Using Risk Matrices. Chemical Engineer, (723), pp. 3437

Mikkelsen, K. L., Spangenberg, S., \& Kines, P. (2010). Safety walkarounds predict injury risk and reduce injury rates in the construction industry. American Journal of Industrial Medicine, 53(6), 601-607.

Miles, M. (1984). Qualitative data analysis : a sourcebook of new methods. Beverly Hills: Beverly Hills : Sage Publications.

Miller, G. (1994). The Magical Number Seven, Plus or Minus Two: Some Limits on Our Capacity for Processing Information. Psychological Review, 101(2), 343-352. 
Miller, L., Huelsman, T., Clark, B., \& Sokolovic, T. (2015). Understanding risk assessment practices at manufacturing companies. Deloitte Touche Tohmatsu Limited. Retrieved from http://www2.deloitte.com/

Mingers, J. (2003). A classification of the philosophical assumptions of management science methods. Journal of the Operational Research Society, 54(6), 550-570.

Mingers, J., \& Brocklesby, J. (1997). Multimethodology: Towards a framework for mixing methodologies. Omega, 25(5), 489-509.

Mintzberg, H. (1971). Managerial work: analysis from observation. Management Science, 18(2), 97-110.

Mintzberg, H. (1990). The Manager's Job: Folklore and Fact. Harvard Business Review, March-April, 163-176.

Mirzaei, M. (2016). Exploring Applicability of TOC to projects: Critical Chain Project Management and Beyond. (PhD Thesis), Victoria University of Wellington, Wellington.

Modarres, M. (2006). Risk analysis in engineering: techniques, tools, and trends. Boca Raton, FL: CRC Press.

Modarres, M. (2017). Reliability engineering and risk analysis: a practical guide (3rd ed.). Boca Raton: Taylor \& Francis.

Model Work Health and Safety Bill 2011, Australia. Available at http://www.safeworkaustralia.gov.au/

Modell, S. (2009). In defence of triangulation: A critical realist approach to mixed methods research in management accounting. Management Accounting Research, 20(3), 208-221.

Molde, C. (2011). Controlling exposure to dust and bioaerosols on farms growing common commercial mushrooms (Agaricus bisporus). Fact sheet $02 / 11$ for Horticulture Development Company; Sudbury: Health and Safety Executive. Retrieved from http://www.hse.gov.uk/coshh/essentials/pdf/mushroom-factsheet-hdc.pdf

Montibeller, G., \& von Winterfeldt, D. (2015). Cognitive and Motivational Biases in Decision and Risk Analysis. Risk Analysis, 35(7), 1230-1251.

Moore, D. (2007). A systems analysis of quadbike loss of control events on New Zealand farms. (PhD Thesis), Massey University, Palmerston North. Retrieved from https://mro.massey.ac.nz/handle/10179/624

Moore, R. (2009). Shaping More Sustainable Communities: A Case Study In Urban Water Management. (MMS Thesis), Victoria University of Wellington.

Moore, R., \& Mabin, V. (2018). Reaching Community Consensus on Reforms for More Sustainable Urban Water Management Systems. In Stowell, F. (Ed.), Systems Research for Real-World Challenges (pp. 67-101). Hershey, PA, USA: IGI Global.

Morgan, N. (2004). Effective brainstorming techniques AdMedia, 19(3), 76-76.

Mori, S., Nakagawa-Yoshida, K., Tsuchihashi, H., et al. (1998). Mushroom worker's lung resulting from indoor cultivation of Pleurotus osteatus. Occupational Medicine, 48(7), 465-468.

Morillas, R. M., Rubio-Romero, J. C., \& Fuertes, A. A comparative analysis of occupational health and safety risk prevention practices in Sweden and Spain. Journal of Safety Research, 47, 57-65.

Morrison, M., \& Morgan, M. (1999a). Introduction. In Morgan, M. \& Morrison, M. (Eds.), Models as mediators: perspectives on natural and social science (pp. 1-9). Cambridge: Cambridge University Press.

Morrison, M., \& Morgan, M. (1999b). Models as mediating instruments. In Morgan, M. \& Morrison, M. (Eds.), Models as mediators: perspectives on natural and social science. Cambridge: Cambridge University Press.

MoT. (2013). The social cost of road crashes and injuries: June 2013 update. Wellington: Author. Retrieved from http://www.transport.govt.nz/

Mowll, R., Brunsdon, D., Wilde, F., \& Leslie, P. (2013). Understanding the impact of a major earthquake on Wellington lifelines. Bulletin of the New Zealand National Society for Earthquake Engineering, 46(2), 109-115. 
Muir, D., Lovell, M., \& Peace, C. (1981). Health hazards in natural history museum work. Museums Journal, 80(4), 205-206.

Mullen, P. (2007). How management behaviours associated with successful health and safety performance relate to those associated with success in other domains.

Research Report RR744 Sudbury, UK: HSE Books. Retrieved from http://www.hse.gov.uk/

Mushroom Growers Federation NZ Ltd. (n.d.). Mushroom growing process. Retrieved 20 February 2018, from http://www.mushroomgrowers.org.nzl

Myers, M. L. (2016). ATV Overturns: Engineering Controls to Prevent Crush Injuries. Professional Safety, 61(8).

Myers, M. L., \& Cole, H. (2016). Crush Prevention Device Safety for ATVs. 2016 ISASH Annual Conference, Lexington, International Society for Agricultual Safety and Health.

Naor, M., Bernardes, E. S., \& Coman, A. (2012). Theory of constraints: is it a theory and a good one? International Journal of Production Research, 51(2), 1-13.

National Research Council. (2009). Science and decisions: advancing risk assessment. Washington, D.C.: National Academies Press.

Naval Weapons Centre. (1976). Risk Analysis. Technical Publication Arlington, VA: Author.

Neathey, F., Sinclair, A., Rick, J., et al. (2006). An evaluation of the five steps to risk assessment. Research Report 476 for Health and Safety Executive; Sudbury: HSE Books. Retrieved from http://www.hse.gov.uk/research/rrhtm/index.htm

New Zealand Stock Exchange. (2017). Corporate Governance Code. Standard Wellington. Retrieved from https://nzx.com/files/static/cmsdocuments//NZX Corporate Governance Code 2017.pdf

Newman Taylor, A. (1994). Extrinsic allergic alveolitis. In Raffle, P., Adams, P., Baxter, P. \& Lee, W. (Eds.), Hunter's Diseases of Occupations (8th ed.). London: Edward Arnold.

Nickerson, R. C., Varshney, U., \& Muntermann, J. (2013). A method for taxonomy development and its application in information systems. European Journal of Information Systems, 22(3), 336-359.

Nielsen, V. L., \& Parker, C. (2012). Mixed Motives: Economic, Social, and Normative Motivations in Business Compliance. Law \& Policy, 34(4), 428-462.

Niven, P. (2014). Balanced Scorecard Evolution: A Dynamic Approach to Strategy Execution: Wiley.

NOHSC. (2005). National Standard for Construction Work. Standard Canberra: National Occupational Health and Safety Commission. Retrieved from https://www.safeworkaustralia.gov.au/doc/national-standard-construction-worknohsc1016-2005

Nutt, P. (2002). Why decisions fail: avoiding the blunders and traps that lead to debacles. San Francisco: Berrett-Koehler.

Nutt, P., \& Wilson, D. (2010). Crucial Trends and Issues in Strategic Decision Making. In Nutt, P. \& Wilson, D. (Eds.), Handbook of decision making (pp. 3-29). Chichester: Wiley.

NZS4104 NZS 4104:1994. Seismic Restraint of Building Contents. Wellington: Standards New Zealand.

OECD. (2004). Principles of Corporate Governance. Paris: Author. Retrieved from http://www.oecd.org/document/22/0,2340,en 26492011853155810211111 1,00. $\underline{\mathrm{html}}$

Oliva, F. L. (2016). A maturity model for enterprise risk management. International Journal of Production Economics, 173, 66-79.

Oreskes, N., \& Conway, E. (2010). Merchants of doubt. London: Bloomsbury Press.

OSH. (2002). Safe Use of ATVs on New Zealand Farms. Wellington: Department of Labour. OSPRI. (2017a). Quad bike ban addresses safety concerns. Retrieved 3 March 2018, from https://www.ospri.co.nzl 
OSPRI. (2017b). Quad Bike Safety Requirements. Fact Sheet HSSE2 Wellington: Author. Retrieved from https://www.ospri.co.nz/assets/Uploads/Documents/Quad-BikeSafety-Requirements.pdf

Owen, C. (2018). How emergency services organisations can - and do - utilise research. Australian Journal of Emergency Management, 33(2), 28-33.

Panagiotou, G. (2003). Bringing SWOT into Focus. Business Strategy Review, 14(2), 8-10.

Papazoglou, I., Bari, R., Buslik, A., et al. (1984). Probabilistic Safety Analysis Procedures Guide. Guidance Note NUREG/CR-2815, BNL-NUREG-51559 Washington DC:

Department of Nuclear Energy. Retrieved from https://www.nrc.gov/docs/ML0635/ML063550253.pdf

Parker, C. (2002). The Open Corporation: effective self-regulation and democracy. Cambridge: Cambridge University Press.

Pashorina-Nichols, V. (2016). Occupational Health And Safety: Why And How Should Worker Participation Be Enhanced In New Zealand? New Zealand Journal of Employment Relations, 41(2), 71-86.

Paterson, A., Mora, K., \& Thomas, J. (2013). An instrument quad bike study. Research Report 528095.00 for ACC Research; Wellington: Opus International Consultants Limited.

Peace, C. (1974). Noise in the environment. (BScThesis), University of Aston in Birmingham, Birmingham.

Peace, C. (1980). The use of chemicals in small workplaces. Health and Safety at Work Act 1974: Where are we now?, Lancaster University, Environmental Health Officers Association, North West Centre.

Peace, C. (1996). Free from patent defect or patently defective? (MScThesis), University of Aston in Birmingham, Birmingham.

Peace, C. (2013). Advice on the risk estimation matrix used by DAFF Biosecurity as part of the Import Risk Analysis process. Client Report Canberra: Australian Senate Rural and Regional Affairs and Transport Committee. Retrieved from http://www.riskmgmt.co.nz/images/general/RML 2013 CR0127 ASRRATC matrix f inal.pdf

Peace, C. (2017a). Are you sure? Lexicological difficulties arising from risk terminology. Risk in an Interconnected World, Melbourne, Society for Risk Analysis. Retrieved from http://www.sraanzconference.org.nzl

Peace, C. (2017b). The reasonably practicable test and work health and safety-related risk assessments New Zealand Journal of Employment Relations, 42(2), 61-78.

Peace, C. (2017c). The risk matrix: uncertain results? Policy and Practice in Health and Safety, 15(2), 131-144.

Peace, C. (2017d). Understanding and assessing risk. Course Handbook. Risk Management Ltd. Wellington.

Peace, C., \& Mabin, V. (2019). Risk techniques identification key. Risk and Decision Making conference, Wellington, Society for Risk Analysis.

Peace, C., Mabin, V., \& Cordery, C. (2017). Due diligence: a panacea for health and safety risk governance? Policy and Practice in Health and Safety, 15(1), 19-37.

Peirce, C. S. (1931). Collected papers of Charles Sanders Peirce Cambridge: Harvard University Press.

Pellow, A., \& Wilson, T. (1993). The management information requirements of heads of university departments: a critical success factors approach. Journal of Information Science, 19, 425-437.

Perrin, L., Gabas, N., Corriou, J.-P., \& Laurent, A. (2018). Promoting safety teaching: An essential requirement for the chemical engineering education in the French universities. Journal of Loss Prevention in the Process Industries, 54, 190-195.

Perrow, C. (1999). Normal Accidents: living with high-risk technologies. Princeton, NJ: Princeton University Press.

Peters, T., \& Waterman, R. (1982). In Search of Excellence: lessons from America's bestrun companies. New York: Harper \& Row. 
Petersen, K. (2017). Visualizing Risk: Drawing Together and Pushing Apart with Sociotechnical Practices. Journal of Contingencies and Crisis Management, 25(1), 39-50.

Petty, R., \& Cacioppo, J. (1986). The elaboration likelihood model of persuasion. Advances in Experimental Social Psychology, 18, 123-205.

Pharo, H. (2002). Acceptable biosecurity risk in New Zealand. (Master of Public PolicyThesis), Victoria University of Wellington, Wellington.

Pharo, H. (2004). Acceptable Risk in Animal Biosecurity Import Risk Analysis - the limits of rationalism. Public Sector, 27(3), 8-14.

Pinto, A., Ribeiro, R. A., \& Nunes, I. L. (2013). Ensuring the Quality of Occupational Safety Risk Assessment. Risk Analysis, 33(3), 409-419.

PMI. (2013). A Guide to the Project Management Body of Knowledge (5th ed.). Pennsylvania: Project Management Institute.

Popper, K. (1959). The logic of scientific discovery. London: Routledge.

Powell, F. (2010). Urban earthquake events and businesses: Learning from the 2007 Gisborne earthquake in New Zealand. Australian Journal of Emergency Management, 25(3), 54-59.

Powell, F., \& Harding, A. (2009). Business recovery and the rebuilding of commercial property. Dravitzki, V. (Ed.), Shaken Up: proceedings of a workshop on recovery following the Gisborne earthquake, pp 38-59 Wellington, Opus International Consultants Limited.

Power, W. (2013). Review of Tsunami Hazard in New Zealand. Consultancy Report Avalon: GNS Science. Retrieved from http://www.civildefence.govt.nzl

Pretty, D. (2011). The Price/Earnings Ratio: new perspectives for achieving bottom-line stability. White Paper Johnston, RI: FM Global. Retrieved from www.fmglobal.com

Proctor, A. (2009). Creative problem solving for managers (3rd ed.). Abingdon: Routledge.

Purdy, G. (2010). ISO 31000:2009—Setting a New Standard for Risk Management. Risk Analysis, 30(6), 881-886.

Quail, R. (2010). How to plan and run a risk management workshop. In Fraser, J. \& Simkins, B. (Eds.), Enterprise Risk Management - Today's Leading Research and Best Practices for Tomorrow's Executives (pp. 155-170). New Jersey: Wiley.

Rae, A., \& Alexander, R. (2017). Forecasts or fortune-telling: When are expert judgements of safety risk valid? Safety Science, 99, 156-165.

Rafele, C., Hillson, D., \& Grimaldi, S. (2004). Understanding Project Risk Exposure Using the Two-Dimensional Risk Breakdown Matrix. PMI Global Congress, Edinburgh, Project Management Institute. Retrieved from http://www.risk-doctor.com/index.asp

Rahman, S.-u. (1998). Theory of constraints. International Journal of Operations \& Production Management, 18(4), 336-355.

Rasmussen, J. (1982). Human reliability in risk analysis. In Green, A. (Ed.), High Risk Safety Technology (pp. 143-170). Chichester: John Wiley \& Sons.

Rasmussen, J., \& Jensen, A. (1974). Mental procedures in real life tasks: A case study of electronic trouble shooting. Ergonomics, 17(3), 293-307.

Raspotnig, C., \& Opdahl, A. (2013). Comparing risk identification techniques for safety and security requirements. Journal of Systems and Software, 86(4), 1124-1151.

Raz, T., \& Hillson, D. (2005). A Comparative Review of Risk Management Standards. Risk Management: an international journal, 7(4), 53-66.

Raz, T., \& Michael, E. (2001). Use and benefits of tools for project risk management. International Journal of Project Management, 19(1), 9-17.

Reason, J. (1990). Human Error. Aldershot: Cambridge University Press.

Reason, J. (1998). Achieving a safe culture: Theory and practice. Work \& Stress, 12(3), 293306.

Recker, J., Rosemann, M., Indulska, M., \& Green, P. (2009). Business Process Modeling- A Comparative Analysis. Journal of the Association for Information Systems, 10(4), 333-363. 
Regan, H. M., Colyvan, M., \& Burgman, M. A. (2002). A taxonomy and treatment of uncertainty for ecology and conservation biology. Ecological Applications, 12(2), 618628.

Renn, O. (2008a). Risk governance: coping with uncertainty in a complex world. London: Earthscan Publications Ltd.

Renn, O. (2008b). White Paper on Risk Governance: Toward an Integrative Framework: Global Risk Governance. In Renn, O. \& Walker, K. D. (Eds.), (Vol. 1, pp. 3-73): Springer Netherlands.

Rockart, J. F. (1979). Chief executives define their own data needs. Harvard Business Review, 57(2), 81-93.

Rockett, J. P. (1999). Definitions Are Not What They Seem. Risk Management: an international journal, 1(3), 37-47.

Rogers, P. (2011). Development of Resilient Australia: Enhancing the PPRR Approach with Anticipation, Assessment and Registration of Risks. Australian Journal of Emergency Management, 26(1), 54-58.

Rojahn, C., \& Scawthorn, C. (2002). Rapid Visual Screening of Buildings for Potential Seismic Hazards: A Handbook. Washington, DC: Federal Emergency Management Agency. Retrieved from https://www.fema.gov/media-library/assets/documents/15212

Royal Commission on the Pike River Coal Mine Tragedy, (2012) Vol. 2 Wellington, retrieved from www.pikeriver.royalcommission.govt.nz.

Russell, J. P. (2008). Conducting a Document Review: Compare management system records to requirements. Quality Progress, 41(12), 64-67.

Russo, E., Schoemaker, P., \& Hittleman, M. (2002). Winning decisions: getting it right the first time. New York: Doubleday.

SA HB 89:2012. Risk management - Guidelines on risk assessment techniques. Sydney: Standards Australia.

SA/IIA HB 158:2010. Delivering assurance based on AS/NZS ISO31000: 2009. Sydney: Standards Australia.

SA/SNZ4801:2001. Occupational Health and Safety Management Systems - specification with guidance for use. Wellington: Standards New Zealand.

SAS Institute Inc. (2012). The Art of Balancing Risk and Reward: The role of the board in setting, implementing and monitoring risk appetite. Working Paper: Author. Retrieved from www.sas.com/

Saunders, M., Lewis, P., \& Thornhill, A. (2007). Research Methods for Business Students (4th ed.). Harlow: Pearson Education Ltd.

Schachter, E. N., Zuskin, E., Pucarin-Cvetkovic, J., et al. (2011). Response to Oyster Mushroom (Pleurotus ostreatus) Extract by Sensitized and Nonsensitized Guinea Pig Trachea. Lung, 189(4), 305-310.

Scheinkopf, L. (1999). Thinking for a change: Putting the TOC Thinking Processes to Use. Boca Raton, FL: CRC Press.

Schleyer, G., Duan, R. F., Stacey, N., \& Julian Williamson. (2005). Risk Education in Engineering: The development of a new syllabus. Research Report HSL/2005/22 for Health and Safety Executive; Sudbury: HSE Books. Retrieved from http://www.hse.gov.uk/research/rrhtm/index.htm

Schmeer, K. (2001). Stakeholder analysis guidelines. Amsterdam: Ministry of Health. Retrieved from http://www.eestum.eu/

Schnietz, K. E., \& Epstein, M. J. (2005). Exploring the Financial Value of a Reputation for Corporate Social Responsibility During a Crisis. Corporate Reputation Review, 7(4), 327-345.

Schrader, G., MacLeod, A., Mittinty, M., et al. (2010). Enhancements of pest risk analysis techniques. EPPO Bulletin, 40(1), 107-120.

Schwartz, M., Dunfee, T., \& Kline, M. (2005). Tone at the Top: An Ethics Code for Directors? Journal of Business Ethics, 58(1-3), 79-100.

Schwartz, P. (1996). The Art of the Long View. New York: Doubleday. 
Scientific Steering Committee. (2000). Harmonisation of Risk Assessment Procedures. Advisory Paper First Report for European Commission; Brussels: European Commission. Retrieved from http://www.bfr.bund.de/cm/343/first report on the harmonisation of risk assessme nt procedures.pdf

Senti, G., Leser, C., Lundberg, M., \& Wüthrich, B. (2000). Allergic asthma to shiitake and oyster mushroom. Allergy, 55(10), 975-976.

Seville, E., Hawker, C., \& Lyttle, J. (2011). Shaken but not Stirred: A University's Resilience in the Face of Adversity, The 4th September 2010 Earthquake. Report Christchurch: University of Canterbury. Retrieved from https://ir.canterbury.ac.nz/xmlui/bitstream/handle/10092/9497/12646661 shakenbutn otstirred.pdf?sequence $=1 \&$ isAllowed $=y$

Seville, E., Hawker, C., \& Lyttle, J. (2012). Resilience Tested: $A$ year and a half of ten thousand aftershocks. Report Christchurch: University of Canterbury. Retrieved from http://www.canterbury.ac.nz/emergency/documents/resiliencetested.pdf

Shanks, D., \& Meares, J. (2013). Pike River Tragedy. Investigation Report Wellington: Ministry of Business, Innovation and Employment. Retrieved from http://www.mbie.govt.nz/

Sharpe, M., \& Watt, E. (2007, 22 December). The $\$ 30$ million shockwave, Dominion Post.

Shulruf, B., \& Balemi, A. (2010). Risk and preventive factors for fatalities in all-terrain vehicle accidents in New Zealand. Accident Analysis \& Prevention, 42(2), 612-618.

Sikich, G. (2003). Integrated Business Continuity: Maintaining Resilience in Uncertain Times. Tulsa: PenWell Corporation.

Simon, H. A. (1976). Administrative behaviour (2nd ed.). New York: Free Press.

Simon, H. A. (1979). Rational Decision Making in Business Organization. American Economic Review, 69(4), 493-513.

Simpson, B. (2009). Pragmatism, Mead and the Practice Turn. Organization Studies, 30(12), 1329-1347.

Sitkin, S. B., \& Pablo, A. L. (1992). Reconceptualizing the Determinants of Risk Behavior. Academy of Management Review, 17(1), 9-38.

Slovic, P. (1987). Perception of risk. Science, 236(4799), 280-285.

Slovic, P. (1999). Trust, Emotion, Sex, Politics, and Science: Surveying the RiskAssessment Battlefield. Risk Analysis, 19(4), 689-701.

Slovic, P., Fischhoff, B., \& Lichtenstein, S. (2000). Rating the risks. In Slovic, P. (Ed.), The Perception of Risk (pp. 104-120). London: Earthscan Publications Ltd.

Smallman, C. (1996). Challenging the orthodoxy in risk management. Safety Science, 22(13), 245-262.

Smallman, C. (2006). In search of relevance: conventional or critical management inquiry? Management Decision, 44(6), 771-782.

Smith, D. (2011). Reliability, maintainability and risk (8th ed.). Oxford: ButterworthHeinemann.

SRA. (2015). Glossary. Retrieved from http://www.sra.org/resources.

Stagg, S., Bowry, A., Kelsey, A., \& Crook, B. (2010). Bioaerosol emissions from waste composting and the potential for workers' exposure. Research Report RR 786 for Health and Safety Executive; Sudbury: HSE Books. Retrieved from http://www.hse.gov.uk/research/rrhtm/index.htm

Stevenson, J., Kachali, H., Whitman, Z., et al. (2011). Preliminary observations of the impacts of the 22 February Christchurch had on organisations and the economy: report from the field (22 February - 22 March 2011. Bulletin of the New Zealand National Society for Earthquake Engineering, 44(2), 65-76.

Stewart, C. (1974). Mushroom worker's lung - two outbreaks. Thorax, 29, 252-257.

Stewart, M., \& Melchers, R. (1997). Probabilistic risk assessment of engineering systems. New York: Chapman \& Hall.

Stulz, R. M. (2008). Risk Management Failures: What Are They and When Do They Happen? Journal of Applied Corporate Finance, 20(4), 39-48. 
Sue, V., \& Ritter, L. (2012). Conducting online surveys (2nd ed.). Thousand Oaks, CA: Sage Publications.

Suokas, J., \& Rouhiainen, V. (1993). Quality Management of Safety and Risk Analysis. Amsterdam: Elsevier Science Publishing Company, Inc.

Surowiecki, J. (2005). The Wisdom of Crowds. London: Abacus.

Suter, G., Barnthouse, L., Bartell, S., et al. (2007). Ecological risk assessment. Boca Raton, FL: CRC Press.

Sutton, R. (2006). Eight Tips for Better Brainstorming. BusinessWeek Online, 24-24.

Swallom, D., Lindberg, R., \& Smith-Jackson, T. (2003). System Safety Principles and Methods Handbook of Human Systems Integration (pp. 497-540). Hoboken, NJ: John Wiley \& Sons.

Swan, J., Kelsey, A., Crook, B., \& Gilbert, E. (2003). Occupational and environmental exposure to bioaerosols from composts and potential health effects - A critical review of published data. Research Report RR 130 Sudbury: HSE Books. Retrieved from http://www.hse.gov.uk/research/rrhtm/rr130.htm

Swann, C. D., \& Preston, M. L. (1995). Twenty-five years of HAZOPs. Journal of Loss Prevention in the Process Industries, 8(6), 349-353.

Sylvan, D. A., \& Thorson, S. J. (1980). Choosing appropriate techniques for socio-political forecasting. Policy Sciences, 12(3), 265-282.

Tanaka, H., Saikai, T., Sugawara, H., et al. (2002). Workplace-related chronic cough on a mushroom farm. Chest, 122(3), 1080-1085.

Targoutzidis, A. (2010). Incorporating human factors into a simplified "bow-tie" approach for workplace risk assessment. Safety Science, 48(2), 145-156.

Tashakkori, A., \& Teddlie, C. (1998). Mixed methodology: Combining qualitative and quantitative approaches. Thousand Oaks, Ca: Sage Publications.

Tattam, D., \& Esteban, A. (2013, April). Risk velocity - the third dimension of risk? Keeping Good Companies, 65(3), pp. 146-149

Taylor, J., \& Van Every, E. (2000). The emergent organization: communication as its site and surface. New York: Taylor \& Francis.

Taylor, R. (2015). Teaching health and safety in undergraduate engineering courses. Leicester: Institution of Occupational Safety and Health,. Retrieved from www.iosh.co.uk/freeguides

Teddlie, C., \& Tashakkori, A. (2012). Common "Core" Characteristics of Mixed Methods Research: A Review of Critical Issues and Call for Greater Convergence. American Behavioral Scientist, 56(6), 774-788.

Tetlock, P. (2006). Expert political judgment: how good is it? How can we know? Princeton, $\mathrm{NJ}$ : Princeton University Press.

Tetlock, P., \& Gardner, D. (2015). Superforecasting: The art and science of forecasting: Random House.

Thaler, R., \& Sunstein, C. (2008). Nudge: Improving decisions about health, wealth and happiness. New Haven: Yale University Press.

Toffel, M. (2016). Enhancing the Practical Relevance of Research. Production and Operations Management, 25(9), 1493-1505.

Toman, M. (2014). The need for multiple types of information to inform climate change assessment. Working Paper WPS7094 Washington, DC: World Bank. Retrieved from http://www-wds.worldbank.org/

Trainor, M., Wright, S., O'Hara, R., \& Dickety, N. (2002). Risk Assessment: The Extent of Adoption by Industry. Research Report RAS/02/12 for Health and Safety Executive; Sudbury: Health and Safety Laboratory.

Transport and Industrial Relations Committee. (2015). Health and Safety Reform Bill. Wellington: NZ House of Representatives. Retrieved from http://www.parliament.nz/

Trbojevic, V. (2008). Optimising hazard management by workforce engagement and supervision. Research Report RR 637 for Health and Safety Executive; Sudbury: HSE Books. Retrieved from http://http://www.hse.gov.uk/research/rrhtm/index.htmrrhtm/ 
Trimpop, R. (1994). The Psychology of Risk-Taking Behaviour. Amsterdam: Elsevier Science Bv.

Turner, B., \& Pidgeon, N. (1997). Man-made disasters (2nd ed.). Oxford: ButterworthHeinemann.

Turney, R., \& Pitblado, R. (1996). Risk assessment in the process industries (2nd ed.). Rugby: Institution of Chemical Engineers.

Van de Ven, A. H., \& Johnson, P. E. (2006). Knowledge for theory and practice. Academy of Management Review, 31(4), 802.

Van Eerd, D. (2019). Knowledge transfer and exchange in health and safety: a rapid review. Policy and Practice in Health and Safety, 17(1), 54-77.

Van Eerd, D., Cardoso, S., Irvin, E., et al. (2017). Occupational safety and health knowledge users' perspectives about research use. Policy and Practice in Health and Safety, 419.

van Kampen, V., Hoffmeyer, F., Deckert, A., et al. (2016). Effects of bioaerosol exposure on respiratory health in compost workers: a 13-year follow-up study. Occupational and Environmental Medicine, 73(12), 829.

Vandewalle, D., Nerstad, C. G. L., \& Dysvik, A. (2019). Goal Orientation: A Review of the Miles Traveled and the Miles to Go. Annual Review of Organizational Psychology and Organizational Behavior, 6(1), 115-144.

Varga-Atkins, T., \& O'Brien, M. (2009). From drawings to diagrams: maintaining researcher control during graphic elicitation in qualitative interviews. International Journal of Research \& Method in Education, 32(1), 53-67.

Venning J in Martin Simmons Air Conditioning Services Ltd v Department of Labour (2008), High Court, Auckland, CRI 2007-404-249 777;

Vereda, A., Quirce, S., Fernández-Nieto, M., et al. (2007). Occupational asthma due to spores of Pleurotus ostreatus. Allergy, 62(2), 211-212.

Vermeulen, F. (2005). On rigor and relevance: fostering dialectic progress in management research. Academy of Management Journal, 48(6), 978-982.

Voss, C., Tsikriktsis, N., \& Frohlich, M. (2002). Case research in operations management. International Journal of Operations \& Production Management, 22(2), 195-219.

Wachinger, G., Renn, O., Begg, C., \& Kuhlicke, C. (2013). The Risk Perception ParadoxImplications for Governance and Communication of Natural Hazards. Risk Analysis, 33(6), 1049-1065.

Walker, P. L., Shenkir, W. G., \& Barton, T. L. (2003). ERM in practice. Internal Auditor, 60(4), 51.

Warner, F. (Ed.). (1983). Risk Assessment: A Study Group Report. London: The Royal Society.

Warner, F. (Ed.). (1992). Risk: analysis, perception and management. London: The Royal Society.

Waterman, R., Peters, T., \& Phillips, J. (1980). Structure is not Organization. Business Horizons, 23(3), 14-25.

Watson, K. J., Blackstone, J. H., \& Gardiner, S. C. (2007). The evolution of a management philosophy: The theory of constraints. Journal of Operations Management, 25(2), 387-402.

Weed, D. L. (2005). Weight of Evidence: A Review of Concept and Methods. Risk Analysis: An International Journal, 25(6), 1545-1557.

Weick, K. (2016). Constrained Comprehending: The Experience of Organizational Inquiry. Administrative Science Quarterly, 61(3), 333-346.

Weick, K., \& Sutcliffe, K. (2007). Managing the unexpected : resilient performance in an age of uncertainty (2nd ed.). San Francisco: Jossey-Bass.

Weick, K. E., \& Roberts, K. H. (1993). Collective Mind in Organizations: Heedful Interrelating on Flight Decks. Administrative Science Quarterly, 38(3), 357-381.

Wein, L. M. (2009). Homeland Security: From Mathematical Models to Policy Implementation. Operations Research, 57(4), 801-811. 
Weinstein, M., Gambatese, J., \& Hecker, S. (2005). Can Design Improve Construction Safety?: Assessing the Impact of a Collaborative Safety-in-Design Process. Journal of Construction Engineering \& Management, 131(10), 1125-1134.

Wendler, R. (2012). The maturity of maturity model research: A systematic mapping study. Information and Software Technology, 54(12), 1317-1339.

Whyte, J., Sacks, R., Zhou, W., \& Haffegee, A. (2013). Building safely by design: Using digital design models to improve planning for safe construction. Research Report 13.2 for IOSH Research Committee; Leicester: IOSH Publishing Ltd. Retrieved from http://www.iosh.co.uk/designsafely

Wiedemann, P., Boerner, F., Dürrenberger, G., et al. (2013). Supporting non-experts in judging the credibility of risk assessments (CORA). Science of The Total Environment, 463-464, 624-630.

Wikipedia. (2013). Lake Grassmere earthquake. Retrieved 25 January 2017, from https://en.wikipedia.org

Wikipedia. (2017). 2013 Seddon earthquake. Retrieved 25 January 2017, from https://en.wikipedia.org

Williams, J. C. (1985). Validation of human reliability assessment techniques. Reliability Engineering, 11(3), 149-162.

Williams, T. (1995). A classified bibliography of recent research relating to project risk management. European Journal of Operational Research, 85(1), 18-38.

WOAH. (2014). Terrestrial Animal Health Code. International agreement Paris: World Organisation for Animal Health. Retrieved from http://www.oie.int/internationalstandard-setting/terrestrial-code/access-online/

Wood, A., Duijiff, J., \& Christey, G. (2013). Quad bike injuries in Waikato, New Zealand: an institutional review from 2007-2011. ANZ Journal of Surgery, 83, 206-210.

Wood, T. (2003). Formats for fire hazard inspecting, surveying and mapping. In Cote, A., Hall, J., Powell, P. \& Grant, C. (Eds.), Fire Protection Handbook (19th ed.). Quincy, MA: National Fire Protection Association, Inc.

Woods, M. (2009). A contingency theory perspective on the risk management control system within Birmingham City Council. Management Accounting Research, 20(1), 69-81.

Woods, M. (2011). Risk Management in Organizations: An Integrated Case Study Approach. New York: Routledge.

WorkSafe NZ. (2014). Safe use of quad bikes. Guidance Note Wellington: WorkSafe NZ. Retrieved from https://worksafe.govt.nzl

Wynne, B. (1992). Risk and social learning: reification to engagement. In Krimsky, S. \& Golding, D. (Eds.), Social theories of risk. Westport, CT: Praeger.

Xin, Y., Chai, K.-H., Ojanen, V., \& Brombacher, A. (2013). The moderating effects of service solution characteristics on competitive advantage. Service Industries Journal, 33(15/16), 1633-1658.

Yaraghi, N., \& Langhe, R. G. (2011). Critical success factors for risk management systems. Journal of Risk Research, 14(5), 551-581.

Yin, R. (2009). Case study research: design and methods. Los Angeles, CA: Sage Publications Inc.

Zardo, P., \& Pryor, P. (2017). OHS Body of Knowledge: The OHS Professional as a 'Critical Consumer' of Research. Tullamarine, VIC: Safety Institute of Australia Ltd. Retrieved from https://www.ohsbok.org.au/download-the-body-of-knowledge/

Zijp, M., Heijungs, R., van der Voet, E., et al. (2015). An Identification Key for Selecting Methods for Sustainability Assessments. Sustainability, 7(3), 2490-2512.

Zinn, J., \& Taylor-Gooby, P. (2006). Risk as an interdisciplinary research area. In TaylorGooby, P. \& Zinn, J. (Eds.), Risk in Social Science. Oxford: Oxford University Press.

Zotov, D., Wright, A., \& Hunt, L. (2007). Grappling with complexity: Analysing an accident with the theory of constraints. In Anca, J. (Ed.), Multimodal Safety Management and Human Factors: Crossing the Borders of Medical, Aviation, Road and Rail Industries (pp. 83-106). Aldershot: Ashgate Publishing Ltd. 


\section{Additional TOC publications which include Goal Trees/IO Maps}

Mirzaei, M., \& Mabin, V. (2017). Agile project management and public policy development projects: A case study from New Zealand. New Zealand Journal of Applied Business Research, 15(1), 59-75.

Mirzaei, M., \& Mabin, V. (2019). Critical Chain project management: A case study in the Software Industry. International Journal of Management and Applied Science, 5(3), 25-31.

\section{Additional conference papers on TOC which include Goal Trees/IO Maps}

Fogarty, K., \& Mabin, V. (2016). An exploratory study of commerce graduate problemsolving skills in the public sector: the alignment between stakeholders' goals and conceptualisations. Labour, Employment and Work, Wellington, Centre for Labour, Employment and Work.

Kimani, S., Mabin, V., \& Davies, J. (2014, 17-19 November). Understanding the causes of undesirable experiences of teaching in a Business School: The Theory of Constraints-Thinking Processes (TOC-TP) approach, Proceedings of the ICER2014 Conference, $7^{\text {th }}$ International Conference of Education, Research and Innovation Seville, Spain,

Kimani, S., Mabin, V., \& Davies, J. (2014). Exploring the Impact of Undesirable Student and Staff Experiences on the Performance of a Business School in Kenya. International Teaching \& Learning Conference in Higher Education, Singapore

Kimani, S., Mabin, V., \& Davies, J. (2014). Using Theory of Constraints Thinking Processes to explore Business School students learning experiences. Proceedings of the 48th Annual Conference of the ORSNZ, Wellington, Operations Research Society of New Zealand. Retrieved from https://secure.orsnz.org.nz/conf48/index.php

Kimani, S., Mabin, V., \& Davies, J. (2015, 31 March-3 April). Exploring Business School Students' Learning Experiences - A TOC Systems-based Approach, Proceedings of the $44^{\text {th }}$ Annual Meeting of the Western Decision Sciences Institute Ed Bell J, Maui

Kimani, S., Mabin, V., \& Davies, J. (2016, 10-12 June). Application of Theory of ConstraintsThinking Process to Achievement of University Students' Learning Goals. Reorienting the curriculum for sustainability, Proceedings of the $8^{\text {th }}$ Interdisciplinary Session, Adhiambo J.M \& Kang'ethe N.S Eds pp1-20 Nairobi, Kenya, CUEA Press.

Kimani, S., Mabin, V., \& Davies, J. (2016, June). What factors impact negatively on teaching experiences of university lecturers and what are their root causes?, Proceedings of the $9^{\text {th }}$ Interdisciplinary Session, Nairobi, Kenya; CUEA.

Mabin, V. (2009, December). Eating the Elephant! Applying Theory of Constraints in Assurance of Learning, Proceedings of the $44^{\text {th }}$ Annual Conference of the ORSNZ, pp282-291, Christchurch, Operational Research Society of New Zealand.

Mabin, V. (2010, 20-23 November). Eating the Elephant! Using the Theory of Constraints for Assurance of Learning, Proceedings of the $41^{\text {st }}$ Annual Meeting of the Decision Sciences Institute, Ed Sriram Narayanam, San Diego, Decision Sciences Institute.

Mabin, V. (2014, 17-19 November). Using systems thinking tools to guide the establishment of an Assurance of Learning system, Proceedings of the ICER2014 Conference, $7^{\text {th }}$ International Conference of Education, Research and Innovation, Seville, Spain

Mirzaei, M., \& Mabin, V. (2013). PhD project in light of project Management. Proceedings of $47^{\text {th }}$ Annual Conference of the ORSNZ, Hamilton, Retrieved from https://secure.orsnz.org.nz/conf47/program/Papers/nzsaorsnz2013 submission 81.pdf 
Mirzaei, M., \& Mabin, V. (2014). Exploring constraints in projects: A construction case study. Proceedings of the $48^{\text {th }}$ Annual Conference of the ORSNZ, Wellington, ORSNZ. Retrieved from https://secure.orsnz.org.nz/conf48/program/Papers/nzsaorsnz2014 paper 24.pdf

Mirzaei, M., \& Mabin, V. (2015, 24-26 November). Practicalities of using Scrum for policy projects, Proceedings of the $48^{\text {th }}$ Annual Conference of the ORSNZ Wellington, ORSNZ

Mirzaei, M., \& Mabin, V. (2018). Critical Chain project management: A case study in the Software Industry. 156th International Conference on Science Technology and Management, Auckland, International Association for Science, Technology and Management.

Pongsart, G. (2009, December). Improving research students' performance by two contrasting methodologies: Theory of Constraints (TOC) and Appreciative Inquiry (AI) Proceedings of the $44^{\text {th }}$ Annual Conference of the ORSNZ, pp246-255, Christchurch, ORSNZ. 


\section{Appendix A. NVivo codes based on goal tree CSF and NC}

Critical success factors and necessary conditions in the tentative goal tree (section 3.2) were used to develop the NVivo nodes in Table 63. "Good practice and pitfalls" criteria (Gadd et al, 2003, p. 41) were classified and placed in the table together with criteria from the credibility of risk assessment framework (Wiedemann et al, 2013) and the risk management process (ISO31000, 2009). NVivo was used to analyse documents and interview transcripts from the case studies.

\section{Notes to the table:}

$\mathrm{CSF}=$ critical success factor

$\mathrm{NC}=$ necessary condition

ISO = ISO31000 (2009) risk management paragraph number

CORA = credibility of risk assessment (Wiedemann et al, 2013)

GPP $=$ good practice and pitfalls (Gadd et al, 2003)

Table 63. NVivo nodes

\begin{tabular}{|c|c|c|c|}
\hline $\begin{array}{l}\text { Model } \\
\text { reference } \\
\text { number }\end{array}$ & Parent nodes & Child nodes & Detail \\
\hline 01 & $\begin{array}{l}\text { Effective risk } \\
\text { assessment }\end{array}$ & & \\
\hline CSF 01 & $\begin{array}{l}\text { Risk assessment } \\
\text { appropriately } \\
\text { communicated to } \\
\text { decision makers }\end{array}$ & & \\
\hline CORA 6.1 & & $\begin{array}{l}\text { Conclusions } \\
\text { contain two-sided } \\
\text { argument }\end{array}$ & $\begin{array}{l}\text { The report provides a balanced } \\
\text { discussion of the pros and cons for the } \\
\text { conclusions; the strengths and } \\
\text { weaknesses of the available evidence are } \\
\text { indicated }\end{array}$ \\
\hline CORA 6.2 & & $\begin{array}{l}\text { Evidence-based } \\
\text { conclusions }\end{array}$ & $\begin{array}{l}\text { The conclusions are explicitly linked to the } \\
\text { evidence discussed in the body of the } \\
\text { report }\end{array}$ \\
\hline CORA 6.3 & & $\begin{array}{l}\text { Uncertainty } \\
\text { reporting }\end{array}$ & $\begin{array}{l}\text { Information is available about any } \\
\text { uncertainties in the conclusions or } \\
\text { assumptions made }\end{array}$ \\
\hline CORA 6.4 & & $\begin{array}{l}\text { There is a plain } \\
\text { language } \\
\text { summary }\end{array}$ & \\
\hline GPP 1.1 & & $\begin{array}{l}\text { Assessment } \\
\text { details recorded }\end{array}$ & $\begin{array}{l}\text { Assessment process details are recorded } \\
\text { in a clear, auditable way }\end{array}$ \\
\hline GPP 1.2 & & $\begin{array}{l}\text { Any uncertainties } \\
\text { or assumptions } \\
\text { are clearly stated }\end{array}$ & $\begin{array}{l}\text { Key uncertainties and assumptions are } \\
\text { identified and taken into account }\end{array}$ \\
\hline GPP 1.3 & & $\begin{array}{l}\text { Assessment } \\
\text { date(s) recorded }\end{array}$ & The date(s) of the assessment is recorded \\
\hline
\end{tabular}




\begin{tabular}{|c|c|c|c|}
\hline $\begin{array}{l}\text { Model } \\
\text { reference } \\
\text { number }\end{array}$ & Parent nodes & Child nodes & Detail \\
\hline GPP 5.3 & & $\begin{array}{l}\text { Report strengths } \\
\text { and limitations }\end{array}$ & $\begin{array}{l}\text { Strengths and limitations of different } \\
\text { measures are explained }\end{array}$ \\
\hline CSF 02 & $\begin{array}{l}\text { All relevant factors are } \\
\text { reported }\end{array}$ & & \\
\hline CORA 4.1 & & $\begin{array}{l}\text { Assessment } \\
\text { process has } \\
\text { conceptual clarity }\end{array}$ & The report has a sound conceptual base \\
\hline CORA 4.3 & & $\begin{array}{l}\text { Method of quality } \\
\text { assurance is clear }\end{array}$ & $\begin{array}{l}\text { The report states procedures used to } \\
\text { assure the quality of the assessment }\end{array}$ \\
\hline CORA 4.4 & & $\begin{array}{l}\text { Procedure for } \\
\text { weighing } \\
\text { evidence is clear }\end{array}$ & $\begin{array}{l}\text { The process of weighing the various input } \\
\text { studies is explained as well as how they } \\
\text { are combined leading to the conclusions }\end{array}$ \\
\hline ISO 5.3.2 & & $\begin{array}{l}\text { The external } \\
\text { context is } \\
\text { understood }\end{array}$ & $\begin{array}{l}\text { The external business environment is } \\
\text { correctly described and understood }\end{array}$ \\
\hline ISO 5.3.3 & & $\begin{array}{l}\text { The internal } \\
\text { context is } \\
\text { understood }\end{array}$ & $\begin{array}{l}\text { The internal business environment is } \\
\text { correctly described and understood }\end{array}$ \\
\hline ISO 5.5 .2 & & $\begin{array}{l}\text { Treatment options } \\
\text { identified for } \\
\text { unacceptable } \\
\text { risks }\end{array}$ & $\begin{array}{l}\text { Treatment options identified consider } \\
\text { costs, benefits and contextual factors }\end{array}$ \\
\hline ISO 5.5 .3 & & $\begin{array}{l}\text { Treatment plans } \\
\text { are prepared for } \\
\text { unacceptable } \\
\text { risks }\end{array}$ & Plans document treatment implementation \\
\hline NC 13 & $\begin{array}{l}\text { Appropriate language, } \\
\text { graphics \& layout used }\end{array}$ & & \\
\hline NC 12 & $\begin{array}{l}\text { Systematic hazard or } \\
\text { risk identification }\end{array}$ & & \\
\hline ISO 5.4 .2 & & $\begin{array}{l}\text { Comprehensive } \\
\text { list of risks } \\
\text { identified }\end{array}$ & $\begin{array}{l}\text { Appropriate techniques are used to } \\
\text { identify risks that could affect the } \\
\text { achievement of objectives }\end{array}$ \\
\hline GPP 3.1 & & $\begin{array}{l}\text { Systematic } \\
\text { hazard or risk } \\
\text { identification }\end{array}$ & $\begin{array}{l}\text { Identification techniques are named, } \\
\text { relevant and appropriately used }\end{array}$ \\
\hline NC 11 & $\begin{array}{l}\text { Appropriate risk } \\
\text { analysis techniques } \\
\text { used }\end{array}$ & & \\
\hline GPP 3.4 & & $\begin{array}{l}\text { Relevant data } \\
\text { used }\end{array}$ & Data used is fit for purpose \\
\hline GPP 3.5 & & $\begin{array}{l}\text { Historical or } \\
\text { predictive data }\end{array}$ & $\begin{array}{l}\text { Any historical or predictive data is justified } \\
\text { and acceptable }\end{array}$ \\
\hline GPP 4.1 & & $\begin{array}{l}\text { Consequence } \\
\text { techniques used }\end{array}$ & Consequence techniques used are stated \\
\hline
\end{tabular}




\begin{tabular}{|c|c|c|c|}
\hline $\begin{array}{l}\text { Model } \\
\text { reference } \\
\text { number }\end{array}$ & Parent nodes & Child nodes & Detail \\
\hline GPP 4.2 & & $\begin{array}{l}\text { Estimation } \\
\text { techniques used } \\
\text { are stated }\end{array}$ & \\
\hline GPP 5.1 & & $\begin{array}{l}\text { Models used are } \\
\text { justified and fit for } \\
\text { purpose }\end{array}$ & \\
\hline GPP 6.1 & & $\begin{array}{l}\text { Job-related } \\
\text { human factors } \\
\text { included }\end{array}$ & \\
\hline GPP 6.2 & & $\begin{array}{l}\text { Individual-related } \\
\text { human factors } \\
\text { included }\end{array}$ & \\
\hline GPP 6.3 & & $\begin{array}{l}\text { Organisation- } \\
\text { related human } \\
\text { factors included }\end{array}$ & \\
\hline ISO 5.4 .3 & & $\begin{array}{l}\text { The risks are } \\
\text { understood }\end{array}$ & $\begin{array}{l}\text { Appropriate risk analysis techniques are } \\
\text { used to help understand and evaluate } \\
\text { risks }\end{array}$ \\
\hline NC 10 & $\begin{array}{l}\text { Appropriate risk } \\
\text { evaluation techniques } \\
\text { used }\end{array}$ & & \\
\hline ISO 5.4 .4 & & $\begin{array}{l}\text { Risks were } \\
\text { evaluated against } \\
\text { risk criteria }\end{array}$ & $\begin{array}{l}\text { Risk acceptance decisions take account } \\
\text { of the nature and level of risk found in risk } \\
\text { analysis and the risk criteria }\end{array}$ \\
\hline GPP 5.2 & & $\begin{array}{l}\text { Risk estimates } \\
\text { are expressed in } \\
\text { understandable } \\
\text { terms }\end{array}$ & \\
\hline NC 07 & $\begin{array}{l}\text { Competent and } \\
\text { impartial risk assessor } \\
\text { or team leader }\end{array}$ & & \\
\hline GPP 1.4 & & $\begin{array}{l}\text { Assessment } \\
\text { participants } \\
\text { named }\end{array}$ & $\begin{array}{l}\text { Names, affiliations, job titles of } \\
\text { assessment participants are recorded }\end{array}$ \\
\hline CORA 2.1 & & $\begin{array}{l}\text { Mandate and } \\
\text { accountability }\end{array}$ & $\begin{array}{l}\text { The report includes information on the } \\
\text { mandate and accountability of the } \\
\text { assessment group }\end{array}$ \\
\hline CORA 3.1 & & $\begin{array}{l}\text { Criteria for } \\
\text { selecting experts } \\
\text { stated }\end{array}$ & $\begin{array}{l}\text { The criteria upon which the selection of } \\
\text { the experts was based are disclosed }\end{array}$ \\
\hline CORA 3.2 & & $\begin{array}{l}\text { Composition of } \\
\text { the expert group } \\
\text { stated }\end{array}$ & $\begin{array}{l}\text { The composition of the expert group is } \\
\text { explained, the kind of experts included } \\
\text { identified and the spectrum of required } \\
\text { expertise covered }\end{array}$ \\
\hline CORA 3.3 & & $\begin{array}{l}\text { Assurance of } \\
\text { impartiality }\end{array}$ & $\begin{array}{l}\text { The procedures applied to ensure an } \\
\text { impartial view (ie, free of vested interests) } \\
\text { is described }\end{array}$ \\
\hline NC 08 & Risk is correctly framed & & \\
\hline
\end{tabular}




\begin{tabular}{|c|c|c|c|}
\hline $\begin{array}{l}\text { Model } \\
\text { reference } \\
\text { number }\end{array}$ & Parent nodes & Child nodes & Detail \\
\hline NC 07 & $\begin{array}{l}\text { Criteria for risk } \\
\text { assessment set }\end{array}$ & & \\
\hline ISO 5.3.5 & & $\begin{array}{l}\text { Risk criteria for } \\
\text { risk evaluation are } \\
\text { set }\end{array}$ & $\begin{array}{l}\text { Risk criteria reflect the values, objectives } \\
\text { and resources of the organisation and its } \\
\text { context }\end{array}$ \\
\hline NC 08 & $\begin{array}{l}\text { Relevant qualifications } \\
\text { and experience of } \\
\text { assessors stated }\end{array}$ & & \\
\hline CORA 1.1 & & Authorship stated & $\begin{array}{l}\text { The report discloses the names and } \\
\text { affiliations of the experts who conducted } \\
\text { the assessment }\end{array}$ \\
\hline GPP 3.2 & & $\begin{array}{l}\text { QRA assessors } \\
\text { competence }\end{array}$ & $\begin{array}{l}\text { If a QRA was carried out the qualifications } \\
\text { and experience of assessors is stated }\end{array}$ \\
\hline NC 04 & $\begin{array}{l}\text { Impartiality in funding } \\
\text { and mandate }\end{array}$ & & \\
\hline CORA 2.2 & & Funding stated & $\begin{array}{l}\text { Information is available about the funding } \\
\text { of the assessment group }\end{array}$ \\
\hline NC 10 & $\begin{array}{l}\text { Stakeholders and risk } \\
\text { assessors have a } \\
\text { shared understanding of } \\
\text { risk }\end{array}$ & & \\
\hline NC 11 & $\begin{array}{l}\text { Appropriate } \\
\text { engagement with } \\
\text { stakeholders }\end{array}$ & & \\
\hline ISO 5.2 & & $\begin{array}{l}\text { Communication } \\
\text { and consultation } \\
\text { take place during } \\
\text { all stages }\end{array}$ & $\begin{array}{l}\text { Stakeholders are identified and plans } \\
\text { made and implemented to ensure their } \\
\text { "voice" is heard at all stages of the risk } \\
\text { assessment }\end{array}$ \\
\hline CORA 4.5 & & $\begin{array}{l}\text { Consensus } \\
\text { finding procedure }\end{array}$ & $\begin{array}{l}\text { Information is available about the } \\
\text { procedure for finding consensus among } \\
\text { the experts }\end{array}$ \\
\hline CORA 5.1 & $\begin{array}{l}\text { Discourse and conflict } \\
\text { resolution }\end{array}$ & $\begin{array}{l}\text { Public } \\
\text { consultation and } \\
\text { stakeholder } \\
\text { participation }\end{array}$ & $\begin{array}{l}\text { Stakeholders are identified and plans } \\
\text { made and implemented to ensure their } \\
\text { "voice" is heard at all stages of the risk } \\
\text { assessment }\end{array}$ \\
\hline CORA 5.2 & & $\begin{array}{l}\text { Special } \\
\text { procedures for } \\
\text { addressing } \\
\text { controversies }\end{array}$ & $\begin{array}{l}\text { Information about a special procedure that } \\
\text { addresses scientific or technical } \\
\text { controversies is available }\end{array}$ \\
\hline NC 12 & $\begin{array}{l}\text { Literature or document } \\
\text { review fairly sets out } \\
\text { data }\end{array}$ & & \\
\hline CORA 4.2 & & $\begin{array}{l}\text { Method of } \\
\text { literature search }\end{array}$ & $\begin{array}{l}\text { The literature search/document review is } \\
\text { described and demonstrably unbiased }\end{array}$ \\
\hline GPP 3.3 & & $\begin{array}{l}\text { Data sources } \\
\text { documented }\end{array}$ & $\begin{array}{l}\text { Sources of data are documented and } \\
\text { traceable }\end{array}$ \\
\hline
\end{tabular}




\begin{tabular}{|l|l|l|l|}
\hline $\begin{array}{c}\text { Model } \\
\text { reference } \\
\text { number }\end{array}$ & \multicolumn{1}{|c|}{ Parent nodes } & \multicolumn{1}{|c|}{ Child nodes } & \multicolumn{1}{|c|}{ Detail } \\
\hline NC 13 & $\begin{array}{l}\text { Terms of reference for } \\
\text { risk assessment are } \\
\text { clear }\end{array}$ & & \\
\hline ISO 5.3.4 & & $\begin{array}{l}\text { Objectives of the } \\
\text { risk assessment } \\
\text { are set }\end{array}$ & $\begin{array}{l}\text { Scope or other parameters for the risk } \\
\text { assessment are set and adhered to }\end{array}$ \\
\hline CORA 1.2 & $\begin{array}{l}\text { Objectives and } \\
\text { scope }\end{array}$ & $\begin{array}{l}\text { Scope or other parameters for the risk } \\
\text { assessment are set and adhered to }\end{array}$ \\
\hline GPP 2.1 & Accountability & $\begin{array}{l}\text { Terms of } \\
\text { reference stated }\end{array}$ & $\begin{array}{l}\text { Terms of reference, scope, boundaries } \\
\text { and objectives are stated }\end{array}$ \\
\hline
\end{tabular}

Source: adapted from the tentative goal tree (section 3.2) 


\section{Appendix B. Human Ethics Committee Approvals}

\section{B.1 Online survey}

From: researchmaster-help@vuw.ac.nz

Subject: Human Ethics application approved

Date: 6 May 2014 at 6:14 PM

To: chris.peace@riskmgmt.co.nz

Cc: Vicky.Mabin@vuw.ac.nz

Dear Christopher Peace,

Thank you for your application for ethical approval (The effectiveness of risk assessments in informing decision makers: practice and perceptions, reference 0000020644 ), which has now been considered by the Standing Committee of the Human Ethics Committee.

Your application is approved as of today. You will receive an approval memo in the near future.

You may wish to check whether there are any new comments on your application. To do this, click on the Comments button (it looks like a speech bubble). If any particular page has comments, they will be marked with a flag on the left hand side of the screen. To access them, navigate to the desired page, and then click on the Page Comments button (it looks like a speech bubble with a page behind it).

Best wishes with the research

Human Ethics Committee

\section{B.2 Case studies}

From: ResearchMaster Help ResearchMaster-Help@vuw.ac.nz

Subject: Human Ethics Approved (Pipitea Subcommittee). Automated Email, Do Not Reply.

Date: 21 September 2015 at 6:00 PM

To: Vicky Mabin vicky.mabin@vuw.ac.nz, Carolyn Cordery carolyn.cordery@vuw.ac.nz, chris.peace@riskmgmt.co.nz

Cc: Maggie Teleki maggie.teleki@vuw.ac.nz

Dear Christopher Peace,

Thank you for your application for ethical approval (The effectiveness of risk assessments in informing decision makers, reference 0000022338 ), which has now been considered by the Pipitea Sub-Committee of the Human Ethics Committee.

Your application is approved as of today.

You may wish to check whether there are any new comments on your application. To do this, click on the Comments button (it looks like a speech bubble). If any particular page has comments, they will be marked with a flag on the left hand side of the screen. To access them, navigate to the desired page, and then click on the Page Comments button (it looks like a speech screen. To access them, navigat
bubble with a page behind it).

Best wishes with the research.

Pipitea Human Ethics Sub-Committee

*****This is an automated email. Do not reply to this email address $\mathrm{s}^{* \star * * * *}$

Pipitea Ethics subcommittee queries can be sent to: pipitea-hec@vuw.ac.nz

\section{B.3 Risk canvas}

From: ResearchMaster Help ResearchMaster-Help@vuw.ac.nz

Subject: Human Ethics Approved (Pipitea Subcommittee). Automated Email, Do Not Reply.

Date: 16 June 2016 at 5:35 PM

To: Vicky Mabin vicky.mabin@vuw.ac.nz, Carolyn Cordery carolyn.cordery@vuw.ac.nz, chris.peace@riskmgmt.co.nz

Cc: Maggie Teleki maggie.teleki@vuw.ac.nz

Dear Christopher Peace

Thank you for your application for ethical approval (The effectiveness of risk assessments using the "risk canvas", reference 0000023249 ), which has now been considered by the Pipitea Sub-Committee of the Human Ethics Committee.

Your application is approved as of today.

You may wish to check whether there are any new comments on your application. To do this, click on the Comments button (it looks like a speech bubble). If any particular page has comments, they will be marked with a flag on the left hand side of the screen. To access them, navigate to the desired page, and then click on the Page Comments button (it looks like a speech bubble with a page behind it).

Best wishes with the research.

Pipitea Human Ethics Sub-Committee

*****This is an automated email. Do not reply to this email address $\mathrm{s}^{* * * * * * *}$

Pipitea Ethics subcommittee queries can be sent to: pipitea-hec@vuw.ac.nz 